\title{
Private-sector standards as technical barriers in international trade in goods : in search of WTO disciplines
}

Citation for published version (APA):

Kudryavtsev, A. (2015). Private-sector standards as technical barriers in international trade in goods : in search of WTO disciplines. [Doctoral Thesis, Maastricht University]. Wolf Legal Publishers. https://doi.org/10.26481/dis.20150902ak

Document status and date:

Published: 01/01/2015

DOI:

10.26481/dis.20150902ak

Document Version:

Publisher's PDF, also known as Version of record

Please check the document version of this publication:

- A submitted manuscript is the version of the article upon submission and before peer-review. There can be important differences between the submitted version and the official published version of record.

People interested in the research are advised to contact the author for the final version of the publication, or visit the DOI to the publisher's website.

- The final author version and the galley proof are versions of the publication after peer review.

- The final published version features the final layout of the paper including the volume, issue and page numbers.

Link to publication

\footnotetext{
General rights rights.

- You may freely distribute the URL identifying the publication in the public portal. please follow below link for the End User Agreement:

www.umlib.nl/taverne-license

Take down policy

If you believe that this document breaches copyright please contact us at:

repository@maastrichtuniversity.nl

providing details and we will investigate your claim.
}

Copyright and moral rights for the publications made accessible in the public portal are retained by the authors and/or other copyright owners and it is a condition of accessing publications that users recognise and abide by the legal requirements associated with these

- Users may download and print one copy of any publication from the public portal for the purpose of private study or research.

- You may not further distribute the material or use it for any profit-making activity or commercial gain

If the publication is distributed under the terms of Article 25fa of the Dutch Copyright Act, indicated by the "Taverne" license above, 


\section{Private-Sector Standards as Technical Barriers in International Trade in Goods: In Search of WTO Disciplines}

Arkady Kudryavtsev

ฟ 
Private-Sector Standards as Technical Barriers in International Trade in Goods:

In Search of WTO Disciplines

Arkady Kudryavtsev

ISBN: 978-94-6240-255-3

Cover image from WWF website: http://wwf.panda.org/

Layout and cover design by SeeSaw Design

Published by:

Wolf Legal Publishers (WLP)

PO Box 313

5060 AH Oisterwijk

The Netherlands

E-Mail: info@wolfpublishers.nl

www.wolfpublishers.com

All rights reserved. No part of this publication may be reproduced, stored in a retrieval system, or transmitted in any form or by any means, electronic, mechanical, photocopying, recording or otherwise, without prior written permission of the publisher. Whilst the authors, editors and publisher have tried to ensure the accuracy of this publication, the publisher, authors and editors cannot accept responsibility for any errors, omissions, misstatements, or mistakes and accept no responsibility for the use of the information presented in this work.

(C) Arkady Kudryavtsev / WLP 2015 


\title{
Private-Sector Standards as Technical Barriers in International Trade in Goods: In Search of WTO Disciplines
}

\author{
DISSERTATION \\ to obtain the degree of Doctor \\ at Maastricht University, \\ on the authority of the Rector Magnificus, \\ Prof. dr. L.L.G. Soete \\ in accordance with the decision of the Board of Deans, \\ to be defended in public \\ on Wednesday 2 September 2015, at 12.00 hours \\ by \\ Arkady Kudryavtsev
}




\section{Supervisor:}

Prof. dr. P. Van den Bossche

\section{Co-supervisor:}

Dr. D. Prévost

\section{Assessment Committee:}

Prof. dr. A. Kamperman Sanders (Chairman)

Prof. dr. Th. Conzelmann

Prof. dr. G. Marceau (University of Geneva, Switzerland)

Dr. G. Marin-Duran (University of Edinburgh, United Kingdom)

Prof. dr. J. Vidmar 


\section{ACKNOWLEDGements}

$\mathrm{W}$ hen I came to Maastricht at the end of August 2008, four years to be spent at the Maastricht University writing my $\mathrm{PhD}$ dissertation and teaching seemed like a very long way to go. However, time ran very quickly and I soon realized that starting and continuing a $\mathrm{PhD}$ research project is not really a big deal, finishing it is the main challenge. Undoubtedly, the time spent at the Faculty of Law of the Maastricht University became one of the most interesting, productive and challenging times in my life. Writing chapters of my PhD, having valuable and constructive discussions with my supervisors, contributing to the teaching of various courses on diverse subjects, and participating in scientific conferences and meetings - all these were great and unforgettable experiences. The same is also very true for the time I spent in Geneva while working as a legal intern, and then, some time afterwards, as a dispute settlement lawyer at the Legal Affairs Division of the WTO Secretariat.

The time during which I conducted my $\mathrm{PhD}$ research is remarkable for me not only from a professional point of view, but also from a personal one due to the important and happy developments in my life - getting married to my beloved wife Katya in Maastricht and becoming a father of the cutest baby-son Aleksey in Geneva. Although the career and personal developments caused some delay in the finalizing of my $\mathrm{PhD}$ dissertation, I am very happy that I finally completed it and achieved this milestone. But before finally concluding this chapter of my life, I would like to wholeheartedly thank all the people who made my life and work in Maastricht and Geneva so interesting and special.

First of all, of course, I would like to express my sincere gratitude to my PhD supervisors, Prof. Peter Van den Bossche and Dr. Denise Prévost. Certainly, without their valuable advice, care and patience, the completion of this research would not have been possible. I would also like to sincerely thank the members of the Assessment Committee for my $\mathrm{PhD}$ dissertation, Prof. Anselm Kamperman Sanders, Prof. Thomas Conzelmann, Prof. Gabrielle Marceau, Dr. Gracia Marin-Duran, and Prof. Jure Vidmar, for their interest in my research project and for finding the time in their busy schedules to read my manuscript.

Undoubtedly, this $\mathrm{PhD}$ dissertation owes a lot to the Faculty of Law of the Maastricht University and to its Department of International and European Law. It was a great pleasure indeed to work in such an encouraging, lively and friendly environment. I would thus like to express my gratitude to the former and the current deans of the Faculty, Prof. Aalt Willem Heringa and Prof. Hildegard Schneider, and to the Head of the Department, Prof. Fons Coomans. My sincere thanks also goes to the management of 
the Institute for Globalization and International Regulation (IGIR), and the management of the Ius Commune Research School for the very useful and challenging training events organised for $\mathrm{PhD}$ candidates.

My time at the Maastricht University, as well as in Maastricht in general, would certainly not have been as pleasant and interesting as it was had I not shared it with my colleagues and friends. I would therefore like to use this opportunity to express warm words of appreciation to my friends and former colleagues Iveta Alexovicova, Siamak Amoozeidi, Leïla Choukroune, Florin Coman-Kund, Birsen Erdogan, Carol Forde, Vladimir Gordeev, Pablo Iglesias-Rodríguez, Phyllis Livaha, Elisa Malathouni, Nishara Mendis, Anke and Roland Moerland, Marieke Mur, Daniar Natakusumah, Anna Ogorodova, Mira Scholten, Dalindyebo Shabalala, Olga SkriabikoffCoenen and Johan Coenen, Laura Tilindyte, Stefan Weishaar, Nevena Zhelyazkova and last, but definitely not least, Marco Zinzani. I would also like to thank many of my former colleagues at the Faculty of Law, including Iveta Alexovicova, Stefaan Van den Bogaert, Raluca Frunza, Remy Jorritsma, Anne Pieter van der Mei, Andrea Ott, Fabián Raimondo, Sarah Schoenmaekers, Mark Seitter, and Jennifer Sellin for the great teaching experiences I was lucky enough to have with them.

The invaluable experience of working at the Legal Affairs Division of the WTO Secretariat contributed significantly to the further development of my knowledge of WTO law and legal drafting skills which, in turn, undoubtedly affected the outcomes of my $\mathrm{PhD}$ research. For this I would like to express my sincere gratitude to my former colleagues at the Division, including Alvaro Antoni, Jorge Castro, Graham Cook, Valerie Hughes, Rodd Izadnia, Aegyoung Jung, Reto Malacrida, Gabrielle Marceau, Dean Merriman, Zila Milupi, Tania Parcero Herrera, Julie Pain, Maria J. Pereyra, Manuel Sanchez Miranda and Chibole Wakoli. I also want to thank my good friends Vitaliy Pogoretskyy, and Alexander and Olga Mishin for sharing many pleasant moments in Geneva with me and my family.

Finally and very importantly, I want to thank my parents Raisa and Sergey, my older brother Gleb, my grandpa Efim, my mother-in-law Marina, our close family friend Masha and, of course, my wife Katya and son Aleksey for their continuing help, encouragement and support throughout the years of my $\mathrm{PhD}$ research. I very much appreciate your love and care and am very lucky to have such a wonderful family.

The manuscript of this dissertation was finalized on April 10, 2015. Further developments related to the topic have not been taken into account and will be the subject of future work. 
$\boldsymbol{\zeta}$ If you think of standardization as the best that you know today, but which is to be improved tomorrow; you get somewhere.

Henry Ford 


\section{TABLE OF Contents}

Acknowledgements …..........................................................................................................................i

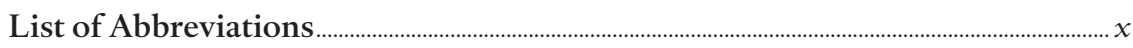

List of Figures .............................................................................................................

CHAPTER I: Introduction ........................................................................................................... I

1.1 Problem Statement ............................................................................................................................2

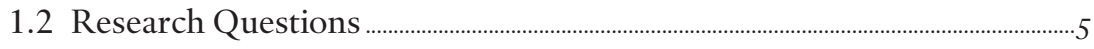

1.3 Structure of the Study ............................................................................................................. 6

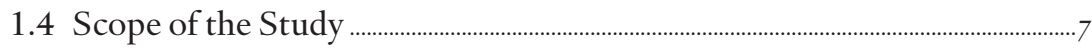

1.5 Relevance of the Study ............................................................................................ 8

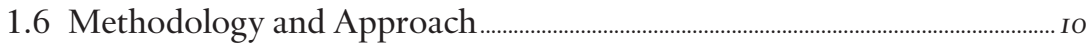

CHAPTER II: The "World” of Private-Sector Standards .............................. I3

2.1 Defining the Concept of a Private-Sector Standard........................................ I4

2.1.1 Main Characteristics of Private-Sector Standards and Their Conformity Assessment Procedures............................................... I6

2.1.1.1 Defining the Concept of a Standard..................................................................

2.1.1.2 Mandatory or Voluntary? ............................................................................I7

2.1.1.3 Excluding Services and Consensus Rule......................................................19

2.1.1.4 Main Characteristics of Private-Sector Standards.....................................20

2.1.1.5 Some Examples of Private Sector Standards .................................................22

2.1.1.6 Reasons for Using the Term "Private-Sector Standard" .........................24

2.1.1.7 Brief Definition of a Private-Sector Standard and its Conformity Assessment Procedure..................................................25

2.1.2 Operational Stages of Private-Sector Standards ...........................................26

2.1.2.1 Preparation of a Standard .................................................................................26

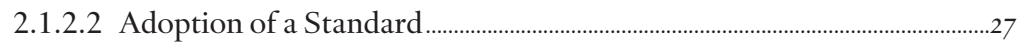

2.1.2.3 Application of a Standard.........................................................................................27

2.1.2.4 Implementation of a Standard ...................................................................28

2.1.2.5 Conformity Assessment and Enforcement of a Standard ......................29

2.2 Typology of Private-Sector Standards ....................................................................29

2.2.1 Choice of Relevant Criteria for Typology of Private-Sector Standards ..................................................................30

2.2.2 Forms of Private-Sector Standards............................................................32

2.2.3 Types of Organizations Adopting Private-Sector Standards....................34

2.2.3.1 How a Document Becomes a Private-Sector Standard:

De Facto and De Jure Private-Sector Standards ...........................................35

2.2.3.2 Private-Sector Standards Developed by Different Types of Organizations................................................................3 
2.2.3.2.1 Individual Company Private-Sector Standards $\cdot 39$

2.2.3.2.2 Collective Private-Sector Standards................................................................4I

2.2.3.2.2.1 Advantages of Collective Private-Sector Standards ............................... II

2.2.3.2.2.2 Forms of Incorporation of Private Standard-Setting Entities ............43

2.2.3.2.2.3 National, Regional and International Private-Sector Standards ......46

2.2.4 Level of Governmental Involvement or Incentives for the Adoption and Application of Private-Sector Standards.......................49

2.2.4.1 Private-Sector Standards vs. Public-Sector Standards ...............................49

2.2.4.2 Public and Private-Sector Standards vs. Technical Regulations.............5I

2.2.4.3 Resolving Private vs. Public Dilemma:

Which Standards Are Relevant? ................................................................................54

2.2.4.3.1 International Standard-Setting Organizations..........................................55

2.2.4.3.2 Regional Standards-Setting Organizations ………………………………..57

2.2.4.3.3 National Standards Bodies......................................................................... 58

2.2.4.3.4 The Private-Public Regulatory Continuum................................................ 60

2.2.5 Objectives of Private-Sector Standards ..........................................................62

2.2.6 Targeted Organizations for the Implementation of Private-Sector Standards ....................................................................................64

2.2.7 Targeted Clients of Private-Sector Standards .....................................................67

2.2.8 Scope of Private-Sector Standards:

Product and Process Requirements ............................................................................ 69

2.2.9 Conformity Assessment Systems

of Private-Sector Standards .....................................................................................74

2.3 Role of Private-Sector Standards in International Trade.................................77

2.3.1 The Proliferation of Private-Sector Standards .....................................................78

2.3.2 Reasons for the Proliferation

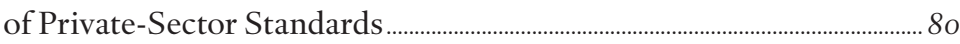

2.3.2.1 The Globalization of International Trade ........................................................8I

2.3.2.2 Evolving Consumer Demands and Business Reputation...........................84

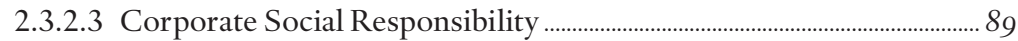

2.3.2.4 Increased Business Concentration ..................................................................... 92

2.3.2.5 Changes in the Regulatory Environment......................................................95

2.3.2.5.1 Shifts in the Regulatory Approach to Process-Based Criteria...........96

2.3.2.5.2 Insufficient Flexibility, Effectiveness and the Mobility of Public Regulation .......................................................... IOI

2.3.2.5.3 Product Liability Rules and Risk Management ..................................... IO

2.3.3 Effects of Private-Sector Standards on International Trade ................... Io6

2.3.3.1 Positive Effects of Private-Sector Standards ..................................................IO7

2.3.3.2 Challenges Posed by Private-Sector Standards ......................................... III

2.3.4 Meeting the Challenges Posed

by Private-Sector Standards ...............................................................................II8

2.3.4.1 Private-Sector Standards and WTO Rules ................................................. II

2.3.4.2 Private-Sector Standards, IP Rights and Competition Law ..................I23 


\section{CHAPTER III: Private-Sector Standards under the GATT 1994 and the International Law Rules on the Attribution of Conduct to WTO Members......................................................... 35}

3.1 Scope of Application of the GATT 1994 ........................................................... I36

3.1.1 Material Scope of Application of the GATT 1994:

Mandatory or Voluntary Measures? .......................................................................I37

3.1.2 Personal Scope of Application of the GATT 1994_....................................... I4I

3.1.2.1 Responsibility of WTO Members under the GATT 1994

for Their Measures Affecting Private Behaviour......................................... I43

3.1.2.2 Are There Implicit or Explicit Positive Obligations to Discipline Private Conduct Under the GATT 1994? .......................... I46

3.1.3 Temporal Scope of Application of the GATT 1994 ...................................... I48

3.2 Attribution of Private Conduct to WTO Members.......................................... I49

3.2.1 Attribution of Private Conduct to States Under the General Rules of Customary International Law 150

3.2.1.1 Conduct of State Organs and Entities

Exercising Elements of Governmental Authority ……………...................I5I

3.2.1.2 Conduct Directed or Controlled by a State, or Accepted by a State as Its Own

3.2.2 Attribution of Private Conduct to WTO Members Under the GATT 1994 and Certain Other WTO Agreements.

3.2.2.1 Practice on the Attribution of Private

Conduct Under the GATT 1994.

3.2.2.1.1 General Approach to the Attribution of Private Conduct Under the GATT 1994.................................................159

3.2.2.1.2 Attribution of Conduct of State Trading Enterprises Under the GATT 1994 163

3.2.2.2 Practice on the Attribution of Private Conduct Under Certain Other WTO Agreements. .167

3.2.2.2.1 Attribution of Private Conduct Under the SCM Agreement............. 167

3.2.2.2.2 Attribution of Private Conduct Under the Agreement on Agriculture........................................................... 172

3.3 Relevant Rules of the GATT 1994.

3.3.1 Non-Discrimination Obligations:

Most-Favoured-Nation and National Treatment ...............................................

3.3.1.1 Essence of MFN Treatment Obligation .............................................................

3.3.1.2 Essence of National Treatment Obligation................................................ 178

3.3.1.3 "Like Products" in Articles I:1 and III:4

3.3.1.4 Any Advantage "Accorded Immediately and Unconditionally" in Article I:1 ............................................................. 88

3.3.1.5 "Treatment No Less Favourable" in Article III:4 ........................................ I9o

3.3.2 Rules on the Publication and Administration of Trade Laws and 
Regulations

3.3.2.1 Publication of Trade Laws and Regulations .................................................. 195

3.3.2.2 Administration of Trade Laws and Regulations ...........................................

3.3.3 Elimination of Quantitative Restrictions

on the Importation or Exportation of Products ................................................2OI

3.3.4 General Exceptions From the GATT Obligations.............................................207

3.3.4.1 Measures Necessary to Protect Public Morals ...............................................2II

3.3.4.2 Measures Necessary to Protect Life or Health..........................................2I4

3.3.4.3 Measures Necessary to Secure

Compliance With Laws or Regulations ……………………………………....217

3.3.4.4 Measures Relating to the Conservation of Exhaustible Natural Resources.....................................................................219

3.3.4.5 Chapeau of Article XX ..........................................................................................224

3.3.5 Non-Violation and Situation Complaints .................................................................230

3.3.6 Processes and Production Methods Under the GATT 1994.................. 233

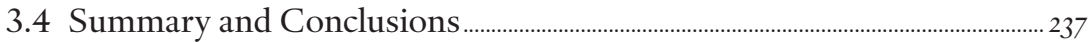

CHAPTER IV: Private-Sector Standards and the TBT Agreement...24I

4.1 Scope of Application of the TBT Agreement .............................................................243

4.1.1 Material Scope of Application of the TBT Agreement.................................24

4.1.1.1 Technical Regulation..........................................................................................245

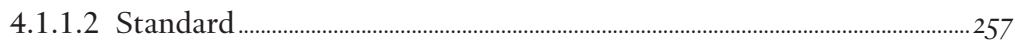

4.1.1.3 Conformity Assessment Procedures..................................................................267

4.1.1.4 Processes and Production Methods Under the TBT Agreement......269

4.1.1.4.1 Negotiation History of the TBT Agreement and PPMs....................... 272

4.1.1.4.2 Dispute Settlement Practice Under the TBT Agreement and PPMs ....................................................................278

4.1.2 Relationship of the TBT Agreement

With Other WTO Agreements .................................................................................28I

4.1.2.1 Relationship With the GATS................................................................28I

4.1.2.2 Relationship With the Agreement on Government Procurement.............................................................................282

4.1.2.3 Relationship With the SPS Agreement .............................................................28

4.1.2.4 Relationship With the GATT 1994 ........................................................284

4.1.3 Personal Scope of Application of the TBT Agreement .................................287

4.1.3.1 Central and Local Governmental Bodies ...................................................287

4.1.3.2 Non-Governmental Bodies ..............................................................................28

4.1.3.3 Regional Bodies......................................................................................................290

4.1.4 Temporal Scope of Application of the TBT Agreement.............................292

4.2 Obligations of WTO Members With

Respect to Different Types of Bodies ........................................................................29

4.2.1 Positive Obligations...................................................................................................295

4.2.1.1 Positive Obligations With Respect to Technical Regulations ..............295 
4.2.1.2 Positive Obligations With Respect to Standards . .296

4.2.1.3 Positive Obligations With Respect to Conformity Assessment Procedures ............................................................297

4.2.1.4 Available "Reasonable" Measures ............................................................298

4.2.2 Negative Obligations ...................................................................................................

4.3 Main Disciplines of the TBT Agreement .............................................................3I2

4.3.1 MFN and National Treatment Obligations...........................................................3I3

4.3.2 Prohibition of Unnecessary Obstacles to Trade.............................................. 319

4.3.3 Harmonization Based on

Relevant International Standards .....................................................................323

4.3.4 Other Obligations .......................................................................................................

4.3.4.1 Equivalence and Mutual Recognition ..................................................................333

4.3.4.2 Product Requirements in Terms of Performance ..........................................333

4.3.4.3 Transparency and Notification ........................................................................334

4.3.5 TBT Agreement and Developing Country Members....................................338

4.3.5.1 Technical Assistance ..................................................................................................38

4.3.5.2 Special and Differential Treatment ..................................................................339

4.4 Summary and Conclusions ......................................................................................................340

CHAPTER V: Private-Sector Standards and the SPS Agreement .......347

5.1 Scope of Application of the SPS Agreement ...............................................................35

5.1.1 Material Scope of Application of the SPS Agreement.....................................35

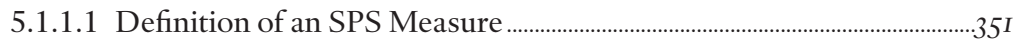

5.1.1.1.1 Purpose of an SPS Measure …………………………………………………......353

5.1.1.1.2 Other Substantive Criteria for an SPS Measure.........................................363

5.1.1.1.3 SPS Measures: Voluntary vs. Mandatory ....................................................366

5.1.1.2 Measures Affecting International Trade........................................................372

5.1.2 Relationship With the GATT 1994 ...................................................................374

5.1.3 Personal Scope of Application of the SPS Agreement...................................379

5.1.4 Temporal Scope of Application of the SPS Agreement...............................38

5.2 Obligations of WTO Members With

Respect to Different Types of Bodies ……………………………………………….....39o

5.2.1 Positive Obligations.....................................................................................................................

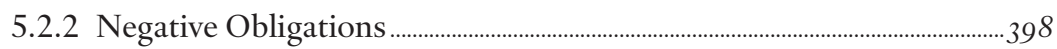

5.2.3 Work of the SPS Committee With Respect to Article 13

of the SPS Agreement and Private-Sector Standards.................................. 400

5.3 Main Disciplines of the SPS Agreement...............................................................4I2

5.3.1 Right to Take SPS Measures and the Burden of Proof .............................. 413

5.3.2 Basic Limitations on the Right to Take SPS Measures...............................4I6

5.3.2.1 Necessity Requirement .........................................................................................4I6

5.3.2.2 The Use of Scientific Principles and Evidence........................................... 
5.3.2.3 The Prohibition of Arbitrary or Unjustifiable

Discrimination and Disguised Restrictions on Trade.

5.3.3 Promotion of Harmonization

Based on International Standards

5.3.3.1 Relationship Between the Provisions of Article 3 ……………………....426

5.3.3.2 International Standard Under the SPS Agreement....................................427

5.3.3.3 Measures "Based on" and

"Conforming to" International Standards .429

5.3.3.4 Higher Level of SPS Protection

Than in an International Standard...................................................................... $43^{I}$

5.3.4 Risk Analysis Disciplines and Provisional Measures................................... 434

5.3.4.1 Risk Assessment Obligations ……………………………………………....435

5.3.4.1.1 Nature of the Risk Assessment ……………………………………….....435

5.3.4.1.2 SPS Measures Based on Risk Assessment ................................................4 4 I

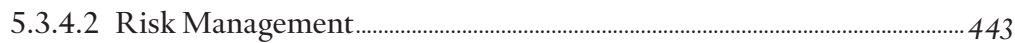

5.3.4.2.1 Choice of Appropriate Level of Protection.............................................. 444

5.3.4.2.2 Choice of an SPS Measure .............................................................................449

5.3.4.3 Provisional SPS Measures and

the Role of the Precautionary Principle..........................................................453

5.3.4.3.1 Precautionary Approach and Article 5.7 of the SPS Agreement ....454

5.3.4.3.2 Relationship of Article 5.7 With Other

Relevant Provisions of the SPS Agreement ................................................456

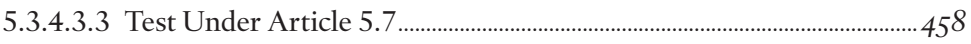

5.3.5 Other Relevant Disciplines of the SPS Agreement .......................................464

5.3.5.1 Equivalence and Adaptation to Regional Conditions ............................465

5.3.5.1.1 Equivalence ............................................................................................. 465

5.3.5.1.2 Adaptation to Regional Conditions ………………………………………...466

5.3.5.2 Control, Inspection and Approval Procedures.............................................468

5.3.5.3 Transparency and Notification ...............................................................................475

5.3.5.4 Provisions With Respect to Developing Countries ................................. 479

5.4 Summary and Conclusions .....................................................................................4 482

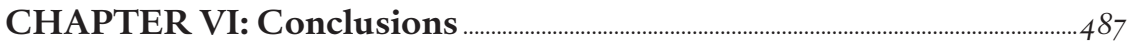

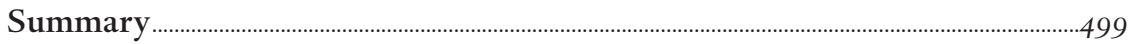

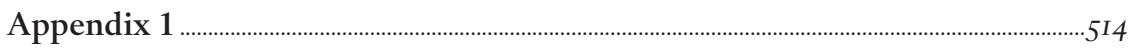

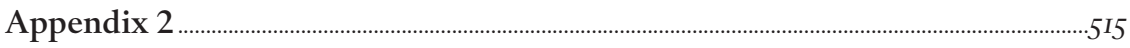

Appendix $3 \ldots \cdots \cdots \cdots \cdots \cdots \cdots \cdots \cdots \cdots \cdots \cdots \cdots \cdots \cdots \cdots \cdots \cdots \cdots \cdots \cdots \cdots \cdots \cdots \cdots \cdots \cdots \cdots \cdots \cdots \cdots \cdots \cdots \cdots \cdots \cdots \cdots \cdots \cdots \cdots \cdots \cdots \cdots \cdots \cdots \cdots \cdots \cdots \cdots \cdots \cdots \cdots \cdots \cdots \cdots \cdots \cdots \cdots \cdots \cdots \cdots$

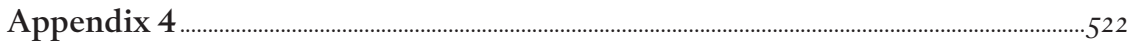

Valorization Addendum .......................................................................................................

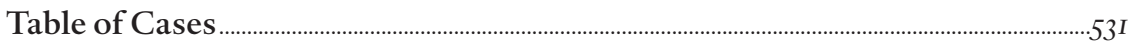

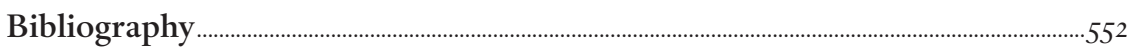

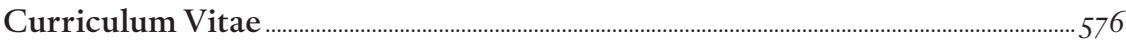




\section{List of Abbreviations}

AFS

AIDCP

AMS

ANS

ANSI

ASEAN

B2B

B2C

BRC

BSE

BSI

C.A.F.E. Practices

$\mathrm{CCF}$

CCP

CEN

CENELEC

CFR

CNEN

Code of Good Practice

Codex

COOL

CSR

CTE

CWB

DJAI

DOC

DSU

DVI

EC

ECJ

EEC

EFTA
Assured Food Standards

Agreement on the International

Dolphin Conservation Program

Advanced Marketing Service

American National Standard

American National Standards Institute

Association of Southeast Asian Nations

Business to Business

Business to Consumer

British Retail Consortium

Bovine Spongiform Encephalopathy

British Standards Institute

Coffee And Farmer Equity Practices

Choose Cruelty Free

Critical Control Point

European Committee for Standardization

European Committee for

Electrotechnical Standardization

Code of Federal Regulations

Explanatory Notes to the

Combined Nomenclature

Annex 3 of the TBT Agreement -

"Code of Good Practice for the Preparation,

Adoption and Application of Standards"

Codex Alimentarius Commission

Country Of Origin Labelling

Corporate Social Responsibility

Committee on Trade and Environment

Canadian Wheat Board

Advance Sworn Import Declaration

Department Of Commerce

Dispute Settlement Understanding

Digital Video Interface

European Communities

European Court of Justice

European Economic Community

European Free Trade Association 
EMD

Equivalence Decision

ETP

ETSI

EU

EUREP

e-WG

FAO

FCD

FIRA

FLO

FMI

FRAND

FRY

FSC

FTC

G.A.P.

GATS

GATT

GDP

GE

GM

GMO

GPA

HACCP

HDE

IC

ICJ

ICT

ICTY

IEC

IFS

IICA
European Marketing Distribution

Decision on the Implementation of Article 4 of the Agreement on the Application of Sanitary and Phytosanitary Measures

Eastern Tropical Pacific Ocean

European Telecommunications

Standards Institute

European Union

Euro-Retailer Produce Working Group

Electronic Working Group

Food and Agriculture Organization

of the United Nations

Fédération des Entreprises du

Commerce et de la Distribution

Foreign Investment Review Act

Fairtrade Labelling Organization

Food Marketing Institute

Fair, Reasonable And Non Discriminatory

Former Republic of Yugoslavia

Forest Stewardship Council

Federal Trade Commission

Good agricultural practices

General Agreement on Trade in Services

General Agreement on Tariffs and Trade

Gross Domestic Product

General Electric

Genetically Modified

Genetically Modified Organism

Agreement on Government Procurement

Hazard Analysis and Critical Control Points

Hauptverband des Deutschen Einzelhandels

Indigenous Communities

International Court of Justice

Information and Communication Technology

International Tribunal for the

Former Yugoslavia

International Electrotechnical Commission

International Food Standard

Inter-American Institute for

Cooperation on Agriculture 
ILC

IP

IPPC

IRA

ISO

IT

JEDEC

LCA

LPMO

MERCOSUR

MFN

MRL

MRM

MSC

NAFTA

NBN

NEN

NGO

NLCF

npr-PPM

NSB

OECD

OIE

OJEU

P.Q.C.

PDF

PEFC

PPA

PPM

PSS

QR

QS

RAND

RTRR

SABS
International Law Commission

Intellectual Property

International Plant Protection Convention

Import Risk Analysis

International Organization for Standardization

Information Technology

Joint Electron Devices Engineering Council

Life-Cycle Analysis

Livestock Products Marketing Organization

Mercado Común del Sur

Most-Favoured Nation

Maximum Residue Level

Marine Resource Management

Marine Stewardship Council

North American Free Trade Agreement

Bureau voor Normalisatie /

Bureau de Normalisation

The Netherlands Standardization Institute

Non-Governmental Organization

National Livestock Cooperatives Federation

Non-Product Related Processes

and Production Method

National Standards Body

Organisation for Economic

Co-operation and Development

World Organization for Animal Health

Official Journal of the European Union

Percorso Qualità Conad

Portable Document Format

Programme for the Endorsement of Forest Certification

Protocol of Provisional Application

Processes and Production Method

Private-Sector Standard

Quantitative Restriction

Qualitat Sicherheit

Reasonable And Non Discriminatory

Restrictive Trade-Related Requirement

South African Bureau of Standards 
SCM Agreement

SCT

SDRAM

SDT

SFI

SOCB

SOE

SPS

SPS Agreement

SPS Committee

SQF

SQFI

Standards Code

STE

TBT Agreement

TBT Committee

TED

TRIPS

UK

UN

UNCTAD

US

VCLT

VESA

VHS

WGTCP

WHO

WTO

WTO Agreement

WWF
Agreement on Subsidies and

Countervailing Measures

Separate Custom Territory

Synchronous Dynamic Random

Access Memory

Special and Differential Treatment

Sustainable Forestry Initiative

State-Owned Commercial Bank

State-Owned Enterprise

Sanitary and Phytosanitary

Agreement on the Application of

Sanitary and Phytosanitary Measures

Committee on Sanitary and

Phytosanitary Measures

Safe Quality Food

Safe Quality Food Institute

Tokyo Round Agreement on

Technical Barriers to Trade

State Trading Enterprise

Agreement on Technical Barriers to Trade

Committee on Technical Barriers to Trade

Turtle Exclusion Devise

Agreement on Trade-Related Aspects

of Intellectual Property Rights

United Kingdom

United Nations

United Nations Conference on

Trade and Development

United States

Vienna Convention on the

Law of Treaties 1969

Video Electronics Standards Association

Video Home System

Working Group on the Interaction between Trade and Competition Policy

World Health Organization

World Trade Organization

Marrakesh Agreement Establishing

the World Trade Organization

World Wide Fund for Nature 


\section{List OF Figures}

Figure 1: Classification and examples of private-sector standards based on types of standard-setting entities

Figure 2: $\quad$ Types of standards

Figure 3: Types of technical regulations

Figure 4: Relationships between private / public-sector standards, and technical regulations

Figure 5: Private-public regulatory continuum

Figure 6: Examples of the B2B private-sector standard logos

Figure 7: Examples of product labels of the B2C private-sector standards 


\section{CHAPTER I \\ INTRODUCTION}

$\mathrm{P}$ rivate-sector standards play an increasingly important role in international trade. ${ }^{1}$ Nowadays, these standards are widely adopted and applied within national and international markets by a large variety of players, including supermarket chains, transnational corporations, and manufacturers of goods. ${ }^{2}$ In fact, private-sector standards may be used throughout entire industry sectors under the administration of industry associations or non-governmental organizations (NGOs) on a national or international level. ${ }^{3}$ This is especially true for the "developed world" markets, where consumer demands, intense market competition and a regulatory environment generated the phenomenon which some authors call "racing to the top" in private regulatory requirements. ${ }^{4}$ Indeed, business actors, in order to satisfy high consumer demands, to differentiate their products from competitive ones or to protect their brand reputation, very often apply private requirements to products in addition to standards and regulations adopted and enforced by public authorities.

Recent years have seen a significant proliferation of private-sector standards. One could, perhaps, argue that the use of private-sector standards became an objective reality of the 21st century. Moreover, the provision of services with respect to certification under such standards has grown into quite a significant and lucrative business. Especially in developed countries, due to globalization, new types of health threats, environmental degradation and global warming, there is an ongoing and increasing

1 Some parts of the following discussion in this Chapter are based on: Arkady Kudryavtsev, "Private Standardization and International Trade in Goods: Any WTO Law Implications for Domestic Regulation?", the research paper presented at the SIEL Third Biennial Conference, Singapore 2012, available at the SSRN website: http://papers.ssrn.com/sol3/papers.cfm?abstract_id=2082022 (last visited February 7, 2015).

2 For example, many large retailers, such as Tesco, Royal Ahold (Albert Heijn), Aldi, and Marks \& Spencer, develop and adopt their own standards and labelling schemes for certain food products. Many retailers also apply collective private standards, such as GLOBALG.A.P.. Food and consumer products with private labels (which signify the products' compliance with a certain private-sector standard) may also be widely found in the markets today. For example, fish cans with the Marine Stewardship Council (MSC) label, toilet paper with the Forest Stewardship Council (FSC) label, bananas and chocolate with the Fairtrade label.

3 See: Linda Fulponi, "Private Standard Schemes And Developing Country Access To Global Value Chains: Challenges And Opportunities Emerging From Four Case Studies", AGR/CA/APM(2006)20/FINAL, OECD, August 2007, paras. 7 - 8.

4 See: Grace Chia-Hui Lee, "Private Food Standards and Their Impacts on Developing Countries”, European Commission DG Trade Unit G2, Brussels, 2006, p. 8. 
concern among consumers with respect to safety, quality, sustainability, environmental and social impact of products and production processes. The requirements of governmental regulations and standards in this respect are frequently regarded to be insufficient by consumers, corporations and NGOs. These considerations frequently drive private actors to develop and adopt their own, as a rule, more stringent or detailed guidelines, requirements or recommendations, i.e., standards. Moreover, in principle, privatesector standards may be developed and applied in spheres where public regulation does not exist at all or is very limited. So-called "stewardship programs", such as the Marine Stewardship Council (MSC) or the Forest Stewardship Council (FSC), promoting sustainable production of appropriate products through product labelling for consumers' information, are good examples of this. ${ }^{5}$

There are various reasons for the proliferation and wide scale application of private-sector standards. As previously mentioned, the considerable increase in the development and application of these standards is, to a large extent, driven by increased consumers' concerns over the safety and quality of products as well as the social and environmental impact of production processes. Business corporations frequently respond to such demands through the application of stringent private-sector standards and the development of corporate social responsibility (CSR) policies, which also often include the application of these standards. In this respect, the application of private-sector standards may provide competitive advantages in terms of superior quality claims and brand reputation. ${ }^{6}$ Moreover, the application of strict private-sector standards by producers or sellers may be viewed as a "due diligence" measure in relation to products' safety and quality, and thus may serve as a defence in cases of product liability claims. Finally, private-sector standards may also increase the efficiency and profitability of production through the application of the most advanced technologies and know-how, establishing common terminology and the interoperability of products.

\subsection{Problem Statement}

Undoubtedly, the process of proliferation and the widespread use of privatesector standards in the markets of goods may generate important challenges

\footnotetext{
5 See, for example: A. Marx, E. Becault, et al., "Private Standards in Forestry: Assessing the Legitimacy and Effectiveness of the Forest Stewardship Council", at: A. Marx, M. Maertens, J. Swinnen, J. Wouters, Private Standards and Global Governance. Economic, Legal and Political Perspectives, Edward Elgar, Cheltenham, UK, 2012.

${ }^{6}$ See: Ibid., p. 8.
} 
for some interested stakeholders. Therefore, it is not surprising that the role of private-sector standards and their effects in international trade are highly topical issues for discussion today in various fora, including the World Trade Organization (WTO), the Organisation for Economic Co-operation and Development (OECD), the United Nations Conference on Trade and Development (UNCTAD), the Food and Agriculture Organization of the United Nations (FAO) and the World Bank. ${ }^{7}$ Being adopted and applied by non-governmental entities, private-sector standards are voluntary de jure, i.e. their application is not legally mandatory. However, due to the immense purchasing power of the big retail chains and multinational corporations which frequently apply such standards, compliance with these standards may become mandatory de facto for suppliers in order to gain real market access. ${ }^{8}$

In this respect, arguably, private-sector standards may both create positive effects and pose challenges for international trade and development. On the one hand, private-sector standards, if properly complied with, may potentially guarantee long-term market access for certified products, appropriate price premiums for producers, enhanced product safety and quality, and dissemination of modern, efficient and environmentally friendly technologies. Private-sector standards may also contribute to the differentiation of products and the creation of niche-markets, favourable for smallscale and developing country producers. ${ }^{9}$

However, on the other hand, it seems that this potential of private-sector standards often fails to materialize for many small-scale, medium-sized and developing country producers. Indeed, the trade-restrictive effects of

\section{For example, see: Report of the Ad Hoc Working Group on SPS-Related} Private Standards to the SPS Committee, WTO, SPS Committee, G/SPS/W/256, Geneva, 3 March 2011; Private Standards and the SPS Agreement. Note by the Secretariat, WTO, SPS Committee, G/SPS/GEN/746, Geneva, 24 January 2007; Linda Fulponi, "Private Standard Schemes And Developing Country Access To Global Value Chains: Challenges And Opportunities Emerging From Four Case Studies", AGR/CA/APM(2006)20/FINAL, OECD, August 2007; Food Safety and Environmental Requirements in Export Markets - Friend or Foe for Producers of Fruit and Vegetables in Asian Developing Countries?, UNCTAD, UNCTAD/DITC/ TED/2006/8, New York and Geneva, 2007; Spencer Henson, John Humphrey, "The Impacts of Private Food Safety Standards on the Food Chain and on Public StandardSetting Processes", Codex thirty-second Session, FAO, WHO, Codex Alimentarius Commission, Rome, May 2009; "Eco-Labeling Standards, Green Procurement and the WTO: Significance for World Bank Borrowers”, Center for International Environmental Law, Washington, DC, Geneva, Switzerland, March, 2005.

8 See: Samir R. Gandhi, "Voluntary Environmental Standards: The Interplay Between Private Initiatives, Trade Rules and the Global Decision-Making Process", $3^{\text {rd }}$ Global Administrative Law Seminar, Viterbo, June 15 - 16, 2007, pp. 4 - 5.

9 For example, see: Spencer Henson, Steven Jaffee, "Understanding Developing Country Strategic Responses to the Enhancement of Food Safety Standards”, World Economy, 31(4), 2008, p. 552. 
private-sector standards became a subject of concern, frequently voiced by producers, developing countries and scholars. ${ }^{10}$ Application of privatesector standards by big corporations or entire industries may create severe market access difficulties for various producers. This might be the case if such standards present unnecessary, unjustified or inappropriate requirements for local methods of production, thus having discriminatory or excessively trade-restrictive effects. Moreover, the costs of compliance and certification under private-sector standards are often too expensive for small-scale, medium-sized and developing country producers. Meanwhile, there is frequently no guarantee of fair distribution of a price premium for compliance with a standard along a supply chain. ${ }^{11}$ In addition, the diversity of private-sector standards per se and their lack of harmonization pose a serious problem, since producers have to comply with multiple and varying private requirements.

The WTO is the major international organization dealing with issues of international trade in goods on a multilateral level. The rules of the WTO (i.e. WTO law) establish an important international legal framework for the application of technical barriers to trade in goods by WTO Members, such as regulations and standards. In this regard, the relevant WTO agreements include the General Agreement on Tariffs and Trade 1994 (GATT 1994), the Agreement on Technical Barriers to Trade (TBT Agreement) and the Agreement on the Application of Sanitary and Phytosanitary Measures (SPS Agreement). Provisions of these agreements are often at issue with respect to the effects of private-sector standards on international trade.

It seems indeed that the wide scale application of private-sector standards presents serious challenges for the WTO system. Arguably, if compliance with the requirements of private-sector standards becomes a predominant factor for real access to the markets of WTO Members while the WTO is not able to address it, this may potentially render the WTO regulatory system for technical barriers to trade practically irrelevant. ${ }^{12}$ Moreover, if

10 For example, see: Steven Bernstein, Erin Hannah, "Non-State Global Standard Setting and the WTO: Legitimacy and the Need for Regulatory Space", Journal of International Economic Law, 11(3), 2008, p. 575; Private Sector Standards and Developing Country Exports of Fresh Fruit and Vegetables. Communication from the United Nations Conference on Trade and Development (UNCTAD), WTO, SPS Committee, G/SPS/GEN/761, 26 February 2007, para. 6; Possible Actions for the SPS Committee Regarding SPS-Related Private Standards. Note by the Secretariat, WTO, SPS Committee, G/SPS/W/247/Rev.3, Geneva, 11 October 2010, para. 32.

11 See: Private Voluntary Standards and Developing Country Market Access: Preliminary Results. Communication from OECD, Linda Fulponi, WTO, SPS Committee, G/SPS/GEN/763, Geneva, 27 February 2007, paras. 15 - 17.

12 Of course, this might appear to be the case if one assumes that the WTO rules are only applicable to governmental measures and do not apply to private regulatory requirements under any circumstances. 
WTO Members are allowed to encourage and provide meaningful incentives for the development, adoption and application of the WTO inconsistent private-sector standards, the relevant rules of WTO law could thus be circumvented by the Members through such, so to speak, "creative" regulatory policies. In other words, arguably, private-sector standards may pose the risk of "blurring" the existing WTO legal framework for technical barriers to trade in goods. ${ }^{13}$ This, in turn, might seriously affect the credibility of the WTO system, especially in the eyes of developing countries which expected to gain real benefits with respect to market access for their goods from the WTO rules at the time they were negotiated.

\subsection{Research Questions}

Since the WTO is an international intergovernmental organization, the rules of this organization per se create rights and obligations only for its Members, and not for private parties. Accordingly, it is quite clear that the rules of WTO law on technical barriers to trade in goods may not apply directly to private standard-setting organizations. However, in principle, the rules of WTO law, whether explicitly or implicitly, might oblige WTO Members to adopt certain measures in order to discipline private trade-restrictive behaviour, including the development, adoption and application of private-sector standards. Furthermore, the WTO rules might also prohibit the Members to perform certain actions with respect to such sort of private behaviour, for example, to support or encourage the development and application of certain private-sector standards.

Thus, in order to find out the implications of the WTO rules for the regulation of private-sector standards and private standard-setting activities in international trade in goods, it is necessary to examine the relevant provisions of the WTO agreements. In this respect, the main research question to be answered in the present study may be formulated as follows:

What are the implications of WTO law, if any, for the regulation of the development, adoption and application of private-sector standards in international trade in goods; and in this respect, which rules of WTO law may be relevant, and what kind of obligations or rights may these rules reasonably entail for WTO Members?

Clearly, this main research question is quite a complex and multifaceted one. Therefore, it seems useful to identify a number of important sub-questions

13 See: Private Standards and the SPS Agreement. Note by the Secretariat, WTO, SPS Committee, G/SPS/GEN/746, Geneva, 24 January 2007, para. 9. 
to be addressed in the process of the discussion through the chapters of the present study. They are:

- What is a "private-sector standard"? How can it be defined and distinguished from a public standard or a regulation?

- Which types of private-sector standards can be distinguished and how can they be classified? How do private-sector standards operate in the market?

- What are the reasons for the proliferation of private-sector standards and what are their effects on international trade?

- Which rules of the WTO agreements are relevant for the regulation of privatesector standards and private standard-setting activities in international trade in goods? What is the meaning of such WTO rules and how have they been interpreted in the WTO dispute settlement practice?

- What kind of obligations and rights the relevant WTO rules may reasonably entail for WTO Members and under which conditions?

- And, finally, what kinds of tools, if any, in principle, are reasonably available to WTO Members in their domestic legal orders for disciplining private standard-setting activities? ${ }^{14}$

\subsection{Structure of the Study}

Based on the main research question and sub-questions, this study is structured on six chapters. This first chapter introduces the problems related to private-sector standards, provides the research questions and explains the methodology of the study. Chapter II describes the "world" of privatesector standards through defining the concept of such a standard and differentiating it from other standards, rules or regulations. It also explains how private-sector standards operate, offers a typology of private-sector standards based on relevant criteria, and discusses the reasons for the proliferation of private-sector standards operating on markets and their effects on international trade in goods. Chapter II further explains possible approaches to dealing with the challenges posed by private-sector standards and the role of WTO law in this respect. Finally, it briefly outlines the WTO agreements, which are, to a greater or lesser extent, relevant for the present study.

Chapters III, IV and V discuss relevant provisions of the three WTO agreements dealing with technical barriers in international trade in goods: the GATT 1994, the TBT Agreement and the SPS Agreement. In particular, the chapters examine the types of measures addressed by these

14 This last sub-question in fact appears to be closely related to the previous one, since, arguably, the rights and obligations provided in the relevant WTO rules must be interpreted in the light of what is reasonable to expect from the WTO Members' governments in exercising their domestic regulatory functions. 
agreements, the issue of attribution of private actions to WTO Members under these agreements, and the meaning and scope of the relevant obligations of the Members. Finally, Chapter VI summarises the conclusions of the present study with the purpose of providing an answer to the main research question. In particular, it contains some concluding remarks on the issues of applicability of the WTO rules to private sector standards and on the regulatory tools, which are reasonably available to WTO Members in their domestic legal orders for disciplining private standard-setting activities in the light of their obligations under WTO law.

\subsection{Scope of the Study}

It is important to note that the present study does not propose discussing the prospects for regulation of private-sector standards by the WTO rules in all market sectors and from all possible perspectives. First of all, this study only deals with private-sector standards in international trade in goods. Therefore, it does not address the standards which are only applied to domestic goods and do not have any potential consequences for international trade in goods. However, due to the process of globalization of international trade, this limitation of the scope of the present study is indeed not very significant, since most private-sector standards applied in markets nowadays have or may potentially have repercussions for exporters or importers of goods. ${ }^{15}$

Second, the present study addresses private-sector standards only as technical barriers to trade in goods. This means that the scope of this study does not cover all private-sector standards in all sectors of international trade. Nor does it include all rules of the WTO, which might be relevant for the regulation of all such standards in general. In this respect, this study does not deal with private-sector standards in international trade in services and the WTO rules on trade in services as set out in the General Agreement on Trade in Services (GATS). Furthermore, the scope of the present study does not cover product specifications and requirements used by public authorities of WTO Members for the purposes of governmental procurement or rules applied for the distribution of governmental subsidies. Therefore, the scope does not include the WTO rules on governmental procurement and on provision of subsidies as prescribed in the Agreement on Government Procurement (GPA) and the Agreement on Subsidies and Countervailing Measures (SCM Agreement) respectively. Finally, this study does not deal in much detail with the issues of the relationship between private-sector standards and intellectual property (IP)

15 For more discussion regarding this issue, see: Section 2.2.3.2.2.3 of Chapter II. 
rights, including the rules on protection of IP rights prescribed in the WTO Agreement on Trade-Related Aspects of Intellectual Property Rights (TRIPS). ${ }^{16}$

Of course, these limitations of the scope of the present study are not in place as a consequence of the unimportance of the issues concerned. For example, private-sector standards in the area of trade in services are of crucial economic importance - one can simply think of the banking or accounting private standards. ${ }^{17}$ Indeed, this and other areas of private standard-setting mentioned above are so important, complex and multifaceted, that they may become interesting subjects for separate comprehensive studies. Unfortunately, the time and space limitations of the present research project do not allow the thorough addressing of these complex topics. Moreover, in some of these areas of private standard-setting, such as trade in services, the available scientific literature is very limited and there are almost no relevant WTO rules. In fact, arguably, at least currently, the rules on the regulation of international trade in goods constitute the most elaborated area of WTO law. Therefore, it seems to be most appropriate to start the examination of the relevant WTO rules with those applicable to technical barriers in international trade in goods.

\subsection{Relevance of the Study}

The relevance of the present study may be demonstrated from both scientific and practical perspectives. The scientific relevance is ascertained by the importance and complexity of the challenges posed by private-sector standards for international trade in goods and for the WTO legal rules operating in this area, as described above. However, notwithstanding that a number of reports, research papers and publications on private-sector standards in trade in goods and the implications of WTO law for their regulation does exist, ${ }^{18}$ comprehensive monographic legal research on the

16 For more information about the GATS, the GPA, the SCM Agreement and the TRIPS, as well as on the relationship between private-sector standards and IP rights, see: Sections 2.3.4.1 and 2.3.4.2 of Chapter II.

17 See, for example: R. Bismuth, "Financial Sector Regulation and Financial Services Liberalization at the Crossroads: The Relevance of International Financial Standards in WTO Law", Journal of World Trade, 44(2), 2010; W. W. Bratton, "Private Standards, Public Governance: A New Look at the Financial Accounting Standards Board”, Boston College Law Review, 48, January, 2007; L. A. Cunningham, "Private Standards in Public Law: Copyright, Lawmaking and the Case of Accounting", Michigan Law Review, 104, November, 2005.

18 See, for example: Linda Fulponi, "Private Standard Schemes And Developing Country Access To Global Value Chains: Challenges And Opportunities Emerging From Four Case Studies”, AGR/CA/APM(2006)20/FINAL, OECD, August 
matter has not yet been undertaken. In this respect, the present study aims to contribute to the body of legal literature and research on this important topic. Indeed, analyzing the work on private-sector standards undertaken by various organizations and authors from various perspectives, together with examining the relevant rules of WTO law, helps to clarify the "picture" of the existing international regulatory framework in the area. This may also contribute to the exploring of possible avenues of interpretation and the further development of WTO rules for addressing such private (potentially) trade-restrictive behaviour as the development, adoption and application of private-sector standards.

The practical relevance of the present study exists due to the importance of real life issues arising with respect to private-sector standards. As has

2007; Linda Fulponi, "Final Report on Private Standards and the Shaping of the Agro-Food System”, AGR/CA/APM(2006)9/FINAL, OECD, Working Party on Agricultural Policies and Markets, July 2006; Vangelis Vitalis, "Private Voluntary Eco-Labels: Trade Distorting, Discriminatory and Environmentally Disappointing", OECD, Paris, 2002; Food Safety and Environmental Requirements in Export Markets - Friend or Foe for Producers of Fruit and Vegetables in Asian Developing Countries?, UNCTAD, UNCTAD/DITC/TED/2006/8, New York and Geneva, 2007; Private Sector Standards and Developing Country Exports of Fresh Fruit and Vegetables. Communication from the United Nations Conference on Trade and Development (UNCTAD), WTO, SPS Committee, G/SPS/GEN/761, 26 February 2007; Spencer Henson, John Humphrey, "The Impacts of Private Food Safety Standards on the Food Chain and on Public Standard-Setting Processes", Codex thirty-second Session, FAO, WHO, Codex Alimentarius Commission, Rome, May 2009; Cora Dankers, Pascal Liu, "Environmental and Social Standards, Certification and Labelling for Cash Crops”, FAO, Rome, 2003; Cora Dankers, Pascal Liu, "Private Standards in the United States and European Union Markets for Fruit and Vegetables - Implications for developing countries”, FAO Commodity Studies, 3, FAO, 2007; Steven Jaffee, Spencer Henson, "Standards and Agro-Food Exports from Developing Countries: Rebalancing the Debate", Policy Research Working Paper 3348, World Bank, June 2004; "Eco-Labeling Standards, Green Procurement and the WTO: Significance for World Bank Borrowers", Center for International Environmental Law, Washington, DC, Geneva, Switzerland, March, 2005; A. Akyoo and E. Lazaro, "The Spice Industry in Tanzania: General Profile, Supply Chain Structure, and Food Standards Compliance Issues", DIIS Working Paper no 2007/8, Danish Institute for International Studies, Copenhagen, 2007; J. Allshouse, J. C. Buzby, et al., "International Trade and Seafood Safety", at: J. C. Buzby, International Trade and Food Safety: Economic Theory and Case Studies, 828 United States Department of Agriculture, Economics Research Service, Washington D.C., 2003; S. Asfaw, D. Mithöfer, et al., "What Impact Are EU Supermarket Standards Having on Developing Countries Export of High-Value Horticultural Products? Evidence from Kenya", Paper for the 105th EAAE Seminar 'International Marketing and International Trade of Quality Food Products', Bologna, Italy, University of Hanover, Hanover, Germany, March 8-10, 2007; J. A. Berdegué, F. Balsevich, et al., "Central America Supermarkets' Private Standards of Quality and Safety in Procurement of Fresh Fruits and Vegetables”, Food Policy, 30, 2005; A. Graffham, E. Karehu, et al., "Impact of EurepGAP on Small-Scale Vegetable Growers in Kenya", Fresh Insights 6, September 2007. 
been explained above in Section 1.1 of the present Chapter, these issues are highly relevant for various actors operating in the areas of standard-setting, as well as the marketing and consumption of goods: WTO Members, national standards bodies (NSBs), international standardizing organizations, standard-setting NGOs, business corporations and even ordinary consumers. It seems fair to argue that all these actors are, to a greater or lesser extent, interested in having a clear understanding of the "rules of the game" with respect to private-sector standards operating on markets. Accordingly, the present study aims for the clarification of such rules applicable on multilateral level according to the relevant provisions of WTO law.

\subsection{Methodology and Approach}

The present study mainly uses two methods in the course of its discussion: descriptive and normative. Therefore, according to the method predominantly used, this study can be divided into two major parts - descriptive and normative. The descriptive part mainly consists of Chapter II, which, based on the relevant literature and existing studies on private-sector standards, describes, among other important issues, the concept of such standards, their functioning and effects, and challenges posed by these standards, including the challenges posed by them to the WTO legal system. The descriptive part serves as the foundation for the second, normative, part, which includes all subsequent chapters of the present study. The normative part deals with issues of the regulation of private-sector standards and private standard-setting activities by the rules of WTO law. In particular, it discusses the relevant rules of the aforementioned three WTO agreements ${ }^{19}$ and their interpretation given in WTO dispute settlement practice, as well as in legal doctrine, with the aim of finding possible implications of these rules for the regulation of private-sector standards. This, in turn, aims to allow for the arrival at well founded conclusions and the making of meaningful proposals for addressing the challenges posed by private-sector standards.

The approach taken in the present study could be explained by the fact that, first of all, this is a legal study devoted to the clarification of the WTO legal framework for private-sector standards as technical barriers in international trade in goods. This is not a descriptive report on the characteristics or effects of some private-sector standards in certain areas of regulation, e.g. protection of environment, safety and quality of products. Accordingly, there are no detailed case studies of particular private-sector standards in the present study. And in fact, a considerable number of case studies on the characteristics and effects of certain important private-sector standards

19 See: Section 1.1 of the present Chapter. 
have already been carried out by various organizations and independent researchers. These studies may and will be used, as relevant, in the descriptive part of the present study, for example, in the context of the development of the typology of private-sector standards and the discussion of the effects of private-sector standards on international trade in goods. However, the descriptive part serves as only a foundation for the legal research on possible implications of WTO rules for the regulation of various private-sector standards as technical barriers in international trade in goods.

Finally, it is worth noting that the present study is not aimed at focusing on private-sector standards from a particular perspective, e.g. a developed or developing country perspective. Indeed, a more general and independent approach incorporating an analysis of the interests of all WTO Members, whether least developed, developing or developed, seems to be more efficient due to several reasons. First, in principle, it could be reasonably assumed that under certain circumstances, private-sector standards have the potential to create problems and challenges not only for developing country producers, but also for some producers from developed countries, e.g. smallholders. Second, the WTO is a multilateral system, reflecting the compromise achieved among all its Members. Therefore, discussing the interests of one group of Members without taking into account the interests of the others seems to be counterproductive, since the consensus of all WTO Members in practice is required for the adoption or amendment of WTO rules. 


\title{
CHAPTER II \\ THE “WORLD” OF PRIVATE-SECTOR STANDARDS
}

\begin{abstract}
A
$s$ briefly explained in the Introduction, Chapter I, private-sector standards are developed and adopted by various types of NGOs and industry associations for use by business actors in a supply chain. ${ }^{20}$ These standards may also be developed and applied by business actors themselves (usually big ones) for their own needs. Since private-sector standards are legally voluntary, business actors, as a rule, choose to apply them due to various commercial and / or ethical considerations: higher efficiency of production and business, protection of a brand reputation, increased consumer demand on products, protection of the environment and good labour conditions, etc. These interests of business actors are indeed all interconnected, since in many countries nowadays, consumers do care about the environmental and social impact of products and production; many consumers are eager to take these factors into account in making their product choice. In this respect, private-sector standards frequently present higher or more extensive requirements on products and / or production processes than appropriate requirements contained in governmental / public regulatory rules - public standards and regulations. ${ }^{21}$

Consequently, obviously, private-sector standards coexist in national and international regulatory environments, together with public standards and regulations, ${ }^{22}$ as well as with international standards developed by international standard-setting organizations. However, as will be demonstrated further, private and public regulatory measures may sometimes be interlinked and are not always easy to distinguish. This is due to the variety
\end{abstract}

20 Some parts of the following discussion in this Chapter are based on: Arkady Kudryavtsev, "Private Standardization and International Trade in Goods: Any WTO Law Implications for Domestic Regulation?", the research paper presented at the SIEL Third Biennial Conference, Singapore 2012, available at the SSRN website: http://papers.ssrn.com/sol3/papers.cfm?abstract_id $=2082022$ (last visited February 7, 2015).

21 See: Spencer Henson, John Humphrey, "The Impacts of Private Food Safety Standards on the Food Chain and on Public Standard-Setting Processes", Codex thirty-second Session, FAO, WHO, Codex Alimentarius Commission, Rome, May 2009, p. 3.

22 The term "regulation" is mainly used in three possible meanings: 1 . Regulation in general as a process performed by governmental / non-governmental authorities and private parties, e.g. "public and private regulation"; 2. Mandatory legal rules, including laws and other governmental normative acts; 3 . Specific type of legislative acts, e.g. EU Regulation. In the present study, the term "regulation" will be used mostly in its second meaning. In this respect, a "technical regulation", as defined in Annex 1 of the WTO TBT Agreement, constitutes a form of regulation. For more information, see: Section 2.1.1.2 of the present Chapter. 
of regulatory forms and approaches, as well as to the large diversity of actors who may be involved in the development, adoption and application of standards on national and international levels. ${ }^{23}$

The present Chapter aims to describe the "world" of private-sector standards and the role of these standards in contemporary international trade. Indeed, before going into a detailed discussion about the prospects for legal regulation of these standards, it is necessary to define what a private-sector standard is and what its main characteristics are. This discussion will also help to distinguish private-sector standards from other governmental and non-governmental regulatory measures. For these purposes, the Chapter also attempts to present a typology of private-sector standards based on various criteria relevant for the legal regulation of these standards and their distinction from other types of regulatory measures. The Chapter further briefly describes reasons for the proliferation of private-sector standards, effects of private-sector standards on international trade, and challenges and opportunities posed by these standards for business actors.

\subsection{Defining the Concept of a Private-Sector Standard}

It is most appropriate to start discussing private-sector standards with the definition of the concept of a private-sector standard, in so doing, identifying and delimiting the subject of the present research. Then, it seems logical to provide a brief and systematic classification or typology of privatesector standards. At first sight, nothing could be easier if one assumes that the scope of the term "private-sector standard" may be clearly identified through a brief definition, and that private-sector standards can always be manifestly distinguished from public standards and technical regulations. However, it is important to realize that the reality is much more complicated.

Generally, standards and technical regulations may be adopted and enforced by a variety of entities including central and local (municipal) bodies; non-governmental bodies or organizations empowered to exercise elements of governmental authority. Especially in the case of standards and standard-setting, the role of the private sector is very important: standards

23 See: Spencer Henson, John Humphrey, "The Impacts of Private Food Safety Standards on the Food Chain and on Public Standard-Setting Processes", Codex thirty-second Session, FAO, WHO, Codex Alimentarius Commission, Rome, May 2009, pp. 4-5; see also: Spencer Henson, "The Role of Public and Private Standards in Regulating International Food Markets", Food Regulation and Trade: Institutional Framework, Concepts of Analysis and Empirical Evidence, IATRC, Bonn, Germany, May 28-30, 2006, pp. 4-6. 
may be developed, adopted and applied by different types of NGOs, industry associations and private corporations. ${ }^{24}$ Governments may or may not be involved at different regulatory stages. Indeed, today, taking into account the extremely complicated regulatory environments of industrialized countries, frequently it is not only very difficult to draw a clear line between private and public types of regulation, but also hardly possible to do so. The same is true for the differentiation between mandatory governmental technical regulations and voluntary governmental / non-governmental standards. Voluntary private-sector standards may acquire a more or less mandatory character through certain governmental incentives for their development or application. ${ }^{25}$ The relationship between public and private regulation, as well as the attribution of private regulatory behaviour to public bodies will be recurring themes of the present study.

Consequently, there is a feeling of indeterminacy appearing through the discussion in this Section that seems to be unavoidable. Nonetheless, in the author's view, this is advantageous rather than disadvantageous for the outcomes of the discussion. ${ }^{26}$ In fact, the aim of this Section is not to present a clear definition and an exhaustive typology of private-sector standards, thus creating a simplified and unrealistic picture. The aim is rather to outline the criteria for the identification and classification of private-sector standards, which are relevant for the following two objectives: 1. distinguishing private-sector standards from forms of public regulation and other forms of private regulation; 2. discussion and clarification of the legal regulatory framework for private-sector standards. These criteria may help on a case-by-case basis in identifying private-sector standards and the legal norms applicable to them. Accordingly, it is also necessary to note that the definition of private-sector standard and the typology of these standards as set out in this Section are proposed mainly for the purposes of the present study. The author therefore does not claim that they will necessarily be appropriate in the context of other relevant research projects.

24 See: Cora Dankers, Pascal Liu, "Environmental and Social Standards, Certification and Labelling for Cash Crops", FAO, Rome, 2003, p. 13-14.

25 See: Spencer Henson, John Humphrey, "The Impacts of Private Food Safety Standards on the Food Chain and on Public Standard-Setting Processes", Codex thirty-second Session, FAO, WHO, Codex Alimentarius Commission, Rome, May 2009 , p. 5.

26 Indeed, in the author's view, many of the studies on private-sector standards and the prospects for their legal regulation undertaken thus far have suffered from a simplified approach to the differentiation between public and private regulatory measures. This, of course, had certain implications for the results of these studies. 


\subsubsection{Main Characteristics of Private-Sector Standards and Their Conformity Assessment Procedures}

To understand the meaning and scope of the term "private-sector standard", it is necessary to define this term and explain why the term "privatesector standard" is used in the present study. In doing so, it seems appropriate to provide the general description of the relevant characteristics of private-sector standards. However, before proceeding with a discussion on the definition and characteristics of private-sector standards, it is clearly necessary to provide an explanation of the meaning of the term "standard" perse.

\subsubsection{Defining the Concept of a Standard}

The word "standard" is quite polysemantic. Among the twenty-eight possible meanings of this term specified by the Oxford English Dictionary, the most appropriate definitions for the purposes of this discussion seem to be the following: "an authoritative or recognized exemplar of correctness, perfection, or some definite degree of any quality"; "a rule, principle, or means of judgement or estimation; a criterion, measure" and "a definite level of excellence, attainment, wealth, or the like, or a definite degree of any quality, viewed as a prescribed object of endeavour or as the measure of what is adequate for some purpose" ${ }^{27}$ These definitions are quite broad, however, and therefore, perhaps, not really useful. Hence, it is visibly more appropriate to search for a definition of the term "standard" in the specialized acts and documents related to the regulation of standardizing activities. The ISO/IEC Guide 2 - the document developed by International Organization for Standardization (ISO) and International Electrotechnical Commission (IEC) containing general terms and definitions in the area of standardization - may be one of the major relevant authorities. ${ }^{28}$ According to the ISO/IEC Guide 2:

27 See: Oxford English Dictionary Online, see: http://dictionary.oed.com (last visited November 20, 2014).

28 "ISO (International Organization for Standardization) is the world's largest developer and publisher of International Standards"; "The IEC [International Electrotechnical Commission] is the world's leading organization that prepares and publishes International Standards for all electrical, electronic and related technologies - collectively known as "electrotechnology" “; see respectively: http://www.iso.org/iso/about.htm; http://www.iec.ch (last visited November 20, 2014). "ISO/IEC Guide 2 provides general terms and definitions concerning standardization and related activities. It is intended to contribute fundamentally towards mutual understanding amongst the members of ISO and IEC and the various governmental and non-governmental agencies involved in standardization at international, regional and national levels"; see: Submission by the ISO to the meeting of the TBT Committee, WTO TBT Committee, G/TBT/GEN/38, para. 5. The Guide is periodically reviewed; the last version is the eighth edition - ISO/IEC 
In science and technology, the English word "standard" is used with two different meanings: as a normative document [...] (in French “norme”, in Russian “стандарт”) and also as a measurement standard (in French “étalon”, in Russian “эталон”). This Guide is concerned solely with the first meaning. ${ }^{29}$

The definition 3.2 of the Guide defines the term "standard" in the following way:

Document, established by consensus and approved by a recognized body, that provides, for common and repeated use, rules, guidelines or characteristics for activities or their results, aimed at the achievement of the optimum degree of order in a given context.

Note: Standards should be based on the consolidated results of science, technology and experience, and aimed at the promotion of optimum community benefits. ${ }^{30}$

\subsubsection{Mandatory or Voluntary?}

It is important to note that the definition of a standard as quoted above does not specify whether it covers only legally non-mandatory (i.e. voluntary) documents or legally mandatory ones as well. Arguably, this makes the definition very broad, since according to its wording, in principle, a substantial part of governmental mandatory regulations may fall under the definition of standard. ${ }^{31}$ Indeed, one may notice certain differences in the use of this term in the literature belonging to different areas of science, where the term "standard" sometimes appears to cover not only legally voluntary, but also legally mandatory measures. ${ }^{32}$

Guide 2:2004, Standardization and Related Activities - General Vocabulary.

29 ISO/IEC Guide 2: 2004, Standardization and Related Activities - General Vocabulary, Introduction.

30 ISO/IEC Guide 2: 2004, Standardization and Related Activities - General Vocabulary, definition 3.2. See also: Negotiating History of the Coverage of the Agreement on Technical Barriers to Trade with Regard to Labelling Requirements, Voluntary Standards and Production Methods Unrelated to Product Characteristics. Note by Secretariat, TBT Committee, CTE, WT/CTE/W/10, G/TBT/W/11, Geneva, 29 August 1995, para. XL

31 The ISO/IEC Guide 2 is indeed a bit confusing in this respect. On the one hand, its definition of standard does not clearly exclude legally mandatory measures, e.g. regulations. However, on the other hand, the definitions of regulation and technical regulation are provided in a different part of the Guide than the definition of standard and the description of types of standards.

32 Undoubtedly, another important contributing factor to the discrepancies in understanding the term "standard" is its interdisciplinary character. This term is widely used within natural, political, legal, economic and other sciences. Meanwhile, different sciences tend to generate and operate with their own terminological 
However, it is more common nowadays to understand the term "standard" as referring only to legally voluntary documents, which are not binding for compliance by market players. Nonetheless, the rules of a standard may be made mandatory through their incorporation into mandatory governmental regulations. Indeed, according to the definition of technical regulation in the ISO/IEC Guide 2, technical regulation may refer to or incorporate the content of a standard. ${ }^{33}$ The terminology adopted in the framework of the WTO adheres to such an approach as well. In this regard, the WTO TBT Agreement distinguishes two types of measures: ${ }^{34}$ mandatory technical regulations and voluntary standards. ${ }^{35}$ Standard is defined in Annex 1 of the TBT Agreement as:

Document approved by a recognized body, that provides, for common and repeated use, rules, guidelines or characteristics for products or related processes and production methods, with which compliance is not mandatory. It may also include or deal exclusively with terminology, symbols, packaging, marking or labelling requirements as they apply to a product, process or production method.

Although in the author's view, the relevant terminology of the TBT Agreement is more consistent and logical, perhaps it would be not prudent for the author to make a conclusive judgment on which terminology is better or correct. The question is which terminology should be used for the present study. Since this study is aimed at exploring the modes and perspectives of the application of WTO law to private-sector standards, it seems logical to follow the terminology and approach of the TBT Agreement. Therefore, the term "standard" will be used only for legally voluntary measures, while the terms "technical regulation" or "regulation" will be applied to legally mandatory measures.

vocabulary; and meanings of the same terms may vary substantially from science to science.

33 See: ISO/IEC Guide 2: 2004, Standardization and Related Activities - General Vocabulary, definitions 3.6 and 3.6.1:

regulation - document providing binding legislative rules, that is adopted by an authority.

technical regulation - regulation that provides technical requirements, either directly or by referring to or incorporating the content of a standard, technical specification or code of practice.

34 For more information about the status and the content of the TBT Agreement, see: Chapter IV.

35 The difference between the definitions of standard contained in the ISO/IEC Guide 2 and the TBT Agreement is indeed emphasized in the Explanatory Note to the definition of standard in Annex 1 of the TBT Agreement: "Standards as defined by ISO/IEC Guide 2 may be mandatory or voluntary. For the purpose of this Agreement standards are defined as voluntary and technical regulations as mandatory documents". 


\subsubsection{Excluding Services and Consensus Rule}

There are also a few other important differences between the definitions of standard in the ISO/IEC Guide 2 and the TBT Agreement. First, the ISO/IEC Guide definition provides that a standard may address "characteristics for activities or their results". Such wording means that this definition of standard covers not only products and production processes (also commonly known as processes and production methods, PPMs), but also services. The definition of standard in the TBT Agreement covers only products and PPMs, and technical barriers to trade in services are explicitly excluded from the Agreement's scope. ${ }^{36}$ Since the present study deals only with private-sector standards related to trade in products (not services), this approach of the TBT Agreement will be followed here as well. In fact, as has been noted in the Introduction, Chapter I, trade in services is a separate complex area of national and international regulation; thus, privatesector standards in trade in services may be a good subject for a separate research project.

Second, the definition of standard in the ISO/IEC Guide 2 requires that the standard must be established by consensus; the definition of the TBT Agreement does not present such a requirement. Moreover, the Explanatory Note to the definition of standard in Annex 1 of the TBT Agreement clarifies that consensus is not inevitably a necessary procedure for the adoption of a standard within the meaning of the Agreement.

Generally, it is worth noting that the understanding of the decisionmaking process by consensus is, to a certain extent, different in the ISO/ IEC framework for standardization and in the WTO legal framework. On the one hand, according to the ISO/IEC Guide 2, "consensus" is:

general agreement, characterized by the absence of sustained opposition to substantial issues by any important part of the concerned interests and by a process that involves seeking to take into account the views of all parties concerned and to reconcile any conflicting arguments.

Note: Consensus need not imply unanimity. ${ }^{37}$

It is, however, not completely clear what certain terminology in this definition, such as "sustained opposition", "substantial issue" and "important part of the concerned interests", exactly mean. Therefore, at least from a

36 See the Explanatory Note to the definition of a standard in the TBT Agreement: "The terms as defined in ISO/IEC Guide 2 cover products, processes and services. This Agreement deals only with technical regulations, standards and conformity assessment procedures related to products or processes and production methods".

37 ISO/IEC Guide 2: 2004, Standardization and Related Activities - General Vocabulary, definition 1.7. 
legal point of view, this definition of consensus appears quite vague. On the other hand, the Marrakesh Agreement Establishing the World Trade Organization (the WTO Agreement) provides:

The body concerned shall be deemed to have decided by consensus on a matter submitted for its consideration, if no Member, present at the meeting when the decision is taken, formally objects to the proposed decision. ${ }^{38}$

The author does not intend to engage in a discussion here on which understanding of the term "consensus" is more accurate. In any case, taking into account the variety of existing private-sector standards as well as the variety of standard-setting procedures in different organizations and agencies, it does not seem appropriate to limit the discussion to only standards approved by consensus. This is especially so because a private-sector standard adopted by individual producers and retailers would, as a rule, not have been subject to any kind of "decision-making" involving other actors. Accordingly, in the present study, approval by consensus will not be regarded as a prerequisite for a document to qualify as a standard.

\subsubsection{Main Characteristics of Private-Sector Standards}

The following characteristics of the term "standard" are common between both definitions in the ISO/IEC Guide 2 and the TBT Agreement:

- First, a standard is a "document". According to the ISO/IEC Guide 2, the term "document" "is to be understood as any medium with information recorded on or in it". ${ }^{39}$ This means that, for example, unwritten rules, customs, traditions, and any other verbal statements may not be regarded as standards.

- Second, the document must be approved by a "recognized body". It is, however, not clear what type of entities the term "body" implies, and by whom such a "body" would be recognized: by national governments, national or international market players, or other national and international standardsetting organizations. The definition of the term "body" from the ISO/IEC Guide 2 does not provide much information in this respect:

Body (responsible for standards and regulations) - legal or administrative entity that has specific tasks and composition.

Note: Examples of bodies are organizations, authorities, companies and foundations. ${ }^{40}$

38 Marrakesh Agreement Establishing the World Trade Organization, footnote 1 to Article IX.

39 ISO/IEC Guide 2: 2004, Standardization and Related Activities - General Vocabulary, Note 2 to definition 3.1 .

40 ISO/IEC Guide 2: 2004, Standardization and Related Activities - General Vocabulary, definition 4.1 . 
Furthermore, according to the Guide, an "organization" is a type of body "that is based on the membership of other bodies or individuals and has an established constitution and its own administration". ${ }^{41}$

The ISO/IEC Guide 2 also contains a definition of a "standardizing body" - a "body that has recognized activities in standardization". ${ }^{42}$ Moreover, interestingly, the ISO/IEC Guide 2 contains a separate definition of another quite similar term - "standards body", which is defined as:

standardizing body recognized at national, regional or international level, that has as a principal function, by virtue of its statutes, the preparation, approval or adoption of standards that are made available to the public.

Note: A standards body may also have other principal functions. ${ }^{43}$

It is again apparent that both definitions provide that a body must be "recognized" as a standardizing one, and in the case of a "standards body", standard-setting activities must be a "principal function" of the body. However, the exact meanings of these terms are not really clear. Moreover, it is also not clear whether these two terms are aimed to address all possible standard-setting organizations, or if there are such organizations which are not covered by these terms.

The meaning and the scope of the term "recognized body" will be discussed in more detail in Chapter IV, dealing with the relevant provisions of the TBT Agreement. However, for the purposes of defining the term "private-sector standard", it will be assumed that standards, in principle, may be developed and adopted by any type of governmental or non-governmental agency or organization, including non-profit organizations and business corporations. It may be argued that such approach is also shared by the ISO/IEC Guide 2, taking into account the references to "organizations", "companies and foundations" in the Note to the definition of the term "body", quoted above. Moreover, interestingly, the ISO/IEC Guide 2 , with reference to "other standards", further explains that "[s]tandards may also be adopted on other bases, e.g. branch standards and company standards". ${ }^{44}$

- Third, the document must provide rules, guidelines or characteristics for products or PPMs (including the requirements related to the products'

41 ISO/IEC Guide 2: 2004, Standardization and Related Activities - General Vocabulary, definition 4.2 .

42 ISO/IEC Guide 2: 2004, Standardization and Related Activities - General Vocabulary, definition 4.3.

43 ISO/IEC Guide 2: 2004, Standardization and Related Activities - General Vocabulary, definition 4.4 .

44 ISO/IEC Guide 2: 2004, Standardization and Related Activities - General Vocabulary, Note to definition 3.2.2. 
marking and labelling, products terminology and symbols or packaging). This means that a standard must present certain rules or guidelines related to specific characteristics of products (including their appearance, e.g. labelling) or to methods of their production (PPMs). Therefore, arguably, such measures as, for example, certain selling arrangements (rules generally describing when, how and where products can be sold) or limitations / prohibitions on product advertising cannot be regarded as standards providing that they are not based on product characteristics or PPMs.

- Fourth, the rules, guidelines or characteristics must be provided "for common and repeated use". Arguably, this wording does not directly require that a standard be applied "commonly and repeatedly" by a large number of organizations. One possible interpretation is that a standard should be aimed for "common and repeated use" during its development, but its widespread application among business actors is not required. Moreover, arguably, the "common and repeated use" of a standard may take place even if applied by one corporation to all its suppliers, if this is a big multinational corporation having a substantial market share. At the same time, it seems that this criterion does exclude from the scope of the term "standard", the one-time sale of goods contracts specifying product characteristics, since they are not meant to be used commonly and repeatedly. ${ }^{45}$ Thus, arguably, the criterion of the "common and repeated use" implies that a standard as a document must have certain degree of normativity. In this respect, remarkably, the ISO/IEC Guide 2 contains the definition of the term "normative document", which reads as follows:

document that provides rules, guidelines or characteristics for activities or their results.

Note 1: The term "normative document" is a generic term that covers such documents as standards, technical specifications, codes of practice and regulations. ${ }^{46}$

\subsubsection{Some Examples of Private Sector Standards}

Private-sector standards may be described as standards adopted by nongovernmental entities in a broad sense, including environmental or human rights non-profit organizations, business corporations, industry associations and other types of NGOs. To understand the variety of such non-governmental entities, which may develop and adopt private-sector standards, it is worth providing some examples. GLOBALG.A.P. (formerly known

45 This is, however, not so clear with respect to the forms of contracts used repeatedly by companies in their relations with suppliers. This issue will be further discussed in Section 2.2.3.2.1 of the present Chapter.

46 ISO/IEC Guide 2: 2004, Standardization and Related Activities - General Vocabulary, definition 3.1. It is worth noting, however, that the ISO/IEC Guide 2 still uses the term "document" and not the term "normative document" in the definition of "standard". 
as EUREPG.A.P.), for instance, is a private standard-setting organization which develops and adopts private-sector standards for the certification of good agricultural practices (G.A.P.) in farm agricultural production. Originally it was founded by the consortium of European retailers, the Euro-Retailer Produce Working Group (EUREP), and was formally established as the limited liability company FoodPLUS GmbH incorporated in Cologne, Germany, where its headquarters and secretariat are based. ${ }^{47}$ GLOBALG.A.P. aims to establish one common G.A.P. standard "capable of fitting to the whole of global agriculture", and has an international membership consisting of producers / suppliers, retailers and other associated members. ${ }^{48}$ Another example is the Marine Stewardship Council (MSC); an international non-profit organization administering one of the "world's leading certification and eco-labelling programs for sustainable seafood". ${ }^{49}$ The MSC was originally founded by the World Wide Fund for Nature and by the multinational corporation Unilever, and has its head office in London. ${ }^{50}$ Finally, "Nature's Choice" is an example of a private-sector standard developed by the commercial corporation Tesco PLC, which is the largest British grocery and general merchandising retail chain, and the third largest in the world. "The standard was developed to ensure that [...] top quality fresh produce comes [to Tesco supermarkets] from growers who use good agricultural practices, operate in an environmentally responsible way and with proper regard for the health and well being of their staff'. ${ }^{51}$

47 See: http://www.globalgap.org/cms/front_content.php?idcat=19; http://www.globalgap.org/cms/front_content.php?idcat=13 (last visited November 20, 2014).

48 See: http://www.globalgap.org/cms/front_content.php?idcat=2; http://www.globalgap.org/cms/front_content.php?idcat=20 (last visited November 20, 2014). See also: Valeska Weymann, "GLOBALGAP Aquaculture Standard. Towards More Species Coverage”, News. Good Agricultural Practice, October 2008; Linda Fulponi, "Final Report on Private Standards and the Shaping of the Agro-Food System”, AGR/CA/APM(2006)9/FINAL, OECD, Working Party on Agricultural Policies and Markets, July 2006, p. 20.

49 See: http://www.msc.org/about-us/governance; http://www.msc.org/about-us (last visited November 20, 2014). See also: Frans van Waarden, "Governing Global Commons: The Public-Private Protection of Fish and Forests", at: Axel Marx, Miet Maertens, Johan Swinnen, Jan Wouters, Private Standards and Global Governance. Economic, Legal and Political Perspectives, Edward Elgar, Cheltenham, UK, 2012, pp. $33-36$.

50 See: http://www.alaskaoceans.net/aboutus/msc.htm; http://www.msc.org/about-us/offices-staff (last visited November 20, 2014).

51 See: http://www.tescofarming.com/tnc.asp (last visited November 20, 2014). 


\subsubsection{Reasons for Using the Term "Private-Sector Standard"}

In the relevant literature, private-sector standards are also frequently referred to as "private voluntary standards" or, simply, as "private standards" ${ }^{52}$ Arguably, the term "private-sector standard" is more accurate because the wording "private voluntary standard" presupposes that such standards are "voluntary".

Because the application of private-sector standards by business corporations is de jure non-mandatory and usually done on their own initiative, the application of such standards by corporations constitutes a substantial part of the process commonly referred to as "business self-regulation". It should be noted that private-sector standards indeed are always voluntary from a legal point of view, i.e. they are legally non-binding. However, these standards may become to significant extent mandatory de facto for market access, if they are widely applied in a market. This may be the case, for example, due to the tremendous purchasing power of multinational corporations, retail chains and other companies, or even entire industries which substantially control a market and apply certain private-sector standards. This problem is widely recognized in the relevant literature and is also frequently complained about by producers (especially small-scale ones) from developing countries. ${ }^{53}$ Moreover, governments may, in principle, provide certain incentives for the implementation of private-sector standards, thus also rendering them not completely voluntary de facto for market players. Thus, in order to prevent any premature judgment about the voluntary or non-voluntary character of all private-sector standards, it seems more appropriate to avoid using the word "voluntary" when addressing these standards.

The use of the term "private" on its own next to "standard" may have certain drawbacks as well. Governments may, in principle, entrust

52 See, for example: Private Voluntary Standards and Developing Country Market Access: Preliminary Results. Communication from OECD, Linda Fulponi, WTO, SPS Committee, G/SPS/GEN/763, Geneva, 27 February 2007; Private Voluntary Standards within the WTO Multilateral Framework: Submission by the United Kingdom. A report prepared by Digby Gascoine and O'Connor and Company, WTO, SPS Committee, G/SPS/GEN/802, Geneva, 9 October 2007; Grace ChiaHui Lee, "Private Food Standards and Their Impacts on Developing Countries", European Commission DG Trade Unit G2, Brussels, 2006; Linda Fulponi, "Final Report on Private Standards and the Shaping of the Agro-Food System", AGR/CA/ $\operatorname{APM}(2006) 9 / F I N A L$, OECD, Working Party on Agricultural Policies and Markets, July 2006.

53 See: Private Standards and the SPS Agreement. Note by the Secretariat, WTO, SPS Committee, G/SPS/GEN/746, Geneva, 24 January 2007, para. 9;Samir R. Gandhi, "Disciplining Voluntary Environmental Standards at the WTO: An Indian Legal Viewpoint”, Working Paper No.181, Indian Council for Research on International Economic Relations, 2006, p. 8. 
non-governmental entities to perform certain governmental functions, including public standard-setting. In fact, in quite a number of countries, the main national standards bodies (NSBs) are incorporated as private nongovernmental entities, such as standardizing institutes, national partnerships, or industry associations. The legal status of such NSBs or other national standardizing organizations which function as private organizations shall not affect the public nature of these organizations and of the standards they adopt. Indeed, governments shall not be allowed to hide behind a "private veil" and commit the acts which otherwise would be prohibited for their bodies and agencies. Therefore, the use of the term "private-sector standard" instead of "private standard" in the present study is meant to emphasize that such standards should be developed and adopted not only by private entities, but also by entities acting within the private sector domain rather than the public sector domain. Thus, standards developed by private institutions which are specially entrusted by governments to develop public standards may, in principle, not be regarded as private-sector standards for the purposes of the present study. However, as will be demonstrated hereafter, the distinction between private and public measures is not always clear in practice, and this distinction will be an important recurring theme in the chapters of this study.

\subsubsection{Brief Definition of a Private-Sector Standard and its Conformity Assessment Procedure}

Taking into account the issues discussed above, a private-sector standard will be defined as follows for the purposes of this study:

Document approved by a private entity within the private sector, that provides, for common and repeated use, rules, guidelines or characteristics for products or processes and production methods (including rules or guidelines on terminology, symbols, packaging, marking and labelling etc.), with which compliance is legally not mandatory.

Verification that the requirements of a private-sector standard are fulfilled occurs through "conformity assessment procedures" - another important term in the context of technical barriers to trade in general, and standards in particular. Using the general definition of conformity assessment procedures contained in Annex 1 of the TBT Agreement, ${ }^{54}$ the conformity assessment procedures for private-sector standards could be defined as:

54 Annex 1.3 of the TBT Agreement provides the following definition of conformity assessment procedures: "Any procedure used, directly or indirectly, to determine that relevant requirements in technical regulations or standards are fulfilled". 
Any procedure used, directly or indirectly, to determine that relevant requirements of private-sector standards are fulfilled.

\subsubsection{Operational Stages of Private-Sector Standards}

Private-sector standards, as well as public standards, have certain operational stages, which need to be distinguished in order to properly understand how the process regarding the operation of standards works. ${ }^{55}$

\subsubsection{Preparation of a Standard}

At the stage of the preparation (or development) of a standard, the rules and procedures presented by a standard are actually formulated. This may include drafting a project of a standard within technical committees, discussing a text of a draft standard with interested stakeholders, publishing a draft standard, and receiving and considering comments on the draft. Various private and public standardizing organizations may have different rules for the procedures of standard-setting, providing for different levels of transparency and stakeholder involvement. Over the past decades there have been governmental and private attempts to harmonize these procedures to a certain extent for both public and private standards in order to ensure their improved transparency and legitimacy. For example, the WTO TBT Agreement contains Annex 3 - "Code of Good Practice for the Preparation, Adoption and Application of Standards" (Code of Good Practice). This Annex details the appropriate requirements for standardizing bodies concerning openness and transparency of standard-setting processes. Another example is ISEAL Alliance, "the global association for social and environmental standards", ${ }^{56}$ which develops codes of good practice with regard to standard-setting procedures, compliance verification and standards' impact assessment for its members, which are the leading private standard developing organizations. ${ }^{57}$

55 The list of operational stages of private-sector standards is based on: Spencer Henson, John Humphrey, "The Impacts of Private Food Safety Standards on the Food Chain and on Public Standard-Setting Processes", Codex thirty-second Session, FAO, WHO, Codex Alimentarius Commission, Rome, May 2009, pp. 7 - 8; Spencer Henson, John Humphrey, "Private Standards in Global Agri-Food Chains", at: Axel Marx, Miet Maertens, Johan Swinnen, Jan Wouters, Private Standards and Global Governance. Economic, Legal and Political Perspectives, Edward Elgar, Cheltenham, UK, 2012, pp. $99-101$.

56 See: http://www.isealalliance.org/content/about-us (last visited November 20, 2014).

57 The ISEAL membership includes the FLO, the MSC, the FSC and some other private standard-setting organizations; see: http://www.isealalliance.org/content/about-us (last visited November 20, 2014). 


\subsubsection{Adoption of a Standard}

The adoption of a standard means the final approval of the text of a standard by a standard-setting entity. A standard is usually adopted after the completion of a discussion and a consideration of the comments on the draft text of a standard. Depending on the rules of the procedure of a standardizing organization, adoption may be based or not based on consensus. Adoption is usually followed by the publication of the final text of a standard. The described meaning of the term "adoption" is used in the Code of Good Practice in Annex 3 of the TBT Agreement. ${ }^{58}$ However, according to the ISO/IEC Guide 2, the term "adoption", with respect to standards, is also "sometimes used to cover the same concept as "taking over", e.g. the "adoption of an international standard in a national standard". ${ }^{59}$ In the relevant literature, the term "adoption" may, at times, also mean the decision by an entity to apply a standard to its suppliers, e.g. a "private company can adopt a standard by requiring its suppliers to use it". ${ }^{60}$ In order to avoid any confusion, the present study will use the term "adoption" only in its first sense, as this is done in the Code of Good Practice of the TBT Agreement.

The preparation and adoption of standards together are often called standard-setting or standardization.

\subsubsection{Application of a Standard}

Because standards, unlike technical regulations, are legally non-mandatory, the crucial element of standards' operation is their application by particular private or public entities in a business sector. In fact, it is the application that makes standards operational in markets. The application of a standard means that a decision has been made by a business entity to demand that its suppliers comply with the requirements of a standard. Such compliance by suppliers may be verified by a business entity itself or confirmed by a certificate issued by a third party. A business entity may apply its own standards or standards developed by any other non-governmental or governmental standard-setting organization. A clear example of the application of a standard would be a decision by a supermarket chain to procure from its suppliers only fruits and vegetables certified under GLOBALG.A.P. standards.

58 See, for example, the obligation of a standardizing body to publish a standard promptly after its adoption in para. O of Annex 3 of the TBT Agreement.

59 ISO/IEC Guide 2: 2004, Standardization and Related Activities General Vocabulary, Note to definition 10.1.

60 Spencer Henson, John Humphrey, "The Impacts of Private Food Safety Standards on the Food Chain and on Public Standard-Setting Processes", Codex thirty-second Session, FAO, WHO, Codex Alimentarius Commission, Rome, May 2009, p. 7. 


\subsubsection{Implementation of a Standard}

The implementation of a standard (or compliance with a standard) is carried out by an entity which decides to comply with the requirements of a standard. Business actors, i.e. suppliers of the products, implement a standard because they are faced with such a demand from their buyers, or because they choose to do so on their own initiative. Following on the previous example of fruit and vegetables, the implementation of a standard by the farm would take place if the compliance of the farm with the requirements of GLOBALG.A.P. has been confirmed by a certification process which then allows the farm to supply its produce to a supermarket chain. In principle, the same entity may both apply and implement private-sector standards at the same time. This may, for example, occur in cases of internally applied private-sector standards, i.e. standards used by companies for the regulation of their own production processes without presenting requirements to suppliers. ${ }^{61}$ Such documents may include companies' codes of conduct and codes of good practices, or standards for production processes at particular stages adopted by corporations themselves or by standard-setting NGOs. For example, the multinational corporation Royal Dutch Shell claims to base all its activities on its own "Business Principles and Code of Conduct" which is further "translated into specific requirements through a set of company-wide commitments and standards", ${ }^{62}$ e.g. standards on the minimal health management of workers, animal testing, security and biodiversity standards ${ }^{63}$ Another situation where a company may both apply and implement a private-sector standard at the same time is in the case of a supply chain. For example, in the case of the Marine Stewardship Council (MSC), which provides the standard for sustainably produced seafood, a seafood processing company may apply the MSC standards if it requires all its suppliers (fishing companies) to implement this standard as confirmed by the certification. At the same time the seafood processing company itself has to implement the MSC standards ${ }^{64}$ and get certified in order to supply its products to a supermarket chain applying this standard.

${ }^{61}$ For more information concerning the internally applied private-sector standards, see Section 2.2.6 of the present Chapter.

${ }^{62}$ http://www.shell.com/home/content/environment_society/integrated_approach/ our_commitments_and_standards/dir_commitments_standards.html (last visited November 20, 2014).

63 See: http://www.shell.com/home/content/environment_society/integrated_ approach/our_commitments_and_standards/dir_commitments_standards.html (last visited November 20, 2014).

${ }^{64}$ In particular, the MSC Chain of Custody Standard for Seafood Traceability, see: http://www.msc.org/about-us/standards/standards/chain-of-custody (last visited November 20, 2014). 
It is worth noting in this respect that the processes of application and implementation of a standard are frequently hard, if possible at all, to distinguish. And this may not only be the case in the two situations described in the paragraph above. In fact, a producer supplying a product may decide independently (i.e. without demands posed by its buyers) to offer its products in the market as produced in conformity with a relevant private-sector standard. And in this sense it can be said that the producer not only "implements" but also "applies" the standard. Moreover, a single standard may, in principle, contain recommendations relevant with respect to the suppliers of a corporation, as well as with respect to a corporation's own production processes. The corporation would thus both apply and implement such a standard. In other words, the "application" and "implementation" of a standard shall be viewed as "two sides of the same coin". In the context of the present study the distinction between the terms "application" and "implementation" of a standard is useful mainly for the purposes of clarity in describing the process of operation of a standard in a supplier-buyer relationship, i.e. a buyer "applies" a standard by demanding compliance with it by a supplier, and the supplier "implements" the standard by complying with its recommendations.

\subsubsection{Conformity Assessment and Enforcement of a Standard}

A conformity assessment (or verification) with a standard is performed through conformity assessment procedures as defined and briefly described above. ${ }^{65}$ The enforcement of a standard is based on the results of the conformity assessment and implies sanctions for non-compliance with the requirements of a standard. In the case of private-sector standards, the main possible sanction is a refusal, by a company demanding compliance with a certain standard, to buy a product. In principle, however, this may be also lower the purchasing price or the volume of purchased products.

\subsection{Typology of Private-Sector Standards}

As may be already seen from the discussion above, the "world" of privatesector standards is very diverse and complex. Taking this into account, the selective study of any particular private-sector standard (or group of such standards) may appear to not really be representative with respect to the entire body of private standard schemes. The present study aims to shed some light on the prospects of the regulation (and possible conditions thereof) of the entire body of private-sector standards by WTO legal rules.

65 For more information about the conformity assessment systems for private-sector standards, see Section 2.2.9 of the present Chapter. 
In this respect, a certain level of generalization is inevitable. The present study therefore adopts another approach, i.e. making a typology of privatesector standards based on appropriate criteria. In fact, several attempts to create such a typology or classify private-sector standards can be found in the relevant literature. ${ }^{66}$ However, this typology of private-sector standards will be made specifically for the purposes of the present study and will be based on the criteria relevant for this study. At the same time, in order to highlight more practical details for further discussion and to avoid it being merely theoretical, the typology will provide particular examples of relevant private-sector standards.

\subsubsection{Choice of Relevant Criteria for Typology of Private-Sector Standards}

The criteria for making the typology of private-sector standards are chosen specifically for the purposes of the present study ${ }^{67}$ These chosen criteria are supposed to assist with clarifying the subject of the study, i.e. which types of private-sector standards are particularly important and relevant for the present study and which ones are not. The criteria for the typology have been chosen on the basis of their relevance for the legal regulation of private-sector standards within the WTO legal framework. The legal regulation of private-sector standards is a very complex issue, and many classification criteria might in fact be appropriate. The present typology of private-sector standards does therefore not claim to incorporate all possible criteria.

The first criterion for the typology is the form of private-sector standards. The form of the standard implies the types of documents which may contain private-sector standards, e.g. standard code, codes of good practices, production manuals, etc. In principle, and depending on the form of

66 See: Spencer Henson, John Humphrey, "The Impacts of Private Food Safety Standards on the Food Chain and on Public Standard-Setting Processes", Codex thirty-second Session, FAO, WHO, Codex Alimentarius Commission, Rome, May 2009, pp. 4-8; Pascal Liu, "Private standards in international trade: issues and opportunities", Contribution to Workshop on Environment-Related Private Standards, Certification and Labelling Requirements, WTO, Geneva, July 9, 2009, pp. 3-7; Cora Dankers, Pascal Liu, "Private Standards in the United States and European Union Markets for Fruit and Vegetables - Implications for developing countries", FAO Commodity Studies, 3, FAO, 2007, pp. 15 - 76.

67 Some of these criteria are also used in other studies, for example: Spencer Henson, John Humphrey, "The Impacts of Private Food Safety Standards on the Food Chain and on Public Standard-Setting Processes", Codex thirty-second Session, FAO, WHO, Codex Alimentarius Commission, Rome, May 2009, pp. 4-8; Pascal Liu, "Private standards in international trade: issues and opportunities", Contribution to Workshop on Environment-Related Private Standards, Certification and Labelling Requirements, WTO, Geneva, July 9, 2009, pp. 3-7. 
private-sector standards, different legal norms may be applicable. This criterion is also helpful in differentiating between standards in general and private-sector standards in particular from other types of documents.

The second criterion is the type of organizations adopting privatesector standards. As has been mentioned above, private-sector standards may be developed and adopted by various types of private entities: by international and national NGOs, national and transnational corporations, etc. The type of adopting organization is very important for the differentiation of private-sector standards from public standards. It may be also relevant for identification of the appropriate legal regulatory regime for a particular private-sector standard, as well as for the issues of attribution and jurisdiction, i.e. whether a particular State could actually influence or control the standardizing activities of an international NGO or a transnational corporation.

The third and very important criterion for the typology is the level of governmental involvement or incentives for the development and application of private-sector standards. This criterion is crucial for addressing the issues of legal regulation of private-sector standards. On the one hand, this criterion will help with the differentiation between private-sector standards and public governmental or non-governmental standards. It may also help to distinguish voluntary private-sector standards from mandatory regulatory measures. On the other hand, the criterion of governmental involvement is relevant for the issue of attribution of private standard-setting activities to public authorities. The attribution process in this context addresses the question of when a State may be held responsible for development and / or application of private-sector standards by private organizations. Taking into account that it is mostly States who have obligations under WTO law, ${ }^{68}$ the issue of attribution of private activities to governmental authorities is essential for the present study.

Objectives of private-sector standards is the fourth criterion for the typology. The objectives of private-sector standards may play an important role in the legal regulation of standards, taking into account the following

68 Indeed, almost all Members of the WTO are States. However, WTO membership also includes the European Union (EU) and three Separate Custom Territories (SCTs): Hong Kong (China), Macau (China) and Chinese Taipei. The SCTs possess "full autonomy in the conduct of their external commercial relations and in the other matters covered by the WTO Agreement"; see: Peter Van den Bossche, Werner Zdouc, The Law and Policy of the World Trade Organization. Text, Cases and Materials, 3d Edition, CUP, 2013, pp. $104-105$.

See also: The World Trade Organization in Brief, WTO, Geneva, 2009, available at: http://www.wto.org/english/res_e/doload_e/inbr_e.pdf (last visited November 20, 2014). 
relevant issues: 1 . whether certain objectives may be recognized as important and legitimate; and 2. what WTO agreement might be applicable.

Targeted organizations for the implementation of private-sector standards is the fifth criterion of the typology. This criterion entails the classification of private-sector standards depending on the type of entities which are required to implement a standard, i.e. comply with it. In fact, this criterion is very important as it can help with understanding which types of private-sector standards may create serious barriers to international trade and for which entities. This, in its turn, may help with identifying which private-sector standards are the most relevant for the present study.

The sixth criterion of the typology is the targeted clients of privatesector standards. The targeted clients of private-sector standards are the persons who are actually informed about the implementation of and compliance with the standards. Compliance with a private-sector standard can be communicated only to business entities applying a standard (such as bulk buyers or retailers) through the provision of a certificate or mark of compliance. The information about compliance with a private-sector standard may also be targeted at consumers through product marking or labelling, aimed at influencing consumer preferences. The applicability of legal norms, for example norms of WTO law, competition law, and consumer protection legislation, may depend on the type of targeted clients of a particular private-sector standard.

The seventh criterion for the typology is the scope of private-sector standards. The scope may include products characteristics, and / or production methods, which may significantly affect the trade-restrictiveness of a particular private-sector standard and the applicability of legal norms.

Finally, the eighth criterion is the type of conformity assessment systems. As has been discussed above, conformity assessment is an essential operational element of private-sector standards; and legal regulation of the standards alone without paying attention to their conformity assessment procedures is hardly possible. Thus, the typology of private-sector standards based on this criterion might be helpful in finding appropriate approaches for the legal regulation of their conformity assessment procedures.

\subsubsection{Forms of Private-Sector Standards}

A private-sector standard, as has been explained in Section 2.2.1 above, is a document. Moreover, an elaborated private-sector standards scheme may consist of a group of documents. These documents may have different forms and may bear different kinds of names. Besides the name "standard", such documents may also be called "technical specification", "code of (good) practices", "code of conduct", "production code", "internal 
regulation", etc. Obviously, the name of a document per se is not so important; what really matters is its content: the document must provide rules, guidelines or characteristics for products or PPMs for common and repeated use. It seems that a similar approach is taken in the ISO/IEC Guide 2 with respect to standards in general. The Guide provides the definitions of the terms "technical specification" ${ }^{69}$ and "code of practice", ${ }^{70}$ both of which contain Explanatory Notes clarifying that both types of documents "may be a standard, a part of a standard or independent of a standard". ${ }^{71}$ The documents containing private-sector standards may consist of chapters, sections, articles and paragraphs, or have any other subdivision, which allows for the systemization of prescribed requirements.

Furthermore, a private-sector standard must be a document approved by an adopting organization. Therefore, there must be some documentary confirmation of the approval, e.g. signatures of authorized representatives of a standardizing organization on the text of standard, or appropriate statements in the minutes of an authorized body's session of a standardizing entity.

The issue that deserves special discussion with regard to the form of a private-sector standard is whether the requirements for product characteristics or PPMs contained in a supply contract concluded between business entities may be regarded as a private-sector standard. A similar question arises with respect to model contracts for the supply of products, approved and used by corporations. As has been explained in Section 2.1.1.4 above, a private-sector standard (as well as any other standard) must provide rules, guidelines or characteristics for products or PPMs for "common and repeated use". On the one hand, a supply contract may be used "repeatedly" if this is a long-term contract for a large or unlimited number of consignments. On the other hand, however, supply contracts as such are not aimed at "common" use, as they are applicable only to their parties. Thus, at least from the formal point of view, a supply contract per se, as a document concluded between contracting parties can, arguably, not constitute a private-sector standard.

However, it could be argued that if a kind of supply contract is used by a business corporation "commonly" and "repeatedly" in relation to all or

69 "[D]ocument that prescribes technical requirements to be fulfilled by a product, process or service"; see: ISO/IEC Guide 2: 2004, Standardization and Related Activities - General Vocabulary, definition 3.4.

70 "[D]ocument that recommends practices or procedures for the design, manufacture, installation, maintenance or utilization of equipment, structures or products"; see: ISO/IEC Guide 2: 2004, Standardization and Related Activities - General Vocabulary, definition 3.5 .

${ }^{71}$ ISO/IEC Guide 2: 2004, Standardization and Related Activities - General Vocabulary, definitions 3.4 and 3.5 . 
most of its suppliers, it becomes a model contract approved and applied by the corporation. Model supply contracts used by purchasing corporations (especially big multinational ones) and containing requirements for characteristics of products and / or PPMs appear to be relevant. As has been explained, the content of a document and not its name shall be the decisive factor for determining whether a certain document may be regarded as a private-sector standard. Of course, this must be also true for model contracts of supply approved and used by corporations. Thus, in principle, if a model contract of supply satisfies the criteria of definition of a privatesector standard as described before, such a document could be regarded as the standard. In this regard, a lot will depend on how "commonly" and "repeatedly" a model contract of supply is used, whether it has been officially approved by corporate management for regular use and, of course, whether it specifies characteristics of products or PPMs.

Finally, it is worth noting that supply contracts may contain references to a private-sector standard to be applied to a supplied product or its PPMs. In fact, such a reference usually indicates an application of a standard to supplied goods by a buyer, and an agreement by a supplier to comply with the standard. In principle, however, a similar result could be achieved by a buyer through the literal incorporation of certain key requirements of a private-sector standard into the text of a contract without referring directly to the standard. This could make the task of distinguishing between private-sector standards, the process of their application, and contracts of supply quite complicated. It seems that the only way to resolve this potential problem is to deal with each particular situation and document on a case-by-case basis through analysing to what extent the document at hand satisfies the criteria of the definition of a private-sector standard described in Section 2.1.1.4 above.

Thus, as was mentioned in Section 2.2.1 the form of a document may play an important role in assessing whether the document may qualify as a private-sector standard and in distinguishing such standards from other types of documents.

\subsubsection{Types of Organizations Adopting Private-Sector Standards}

The above discussion of the forms of private-sector standards demonstrates how difficult it is, if possible at all, to draw a clear border between documents constituting private-sector standards and various types of other documents developed by various private entities. In this respect, among other issues, the key issues are who may develop and adopt private-sector standards, and how / why a document becomes a standard. The following 
sections attempt to present the typology of private-sector standards based on the types of entities which may create such standards.

\subsubsection{How a Document Becomes a Private-Sector Standard: De Facto and De Jure Private-Sector Standards}

Based on the type of adopting entity and the process of their adoption, standards in the relevant literature are sometimes divided into two categories: de facto and de jure standards. ${ }^{72}$ "A de facto standard is created when a particular technology is widely implemented by market players and accepted by the public so that such a technology becomes a dominant technology in the market, even if it has not been adopted by a formal standard setting body". ${ }^{73}$ In other words, de facto private-sector standards may be developed, adopted, applied and implemented by commercial corporations as part of their normal business activities. These corporations do not have standard-setting as their main profile activity, and standards they adopt and use are primarily aimed at improving the efficiency of their production processes and / or enhancing the competitive opportunities of their products. In the process of competition with other company standards representing alternative technologies, one company's standard may be so successful that it becomes dominant in a market.

The open competition of company standards reflecting different technologies is widely recognized to be a positive phenomenon, as only the best "winning" technologies will be turned into a standard. However, some negative threats of this process may also occur. For example, once an industry becomes "locked" into a certain standard which has won the market competition, it may be difficult for a new and more advanced technology to replace the old standard due to its having been applied by the entire industry, and, most importantly, by the biggest players in a market. From this perspective, it is arguably more difficult for smaller companies with lesser resources to promote their standards through market competition. Moreover, the dominance of a de facto standard may appear to be largely the result of a dominant position of a corporation in a market, and not of fair market competition.

A good example of a de facto standard is the Video Home System (VHS) format standard for video cassette recorders developed by the Japanese company JVC. The VHS standard gradually won the competition against Betamax - the video cassette format standard developed by another Japanese company Sony. In the 1980s and 1990s, VHS became dominant

72 See for example: "Standards and Patents", Standing Committee on the Law of Patents, Thirteenth Session, SCP/13/2, Document prepared by the Secretariat, WIPO, Geneva, February 18, 2009

73 Ibid., para. 35. 
in the world market of video cassettes and video tape recorders. However, at the end of $20^{\text {th }}$ century, this format of video recording was again largely pushed out of the market by advancing CD and DVD optical disk technologies. ${ }^{74}$ Another well known example of a de facto standard is Microsoft Word "doc" and "docx" file extension formats for text documents which, to a large extent, reign in the market due to the market dominance of Microsoft and its MS Office program pack.

De jure private-sector standards are predominantly collective privatesector standards ${ }^{75}$ adopted by specialized private standard-setting organizations. Such specialized private organizations may include industry associations and other NGOs which have standard-setting as their primary function. Such specialized organizations also usually engage (or at least claim to do so) in the standard-setting processes of a wide range of interested stakeholders in order to facilitate the processes. ${ }^{76}$ This is aimed at providing legitimacy to adopted standards and making them more functional and attractive for business actors.

A good example of a de jure private-sector standard is GLOBALG.A.P. standard which was developed and adopted by a private non-profit organization for ensuring good agricultural practices in agricultural production processes. GLOBALG.A.P. membership includes agricultural producers, suppliers, retailers and other interested parties in the area of agricultural production and services, thus allowing for a wide stakeholder involvement in the standard-setting process. ${ }^{77}$ Another example of a de jure private-sector standard is the BRC Global Standards for food and consumer products developed by the British Retail Consortium (BRC). ${ }^{78}$ According to the BRC organization scheme for governance, standard-setting and certification, the key stakeholders (including manufacturers, retailers and certification

74 The DVD optical disc storage format was initially developed by the corporations Toshiba and Time Warner in 1995 as an alternative to the compact disc (CD) format.

75 For a discussion concerning collective private-sector standards, see Section 2.2.3.2.2 of the present Chapter.

76 "Standards and Patents", Standing Committee on the Law of Patents, Thirteenth Session, SCP/13/2, Document prepared by the Secretariat, WIPO, Geneva, February 18, 2009, para. 35.

77 See: http://www.globalgap.org/cms/front_content.php?idcat=20 (last visited November 20, 2014).

78 See: http://www.brcglobalstandards.com/standards (last visited November 20, 2014). See also: Sally Washington, Lahsen Ababouch, "Private Standards and Certification in Fisheries and Aquaculture. Current Practice and Emerging Issues", FAO, Rome, 2011, p. 80; T. Cooper, "Picture This: Promoting Sustainable Fisheries through Eco-Labeling and Product Certification”, Ocean and Coastal Law Journal, 10, 2004 / 2005. 
bodies) are represented on the level of technical advisory committees. ${ }^{79}$ Moreover, renowned private eco-labelling schemes such as the MSC, the $\mathrm{FSC}^{80}$ and the PEFC ${ }^{81}$ may also be regarded as de jure private-sector standards because they are developed by specialized private non-profit organizations which claim to have a sufficient representation of all the relevant stakeholders during the standard-setting processes ${ }^{82}$

It is worth noting, however, that de facto and de jure standards do not exist in isolation. A technology provided in a company as a de facto standard may become so predominant within an industry that it eventually may become a standard approved by an industry association or even an international standard-setting organization, thus becoming an industry or international standard de jure. For example, the Portable Document Format (PDF) for computer text files was initially developed and adopted in 1993 by a private American computer software company Adobe Systems, and was then

79 See: http://www.brcglobalstandards.com/about-the-standards/governance-of-thestandards (last visited November 20, 2014).

80 Forest Stewardship Council (FSC) "is an independent, non-governmental, notfor-profit organization established to promote the responsible management of the world's forests. [...] The FSC label provides a credible link between responsible production and consumption of forest products, enabling consumers and businesses to make purchasing decisions that benefit people and the environment as well as providing ongoing business value”; see: http://www.fsc.org/about-fsc.html (last visited November 20, 2014). See also: Frans van Waarden, "Governing Global Commons: The Public-Private Protection of Fish and Forests", at: Axel Marx, Miet Maertens, Johan Swinnen, Jan Wouters, Private Standards and Global Governance. Economic, Legal and Political Perspectives, Edward Elgar, Cheltenham, UK, 2012, pp. 28 - 33; Axel Marx, Emilie Becault, Jan Wouters, "Private Standards in Forestry: Assessing the Legitimacy and Effectiveness of the Forest Stewardship Council", at: Axel Marx, Miet Maertens, Johan Swinnen, Jan Wouters, Private Standards and Global Governance. Economic, Legal and Political Perspectives, Edward Elgar, Cheltenham, UK, 2012, pp. $64-67$.

81 According to the PEFC website: "The Programme for the Endorsement of Forest Certification (PEFC) is an international non-profit, non-governmental organization dedicated to promoting Sustainable Forest Management (SFM) through independent third-party certification. PEFC works throughout the entire forest supply chain to promote good practice in the forest and to ensure that timber and non-timber forest products are produced with respect for the highest ecological, social and ethical standards. Thanks to its eco-label, customers and consumers are able to identify products from sustainably managed forests"; see: http://www.pefc.org/index.php/about-pefc/who-we-are (last visited November 20, 2014).

82 For example, the statements about the wide stakeholders involvement may be found on the websites of the MSC, the FSC and the PEFC, see:

http://www.msc.org/about-us/governance, http://www.fsc.org/governance.html and http://www.pefc.org/index.php/about-pefc/what-makes-pefc-unique (last visited November 20, 2014). 
taken over by other companies. However, the PDF file standard was later approved by the ISO and became an international standard.$^{83}$

\subsubsection{Private-Sector Standards Developed by Different Types of Organizations}

Private-sector standards may be developed by a variety of private organizations which have different rules for stakeholder involvement and the various procedures for standard-setting. ${ }^{84}$ Figure 1 below provides the outline of the classification of private-sector standards based on the types of standard-setting entities together with examples of these standards.

\section{Figure 1: Classification and examples of private-sector standards based on types of standard-setting entities ${ }^{85}$}

\begin{tabular}{|c|c|c|c|}
\hline \multirow{2}{*}{$\begin{array}{c}\text { Individual } \\
\text { Company Private- } \\
\text { Sector Standards }\end{array}$} & \multicolumn{3}{|c|}{ Collective Private-Sector Standards } \\
\hline & National & Regional & International \\
\hline $\begin{array}{l}\text { - Ahold's labelling } \\
\text { schemes and } \\
\text { standards for } \\
\text { food safety } \\
\text { - Aldi consumer } \\
\text { quality insurance } \\
\text { - Tesco Natures } \\
\text { Choice } \\
\text { - Marks \& } \\
\text { Spencer "Air }\end{array}$ & $\begin{array}{l}\text { - Assured Food } \\
\text { Standards (UK) } \\
\text { - British Retail } \\
\text { Consortium } \\
\text { Global Standard } \\
\text { - Freedom } \\
\text { Food (UK) } \\
\text { - Qualitat } \\
\text { Sicherheit (QS) } \\
\text { - Assured } \\
\text { Combinable Crops } \\
\text { Scheme (UK) }\end{array}$ & $\begin{array}{l}\text { - EUREPG.A.P. } \\
\text { (predecessor of } \\
\text { GLOBALG.A.P.) } \\
\text { - Nordic Swan } \\
\text { - RugMark - } \\
\text { "Goodweave" } \\
\text { labelling (North } \\
\text { America) } \\
\text { - SFI-Sustainable } \\
\text { Forestry Initiative } \\
\text { (North America) }\end{array}$ & $\begin{array}{l}\text { - GLOBALG.A.P. } \\
\text { - International Food } \\
\text { Standard (IFS) } \\
\text { - Safe Quality Food } \\
\text { (SQF) 1000/ } 2000 \\
\text { - Fairtrade Labelling } \\
\text { Organization } \\
\text { (FLO) } \\
\text { - Marine } \\
\text { Stewardship } \\
\text { Council (MSC) } \\
\text { - Forest } \\
\text { Stewardship } \\
\text { Council (FSC) }\end{array}$ \\
\hline
\end{tabular}

83 In particular, the PDF file format was introduced into the ISO standard "ISO 320001:2008 - Document management - portable document format - Part 1: PDF 1.7".

84 See: Spencer Henson, John Humphrey, "Private Standards in Global Agri-Food Chains", at: Axel Marx, Miet Maertens, Johan Swinnen, Jan Wouters, Private Standards and Global Governance. Economic, Legal and Political Perspectives, Edward Elgar, Cheltenham, UK, 2012, p. 99.

85 Based on: Private Standards and the SPS Agreement. Note by the Secretariat, WTO, SPS Committee, G/SPS/GEN/746, Geneva, 24 January 2007WTO 2007/746, para. 5. See also: Spencer Henson, John Humphrey, "The Impacts of Private Food Safety Standards on the Food Chain and on Public Standard-Setting Processes", Codex thirty-second Session, FAO, WHO, Codex Alimentarius Commission, Rome, May 2009, p. 4; M. Aragrande, A. Segré, E. Gentile, G. Malorgio, E. Giraud Heraud, R. Robles Robles, E. Halicka, A. Loi, M. Bruni, "Food Supply Chains Dynamics and Quality Certification”, Final Report, EU DG Joint Research Centre, Brussels, 31 May 2005, pp. $52-89$. 


\subsection{Individual Company Private-Sector Standards}

Individual company private-sector standards are developed by commercial corporations, usually for their own purposes and use. Many big and multinational corporations like Shell, Nokia, Sony and Microsoft have their own standards related to product quality, the wellbeing of workers, and the environmental impact and sustainability of production processes. The information about adherence to such company standards (which, of course, as a rule is claimed to be high) is usually published on the corporations' websites or may be advertised through other sources, e.g. mass media and press. In this respect, the company standards aim to contribute to the maintenance of good brand reputation among consumers, to increase the competitive opportunities of products, and to differentiate particular products from other competitive products.

Compliance of products with company standards may be also communicated to consumers by companies through the labelling on their products. This is common, for example, in the retail business. For instance, the originally Dutch multinational conglomerate of supermarkets Ahold has its own labelling schemes for healthy and organic products; ${ }^{86}$ the French retailer Carrefour has the "Filière Qualité" standard and labelling for product safety and quality; ${ }^{87}$ one of the biggest British retailers, Marks \& Spencer, uses "Air Freighted" labelling for the products carried by air, which aims to point out to consumers the carbon emission impact of this way of transportation. ${ }^{88}$ Big retailers also frequently apply their own product standards which are not connected with the labelling, such as the consumer quality insurance used in Aldi (Germany), ${ }^{89}$ Ahold's standards for food safety, ${ }^{90}$

86 E.g. "Gezonde Keuze" (healthy choice) labelling in Albert Heijn - Dutch supermarket chain belonging to Ahold; "Good for You" label in Albert - Czech subsidiary of Ahold; green keyhole and "ICA Gott Liv" (good life) labels used by the ICA - Ahold's supermarket chain in the Nordic countries; and "Healthy Ideas" label used by the Ahold's subsidiaries in the US. Ahold's labels for organic products include "AH puur \& eerlijk" (pure and honest) in Albert Heijn, the Netherlands; "Albert's Bio" in Albert, Czech Republic; "ICA I love eco" in ICA supermarkets in the Nordic Countries (Denmark, Sweden and Norway); see: Ahold's Corporate Responsibility Report 2009, pp. 10 - 11, 13, available at: http://www. annualreport2009.ahold.com/documents/reports/Ahold_CR_2009.pdf (last visited November 20, 2014).

87 See: http://www.carrefour.com/cdc/responsible-commerce/product-safety-andquality (last visited November 20, 2014).

88 See: http://corporate.marksandspencer.com/howwedobusiness/our_policies/ climate/commitments (last visited November 20, 2014).

89 See: http://aldi.com.au/au/html/company/consumer_quality_assurance.htm (last visited November 20, 2014).

90 See: Ahold's Corporate Responsibility Report 2009, pp. 10 - 12, 16 - 17, available at: http://www.annualreport2009.ahold.com/documents/reports/Ahold_CR_2009. pdf (last visited November 20, 2014). 
and Tesco Nature's Choice standard for the quality of fresh produce used by Tesco (UK). ${ }^{91}$ Sometimes specialized firms may assist corporations in developing their individual company standards, or may even develop such standards for them on a commercial basis, taking into account the particular demands of the client. For example, Starbucks, the international coffeehouse chain, applies guidelines developed with the help of the specialized organization Conservation International to their coffee procurements (Coffee and Farmer Equity (C.A.F.E.) Practices). ${ }^{92}$ In some of the relevant literature, such specialized organizations, which develop standards for business corporations, are called "private standards firms". ${ }^{93}$

Since they are developed by business corporations themselves, individual company standards are, arguably, the best suited to address companies' needs in regulating their products and production methods, e.g. product quality, environmental and social impact of products and production, etc. However, individual company standards may also have certain disadvantages. First, they may lack legitimacy because the involvement of interested stakeholders in companies' standard-setting procedures is, as a rule, quite limited, if it exists at all. Second, companies are frequently inclined to develop and adopt their own standards primarily for the purposes of differentiating their products from competitive ones, and not for the promotion of other important societal objectives. Company standards may thus arguably have more chances to present arbitrary and unjustified requirements, based not on objective information and scientific evidence, but on myths spread among certain consumer groups. Third, standards adopted by different companies (e.g. big retailers) and applied to their suppliers may differ substantially. This entails a heavy burden for the suppliers who have to comply with different sets of company standards and also have to prove such compliance to each appropriate company-buyer.

Finally, the development and application of individual company standards (including the verification of compliance) is rather costly and may require significant resources from corporations. Not all corporations could therefore, in principle, afford this "luxury"; only the biggest and most powerful ones. Thus, companies, including big retailers and other multinational

91 See: http://www.tescofarming.com/tnc.asp (last visited November 20, 2014).

92 See: http://www.starbucks.com/responsibility/sourcing/coffee (last visited November 20, 2014).

93 For instance, see: Spencer Henson, John Humphrey, "The Impacts of Private Food Safety Standards on the Food Chain and on Public Standard-Setting Processes", Codex thirty-second Session, FAO, WHO, Codex Alimentarius Commission, Rome, May 2009, pp. 18-19. Spencer Henson and John Humphrey also provide some more examples of standards developed by private standards firms, such as "ProSafe Certified", "SCS Clean Food Standards", etc.; 
corporations, more and more opt nowadays for the application of collective private-sector standards.

\subsection{Collective Private-Sector Standards}

Collective private-sector standards are the standards developed and adopted by various types of NGOs, such as industry associations, research institutes, and non-profit organizations. The organizations developing and adopting collective private-sector standards do not apply such standards themselves. These standards are meant for collective application by various corporations doing business in a relevant field. Thus, the success of a collective private-sector standard depends, to large extent, on the scale of its application and implementation by business actors. Considering its interest in the outcomes of standard-setting processes, businesses are usually interested in being actively involved in these processes and in participating in the governance of those private standard-setting organizations. Moreover, private standard-setting organizations as such are sometimes founded by business corporations. One good example is GLOBALG.A.P., originally EUREPG.A.P., founded by an association of European retailers. Another interesting example is the MSC, which was established by the World Wide Fund for Nature (WWF) and by the Anglo-Dutch multinational corporation Unilever. ${ }^{94}$

To ensure a higher level of legitimacy and acceptance of their standards among applying and implementing business entities, the standardizing NGOs, as a rule, are interested in involving various stakeholders in their standard-setting processes, e.g. producers, suppliers, buyers and consumers. In fact, collective private-sector standards are called so not only because they are collectively applied by business actors, but also because they are collectively developed and adopted.

\subsection{Advantages of Collective Private-Sector Standards}

Collective private-sector standards are used more and more widely today in comparison with individual company standards, because they seem to have certain advantages. ${ }^{95}$ First, as has been pointed out above, these standards

94 See: http://www.globalgap.org/uk_en/who-we-are/history; http://www.msc.org/ about-us; http://www.alaskaoceans.net/aboutus/msc.htm (last visited November 20, 2014).

95 For example, according to Spencer Henson and John Humphrey "a shift from individual food firm and third party firm standards to collective private standards, developed by industry organizations and the formation of private standards coalitions" is taking place in Europe; see: Spencer Henson, John Humphrey, "The Impacts of Private Food Safety Standards on the Food Chain and on Public Standard-Setting Processes", Codex thirty-second Session, FAO, WHO, Codex Alimentarius Commission, Rome, May 2009, p. 18. 
tend to have more legitimacy as the range of interested stakeholders participating in standard-setting is usually broader than in the case of company standards. ${ }^{96}$ Second, the application of the collective standards may be cheaper because there is much less need to spend companies' limited resources on the development of useful standards. Moreover, conformity assessment under such standards is usually done not by applying corporations, but by the standard-setting NGOs or, even more frequently, by an independent and specialized third-party certifier. Third, the implementation of the collective standards is also easier and cheaper for business entities or product suppliers, as they have to comply with and certify themselves under a single (or a limited number of) collective standard(s) accepted by an entire industry instead of getting certified under the standards of each individual company-buyer. Finally, collective private-sector standards are attractive for business corporations because they may significantly contribute to the formation of so-called "level playing field", where each corporation plays according to the same rules and thus has the same competitive opportunities.

In this respect, Spencer Henson and John Humphrey describe the shift from individual company standards to the collective standard schemes with respect to private food safety standards in Europe in the following way:

The genesis of private food safety standards in Europe can be traced back to the UK food retail sector in the mid-1990s. At this time, most of the major retailers had either developed their own food safety standards, and often inspected suppliers using their own technologists, or had adopted the standards developed and certified by a number of independent organisations or companies (for example EFSIS, RSSL, LawCred, etc.). It was recognised, however, that there was a considerable degree of overlap in the requirements of the major food retailers and that food processors supplying a number of these firms were subject to multiple audits. Thus, the concept of a collective private food safety standard evolved. It is not surprising that the BRC was involved; this was an existing trade organisation through which the food retailers already interacted on issues of common interest. Thus, the BRC Standard (now called the BRC Global Standard for Food Safety) emerged in 1998. As a consequence, most (but not all) of the major UK food retailers started to move

96 This, however, does not exclude the possibility of complaints about the lack of legitimacy of the collective private-sector standards as well. Such complaints are quite common in fact, as there may always be an uncertainty with respect to the issue of who may participate in the standard-setting, how to inform interested stakeholders, and how to ensure the proper protection of the interests of small-scale and developing country producers and enable them to participate effectively in standard-setting processes. 
away from implementing their own individual firm food safety standards, while existing independent standards organisations and companies shifted the focus of their business to certification against the BRC Standard. [...]

In turn, retailers in continental Europe saw the utility of a collective private food safety, and in 2000 a group of leading German food retailers developed the International Food Standard (IFS), again through an existing trade organisation, the Hauptverband des Deutschen Einzelhandels (HDE). In 2003, the Fédération des Entreprises du Commerce et de la Distribution (FCD), an organisation representing French food retailers, became involved in the further elaboration of the IFS. In so doing, the IFS became the first pan-European collective post-farm-gate private food safety standard. ${ }^{97}$

\subsection{Forms of Incorporation of Private Standard-Setting Entities}

As has been mentioned above, collective private-sector standards may be developed by research institutes, industry associations, private standards coalitions, different types of NGOs dealing with the protection of the environment, human rights, animal welfare, etc. These private organizations setting collective private-sector standards may be completely non-profit, i.e. fully subsidized by their members, or they may finance their activities through other, more commercial ways, such as revenues collected from the sales of texts of standards and guidelines for their application and implementation, charges for certification, or charges levied from accredited certification bodies, which, in turn, charge business corporations - i.e. suppliers of products - for certification under a standard.

It is understandable why business corporations - i.e. buyers of products - may prefer not to bear the costs of standard-setting work and certification under the private-sector standards they apply to products delivered by their suppliers. Instead, they opt to shift those costs (which may sometimes be quite substantial) to business corporations, i.e. the suppliers of products, who have to comply with a standard. In this respect, it could be argued that the setting of private-sector standards and certification under these standards has, over the past few decades, grown into quite an important and lucrative business. However, many private standard-setting and certifying organizations do not view their activities as commercial ones and position themselves as private non-profit organizations contributing to the protection of important societal objectives.

97 Spencer Henson, John Humphrey, "The Impacts of Private Food Safety Standards on the Food Chain and on Public Standard-Setting Processes", Codex thirty-second Session, FAO, WHO, Codex Alimentarius Commission, Rome, May 2009, p. 19. 
Research institutes are the institutions whose tasks include, in addition to standardization, research, education, technical assistance and consultancy. For instance, the Safe Quality Food (SQF) standards for food safety and quality (series 1000/2000) are adopted and administered by the SQF Institute (SQFI) located in Virginia, the US, which is a division of the Food Marketing Institute (FMI) in the US. The tasks of the SQF Institute include the participation in "programs in public affairs, food safety, research, education and industry relations on behalf of its 1,500 member companies - food retailers and wholesalers - in the United States and around the world" ${ }^{98}$

Industry associations usually represent the interests of certain industries (e.g. retailers, bakers, steel producers, etc.); for example, the abovementioned BRC Global Standards for food and consumer products and IFS were both developed respectively by British and German associations of retailers. Another example is the standards developed by AIB International - the North American industry association for bakers. ${ }^{99}$

Private standards coalitions may be formed between several industries whose interests interplay through a supply chain, e.g. the coalition between retailers, farmers, food processors and traders; even consumer organizations may sometimes be involved as well. GLOBALG.A.P. is an example of a standard developed by a private standards coalition, since the governance over this standard scheme is exercised by the "global partnership of voluntary members", which includes food producers, suppliers, processors, retailers and other interested parties. ${ }^{100}$ Another example of a private standards coalition is the Assured Food Standards (AFS) - "the independent organization set up to manage, develop and promote the Red Tractor as a mark of safe, quality, affordable food that the public can trust" ${ }^{101}$ The membership of the AFS includes such industry associations and organizations as "the National Farmers' Union (England and Wales), the Ulster Farmers' Union, the Agriculture and Horticulture Development Board, Dairy UK and the British Retail Consortium. The Food and Drink Federation also provides valued input”. ${ }^{102}$

98 See: http://www.sqfi.com/about_us.htm (last visited November 20, 2014). See also: Sally Washington, Lahsen Ababouch, "Private Standards and Certification in Fisheries and Aquaculture. Current Practice and Emerging Issues", FAO, Rome, 2011, p. 81.

99 See: https://www.aibonline.org/about (last visited November 20, 2014).

100 See: http://www.globalgap.org/cms/front_content.php?idcat $=4$ (last visited November 20, 2014).

101 See: http://www.redtractor.org.uk/site/REDT/Templates/GeneralWho. aspx?pageid $=14 \& c c=G B$ (last visited November 20, 2014).

102 See: http://www.redtractor.org.uk/site/REDT/Templates/GeneralWho. aspx? pageid $=14 \& c c=G B$ (last visited November 20, 2014). 
Other types of NGOs which develop collective private-sector standards may include environmental non-profit organizations, such as the MSC (labelling and certification scheme for sustainable fishery products), FSC and PEFC (labelling and certification schemes for sustainably produced wood products; Rainforest Alliance (labelling and certification scheme dealing with the conservation of biodiversity and sustainable livelihood in forestry ${ }^{103}$; non-profit organizations dealing with the protection of human rights and ethical values, such as "RugMark" (the US NGO administering the "Goodweave" labelling and certification scheme for rugs produced in developing countries without the use of child labour), ${ }^{104}$ and Choose Cruelty Free (CCF, the Australian NGO administering the "Not tested on animals" labelling and certification scheme). ${ }^{105}$

The world of collective private setting entities is very diverse and it is hardly possible to classify all of them in a single category from those specified above. On the one hand, all private standard-setting organizations are legally incorporated as some form of NGO in one country or in a group of countries, and this makes all of these organizations similar in certain respects. On the other hand, however, every private standard-setting organization is unique, as it has its own individual characteristics, including corporate rules and governance structure. These characteristics usually reflect the tasks of an organization as well as requirements presented to NGOs in the domestic company law in the country of incorporation.

Furthermore, private standard-setting organizations are constantly developing and evolving. Such an organization may start as a research institute or an industry association and end up as a private standards coalition. This is in fact happening as a result of the widening of stakeholder involvement in the governance structure of NGOs. For example, the SQFI, being a research institute on the one hand, may now also be regarded as an industry association, since, as was mentioned above, its membership incorporates over 1,500 companies - retailers and wholesalers. GLOBALG.A.P., one of the world's biggest private standards coalitions which sets the standards for agricultural products, was started as EUREPG.A.P., the initiative of the Euro-Retailer Produce Working Group (EUREP) - the European industry association of retailers. ${ }^{106}$ As was stated earlier, the MSC was originally founded by two organizations and is now an independent non-profit organization with such bodies as the Board of Trustees, the Technical Advisory

103 See: http://www.rainforest-alliance.org/about.cfm?id=mission (last visited November 20, 2014).

104 See: http://www.goodweave.org/about.php?cid=1 (last visited November 20, 2014).

105 See: http://www.choosecrueltyfree.org.au/about.html (last visited November 20, 2014).

106 See: http://www.globalgap.org/cms/front_content.php?idcat=19 (last visited November 20, 2014). 
Board and the Stakeholders Council, which ensure a much broader stakeholder involvement in its standardizing activities. ${ }^{107}$ Indeed, these examples demonstrate that an effective classification of collective private-sector standards based on a specific form of incorporation of the entities which adopted them is hardly possible. ${ }^{108}$

\subsection{National, Regional and International Private-Sector Standards}

As reflected in Figure 1, based on the type of private organization developing and adopting a standard, collective private-sector standards may be classified into national, regional and international standards.

National collective private-sector standards are developed and adopted by national private standard-setting organizations. The BRC Global Standards and the ASF standards with the "Red Tractor" logo, mentioned above, are examples of such standards, since both of them are adopted by UK-based NGOs and, at least originally, were developed for the British market. EUREPG.A.P., before it was transformed into GLOBALG.A.P., could serve as an example of a regional collective private-sector standard, developed for the European region. Another example is Nordic Swanan eco-labelling scheme for ecologically friendly and sustainably produced products popular in the region of Nordic countries. ${ }^{109}$

International collective private-sector standards are the privatesector standards developed and adopted by international private standardsetting organizations. The international character of a standard-setting organization may be reflected in the governance structure of an organization and / or the involvement of stakeholders into its standard-setting processes. Collective international private-sector standards may be also adopted and administered by a network of NGOs, incorporated in different countries. For example, GLOBALG.A.P., which has its head office in Cologne, Germany (FoodPLUS GmbH), "has staff and representatives based all around the world in countries including Germany, UK, Spain, South Africa, Uruguay and China". ${ }^{110}$ GLOBALG.A.P. describes itself as "a global partnership of voluntary members, bringing together like-minded

107 See: http://www.msc.org/about-us/governance/structure (last visited November 20, 2014).

108 That is why this criterion is not included into Figure 1 above. However, such attempt has been made in the literature, see: Spencer Henson, John Humphrey, "The Impacts of Private Food Safety Standards on the Food Chain and on Public Standard-Setting Processes", Codex thirty-second Session, FAO, WHO, Codex Alimentarius Commission, Rome, May 2009, p. 19.

109 See: http://www.ecolabelling.org/ecolabel/nordic-ecolabel-or-swan, http://www.svanen.nu (last visited November 20, 2014).

110 See: http://www.globalgap.org/cms/front_content.php?idcat=13 (last visited November 20, 2014). 
parties with the shared vision of harmonising Good Agricultural Practice (G.A.P.) world-wide. The partnership is open to any organisation that agrees to the Terms of Reference". ${ }^{111}$ The membership of GLOBALG.A.P. consists of producers / suppliers, retailers and other associate members from different parts of the world.

Another example of an international private-sector standard is the Fairtrade Labelling Organizations (FLO) standard and labelling scheme, "designed to support the sustainable development of small-scale producers and agricultural workers in the poorest countries in the world". ${ }^{112}$ The membership of the FLO includes three producer networks, 25 Fairtrade organizations, Fairtrade International, and FLOCERT, the independent certification body of the global Fairtrade system. ${ }^{113}$ The headquarters of the FLO is situated in Bonn, Germany. ${ }^{114}$ The FLO labels can be found on many products sold in supermarkets worldwide, e.g. bananas, coffee and tea, ice-cream, etc. Such administrators of the renowned eco-labelling and certification programs as the MSC and the FSC also describe themselves as tan international non-profit organizations with international membership and stakeholder involvement. ${ }^{115}$

However, it is worth noting that the classification of collective privatesector standards into national, regional and international is very relative. Indeed, the "private standards landscape is highly dynamic", ${ }^{116}$ the standards are constantly evolving and developing, and national private-sector standards may quickly become regional or international. In fact, due to the process of globalization this classification gradually loses its relevance, since strictly national and regional private-sector standards are becoming very rare. Indeed, as has been mentioned above, the European agricultural standard EUREPG.A.P., for example, evolved rather quickly into GLOBALG.A.P.; the BRC standards, originally developed for the UK has since become BRC Global Standards; the SQF standards became international with the widening of the membership which originally was the North American SQF Institute. Similar evolutions have taken place with the MSC and the FSC labelling and certification schemes.

111 See: http://www.globalgap.org/cms/front_content.php?idcat=4 (last visited November 20, 2014).

112 See: http://www.fairtrade.net/aims_of_fairtrade_standards.html (last visited November 20, 2014).

113 See: http://www.fairtrade.net/who-we-are.html (last visited November 20, 2014).

114 See: http://www.fairtrade.net/about_us.html (last visited November 20, 2014).

115 See: http://www.msc.org/about-us/governance, http://www.fsc.org/governance. html (last visited November 20, 2014).

116 Spencer Henson, John Humphrey, "The Impacts of Private Food Safety Standards on the Food Chain and on Public Standard-Setting Processes", Codex thirty-second Session, FAO, WHO, Codex Alimentarius Commission, Rome, May 2009, p. 7. 
In addition, it should be noted that today, due to the process of globalization of international trade, national and regional collective private-sector standards, as well as individual company standards, may have a lot of international impact, since the standards may be applied to and implemented by suppliers and traders from different countries. This is especially true if one takes into account the fact that global markets, to a large extent, are controlled by multinational corporations nowadays, which are frequently very active in the application of private-sector standards, either their own or collective ones. Arguably, this trend of the internationalization of privatesector standards is less strong within the area of private labelling and certification schemes targeted at consumers, as labels must be understandable for consumers. In this respect, language and cultural differences between consumers in different countries may play a certain role. ${ }^{117}$ However, the general trend of internationalization in both the development and application of private-sector standards is quite obvious today. Indeed, it seems that this trend is going to develop further in the future due to the process of globalization of international trade and the challenges related to public health, human rights and the environment entailed in this process.

Thus, as has been mentioned in Section 2.2.1 the type of adopting organization may be quite important for differentiating private-sector standards from public standards. It may be also relevant for the identification of the appropriate legal regulatory regime for a particular private-sector standard, as well as for the issues of attribution and jurisdiction, i.e. whether a particular State could actually influence or control the standardizing activities of an international NGO or a transnational corporation.

117 In fact, consumers usually need time to understand, memorize and trust the labels. In this respect, for example, the Swedish "KRAV" label, which is highly successful label for organic food products in Sweden, would probably not provide a lot of useful information to non-Swedish consumers; for further information on "KRAV" labelling see: http://www.krav.se/System/Spraklankar/In-English/About-KRAV/ (last visited November 20,2014). That is why some multinational retailers have different labels for different countries in appropriate languages; for instance the Dutch multinational retail consortium Ahold uses the following organic product labels: "AH puur \& eerlijk" (pure and honest) in Albert Heijn supermarkets, the Netherlands; "Albert's Bio" in Albert supermarkets, Czech Republic; "ICA I love eco" ICA supermarkets in the Nordic region; see: Ahold's Corporate Responsibility Report 2009, p. 13, available at: http://www.annualreport2009.ahold.com/ documents/reports/Ahold_CR_2009.pdf (last visited November 20, 2014). However, very frequently national private labelling schemes still do "go abroad", as in the case of the originally French label for traditionally produced poultry products, "Label Rouge"; see: http://www.poultrylabelrouge.com/012_volaille_ LR.php

(last visited November 20, 2014). 


\subsubsection{Level of Governmental Involvement or Incentives for the Adoption and Application of Private-Sector Standards}

The level of governmental involvement and incentives for the preparation, adoption and application of private-sector standards is a very important criterion for differentiating these standards from public-sector standards and mandatory technical regulations. In fact, the border between private and public regulatory measures is not really as straightforward as one might assume. On the one hand, private organizations may be empowered by governments to perform certain public functions and, as such, the standards adopted by such organizations will belong to the public sector. On the other hand, public authorities may be owners or co-founders of private standard-setting organizations, or they may participate in the activities of those organizations in certain way. Moreover, state-owned enterprises (SOEs), i.e. commercial corporations fully owned or controlled by governments, in principle, may also adopt and apply private-sector standards. It would seem therefore that the private nature of an entity adopting a standard may not be the only basis for differentiating between private and public-sector standards.

Furthermore, even if adopted by private entities without governmental intervention, private-sector standards at the stage of their application may receive governmental support or incentives. Such support or incentives, if substantial enough, may make the standards de facto mandatory for the market players. Of course, governments may also make the requirements of private-sector standards obligatory through references or incorporation into legislation. The level of governmental involvement and incentives may thus be decisive, also with respect to the issue of attribution of private regulatory actions (i.e. private-sector standards) to governmental authorities.

\subsubsection{Private-Sector Standards vs. Public-Sector Standards}

Figure 2 attempts to depict schematically the relationship between private and public-sector standards depending on the types of entities involved in the operational elements (stages) of these standards. ${ }^{118}$

118 Figure 2 was created by the author and is based, to certain extent, on Figures 2 and 3 in: Spencer Henson, John Humphrey, "The Impacts of Private Food Safety Standards on the Food Chain and on Public Standard-Setting Processes”, Codex thirty-second Session, FAO, WHO, Codex Alimentarius Commission, Rome, May 2009, pp. 5, 8. 


\section{Figure 2: Types of standards}

\begin{tabular}{|c|c|c|c|}
\hline \multirow{2}{*}{$\begin{array}{c}\text { Operational } \\
\text { Stages }\end{array}$} & Public-Sector Standards & Private-Sector Standards (PSS) \\
\cline { 2 - 5 } and Adoption & $\begin{array}{c}\text { Public standard-setting } \\
\text { bodies / private standard- } \\
\text { setting organizations } \\
\text { exercising public functions } \\
\text { / private standard-setting } \\
\text { organizations with } \\
\text { significant involvement } \\
\text { of a government }\end{array}$ & Private standard-setting organizations \\
\hline Application & $\begin{array}{c}\text { With or without } \\
\text { insignificant } \\
\text { governmental } \\
\text { incentives }\end{array}$ & Buyers & With some insignificant \\
governmental incentives & $\begin{array}{c}\text { Without any } \\
\text { governmental } \\
\text { incentives - } \\
\text { "purely" PSS }\end{array}$ \\
\hline Implementation & \multicolumn{3}{|c|}{ Suppliers } \\
\hline $\begin{array}{c}\text { Conformity } \\
\text { Assessment }\end{array}$ & $\begin{array}{c}\text { Public/ private auditors } \\
\text { and certification bodies }\end{array}$ & Private auditors and certification bodies \\
\hline Enforcement & $\begin{array}{c}\text { Buyers } \\
\text { insignificant governmental } \\
\text { incentives }\end{array}$ & $\begin{array}{l}\text { With some insignificant } \\
\text { governmental incentives }\end{array}$ & $\begin{array}{c}\text { Without any } \\
\text { governmental } \\
\text { incentives - } \\
\text { "purely" PSS }\end{array}$ \\
\hline
\end{tabular}

As may be seen from Figure 2, private-sector standards are prepared and adopted by private standard-setting organizations, whereas public-sector standards are adopted by public or private organizations acting within the public domain. In this respect, it is worth noting that a private standardsetting organization may appear to act within the public domain, not only if the organization is officially authorized (de jure) by a government to develop public standards. Governmental bodies may also be significantly involved in the process of development and the adoption of a standard by a private organization, which would effectively transfer such a standard into a de facto public one. This is because a market player witnessing the governmental involvement may reasonably assume that the standard is backed by a government. In fact, in the words of the definitions of standard, as described in Section 2.1.1 of the present Chapter, the significant involvement of a government in the standard-setting activities of a private organization may indicate that this organization is "recognized" by governmental authorities as a standardizing body. For example, membership and participation of a governmental body in a private standard-setting organization may allow the government to substantially influence or control standardizing 
processes which would bring standards developed by the organization into the public domain.

However, not all governmental involvement in the operations of private standard-setting organizations may entail such a result; indeed, the involvement must be significant, i.e. sufficient enough to make market players believe that a standard is attributable to a government. For instance, mere financial subsidies received by a private standard-setting organization from a government, arguably, seem insufficient to turn a standard adopted by this organization into a public one. In this respect, it is hardly possible to draw a clear borderline between public and private-sector standards, and the determination may be done only on a case-by-case basis depending on the role of the government in the functioning of a private standard-setting organization and its standardizing activities.

Both public and private-sector standards are applied, implemented and enforced by private entities, i.e. market players. Conformity assessment under public-sector standards may be performed by either public auditors / certification bodies, or by private bodies authorized by public authorities to conduct conformity assessment. Conformity assessment under privatesector standards is performed by private auditors / certification bodies. As shown in Figure 2, the application and enforcement of both public and private-sector standards may or may not enjoy some governmental incentives, but only if these incentives are relatively insignificant. Indeed, if the governmental incentives become significant enough, this will likely turn a voluntary standard into a de facto mandatory technical regulation. For instance, the insignificant governmental incentives may amount to the governmental subsidizing of an advertising campaign for the application of a private-sector standard. Private-sector standards which do not receive any governmental incentives on all their operational stages are referred to in Figure 2 as the "purely" private-sector standards.

However, as mentioned above, if the amount of governmental incentives for the application and enforcement of a private-sector standard passes a certain threshold, such a standard may become mandatory de facto for market players and could therefore, as will be discussed below, be regarded as a technical regulation.

\subsubsection{Public and Private-Sector Standards vs. Technical Regulations}

Figure 3 attempts to demonstrate the relationship between public and private-sector standards on the one hand, and technical regulations on the other. In particular, it schematically shows under which circumstances a voluntary public or private-sector standard may turn into a mandatory technical regulation. 


\section{Figure 3: Types of technical regulations}

\begin{tabular}{|c|c|c|c|}
\hline \multirow{3}{*}{$\begin{array}{l}\text { Operational } \\
\text { Stages }\end{array}$} & \multicolumn{3}{|c|}{ Technical Regulations } \\
\hline & \multirow{2}{*}{$\begin{array}{l}\text { Laws and Other Types } \\
\text { of Mandatory Legal } \\
\text { Normative Acts }\end{array}$} & \multicolumn{2}{|c|}{$\begin{array}{l}\text { Governmentally Mandated Public/ } \\
\text { Private-Sector Standards }\end{array}$} \\
\hline & & $\begin{array}{l}\text { Legally } \\
\text { Mandated }\end{array}$ & $\begin{array}{c}\text { De facto Mandated } \\
\text { (due to significant } \\
\text { governmental incentives) }\end{array}$ \\
\hline $\begin{array}{l}\text { Preparation } \\
\text { and Adoption }\end{array}$ & $\begin{array}{l}\text { Legislator / public } \\
\text { regulators }\end{array}$ & \multicolumn{2}{|c|}{$\begin{array}{l}\text { Public / private standard-setting } \\
\text { bodies / organizations }\end{array}$} \\
\hline Application & \multicolumn{2}{|c|}{ Legislator / public regulators } & $\begin{array}{c}\text { Private entities (buyers) } \\
\text { due to significant } \\
\text { governmental incentives }\end{array}$ \\
\hline Implementation & $\begin{array}{l}\text { Everybody to whom it is } \\
\text { addressed: private entities } \\
\text { (buyers and suppliers) } \\
\text { and public bodies }\end{array}$ & \multicolumn{2}{|c|}{ Private entities (buyers and suppliers) } \\
\hline $\begin{array}{l}\text { Conformity } \\
\text { Assessment }\end{array}$ & \multicolumn{3}{|c|}{$\begin{array}{c}\text { Public / specially authorized private inspectorates, } \\
\text { auditors or other certification bodies }\end{array}$} \\
\hline Enforcement & \multicolumn{2}{|c|}{ Administrative bodies or courts } & $\begin{array}{c}\text { Private entities (buyers) } \\
\text { due to significant } \\
\text { governmental incentives }\end{array}$ \\
\hline
\end{tabular}

As shown in Figure 3, technical regulations may in principle be subdivided into two groups: 1 . mandatory laws and other mandatory regulations; and 2 . governmentally mandated public or private-sector standards. A standard may be mandated by a government legally (de jure) through its incorporation into or appropriate reference to it in a law or other mandatory regulation. Or a standard may also be mandated de facto through significant governmental incentives provided for the application and enforcement of the standard. Indeed, governments may choose not to prescribe or prohibit certain actions directly, but to create a system which encourages or discourages private actions through some benefits or negative consequences. Although formally such a system would allow elements of private choice, in reality private actors might have no choice but to comply with the requirements of the standard in order to stay in a market. Arguably, tax benefits or the presumption of compliance with statutory requirements would be clear examples of significant governmental incentives for the application and enforcement of a public or private-sector standard.

But which governmental incentives may be regarded as significant and sufficient to transform a voluntary standard into a mandatory de facto technical regulation? Again, it is hardly possible to provide a general answer to this question. It seems that the answer could be given only on a case-bycase basis considering the particular governmental incentives taken in the 
overall regulatory environment of a particular country. In this respect, as is reflected in Figures 2 and 3, the key distinctions between voluntary standards and mandatory technical regulations may be found at the stages of application and enforcement of these measures. It is also worth noting that, as provided in Figure 3, the application of technical regulations in the form of laws, regulations and legally mandated standards is done by a public regulator, as private entities do not have a choice whether to apply such measures or not; such measures are indeed binding for all appropriate private actors. The enforcement of such measures is thus performed through appropriate administrative bodies or courts.

In addition to the type of adopting entity, the level of governmental involvement or incentives at appropriate operational stages of a measure is the key criterion for differentiating between public-sector standards, private-sector standards and technical regulations. Figure 4 aims to further illustrate the relationship between these three types of measures.

\section{Figure 4: Relationships between private / public-sector standards, and technical regulations}

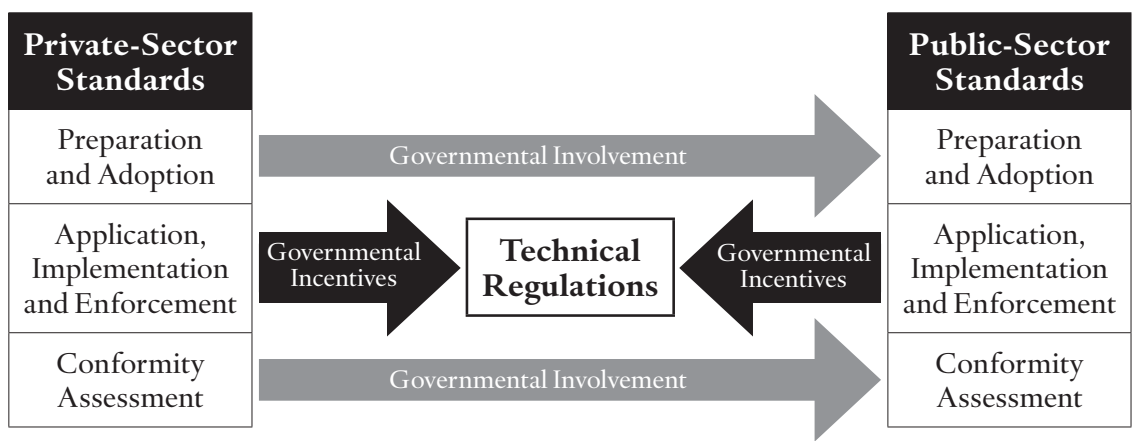

As demonstrated in Figure 4, the operational stages of application, implementation and enforcement are decisive in drawing the distinction between private- and public-sector standards on the one hand, and technical regulations on the other. This distinction appears to be mainly based on the level of governmental involvement or incentives provided during these stages. In fact, significant involvement or incentives could also be provided by a government at the stages of preparation and adoption of a document, as well as conformity assessment. However, this would arguably not make the document mandatory per se, i.e. it would remain a standard which is voluntary for application. Such governmental involvement or incentives may thus only transfer a standard from the private to the public domain. These are namely the governmental involvement or incentives provided for the application, implementation and enforcement of a document which may 
make it a technical regulation, mandatory either de jure or de facto. In this respect, mandating a document de jure, through legal requirements, could be viewed as the highest possible level of governmental involvement or incentives which could be provided.

\subsubsection{Resolving Private vs. Public Dilemma: Which Standards Are Relevant?}

Strictly speaking, since the present study is dealing with the international legal regulation of private-sector standards, it is primarily the standards which fall within the column "Private-Sector Standards (PSS)" of Figures 2 and 4 which are included in the scope of the research. However, as has been demonstrated above, the distinction between private-sector standards and public standards or technical regulations is not really clear cut and depends on the level of governmental involvement or incentives at the different stages of operation of a measure. As a result, such a distinction may be done only on a case-by-case basis, and it is hardly possible to discern general criteria in this respect. Thus, the present study may also touch on certain "borderline" situations where there is no clarity about whether a standard belongs to the public sector or the private sector.

The difficulty in differentiating between public and private-sector standards may be traced to the definitions of the ISO/IEC Guide 2. The Guide provides the definitions of national, regional and international standardizing / standards organizations and bodies. Based on this, it further defines national, regional and international standards. According to the Guide, a national standards body (NSB) is a "standards body recognized at the national level that is eligible to be the national member of the corresponding international and regional standards organizations". ${ }^{119}$ A regional standardizing / standards organization is defined as a standardizing / standards "organization whose membership is open to the relevant national body from each country within one geographical, political or economic area only". ${ }^{120}$ An international standardizing / standards organization, according to the Guide, is the standardizing / standards "organization whose membership is open to the relevant national body from every country". ${ }^{121}$

As can be seen, there are no direct references to the public or private nature of the defined NSBs and regional / international standardizing bodies. It would seem therefore that NSBs are generally constituted as either public

119 ISO/IEC Guide 2: 2004, Standardization and Related Activities - General Vocabulary, definition 4.4.1.

120 ISO/IEC Guide 2: 2004, Standardization and Related Activities - General Vocabulary, definitions 4.3.1, 4.4.2

121 ISO/IEC Guide 2: 2004, Standardization and Related Activities - General Vocabulary, definitions 4.3.2, 4.4.3. 
agencies or private organizations empowered to perform public (governmental) functions, including countries' representation in regional and international standard-setting organizations. Indeed, in the words of the definition of NSB, this would make such a body "recognized at the national level" by national governmental authorities. Arguably, it follows that the definitions of regional and international standardizing organizations in the Guide also primarily cover public (i.e. intergovernmental) organizations or mixed public-private organizations with a representation of NSBs, and not international NGOs or multinational corporations. However, such conclusions, although seemingly logical, do not obviously follow from the definitions which arguably leaves room also for other broader interpretations.

To illustrate how complicated it may be to make the distinction between public and private-sector organizations / bodies, some interesting and important examples of NSBs, international and regional standardizing organizations will be provided.

\subsection{International Standard-Setting Organizations}

International standards may be developed by public international (intergovernmental) organizations, such as the Codex Alimentarius Commission (Codex) or the World Organization for Animal Health (OIE), formally known as the International Office of Epizootics, but still using its historical acronym. The Codex was created by FAO and by the World Health Organization (WHO), both specialized agencies of the UN, and is tasked with developing international standards and guidelines for food products. ${ }^{122}$ Membership in the Codex is open to "all Member Nations and Associate Members of FAO and WHO" and currently comprises 186 Codex Members - 185 member countries and one member organization, the European Union (EU). ${ }^{123}$ The Codex also has about 229 observers, including UN agencies, other international intergovernmental organisations and NGOs. ${ }^{124}$ Similarly, the OIE is the intergovernmental organisation responsible for improving animal health worldwide. It is recognised as a reference organisation by the WTO and in 2014 had a total of 180 member

122 See: http://www.codexalimentarius.net/web/members_area.jsp?lang=EN (last visited November 20, 2014).

123 Until entry into force of the Treaty of Lisboan on December 1, 2009, the European Union (EU) coexisted with the European Community (EC), which formed the most advanced supranational pillar of the Union. After the Treaty of Lisboan came into force, the EC ceased to exist and was fully transformed in to the EU.

124 See: http://www.codexalimentarius.org/members-observers/en/ (last visited November 20, 2014). See also: Report "Understanding the Codex Alimentarius", WHO/FAO, third edition, Rome, 2006, p. 14, available at: ftp://ftp.fao.org/codex/Publications/understanding/Understanding_EN.pdf (last visited November 20, 2014). Mariëlle D. Masson-Matthee, The Codex Alimentarius Commission and Its Standards, T.M.C. Asser Press, 2007. 
countries. ${ }^{125}$ Obviously international standards developed and adopted by such intergovernmental organizations have a public nature and may not be regarded as international private-sector standards.

However, the situation is more complicated with respect to the International Organization for Standardization (ISO), "the world's largest developer of voluntary International Standards", which describes itself as an independent non-governmental organization based in Geneva. ${ }^{126}$ According to its website, the ISO is a network of NSBs. The membership of the ISO comprises NSBs from 163 countries, one member per country; the members may take part in the activities of the main bodies of the ISO, which include: General Assembly, Council, Technical Management Board (which establishes technical committees for development of standards) and Central Secretariat in Geneva. ${ }^{127}$

Although individuals or companies cannot become ISO members, the ISO forms a bridge between the public and private sectors. On the one hand, many of its members are part of the governmental structure of their countries, or are mandated by their government. On the other hand, other members have their roots uniquely in the private sector, having been set up by national partnerships of industry associations. Thus, in this respect, the unique feature of the ISO is that States are represented in this organization either by governmental or non-governmental NSBs, which makes the ISO a hybrid public-private organization.

However, non-governmental NSBs which are the members of the ISO, are empowered by national governments to represent them at the organization, and usually also to perform an important public role in the area of standardization back home. Moreover, many of NSBs comprising the membership of the ISO are indeed formed as governmental standardizing bodies. Taking this into account, it seems that the ISO belongs primarily to the public sector. And thus, international standards developed by the ISO can hardly be regarded as international private-sector standards, at least for the purposes of the present study. ${ }^{128}$ In fact, the ISO, in its brochure enti-

\footnotetext{
125 See: http://www.oie.int/about-us/ (last visited November 20, 2014).

126 See: http://www.iso.org/iso/home/about/about_governance.htm (last visited November 20, 2014). See also: D. A. Wirth, "The International Organization for Standardization: Private Voluntary Standards as Swords and Shields”, Boston College Environmental Affairs Law Review, 36, 2009.

127 See: http://www.iso.org/iso/home/about/about_governance.htm (last visited November 20, 2014).

128 However, there are different views in this respect. For example, in some of the documents of the WTO SPS Committee, several ISO standards were specified as the examples of private standards; see: Private Standards and the SPS Agreement. Note by the Secretariat, WTO, SPS Committee, G/SPS/GEN/746, Geneva, 24 January 2007, para. 5.
} 
tled "International Standards and "Private Standards”", distinguishes itself from private standard-setting organizations and names itself the "formal international standardizing organization". Accordingly, in the brochure the ISO standards are called the "formal international standards" in comparison with "private international standards", of which the GLOBALG.A.P. is provided as an example. ${ }^{129}$

\subsection{Regional Standards-Setting Organizations}

As examples of regional standardizing bodies whose form of incorporation might also be a bit confusing, it is worth mentioning the main three European standard-setting institutions: 1. the European Committee for Standardization (CEN, after the French Comité Européen de Normalisation); 2. the European Committee for Electrotechnical Standardization (CENELEC, after the French Comité Européen de Normalisation Électrotechnique); and 3. the European Telecommunications Standards Institute (ETSI). These important European institutions are in fact established as independent non-profit organizations incorporated under Belgian law (the CEN, the CENELEC) and French law (the ETSI). ${ }^{130}$ Members of the CEN and the CENELEC are NSBs (for the CENELEC - the National Electortechnical Committees) from 33 European countries, including all 28 Member States of the EU, three members of the European Free Trade Association (EFTA), namely Iceland, Norway and Switzerland, and the Former Yugoslav Republic of Macedonia, and Turkey. ${ }^{131}$ However, the membership of the ETSI is structured quite differently. It is formed through the direct representation of interested stakeholders and includes around 800 members from 64 countries across five continents. These comprise the administrative bodies and national standards organizations, network operators, manufacturers, users, service providers, research bodies, universities, consultancy companies and partnerships, and others. ${ }^{132}$

The CEN, the CENELEC and the ETSI, at first sight, could be regarded as regional private standard-setting bodies. However, these standard-setting institutions are officially recognized to be "European standardisation organisations" of the EU according to the Regulation (EU) No. 1025/2012 and are authorized to adopt the voluntary "European standards" in the

129 See: International Standards and "Private Standards”, ISO, Geneva, February 2010, pp. 6-7.

130 See: http://www.cen.eu/about/Pages/default.aspx; http://www.cenelec.eu/ aboutcenelec/whoweare/index.html; http://www.etsi.org/WebSite/AboutETSI/ Introduction/introduction.aspx (last visited November 20, 2014).

131 See: http://standards.cen.eu/dyn/www/f?p=CENWEB:5; http://www.cenelec.eu/ aboutcenelec/whoweare/ceneleccommunity/members/index.html (last visited November 20,2014).

132 See: http://www.etsi.org/index.php/membership (last visited November 20, 2014). 
field of their competence. ${ }^{133}$ The European standards are aimed at the harmonization of product requirements and removal of trade barriers on the European market.

The Regulation No. 1025/2012 sets the framework for using the European standards in support of the EU legislation and policies. According to the Regulation, the European standards are always developed following the standardisation requests (mandates) of the EU Commission addressed to the three European standardisation organisations. The Commission is obliged to notify the relevant stakeholders through a publicly available Notification System before taking specific standardisation policy actions and issuing the standardisation requests. Voluntary European standards, developed after the Commission's mandates, can be used in support of the EU harmonization legislation to provide detailed technical specifications in order to fulfil legally binding objectives provided in the relevant legislation. In such a case, the reference to such a harmonised standard shall be published without delay in the Official Journal of the European Union (OJEU). However, the mandated European standards can also support the policy actions having no direct links to the EU legislation, e.g. promoting innovation and new technologies, interoperability, competitiveness, and for the purposes of public procurement. ${ }^{134}$

Thus, the role of the CEN, the CENELEC and the ETSI within the EU regulatory practice, suggests that the standards adopted by these European standardisation organisations have a public nature and may not be treated as regional private-sector standards, at least for the purposes of the present study. Indeed, it can hardly be argued that these three standardization bodies act within the private sector because they in fact perform important public functions within the EU according to the EU legislation. And since the EU is a Member of the WTO, the EU would, arguably, bear the responsibility for standards adopted by these three regional standardizing bodies.

\subsection{National Standards Bodies}

As has been discussed above, countries are represented in the ISO by their NSBs. Indeed, depending on the political, economic and historical factors of different countries, their NSBs may either have a governmental or nongovernmental nature. On the one hand, for example, the NSB representing

133 See: Regulation (EU) No. 1025/2012 Of the European Parliament and of the Council of 25 October 2012 on European standardisation, Official Journal of the European Union, 14 November 2012, preamble, paras. 2 - 7.

134 See: Regulation (EU) No. 1025/2012 Of the European Parliament and of the Council of 25 October 2012 on European standardisation, Official Journal of the European Union, 14 November 2012, preamble, Articles 8 - 12. See also: http://ec.europa.eu/enterprise/policies/european-standards/standardisation-policy/ general-framework/index_en.htm\#h2-1 (last visited November 20, 2014). 
Belgium in the ISO is the Belgian Standards Bureau (NBN, after the Flemish / French Bureau voor Normalisatie / Bureau de Normalisation). The NBN was created by the governmental Standardization Act of 3 April 2003 as "a public organization with a legal personality", ${ }^{135}$ and, obviously, is a public standardizing body. Similarly, the South African Bureau of Standards (SABS), the NSB representing South Africa in the ISO, undoubtedly is a public standardizing body because it is "a statutory body that was established in terms of the Standards Act, 1945 [...] and continues to operate in terms of the latest edition of the Standards Act, 2008 [...] as the national institution for the promotion and maintenance of standardization". ${ }^{136}$

On the other hand, the United States are represented in the ISO by the American National Standards Institute (ANSI), which is "a private, non-profit membership organization supported by a diverse constituency of private and public sector organizations" and founded by "five engineering societies and three government agencies". ${ }^{137}$ Although the ANSI itself does not develop standards, it oversees the development and application of the so-called American National Standards (ANSs) through accreditation of standards developers and conformity assessment systems. ${ }^{138}$ Similarly, the members of the ISO on behalf of the United Kingdom, British Standards Institute (BSI), and on behalf of the Netherlands, the Netherlands Standardization Institute (NEN), were both established as private non-profit organization. Both the BSI and the NEN are recognized as NSBs which produce national standards. ${ }^{139}$

It is clear therefore that all such NSBs, although established as private entities, perform public (governmental) functions in the area of standardization as they are specially authorized by governments to develop national

135 See: http://www.iso.org/iso/about/iso_members/iso_member_body.htm?member_ id=1561; see also: http://www.nbn.be/EN/nbnbrief.html

(last visited November 20, 2014).

136 See: https://www.sabs.co.za/index.php?page=aboutus; see also: http://www.iso.org/iso/about/iso_members/iso_member_body.htm?member_ id $=1485$ (last visited November 20, 2014).

137 See: http://www.ansi.org/about_ansi/introduction/introduction. aspx?menuid=1 (last visited November 20, 2014).

138 "ANSI currently provides a forum for more than 200 ANSI-accredited standards developers representing approximately 200 distinct organizations in the private and public sectors"; see: http://www.ansi.org/standards_activities/overview/overview. aspx?menuid=3 (last visited November 20,2014).

139 Founded in 1901, the BSI was actually the world's first NSB; see: http://www. bsigroup.com/en/Standards-and-Publications/About-BSI-British-Standards. See also: http://www.bsigroup.com/en/Standards-and-Publications/AboutBSI-British-Standards/History; http://www.iso.org/iso/about/iso_members/ iso_member_body.htm?member_id=2027; NEN Brochure "The Right Track", 2002, p. 8, available at: http://www2.nen.nl/cmsprod/groups/public/documents/ bestand/185033.pdf (last visited November 20, 2014). 
standards and are recognized by governments as NSBs. Therefore, at least for the purposes of this study, these NSBs belong to the public sector and adopt public standards.

\subsection{The Private-Public Regulatory Continuum}

As discussed above, it is sometimes difficult to distinguish between public and private-sector standards. It is also worth noting that the status of a particular regulatory measure as a private- or public-sector standard, or as a technical regulation, may change in time. This depends on the increase / decrease of governmental involvement or incentives received by a measure at the appropriate operational stages. For example, as a result of referencing the ISO 9000 standard on quality management systems in the EU directives covering the CE marking for telecommunications and electronic products, this standard became a part of the mandatory technical regulation (i.e. a legally mandated standard) on the EU market. ${ }^{140}$ And vice-versa, the French private labelling and certification scheme "Label Rouge" for traditionally produced poultry products was originally developed by the French governmental authorities and then transposed to the private sector. ${ }^{141}$ Similarly, the SQF series of standards were originally developed by the Australian government and was later accrued by the Food Marketing Institute (FMI), representing the association of retailers and wholesalers in the US. ${ }^{142}$

Generally, public and private forms of regulation are frequently interconnected and influence each other. In this respect, Spencer Henson and John Humphrey note the "blurring" of the borders between public and private regulation, as well as "the emergence of a continuum between public and private modes of regulation". ${ }^{143}$

In fact, even a private-sector standard which does not receive any governmental involvement or incentives in any of its operational stages (called in Figure 2 "purely" private-sector standards), may be subject to some governmental influence or indirect support. For example, when national courts (which obviously are public governmental bodies) consider tort cases or other claims for compensation of damages, they may regard compliance with a private-sector standard as evidence of the well-exercised "duty of

140 Spencer Henson, John Humphrey, "The Impacts of Private Food Safety Standards on the Food Chain and on Public Standard-Setting Processes", Codex thirty-second Session, FAO, WHO, Codex Alimentarius Commission, Rome, May 2009, pp. $5,8$.

141 See: http://www.poultrylabelrouge.com/012_volaille_LR.php (last visited November 20, 2014). See also: Spencer Henson, John Humphrey, "The Impacts of Private Food Safety Standards on the Food Chain and on Public Standard-Setting Processes", Codex thirty-second Session, FAO, WHO, Codex Alimentarius Commission, Rome, May 2009, p. 5.

142 Ibid., p. 5.

143 Ibid., p. 5. 
care" or due diligence. Such an approach to compliance with private-sector standards by national courts is widespread in many developed countries, and especially in common law jurisdictions such as the UK and the US. In fact, it is argued that, in the UK, changes in the product liability legislation connected with the strict liability of sellers for damages caused by defective products, became one of the reasons for the proliferation of private-sector standard schemes. Thus, on the one hand, such an approach by national courts to compliance with private-sector standards may provide certain incentives for their development and application, as business actors may be inclined to use these standards to minimize the liability risks. On the other hand, however, in deciding liability disputes, it is indeed reasonable to expect that a court takes into account all the relevant evidence submitted by the parties, including compliance (or non-compliance) with private-sector standards. Of course, courts, in principle, enjoy a lot of discretion in considering the evidence and would decide in each particular case what weight to give to the presented evidence, including the facts related to private-sector standards. It would seem therefore that the consideration by a court of the issues regarding compliance / non-compliance with a private-sector standard, could be hardly viewed as significant governmental incentives sufficient to transform a private-sector standard into a public one.

At the same time, this discussion demonstrates that the concept of "purely" private-sector standards used in Figure 2 seems to be rather artificial, as any private-sector standards may, in principle, be subject to a certain amount of influence exercised by public authorities. If this influence (i.e. governmental involvement or incentives) is marginal or insignificant, it does not change the nature of a private-sector standard. However, if the governmental involvement or incentives become significant enough, a private-sector standard may move into the "public domain" and become a public standard or even a mandatory de facto technical regulation. In any case, it is worth noting that private-sector standards do not function in isolation from public rules. In fact, they operate within national legal regimes and therefore frequently have to interact with public substantive and procedural rules, e.g. rules on environmental protection, sanitary rules, procedural rules in courts, etc. Thus, it seems that the relationship between private-sector standards, public standards and technical regulations may be described as a continuum depending on the level of governmental involvement or incentives with "purely" private-sector standards on one end and mandatory technical regulations on the other. Figure 5 below represents this continuum in schematic form. 
Figure 5: Private-public regulatory continuum

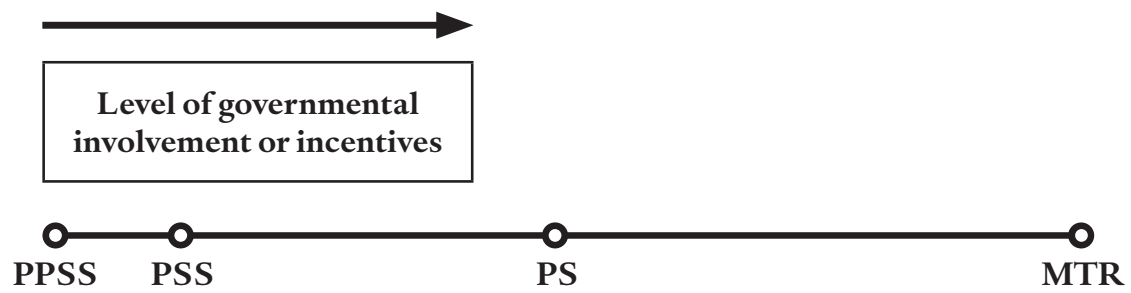

Legend:

PPSS - "purely" private-sector standards

PSS - private-sector standards

PS - public standards

MTR - mandatory technical regulations

According to Figure 5, "purely" private-sector standards are those which receive zero governmental involvement or incentives during their development, adoption and application. However, as has been noted above, this notion appears to be artificial to a certain extent, as private-sector standards function within national legal systems and usually experience at least some governmental influence, even if this is very little or marginal. Thus, if the adoption and / or application of a standard receives an insignificant amount of governmental involvement or incentives, it could still be regarded as a private-sector standard. However, when the governmental involvement or incentives become more significant, this may transform a private-sector standard into a public one. In this respect, the development and adoption of a public standard by a public body (which apparently constitutes significant governmental involvement per se) could also be regarded as a meaningful incentive for its application by market players, although the standard remains legally voluntary. This seems to be the case regarding the important role public bodies may play in national regulatory systems and societies. The highest possible level of governmental support and incentives for a norm is making its application legally mandatory, thus transforming it into a mandatory technical regulation.

\subsubsection{Objectives of Private-Sector Standards}

Private-sector standards may pursue various objectives in setting requirements for products or production processes. Arguably, these objectives may be classified into three groups: technical objectives, societal objectives and commercial objectives. ${ }^{144}$

144 For example, for an overview of a private-sector standard applied on the markets 
The first group is denominated as technical objectives as the objectives pursued by private-sector standard are directly related to technical aspects of production. This group of objectives includes the establishment of common terminology, the interoperability of products, and the development and application of efficient production technologies.

The second group of objectives of private-sector standards is quite broadly defined as societal objectives because they cover important societal values. The societal objectives include the protection of the natural environment, for example sustainable forestry and fishery, the protection of endangered species and biodiversity, the reduction of carbon emissions to the atmosphere in connection with the process of global warming, the prevention or minimization of air, water and soil pollution, etc. Societal objectives may also include the protection of human rights and labour conditions, e.g. the prohibition of forced and child labour, safe and healthy working conditions, minimal wages and other labour guarantees. In this regard, the process of business self-regulation aimed at the protection of important societal objectives is often called "corporate social responsibility" (CSR). ${ }^{145}$ Consumer rights, and product safety and quality are, obviously, also very important societal objectives. Indeed, consumers have the right to enjoy safe products of high or, at least, satisfactory quality, and to be sufficiently informed about product characteristics or about certain aspects of production which consumers consider important.

Finally, the third group of objectives of private-sector standards may be defined as commercial or business objectives. These objectives primarily include: differentiation of products from competitive ones, creation of separate product niche-markets, promotion of brand reputation, and as a result, higher business profitability. For example, standards for organic food products effectively create rapidly growing niche-market for organic food.

of fruits and vegetables of the EU and North America, based on objectives of the standards, see: Cora Dankers, Pascal Liu, "Private Standards in the United States and European Union Markets for Fruit and Vegetables - Implications for developing countries", FAO Commodity Studies, 3, FAO, 2007, pp. 15 - 76.

145 For more information on CSR, see Section 2.3.2.3 of the present Chapter. See also: J. L. Johnson, "Public-Private-Public Convergence: How the Private Actor Can Shape Public International Labor Standards", Brooklyn Journal of International Law, 24, 1998; F. Mansoor, "Laughter and Tears of Developing Countries: The WTO and the Protection of International Labor Standards", International Trade Law Journal, 14, 2005; Y. Moorman, "Integration of ILO Core Rights Labor Standards into the WTO", Columbia Journal of Transnational Law, 39, 2001; J. Rollo and L. A. Winter, "Developing Countries and the Next Round of WTO Negotiations - Subsidiarity and Governance Challenges for the WTO: Environmental and Labour Standards", The World Economy, 23(4), 2000; D. A. Zaheer, "Breaking the Deadlock: Why and How Developing Countries Should Accept Labor Standards in the WTO”, Stanford Journal of Law, Business \& Finance, 9, 2003. 
The possible objectives of private-sector standards enumerated above are as interconnected as many other things in today's globalized world. For instance, the MSC standards and labelling primarily deal with the certification of sustainable fishery, i.e. protection of environment and marine resources. However, the MSC label on fish products also aims to satisfy the rights of consumers to be informed about the environmental impact of the fishery processes. At the same time, the MSC label may affect consumers' choices between competitive products, differentiating the product carrying the label and providing it with a competitive advantage. In fact, it seems fair to argue that many private-sector standards, in addition to their primary goal, have a commercial objective as well. This is because private-sector standards are applied by commercial corporations on a voluntary basis; and the corporations would not apply the standards to their own detriment or regardless of their own business interests.

Private-sector standards may be aimed at addressing a single primary objective or multiple ones. Thus, based on the number of primary objectives of private-sector standards, it is possible to classify them into singleand multiple-issue private-sector standards. Such labelling schemes as MSC and FSC may be regarded as single-issue labelling schemes because their primary objective is the sustainable management of marine and forest resources, i.e. environmental objectives. FLO and GLOBALG.A.P. may be described as multiple-issue standards because they address various groups of objectives, including product quality, sustainable production, the environmental impact of production, worker welfare, fair prices, and the sustainable development of producers from least-developed countries (in case of FLO), etc.

\subsubsection{Targeted Organizations for the Implementation of Private-Sector Standards}

Private-sector standards may be targeted for implementation and compliance by a business entity which applies a standard or by other business entities supplying products to an entity applying a standard. In this respect, private-sector standards may be applied internally and externally. The internally applied private-sector standards are used by corporations for their internal purposes, i.e. for the regulation of their own production methods and characteristics of final products. In fact, in practice, each relatively large corporation has its own internal rules, standards or codes of conducts, which regulate their own business activities. ${ }^{146}$ Moreover, cor-

146 For example, McDonalds Corporation, according to its website, have their own rules and standards concerning environmental responsibility, including energy efficiency, sustainable packaging and waste management, green restaurant design, etc.; see: http://www.aboutmcdonalds.com/mcd/csr/about/ 
porations may apply private-sector standards developed by other private standard-setting organizations and institutions to their own activities (that means implementation at the same time). Conformity assessment under such standards may be also conducted by an independent private entity. For example, many corporations apply and implement the ISO 9001:2008 standard on quality management systems in their production processes; conformity assessment with this standard is also exercised by independent certification bodies. ${ }^{147}$ An internally applied private-sector standard is applied by a market player to its own business activities which means that such a standard is applied and implemented by a same corporation, i.e. such a standard does not present requirements for other business entities - the suppliers of goods. In this respect, it could be said that the internally applied private-sector standards do indeed contribute substantially to the so-called process of business self-regulation.

The externally applied private-sector standards are applied and implemented by different entities. They are applied by buyers and implemented by their suppliers. Thus, these standards are common in the procurement of goods and supply chain management. The externally applied private-sector standards may be developed by companies that are buyers themselves or by industry associations and other NGOs. For instance, as has been mentioned before, big retailers such as Aldi (Germany), Ahold (which includes the Dutch Albert Heijn and Etos), Tesco, Marks \& Spencer (UK) and Carrefour (France) apply their own standards related to quality and the environmental impact of the products they sell. Suppliers of these retailers have to implement these standards and comply with their requirements if they want their products to be sold through the retailers. Similarly, for instance, GLOBALG.A.P. standards and BRC standards, which are developed by the industry associations, are widely applied today by the largest product processors and retailers to their suppliers. ${ }^{148}$

In fact, it might be difficult to apply the classification of private-sector standards as described above to private labelling schemes such as those administered by the MSC and the FSC. This is because the product labelling,

environmental_responsibility.html. The same is true for Siemens - one of the World's largest engineering groups based in Europe; see: http://www.siemens.com/ responsibility/en/environment/factors.htm; American multinational conglomerate General Electric, see: http://www.ge.com/citizenship/performance_areas/ environment_health_safety.jsp (last visited November 20,2014) and many other national and multinational corporations. See: http://www.iso.org/iso/iso_9000 (last visited November 20, 2014) Products certification from its suppliers of non-food consumer products; see: Ahold's Corporate Responsibility Report 2009, p. 17, available at: http://www.annualreport2009.ahold.com/documents/reports/Ahold_CR_2009. pdf (last visited November 20, 2014). 
first of all, is addressed to consumers, so that they can make informed decisions about the choice of products. As a rule, private labelling schemes may thus be characterized as the internally applied private-sector standards, because a decision of a business actor to comply with the requirements of such a scheme is usually taken by the actor itself. And compliance with a private-sector standard is motivated solely by tests and the preferences of consumers. However, if certification under a labelling scheme (thus, confirmed by a label on a product) is required by a business corporation purchasing products, such a labelling scheme may be viewed as an externally applied private-sector standard as well. This in fact demonstrates that there is no clear border between these two types of private-sector standards, and that the same standard may appear to be applied internally and externally depending on the circumstances.

On the one hand, since the present study is dealing with private-sector standards as technical barriers to trade, it seems that externally applied private-sector standards are the most relevant for the purposes of the study. To a large extent this is indeed true because it is logical to speak about technical barriers to trade when, in order to gain market access, a group of companies (suppliers) have to comply with a standard imposed by another company or group of companies (buyers). On the other hand, internally applied private-sector standards may appear to be relevant as well. And this is not only due to the lack of a clear cut border between the internally and externally applied standards, as demonstrated above with the example of labelling schemes. In fact, internally applied private-sector standards on technical issues and the interoperability of products may frequently have external implications. A good example is a company standard which becomes a de facto standard dominating within a certain industry. In such a case, private business entities may be forced to implement a private-sector standard not because this standard is applied by their buyers, but because the vast majority of other producers (or one or several dominant producers) use the same standard. Thus, business entities have to comply with such standard in order to remain competitive in a market and to ensure interoperability of their products with products of other producers.

For instance, it may be argued that in the market of word processing software today, a computer program, which is not able to work with the file extension formats "doc" or "docx" (the formats used by the word processor Microsoft Word), will not be competitive due to the dominance of these file extension formats in the market. Similarly, it would hardly be possible for a company to undertake the mass production of DVD discs with a size or shape different to the standardized one, since no device would be able to play them.

Furthermore, internally applied private company standards dealing with the technical characteristics and interoperability of products, even if 
they have not yet become de facto industry standards (not so widely applied in the market), may still have certain external implications for the companies wishing to produce compatible products. Such a situation may arise not only in the market of computer software, where the compatibility of different computer programs (dependent on a programming "source code" or file formats, etc.) is often at issue, but also in the other areas of technology and production. For instance, different companies producing printing machines (like Epson and Hewlett-Packard) have different standards for the ink cartridges. If another company wants to produce cartridges for printing machines of a particular firm, it has to use the standards of this firm.

Thus, in principle, both internally and externally applied private-sector standards may present technical barriers to trade. However, the different nature of these standards (particularly, nature of their application) may require different approaches to dealing with the technical barriers they may create. In this respect, on the one hand, for externally applied private-sector standards, among other relevant issues, the issues of non-discrimination, necessity and scientific justification of prescribed requirements may appear to be the most relevant. On the other hand, while the issues of harmonization and openness / transparency of standard-setting procedures are important also for externally applied private-sector standards, they are, arguably, even more relevant for internally applied standards dealing with technical characteristics and the interoperability of products.

\subsubsection{Targeted Clients of Private-Sector Standards}

Information about compliance with a private-sector standard may be targeted at various types of entities, i.e. private-sector standards may have different targeted clients. Those private-sector standards which primarily target business corporations are usually called "business to business" (or B2B) standards. And the private-sector standards which are mainly targeted at consumers of products are called "business to consumer" (or B2C) standards. On the one hand, because business corporations may be the final consumers of products as well, corporations per se are not excluded from the targeted clients of the B2C standards. ${ }^{149}$ On the other hand, the B2B standards target business corporations which do not behave as consumers but as business entities, i.e. they purchase products for use in production or resale.

Because business corporations usually purchase products in big consignments, the B2B standards, as a rule, are not accompanied by labelling

149 For example, business corporations may procure coffee or tea for consumption by employees, or paper to be used in everyday working activities. In such procurement, compliance with private-sector standard schemes confirmed by a product labelling may be taken into account by the corporations. 
on a product as such. A certificate or stamp of compliance, together with a product consignment, is regarded as sufficient for a business entity to know about product compliance with a private-sector standard. The B2C standards, on the other hand, usually include labelling on a final product aimed at providing information to consumers about compliance with a standard. The B2C standards are aimed at influencing consumer choice of products and, as such, the labelling is also supposed to provide information to consumers about the content and the objective of a standard. This may be done through illustration, brief note, or both.

Thus, in connection with the criterion of targeted clients, private-sector standards may also be classified into standards accompanied and not accompanied by labelling on a final product. Figure 6 below provides some examples of logos of the $\mathrm{B} 2 \mathrm{~B}$ private-sector standards although these are not provided on the labelling of final products. Figure 7 shows some of the many examples of renowned product labels of the B2C standards.

\section{Figure 6: Examples of the B2B private-sector standard logos}

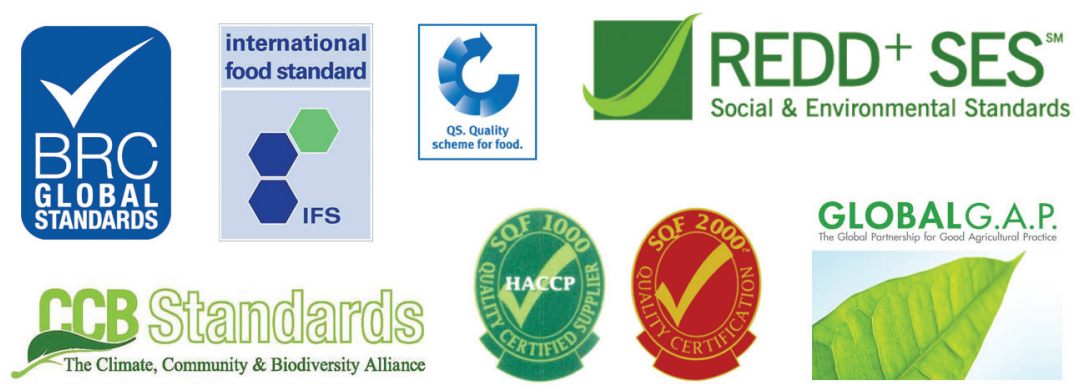


Figure 7: Examples of product labels of the B2C private-sector standards
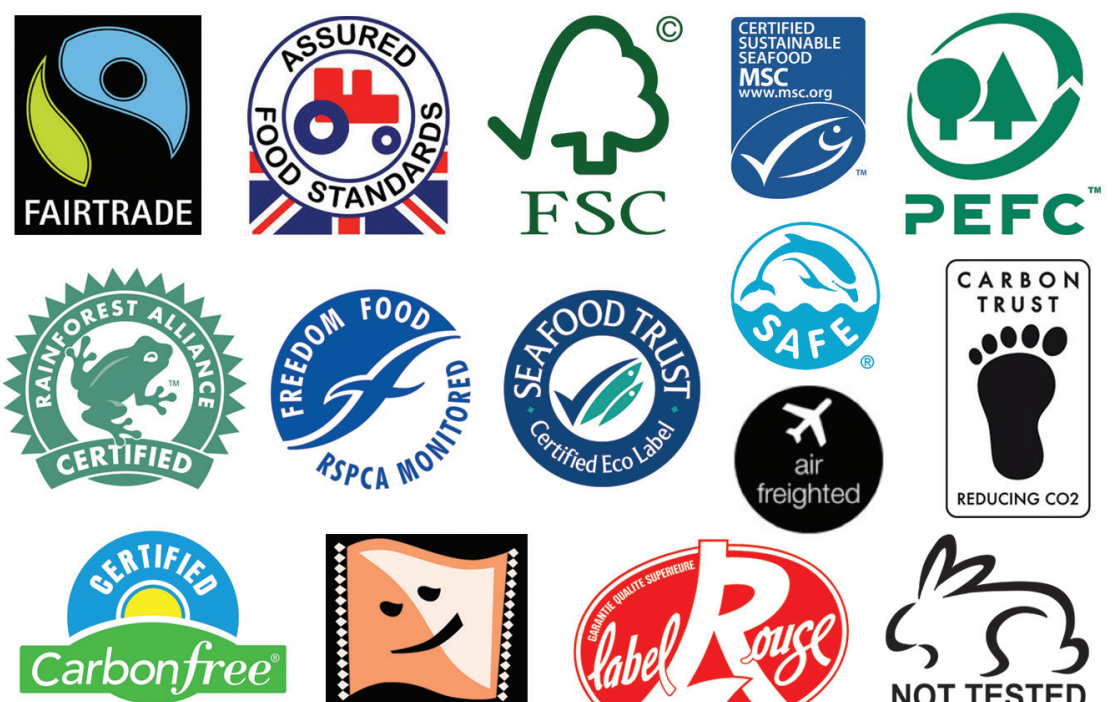

_ Carbonfund.org -
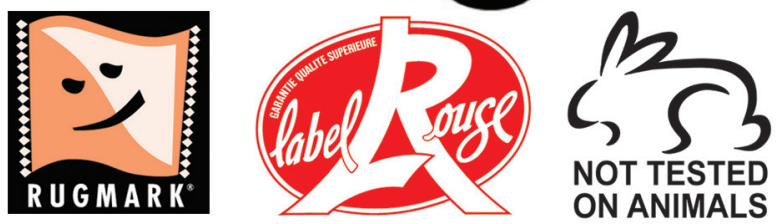

Many of the B2B private-sector standards address issues of food safety and quality, good agricultural practices, traceability and the interoperability of products. ${ }^{150}$ GLOBALG.A.P. and BRC Global Standards are clear examples of the B2B private-sector standards, as the information about certification under these standards is notified only to business entities, such as retailers. Consumers who buy products from these retailers might not be aware of the application of such standards. Such renowned private labelling schemes as the MSC, the FSC, the PEFC, the FLO, the Rainforest Alliance and the Assured Food Standards with its "Red Tractor" label, are the B2C standards. Because the B2C standards are aimed at influencing consumer choice, they frequently address product quality, the environmental impact of production, ethical issues such as labour conditions, and animal welfare.

\subsubsection{Scope of Private-Sector Standards: Product and Process Requirements}

Private-sector standards may present requirements with respect to product characteristics or PPMs, or both. PPMs may be classified into two

150 Pascal Liu, "Private standards in international trade: issues and opportunities", Contribution to Workshop on Environment-Related Private Standards,

Certification and Labelling Requirements, WTO, Geneva, July 9, 2009, p. 5. 
categories: "related PPMs" (or incorporated PPMs) and "non-product related PPMs" (or unincorporated PPMs, hereinafter referred to as nprPPMs). Related PPMs have a clear effect on final product characteristics and may be traced in the characteristics of a product as such. For example, if there is a direct dependency between the amount of pesticides used during the growing of certain vegetables and the final pesticide residues in these vegetables, a requirement limiting the amount of pesticides used during the process of growing would be a requirement on a related PPM.

Npr-PPMs, on the contrary, do not necessarily have any effect on the final characteristics of a product. For example, a carpet produced with the use of forced child labour materially may not be any different from a carpet produced by a qualified well-paid worker; and the requirement that no child labour shall be used in the process of the carpet's production would be a requirement on a npr-PPM. Other examples of npr-PPM-based requirements are the rules on sustainable fishing processes for fishing fleets or rules on the amounts of $\mathrm{CO} 2$ emissions during production processes. ${ }^{151}$

With respect to the differentiation of product and process requirements presented by standards, the ISO/IEC Guide 2 distinguish between product standards and process standards. ${ }^{152}$ Product standard is defined in the ISO/IEC Guide 2 as:

standard that specifies requirements to be fulfilled by a product or a group of products, to establish its fitness for purpose.

Note 1: A product standard may include in addition to the fitness for purpose requirements, directly or by reference, aspects such as terminology, sampling, testing, packaging and labelling and, sometimes, processing requirements.

Note 2: A product standard can be either complete or not, according to whether it specifies all or only a part of the necessary requirements. In this respect, one may differentiate between

151 Christiane R. Conrad also uses the term "non-physical aspects" (NPAs) of products with respect to npr-PPMs; see: Christiane R. Conrad, Process and Production Methods (PPMs) in WTO Law. Interfacing Trade and Social Goals, CUP, 2011, p. 61 - 63. Also for more discussion on different types of PPMs, see: Peter Van den Bossche, Werner Zdouc, The Law and Policy of the World Trade Organization. Text, Cases and Materials, 3d Edition, CUP, 2013, pp. 854 - 855; Rüdiger Wolfrum, Peter-Tobias Stoll, Anja Seibert-Fohr, WTO: Technical Barriers and SPS Measures, Nijhoff, Leiden, 2007, pp. 195 - 196; Manoj Joshi, "Are Eco-labels Consistent with World Trade Organization Agreements?”, Journal of World Trade, 38(1), 2004, p.74.

152 The ISO/IEC Guide 2 also contains the definition of "service standard": "standard that specifies requirements to be fulfilled by a service, to establish its fitness for purpose. Note: Service standards may be prepared in fields such as laundering, hotel-keeping, transport, car-servicing, telecommunications, insurance, banking, trading". However, as was stated previously, the present research does not cover private-sector standards in the area of trade in services. 
standards such as dimensional, material, and technical delivery standards. ${ }^{153}$

Interestingly, as can be seen from Note 1 of this definition, a product standard may also address the terminology, packaging and labelling, and even testing and sampling. With respect to the marking and labelling of products, the distinction between the requirements for product characteristics and the requirements for PPMs is in fact not so clear. On the one hand, the presence of a visible label or mark on a product as such or on its packaging may be regarded as a product characteristic. On the other hand, the label or mark may frequently address PPM-based issues, including npr-PPMs. ${ }^{154}$

The issue of terminology may relate to the naming of products or their ingredients. The ISO/IEC Guide 2 contains a separate definition for a terminology standard:

standard that is concerned with terms, usually accompanied by their definitions, and sometimes by explanatory notes, illustrations, examples, etc. ${ }^{155}$

The issues of interoperability or compatibility of products, according to the ISO/IEC Guide 2, may be addressed by an interface standard, which is defined as:

standard that specifies requirements concerned with the compatibility of products or systems at their points of interconnection. ${ }^{156}$

The sampling and testing of products, as a rule, is performed in the context of assessment of conformity with requirements of private-sector standards. In principle, sampling and testing has a more procedural nature and does not address product characteristics or PPMs as such. Hence, in the present study, the requirements related to sampling and testing are regarded as conformity assessment procedures with private-sector standards and not as the requirements of standards as such. ${ }^{157}$

153 ISO/IEC Guide 2: 2004, Standardization and Related Activities

- General Vocabulary, definition 5.4.

154 For further discussion on the regulation of PPMs under the GATT 1994 and the TBT Agreement, see Section 3.3.6 of Chapter III and Section 4.1.1.4 of Chapter IV.

155 ISO/IEC Guide 2: 2004, Standardization and Related Activities

- General Vocabulary, definition 5.2.

156 ISO/IEC Guide 2: 2004, Standardization and Related Activities

- General Vocabulary, definition 5.7.

157 However, it may be noticed that the ISO/IEC Guide 2 contains separate definition for testing standard: "standard that is concerned with test methods, sometimes supplemented with other provisions related to testing, such as sampling, use of statistical methods, sequence of tests"; see: ISO/IEC Guide 2: 2004, 
A process standard is quite broadly defined in the ISO/IEC Guide 2 as: standard that specifies requirements to be fulfilled by a process, to establish its fitness for purpose. ${ }^{158}$

Thus, according to this definition, PPM-based private-sector standards may be regarded as process standards in terms of the ISO/IEC Guide 2.

Depending on the content and coverage of a standard, the ISO/IEC Guide 2 also distinguishes a basic standard, and defines it as a:

standard that has a wide-ranging coverage or contains general provisions for one particular field.

Note: A basic standard may function as a standard for direct application or as a basis for other standards. ${ }^{159}$

The text of the ISO/IEC Guide 2 further points out that although the aforementioned "terms and definitions are not intended to provide a systematic classification or comprehensive list of possible types of standards. They indicate some common types only. These are not mutually exclusive". ${ }^{160}$

In fact, many standards include both product-based and PPM-based requirements. For example, standards for organic food products may present requirements related to the absence of certain undesirable elements, e.g. contaminants, pesticide residues, and genetically modified organisms (GMOs). At the same time, such standards may contain requirements related to the management of pesticides, the use of fertilizers, plant propagation and methods of cultivation, animal breading and welfare, etc.

However, the common use of npr-PPM-based requirements arguably forms one of the distinctive features of private-sector standards in comparison with public standards and technical regulations. Indeed, many private-sector standards are specially aimed at addressing npr-PPM-based issues. GLOBALG.A.P., for instance, although it includes requirements for the quality of agricultural products, mainly focuses on production processes that are non-traceable in the final product: crops propagation, animal breading, the management of pesticides and fertilizers, workers' welfare, the environmental impact of production, etc. In fact, the focus of GLOBALG.A.P. on processes is fairly reflected in its name - Global Good Agricultural Practices. Many private-sector standards and labelling

Standardization and Related Activities - General Vocabulary, definition 5.3.

158 ISO/IEC Guide 2: 2004, Standardization and Related Activities

- General Vocabulary, definition 5.5.

159 ISO/IEC Guide 2: 2004, Standardization and Related Activities

- General Vocabulary, definition 5.1.

160 ISO/IEC Guide 2: 2004, Standardization and Related Activities

- General Vocabulary, Note to para. 5. 
schemes address solely npr-PPM-based issues. In fact, the large majority of eco-labelling and ethical labelling schemes, such as the FSC, the MSC, the PEFC, and the Rainforest Alliance described earlier, are based on npr-PPM criteria.

There are several reasons for the common use of such npr-PPM-based requirements in private-sector standards. First, the application of such requirements allows for more efficient risk management and higher guarantees for safety and quality of products. In this respect, the control of production processes seems to be more effective and sometimes even less costly in comparison with the control of final products through testing and sampling, which realistically allows one to control only a limited number of products. Second, npr-PPM-based requirements address important societal objectives related to production processes which might not be addressed through the product-based rules.

Perhaps, it would be incorrect to assume that npr-PPM-based requirements are, in general, always more trade-restrictive than the product-based ones. However, npr-PPM-based requirements may indeed potentially create a lot of difficulties for producers, especially for those who might not have sufficient capacity to adapt according to such requirements, e.g. smallscale producers and producers from developing countries. Npr-PPM-based requirements of private-sector standards may be unjustified, irrelevant or be applied rigidly without taking into account local conditions of production. Moreover, the possible variety of npr-PPM-based requirements of different standards per se may present a challenge because producers might have to establish and maintain different production procedures for different markets, which might be quite costly and require significant investments. Finally, it is worth noting that npr-PPM-based requirements, in principle, are frequently more sensitive for producers than the product-based ones, as they prescribe to producers (which may be based in different countries) "how to live", so to speak, and not how the final result can be achieved.

The political and economic sensitivity of npr-PPM-based requirements is perhaps what prevents governments from using these requirements more widely in their public standards and technical regulations, especially if they want to avoid trade disputes with other States. ${ }^{161}$ And indeed the common

161 However, this does not mean that governments do not at all use such requirements in their public regulations and standards; arguably npr-PPM-based requirements are simply more common in private-sector standards. For instance, the US government initiated and administrated the "Dolphin safe" labelling for tuna products, when the tuna was fished with a method safe for dolphins; see: Earth Island Institute v. Hogarth, 494 F.3d 757 (9th Cir. 2007); see also: Panel and Appellate Body Reports, US - Tuna II (Mexico). Another example is the implementation by food business operators of the procedures based on the Hazard Analysis and Critical Control Points (HACCP) required by the EU Regulation No 852/2004 on the 
use of npr-PPM-based requirements in private-sector standards is one of the reasons for the many complaints about the trade-restrictive effects of these standards.

\subsubsection{Conformity Assessment Systems of Private-Sector Standards}

The assessment of compliance with the requirements of private-sector standards is performed through conformity assessment procedures. Conformity assessment is defined by ISO and IEC in the ISO/IEC 17000: 2004 as:

demonstration that specified requirements $[\ldots]$ relating to a product $[\ldots]$, process, system, person or body are fulfilled. ${ }^{162}$

Conformity assessment is performed by conformity assessment bodies, defined in the ISO/IEC 17000: 2004 as a "body that performs conformity assessment services". ${ }^{163}$ Conformity assessment under public standards and technical regulations may be performed by both governmental and nongovernmental bodies. Conformity assessment under private-sector standards is, by definition, performed by private non-governmental entities.

Conformity assessment is quite a general term and includes different types of procedures, which may be necessary to verify compliance with a standard. These procedures may include sampling and testing, inspection, audit and surveillance. ${ }^{164}$ Sampling and testing usually involves collecting

hygiene of foodstuffs; see: Regulation (EC) No 852/2004 on the hygiene of foodstuffs, Official Journal of the European Communities, 30 April 2004, available at: http://eur-lex.europa.eu/LexUriServ/LexUriServ.do?uri=OJ:L:2004:139:0001:005 4:EN:PDF (last visited November 20, 2014). For more information about HACCP, see Section 2.3.2.5.1 in the present Chapter. See also: M. Greaker,

"Eco-labels, Trade and Protectionism", Environmental \& Resourse Economics, 33, 2006; A. Green, "Climate Change, Regulatory Policy and the WTO.

How Constraining are Trade Rules”, Journal of International Economic Law, 8(1), 2005

162 ISO/IEC 17000: 2004 "Conformity Assessment - Vocabulary and General Principles", definition 2.1. Before adoption of the ISO/IEC 17000: 2004, the definitions related to conformity assessment were placed in the 1991 and 1996 editions of the ISO/IEC Guide 2. However, in 2000 it was decided "to take conformity assessment terminology [...] out of ISO/IEC Guide 2 and provide instead a self-contained vocabulary"; see: ISO/IEC 17000: 2004, Conformity Assessment - Vocabulary and General Principles, para. 0 - Introduction. See also the definition of conformity assessment in Annex 1.3 of the TBT Agreement cited in Section 2.1.1.7 of the present Chapter.

163 ISO/IEC 17000: 2004, Conformity Assessment - Vocabulary and General Principles, definition 2.5.

164 See: ISO/IEC 17000: 2004, Conformity Assessment - Vocabulary and General Principles, Note 1 to definition 2.1. 
samples of a particular product and evaluating their qualities against the appropriate requirements. ${ }^{165}$ Inspection and audit may include sampling and testing, but is also usually accompanied by the visual control of a product at an assigned location, taking records, and making an evaluation. The ISO/ IEC 17000: 2004 provides the following definition of "inspection":

examination of a product design, product $[\ldots]$, process or installation and determination of its conformity with specific requirements or, on the basis of professional judgement, with general requirements.

Note: Inspection of a process may include inspection of persons, facilities, technology and methodology. ${ }^{166}$

"Audit" is defined in the ISO/IEC 17000: 2004 as:

systematic, independent, documented process for obtaining records, statements of fact or other relevant information and assessing them objectively to determine the extent to which specified requirements $[\ldots]$ are fulfilled. ${ }^{167}$

Surveillance means a repeated and contentious verification process. In the ISO/IEC 17000: 2004 it is defined as:

systematic iteration of conformity assessment activities as a basis for maintaining the validity of the statement of conformity. ${ }^{168}$

It is generally possible to distinguish between three types of conformity assessment of private-sector standards, depending on the party performing the assessment: first-, second- and third-party verification or assessment. ${ }^{169}$ First-party verification, also known as self-declaration claims, is a

165 According to the ISO/IEC 17000: 2004, "sampling" is the "provision of a sample of the object of conformity assessment, according to a procedure"; and "testing" - "determination of one or more characteristics of an object of conformity assessment, according to a procedure [...]. Note: "Testing" typically applies to materials, products or processes". See: ISO/IEC 17000: 2004, Conformity Assessment - Vocabulary and General Principles, definitions 4.1 and 4.2.

166 ISO/IEC 17000: 2004, Conformity Assessment - Vocabulary and General Principles, definition 4.3.

167 ISO/IEC 17000: 2004, Conformity Assessment - Vocabulary and General Principles, definition 4.4.

168 ISO/IEC 17000: 2004, Conformity Assessment - Vocabulary and General Principles, definition 6.1.

169 See the definition of first-, second- and third-party conformity assessment activities in ISO/IEC 17000: 2004, Conformity Assessment - Vocabulary and General Principles, definitions 2.2 - 2.4. See also: World Trade Report. Exploring the Links Between Trade, Standards and the WTO, WTO, 2005, pp. 97 - 98. See also: Sally Washington, Lahsen Ababouch, "Private Standards and Certification in Fisheries and Aquaculture. Current Practice and Emerging Issues”, FAO, Rome, 2011, 
declaration of conformity by a producer or a supplier in relation to its own products based on self-evaluation and self-control. This type of verification is very common for private-sector standards which are applied internally by business corporations. Indeed, producers in different industries (e.g. cars, computers, cell phones, etc.) frequently have special staff members to verify compliance with public and private-sector standards (including the company own ones) devoted, for example, to the safety and quality of products.

Second-party verification is performed by product buyers, i.e. by the second interested party. This type of verification is widespread in supply chains, for instance among retailers and food processors procuring products in large quantities and applying standards to them. For example, such large retail chains as Tesco, Marks \& Spencer, and Ahold frequently verify themselves whether their suppliers are in compliance with the standards these retail chains adopt and apply.

Third-party verification is conducted by an independent organization competent in the matter and which is not involved in the business transactions between a buyer and a supplier. That is why it is often regarded to be more objective than the other two types of conformity assessment. Third party verification is also called "certification"; that is, "third-party attestation [...] related to products, processes, systems or persons". ${ }^{170}$ Certification is usually a sophisticated process comprising different stages, such as complex evaluation, verification, and assurance of conformity with requirements of a standard. After completion of a process of certification, compliance is usually confirmed by an official document (certificate) issued by a certification body (certifier). ${ }^{171}$ The role of a certifier may be played either by a standard-setting organization itself, or by other authorised organizations, i.e. an accredited certification body. The process of accreditation is usually performed by a standard-setting organization and aimed at ensuring that a certification body has the appropriate competence and capacity to perform conformity assessment. ${ }^{172}$ In the case of public standards and technical regulations, the

pp. $10-11$.

170 According to the ISO/IEC 17000: 2004, "attestation" is the "issue of a statement, based on a decision following review [...], that fulfillment of specified requirements [...] has been demonstrated"; see: ISO/IEC 17000: 2004, Conformity Assessment - Vocabulary and General Principles, definitions 5.2, 5.5.

171 For more information on types and classification of conformity assessment procedures, see: "Eco-Labeling Standards, Green Procurement and the WTO: Significance for World Bank Borrowers", Center for International Environmental Law, Washington, DC, Geneva, Switzerland, March, 2005, p. 97 - 100; L. Busch, D. Thiagarajan, et al., "The Relationship of Third-Party Certification (TPC) to Sanitary/Phytosanitary (SPS) Measures and the International Agri-Food Trade: Final Report”, RAISE SPS Global Analytical Report, 9, USAID, Washington, December 2005.

172 The term "accreditation" is defined as "third-party attestation [...] related to 
accreditation of certifiers may be performed by public standard-setting bodies or other authorised governmental or non-governmental bodies; in case of private-sector standards, it is usually performed by private standard-setting organizations.

The majority of collective private-standard schemes, such as GLOBALG.A.P., the MSC, the FSC and the FLO, use conformity assessment through third-party verification, i.e. certification procedures. Moreover, for many collective private-sector standards, the certification is performed by separate accredited certification organizations. Such practices exist for several reasons. First, private standard-setting organizations themselves, as a rule, avoid being directly involved in certification processes, as such an involvement may compromise their independence in the development of standards. In other words, such a separation of tasks is aimed at preventing possible conflicts of interests. This approach follows the renowned concept of separation of powers, i.e. legislative (standard-setting) and executive (certification). Second, many collective private-standards are applied globally or regionally; thus, a developed global or regional network of accredited certifiers makes it faster, cheaper and more convenient for business entities from various regions to get certified. This, in turn, may contribute to the popularity of a standard within a business sector.

Generally, considering the conformity assessment systems discussed above, the accreditation fees levied from certification bodies, together with membership fees and the sales of standards' texts, usually form the main sources of revenue for standard-setting organizations. Certification bodies, in turn, are usually financed through certification fees collected from business corporations for the performance of the certification process.

\subsection{Role of Private-Sector Standards in International Trade}

As demonstrated by the typology of private-sector standards provided above, these standards are remarkably diverse with respect to the entities developing and adopting them, performing conformity assessment, and also in terms of the requirements they present. Indeed, as has been observed by Spenser Henson and John Humphrey:

There is a substantial range of private sector standards, developed by distinct types of organisations to serve diverse purposes and

a conformity assessment body [...] conveying formal demonstration of its competence to carry out specific conformity assessment tasks"; see: ISO/IEC 17000: 2004, Conformity Assessment - Vocabulary and General Principles, definition 5.6. 
with different geographical and functional scope. Given this large number of standards, the organisations that sponsor them, their reach and their continued proliferation, it is not surprising that there has been a lack of clarity about private standards that has impeded understanding on this subject. ${ }^{173}$

Private-sector standards do indeed play an important role in production and trade nowadays. However, due to the complexity and diversity of the "world" of private-sector standards, the role of those standards is quite difficult to understand and to evaluate. The present Section attempts to shed some light on the role of private-sector standards in international trade. With this purpose in mind, the proliferation of private-sector standards during the past few decades and the reasons for this proliferation shall be discussed. It further briefly addresses the possible effects of private-sector standards on international trade. Finally, the Section provides brief explanations about the WTO regulatory system for international trade and the WTO agreements which may be relevant for the legal regulation of privatesector standards.

\subsubsection{The Proliferation of Private-Sector Standards}

There are hundreds, and perhaps even thousands, of operational private standards schemes nowadays. For example, in 2007 UNCTAD estimated the number of private standard schemes as being around 400 and subject to a continued increase. ${ }^{174}$ However, UNCTAD does not explain which method or data were used in order to calculate this number. On the other hand, the 2006 Report prepared by the European Commission estimated the number of private food standard schemes operational within the EU to be about $400 .{ }^{175}$ In fact, the real number of private-sector standards is hardly possible to count as new private standards schemes continue to emerge, and also because it is generally quite difficult, if possible at all, to track all standardizing activities within private sector.

Private-sector standards have proliferated quite rapidly over the past 15-20 years. It is worth noting that standard-setting was traditionally

173 Spencer Henson, John Humphrey, "The Impacts of Private Food Safety Standards on the Food Chain and on Public Standard-Setting Processes", Codex thirty-second Session, FAO, WHO, Codex Alimentarius Commission, Rome, May 2009, p. 3.

174 See: Private Standards and the SPS Agreement. Note by the Secretariat, WTO, SPS Committee, G/SPS/GEN/746, Geneva, 24 January 2007, para. 3. See also: Tomasz Wlostowski, "Selected Observations on Regulation of Private Standards by the WTO”, Polish Yearbook of International Law, XXX, 2010, p. 207.

175 See: Grace Chia-Hui Lee, "Private Food Standards and Their Impacts on Developing Countries”, European Commission DG Trade Unit G2, Brussels, 2006, pp. 35, 38. 
considered to be a public function. Historically, it was performed either by governmental bodies or by private entities authorized to perform this public function and officially recognized by public authorities. However, for the past several decades this "public monopoly" gradually disappeared, and nowadays standard-setting is frequently accomplished by many business players in a production or supply chain, as well as by standard-setting coalitions, industry associations and NGOs. This phenomenon is sometimes identified in the relevant literature as a process of "privatization" of market governance. ${ }^{176}$ This "privatization" is claimed to be a part of a larger process, namely the constitution of private governance through the expansion of private regulation accompanied with the devolution of public governance in certain areas. ${ }^{177}$ Nowadays, governments constrained by national borders and political interests, frequently have difficulties in addressing the challenges presented by globalization. ${ }^{178}$ At the same time, globalization as such results in the growth of power and influence of private actors, such as multinational corporations and NGOs. As a result, multinational corporations, industry associations, and environmental and human rights NGOs are becoming more and more active in developing and setting "rules of the game" in order to ensure the protection of important societal and business objectives, and to establish the so-called "level playing field" for all market players.

Of course, the societal and environmental problems of the contemporary globalized world can hardly be resolved by national governments and public international organizations alone. Indeed, considerable progress in dealing with these problems may be achieved only through the active participation and support of the private sector; and in this respect, the rise of private-sector standards at the end of 20th century does not come as a surprise. ${ }^{179}$

176 See: Spencer Henson, John Humphrey, "The Impacts of Private Food Safety Standards on the Food Chain and on Public Standard-Setting Processes", Codex thirty-second Session, FAO, WHO, Codex Alimentarius Commission, Rome, May 2009, pp. 9, 11.

177 Harm Schepel refers to the "collapsing state and society" and "global law without a State" in this regard; see: Harm Schepel, The Constitution of Private Governance: Product Standards in the Regulation of Integrating Markets, Oxford [etc.] : Hart, 2005, pp. 11, 19 - 21, 404-405; see also: Spencer Henson, John Humphrey, "The Impacts of Private Food Safety Standards on the Food Chain and on Public Standard-Setting Processes", Codex thirty-second Session, FAO, WHO, Codex Alimentarius Commission, Rome, May 2009, p. 11.

178 See: Harm Schepel, The Constitution of Private Governance: Product Standards in the Regulation of Integrating Markets, Oxford [etc.] : Hart, 2005, pp. 21 - 23.

179 See: Grace Chia-Hui Lee, "Private Food Standards and Their Impacts on Developing Countries”, European Commission DG Trade Unit G2, Brussels, 2006, p. 8. 


\subsubsection{Reasons for the Proliferation of Private-Sector Standards}

At first sight, it seems strange that business actors voluntarily accept for themselves more stringent and extensive rules than is prescribed by legislation. More stringent rules may entail higher costs for compliance and verification and, as a result, higher product costs and less competitive opportunities. In other words, as Grace Chia-Hui Lee put it: "Economic theory tells us that market forces do not necessarily serve the perceived public interest”. 180

Accordingly, when the regulation of product safety, quality, environmental sustainability, etc., is left to private entities, one could expect "a race to the bottom", i.e. the phenomenon provoked by the industries' desire to cut the costs of production. This phenomenon is frequently complained about in the context of international trade and globalization when corporations may have incentives to move their production facilities into developing countries with less stringent labour and environmental legislation, and lower the wages of employees and other production costs. In this respect, governments of developing countries might be tempted to further decrease their appropriate regulatory requirements in order to attract investments.

However, with respect to private-sector standards, the contrary tendency occurs: rather than "a race to the bottom", "a race to the top" is taking place. ${ }^{181}$ Indeed, the very existence of many private-sector standards, like private environmental standards or private-sector standards for food quality, are justified if they present more stringent or extensive requirements than governmental standards or technical regulations, rather than merely duplicating them. Moreover, private-sector standards do not only present more stringent or extensive requirements for products or PPMs in comparison with governmental requirements, they also constantly evolve and compete with each other which frequently results in even more exhaustive and stricter requirements. ${ }^{182}$ For example, the trend of "a race to the top" in requirements presented by private-sector standards may often be observed in the product sourcing patterns of big supermarket chains. Indeed, as is rightly noted by Grace Chia-Hui Lee, the "supermarkets require their suppliers to get certified by ever-increasing private standards and compete on grounds of food safety and quality”. ${ }^{183}$

\footnotetext{
180 Ibid., p. 8.

181 See: Ibid., p. 8.

182 See: J.J. McCluskey, "Public and Private Food Quality Standards: Recent Trends and Strategic Incentives”, at: Johan F.M. Swinnen, Global Supply Chains, Standards and the Poor. How the Globalization of Food Systems and Standards Affects Rural Development and Poverty, CABI, Trowbridge, 2007, pp. 22 -23.

183 Grace Chia-Hui Lee, "Private Food Standards and Their Impacts on Developing
} 
The facts described above bring us to an important question: why do private-sector standards emerge, continue to thrive and proliferate in the contemporary business environment? And why do business corporations choose to apply them? Indeed, there may be various reasons for the proliferation of private-sector standards and, due to complexity of the phenomenon, it is hardly possible to identify and distinguish all the possible reasons. But whatever these reasons are, they are very much interconnected and interdependent as are many other factors in the contemporary globalized world. In fact, the main trends of our age, namely processes of globalization, industrial / technological development, and the social / environmental challenges these processes present, may be regarded as the initial sources of all the reasons for the proliferation of private-sector standards. ${ }^{184}$

\subsubsection{The Globalization of International Trade}

The globalization of international trade, accompanied by the movement of goods worldwide, indeed presents significant challenges related to the control of safety and quality of products from various parts of the world. ${ }^{185}$ Recent decades have seen national and regional epidemics of various old and new dangerous diseases, such as bird flu, swine flu, salmonella, and bovine spongiform encephalopathy (BSE). These developments often entailed widely publicized food scares and demonstrated the economic and political significance of threats related to plant, animal or human health. ${ }^{186}$ Products contaminated with toxins and other dangerous substances became the subject of public concern, renowned scandals, and trade disputes.

Countries”, European Commission DG Trade Unit G2, Brussels, 2006, p. 8.

184 See: Pascal Liu, "Private Standards in International Trade: Issues and Opportunities", Workshop on Environment-Related Private Standards, Certification and Labelling Requirements Geneva, Switzerland, July 9, 2009, p.2; see also: Linda Fulponi, "The Globalization of Private Standards and the Agri-food System", at: Johan F.M. Swinnen, Global Supply Chains, Standards and the Poor. How the Globalization of Food Systems and Standards Affects Rural Development and Poverty, Cromwell Press, Trowbridge, 2007, p. 5. See also: Fabrizio Cafaggi, "New Foundations of Transnational Private Regulation”, Journal of Law and Society, 38(1), 2011.

185 See: David Plunkett, Caroline Smith DeWaal, "Who Is Responsible for the Safety of Food in a Global Market? Government Certification v. Importer Accountability as Models for Assuring the Safety of Internationally Traded Foods”, Food and Drug Law Journal, 63(3), 2008, p. 657.

186 See: Spencer Henson, Steven Jaffee, "Understanding Developing Country Strategic Responses to the Enhancement of Food Safety Standards", World Economy, 31(4), 2008, p. 549; see also: Grace Chia-Hui Lee, "Private Food Standards and Their Impacts on Developing Countries", European Commission DG Trade Unit G2, Brussels, 2006, p. 8; T. E. Josling, D. Roberts, et al., "Food Regulation and Trade: Toward a Safe and Open Global Food System”, Institute for International Economics, Washington DC, 2004. 
The Economist described such concerns with respect to certain Chinese products in the following way in 2007:

It has been a rough few months for China's exporters. In March tainted pet food originating in China was found to be killing animals in America. Since then Chinese shipments of toxic toothpaste, toys and seafood, as well as hundreds of thousands of faulty tyres, have all caused big safety scares. The defective goods that have long bedevilled Chinese consumers are beginning to spread to the outside world - a trend that is exacerbating concern about China's burgeoning exports.

Tales of dangerously shoddy manufacturing within China are nothing new. In 2004 bogus baby formula killed dozens of infants. More recently the Chinese media have reported half a dozen dead and many ill from a flawed antibiotic, 11 dead from tainted injections, 56 people ill as a result of contaminated meat, toxic snacks pulled off shelves and fake blood protein discovered in hospitals. [...]

But safety lapses have only recently begun to attract the attention of foreigners. On July 1st Charles Schumer, an American senator who is a vocal critic of China, issued a report noting that $60 \%$ of goods recalled by America's main safety regulator came from China. In June alone, the report says, dangerous faults or poisons prompted the recall of 68,000 folding chairs, 2,300 toy barbecue grills, $1.2 \mathrm{~m}$ space heaters, 5,300 earrings, $1.5 \mathrm{~m}$ "Thomas the Tank Engine" toy trains and 19,000 children's necklaces. America's Food and Drug Administration has also rejected several shipments of contaminated food from China this year, and a wholesaler in New Jersey has recalled Chinese chocolates containing potentially carcinogenic ingredients.

Skittish Americans are not the only ones worried about Chinese exports. In Panama around 100 people are reported to have died after ingesting tainted cough syrup from China. In Hong Kong, stores routinely sell staple goods such as eggs and milk from China more cheaply than those from other countries - a good indicator of the perceived danger. Legislators in the territory upbraided the government for lax safety standards on July 4th. In response, it pledged to develop a food supply "traceability system" to find and remedy problems at their source - in China. The European Union has also expressed concern. [...]

Mr Schumer fears that many faults are never detected. After all, in America as in most countries, only a relatively small proportion of imports is inspected. ${ }^{187}$

187 "Chinese Manufacturing. The Diddle Kingdom. Tainted Chinese Goods Prompt safety Scares Around the World", The Economist, Hong Kong, July 5, 2007, 
A more recent example is the highly publicized Chinese milk scandal which took place in 2008 - 2009 in China, when powdered baby milk and other dairy products were found to be contaminated with the dangerous industrial chemical, melamine. ${ }^{188}$ Six babies died and some 300000 got sick in China because of the contaminated milk products. The scandal sparked worldwide safety concerns, followed by the banning or introduction of additional control measures for Chinese dairy products by many countries, including the US and the EU. ${ }^{189}$ Obviously safety and quality concerns of consumers are not only relevant for Chinese products. For instance, the safety of products containing asbestos, poultry meet treated (cleaned) with chemicals, hormone-treated meat, and products containing GMOs - often called "Frankenstein products" - became the subject of intense public and international debates. Some of these debates even materialized as WTO trade disputes with participation from the EU, the US, Canada, Australia and other developed and developing WTO Members. ${ }^{190}$

Threats related to the safety and quality of products affect preferences and the perception of risks by consumers, as well as the regulatory policies followed by public authorities and private parties. Companies which want to ensure the safety and quality of supplied products sourced from different parts of the world have responded to these challenges of trade globalization by applying their own or collective private-sector standards. FAO economist, Pascal Liu, describes this process in the following way:

Firms increasingly source their raw materials, components and products from a large number of suppliers worldwide. In the past, backward integration through ownership was a favoured strategy to secure scarce supply and ensure product quality. For example, retailers would take over food processing companies while food processors would invest in agricultural production units. However, control through ownership is complex, costly and entails risks, especially for firms that are not experienced in the industry. The situation of surplus production that developed in the agricultural sector from the 1980s made it less important

available at: http://www.economist.com/node/9443105 (last visited November 20, 2014).

188 See: “Timeline: China Milk Scandal”, BBC, available at: http://news.bbc.co.uk/2/ hi/7720404.stm (last visited November 20, 2014).

189 See: "Tainted Milk Scandal Resurface in China”, BBC, available at: http://news.bbc.co.uk/2/hi/8478195.stm (last visited November 20, 2014).

190 See: Panel and Appellate Body Reports in EC - Asbestos, EC - Hormones; Panel Report, EC - Approval and Marketing of Biotech Products; Request for the Establishment of a Panel by the US in DS389 EC - Poultry (US). See also: G. P. Gruère and D. Sengupta, "Biosafety and Perceived Commercial Risks. The Role of GM-Free Private Standards”, Brief Number 15, International Food Policy Research Institute, 2009. 
to secure access to supply. And progress in information and communication technology made it possible to control the supply chain through the use of standards. In a market situation of abundant supply, standards give a sufficient degree of control over product quality and do not require large investments and the involvement in the management of suppliers. Thus, backward integration through ownership has tended to be replaced by a lighter form of integration through standards. Such a trend has been observed in the banana industry, where multinational companies have sold some of their plantations and increasingly used standards since the 1990s. ${ }^{191}$

Thus, the application of private-sector standards by private firms allows them to maintain a certain degree of control over their suppliers. This, in turn, is seen to provide better guarantees for the safety and quality of supplied products in view of the challenges presented by trade globalization and the sourcing of products worldwide. At the same time, the application of private-sector standards may be also viewed as a soft tool for business integration, i.e. the creation of a "level playing field" for businesses in markets.

\subsubsection{Evolving Consumer Demands and Business Reputation}

It is a matter of fact that consumer demands have been changing with the evolution of people's lifestyle and societal values. ${ }^{192}$ Economic development and an increase in people's incomes have stimulated better awareness and higher demands of consumers regarding products and their production processes. In fact, the focus of consumer demands, with respect to products, has shifted significantly over the past few decades and is reflected in public and private regulatory norms. First of all, due to the globalization of international trade and product safety scares described above, consumers have become more concerned about the safety and quality of products they buy. A lot of consumers opt for renowned brands with proven safety and quality records.

Furthermore, important problems of the contemporary world, such as global warming, the cruel treatment of animals, and the violation of human rights in certain countries, may also significantly influence consumer behaviour. Nowadays, at least in many developed countries, consumers are frequently concerned not only with qualities of a final product, e.g. the presence of certain substances like genetically modified organisms or

191 Pascal Liu, "Private Standards in International Trade: Issues and Opportunities", Workshop on Environment-Related Private Standards, Certification and Labelling Requirements Geneva, Switzerland, July 9, 2009, p. 2.

192 Private Voluntary Standards and Developing Country Market Access: Preliminary Results. Communication from OECD, Linda Fulponi, WTO, SPS Committee, G/SPS/GEN/763, Geneva, 27 February 2007, p. 6 
ozone depleting substances, but are also more and more interested in being informed about the ways of production. For example, they want to know whether tuna out of a can sold in a supermarket was fished sustainably and without harm to endangered species, or whether printing paper was produced out of timber delivered from sustainably managed forests, or even how much carbon gas was emitted into the atmosphere during the production of a certain product. In this respect, consumers may frequently be ready to pay a price premium not only for healthier food and for products of a higher quality, but also for products produced in responsible and sustainable ways, both socially and environmentally. Private-sector standards could therefore be said to ensure price premiums for complying products, as well as inform consumers through product labelling about product characteristics and their production methods.

Consumer attitudes to the safety and quality of products, and their attention to the effects of production processes on the environment and society, are reflected in another phenomenon. Consumers do not only care about what they buy nowadays, but also from whom they buy, e.g. whether a producer has a good reputation and implements sustainability policies, whether a supermarket chain ensures product safety / quality, whether food production is environmentally sustainable throughout the supply chain, etc. Every marketing expert knows how important brand reputation and the reputation of a business corporation in general is for commercial success. This reputation may require a lot of time and resources to build, but it may be very easily destroyed through a product safety / quality scandal, or bad publicity related to the negative effects of business activities on the environment or society.

For example, claims in mass media that a chocolate producer manufactures chocolate by sourcing cocoa from developing countries using child or slave labour, could be detrimental to the reputations of both the chocolate producer and the retailer selling this chocolate to consumers. This information may result in a decrease of sales and direct financial losses for the producer and the retailer, even if they were both not actually aware of the use of child or slave labour. Another particular example is the bad publicity about the business activities of the multinational oil company, Royal Dutch Shell, in Nigeria. The scandals about oil spills and their detrimental effects on the traditional living environment of the local population caused a lot of damage to the company's reputation and also entailed high costs for settling the related law suits. ${ }^{193}$

193 And this is the case notwithstanding the fact that Royal Dutch Shell, in the majority of cases, attributed the fault to acts of sabotage committed by locals and the incapacity of governmental authorities to ensure security of pipelines, see: "Shell hit by $\$ 1.5$ bn Nigeria spill claim", Guardian, August 26, 2004, available at: http://www.guardian.co.uk/business/2004/aug/26/environment.oilandpetrol 
In this respect, the role of national and international NGOs in shaping public opinion has significantly increased over the past several decades. Nowadays NGOs are undoubtedly the most important element of societal supervision over the activities of business corporations, and especially of multinational corporations. NGOs perform a lot of research and collect information on the effects of corporate business activities on local communities and the environment, and they usually make the appropriate information available to the public through printed publications or mass media. In this respect, such important elements of democratic societies as independent journalism and diverse mass media sources, are key factors in raising public awareness about social, environmental, economic and political problems. Indeed, together with NGOs, free mass media plays a very significant role in shaping public opinion.

Because consumer demands in particular societies are very dependent on the level of life and wellbeing of the population, these demands are not the same around the world. In general, arguably, consumer demands tend to be higher in developed countries than in developing countries, and, especially, than in least-developed ones. Moreover, products which are produced to meet the expectations of consumers in developed countries may be too expensive for developing countries and may thus not find a market there. That is why producers who want to export their products abroad have to, in practice, deal with differing demands and conditions in different markets. It is frequently said that such differences present bigger problems for producers from developing countries (especially for the small-scale ones) who may have substantial difficulties in adjusting to the higher requirements of the developed world.

Generally, in a large majority of developed and many developing countries, consumers expect a great deal from producers and retailers in terms of product quality, safety and environmental sustainability. For example, in the area of food products, safety and quality remain the key factors. But at the same time, other attributes, mostly related to food production processes, are growing in importance, such as animal welfare, labour rights, the environmental impact of production ${ }^{194}$ and even fairness of a price premium distribution. ${ }^{195}$ The widespread application of private-sector

(last visited November 20, 2014).

194 See: Linda Fulponi, "The Globalization of Private Standards and the Agri-food System”, at: Johan F.M. Swinnen, Global Supply Chains, Standards and the Poor. How the Globalization of Food Systems and Standards Affects Rural Development and Poverty, Cromwell Press, Trowbridge, 2007, p. 6.

195 For example, the Fair Trade labelling scheme is aimed at certifying not only sustainable ways of agricultural production, but also at ensuring fair prices for sustainably produced products; see: http://www.fairtrade.net/aims_of_fairtrade_ standards.html (last visited November 20, 2014). 
standards is, to large extent, a businesses' response to evolving consumer demands. Product producers, suppliers and retailers, through the application of private-sector standards, want to satisfy these demands and protect their reputations. ${ }^{196}$ The application of private-sector standards, including private labelling schemes, is aimed at assuring consumers not only of the safety and quality of products, but also that certain important societal objectives have been met during the production processes.

Thus, the evolution of consumer demands is undoubtedly influencing the ways of doing business throughout the supply chain. ${ }^{197}$ Companies are interested in promoting their reputations and brands by informing consumers about the positive social and environmental impacts of their businesses, and about steps taken to protect the environment and endangered species of flora and fauna, or other non-economic values. Consumers may be informed by corporations about the positive social or environmental effects of their business activities by advertising in mass media, posting the information on the internet, or through informative labels or marking provided on products.

A business corporation doing business without due regard for the protection of social and environmental values, runs the risk of becoming the subject of a scandal or bad publicity related to negative environmental or social impacts of its business activities. Such bad publicity may seriously affect a firm's reputation and, as a result, the profitability of that business. Thus, the reputation of companies is one of the main driving forces for the increased application of private-sector standards in the business sector. Indeed, according to a survey conducted by OECD with respect to the use of private-sector standards in the food sector, the answers to the question "What are the main economic incentives for standards?" were summarized as follows:

The response of all retailers and food companies could be summarized in one word: reputation.

Providing consumers with products that meet consistent quality and safety standards that go beyond the minimum requirements was seen as essential to building reputation, the key to current and future earnings flows. The use of private standards was seen as a way to maintain and possibly enhance firm reputation. ${ }^{198}$

196 See: Linda Fulponi, "Private Voluntary Standards in the Food System: the Perspective of Major Food Retailers in OECD Countries”, Food Policy, 31(1), 2006, p. 6.

197 See: Private Voluntary Standards and Developing Country Market Access: Preliminary Results. Communication from OECD, Linda Fulponi, WTO, SPS Committee, G/SPS/GEN/763, Geneva, 27 February 2007, p. 6.

198 Linda Fulponi, "Final Report on Private Standards and the Shaping of the Agro-Food System”, AGR/CA/APM(2006)9/FINAL, OECD, Working Party on 
However, in the eyes of consumers, the roles of governments remain very important in the regulation and control of products and production processes. For example, particularly in the food sector, consumers in developed countries expect a lot from their governments, as was evidenced by the OECD survey conducted among consumer associations.

In a survey of consumer concerns in the food area, done through representative consumer associations, results indicate that food safety, environmental effects and health were major concerns. When asked who should be responsible for determining setting standards or behavioural rules over food safety, quality, environmental effects, labour standards and animal welfare, all consumer associations felt that it was the government's role to regulate all these areas.

Only in the area of quality did consumers concede a slight advantage towards industry self-regulation or private-public partnerships, the meshing of government regulations and industry monitoring via quality management systems is a significant step. ${ }^{199}$

Evolving consumer demands thus influence not only private regulation in the form of development and the application of private-sector standards, but the public type of regulation as well. In the end, consumers view public authorities as bearing the basic responsibility for ensuring the safety of products and for compliance of products and PPMs with basic social and environmental requirements. In other words, whatever role private-sector standards are playing or will play in the future with regard to the regulation of supply chains, they will always coexist and interact with public technical regulations and standards providing public requirements. At the same time, because private regulatory systems are frequently more dynamic and flexible, governmental authorities may take private regulatory norms as an example for further developing public regulatory regimes. ${ }^{200}$

Agricultural Policies and Markets, July 2006, p. 23. See also: V. Haufler, "Private Sector and International Standards-Setting: The Challenge for Business and Government", Discussion Paper 3, Study Group on the Role of the Private Sector, Carnegie, 2008.

199 Private Voluntary Standards and Developing Country Market Access: Preliminary Results. Communication from OECD, Linda Fulponi, WTO, SPS Committee, G/SPS/GEN/763, Geneva, 27 February 2007, pp. $6-7$.

200 See: Linda Fulponi, "The Globalization of Private Standards and the Agri-food System”, at: Johan F.M. Swinnen, Global Supply Chains, Standards and the Poor. How the Globalization of Food Systems and Standards Affects Rural Development and Poverty, Cromwell Press, Trowbridge, 2007, p. 7. See also: Ludo Cuyvers, Tim De Meyer, "Market-Driven Promotion of International Labour Standards in Southeast Asia: the Corporatization of Social Justice", at: Axel Marx, Miet Maertens, Johan Swinnen, Jan Wouters, Private Standards and Global Governance. Economic, Legal 


\subsubsection{Corporate Social Responsibility}

The use of private-sector standards may also be seen in a broader context. Due to the evolution of consumer demands, as discussed above, the protection of certain public societal and environmental objectives have become a part of business policies and business models in many countries. In other words, due to consumer concerns and the interdependence of businesses' reputations and profitability, certain public objectives have become commercialized, so to speak. In this respect, the businesses' commitment to the protection of certain important public objectives is driven by the reason that is sometimes referred to as "enlightened self-interest". ${ }^{201}$ This commercial enlightened self-interest results in the phenomenon called "corporate social responsibility" (CSR).

CSR is the form of a businesses' self-regulation which is incorporated into the business model of a company ${ }^{202} \mathrm{CSR}$ presupposes that a corporation takes an environmentally and socially responsible approach to doing business. In this respect, companies, when engaging in certain environmental or social commitments, do not do it directly on the basis of a cost-benefits analysis in each particular case. Rather, the protection of certain important public objectives is taken as the background or necessary condition of business activities. Therefore, behind the businesses' commitment to CSR, lies an understanding that long-term investments in sustainable and responsible production policies are more beneficial than possible short-term gains from environmentally and socially irresponsible activities.

In this respect, it seems to be incorrect to characterize CSR as "sacrificing" profits in the name of protection of important societal goals. In fact, companies' commitment to CSR may provide competitive advantages not only in terms of maintaining a good reputation, but also in the form

and Political Perspectives, Edward Elgar, Cheltenham, UK, 2012, pp. 114-116. See also: G. P. Gruère and D. Sengupta, "Biosafety and Perceived Commercial Risks. The Role of GM-Free Private Standards”, Brief Number 15, International Food Policy Research Institute, 2009.

201 See: "Do it right. Corporate responsibility is largely a matter of enlightened selfinterest", The Economist, January 17, 2008, available at: http://www.economist. com/node/10491124?story_id=10491124 (last visited November 20, 2014).

202 There is no official definition of CSR. One definition proposed by the European Commission is "a concept whereby companies integrate social and environmental concerns in their business operations and in their interaction with their stakeholders on a voluntary basis"; see: Communication from the Commission concerning Corporate Social Responsibility: A Business Contribution to Sustainable Development, Brussels, 2 July 2002, COM(2002), 347 final, p. 3, available at: http://trade.ec.europa.eu/doclib/docs/2006/february/tradoc_127374. pdf (last visited November 20, 2014). See also: Private Standards and the SPS Agreement. Note by the Secretariat, WTO, SPS Committee, G/SPS/GEN/746, Geneva, 24 January 2007, para. 4. 
of improved efficiency and better conditions for business activities. Michel Porter and Mark Kramer demonstrate the relationship between CSR and competitive advantage in the following way:

The principle of sustainability appeals to enlightened selfinterest, often invoking the so-called triple bottom line of economic, social, and environmental performance. In other words, companies should operate in ways that secure long-term economic performance by avoiding short-term behaviour that is socially detrimental or environmentally wasteful. The principle works best for issues that coincide with a company's economic or regulatory interests. DuPont, for example, has saved over $\$ 2$ billion from reduction of energy use since 1990. Changes to the materials McDonald's uses to wrap its food have reduced its solid waste by $30 \%$. These were smart business decisions entirely apart from their environmental benefits. ${ }^{203}$

Furthermore, the authors argue that CSR and the protection of important societal values are deeply rooted in the interests of business. Business and society are inextricably linked in this respect:

Successful corporations need a healthy society. Education, health care, and equal opportunity are essential to a productive workforce. Safe products and working conditions not only attract customers but lower the internal costs of accidents. Efficient utilization of land, water, energy, and other natural resources makes business more productive. Good government, the rule of law, and property rights are essential for efficiency and innovation. Strong regulatory standards protect both consumers and competitive companies from exploitation. Ultimately, a healthy society creates expanding demand for business, as more human needs are met and aspirations grow. Any business that pursues its ends at the expense of the society in which it operates will find its success to be illusory and ultimately temporary. ${ }^{204}$

Thus, CSR is based on the deep linkage between commercial business and public interests. Companies are therefore interested in integrating the protection of important public values into their daily activities. In fact, nearly all multinational corporations and many big companies develop and follow

203 Michael E. Porter, and Mark R. Kramer, "Strategy \& Society: The Link between Competitive Advantage and Corporate Social Responsibility”, Harvard Business Review, December 2006, p. 4, available at: http://custom.hbsp.harvard.edu/ custom_pdfs/FSGIMR0612D2006122113.pdf (last visited November 20, 2014).

204 Michael E. Porter, and Mark R. Kramer, "Strategy \& Society: The Link between Competitive Advantage and Corporate Social Responsibility”, Harvard Business Review, December 2006, p. 5, available at: http://custom.hbsp.harvard.edu/ custom_pdfs/FSGIMR0612D2006122113.pdf (last visited November 20, 2014). 
their own CSR policies nowadays. The application of CSR policies is particularly important for multinational corporations as they act in different jurisdictions where the level of guarantees for the protection of important societal objectives may vary significantly. Multinational corporations are therefore encouraged to apply the same standards to their activities in various countries notwithstanding possible significant differences in the requirements of local public regulations, different countries' regulatory capacity, and levels of corruption. Taking this into account, OECD developed the OECD Guidelines for Multinational Enterprises which contain recommendations for responsible business conduct by enterprises with respect to human rights, employment conditions, the environment and other important issues. ${ }^{205}$

CSR may be reflected in corporate activities in various ways. One option is philanthropy, which may include monetary donations to local organizations and institutions, financial aid and technical assistance for local development. The community-based approach implies the integration of a corporation into a local community by employing people from the local population, providing education, building houses, schools and other types of local infrastructure. Finally, a corporation may integrate CSR policies into its production processes and business strategy, for example by using low pollution technologies, restoring natural habitats damaged by business activities, and procuring only sustainably produced raw materials from other suppliers. Such integration of CSR into the production processes and business strategy of a corporation is commonly accomplished through the application of private-sector standards. Therefore, in many cases, the use of private-sector standards forms a part of CSR policies. For example, the British retail chain Marks \& Spencer sells a lot of Fairtrade certified food and clothing products and has ambitious plans to expand its Fairtrade certified product range. ${ }^{206}$ Similarly, one of the biggest accounting firms KPMG in UK has a policy of procuring only Fairtrade certified tea and coffee for internal consumption. ${ }^{207}$

CSR is, generally, a rather controversial issue, and CSR policies of many multinational corporations are sometimes criticized by NGOs and environmental groups. Among the important reasons for such criticism is the conflict of protected values, i.e. CSR policies may pay much attention

205 See: OECD Guidelines for Multinational Enterprises, available at: http://www. oecd.org/daf/internationalinvestment/guidelinesformultinationalenterprises/ oecdguidelinesformultinationalenterprises.htm (last visited November 20, 2014).

206 See: Marks \& Spencer, "How We Do Business Report 2010”, pp. 12, 31, 36, available at: http://corporate.marksandspencer.com/documents/publications/2010/ How_We_Do_Business_Report_2010 (last visited November 20,2014).

207 See: http://www.fairtrade.org.uk/work/case_studies/read_a_case_study/default. aspx?ID=40 (last visited November 20, 2014). 
to the protection of one societal value (e.g. the welfare of local population) but disregard or even damage another (e.g. the environment and natural habitats of flora and fauna). ${ }^{208}$ This controversy is very clear in the case of business activities and production which are environmentally unfriendly by definition.

One example is the strip mining of oil sands and the production of crude oil in Canada by the multinational corporations Syncrude and Shell. On the one hand, these corporations aim to satisfy the demand for energy resources, they improve the wellbeing of the local population by employing workers and developing local infrastructure. On the other hand, the strip mining definitely has a detrimental impact on the entire eco-system of the Canadian province, Alberta, where the deposits of oil sands are situated as trees are cut, green forests are transformed into bare deserts, and water flows are polluted and diverted into enormous artificial lakes. The full social and environmental consequences of such oil sands mining remain to be seen in future. And although both multinational corporations claim to perform their business activities in a socially and environmentally responsible way, it is doubtful that an appeal to CSR policies is appropriate in this context.

The application of private-sector standards frequently forms a part of CSR policies and may have complex effects as well. For example, the use of a private-sector standard aimed at protecting endangered species of flora and fauna, may restrict market access for certain small-scale or foreign producers if the criteria of the standard are inflexible or inappropriate for the relevant local conditions of production. This may entail detrimental consequences for local employment and social wellbeing. That is why it is important for business actors to ensure that the private-sector standards they develop and apply have justified and well-balanced requirements, and that the manner of application of these standards is appropriate as well.

\subsubsection{Increased Business Concentration}

The globalization and liberalization of international trade stimulate the processes of business agglomeration and consolidation. ${ }^{209}$ Large companies, as a rule, have certain advantages in the global competition due to the economies of scale, availability of investment and emergency funds, and

208 In fact, many things are interconnected in the contemporary globalized world. Thus, damage to the environment and endangered species may finally result in detrimental effects for the welfare of local population.

209 See: Fabrizio Cafaggi, "Transnational Governance by Contract: Private Regulation abd Contractual Networks in Food Safety”, at: Axel Marx, Miet Maertens, Johan Swinnen, Jan Wouters, Private Standards and Global Governance. Economic, Legal and Political Perspectives, Edward Elgar, Cheltenham, UK, 2012, pp. 197 - 198. 
better access to modern technologies and know-how. ${ }^{210}$ As a result, big corporations may have greater business efficiency and endurance in market fluctuations. Big multinational corporations may also benefit from the possibility of choosing countries for the location of production facilities, i.e. countries with more favourable social and regulatory conditions. Thus, business concentration is the process which, to a large extent, happens naturally in global markets due to the tense competition between market players striving for higher business efficiency and profitability.

However, although the concentration of businesses into large national and multinational corporations may have positive effects for their competitiveness and profitability, such concentration is not always good for society. Smaller producers or traders, being less competitive, may be driven off the market. This, in turn, may result in the extinction of traditional and small-scale businesses, decrease the diversity of products in markets, and have detrimental social consequences like unemployment. Moreover, big corporations may start to abuse their dominant positions after becoming dominant in a market by, for example, manipulating prices or presenting inappropriate conditions for buyers. Several big corporations may also enter into agreements between each other impeding market competition, e.g. fixing market prices (cartel agreements) or dividing the markets (market sharing agreements).

It is thus necessary to ensure a proper balance between the advantages of business concentration and its possible negative effects. Due to the competitive advantages that big corporations have, the natural development of a market may finally end up with the situation of monopoly or oligopoly, i.e. when one or a number of large corporations control an entire market. This may be detrimental for businesses, consumers and the entire society. Governmental authorities therefore have to intervene in the market processes in order to prevent such undesirable business concentrations, as well as to stop and punish abusive or anticompetitive practices. This is usually done through market supervision by national competition authorities based on the domestic provisions of competition (antitrust) law.

Indeed, the substantial concentration of business into large national and multinational corporations or conglomerates is the reality of the current globalized business environment. Giant multinational corporations control the biggest share of many world markets, such as oil and gas operations, banking and insurance, retailing, telecommunication, utilities and software, etc. The yearly sales of many multinational corporations are comparable with, or significantly bigger than, the annual gross domestic

210 See: Linda Fulponi, "Final Report on Private Standards and the Shaping of the Agro-Food System”, AGR/CA/APM(2006)9/FINAL, OECD, Working Party on Agricultural Policies and Markets, July 2006, p. 13. 
products (GDPs) of certain countries. For example, General Electric (GE), the multinational conglomerate of companies doing business in various spheres of energy, technology and infrastructure, was rated in 2010 by Forbes as the second largest multinational corporation in the world; it operated in 160 countries, employed about 300000 people, and had yearly sales over 156 billion US Dollars. ${ }^{211}$ This amount of sales is comparable with the annual GDP of Romania and is much larger than the GDP of the Slovak Republic. ${ }^{212}$

Business concentration is taking place not only in the sphere of production as such, but also in retail business. Indeed, many retailing giants, such as Wal-Mart (US), Marks \& Spencer (UK), Carrefour Group (France), and Ahold (the Netherlands), are among the world's biggest multinational corporations. ${ }^{213}$ In many European countries the ratio of market concentration among the area's five biggest retailers was over $50 \%$ in 2000 , with some countries reaching $80 \% \cdot{ }^{214}$ In Australia in 2002, the combined market share of the two leading retail chains was about $76 \%$; in the United States in 2000, the market share of the five biggest retailers was smaller, namely $27 \%$, but a much higher percentage was present in metropolitan areas. ${ }^{215}$

Thus, as stated in the OECD Report prepared by Linda Fulponi:

Through increasing market concentration and control of shelf space of products, retailers have become the "gatekeepers" to consumers in most OECD countries. [...] But this has increased

211 See: "Global 2000" - the list of the largest multinational corporations for the year 2010, available at the Forbs website: http://www.forbes.com/lists/2010/18/ global-2000-10_The-Global-2000_Rank.html. About General Electric see also the GE "Fact Sheet", available at: http://www.ge.com/company/factsheets/corporate. html (last visited November 20, 2014).

212 In 2009 the GDP of Romania was about 161 billion US Dollars, and the GDP of Slovak Republic was about 88 billion US Dollars; the information is taken from: "World Economic Outlook Database, April 2010", available at the website of International Monetary Fund: http://www.imf.org/external/pubs/ft/weo/2010/01/ weodata/index.aspx (last visited November 20, 2014).

213 See: "Global 2000" - the list of the largest multinational corporations for the year 2010, available at the Forbs website: http://www.forbes.com/lists/2010/18/ global-2000-10_The-Global-2000_Rank.html (last visited November 20, 2014).

214 See: Linda Fulponi, "The Globalization of Private Standards and the Agri-food System”, at: Johan F.M. Swinnen, Global Supply Chains, Standards and the Poor. How the Globalization of Food Systems and Standards Affects Rural Development and Poverty, Cromwell Press, Trowbridge, 2007, p. 7.

215 See: Linda Fulponi, "Final Report on Private Standards and the Shaping of the Agro-Food System”, AGR/CA/APM(2006)9/FINAL, OECD, Working Party on Agricultural Policies and Markets, July 2006, p. 11. See also: T. Reardon, P. Timmer, et al., "The Rapid Rise of Supermarkets in Developing Countries: Induced Organizational, Institutional, and Technological Change in Agrifood Systems", Journal of Agricultural and Development Economics, 1(2), 2004. 
their product responsibility and intensified the need for controlling quality, safety and other attributes to prevent any risk to reputation. This, in turn, has stimulated the development of private standards. ${ }^{216}$

The large size of corporations is associated not only with an increased production and selling capacity, but also with an increased buying power and the ability to impose product requirements and standards on suppliers and competitors. In the case of big retail chains, which already have significant buying power, this power is even further increased through their membership in buyer group associations. For example, the membership of buyers associations such as Advanced Marketing Service (AMS), includes Ahold (the Netherlands), Casino/Opera (France), Edeka (Germany), SuperQuinn (Ireland), Safeway (UK) and others. Another buyers association, European Marketing Distribution (EMD), encompasses many European retailers, such as Spanish Euromadi and French Leclerc. In 2005, the total turnover of AMS members was over 70 billion euro and the turnover of EMD members was 119 billion euro. ${ }^{217}$ Such immense buying power of big retailers and their associations indeed allows them to be the "gatekeepers" of consumer markets and to impose requirements on suppliers through their own or collective private-sector standards.

Thus, big national and multinational corporations seem to have sound reasons for widely applying private-sector standards in their business activities. On the one hand, they bear a lot of responsibility related to ensuring the safety and quality of their products, the maintenance of a good reputation among consumers, and the social and environmental sustainability of production. On the other hand, big corporations can afford to use private-sector standards due to their size and purchasing power. They may dictate strict product and production conditions to their suppliers; they have financial resources and access to high technologies and know-how in order to implement requirements of private-sector standards themselves. In this respect, it is much easier for big national and multinational corporations to apply private-sector standards than for small and medium size business. Thus, the process of business concentration undoubtedly contributes significantly to the proliferation and widespread use of privatesector standards.

\subsubsection{Changes in the Regulatory Environment}

Globalization and evolving consumer demands entail changes in the modes of public and private regulation. These new developments in regulatory

\footnotetext{
216 Ibid., pp. $13-14$.

217 See: Ibid., p. 12.
} 
environments, both public and private, may also be regarded as one of the reasons for the proliferation of private-sector standards. ${ }^{218}$ Indeed, in many countries, especially developed ones, these standards seem to fit quite harmoniously into their regulatory systems of food quality, protection of the environment and human rights, etc. On some occasions, private-sector standards may be adopted and applied to compensate for claimed insufficiency or the immobility of governmental regulations or standards. This may be the case when rules on product characteristics or PPMs are regarded by an industry, consumers and / or civil society to be insufficient or too relaxed, and it takes too much time to develop and adopt new public rules. On other occasions, governments may specifically leave a lot of room for the discretion of private businesses in their laws and regulations, but at the same time they may impose strict rules on the liability for insufficient safety or the quality of products. As a result, corporations choose to apply more stringent private-sector standards in order to minimize liability risks.

\subsection{Shifts in the Regulatory Approach to Process-Based Criteria}

As has been explained, evolving consumer demands and challenges related to the globalization of international trade significantly influence the modes of both public and private regulation. As a result, both public regulations and public or private-sector standards "have witnessed a shift towards management-based approaches", ${ }^{219}$ i.e. control of production processes. There are several reasons for such a shift in regulatory patterns. First of all, it is obvious that production processes, even if not reflected in the characteristics of final products, may have a substantial impact on the environment, the wellbeing of workers and local communities. Corporations and public authorities therefore try to prevent negative effects of production processes through the application of public and private regulatory norms. Moreover, as has been noted above, many consumers choose the products they buy taking into account the information about PPMs on product labelling.

Furthermore, the risks related to product safety and quality might frequently not be adequately addressed through inspections accompanied with checking and testing of final products only. In the eyes of corporations and public authorities, these methods may be insufficient to ensure high levels of protection. Detailed inspections of final products may be quite costly and demand a lot of resources; and, in cases of large consignments

218 See: Axel Marx, Miet Maertens, Johan Swinnen, Jan Wouters, "Introduction: Private Standards and Global Governance", at: Axel Marx, Miet Maertens, Johan Swinnen, Jan Wouters, Private Standards and Global Governance. Economic, Legal and Political Perspectives, Edward Elgar, Cheltenham, UK, 2012, p. 1.

219 Spencer Henson, John Humphrey, "The Impacts of Private Food Safety Standards on the Food Chain and on Public Standard-Setting Processes", Codex thirty-second Session, FAO, WHO, Codex Alimentarius Commission, Rome, May 2009, p. 9. 
of products, it is, as a rule, feasible to check only a limited proportion of a consignment. Thus, in this respect, the process-based regulatory approach is frequently regarded as the most effective to ensure a high level of protection of important societal objectives, including public health and the protection of the environment. One of the key elements of such an approach is the system of traceability, i.e. the system which allows verifying the use of production methods, materials and substances through appropriate records and registration procedures. ${ }^{220}$ Compliance with requirements to PPMs can then be verified by inspecting the production facilities, checking the relevant records and registration books, and other certification procedures.

It is also argued that the certification of production methods and production facilities not only ensures higher guarantees of compliance with requirements, but is also more cost-effective in comparison with checking and testing final products in large consignments. For instance, according to Laurian J. Unnevehr, in the area of food safety, the management based approach and hazards control during production processes may frequently be the most cost-effective:

There is growing adoption in the food industry of management practices that focus on prevention and control of food safety hazards. Many hazards are expensive to test for and may enter food products at several points in the production process. Therefore, documented production practices, that are verified to prevent and control hazards, are becoming accepted as the most cost-effective means of reducing food safety hazards. While testing and verification are essential for establishing good process controls, testing can never be practical as the only means of monitoring safety. ${ }^{221}$

In food production and processing industries, the application of the Hazard Analysis and Critical Control Points (HACCP) systems for ensuring food safety and quality have in fact became very widespread. The HACCP is the systematic approach which focuses on the prevention of food safety risks at the stages of production rather than discovering problems during inspections of final products. To put it simply, the HACCP systems are aimed at identifying production stages with potential food safety hazards, known as Critical Control Points (CCPs), so that key actions can

220 See: Linda Fulponi, "Private Standard Schemes And Developing Country Access To Global Value Chains: Challenges And Opportunities Emerging From Four Case Studies", AGR/CA/APM(2006)20/FINAL, OECD, August 2007, p. $14-15$.

221 Laurian J. Unnevehr (2000), "Food Safety Issues and Fresh Food Product Exports from LDCs", Agricultural Economics 23.3:, p.235; see also: Spencer Henson, John Humphrey, "The Impacts of Private Food Safety Standards on the Food Chain and on Public Standard-Setting Processes", Codex thirty-second Session, FAO, WHO, Codex Alimentarius Commission, Rome, May 2009, p. 9. 
be taken in order to reduce or eliminate the relevant risks. ${ }^{222}$ The HACCP systems therefore are also based on the principle of traceability.

The HACCP systems are incorporated into many private-sector standards devoted to the safety and quality of food products, such as the BRC Global Standard for Food Safety, the International Food Standard (IFS) ${ }^{223}$, the SQF 1000 and $2000^{224}$ and the Dutch HACCP. ${ }^{225}$ Many international standards in the sphere of food safety are based on the HACCP principles as well, for example the ISO 22000:2005 standard "Food Safety Management Systems" 226 , codes of practices developed by the Codex such as the "General Principles of Food Hygiene", the "Code of Practice for Fish and Fishery Products", the "Code of Practice for the Prevention and Reduction of Aflatoxin Contamination in Tree Nuts", etc. ${ }^{227}$ Moreover, many governmental and regional legal acts and standards on food safety also refer to the HACCP. For instance, in the US, the HACCP principles are applied according to parts 120 and 123 of Title 21 of the Code of Federal Regulations (21 CFR), "Food and Drugs". ${ }^{228}$ In the EU, Article 5 of

222 See: J.J. McCluskey, "Public and Private Food Quality Standards: Recent Trends and Strategic Incentives", at: Johan F.M. Swinnen, Global Supply Chains, Standards and the Poor. How the Globalization of Food Systems and Standards Affects Rural Development and Poverty, CABI, Trowbridge, 2007, p. 20; see also: Cora Dankers, Pascal Liu, "Private Standards in the United States and European Union Markets for Fruit and Vegetables - Implications for developing countries", FAO Commodity Studies, 3, FAO, 2007, p. 32.

223 See: Sally Washington, Lahsen Ababouch, "Private Standards and Certification in Fisheries and Aquaculture. Current Practice and Emerging Issues”, FAO, Rome, 2011 , pp. $80-81$.

224 See the information on websites of BRC, IFS and SQFI: http://www. brcglobalstandards.com/standards/food; http://www.bsi-emea.com/Food+Safety/ Standards/IFS.xalter; http://www.sqfi.com/buyers_overview.htm (last visited November 20, 2014).

225 The Dutch HACCP system, or "Requirements for an HACCP based Food Safety System", is the private-sector standard administered by the SCV (Stichting Certificatie Voedselveiligheid) Foundation in the Netherlands. According to its website, "SCV is also the legal owner of the "Requirements" and therefore sets up and maintains the license agreements with accredited Certification Bodies. SCV also acts as a spokesperson for Dutch HACCP certification in international platforms on food safety, e.g. ISO 22000 committee"; see: http://www.foodsafetymanagement.info/net-book. php?op=cms\&pageid=1\&pageid_up=0\&nnl=english; see also Dutch HACCP GFSI Case Study, available at: http://www.myciesnet.com/gfsijoomla/gfsifiles/ GFSI_Case_Study_Dutch_HACCP.pdf (last visited November 20, 2014).

226 See general information about ISO 22000:2005 standard on the ISO website: http://www.iso.org/iso/iso_catalogue/catalogue_tc/catalogue_detail. htm? csnumber $=35466$ (last visited November 20, 2014).

227 The texts of these codes of practices are available free of charge on the Codex website: http://www.codexalimentarius.net (last visited November 20, 2014).

228 The US CFR is available on-line at: http://ecfr.gpoaccess.gov/cgi/t/text/text-id 
Regulation No 852/2004 on the hygiene of foodstuffs requires food business operators to implement the HACCP based procedures. ${ }^{229}$

Thus, both principles of traceability and HACCP are aimed at contributing to the food safety management based on the integrity of the entire food supply chain or, in other words, at contributing to ensuring the safety of food products "from farm to fork" ${ }^{230}$ In this respect, for instance, Regulation No 178/2002 laying down the basic principles of the EU food law, explicitly provides in its preamble that:

In order to ensure the safety of food, it is necessary to consider all aspects of the food production chain as a continuum from and including primary production and the production of animal feed up to and including sale or supply of food to the consumer because each element may have a potential impact on food safety. ${ }^{231}$

Similarly, the Report prepared by the European Commission on the EU import conditions for seafood, explains the principles of the European food law as process-based:

Our citizens have legitimate, high expectations regarding the safety and quality of their food. To meet these expectations, the food law of the European Union implements the principle of quality management and process-oriented controls throughout the food chain - from the fishing vessel or aquaculture farm to the consumer's table. Spot checks on the end product alone would

$\mathrm{x}$ ?sid=5aeedc221664e582064ded32ce1b3deb\&c=ecfr\&tpl=/ecfrbrowse/ Title21/21 tab_02.tpl (last visited November 20,2014).

229 See: Regulation (EC) No 852/2004 on the Hygiene of Foodstuffs, Official Journal of the European Communities, 30 April 2004, available at: http://eur-lex.europa.eu/ LexUriServ/LexUriServ.do? uri=OJ:L:2004:139:0001:0054:EN:PDF. See also: "Guidance Document on the Implementation of Procedures Based on the HACCP Principles, and on the Facilitation of the Implementation of the HACCP Principles in Certain Food Businesses", European Commission, Brussels, November 16, 2005, available at: http://ec.europa.eu/food/food/biosafety/hygienelegislation/ guidance_doc_haccp_en.pdf (last visited November 20, 2014).

230 See: John Humphrey, "Private Standards, Small Farmers and Donor Policy: EUREPGAP in Kenya", IDS WORKING PAPER 308, Institute of Development Studies, University of Sussex, Brighton, UK, July 2008, p. 9; see also: Spencer Henson, John Humphrey, "The Impacts of Private Food Safety Standards on the Food Chain and on Public Standard-Setting Processes", Codex thirty-second Session, FAO, WHO, Codex Alimentarius Commission, Rome, May 2009, pp. 9 - 10.

231 Regulation (EC) No 178/2002 Laying Down the General Principles and Requirements of Food Law, Establishing the European Food Safety Authority and Laying Down Procedures in Matters of Food Safety, Official Journal of the European Communities, 1 February 2002, available at: http://eur-lex.europa.eu/ LexUriServ/LexUriServ.do?uri=OJ:L:2002:031:0001:0024:EN:PDF (last visited November 20, 2014). 
not provide the same level of safety, quality and transparency to the consumer.[...]

Imports of fishery products into the European Union are subject to official certification, which is based on the recognition of the competent authority of the non-EU country by the European Commission. This formal recognition of the reliability of the competent authority is a pre-requisite for the country to be eligible and authorized to export to the European Union. Public authorities with the necessary legal powers and resources must ensure credible inspection and controls throughout the production chain, which cover all relevant aspects of hygiene, public health and, in the case of aquaculture products, also animal health. ${ }^{232}$

Process based requirements are used in public regulations and standards nowadays, especially in those devoted to important issues such as the safety and quality of food products. However, perhaps, it would be safe to say that in other areas of public regulation such requirements, if exist, remain supplementary to product based requirements. This is, arguably, due to the political and legal sensitivity of the matter, as process based requirements imposed by one country should be complied with by foreign producers as well. Such requirements in one country may therefore have significant effects on the production processes in the territories of other sovereign countries. Moreover, if rigidly formulated, process based requirements may appear to be inappropriate, unjustifiable or arbitrary for local production conditions. $^{233}$

In this regard, the situation with private-sector standards is significantly different, because these standards normally contain process based recommendations. In fact, process based requirements became the core of many private-sector standards and labelling schemes. Such requirements may address the impact of production processes on the environment, workers welfare, human rights, the treatment of animals, etc. Driven by consumer demands and desiring to protect their brand reputation, business corporations have an incentive to apply private-sector standards that impose extensive requirements on PPMs. These factors, taken together with the process

232 "EU Import Conditions for Seafood and Other Fishery Products", European Commission, Directorate-General for Health \& Consumers, available at: http:// ec.europa.eu/food/international/trade/im_cond_fish_en.pdf (last visited November 20, 2014); see also: Spencer Henson, John Humphrey, "The Impacts of Private Food Safety Standards on the Food Chain and on Public Standard-Setting Processes", Codex thirty-second Session, FAO, WHO, Codex Alimentarius Commission, Rome, May 2009, p. 10.

233 For more information on process based requirements and the regulation of PPMs under WTO law, see Section 3.3.6 of Chapter III and Section 4.1.1.4 of Chapter IV. 
of business concentration, result in the situation found in many markets today (especially those of developed countries) where compliance with process based requirements of private-sector standards de facto constitutes a condition for real market access.

Private-sector standards thus frequently present more stringent or more detailed requirements in comparison with governmental regulations and standards. Many such requirements are process based and business corporations have to ensure compliance of their production facilities with these requirements in order to get certified under a standard. Although process based criteria may indeed ensure better guarantees for the protection of important societal objectives, they also have the potential to impose serious and arbitrary or unjustified restrictions on international trade.

\subsection{Insufficient Flexibility, Effectiveness and the Mobility of Public Regulation}

The contemporary business environment of global trade is very dynamic. New developments and changes take place every day. For example, new products and technologies appear; new threats to product safety and quality are discovered in forms of viruses, diseases, and dangerous chemical substances; and new scientific evidence becomes available with respect to the safety, or a lack thereof, of products and substances. Moreover, sectors of production and technology such as telecommunications, information technology (IT), software and computer technologies, electro-technical equipment and biotechnologies, have been especially booming in the last few decades.

Rapid growth and the development of these business sectors usually requires flexible and effective regulation. It seems that public regulatory bodies are frequently not able to meet the demands of "the rules of the game" timely and in a suitable and efficient way. Indeed, at least in the majority of democratic and economically developed countries, governmental technical regulations and public standards are usually adopted through more or less open and transparent legislative procedures. During these procedures, many contradicting interests may clash and it is possible that the interests of certain lobbying groups (e.g. retailers) might appear to be insufficiently reflected in the final compromised version of a technical regulation or a public standard, at least in the view of such a group. As a result, such business and non-profit groups may regard public regulatory norms as being insufficiently strict, ineffective or inflexible, and thus unable of ensuring a high level of safety and quality of products and the protection of other important societal objectives. In such cases, to remedy the situation, these groups decide to opt for private regulation and promote the application of private-sector standards to their own activities or to the activities of other business actors. 
Moreover, as is sometimes argued, public regulation is often insufficiently dynamic due to the fact that negotiations and discussions taking place during public legislative and standard-setting processes, may take months or years. For example, in the EU, according to statistical data for the period between 1999 and 2006, the co-decision procedure (the main legislative procedure $)^{234}$ for the legislative proposals completed in the first reading took, on average, 13.7 months (412 days), and then 26.5 months (794 days) if the second reading took place. ${ }^{235}$ Time usually spent by national and regional public standard-setting agencies to develop and adopt public standards is more difficult to track as the draft text of a standard may be prepared and discussed within technical committees over a long period of time. However, it is commonly known that standardizing processes in public standard-setting organizations take quite a lot of time as well. For instance, in one of the main European standardizing bodies, the CENELEC, the process of consultation with National Committees for the purpose of collecting comments takes about six months, and the process of voting on a final draft of a standard takes about three months. ${ }^{236}$

International intergovernmental standard-setting organizations, such as the Codex, also often have rather elaborate and long procedures for the development and adoption of international standards. Normally the standard-setting procedure of the Codex consists of eight steps, commencing with a decision to start the development of a standard and ending with its formal adoption. ${ }^{237}$ Such complex procedures, with broad involvement of Codex members, international organizations, NGOs, and other relevant stakeholders, are aimed at building broad consensus for the adoption of Codex international standards. ${ }^{238}$ Another main developer of international standards, the ISO, a hybrid public-private international standard-setting organization, also develops and adopts its standards in six stages: proposal stage, preparatory stage, committee stage, enquiry stage, approval stage and

234 With entry of the Treaty of Lisboan into the force co-decision procedure gained the official name of "ordinary legislative procedure", see Article 294 of Treaty on the Functioning of European Union, Consolidated version, Official Journal of the European Communities, May 9, 2008.

235 See: "Codecision. May 1999 to December 2006. Some Statistical Data", available at: http://ec.europa.eu/codecision/institutional/analysis/codecision_stat_en.pdf (last visited November 20, 2014).

236 See information on the CENELEC's website, available at: http://www.cenelec.eu/ Cenelec/About+CENELEC/Our+work/How+a+standard+is+made/default.htm (last visited November 20, 2014).

237 For more detailed information on standard-setting procedures of Codex Alimentarius Commission and the schematic presentation of these procedures see: Mariëlle D. Masson-Matthee, The Codex Alimentarius Commission and Its Standards, T.M.C. Asser Press, 2007, pp. 75 - 80.

238 See: Ibid., pp. 80 - 83. 
publication stage. ${ }^{239}$ The ISO "has established the general rule that all ISO standards should be reviewed at intervals of not more than five years" and, on occasions, earlier if it is deemed necessary. ${ }^{240}$ Thus, the development and adoption of international standards by international standard-setting organizations also takes quite a bit of time. Moreover, since many public international standard-setting organizations have a consensus-based approach to the adoption of their standards and aim to take into account comments from many stakeholders, there is a possibility that consensus might be blocked by an interested member of the organization, resulting in delays or the suspension of the standard-setting procedures.

It is worth noting that a lengthy process of development and adoption of a regulation or a public standard is not necessarily a bad thing. On the contrary, it is absolutely normal that open deliberations and negotiations with involvement of many stakeholders take time. In fact, this is an important factor for making legitimate, effective and well-balanced regulatory rules. However, due to rapid developments in the markets and the interests at stake, businesses are frequently not able or willing to wait until a public regulator devises a regulatory solution. Corporations and industry associations therefore commit to private regulatory norms and self-regulation which is done, among other things, through the development and application of private-sector standards. In this respect, private regulation in general, and private-sector standards in particular, are often used to fill the gaps in public regulatory regimes.

In the views of developers and users of private-sector standards, these standards are frequently regarded as more dynamic than public regulatory norms. They may, in principle, be adopted within a short period of time without stringent requirements of standard-setting procedures and the involvement of stakeholders. The processes of development and adoption of private-sector standards therefore usually allow more time efficiency, mobility and flexibility than the appropriate processes for public regulatory rules. They may be easily adjusted to the needs of a particular corporation or industry and may be quickly changed if necessary. However, this may undoubtedly have certain negative consequences for the legitimacy of private-sector standards. In particular, private standard-setting organizations are frequently criticized for a lack of transparency and for the lack of stakeholder involvement in their standard-setting processes. As a result, some private standard-setting organizations try, nowadays, to implement certain

239 "Stages of the Development of International Standards", ISO, available at: http://www.iso.org/iso/standards_development/processes_and_procedures/stages_ description.htm (last visited November 20, 2014).

240 “How Are ISO Standards Developed”, available at: http://www.iso.org/iso/ standards_development/processes_and_procedures/how_are_standards_ developed.htm (last visited November 20, 2014). 
improvements in this respect. Indeed, in the "world" of private-sector standards, the reputation of a standard-setting entity means a lot for ensuring the widest possible application of its standard within a business sector.

\subsection{Product Liability Rules and Risk Management}

Renowned public scares concerning product safety and quality, and related consumer demands, have pushed governmental authorities in many countries to strengthen the legal requirements in the area of product liability. In most developed countries, liability laws nowadays make the seller legally responsible for damage or harm caused by a product sold. ${ }^{241}$ Moreover, regarding a seller's liability for damage or harm caused to a consumer by a faulty product, the rules on product liability in many countries tend to develop in the direction of so-called "strict liability".

Under "strict liability" rules, a seller (e.g. a retailer) may not exonerate itself from liability for damage or harm caused to a consumer by arguing that the damage or harm caused was not really its fault as the safety and quality of a product was guaranteed by a producer or trader. However, a seller may prevent or reduce its liability by demonstrating that it exercised appropriate "due diligence" with respect to the control of the safety and quality of the products it sold. The product liability rules therefore encourage both retailers and producers to develop and implement their own assurance systems for monitoring the safety and quality of products through their supply chains. ${ }^{242}$ The application of individual and collective private-sector standards by business corporations usually forms an important part of such safety / quality assurance systems. The tightening regulatory environment of product liability rules can therefore be said to be one of the major "drivers" of the process of the proliferation of private-sector standards. ${ }^{243}$

241 See: Linda Fulponi, "Final Report on Private Standards and the Shaping of the Agro-Food System”, AGR/CA/APM(2006)9/FINAL, OECD, Working Party on Agricultural Policies and Markets, July 2006, p. 16.

242 See: Spencer Henson, John Humphrey, "The Impacts of Private Food Safety Standards on the Food Chain and on Public Standard-Setting Processes", Codex thirty-second Session, FAO, WHO, Codex Alimentarius Commission, Rome, May 2009, p. 11.

243 See: Pascal Liu, "Private Standards in International Trade: Issues and Opportunities", Workshop on Environment-Related Private Standards, Certification and Labelling Requirements Geneva, Switzerland, July 9, 2009, p. 3; Linda Fulponi, "Private Voluntary Standards in the Food System: the Perspective of Major Food Retailers in OECD Countries”, Food Policy, 31(1), 2006, p. 6; Grace Chia-Hui Lee, "Private Food Standards and Their Impacts on Developing Countries", European Commission DG Trade Unit G2, Brussels, 2006, p. 8; Private Standards and the SPS Agreement. Note by the Secretariat, WTO, SPS Committee, G/SPS/GEN/746, Geneva, 24 January 2007, para. 4. 
One good example in this regard is the food safety regulation in the UK. The Food Safety Act, adopted in 1990, imposed "strict liability" on food business operators with respect to the food products they sell. Before the Act, UK law allowed the so-called "warranty defence" under which a business operator could escape liability if it demonstrated that, when it bought a product, it obtained a written warranty from its supplier that the product was safe and could be legally sold or dealt with. After the Act came into force, such a defence was no longer available and, accordingly, an enforcement action may now be taken against a wholesaler or retailer even if an offense was caused by other parties in a food supply chain (e.g. by food producers, processors or importers). ${ }^{244}$

However, at the same time the UK Food Safety Act contains a "due diligence clause" which states: "It shall be a defence for the person charged to prove that he took all reasonable precautions and exercised all due diligence to avoid the commission of the offence by himself or a by a person under his control". ${ }^{245}$ It seems thus that this clause motivates the development and application of private-sector standards by food retailers as a part of their safety / quality assurance systems as this may be presented as an evidence of "due diligence" exercised by a retailer with respect to supplied products in case of a problem. Indeed, as it is correctly noted by Grace Chia-Hui Lee in the Report prepared by DG Trade of the EU Commission:

Both reputation and financial resources were at stake (liability claims) if firms failed to prove due diligence in detecting and preventing problems in the food chain. ${ }^{246}$

In light of this, it is worth noting that, according to the research undertaken by Linda Fulponi, nearly 70 per cent of interviewed retailers from OECD Member States specified legal liability systems as one of the important

244 See: Grace Chia-Hui Lee, "Private Food Standards and Their Impacts on Developing Countries", European Commission DG Trade Unit G2, Brussels, 2006, p. 8; Spencer Henson, John Humphrey, "The Impacts of Private Food Safety Standards on the Food Chain and on Public Standard-Setting Processes", Codex thirty-second Session, FAO, WHO, Codex Alimentarius Commission, Rome, May 2009, p. 11; Gretchen H. Stanton, "Food Safety-Related Private Standards: The WTO Perspective”, at: Axel Marx, Miet Maertens, Johan Swinnen, Jan Wouters, Private Standards and Global Governance. Economic, Legal and Political Perspectives, Edward Elgar, Cheltenham, UK, 2012, pp. 238 - 239.

245 See the UK Food Safety Act of 1990 quoted in: Linda Fulponi, "Final Report on Private Standards and the Shaping of the Agro-Food System", AGR/CA/ $\operatorname{APM}(2006) 9 / F I N A L$, OECD, Working Party on Agricultural Policies and Markets, July 2006, p. 16. See also: J. C. Buzby, P. D. Frenzen, et al., "Product Liability and Microbial Foodborne Illness", Agricultural Economic Report, 799, United States Department of Agriculture, Economics Research Service, Washington D.C., 2001.

246 Grace Chia-Hui Lee, "Private Food Standards and Their Impacts on Developing Countries", European Commission DG Trade Unit G2, Brussels, 2006, p. 8. 
factors motivating the growth in numbers and in stringency of private-sector standards. ${ }^{247}$

Finally, it is worth noting in general that the application of private-sector standards by business corporations in the framework of their safety / quality assurance systems, or CSR policies, is frequently an important part of their risk management strategies. The prudent evaluation and management of risks related to the safety / quality of products and the social impact of production is indeed a very important factor for businesses' long-term success and sustainability. The information about risk management strategies is therefore frequently included in yearly reports or other reporting documents of business corporations to be considered by shareholders, potential investors and general public. Accordingly, this information may have effects on the attractiveness of businesses for investments, and even on stock prices and business valuation.

\subsubsection{Effects of Private-Sector Standards on International Trade}

The role of private-sector standards and their effects on international trade is a topical issue for discussions today in various forums, including the WTO, OECD, UNCTAD, FAO and the World Bank. ${ }^{248}$ This is because

247 See: Linda Fulponi, "Private Voluntary Standards in the Food System: the Perspective of Major Food Retailers in OECD Countries", Food Policy, 31(1), 2006, p. 6.

248 For overview of the literature on impact of private-sector standards see: Cora Dankers, Pascal Liu, "Private Standards in the United States and European Union Markets for Fruit and Vegetables - Implications for developing countries", FAO Commodity Studies, 3, FAO, 2007, pp. 77 - 114; See also, for example: Report of the Ad Hoc Working Group on SPS-Related Private Standards to the SPS Committee, WTO, SPS Committee, G/SPS/W/256, Geneva, 3 March 2011; Private Standards and the SPS Agreement. Note by the Secretariat, WTO, SPS Committee, G/SPS/GEN/746, Geneva, 24 January 2007; Linda Fulponi, "Private Standard Schemes And Developing Country Access To Global Value Chains: Challenges And Opportunities Emerging From Four Case Studies”, AGR/CA/APM(2006)20/ FINAL, OECD, August 2007; Linda Fulponi, "Final Report on Private Standards and the Shaping of the Agro-Food System", AGR/CA/APM(2006)9/FINAL, OECD, Working Party on Agricultural Policies and Markets, July 2006; Vangelis Vitalis, "Private Voluntary Eco-Labels: Trade Distorting, Discriminatory and Environmentally Disappointing", OECD, Paris, 2002; Food Safety and Environmental Requirements in Export Markets - Friend or Foe for Producers of Fruit and Vegetables in Asian Developing Countries?, UNCTAD, UNCTAD/ DITC/TED/2006/8, New York and Geneva, 2007; Private Sector Standards and Developing Country Exports of Fresh Fruit and Vegetables. Communication from the United Nations Conference on Trade and Development (UNCTAD), WTO, SPS Committee, G/SPS/GEN/761, 26 February 2007; Spencer Henson, John Humphrey, "The Impacts of Private Food Safety Standards on the Food Chain and on Public Standard-Setting Processes", Codex thirty-second Session, FAO, WHO, 
these standards generate serious problems for certain stakeholders in international trade. Indeed, the significant effects of private-sector standards on trade are due to their wide scale application in national and international markets. As was briefly explained in Chapter I, private-sector standards are frequently applied by many of the largest retail chains and multinational corporations with immense purchasing power and big market shares, even though they are fully voluntary de jure. This may render compliance with requirements of such a standard a de facto mandatory condition for real market access. ${ }^{249}$

However, this fact alone does not necessarily mean that the application of private-sector standards is always a "bad thing" for international trade. Private-sector standards, undoubtedly, also have the potential to enhance the safety and quality of products, ensure better protection of important societal objectives, and improve long-term competitiveness and market access for complying products. In this respect, a lot depends on the requirements presented by a private-sector standard to products or PPMs. Thus, depending on their requirements, private-sector standards may have both positive and negative effects on international trade.

\subsubsection{Positive Effects of Private-Sector Standards}

In principle, it seems that private-sector standards may be beneficial for international trade and development. They may contribute to product differentiation and the formation of new and lucrative niche-markets in which developing country producers and other small-scale producers can be more competitive. These standards could also contribute to the guaranteed longterm market access for complying stakeholders, enhanced product safety and quality, and the dissemination of modern, efficient and environmentally friendly technologies. It is indeed quite commonly argued that privatesector standards may have a lot of potential in this respect.

Codex Alimentarius Commission, Rome, May 2009; Cora Dankers, Pascal Liu, "Environmental and Social Standards, Certification and Labelling for Cash Crops", FAO, Rome, 2003; Steven Jaffee, Spencer Henson, "Standards and Agro-Food Exports from Developing Countries: Rebalancing the Debate", Policy Research Working Paper 3348, World Bank, June 2004; "Eco-Labeling Standards, Green Procurement and the WTO: Significance for World Bank Borrowers", Center for International Environmental Law, Washington, DC, Geneva, Switzerland, March, 2005; U. Kleih, F. Ssango, et al., "Impact of EurepGAP on Small-Scale Fruit and Vegetable Growers in Uganda”, Fresh Insights, 10, November 2007

249 See: Samir R. Gandhi, "Voluntary Environmental Standards: The Interplay Between Private Initiatives, Trade Rules and the Global Decision-Making Process", 3rd Global Administrative Law Seminar, Viterbo, June 15-16, 2007, pp. 4 - 5. See also: S. Lewis, "Private Retail Standards Seen Threatening Codex Standards", Food Chemical News, 50(21), 2008. 
In fact, a number of research projects and case studies conducted by OECD, UNCTAD, FAO, the World Bank, and other international organizations identified actual and potential benefits of private-sector standards and labelling schemes in relevant sectors. For example, the research project conducted by OECD with respect to the role and effects of privatesector standards in OECD Member States refers to the improvement in market access for producers which comply with such standards in Austria, Belgium, Ireland, Finland, France and the US. ${ }^{250}$ The potential of privatesector standards to create opportunities for exporters from developing countries in terms of improved environmental and social sustainability, efficiency of production and market access was also indentified in a number of case studies conducted by UNCTAD in the areas of good agricultural practices (G.A.P.) and environmental requirements. ${ }^{251}$

Moreover, several case studies conducted by OECD and UNCTAD with respect to environmental requirements reportedly demonstrated that environmental private-sector standards and labelling schemes, "if well designed and implemented, can create new export opportunities for developing countries while improving the environmental performance of the affected industries". ${ }^{252}$ A number of case studies and research projects conducted by FAO, WHO and the World Bank also identified benefits of compliance with private-sector standards and their potential positive effects. ${ }^{253}$

250 See: Linda Fulponi, "Final Report on Private Standards and the Shaping of the Agro-Food System”, AGR/CA/APM(2006)9/FINAL, OECD, Working Party on Agricultural Policies and Markets, July 2006, p. 30, para. 75.

251 See, for example: Challenges and Opportunities Arising from Private Standards on Food Safety and Environment for Exporters of Fresh Fruit and Vegetables in Asia: Experiences of Malaysia, Thailand and Viet Nam, UNCTAD, UNCTAD/DITC/ TED/2007/6, New York, Geneva, 2007, p. 85; Food Safety and Environmental Requirements in Export Markets - Friend or Foe for Producers of Fruit and Vegetables in Asian Developing Countries?, UNCTAD, UNCTAD/DITC/ TED/2006/8, New York and Geneva, 2007, p. 101; Private Sector Standards and Developing Country Exports of Fresh Fruit and Vegetables. Communication from the United Nations Conference on Trade and Development (UNCTAD), WTO, SPS Committee, G/SPS/GEN/761, 26 February 2007, para. 8; "Private-sectorset Standards and Developing Countries' Exports of Fresh Fruit and Vegetables: Synthesis of Country-case Studies in Africa (Ghana, Kenya, Uganda), Asia (Malaysia, Thailand, Vietnam), and Latin America (Argentina, Brazil, Costa Rica)", Background Note by the UNCTAD secretariat for the FAO-UNCTAD Regional Workshop on Good Agricultural Practices in Eastern and Southern Africa: Practices and Policies, UNCTAD, Nairobi, Kenya, 6-9 March 2007, pp. 7 - 8; A. Casella, "Product Standards and International Trade - Harmonization Through Private Collations?", 54 (2/3), Kyklos, 2001.

252 See, for example: Environmental Requirements and Market Access. Recent Work in OECD and UNCTAD. Note by the Secretariat, WTO, Committee on Trade and Environment, WT/CTE/W/244, 8 December 2006, para. 30.

253 See: Pascal Liu, "Certification in the Value Chain for Fresh Fruits. The example of banana industry", FAO Commodity Studies, 4, FAO, Rome, 2009, pp. 61 - 66; 
For instance, the FAO Report, with respect to value-adding standards operating in the North American food market, concludes as follows:

In contrast, some environmental and ethical certification schemes that target consumers with a recognizable on-product label tend to result in higher product prices and may provide farmers with new market opportunities. The markets for organic and fairtrade foods are of particular interest to small-scale farmers in developing countries, as they usually offer higher prices. ${ }^{254}$

A number of positive effects of SPS-related private-sector standards, in addition to related trade concerns, have also been mentioned by WTO Members in the WTO SPS committee, ${ }^{255}$ namely:

- they help suppliers comply with national and international standards when they prescribe how those standards should be met;

- they promote best practices and improved productivity;

- they give brands a better reputation and help suppliers have access to markets and credit;

- they address emerging risks in a rapid manner, filling gaps, and make it easier for international standards to eventually be adopted. ${ }^{256}$

Spencer Henson, John Humphrey, "The Impacts of Private Food Safety Standards on the Food Chain and on Public Standard-Setting Processes", Codex thirty-second Session, FAO, WHO, Codex Alimentarius Commission, Rome, May 2009, pp. 27 - 35; Cora Dankers, Pascal Liu, "Environmental and Social Standards, Certification and Labelling for Cash Crops", FAO, Rome, 2003, pp. 41 - 70; Nadia Cuffaro, Pascal Liu, "Technical regulations and standards for food exports: trust and the credence goods problem”, Commodity Market Review, FAO, Rome, 2008; pp. 70 - 71; Alice Byers, Daniele Giovannucci, Pascal Liu, "Value-adding standards in the North American food market. Trade opportunities in certified products for developing countries", FAO Commodities and Trade Technical Paper, 11, FAO, Rome, 2008, p. 59; "Food Safety and Agricultural Health Standards: Challenges and Opportunities for Developing Country Exports", Report No. 31207, World Bank, Poverty Reduction \& Economic Management Trade Unit and Agriculture and Rural Development Department, Washington D.C., January 10, 2005, pp. 71 - 72, 112; Spencer Henson, Steven Jaffee, "Understanding Developing Country Strategic Responses to the Enhancement of Food Safety Standards", World Economy, 31(4), 2008, p. 552; Miet Maertens, Johan Swinnen, "Private Standards, Global Food Supply Chains and the Implications for Developing Countries", at: Axel Marx, Miet Maertens, Johan Swinnen, Jan Wouters, Private Standards and Global Governance. Economic, Legal and Political Perspectives, Edward Elgar, Cheltenham, UK, 2012, pp. $159-160$.

254 Alice Byers, Daniele Giovannucci, Pascal Liu, "Value-adding standards in the North American food market. Trade opportunities in certified products for developing countries", FAO Commodities and Trade Technical Paper, 11, FAO, Rome, 2008, p. 59.

255 For more information on the WTO SPS Committee and its work on the issue of SPS-related private-sector standards, see Section 5.2.3 of Chapter V.

256 See: "Members Take First Steps on Private Standards in Food Safety, Animal Plant Health”, March 30 - 31, 2011, WTO News Items 2011, available at: 
Thus, as has been generally stated in one of the notes prepared by the WTO Secretariat for the SPS Committee, "[c]ompliance with private standards can have trade creation effects". ${ }^{257}$ Moreover, in their replies to the questionnaire regarding the effects of SPS-related private-sector standards circulated in the SPS Committee, many WTO Members noted other positive "trade creating" effects of such standards for international trade. These responses are summarized by the WTO Secretariat as follows:

The replies acknowledge that those farmers/producers who manage to comply with private standards maintain a stable presence in a number of major export markets and possibly expand their market share, while those who cannot are displaced. Still, some replies note that the ability of more producers to meet private standard requirements has enhanced competition and reduced ease of market access.

Most replies also acknowledge that private standards may facilitate compliance with international standards, satisfy evolving consumer demands and improve the safety and quality of the traded products even if there is no price premium. They may also lead to more standardized farming, processing, and packaging activities, promoting productivity and predictability. In addition, compliance with private standards may improve a brand's reputation and facilitate access to credit and better stock market access quotation where applicable. Private standards may offer product differentiation opportunities and access to niche markets. While it may not be directly linked to SPS issues, they may also contribute towards social and environmental goals.

Two concrete positive examples were cited; one is FLO-CERT in Ecuador, which offers price premiums and a fund for workers. The other is New Zealand GAP, a private sector initiative which has facilitated New Zealand's access to the international market, as well as adaptation of certain prescriptive requirements of international private standard schemes to local conditions. ${ }^{258}$

http://www.wto.org/english/news_e/news11_e/sps_30mar11_e.htm (last visited November 20, 2014). See also: Report of the Ad Hoc Working Group on SPS-Related Private Standards to the SPS Committee, WTO, SPS Committee, G/SPS/W/256, Geneva, 3 March 2011, para. 25; Possible Actions for the SPS Committee Regarding SPS-Related Private Standards. Note by the Secretariat, WTO, SPS Committee, G/SPS/W/247/Rev.3, Geneva, 11 October 2010, para. 33.

257 Private Standards and the SPS Agreement. Note by the Secretariat, WTO, SPS Committee, G/SPS/GEN/746, Geneva, 24 January 2007, para. 11

258 Effects of SPS-Related Private Standards - Compilation of Replies. Note by the Secretariat, WTO, SPS Committee, G/SPS/GEN/932/Rev.1, Geneva, 10 December 2009; paras. $38-40$. 
Furthermore, in July 2009 the WTO Secretariat organized the "Workshop on Environment-Related Private Standards Certification and Labelling Requirements". The Workshop brought together participants from different types of organizations involved in dealing with private-sector standards in various sectors, such as fisheries (e.g. FAO, the MSC, the Birds Eye Iglo Group Ltd.), coffee (e.g. the Rainforest Alliance, the Starbucks), horticulture (e.g. the Max Havelaar-Foundation, the Soil Association, the Wad African foods Ltd. in Ghana), and forestry (e.g. the FSC, the Tropical Forest Trust, the Malaysian Timber Council). ${ }^{259}$

Participants from the relevant private-standard-setting organizations and business corporations highlighted positive effects brought about by certain private-sector standards and labelling schemes with respect to the protection of important societal values, such as sustainable fishing practices (e.g. the MSC labelling); sustainable and socially responsible coffee growing (e.g. the Rainforest Alliance labelling); fair, sustainable, socially and environmentally responsible production and trade in agricultural products (e.g. the Max Havelaar-Foundation Fair Trade labelling); and sustainable forestry and timber production (e.g. the FSC labelling). One of the keynote speakers, Mr. Pascal Liu from FAO, also pointed out a number of actual and potential benefits of private-sector standards, e.g. the protection of consumers in terms of enhanced product safety and quality; the preservation of natural resources and the environment; improved farm management; agricultural practices and working conditions; and value-adding effects in terms of higher sale prices, product differentiation and product demand. ${ }^{260}$

\subsubsection{Challenges Posed by Private-Sector Standards}

It seems, however, that the potential benefits of private-sector standards do not really materialize for many medium and small-scale producers, especially those from developing countries. On the contrary, a considerable number of concerns have been voiced in different fora, including the WTO, UNCTAD, and OECD, with respect to market access restrictions resulting from private-sector standards and with respect to the difficulties they create for small-scale producers, especially those from developing countries. ${ }^{261}$

259 See the Program of the Workshop, available at: http://www.wto.org/english/ tratop_e/envir_e/events_e.htm (last visited November 20, 2014).

260 See: Pascal Liu, "Private Standards in International Trade: Issues and Opportunities", Workshop on Environment-Related Private Standards, Certification and Labelling Requirements Geneva, Switzerland, July 9, 2009, pp. 12 - 13.

261 See: Private Sector Standards and Developing Country Exports of Fresh Fruit and Vegetables. Communication from the United Nations Conference on Trade and Development (UNCTAD), WTO, SPS Committee, G/SPS/GEN/761, 26 February 2007; Steven Bernstein, Erin Hannah, "Non-State Global Standard Setting and 
Indeed, private-sector standards which are developed and applied without due regard for the interests of all the relevant stakeholders may lack legitimacy, have discriminatory effects, fragment markets artificially, create unnecessary trade barriers, and impose unreasonable or unfair requirements on suppliers, thus restricting market access. Moreover, the proliferation of private standardization presents a challenge per se, in particular for small-scale and developing country producers who have to take into account the variety of requirements presented by different private-sector standards. Compliance with multiple private-sector standards and the related processes of certification may require significant costs and efforts from those producers which they are often not able to afford. ${ }^{262}$ Finally, abusive practices in the application of private-sector standards may result in unjustified discrimination, disguised trade restrictions and the distortion of market competition.

The research projects and case studies conducted by international organizations, such as OECD, UNCTAD, and FAO indicate that these important challenges and problems are related to the application of private-sector standards and their proliferation. ${ }^{263}$ In particular, one of the frequently in-

the WTO: Legitimacy and the Need for Regulatory Space”, Journal of International Economic Law, 11(3), 2008, p. 575; Private Voluntary Standards and Developing Country Market Access: Preliminary Results. Communication from OECD, Linda Fulponi, WTO, SPS Committee, G/SPS/GEN/763, Geneva, 27 February 2007, para. 16; Miet Maertens, Johan Swinnen, "Private Standards, Global Food Supply Chains and the Implications for Developing Countries", at: Axel Marx, Miet Maertens, Johan Swinnen, Jan Wouters, Private Standards and Global Governance. Economic, Legal and Political Perspectives, Edward Elgar, Cheltenham, UK, 2012, pp. 157 - 159; John Humphrey, "Private Standards in Kenyan Horticulture: Did the Donors Respond Effectively to the Challenge?", Paper for Conference 'Towards Priority Actions for Market Development for African Farmers', International Livestock Research Institute, Nairobi, April 2009; M. Iizuka and Y. Borbon-Galvez, "Compliance With the Private Standards and Capacity Building of National Institutions Under Globalization: New Agendas for Developing Countries?”, Working papers Series \#2009-025, UNU-Merit, Maastricht, 2009; K. Mauscha, D. Mithöferb, et al., "Impact of EurepGAP Standard in Kenya: Comparing Smallholders to Large-Scale Vegetable Producers", Conference on International Agricultural Research for Development, University of Bonn, October 11-13, 2006.

See: Spencer Henson, John Humphrey, "The Impacts of Private Food Safety Standards on the Food Chain and on Public Standard-Setting Processes", Codex thirty-second Session, FAO, WHO, Codex Alimentarius Commission, Rome, May 2009, pp. 28 - 29; Nicolas Canivet, "Food Safety Certification”, FAO, 2006, pp. $42-43$.

263 See, for example: Linda Fulponi, "Private Standard Schemes And Developing Country Access To Global Value Chains: Challenges And Opportunities Emerging From Four Case Studies", AGR/CA/APM(2006)20/FINAL, OECD, August 2007, p. 7; Linda Fulponi, "Final Report on Private Standards and the Shaping of the Agro-Food System”, AGR/CA/APM(2006)9/FINAL, OECD, Working Party on Agricultural Policies and Markets, July 2006, p. 30; Environmental Requirements 
voked challenges is the difficulties such standards create for small-scale producers and stakeholders. For instance, four case studies conducted by OECD with respect to agricultural producers in Chile, Ghana, Peru and South Africa came to the following conclusions:

From our evidence required certification of compliance with private voluntary standard schemes contributes to the exclusion of small holders from global value chains even where infrastructures and services operate efficiently and reliably, such as in Chile and South Africa. Only if there is sufficient financial and technical assistance available, as well as continual monitoring and management oversight, are small-holders able to meet the private standards necessary to access GVCs linked to lead retailers in OECD countries. ${ }^{264}$

In the Report on the impact of private food safety standards prepared for FAO and WHO, Spencer Henson and John Humphrey note the following with respect to the effects of GLOBALG.A.P. standards on small-scale producers:

There is an on-going debate about the impact of private standards on small producers, which has presented an increasing spectre of smallholder exclusion (Dolan and Humphrey, 2000; Jaffee, 2003; Okello, 2005; Jensen, 2004; OECD, 2006), with a particular focus on GlobalGAP (see for example Graffham et al., 2007). Evidence from Kenya seems to suggest that the introduction of GlobalGAP has reduced the participation of small farmers in the export vegetable business. A study of 10 exporters by Graffham et al. (2007) shows that the number of small-scale growers fell by more than 50 percent in the year following January 2005 when

and Market Access. Recent Work in OECD and UNCTAD. Note by the Secretariat, WTO, Committee on Trade and Environment, WT/CTE/W/244, 8 December 2006, paras. 17 - 21; The Implications of Private-Sector Standards for Good Agricultural Practices Exploring Options to Facilitate Market Access for Developing-Country Exporters of Fruit and Vegetables: Experiences of Argentina, Brazil and Costa Rica, UNCTAD, UNCTAD/DITC/TED/2007/2, New York, Geneva, 2007, pp. 9 - 10; Spencer Henson, John Humphrey, "The Impacts of Private Food Safety Standards on the Food Chain and on Public Standard-Setting Processes", Codex thirty-second Session, FAO, WHO, Codex Alimentarius Commission, Rome, May 2009, pp. 32 - 33; Robert M. Webb, "Survey of Fresh Fruit and Vegetable Exporters in Sub-Saharan Africa. Changing Buyer Requirements and Their Impact on Supply Chains", PIP - Survey, COLEACP PIP, Brussels, Belgium, May 2009.

264 Linda Fulponi, "Private Standard Schemes And Developing Country Access To Global Value Chains: Challenges And Opportunities Emerging From Four Case Studies", AGR/CA/APM(2006)20/FINAL, OECD, August 2007, pp. 24 -25 , para. 82 . The author of the Report, however, cautions against attributing all challenges faced by small-scale stockholders in competition with big firms to private-sector standards. Big firms also usually have advantages in terms of economies of scale and higher efficiency. 
certification supposedly became obligatory for farmers supplying UK supermarkets. However, the data on this issue appear to be somewhat unreliable. There is evidence of 'churning' of small farmers and the outsourcing of vegetable production from large exporters to subcontracted farms that have developed their own out-grower schemes. As a result, the fall in out-grower numbers at particular exporters registered by Graffham et al. may be offset by increases elsewhere. Sources from Kenya suggest that, on the ground in rural areas, there is no convincing evidence of a largescale expulsion of small farmers from a production segment that has been very lucrative for these farmers in the past. Arguably, had expulsion taken place on a large-scale, one would have expected to find more evidence.

Notwithstanding this uncertainty, there is little doubt that the cost burden per unit of production of introducing GlobalGAP on small farms is much greater than on larger farms. ${ }^{265}$

In the WTO SPS committee, a number of trade concerns have been discussed by WTO Members with respect to SPS-related private-sector standards such as GLOBALG.A.P., SQF and BRC standards, and a few other standards based on HACCP. ${ }^{266}$ The replies of WTO Members in the questionnaire with respect to the effects of SPS-related private-sector standards circulated in the SPS Committee, pointed to the many negative effects of such standards on the export of products. The Members indicated the de facto mandatory character of these standards in developed country markets; their excessively strict and scientifically unjustified requirements (e.g. the requirements to maximum residue levels (MRLs) for pesticides in fruits and vegetables); and high costs of compliance and certification under the standards, which does not necessarily deliver a price premium. The replies also expressed concerns over the multiplicity of private-sector standards

265 Spencer Henson, John Humphrey, "The Impacts of Private Food Safety Standards on the Food Chain and on Public Standard-Setting Processes", Codex thirty-second Session, FAO, WHO, Codex Alimentarius Commission, Rome, May 2009, p. 30. See also: John Humphrey, "Private Standards, Small Farmers and Donor Policy: EUREPGAP in Kenya", IDS WORKING PAPER 308, Institute of Development Studies, University of Sussex, Brighton, UK, July 2008, pp. 78 - 79; Catherine Dolan, John Humphrey, "Governance and Trade in Fresh Vegetables: The Impact of UK Supermarkets on the African Horticulture Industry", Journal of Development Studies, 37(2), 2000, p. 161.

266 See: Private Industry Standards. Communication from Saint Vincent and the Grenadines, WTO, SPS Committee, G/SPS/GEN/766, 28 February 2007, paras. $1-5$; Private Standards and the SPS Agreement. Note by the Secretariat, WTO, SPS Committee, G/SPS/GEN/746, Geneva, 24 January 2007, para. 1; Effects of SPS-Related Private Standards - Compilation of Replies. Note by the Secretariat, WTO, SPS Committee, G/SPS/GEN/932/Rev.1, Geneva, 10 December 2009, paras. 11 - 14. See also: Jan Wouters, "Private Law, Global Governance and the European Union”, KUL, Leuven, March 2012, pp. 7 - 9. 
and the lack of harmonization among them, as well as their disproportionate effects on smallholders who may lack the infrastructure and resources for compliance and certification. Finally, the Members pointed out the lack of transparency and involvement of exporters and other stakeholders in the private standard-setting process, as well as the lack of appropriate appeal procedures with respect to the adopted standards. ${ }^{267}$

One of the notes prepared by the WTO Secretariat for the SPS Committee summarises and classifies the challenges posed by private-sector standards as follows:

Research on the topic of private standards has tended to highlight the challenges which private standards may pose, especially for developing country suppliers. In particular, questions arise as to whether or not these schemes go beyond what is scientifically justified and where the burden of the cost of compliance falls. For ease of reference, the challenges related to private standards may be divided into (1) concerns with the content of private schemes and (2) concerns with the ability of operators to meet them. [...]

Trade concerns with the content of private standards primarily arise from the focus of private schemes on process and production methods (PPMs). The scope of PPMs covered by private standards is wide: covering issues as diverse as HACCP, animal welfare, organics, absence of genetically modified organisms, traceability, environmental impact, labour standards etc.

Trade concerns related to the ability of operators to meet private standards relate to the cost of implementing schemes at firm or farm level and the cost of demonstrating compliance. Private standards tend to be prescriptive, placing detailed requirements on suppliers which do not always allow alternative, but equivalent, ways of achieving the same food safety (or other) outcome. ${ }^{268}$

The WTO Secretariat summarized the trade concerns raised by WTO Members with respect to SPS-related private-sector standards in the following way:

Members have raised a number of concerns regarding SPSrelated private standards, including:

- the lack of a scientific basis for requirements;

267 See: Effects of SPS-Related Private Standards - Compilation of Replies. Note by the Secretariat, WTO, SPS Committee, G/SPS/GEN/932/Rev.1, Geneva, 10 December 2009, paras. $27-37$.

268 Private Standards and the SPS Agreement. Note by the Secretariat, WTO, SPS Committee, G/SPS/GEN/746, Geneva, 24 January 2007, paras. 12 - 14. 
- deviations from international standards or from official governmental requirements (for example, for maximum residue limits);

- the multiplicity of standards and the lack of harmonization among them;

- the costs of compliance and certification, especially with a multitude of standards;

- the lack of transparency, consultation and appeal mechanisms;

- the prescriptive, rather than outcome-based, operational procedures required by private standards, which disregards the concept of equivalence; and

- the disproportionate effect on small- and medium-sized producers and exporters in developing countries. ${ }^{269}$

A number of challenges presented by private-sector standards have also been discussed in the Workshop on Environment-Related Private Standards Certification and Labelling Requirements organized in 2009 by the WTO Secretariat, as was mentioned above. ${ }^{270}$ For instance, one of the keynote speakers, Mr. Pascal Liu from FAO, raised the issue of the inappropriateness of some requirements of private-sector standards and their excessive strictness, as has been claimed by some African smallholders with respect to GLOBALG.A.P. According to Mr. Liu, some European smallscale farmers also have complained that compliance with GLOBALG.A.P. is too costly for them. Mr. Liu further pointed out the challenges of private-sector standard-setting, such as their exclusionary character; a lack of transparency; the absence of a scientific basis for many requirements; the lack of accountability of standard-setting organizations; the high cost of compliance, which may be unaffordable for small-scale producers; and the unfair distribution of the price premium for compliance along the supply chain. ${ }^{271}$ The latter problem was described by Mr. Liu with the use of the data from available case studies as follows:

269 See: Possible Actions for the SPS Committee Regarding SPS-Related Private Standards. Note by the Secretariat, WTO, SPS Committee, G/SPS/W/247/Rev.3, Geneva, 11 October 2010, para. 32; See also: Report of the Ad Hoc Working Group on SPS-Related Private Standards to the SPS Committee, WTO, SPS Committee, G/SPS/W/256, Geneva, 3 March 2011, para. 24; "Members Take First Steps on Private Standards in Food Safety, Animal Plant Health", March 30 - 31, 2011, WTO News Items 2011, available at: http://www.wto.org/english/news_e/ news11_e/sps_30mar11_e.htm (last visited November 20, 2014).

270 See the Program of the Workshop, available at: http://www.wto.org/english/ tratop_e/envir_e/events_e.htm (last visited November 20, 2014).

271 See: Pascal Liu, "Private Standards in International Trade: Issues and Opportunities", Workshop on Environment-Related Private Standards, Certification and Labelling Requirements Geneva, Switzerland, July 9, 2009, pp. 13, 14-18. See also: Spenser Henson, O. Masakure, et al., "Do Fresh Produce Exporters in 
As seen above, certification programme that use an on-product label targeted to consumers may lead to a price premium. In some cases, the premium more than offsets the costs of compliance and certification. This is generally the case for organic and fairtrade certification. However, there is evidence that only a small share of the premium paid by consumers accrues to producers, as most of it is captured by downstream operators, in particular retailers. Case studies of certified banana exports from the Dominican Republic and Peru found that less than $20 \%$ of the premium accrued to the producing country (FAO 2009). The return to exporters was not higher for organic bananas than for conventional bananas. Retailers extracted the largest share of the retail price ( 40 to $50 \%$ ), followed by importers. In a field study on the Dominican Republic, CIRAD (2008) found that grower organizations captured less than $12 \%$ of the retail value of certified bananas while retailers captured between 33 and $40 \%{ }^{272}$

Similar problems and concerns with respect to private-sector standards have been discussed during the Round Table on the main challenges and opportunities posed by private-sector standards in the third section of the Workshop. ${ }^{273}$ Furthermore, the issues of the role and effects of private-sector standards related to carbon footprint labelling and other eco-labelling also came up during the meetings of the WTO TBT Committee and the Committee on Trade and Environment (CTE). ${ }^{274}$

Sub-Saharan Africa Benefit from GlobalGAP Certification?”, InFERG Working Paper No. 2 FT, University of Guelph, Guelph, Ontario, Canada, July 2009.

272 Ibid., pp. $16-17$.

273 See the Program of the Workshop, available at: http://www.wto.org/english/ tratop_e/envir_e/events_e.htm (last visited November 20, 2014).

274 For example, see: Summary Report of the Information Session on Product Carbon Footprint and Labelling Schemes 17 february 2010. Note by the Secretariat, WTO, Committee on Trade and Environment, WT/CTE/M/49/Add.1, 28 May 2010, para. 9; Labelling. Submission by the European Communities, WTO, TBT Committee, Committee on Trade and Environment, G/TBT/W/175, WT/CTE/W/212, 12 June 2002, paras. 3 - 4; Labelling for Environmental Purposes. Submission by the European Communities under Paragraph 32(iii), WTO, Committee on Trade and Environment, WT/CTE/W/225, 6 March 2003, paras. 24 - 27; Environmental Requirements and Market Access. Recent Work in OECD and UNCTAD. Note by the Secretariat, WTO, Committee on Trade and Environment, WT/ CTE/W/244, 8 December 2006, paras. $17-21$. 


\subsubsection{Meeting the Challenges Posed by Private-Sector Standards}

As is apparent from the numerous discussions, research projects and case studies conducted on various fora, private-sector standards do indeed pose important challenges for international trade and development. In principle it is possible to use various measures and mechanisms in order to meet these challenges and reduce the trade-restrictive effects of private-sector standards. Such measures and mechanisms may include, but are not limited to:

- improving the transparency of private standard-setting processes and the participation of interested stakeholders;

- developing mechanisms of accountability of private standard-setting organizations for standards they adopt;

- promoting the appropriateness and reasonableness of requirements presented by private-sector standards through the usage of science as a basis for their requirements, and through the adaptation of these requirements to local conditions;

- encouraging the harmonization of private-sector standards based on international standards, their benchmarking, equivalence and mutual recognition; and

- providing technical assistance to producers, especially to smallholders, for meeting the requirements of private-sector standards and getting certified under the standards. ${ }^{275}$

These measures and mechanisms can be used in three major regulatory approaches applied, either alone or in a combination: 1. private self-regulation; 2. governmental encouragement through certain incentives and socalled "soft law"; and 3. governmental requirements imposed by laws and regulations.

Private-self regulation is relevant when private standard-setting organizations decide, as a matter of good will, to impose certain rules on their own activities related, for instance, to the transparency of standard-setting processes, stakeholder involvement, benchmarking and harmonization, and technical assistance to smallholders. Such rules may be adopted in the form of codes of good practises or other individual or collective documents for private standard-setting organizations. In fact, the reputation of private standard-setting organizations affects a lot the use of their standards by business entities. This reputation may be damaged by negative publicity about shortcomings in the standard-setting work of an organization.

275 For a similar list of measures and mechanisms see, for example: Spencer Henson, John Humphrey, "The Impacts of Private Food Safety Standards on the Food Chain and on Public Standard-Setting Processes”, Codex thirty-second Session, FAO, WHO, Codex Alimentarius Commission, Rome, May 2009, pp. 34 - 36. 
That is why private standard-setting organizations are usually interested in adopting rules to improve transparency and stakeholder involvement in their work nowadays. This may, of course, also be done though collective initiatives, such as creating associations of private standard-setting organizations endorsing good practices in standardization. One example is the ISEAL Alliance, "the global association for social and environmental standards", which develops codes of good practices with regard to standard-setting procedures, compliance verification and standards' impact assessment for its members (which are leading private standard developing organizations, such as the FLO, the MSC, the FSC and some others). ${ }^{276}$

Governments may try to discipline private-sector standards through various non-mandatory "soft law" tools, e.g. the formulation and encouraging of good practices in the field of private standard-setting, or adopting various recommendatory documents in this sphere. In principle, governments may also adopt mandatory "hard law" requirements in this respect through their laws and regulations. ${ }^{277}$ Whether and how to regulate the development, adoption and application of private-sector standards, to a large extent, is indeed a matter of sovereign governmental discretion. However, as has been explained in Chapter I, the primary purpose of this study is to discuss whether, when, and to what extent governments of WTO Members are actually obliged by WTO law to discipline such private behaviour. In this respect, the following sections will briefly outline why the provisions of the WTO are relevant for the regulation of private-sector standards in general, and which WTO agreements shall be considered (and also shall not be considered) in the context of the present study.

\subsubsection{Private-Sector Standards and WTO Rules}

As has been explained in Chapter I, the WTO is the only international organization which establishes multilateral and legally mandatory rules with respect to the liberalization of international trade, thus forming a socalled "rules based system" of international trade. ${ }^{278}$ Because private-sector

276 See: http://www.isealalliance.org/content/about-us (last visited November 20, 2014).

277 However, as has been discussed in Section 2.2.4.2 above, the distinction between voluntary and mandatory "soft law" and "hard law" is not always clear cut. A voluntary measure may well become mandatory de facto due to significant governmental incentives provided by a government in support of such a measure, e.g. tax benefits or subsidies, the presumption of compliance with other mandatory requirements, etc.

278 These rules are indeed almost universal as the WTO membership comprises the large majority of countries and still gradually widens due to the accession of new Members. 
standards create important challenges for international trade, WTO legal norms are often at issue with regard to these standards.

WTO law contains a number of important legal requirements for disciplining the use of technical barriers to trade in goods by WTO Members, such as technical regulations, standards, and other measures which affect the international trade in goods. These requirements include most-favoured nation (MFN) and national treatment obligations, the prohibition of quantitative restrictions and unnecessary / unjustified restrictions on international trade, obligations of harmonization, transparency and notification, technical assistance and special and differential treatment (SDT). The relevant legal provisions in this respect may be found in the WTO agreements dealing with technical barriers to trade in goods, i.e. the GATT 1994, the TBT Agreement, and the SPS Agreement. The GATT 1994 provides the general regulatory framework for measures (including non-tariff barriers to trade) adopted and applied by WTO Members. The TBT Agreement is applicable to technical barriers to trade, such as technical regulations, standards and conformity assessment procedures. The SPS Agreement deals with SPS measures of WTO Members that are targeted at protecting human, animal or plant life or health from pests, diseases, disease-causing organisms and foodborne risks. The relevant provisions of these WTO agreements will thus primarily be examined in the present study. ${ }^{279}$

Other WTO agreements which, in principle, might be relevant with respect to the regulation of various aspects of the development, adoption and application of private-sector standards, are the GATS, the SCM Agreement, the TRIPS Agreement and the GPA. The GATS is a multilateral agreement (i.e. it is mandatory for all WTO Members) located in the separate Annex 1B of the Marrakesh Agreement Establishing the WTO (the WTO Agreement). The GATS is applicable to trade in services as defined in its Articles I:2 and I:3 through four modes of supply. ${ }^{280}$ The SCM Agreement is applicable to subsidies provided by governments to business entities in the forms of "a financial contribution" or "income or price support". ${ }^{281}$ The TRIPS Agreement is a multilateral agreement which

279 For further discussion, see Chapters III to V of the present study. See also: S. Karmakar, "Private Standards on SPS and TBT: Non-Tariff Barriers or Regulatory”, WTO News \& Views, 3(1), 2007.

280 These are: 1 . the cross border mode of supply; 2 . the consumption abroad mode; 3. the commercial presence mode; and 4. the presence of natural persons mode; see Article I:2(a) - (d) of the GATS. See also: Peter Van den Bossche, Werner Zdouc, The Law and Policy of the World Trade Organization. Text, Cases and Materials, 3d Edition, CUP, 2013, pp. 339 - 340.

281 See: Article 1.1 of the SCM Agreement; see also Article XVI of the GATT 1994. The SCM Agreement also is a multilateral agreement located in Annex $1 \mathrm{~A}$ of the WTO Agreement. 
establishes the obligations of WTO Members with respect to the protection of IP rights, such as copyright, patents and trademarks. ${ }^{282}$

Finally, the GPA is a plurilateral trade agreement (it is mandatory only for those WTO Members who opted to participate in it) located in Annex 4 of the WTO Agreement. According to its Article I:1, the GPA "applies to any law, regulation, procedure or practice regarding any procurement" by governmental bodies enlisted in Appendix I by each Party. Currently, 43 WTO Members participate in the GPA (including the EU and its 28 Member States), the majority of which are developed countries, and a number of WTO Members are also candidates for accession and observers. ${ }^{283}$ The GPA 1994 was successfully renegotiated by the Parties, and the revised GPA was approved by the Committee on Government Procurement on 30 March 2012 and offered for acceptance (ratification) by the Parties to the GPA. ${ }^{284}$ On 6 April 2014 the revised GPA entered into force for the first ten parties (constituting two-thirds of the parties to the GPA) to have accepted the Protocol of Amendment of the GPA. ${ }^{285}$

Indeed, as was discussed in Chapter I, the problems related to privatesector standards may also arise in the areas of trade in services (e.g. when a standard contains requirements relating to the characteristics of a service), governmental subsidies (e.g. when a government provides subsidies under the conditions of compliance with a standard), IP rights (e.g. when a patent is implicated in the content of a standard), and government procurement (e.g. when a government decides to procure only products complying with a standard). These issues and problems are, undoubtedly, very interesting and important, and may deserve detailed scrutiny in a number of separate studies. The present study, however, due to limitations in space and scope, is mainly concerned with addressing private-sector standards as technical barriers to trade in goods, and the prospects for regulation of such standards by WTO rules on a multilateral level (and not on a plurilateral level, as is the case with the GPA). Thus, the four WTO agreements briefly described above are not thoroughly examined in the present study. ${ }^{286}$

282 The TRIPS Agreement establishes the minimal standards of protection of IP rights to be obeyed by WTO Members in their domestic legal systems. It is located in the separate Annex 1C of the WTO Agreement.

283 See: http://www.wto.org/english/news_e/news14_e/gpro_29oct14_e.htm (last visited December 15, 2014). In fact, the majority of developing and some developed WTO Members do not currently participate in the GPA; see: Rüdiger Wolfrum, Peter-Tobias Stoll, Anja Seibert-Fohr, WTO: Technical Barriers and SPS Measures, Nijhoff, Leiden, 2007, p. 185.

284 See: WTO Committee On Government Procurement, GPA/113, 2 April 2012.

285 For the eleventh party, Japan, the revision came into force on 16 April 2014. See: http://www.wto.org/english/news_e/news14_e/gpro_07apr14_e.htm (last visited December 15, 2014).

286 However, the following Section 2.3.4.2 of the present Chapter briefly addresses 
It is a matter of fact, that WTO agreements are primarily applicable to the measures adopted and applied by WTO Members, i.e. by their public or governmental bodies. Indeed, under WTO law, only WTO Members (thus predominantly States) have rights and obligations. This means that the WTO legal norms are not directly applicable to private standard-setting organizations. Therefore, in case the provisions of WTO law contain certain requirements with respect to the development, adoption and application of private-sector standards, it would be for WTO Members to discipline such private trade-restrictive behaviour. And, as will be demonstrated in the following chapters, some WTO agreements seem to contain certain obligations for WTO Members with respect to the actions of non-governmental entities. The following chapters will therefore further discuss the meaning and scope of these obligations for WTO Members, i.e. whether and under what conditions these obligations may extend to the development, adoption and application of private-sector standards, and also what tools, if any, are available for governments in their domestic legal systems for disciplining the development, adoption and application of private-sector standards.

In general, it seems reasonable to argue that the relevant provisions of WTO law, with respect to the regulation of technical barriers to trade, could be circumvented by WTO Members if they are allowed to provide significant incentives or support for the development and application of private-sector standards. In other words, WTO Members would be able to hide behind the so-called "private veil" by doing what it is prohibited to do through their governmental bodies. Such practice may, arguably, result in the "blurring" of the existing WTO legal framework for the regulation of technical barriers to trade in goods. ${ }^{287}$ The proliferation of private-sector standards and their wide scale application thus potentially pose significant challenges to the WTO system. A concern in this respect has been well expressed by Argentina in its statement made in the SPS Committee and summarized by the WTO Secretariat as follows:

If the private sector was going to have unnecessarily restrictive standards affecting trade and countries had no forum where to advocate some rationalization of these standards, twenty years of discussions in international fora would have been wasted. The

some issues that arise with respect to the relationship between private-sector standards, IP rights and the TRIPS Agreement; Chapter III briefly describes the relevant rules on the attribution of private actions to WTO Members under the SCM Agreement, the Agreement on Agriculture and the GATS; Chapters IV and V explain the relationship of the TBT Agreement and the SPS Agreement respectively with other WTO agreements, such as the GATS and the GPA.

287 See: Private Standards and the SPS Agreement. Note by the Secretariat, WTO, SPS Committee, G/SPS/GEN/746, Geneva, 24 January 2007, para. 9. 
representative of Argentina was convinced that the rational and legal aspects of these kinds of regulations had to be addressed. ${ }^{288}$

The issue regarding the effects of private-sector standards in international trade in goods was first brought to the WTO in 2005 by Saint Vincent and Grenadines during a meeting of the WTO SPS Committee. Saint Vincent and Grenadines raised a concern about the impact of the private-sector standard scheme then known as EUREPG.A.P. (now GLOBALG.A.P.) which was applied by major supermarket chains in the UK for the export of bananas. According to Saint Vincent and Grenadines, compliance with this private standard scheme (including the SPS requirements thereof) effectively became a condition for market access in the UK for fresh fruit and vegetables. ${ }^{289}$ The request was supported by Jamaica which faced similar problems with respect to EUREPG.A.P. The EU responded that EUREPG.A.P. was a private consortium representing the interests of retailers and could, as such, not be regarded as a body of the EU. Hence, according to the EU, under no conditions could the requirements of EUREPG.A.P. be regarded as those of the EU. Peru and Mexico then raised the issue of interpretation of the relevant provisions of WTO law, and in particular those of the SPS Agreement. ${ }^{290}$

\subsubsection{Private-Sector Standards, IP Rights and Competition Law}

Private-sector standards and standardization are also frequently discussed in the context of their relationship with IP rights and competition (antitrust) law rules. In particular, IP rights such as patents raise a lot of controversial issues with respect to their effects in combination with standards and standard-setting processes. ${ }^{291}$

To explain this briefly, a patent is a form of an IP right which comprises the set of exclusive rights granted by a State to an inventor for a limited period of time, particularly "the sole right to exclude others from making, using, or selling an invention". ${ }^{292}$ In other words, a patent grants to an in-

288 Summary of the Meeting Held on 29-30 June 2005. Note by the Secretariat. Revision, WTO, SPS Committee, G/SPS/R/37/Rev.1, Geneva, 18 August 2005, para. 20.

289 Ibid., para. 16. See also: Private Standards and the SPS Agreement. Note by the Secretariat, WTO, SPS Committee, G/SPS/GEN/746, Geneva, 24 January 2007, para. 1

290 See: Summary of the Meeting Held on 29-30 June 2005. Note by the Secretariat. Revision, WTO, SPS Committee, G/SPS/R/37/Rev.1, Geneva, 18 August 2005, paras. $17-19$.

291 See: "Standards and Patents", Standing Committee on the Law of Patents, Thirteenth Session, SCP/13/2, Document prepared by the Secretariat, WIPO, Geneva, February 18, 2009, paras. $150-161$.

292 See: http://www.oxforddictionaries.com/definition/english/patent 
ventor (a patent holder) a monopoly on the commercial application of the invention. Other business entities may then not commercially use an invention without special authorization (licence) from of a patent holder, which is usually provided in exchange for royalties (licensing fees). As is widely known, monopolies stifle market competition and are thus, in principle, detrimental to market economies. However, in maintaining and enforcing their patent laws, governments seem to accept this as a small sacrifice for the achievement of greater good, i.e. the innovation and development of technology. Indeed, the main idea behind the patenting system is to motivate inventors, through exclusive rights and potential royalties, to make their inventions available to the public for the benefit of society, as inventors might otherwise not be interested in disclosing their inventions. In this respect, and in order to prevent or stop the unauthorised use of patented inventions, national patent laws usually provide for a number of remedies, including injunctions and compensation for damages caused. ${ }^{293}$

In principle, standards may also significantly contribute to innovation through the promotion of most efficient technologies and the interoperability of products. However, a conflict may arise when a patented technology is implicated in a standard adopted and widely applied within an industry. In such a situation an entire industry may become "locked" into a technology, which is included into a standard and is subject to the exclusive rights of one stakeholder. Of course, this would open a lot of "business opportunities" for the stakeholder-patentee. In fact, as will be demonstrated further by some examples of legal disputes, such a problem is particularly pertinent for the Information and Communication Technology (ICT) sector due to the resent boost in ICT innovation, which has been accompanied by the rapid evolution and development of appropriate standards. ${ }^{294}$

Nowadays, most standard-setting organizations attempt to meet these challenges by adopting the relevant rules for standardizing processes. First,

(last visited December 15, 2014).

293 See: "Standards and Patents", Standing Committee on the Law of Patents, Thirteenth Session, SCP/13/2, Document prepared by the Secretariat, WIPO, Geneva, February 18, 2009, paras. 51 - 53; Georg C. F. Greve, "Analysis on Balance: Standardisation and Patents. Comments on the "IPR in ICT Standardisation Workshop”“, Free Software Foundation Europe, December 2, 2008.

294 See: George S. Cary, Mark W. Nelson, Steven J. Kaiser, Alex R. Sistla, "The Case for Antitrust Law to Police the Patent Holdup Problem in Standard Setting", Antitrust Law Journal,(3), 2011, pp. 914-915; Robert M. Webb, “There Is a Better Way: It's Time to Overhaul the Model for Participation in Private StandardSetting”, Journal of Intellectual Property Law,(12), Fall, 2004, pp. 170 - 173; Georg C. F. Greve, "Analysis on Balance: Standardisation and Patents. Comments on the "IPR in ICT Standardisation Workshop”“, Free Software Foundation Europe, December 2, 2008. 
they oblige all participants of standard-setting processes to disclose all their patents relevant for the technology considered for incorporation into a standard. Second, if it appears that the technology under consideration in a standardising process is patented, the technology will not be incorporated into a standard unless a patent holder agrees to grant licences to all interested stakeholders under the so-called "Fair, Reasonable and Non Discriminatory" (FRAND) terms. ${ }^{295}$ However, such practices of standardsetting organizations cannot resolve all potential problems. A holder of the patent to be implicated in a standard might not take part in the standardsetting process. Or if it does, whether intentionally or not, it may still fail to disclose the patent in what is commonly referred to as "patent ambush" situations. ${ }^{296}$ Moreover, a patent holder might, after promising during a standard-setting process to grant licences to all interested stakeholders on the FRAND terms, breach this promise after the adoption of the standard and demand for excessive royalty fees in what is commonly referred to as a "patent hold-up".

In fact, it is also frequently quite difficult to determine what the FRAND licensing terms should be. For instance, what is fair and reasonable for a big corporation may appear to be otherwise for others, e.g. smallholders. Big corporations may also have their own important patents and "trade"

295 Such terms are also sometimes called just "Reasonable and Non Discriminatory" (RAND); see: Georg C. F. Greve, "Analysis on Balance: Standardisation and Patents. Comments on the "IPR in ICT Standardisation Workshop"“, Free Software Foundation Europe, December 2, 2008; "Standards and Patents", Standing Committee on the Law of Patents, Thirteenth Session, SCP/13/2, Document prepared by the Secretariat, WIPO, Geneva, February 18, 2009, paras. 67 - 68; George S. Cary, Mark W. Nelson, Steven J. Kaiser, Alex R. Sistla, "The Case for Antitrust Law to Police the Patent Holdup Problem in Standard Setting”, Antitrust Law Journal,(3), 2011, p. 916.

296 Indeed, persons representing business corporations in standard-setting organization are usually "technocrats" and do not have thorough knowledge of patents and the patenting policies of their employers. Thus, the representatives may act in good faith being unaware of a patent implicated in a standard. However, possible fraudulent practices may not be excluded in this regard as well, e.g. so-called "standards fixing". A good example is the circumstances of the renowned Rambus case, where the company Rambus not only intentionally failed to disclose its relevant patent applications during standard-setting processes, but also amended its applications in order to make it match better standards' conditions. It is also a matter of fact that standard-setting organizations generally are not well-equipped to investigate and discover the patents that could potentially be implicated in standards. See: Georg C. F. Greve, "Analysis on Balance: Standardisation and Patents. Comments on the "IPR in ICT Standardisation Workshop"“, Free Software Foundation Europe, December 2, 2008; Mark Finn, "Case Comment: When the Chips Are Down”, European Intellectual Property Review, 24(5), 2002, p. 286; Robert M. Webb, “There Is a Better Way: It's Time to Overhaul the Model for Participation in Private Standard-Setting”, Journal of Intellectual Property Law,(12), Fall, 2004, pp. 182 - 186; $198-200$. 
their use for the use of a patented technology implicated in a standard, thus creating a so-called "patent pool". Hence the FRAND licensing system is arguably, in general, more favourable for big corporations. Moreover, in the computer software sector it is frequently argued that the FRAND licensing system undermines the very existence of free software because a certain amount of royalties is still payable under the FRAND terms. Finally, it is also not clear what happens with respect to the promised FRAND licensing terms in case of transfer of ownership or in cases where changes take place in the management of a corporation; that is to say, it is not clear whether the new owners or management are obliged to keep the FRAND promises. In this regard, Mr. Charles Schulz from Ars Aperta (an independent consulting firm focusing on open standards and open source software), characterized the (F)RAND licensing system during the "IPR in ITC Standardization" Workshop in Brussels in November 2008 as "RANDom licensing at the sight of competitors".

The complex issues related to the possible conflicts between patent rights, standardization and competition (antitrust) rules have already arisen in a number of controversial disputes in the US and Europe. One rather early example is the Dell case, where the US Federal Trade Commission (FTC) brought a complaint against the Dell Computer Corporation with respect to the company's participation in a 1992 standard-setting process under the auspices of the Video Electronics Standards Association (VESA), which develops standards for computer graphics. According to the FTC, during the consideration of the proposed "VESA Local Bus standard", the Dell Corporation put forward that, to the best of its knowledge, the proposal did not infringe on any trademarks, copyrights or patents possessed by Dell. Over the next eight months, after the new standard was adopted, more than 1.4 million computers were sold using the standard. Dell then communicated to the VESA participants that the new standard infringed its " 481 patent" and demanded that negotiations concerning conditions for the use of the standardized technology be entered into. The FTC complained against the unreasonable restraints for competition which resulted from the behaviour of Dell and, after some negotiation, Dell agreed to drop its claims related to the patent. ${ }^{297}$

Another good example is the renowned Rambus case, where the American technology licensing company, Rambus, tried to enforce its patent, related to synchronous dynamic random access memory (SDRAM) technology, which was implicated in a standard. Rambus was a member of the US Joint Electron Devices Engineering Council (JEDEC) when the

297 See: Dell Corp., 121 F.T.C., pp. 617 - 618; see also: Robert M. Webb, “There Is a Better Way: It's Time to Overhaul the Model for Participation in Private StandardSetting”, Journal of Intellectual Property Law,(12), Fall, 2004, pp. 190 - 193. 
proposals for the new SDRAM standard were brought for consideration by the relevant committee of the standard-setting organization. During the work on the standard, Rambus not only failed to disclose its relevant pending patent applications, as this was required by the JEDEC rules, but also amended these applications to better match the terms of the standard. Later it withdrew from the JEDEC. However, in 1999 the new JEDEC SDRAM standard was adopted, which was followed by attempts by Rambus to enforce its patents and its requests for injunctions against using the patented technology. This became the reason for a number of controversial and even conflicting court decisions in the US and Europe related to claims of fraud, abuse of a patent, and unfair competition. ${ }^{298}$

These, as well as a number of other relevant and renowned cases, ${ }^{299}$ seem to demonstrate that the conflicts between patent rights, standardization and fair competition should mainly be dealt with in the context of two branches of legislation: 1. legislation on IP with respect to patent rights, fraudulent practices and abuse of patents; and 2. competition (antitrust) legislation prohibiting the abuse of a monopoly or a dominant position. ${ }^{300}$

Regarding the relevance of WTO rules in this respect, the WTO system does not contain rules dealing specifically with the protection of competition and the prohibition of abuse of a dominant position. In fact, the multilateral negotiations concerning the interaction between trade and competition policy were, originally, part of the so-called "Singapore issues", adopted as a result of the Ministerial Conference in Singapore in 1996. ${ }^{301}$ Following the Ministerial Conference, the Working Group on

298 See: Rambus, Inc. v. Infineon Tech. AG, 304 F. Supp. 2 d 812 (E. D. Va. 2004); Mark Finn, "Case Comment: When the Chips Are Down", European Intellectual Property Review, 24(5), 2002, pp. 286 - 287; Robert M. Webb, “There Is a Better Way: It's Time to Overhaul the Model for Participation in Private Standard-Setting”, Journal of Intellectual Property Law,(12), Fall, 2004, pp. 183 - 186; 198 - 200.

299 For example, the Union Oil Company of California (Unocal) and the eBay v. MercExchange cases in the US; the United Brands Co. and United Brands Continental $B V$ vs. EC Commission and the Microsoft cases in the EU; see: Robert M. Webb, "There Is a Better Way: It's Time to Overhaul the Model for Participation in Private Standard-Setting”, Journal of Intellectual Property Law,(12), Fall, 2004, pp. 193 - 197; Anselm Kamperman Sanders, "Standards Setting in the ICT Industry? IP or Competition Law? A Comparative Perspective”, Paper prepared for the 5th Annual Conference of the EPIP Association, Maastricht, 2010, pp. 7 - 13; Severin de Wit, “The Case eBay Inc. v. MercExchange LLC, Its Impact on NPE's and Patent Enforcement", at: Christopher Heath, Anselm Kamperman Sanders, Landmark Intellectual Property Cases and Their Legacy, Kluwer Law International, The Netherlands, 2010, pp. $1-3$.

300 See: Anselm Kamperman Sanders, "Standards Setting in the ICT Industry? IP or Competition Law? A Comparative Perspective", Paper prepared for the 5th Annual Conference of the EPIP Association, Maastricht, 2010, pp. 7, 17.

301 See: Singapore Ministerial Declaration, WT/MIN(96)/DEC, 18 December 1996. 
the Interaction between Trade and Competition Policy (WGTCP) was established to study various aspects of the relevant issues with the participation of all WTO Members. ${ }^{302}$ The possibility of multilateral negotiations on the rules of competition was also provided in the Work Program set out in the Doha Ministerial Declaration in 2001. ${ }^{303}$ However, during the Cancun Ministerial Conference in 2003, WTO Members failed to reach an agreement on the inclusion of competition issues in the Doha agenda. Accordingly, in 2004 the WTO General Council decided that the interaction between trade and competition would no longer form part of the Work Program and therefore that no work towards negotiations on these issues would take place within the WTO during the Doha Round. ${ }^{304}$

It is interesting to note that the 2003 edition of one of the renowned textbooks on WTO law and policy refers to the statements made by some developing countries within the WTO WGTCP that "there are about 60 nations without competition laws", and that "[i]mportant WTO Members, such as Singapore and China, for example, have a competition policy but no competition law" ${ }^{305}$ It is doubtful that this data is still correct nowadays, although the point remains: WTO rules do not (at least, directly) oblige WTO Members to have developed and enforceable competition law rules.

As was mentioned in Section 2.3.4.1 above, the WTO system does however contain an agreement for dealing with the protection of IP rights, including patents, namely the TRIPS Agreement which establishes the minimal standards of protection of IP rights to be followed by WTO Members. Interestingly, Article 2.1 of the TRIPS Agreement obliges WTO Members to comply with the relevant provisions of the Paris Convention for the Protection of Industrial Property 1967, which include Articles 10bis and 10 ter thereof. Article 10bis, paragraph (1), imposes the requirement on the Members to ensure the "effective protection against unfair competition". In particular, paragraph (3) of Article 10bis prohibits the following practices:

302 See: http://www.wto.org/english/tratop_e/comp_e/comp_e.htm (last visited December 15, 2014).

303 See: Ministerial Declaration, Ministerial Conference. Fourth Session, WT/MIN(01)/ DEC/1, Doha, Adopted on 14 November 2001, para. 25. For more information on the issue, see also: David J. Cerber, "Competition Law and the WTO: Rethinking the Relationship”, Journal of International Economic Law, 10(3), 2007, pp. 709 - 710; James H. Mathis, "WTO Core Principles and Prohibition: Obligations Related to Private Practices, National Competition Laws and Implications for a Competition Policy Framework”, UNCTAD, New York and Geneva, 2003, p. iii. See also Section 2.3.4.2 of Chapter II.

304 WT/L/579, 2 August 2004.

305 Matsuo Matsushita, Thomas J. Schoenbaum, Petros C. Mavroidis, The World Trade Organization. Law, Practice, and Policy, Oxford University Press, Oxford, 2003, p. 581. 
(i) all acts of such a nature as to create confusion by any means whatever with the establishment, the goods, or the industrial or commercial activities, of a competitor;

(ii) false allegations in the course of trade of such a nature as to discredit the establishment, the goods, or the industrial or commercial activities, of a competitor;

(iii) indications or allegations the use of which in the course of trade is liable to mislead the public as to the nature, the manufacturing process, the characteristics, the suitability for their purpose, or the quantity, of the goods.

Article 10ter of the Paris Convention further obliges WTO Members to provide effective remedies in their domestic legal systems for the protection of market competition. However, it seems that these norms of the Convention are only relevant in the context of the relationship and the interaction between IP rights and the protection of market competition, as has been briefly discussed above.

In addition, it is worth noting that IP rights such as trademarks are also relevant with respect to private-sector standards in connection with certification marks and labelling. In fact, most certification marks and labels under collective private-sector standards constitute a form of trademark protected by IP legislation, including the WTO TRIPS Agreement. Thus, the use of a certification mark or a label on a product by a business entity without proper authorization from a standard owner (which is usually granted through a certification process) would constitute an infringement of a trademark, which may be remedied through appropriate legal tools provided in a national IP legislation.

Undoubtedly, due to their complexity, the issues of the relationship between IP rights, standardization and competition, including the possible implications of the TRIPS Agreement in this respect, deserve special and detailed consideration in a number of separate studies. Indeed, as has been explained in Section 1.4 of Chapter I, the present study is devoted to private-sector standards as technical barriers to trade in goods and is not aimed at covering the IP related trade issues in detail. ${ }^{306}$

306 For more information on the TRIPS Agreement and protection of IP rights under WTO law, see: Peter Van den Bossche, Werner Zdouc, The Law and Policy of the World Trade Organization. Text, Cases and Materials, 3d Edition, CUP, 2013, pp. $951-1012$. 


\subsection{Summary and Conclusions}

As has been demonstrated in the present Chapter, the "world" of privatesector standards is very complex and diverse. As a result, the concept of private-sector standards is hard to describe with precision. Generally, using the definitions of a standard in the ISO/IEC Guide 2 and Annex 1 of the WTO TBT Agreement, a private-sector standard may be defined as a document adopted by a private entity, such as an industry association, an NGO, or a business corporation. This document prescribes the characteristics of products or PPMs for common and repeated use. By definition, it is not legally mandatory for compliance by market players, since it is adopted and applied by private entities.

However, the fact that a standard is adopted by an NGO does not immediately mean that it is a private-sector standard and not a public one. An NGO, in principle may be authorised by a government to perform elements of public authority by developing and adopting standards and, as a result, the standards adopted by such an entity would be public standards. Accordingly, private-sector standards are developed and adopted by NGOs which act within the private sector without exercising elements of governmental authority. In this respect, the differentiation of private-sector standards from public ones in complex situations should, arguably, only be done on a case-by-case basis in the context of the overall regulatory environment of a country. It is also rather difficult, if possible at all, to provide general guidelines on how "commonly" and "repeatedly" a document must be used in order to be regarded as a private-sector standard. The present study adopts a flexible approach in this respect, so that even individual company standards adopted and applied by business corporations may be regarded as private-sector standards.

Although private-sector standards, as well as standards in general, are not legally mandatory for compliance, they may, in principle, become mandatory de facto for suppliers wishing to gain or maintain market access. This may be the case if a standard is applied by large corporations, a group of corporations, or even entire industries which, to large extent, control a market. Moreover, a de jure voluntary private-sector standard may gain a de facto mandatory character if its application is encouraged through significant support or incentives provided by a government. In fact, such governmental support or incentives may transform a private-sector standard into a de facto mandatory regulation. Thus, the distinction between voluntary and mandatory measures is not always clear cut and may depend on the circumstances of each particular case taken in the context of a national regulatory environment. Concluding otherwise would allow States to "camouflage" their mandatory measures as voluntary ones. 
Due to their voluntary character, private-sector standards, as well as standards in general, have several operational stages which are not the same as the operational stages of mandatory measures. First, a private-sector standard is developed and adopted by a private standard-setting entity. It is then applied by business corporations to their own business activities (internally applied standards) or to their suppliers, who have to implement the standard (externally applied standards). The conformity assessment and enforcement of private-sector standards is performed by business corporations purchasing a product or, more commonly, by independent private organizations, i.e. accredited certifiers (third-party verification or certification). The conformity assessment procedures may include such actions as sampling, testing, and the inspection and surveillance of products and production facilities.

The typology of private-sector standards offered in this Chapter is based on multiple criteria relevant for the present study, and is not exhaustive. Private-sector standards may take various forms, such a "standard" per se, a "technical specification", a "code of good practices", a "production code", etc. However, the form and the name of the document are not decisive for its qualification as a private-sector standard. Private-sector standards may be developed and adopted by various private organizations on national, regional and international levels, such as NGOs, industry associations, research institutes and business corporations. Nowadays, private-sector standards developed and adopted by various types of NGOs for application by various business corporations (collective private-sector standards) are becoming more and more widespread. Arguably, this is due to their advantages in comparison with individual company standards, such as lower development and operational costs, and establishing and maintaining a "level playing field" for competition within an industry.

One of the most important criteria of the typology of private-sector standards in the context of the present study is the level of governmental involvement or incentives for the development, adoption and application of private-sector standards. According to this criterion, private-sector standards may be classified into the so-called "purely" private-sector standards which do not receive any governmental support or incentives at any of their operational stages, and into private-sector standards which receive some governmental support or incentives. However, if a private-sector standard receives a considerable or significant amount of governmental support or incentives at some of its operational stages, this well may transform it into a pubic standard or even a mandatory regulation. It is thus worth noting here again that there is no clear cut border between private-sector standards and public standards or regulations, as there is no clear cut border between private and public types of regulation in general. Accordingly, the grey zone 
between these types of measures should be dealt with only on a case-bycase basis depending on the circumstances. ${ }^{307}$

Private-sector standards may address various objectives which, in principle, may be classified into technical, societal and commercial ones. For example, technical objectives may relate to the establishment of common terminology, the interoperability of products, and the application of knowhow and production technologies. Societal objectives may include the safety and quality of products, or the protection of the environment and human rights. Commercial objectives may deal with the differentiation of products and the protection of brand reputation. The information about compliance with private-sector standards may target different clients: 1 . only business corporations (B2B standards); 2. only consumers, usually through the labelling on a product (B2C standards); or 3. both business corporations and consumers. Private-sector standards may address product characteristics, PPMs, marking, labelling or the packaging of products. In this respect, one of the distinctive features of private-sector standards, in comparison with public standards, is that most of them contain requirements regarding PPMs, including non-product related PPMs, i.e. PPMs which do not affect the physical characteristics of a final product. Arguably, this makes them more trade-restrictive in the eyes of producers who have to adjust their production methods to the requirements of different private-sector standards.

Because the private sector is, in principle, quite difficult to monitor and control, it is hardly possible to provide an accurate estimation of the number of operational private-sector standards in markets today. However, private-sector standards are undoubtedly proliferating rapidly, constantly evolving, changing and disappearing. The necessity for certification under certain private-sector standards due to their wide scale application became a business reality in many developed countries. Furthermore, the certification under the standards became an important and profitable business per se. The process of the proliferation of private-sector standards has various reasons. For example, the globalization of international trade brought new challenges in relation to the safety and quality of products, which triggered the rise in consumer concerns and demands. The environmental degradation, pollution, extinction of animal and plant species, violations of human rights and cruel treatment of animals in the course of the production of products roused consumer interest in the methods of production and the development of CSR policies by corporations. Moreover, the process of business concentration and the rise of big multinational corporations

307 In this regard see, for example, the description of the "grey zone school" in legal science in: Joost Pauwelyn, "Is It International Law or Not, and Does It Even Matter?”, at: Joost Pauwelyn, Ramses A. Wessel, Jan Wouters, Informal International Lawmaking, OUP, Oxford, 2012, pp. 128 - 129. 
which frequently apply such standards, turned these corporations into de facto "rule makers" in certain business sectors, e.g. the retail business.

Finally, the evolving regulatory environment also contributed to the process of "privatization" of market governance. In this respect, private actors may decide to develop, adopt and apply private-sector standards because: 1. they consider governmental regulation insufficient, inflexible or ineffective in addressing the emerging risks; 2 . because they would like to better ensure the safety and quality of products by controlling the production processes; or 3. because they want to avoid risks related to product liability, taking into account the widespread evolution of product liability legal rules in the direction of "strict liability".

It is widely recognized that private-sector standards may potentially have many positive effects for international trade and development, such as ensuring solid market access for complying producers, promoting and disseminating the most efficient and sustainable production technologies, and creating niche-markets favourable for small-scale and developing country producers. However, it seems that these potential positive effects are, nowadays, often overshadowed by problems and challenges posed by privatesector standards, which are frequently complained about by small-scale and developing country stakeholders and are confirmed by numerous case studies. In this respect, private-sector standards may present inappropriate or unjustified requirements, have discriminatory effects on products, and entail high costs of compliance and certification, thus driving small-scale producers out of a market. In fact, the proliferation of private-sector standards and the lack of their harmonization present a challenge as such, since producers have to comply with and get certified under the multiple and often differing requirements.

There may be different approaches to meeting the challenges posed by private-sector standards, including improving the transparency of standard-setting processes, providing technical assistance to interested smallholders, and imposing rules with respect to the content of the standards. The regulation of the development, adoption and application of privatesector standards may, in principle, be exercised by private standard-setting organizations themselves (individually or collectively), or by governments. In this regard, the rules of WTO law impose important obligations on the governments of WTO Members to discipline those measures which create technical barriers to trade in goods. In particular, the relevant rules are prescribed in the appropriate provisions of the GATT 1994, the TBT Agreement, and the SPS Agreement. One of the key questions in this respect is whether, under what conditions, and to what extent, if any, WTO Members are obliged to discipline the development, adoption and application of private-sector standards by private entities. The following chapters 
The "World” of Private-Sector Standards

discuss the relevant provisions of these three WTO agreements in detail in order to find an answer to this question. 


\section{CHAPTER III \\ PRIVATE-SECTOR STANDARDS UNDER THE GATT 1994 AND THE INTERNATIONAL LAW RULES ON THE ATTRIBUTION OF CONDUCT TO WTO MEMBERS}

$\mathrm{T}$ he GATT 1994 establishes the general legal framework for measures of WTO Members that affect international trade in goods. This general legal framework, inter alia, covers different kinds of non-tariff barriers to trade, including the use of technical barriers in international trade by WTO Members. Since the present study examines the implications of WTO rules for the legal regulation of private-sector standards as technical barriers to trade in goods, the appropriate disciplines of the GATT 1994 could in fact be quite relevant in this regard. The present Chapter therefore discusses the key disciplines of the GATT 1994, which may be relevant for the regulation of the development, adoption and application of privatesector standards. Furthermore, it also examines whether, and under which conditions, these key disciplines may be applicable to private conduct in general, and to the development, adoption and application of private-sector standards, as a kind of private conduct, in particular.

The GATT 1994 has a predecessor - the GATT 1947. Initially, the system established by the GATT 1947 had a number of serious shortcomings. Indeed, as has been eloquently noted by the former WTO Director General Pascal Lamy during the ceremonies commemorating the 30th anniversary of the GATT/WTO Legal Affairs Division in June 2012:

The original GATT rules applied to a small group of countries and those rules were not always easy to understand by the uninitiated. As famously quoted by John Jackson, Senator Millikin - then Chairman of the US Senate Finance Committee - said in 1951 that "Anyone who reads GATT is likely to have his sanity impaired". 308

Furthermore, the enforcement of the GATT 1947, through the GATT dispute settlement procedures, was weakened by the requirement for consensus to both establish a panel and to adopt a panel report. In this respect, it is easy to recall several unadopted GATT panel reports related to controversial issues surrounding technical barriers to trade, such as the US - Tuna (Mexico, unadopted) and the US - Tuna (EEC, unadopted) cases, which will

308 "Lamy Cites "Very Broad Confidence" in WTO Dispute Settlement", WTO News: Speeches - DG Pascal Lamy, 28 June 2012, available at: http://www.wto.org/ english/news_e/sppl_e/sppl240_e.htm (last visited January 15, 2015). 
be further discussed hereafter. ${ }^{309}$ Moreover, prior to the completion of the Uruguay Round in 1994, there was no appeal mechanism to ensure a uniform approach for the interpretation of the GATT rules by dispute settlement panels.

The Dispute Settlement Understanding (DSU), adopted in the "package" of the results of the Uruguay Round of multilateral trade negotiations, remedied this weakness of the GATT dispute settlement system by providing for "reverse consensus" decision-making to establish panels and adopt their reports. ${ }^{310}$ The DSU also created the Appellate Body, a permanent appeal mechanism for decisions by WTO panels. The GATT 1994, which was also adopted as a result of the Uruguay Round, comprises the text of the GATT 1947 and a number of other legal instruments - decisions, protocols, understandings, etc., incorporated by reference and adopted during the GATT times or upon conclusion of the Round. ${ }^{311}$ The GATT 1947, which has been in operation for almost fifty years, is therefore currently fully superseded by the GATT 1994 and does not exist as an independent treaty anymore. ${ }^{312}$

\subsection{Scope of Application of the GATT 1994}

As has been mentioned before, the GATT 1994 constitutes the general legal framework for measures of WTO Members that affect trade in goods. However, this framework is limited to certain kinds of measures adopted and applied by appropriate bodies of the Members. The GATT 1994 therefore has an appropriate scope of application, which although appears to be rather general, considering the general character of the GATT 1994 itself.

309 See: GATT Panel Report, US - Tuna (Mexico, unadopted); GATT Panel Report, US - Tuna (EEC, unadopted). For more information on these cases, see Section 3.3.6 of the present Chapter.

310 See Articles 6.1, 16.4, 17.14 of the DSU. The reverse consensus in the context of the DSU is the consensus not to establish a panel, or not to adopt a panel's or Appellate Body's report. Obviously, achieving the reverse consensus is virtually impossible since a Member prevailing in a dispute or requesting the establishment of a panel would have to also support the negative decision. In practice, the reverse consensus rule thus resulted in the semi-automatic establishment of WTO panels and the adoption of their reports by the Dispute Settlement Body (DSB).

311 The text of the GATT 1994 per se consists only of $2-3$ pages.

312 The GATT 1947 was brought into operation in 1947 through the Protocol of Provisional Application signed by the GATT Contracting Parties. Due to political difficulties related to the failure of approval of the International Trade Organization (ITO) Charter , the GATT 1947 was never fully adopted by the Contracting Parties. See: Peter Van den Bossche, Werner Zdouc, The Law and Policy of the World Trade Organization. Text, Cases and Materials, 3d Edition, CUP, 2013, pp. 76 - 79. 
In principle, the scope of application of the GATT 1994, as well as the scopes of application of other WTO agreements, may be subdivided into three components: material scope, personal scope and temporal scope. ${ }^{313}$ The material scope indicates what types of measures are covered by the GATT 1994. The personal scope addresses the kind of bodies or entities to whom the obligations of the GATT 1994 apply. And, finally, the temporal scope answers the question about when a "measure" must be adopted and applied in order to be covered by the GATT 1994.

These aspects of the scope of application of the GATT 1994 are indeed quite relevant with respect to the issue of the applicability of its disciplines to private-sector standards. Thus, the following sections discuss the scope of application of the GATT 1994 with the aim of identifying whether it may cover the development, adoption and application of private-sector standards.

\subsubsection{Material Scope of Application of the GATT 1994: Mandatory or Voluntary Measures?}

Disciplines of the GATT 1994 cover "measures" adopted and applied by WTO Members. However, the GATT 1994 does not contain a definition of the term "measure". It also does not contain general provisions explaining what kinds of acts or omissions may constitute a "measure", and in what kinds of documents a "measure" may be reflected, e.g. decisions, regulations, laws, bills, and, perhaps, standards as well. ${ }^{314}$ In this context, and with respect to the development, adoption and application of private-sector standards, the important question which arises is whether the GATT 1994 covers only mandatory measures, such as legislation or decisions; or voluntary ones, such as recommendations or administrative guidance as well.

The GATT 1994 does not directly provide whether it covers only mandatory measures or voluntary ones as well. However, in dispute settlement

313 The material scope of application is also frequently called "substantive" scope. See, for example, the similar classification of the scopes with respect to the TBT Agreement and the SPS Agreement in: Peter Van den Bossche, Denise Prévost, Mariëlle Matthee, "WTO Rules on Technical Barriers to Trade”, Maastricht, 2005-6, pp. 28 - 30; Denise Prévost, Peter Van den Bossche, "The Agreement on the Application of Sanitary and Phytosanitary Meaures”, at: Patrick F.J. Macrory, The World Trade Organization: Legal, Economic and Political Analysis, 1 Springer [etc.], New York, 2005, pp. 244 - 250; Denise Prévost, Balancing Trade and Health in the SPS Agreement: The Development Dimension, Wolf Legal Publishers, Nijmegen, 2009, pp. 515 - 516.

314 The GATT 1994 referrers in several provisions to "regulations" (e.g. Articles III and X) and "standards" in the relevant meaning (e.g. Articles XI:2(b) and XXXVI:1(d); not the "standards of living" as referred to, for example, in Article XVIII:1 ). 
practice, GATT and WTO panels have clarified that it is not possible to make a "bright line" distinction between mandatory and voluntary measures that are suitable for all kinds of situations. In this respect, figuratively speaking, there is a grey zone between the classes of de jure mandatory and purely voluntary measures. A de jure non-mandatory measure may become more or less mandatory de facto due to governmental involvement or incentives for their implementation. ${ }^{315}$ In fact, if provided, such governmental involvement or incentives, as a rule, are meant to influence the behaviour of private actors. The task of making a distinction between mandatory and voluntary measures under the GATT 1994 is therefore related to the issue of attribution of private conduct to WTO Members under this Agreement, as discussed in Section 3.2.2.1 of the present Chapter.

In Japan - Semi-Conductors, for example, the GATT Panel, in principle, recognized that:

[...] not all non-mandatory requests could be regarded as measures within the meaning of Article XI:1. Governmentindustry relations varied from country to country, from industry to industry, and from case to case and were influenced by many factors. There was thus a wide spectrum of government involvement ranging from, for instance, direct government orders to occasional government consultations with advisory committees. The task of the Panel was to determine whether the measures taken in this case would be such as to constitute a contravention of Article XI. ${ }^{316}$

For this determination the Panel considered the two essential criteria:

First, there were reasonable grounds to believe that sufficient incentives or disincentives existed for non-mandatory measures to take effect. Second, the operation of the measures to restrict export of semi-conductors at prices below company-specific costs was essentially dependent on Government action or intervention.[...] The Panel considered that if these two criteria were met, the measures would be operating in a manner equivalent to mandatory requirements such that the difference between the measures and mandatory requirements was only one of form and not of substance, and that there could be therefore no doubt that they fell within the range of measures covered by Article XI.1.317

315 See: Harm Schepel, "Private Regulators in Law”, at: Joost Pauwelyn, Ramses A. Wessel, Jan Wouters, Informal International Lawmaking, OUP, Oxford, 2012, pp. $360-361$.

316 GATT Panel Report, Japan-Semi-Conductors, para. 108. For more information on this case, see Section 3.2.2.1.1 of the present Chapter.

317 GATT Panel Report, Japan -Semi-Conductors, para. 109. 
Similarly, in another GATT case with Japan as a respondent, Japan Agricultural Products I, the Panel found that the informal and de jure nonmandatory administrative guidance issued by the Japanese government was a traditional and quite effective regulatory tool in Japan. Therefore, according to the Panel, the informal guidance used by the Japanese government to impose quantitative restrictions with respect to certain agricultural products could be regarded as a de facto enforcement of the governmental measure within the meaning of GATT Article XI:2(c)(i), since it effectively influenced the behaviour of market actors in Japan. In particular, the Panel noted:

As regards the method used to enforce these measures the Panel found that the practice of "administrative guidance" played an important role. Considering that this practice is a traditional tool of Japanese Government policy based on consensus and peer pressure, the Panel decided to base its judgments on the effectiveness of the measures in spite of the initial lack of transparency. In view of the special characteristics of Japanese society the Panel wishes, however, to stress that its approach in this particular case should not be interpreted as a precedent in other cases where societies are not adapted to this form of enforcing government policies. ${ }^{318}$

An analogous approach was followed in other GATT cases. In CanadaForeign Investment Review Act (FIRA), the GATT Panel examined written purchase and export undertakings under the FIRA submitted by investors regarding the acquiring, establishing and conducting of their business in Canada and conditional approval by the Canadian government. The Panel found that such undertakings were to be regarded as "laws, regulations or requirements" within the meaning of Article III:4, even though the FIRA did not make their submission obligatory. ${ }^{319}$ According to the Panel, although the undertakings could in principle be viewed as "private contractual obligations of particular foreign investors visàvis the Canadian government", once they are approved by the government, they might provide economic advantages to the investors in a way inconsistent with Article III:4 of the GATT. ${ }^{320}$ Similarly, the GATT Panel on EEC - Parts and Components, found that the term "all laws, regulations or requirements" in GATT Article III:4 covered "not only requirements which an enterprise is legally bound to carry out, $[. .$.$] but also those which an enterprise voluntarily accepts in order$ to obtain an advantage from the government". ${ }^{321}$

\footnotetext{
318 GATT Panel Report, Japan - Agricultural Products I, para. 5.4.1.4.

319 See: GATT Panel Report, Canada - FIRA, paras. 5.4-5.5.

See also: Panel Report, Japan - Film, para. 10.51.

320 See: GATT Panel Report, Canada - FIRA, para. 5.6

321 GATT Panel Report, EEC - Parts and Components, para. 5.21
} 
Indeed, various countries may have differing legislative traditions. For example, in Japan it is common for the government to use recommendatory acts instead of legally binding ones; all the market players, however, regard such recommendatory measures to be binding and follow them in practice. Moreover, governments may encourage the compliance with recommendatory norms through certain hard or soft enforcement mechanisms, providing benefits for complying actors or creating obstacles for non-complying actors. Obviously, the choice of such regulatory approaches does not allow WTO Members to avoid responsibility for their WTO law-inconsistent measures. In this regard, in Japan - Film, the Panel, when considering the nature of Japan's measures, noted with respect to the regulatory traditions in Japan:

In Japan, it is accepted that the government sometimes acts through what is referred to as administrative guidance. In such a case, the company receiving guidance from the Government of Japan may not be legally bound to act in accordance with it, but compliance may be expected in light of the power of the government and a system of government incentives and disincentives arising from the wide array of government activities and involvement in the Japanese economy. ${ }^{322}$

The Panel thus concluded that Japan's administrative guidance could constitute a measure within the meaning of Article XXIII:1(b) of the GATT 1994 and further explained:

In our view, a government policy or action need not necessarily have a substantially binding or compulsory nature for it to entail a likelihood of compliance by private actors in a way so as to nullify or impair legitimately expected benefits within the purview of Article XXIII:1(b). Indeed, it is clear that non binding actions, which include sufficient incentives or disincentives for private parties to act in a particular manner, can potentially have adverse effects on competitive conditions of market access. ${ }^{323}$

Finally, it is worth noting that under the GATT 1994, as well as certain other WTO agreements (e.g. the Anti-Dumping Agreement), the determination about whether a measure is covered by the scope of application of a certain provision may be done only with respect to such a particular provision, and not generally with respect to the entire Agreement. This has been quite clearly explained by the Appellate Body in the context of considering claims under the WTO Anti-Dumping Agreement and Article VI of the GATT 1994 (devoted to anti-dumping as well):

322 Panel Report, Japan - Film, para. 10.44. For more information on this case see Section 3.2.2.1.1 of the present Chapter.

323 Panel Report, Japan - Film, para. 10.49. 
This analysis leads us to conclude that there is no basis, either in the practice of the GATT and the WTO generally or in the provisions of the Anti-Dumping Agreement, for finding that only certain types of measure can, as such, be challenged in dispute settlement proceedings under the Anti-Dumping Agreement. Hence we see no reason for concluding that, in principle, nonmandatory measures cannot be challenged "as such".[...]

We do not think that panels are obliged, as a preliminary jurisdictional matter, to examine whether the challenged measure is mandatory. This issue is relevant, if at all, only as part of the panel's assessment of whether the measure is, as such, inconsistent with particular obligations. ${ }^{324}$

The discussion above appears to be relevant with respect to private-sector standards in the sense that they are de jure voluntary measures by definition. In this regard, it seems that de jure voluntary measures (at least governmental ones) may be covered by the relevant provisions of the GATT 1994 only if their application is subject to meaningful governmental involvement or incentives. Moreover, such governmental involvement or incentives must be sufficient in order to make such measures more or less mandatory de facto in a market of a WTO Member. Whether the governmental involvement or incentives are indeed sufficient may be decided only on case-by-case basis. In fact, different countries may have various regulatory and legislative traditions. In Japan, for example, it is common for the government to use recommendatory acts instead of legally binding ones, but as all the market players regard such recommendatory measures to be binding, they follow them in practice. Moreover, governments may encourage compliance with recommendatory norms through certain hard or soft enforcement mechanisms, providing benefits for complying actors or creating obstacles for non-complying actors. Undoubtedly, the choice of such regulatory methods should not allow WTO Members to avoid responsibility for their measures inconsistent with substantive obligations of the GATT 1994.

\subsubsection{Personal Scope of Application of the GATT 1994}

As has been mentioned before, generally, under WTO agreements, including the GATT 1994, only WTO Members (i.e. States, a number of SCTs

324 Appellate Body Report, US - Corrosion-Resistant Steel Sunset Review, paras. 88 - 89. 
and the $\mathrm{EU}^{325}$ ) have rights and obligations. ${ }^{326}$ This means that the obligations contained in the GATT 1994 directly govern actions (or lack thereof) taken by governments of WTO Members in the broad sense, but not the actions taken by private actors. Indeed, according to the general principles of public international law, a treaty binds States that are parties to that treaty. Thus, as such, the WTO Agreement (to which the GATT 1994 is annexed), as a treaty, binds WTO Members, i.e. their governments. ${ }^{327}$ Accordingly, in principle, in the WTO dispute settlement system, WTO Members can challenge measures imposed, whether de jure or de facto, by other Members, i.e. by their organs. ${ }^{328}$ Moreover, according to the WTO Dispute Settlement Understanding (DSU), the WTO dispute settlement system is accessible only to WTO Members (i.e. States, SCTs and the EU); natural persons or legal entities may not bring a claim under the dispute settlement system.

It is clear that the development, adoption and application of private-sector standards per se constitute a kind of private conduct. Therefore, one of the important and quite general questions which arise in the context of the present study is: whether, and if so to what extent, private conduct may be subject to the disciplines under the WTO Agreement (including the GATT 1994 and other WTO agreements annexed to it) and may be enforced through the WTO dispute settlement system?

It seems that actions by non-State actors in certain and quite limited circumstances may also trigger the liability of WTO Members. First of all, it is worth noting that governmental measures of WTO Members may (and in fact usually do) encourage or require private actors in their territories to behave in certain ways. In doing so, the measures of WTO Members may sometimes formally allow some elements of private choice in regulated private behaviour; but, the private actors could nonetheless be strongly encouraged or forced by such governmental measures to behave in certain ways. In such situations, it seems to be more appropriate to speak about the responsibility of WTO Members for their own measures, i.e. for the

325 In fact, originally, the European Communities (EC) was a Member of the WTO. However, as has been mentioned in Section 2.2.4.3.1 of Chapter II, after the Treaty of Lisboan came into force on December 1, 2009, the EC ceased to exist and was fully transformed into the European Union (EU). In the WTO, the rights and obligations of the EC are, as a result, now exercised by the EU, the full legal successor of the former. In order to avoid any confusion and to simplify the matters, the present study always refers to the EU, even when dealing with the WTO disputes, which arose and were resolved before the $\mathrm{EC}$ was transformed into the $\mathrm{EU}$ (so the titles of the relevant cases refer to the EC).

326 See: Section 1.2 of Chapter I and Section 2.3.4.1 of Chapter II.

327 See: Rex J. Zedalis, "When Do the Activities of Private Parties Trigger WTO Rules?”, Journal of International Economic Law, 10(2), 2007, p. 337.

${ }^{328}$ For further discussion in this regard, see Section 3.2.1 of the present Chapter. 
governmental actions which modify normal competitive conditions in a market.

Second, in principle, there might be situations where Members' governments are explicitly or implicitly required by the rules of WTO law, and by the rules of the GATT 1994 in particular, to discipline the behaviour of non-governmental entities, e.g. take certain measures with respect to such entities. Arguably, in these situations and upon meeting appropriate conditions, a WTO Member should be able to bring a dispute against another Member regarding the failure to act in order to discipline the behaviour of the private actor. Moreover, the norms of WTO law may (and in fact frequently do) prescribe to WTO Members appropriate negative obligations to abstain from certain actions, e.g. obligations in the GATT 1994 to abstain from discrimination of foreign products or from imposition of quantitative restrictions on imports or exports, which will be discussed later in the present Chapter. ${ }^{329}$ Indeed, such negative obligations may be also prescribed with respect to private actors, e.g. requirements for WTO Members to abstain from supporting or encouraging certain unwanted behaviour of the actors.

Finally, under the GATT 1994 there may be situations where the actions of private actors may be "attributed" to Members' governments, i.e. the actions are regarded as those performed by the Members.

Thus, in principle, the issue of responsibility of WTO Members under the GATT 1994 in connection with private behaviour might arise mainly from three possible perspectives: 1 . the responsibility of WTO Members for their own governmental measures per se, affecting private behaviour in a prohibited way; 2 . the responsibility of WTO Members under the provisions of the GATT 1994 in cases where these provisions implicitly or explicitly impose the obligations to discipline private behaviour; and 3. the attribution of private conduct to WTO Members. The following two sections discuss the first two possible options. The issues of attribution of private conduct to WTO Members are addressed in detail separately in Section 3.2.2.1 of the present Chapter.

\subsubsection{Responsibility of WTO Members under the GATT 1994 for Their Measures Affecting Private Behaviour}

Generally, provisions of WTO law, and provisions of the GATT 1994 in particular, create rights and obligations only for WTO Members, i.e. for their central or local governmental bodies. This also means that by default, under WTO law, the Members are primarily and fully responsible for the

329 See Section 3.3.1 of the present Chapter. 
actions of their governmental bodies or other entities performing elements of governmental authority.

At the same time, as a matter of fact, governmental measures are usually aimed at achieving changes in the patterns of private behaviour and, as a rule, successfully do so. In this respect, a governmental measure may impose direct requirements on private entities to act or abstain from acting in certain ways. It may also present different options for private behaviour allowing private actors to make choices. Finally, a governmental measure may regulate private behaviour by providing weaker or stronger incentives or disincentives for the actions of private entities without presenting direct requirements. Such incentives or disincentives may include, for example, the creation of more or less favourable conditions for the marketing of products, tax or other monetary benefits or disadvantages, or the presumption of (non-) compliance with other rules or requirements, etc. The choice of regulatory approach by a government, among many factors, may depend on the type and structure of the legal system of a country, regulatory traditions, and regulatory aims to be achieved by a measure. In fact, the WTO dispute settlement jurisprudence quite clearly demonstrates how "creative" WTO Members sometimes may be in framing their measures.

As a result, it is clearly recognized in WTO law and dispute settlement practice that WTO Members shall bear the responsibility for their measures not only if those measures directly require private entities to act or not to act in certain ways. WTO Members shall also be responsible for their measures if they create serious incentives for private entities to act inconsistently with the provisions of WTO agreements, e.g. reduce competitive opportunities for foreign products or support import / export bans that are in violation of the GATT provisions. In this context, therefore the issue of attribution to WTO Members of the private actions forced or induced by governmental measures usually does not arise. ${ }^{330}$ In such a situation, the concerned Members will be held liable for their own governmental measures inconsistent with the GATT 1994, and not for private actions resulting from such measures.

A good example is the Korea - Various Measures on Beef dispute, where the US and Australia challenged the dual retail system for beef products introduced by Korea. According to this system, the small retail outlets of meat products in Korea had to make a choice whether to sell only Korean beef products or only the imported ones, and big retail stores had to establish special areas for the display and sale of foreign beef products. In practice this resulted in a dramatic decrease in the number of outlets willing to sell imported beef products. The Panel, and then on appeal the Appellate Body, found that

330 For further discussion of the issue of attribution, see Section 3.2 of the present Chapter. 
it was a violation of the national treatment obligation by Korea under Article III:4 of the GATT 1994, as the Korean measure resulted in a less favourable treatment of imported beef products. ${ }^{331}$ In particular, the Appellate Body noted in this regard:

We are aware that the dramatic reduction in number of retail outlets for imported beef followed from the decisions of individual retailers who could choose freely to sell the domestic product or the imported product. The legal necessity of making a choice was, however, imposed by the measure itself. The restricted nature of that choice should be noted. [...] In these circumstances, the intervention of some element of private choice does not relieve Korea of responsibility under the GATT 1994 for the resulting establishment of competitive conditions less favourable for the imported product than for the domestic product. $^{332}$

The Appellate Body, however, further noted that a dual retail system for products would not always be inconsistent with WTO rules, especially if such a system results from free private entrepreneurial behaviour:

We are not holding that a dual or parallel distribution system that is not imposed directly or indirectly by law or governmental regulation, but is rather solely the result of private entrepreneurs acting on their own calculations of comparative costs and benefits of differentiated distribution systems, is unlawful under Article III:4 of the GATT 1994. What is addressed by Article III:4 is merely the governmental intervention that affects the conditions under which like goods, domestic and imported, compete in the market within a Member's territory. ${ }^{333}$

Similar reasoning in the context of Article III:4 of the GATT 1994 was again used by the Appellate Body in China - Auto Parts. In particular, the Appellate Body referred to the incentives for manufacturers to limit their use of imported parts relative to domestic parts, which "“affect" the conditions of competition for imported auto parts on the Chinese internal market". ${ }^{334}$

Thus, normally and by default, WTO Members are fully responsible under the GATT 1994 for their own governmental measures if these

331 See: Panel Report, Korea - Various Measures on Beef, paras. 631 - 634; Appellate Body Report, Korea - Various Measures on Beef, paras. 142 - 151. For more information on national treatment obligation under Article III:4, see Section 3.3.1 of the present Chapter.

332 Appellate Body Report, Korea - Various Measures on Beef, para. 146.

333 Appellate Body Report, Korea - Various Measures on Beef, para. 149.

334 Appellate Body Report, China - Auto Parts, para. 195. 
measures distort the normal competitive conditions of a market by forcing (or creating strong incentives / disincentives for) private actors to act in certain ways. Accordingly, for example, if a government of a WTO Member provides significant and effective incentives for application of a private-sector standard on its market, such governmental conduct by itself in certain circumstances may amount to a violation of the GATT disciplines.

\subsubsection{Are There Implicit or Explicit Positive Obligations to Discipline Private Conduct Under the GATT 1994?}

The GATT 1994 does not contain provisions directly requiring WTO Members to take measures with respect to non-governmental entities. Indeed, as will be discussed in detail in Section 3.3 of the present Chapter, the key disciplines of the GATT 1994 include the obligations of Article I (MFN treatment), Article III (national treatment), Article XI:1 (prohibition of quantitative restrictions for import or export) and Article X:3(a) (transparency, uniformity, impartiality and reasonableness in administration of trade laws, regulations and decisions). These obligations, in principle, are directly applicable to WTO Members, i.e. their governmental bodies. However, the question is whether these obligations may imply the responsibility of Members to discipline private trade-restrictive behaviour if such behaviour causes the results analogous to the ones proscribed in the provisions of the GATT 1994 specified above. Figuratively speaking, is it possible to bring a positive "due diligence" obligation with respect to private actors into the GATT 1994 through a "back door"?

This controversial issue has not been thoroughly addressed yet in the WTO dispute settlement jurisprudence under the GATT 1994. It has been discussed, however, although quite collaterally, by the Panel in Argentina - Hides and Leather. One of the aspects of this case was Argentina's regulation authorising representatives of the Argentinean tanning industry to be present during custom clearance procedures for the export of bovine hides by slaughterhouses and other meat producers. ${ }^{335}$ The EU (a complainant) argued that such an authorization in practice amounted to a de facto export restriction on bovine hides in Argentina enforced by the private tanning industry cartel, which was in violation of Article XI:1 of the GATT 1994. In addition, the EU also argued that this regulation violated GATT Article $\mathrm{X}: 3(\mathrm{a})$, because it constituted the administration of a law in a manner that is not "uniform, impartial and reasonable".

The Panel first noted that export restrictions of de facto nature were, undoubtedly, covered by the GATT Article XI:1. ${ }^{336}$ It also pointed out that "[i]

335 Bovine hides are a by-product of meat production by slaughterhouses, and are then purchased by tanneries, which turn the hides into tanned leather.

336 Panel Report, Argentina - Hides and Leather, para. 11.17. 
$\mathrm{t}$ is well-established in GATT/WTO jurisprudence that only governmental measures fall within the ambit of Article XI:1" ${ }^{337}$ However, the Panel then referred to the previous Panel's statement in Japan - Film that there is no bright-line rules distinguishing between governmental and private actions, and that the distinction shall be made on a case-by-case basis depending on the level of governmental involvement or incentives for a private action. ${ }^{338}$ After agreeing with this statement in general, the Panel further observed:

However, we do not think that it follows either from that panel's statement or from the text or context of Article XI:1 that Members are under an obligation to exclude any possibility that governmental measures may enable private parties, directly or indirectly, to restrict trade, where those measures themselves are not trade restrictive. [...]

As we understand it, Article XI:1 does not incorporate an obligation to exercise "due diligence" in the introduction and maintenance of governmental measures beyond the need to ensure the conformity with Article XI: 1 of those measures taken alone. $^{339}$

Thus, the Panel refused to read in Article XI:1 of the GATT 1994 a positive "due diligence" obligation of WTO Members to discipline private behaviour, e.g. preventing cartels and other anticompetitive practices. Finally, it found that the EU did not establish with sufficient evidence "that there is an export restriction made effective by the measure in question within the meaning of Article XI:1 of the GATT 1994" ${ }^{340}$ However, in the end, the Panel did find a violation of Article X:3(a) of the GATT 1994 by Argentina and concluded that the measure did not constitute the administration of "laws, regulations, decisions and rulings" in an "impartial and reasonable" manner. ${ }^{341}$

The Appellate Body has not had a chance yet to comment on this ruling by the Panel. ${ }^{342}$ Arguably, it seems that in some circumstances, the serious failure to act by a WTO Member might be captured by certain key provisions

337 Panel Report, Argentina - Hides and Leather, para. 11.18.

338 Panel Report, Japan - Film, para. 10.56. For more information on this case, see Section 3.2.2.1.1 of the present Chapter.

339 Panel Report, Argentina - Hides and Leather, para. 11.19 and footnote 336.

340 Panel Report, Argentina - Hides and Leather, para. 11.55. See also on this case: Samir R. Gandhi, "Disciplining Voluntary Environmental Standards at the WTO: An Indian Legal Viewpoint", Working Paper No.181, Indian Council for Research on International Economic Relations, 2006, p. 19.

341 See: Panel Report, Argentina - Hides and Leather, paras. 11.100 - 11.101. For more information about the obligations of Article X:3(a) of the GATT 1994, see Section 3.3.2.2 of the present Chapter.

342 The Panel Report in Argentina - Hides and Leather was not appealed. 
of the GATT 1994, e.g. arbitrary or discriminatory non-enforcement or misapplication of domestic legal rules. ${ }^{343}$ However, in view of the Panel's ruling in Argentina - Hides and Leather, it is doubtful that WTO Members have positive obligations to act with respect to the development, adoption and application of private-sector standards under the GATT 1994. Indeed, it seems unlikely that such important and far-reaching "due diligence" obligations for the Members could be brought into the WTO system through a "back door" without explicit legal provisions in this respect.

\subsubsection{Temporal Scope of Application of the GATT 1994}

The GATT 1947 was provisionally adopted by GATT Contracting Parties through the Protocol of Provisional Application (PPA). According to the PPA, Part II of the GATT 1947, which contains essential provisions such as national treatment obligation and the elimination of quantitative restrictions, applied only to the extent that they were not inconsistent with existing legislation of the Contracting Parties. ${ }^{344}$ In other words, the PPA allowed Parties to retain their existing legislation, which was inconsistent with Part II of the GATT 1947.345 This existing legislation exception, also known as the "grandfather rights exception", provided a "safe haven" for the old trade-restrictive laws and regulations of the GATT Contracting Parties and thus did not work in favour of the effectiveness of the system. It is, however, fair to say that the role of this "grandfather right exception" has decreased over the years, as Contracting Parties gradually updated their trade laws and regulations.

However, the situation has changed with the completion of the Uruguay Round and with the adoption of the GATT 1994. The GATT 1994 is applicable in full and does not contain the "grandfather right exceptions".

343 See: Jan Bohanes, Iain Sandford, "The (Untapped) Potential of WTO Rules to Discipline Private Trade-Restrictive Conduct”, Inaugural Conference, Society of International Economic Law, 56/08, Geneva, July, 15-17, 2008, p. 53.

344 The PPA was used in order to avoid difficulties with national ratifications of the GATT 1947. The difficulties were due to the delay (and finally - failure) of the negotiations with respect to the establishment of the International Trade Organization (ITA) which was supposed to provide an institutional framework for the GATT 1947. Thus, according to the PPA, Part I (containing the MFN obligations and tariff schedules) and Part III (mostly containing procedural provisions) of the GATT 1947 were applied in full; and the provisions of Part II (which could require considerable modifications of national legislations of the Contracting Parties) were applied with limitations related to existing national legislations. See: Peter Van den Bossche, Werner Zdouc, The Law and Policy of the World Trade Organization. Text, Cases and Materials, 3d Edition, CUP, 2013, p. 77.

345 However, Contracting Parties were not allowed to adopt new legislation, which would be inconsistent with Part II of the GATT 1947 after its provisional application commenced. 
As a result, WTO Members are obliged to review their measures adopted before the GATT 1994 with respect to their consistency with the provisions of this Agreement if such measures are still in force. Thus, in terms of the temporal scope of application, the GATT 1994 could be applicable to private-sector standards which are currently applied in markets, regardless of the actual date of their development and adoption. In any case, it is worth noting that the proliferation of private-sector standards is a rather recent phenomenon, and the temporal scope of the GATT 1994 could hardly be seen as a problematic issue in this regard.

\subsection{Attribution of Private Conduct to WTO Members}

The GATT 1994, as well as other WTO agreements, generally applies to measures adopted and applied by WTO Members. ${ }^{346}$ However, neither the GATT 1994, nor other relevant WTO agreements directly provides which measures are to be regarded as those of the Members. In other words, the WTO agreements per se do not contain general provisions specifically devoted to the issues of "attribution" of various acts to WTO Members. ${ }^{347}$ Thus, before examining the specific obligations of the GATT 1994 with the aim of identifying to what extent they might be relevant for the regulation of private-sector standards, it is useful to consider the general rules on attribution as applied by international courts and tribunals, as well as the existing practice of WTO dispute settlement in this regard.

It is a matter of fact that WTO law is not a self-contained legal regime, and other norms of public international law may therefore play a significant role in it as well. In fact, WTO law belongs to the overall system of public international law and constitutes an important, and, arguably, one of the most developed and enforceable parts of this system. In this regard, Joost Pauwelyn provides for multiple examples when WTO panels and the Appellate Body "referred to and applied other rules of international law in examining WTO claims", including, among others, the international

346 Some parts of the following discussion in this Section are based on: "Private Actors in the Light of the Rules of General Customary International Law and WTO Law: Prospects for Responsibility of WTO Members for Private Actions”, Background note, prepared by the author during his internship at the Legal Affairs Division, the WTO Secretariat, under the guidance and supervision of Prof. Gabrielle Marceau and Ms. Aegyoung Jung.

347 According to the Oxford Dictionary the verb "attribute" means "regard something as being caused by something"; see: Oxford Dictionaries online, available at http://oxforddictionaries.com (last visited January 15, 2015). Similarly, in the context of the international rules on State responsibility, it is said that an act is "attributable" to a State if, according to appropriate criteria, it is demonstrated that the act was caused by the State, i.e. could be regarded as an act of the State. 
law rules on burden of proof, treaty interpretation and State responsibility. ${ }^{348}$ Indeed, as has been eloquently noted by the Appellate Body in US Gasoline, the rules of WTO law in general, and the rules of the GATT 1994 in particular, are "not to be read in clinical isolation from public international law". 349

Considering therefore that the large majority of WTO Members are States, the customary international law rules on the attribution of acts to States might be quite relevant with respect to issues of attribution of measures to WTO Members. In this regard, the general rules of customary international law devoted to the attribution of acts to States may be viewed as lex generalis in relation to the WTO rules. Consequently, if the rules of a particular WTO agreement deviate from the general customary rules of international law or provide more specific criteria concerning the attribution of measures to WTO Members, such rules may be viewed as lex specialis with respect to the customary rules. 350 The following sections will address the lex generalis and lex specialis on the issue of attribution of measures to WTO Members. The relevant rules of the TBT Agreement and the SPS Agreement deserve special attention in the context of attribution of private-sector standards to WTO Members and thus will be discussed separately in Chapters IV and V of the present study.

\subsubsection{Attribution of Private Conduct to States Under the General Rules of Customary International Law}

It is widely recognised that certain general customary law rules on the attribution of acts to States are found in the Articles on Responsibility of States for Internationally Wrongful Acts (ILC Articles), adopted by the International Law Commission (ILC). ${ }^{351}$ The ILC Articles were then

348 See: Joost Pauwelyn, "The Role of Public International Law in the WTO: How Far Can We Go?”, American Journal of International Law, 95, 2001, pp. 562 - 563.

See also: Peter Van den Bossche, Werner Zdouc, The Law and Policy of the World Trade Organization. Text, Cases and Materials, 3d Edition, CUP, 2013, pp. 60 - 61.

349 Appellate Body Report, US - Gasoline, p. 17. This statement was made by the Appellate Body with respect to the customary international law rules on treaty interpretation as referred to in Article 3.2 of the DSU. It reflects the clear recognition that certain rules of public international law may play an important role in the WTO context.

350 See: Santiago Villalpando, "Attribution of Conduct to the State: How Rules of State Responsibility May Be Applied Within the WTO Dispute Settlement System”, Journal of International Economic Law, 5(2), 2002, pp. 407 - 408.

351 The ILC was established by the UN General Assembly in 1948 with the mandate of "the promotion of the progressive development of international law and its codification". See: Article 1(1) of the Statute of the International Law Commission, Adopted by the General Assembly in Resolution 174 (II) of 21 November 1947. 
"noted" by the UN General Assembly "without prejudice to the question of their future adoption or other appropriate action". ${ }^{352}$

Arguably, not all of the provisions of the ILC Articles reflect the norms of customary international law; indeed, some of them may represent the restatement of the "progressive development" of international law as this is provided in the mandate of the ILC. However, many of the ILC Articles have been recognized to reflect the rules of customary international law in the jurisprudence of the International Court of Justice (ICJ). In particular, this is the case with a large majority of the ILC Articles devoted to attribution of acts to States. ${ }^{353}$ Moreover, WTO panels and the Appellate Body have referred to the provisions of the ILC Articles in their rulings on several occasions. $^{354}$

\subsubsection{Conduct of State Organs and Entities Exercising Elements of Governmental Authority}

According to Articles 4 and 5 of the ILC Articles, States are responsible for the measures adopted and enforced by their organs and persons or entities exercising elements of governmental authority. The Articles read as follows:

\section{Article 4. Conduct of organs of a State}

1. The conduct of any State organ shall be considered an act of that State under international law, whether the organ exercises legislative, executive, judicial or any other functions, whatever position it holds in the organization of the State, and whatever its character as an organ of the central Government or of a territorial unit of the State.

352 See: Responsibility of States for Internationally Wrongful Acts, Resolution adopted by the UN General Assembly, A/RES/56/83, 2002. See also: Articles on Responsibility of States for Internationally Wrongful Acts, ILC, UN Doc. A/56/10, 2001.

353 For example, the ICJ found that the rules of Articles 4 and 8 of the ILC Articles reflect the rules of customary international law in Case Concerning the Application of the Convention on the Prevention and Punishment of the Crime of Genocide (Bosnia and Herzegovina v. Serbia and Montenegro), Merits, ICJ Reports 2007, paras. 385, 398. The same findings were made by the ICJ with respect to Article 5 of the ILC Articles in Case Concerning Armed Activities on the Territory of the Congo (Democratic Republic of the Congo v. Uganda), Merits, ICJ Reports 2005, para. 160.

354 For instance, with respect to the ILC Articles' provisions on attribution, see: Panel Report, Canada-Dairy, para. 7.77, footnote 427; Appellate Body Report, US - Countervailing Duty Investigation on DRAMS, paras. 112, 116; Appellate Body Report, US - Anti-Dumping and Countervailing Duties (China), para. 310. With respect to the ILC Articles' provisions on proportionality of countermeasures, see: Appellate Body Report, US - Cotton Yarn, para. 120, footnote 90. 
2. An organ includes any person or entity which has that status in accordance with the internal law of the State.
Article 5. Conduct of persons or entities exercising elements of governmental authority

The conduct of a person or entity which is not an organ of the State under article 4 but which is empowered by the law of that State to exercise elements of the governmental authority shall be considered an act of the State under international law, provided the person or entity is acting in that capacity in the particular instance. ${ }^{355}$

Article 4 of the ILC Articles apparently attributes to a State the actions of all its organs. According to paragraph 2 of this Article, in order to find out which entities constitute organs of a State, it is necessary to look into the national legislation of the State. However, the term "includes" in paragraph 2 of Article 4 indicates that the provisions of internal law of a State are not fully conclusive in this respect, and it is necessary to take into account whether an entity acts as an organ of a State in practice. The ILC Commentaries to the ILC Articles provide several examples in this respect. For instance, in some countries police have a special status and is established as a non-governmental body; of course, "this cannot mean that for international law purposes they are not organs of the State". ${ }^{356}$ Therefore, in principle, even a non-governmental entity under appropriate conditions may be regarded as a de facto State organ, which would entail the attribution of its actions to a State.

Furthermore, actions of a non-governmental entity may be attributed to a State if the entity exercises elements of governmental authority according to Article 5 of the ILC Articles. As has been explained by the ILC in the Commentaries, this Article is meant to capture the "increasingly common phenomenon of parastatal entities, which exercise elements of governmental authority in place of State organs". ${ }^{357}$ The ILC also further explained in this respect that the ownership of an entity by a State is not a decisive factor for attribution of its action to the State; the decisive factor is that the entity is empowered by the State "to exercise specified elements of governmental authority". 358

355 See: Articles on Responsibility of States for Internationally Wrongful Acts, ILC, UN Doc. A/56/10, 2001, Articles 4 and 5.

356 Commentaries on the Articles on Responsibility of States for Internationally Wrongful Acts, International Law Commission, UN Doc. 1/56/10, 2001, commentaries to Article 4, para. 11. See also: Case Concerning the Application of the Convention on the Prevention and Punishment of the Crime of Genocide (Bosnia and Herzegovina v. Serbia and Montenegro), Merits, ICJ Reports 2007, paras. 390 - 395.

357 Ibid., commentaries to Article 5, para. 1.

358 Ibid., commentaries to Article 5, para. 3. 
According to the Commentaries, Article 5 "does not attempt to identify precisely the scope of "governmental authority" for the purpose of attribution of the conduct of an entity to the State"; and the scope of this term "depends on the particular society, its history and traditions". ${ }^{359}$ Thus, the attribution of acts to a State under the rules of Article 5 may be accomplished only on a case-by-case basis. In addition, it is also worth noting that, according to Article 7 of the ILC Articles, the conduct of a State organ or of an entity empowered to exercise elements of the governmental authority, is attributable to the State even if it "exceeds its authority or contravenes instructions".

\subsubsection{Conduct Directed or Controlled by a State, or Accepted by a State as Its Own}

Articles 8 and 11 of the ILC Articles further provide that acts or omissions may be attributable to a State if the measure is adopted or enforced by other persons and entities acting under the direction or control of a State, or if a State acknowledged and adopted this measure as its own. The Articles read as follows:

\section{Article 8. Conduct directed or controlled by a State}

The conduct of a person or group of persons shall be considered an act of a State under international law if the person or group of persons is in fact acting on the instructions of, or under the direction or control of, that State in carrying out the conduct.

Article 11. Conduct acknowledged and adopted by a State as its own

Conduct which is not attributable to a State under the preceding articles shall nevertheless be considered an act of that State under international law if and to the extent that the State acknowledges and adopts the conduct in question as its own. ${ }^{360}$

The provisions of Article 8 of the ILC Articles deserve particular attention with regard to the issue of attribution of private actions to States. As noted in the Commentaries to the ILC Articles, as a general principle, private actions are not attributable to States. Nevertheless, in certain circumstances such attribution may be and shall be made - when the "specific factual relationship" exists between a private entity engaging in appropriate conduct and a State, i.e. when the entity acts "on the instructions of, or under the direction or control of" the State. ${ }^{361}$

359 Ibid., commentaries to Article 5, para. 6.

360 See: Articles on Responsibility of States for Internationally Wrongful Acts, ILC, UN Doc. A/56/10, 2001, Articles 8 and 11.

361 Commentaries on the Articles on Responsibility of States for Internationally 
According to the Commentaries to the ILC Articles, "attribution to the State of conduct in fact authorized by it is widely accepted in international jurisprudence". ${ }^{362}$ However, the complex issue which arose before the international courts and tribunals in this respect was the nature of the "specific factual relationship" between a private action and a State. In other words, the question is - what exactly constitutes such "direction or control" exercised by a State over a private entity. As is explained in the Commentaries, the principle of Article 8 "does not extend to conduct which was only incidentally or peripherally associated with an operation and which escaped from the State's direction or control". ${ }^{363}$

The degree of control, which must be exercised by a State for the attribution of the private conduct to it, was one of the key issues considered by the ICJ in the renowned Nicaragua case. In this case the question was whether all the actions of the contras (the insurgent group in Nicaragua), including the claimed grave violations of international humanitarian law, were attributable to the US due to the general financial, military and organizational support provided to the contras by the US. The ICJ, on the one hand, held that the US was responsible for general "planning, direction and support" provided to the contras but, on the other hand, rejected the broader claims of Nicaragua that all the conduct of the contras was attributable to the US. ${ }^{364}$ This was due to the absence of proof of "effective control" exercised by the US over the contras. In particular, the ICJ observed in this regard:

Yet despite the heavy subsidies and other support provided to them by the United States, there is no clear evidence of the United States having actually exercised such a degree of control in all fields as to justify treating the contras as acting on its behalf. $[\ldots]$

All the forms of United States participation mentioned above, and even the general control by the respondent State over a force with a high degree of dependency on it, would not in themselves mean, without further evidence, that the United States directed or enforced the perpetration of the acts contrary to human rights

Wrongful Acts, International Law Commission, UN Doc. 1/56/10, 2001, commentaries to Article 8, para. 1. See also: Rüdiger Wolfrum, "State Responsibility for Private Actors: An Old Problem of Renewed Relevance", at: Maurizio Ragazzi, International Responsibility Today: Essays in Memory of Oscar Schachter, Martinus Nijhoff Publisher, Leiden, 2005, pp. 427 - 429. commentaries to Article 8, para. 2.

364 Military and Paramilitary Activities in and against Nicaragua (Nicaragua v. United States of America), Merits, ICJ Reports 1986, para. 292 (3) - (5), (9). 
and humanitarian law alleged by the applicant State. Such acts could well be committed by members of the contras without the control of the United States. For this conduct to give rise to legal responsibility of the United States, it would in principle have to be proved that that State had effective control of the military or paramilitary operations in the course of which the alleged violations were committed..$^{365}$

The "effective control" test for attribution of private actions to States was later reaffirmed in further jurisprudence of the ICJ, e.g. in the Bosnian Genocide case. ${ }^{366}$

Interestingly, however, quite a different approach was taken with respect to the issue of "control" by the Appeals Chamber of the International Tribunal for the Former Yugoslavia (ICTY); although this was also done in rather different context, namely the criminal responsibility of individuals under international criminal law, and not in the context of State responsibility. In the Tadic case considered by the ICTY, the issue of "control" arose in connection with the question of whether the armed conflict in Bosnia and Herzegovina was an international one. The affirmative conclusion in this respect would make the appropriate norms of international humanitarian law (the Geneva Conventions) on the treatment of "protected persons" applicable to the case at hand. ${ }^{367}$

In considering whether the conflict was international, it was necessary to determine whether the authorities of the Former Republic of Yugoslavia (FRY) exercised "control" over the Bosnian Serb Army, which was heavily involved in the armed conflict. The Trial Chamber of the ICTY applied the "effective control" test established by the ICJ in the Nicaragua case, and found that there was no sufficient evidence proving that such a degree of control was in place during the appropriate time of the conflict. ${ }^{368}$ However, on appeal, the Appeals Chamber of the ICTY disagreed with this approach and stated:

The requirement of international law for the attribution to States of acts performed by private individuals is that the State exercises control over the individuals. The degree of control may, however, vary according to the factual circumstances of each

365 Military and Paramilitary Activities in and against Nicaragua (Nicaragua v. United States of America), Merits, ICJ Reports 1986, paras. 109 and 115.

366 Case Concerning the Application of the Convention on the Prevention and Punishment of the Crime of Genocide (Bosnia and Herzegovina v. Serbia and Montenegro), Merits, ICJ Reports 2007, paras. $400-401$.

367 See: Case IT-94-1-A, Prosecutor v. Tadić, ICTY, Appeals Chamber, 15 July 1999, paras. $83-87$.

368 See: Case IT-94-1-T, Prosecutor v. Tadić, Trial Chamber, 7 May 1997, paras. 595, $607-608$. 
case. The Appeals Chamber fails to see why in each and every circumstance international law should require a high threshold for the test of control. [...]

In the case at issue, given that the Bosnian Serb armed forces constituted a "military organization", the control of the FRY authorities over these armed forces required by international law for considering the armed conflict to be international was overall control going beyond the mere financing and equipping of such forces and involving also participation in the planning and supervision of military operations. By contrast, international rules do not require that such control should extend to the issuance of specific orders or instructions relating to single military actions, whether or not such actions were contrary to international humanitarian law. ${ }^{369}$

Thus, the Appeals Chamber of the ICTY found that, at least in the context of the criminal responsibility of individuals under international law, the "effective control" test adopted by the ICJ was not appropriate, and instead the Chamber developed the so-called "overall control" test. ${ }^{370}$ However, as is quite clear from the statement by the Appeals Chamber cited above, the "overall control" test, although not as strict as the former one, still imposes quite a substantial burden of proof for attribution of private conduct to a State.

In addition, according to the ILC, the determination of the existence and the degree of control exercised by a State over a private entity depends on the circumstances of each particular case. Indeed, as has been explained in the Commentaries to the ILC Articles:

In any event it is a matter for appreciation in each case whether particular conduct was or was not carried out under the control of a State, to such an extent that the conduct controlled should be attributed to it. ${ }^{371}$

Furthermore, the Commentaries to the ILC Articles explain, with respect to Article 8, that the ownership of a legal entity by a State per se does not necessarily mean that the conduct of the entity is instructed, directed or controlled by the State within the meaning of Article 8, and therefore does

369 Case IT-94-1-A, Prosecutor v. Tadić, Appeals Chamber, 15 July 1999, paras. 117, 145.

370 See: Commentaries on the Articles on Responsibility of States for Internationally Wrongful Acts, International Law Commission, UN Doc. 1/56/10, 2001, commentaries to Article 8, para. 5.

371 Ibid., commentaries to Article 8, para. 5. The Appellate Body, with reference to this statement in the Commentaries, also noted that the "determination of entrustment or direction will hinge on the particular facts of the case"; see: Appellate Body Report, US - Countervailing Duty Investigation on DRAMS, para. 116. 
not necessary entail attribution of the conduct to the State. Indeed, according to the Commentaries, the conduct of a State-owned entity may be attributable to a State only if the entity exercises elements of governmental authority within the meaning of Article 5 of the ILC Articles:

$[\ldots]$ international law acknowledges the general separateness of corporate entities at the national level, except in those cases where the "corporate veil" is a mere device or a vehicle for fraud or evasion. The fact that the State initially establishes a corporate entity, whether by a special law or otherwise, is not a sufficient basis for the attribution to the State of the subsequent conduct of that entity. Since corporate entities, although owned by and in that sense subject to the control of the State, are considered to be separate, prima facie their conduct in carrying out their activities is not attributable to the State unless they are exercising elements of governmental authority within the meaning of article $5 .{ }^{372}$

Finally, Article 11 of the ILC Articles quoted above, provides that private conduct may be attributed to a State if this conduct is acknowledged or adopted by the State as its own. This basis for the attribution of an act to a State was confirmed, for instance, by the ICJ in the renowned Tehran Hostages case. As noted in the Commentaries to the ILC Articles, in this case the ICJ "drew a clear distinction between the legal situation immediately following the seizure of the United States embassy and its personnel by the militants, and that created by a decree of the Iranian State which expressly approved and maintained the situation". ${ }^{373}$ In particular, the ICJ observed:

The approval given to these facts by the Ayatollah Khomeini and other organs of the Iranian State, and the decision to perpetuate them, translated continuing occupation of the Embassy and detention of the hostages into acts of that State. ${ }^{374}$

Thus, it can be concluded that the rules of customary international law recognize the possibility of attribution of private actions to States. However, clearly such attribution is subject to quite strict requirements affecting the relationship between a State and a non-State actor, including explicit instructions from a State to a non-State actor and the delegation of power

372 Ibid., commentaries to Article 8, para. 6, referring to: Barcelona Traction, Light and Power Company, Limited, Second Phase, I.C.J. Reports 1970, p. 39, para. 56-58. The Commentaries on the ILC Articles with respect to this issue were also referred to by the Appellate Body in: Appellate Body Report, US - Anti-Dumping and Countervailing Duties (China), para. 310; Appellate Body Report, US - Countervailing Duty Investigation on DRAMS, para. 112, footnote 179.

373 Ibid., commentary to Article 11, para. 4.

374 United States Diplomatic and Consular Staff in Tehran, Merits, ICJ Reports 1980, para. 74 . 
from a State to a non-State actor. ${ }^{375}$ At the same time, the differences in approaches taken by the ICJ and the ICTY in dealing with the issue of "control" exercised by a State over a private actor under Article 8 of the ILC Articles, demonstrate that the context and the subject of a dispute may have significant effects on the issue of attribution.

In this regard it could therefore be argued that the degree of control required from WTO Members for attribution of private actions to them in trade disputes might not be the same as (and might even be considerably different to), for example, in cases of attribution of genocide or other grave human rights violations to States. ${ }^{376}$ The following sections will discuss the existing practice of attribution of non-governmental actions to WTO Members under the GATT 1994 and some other WTO agreements.

\subsubsection{Attribution of Private Conduct to WTO Members Under the GATT 1994 and Certain Other WTO Agreements}

As has been explained, the GATT 1994, as well as other WTO agreements, does not contain its own general rules of attribution of measures to WTO Members. However, if private measures were to be non-attributable to WTO Members under any circumstances, undoubtedly this would open opportunities for abuses, since WTO Members could then disguise their own measures as non-governmental ones. Therefore, it is quite clear that non-governmental measures under certain conditions may be and shall be attributed to WTO Members. Indeed, this may be done based on the relevant provisions of the WTO agreements alone, or taken together with the rules of general customary international law devoted to attribution of acts to States, as has been discussed above. The following sections address the relevant rules and the dispute settlement practice on the attribution of non-governmental measures to WTO Members under the GATT 1994 and some other WTO agreements. The relevant provisions of the TBT Agreement and the SPS Agreement are discussed separately and in detail in Chapters IV and V of the present study.

375 See: Rex J. Zedalis, "When Do the Activities of Private Parties Trigger WTO Rules?”, Journal of International Economic Law, 10(2), 2007, pp. 352 - 353.

376 See: Alberto Alvarez-Jimenez, "International State Responsibility for Acts of Non-State Actors: The Recent Standards Set by the International Court of Justice in Genocide and why the WTO Appellate Body Should not Embrace them", Syracuse Journal of International Law and Commerce, 35, 2007, pp. 24 - 25. See also: Rüdiger Wolfrum, "State Responsibility for Private Actors: An Old Problem of Renewed Relevance", at: Maurizio Ragazzi, International Responsibility Today: Essays in Memory of Oscar Schachter, Martinus Nijhoff Publisher, Leiden, 2005, p. 429. 


\subsubsection{Practice on the Attribution of Private Conduct Under the GATT 1994}

As has been explained in Section 3.1.2.1 of this Chapter, the key disciplines of the GATT 1994 are applicable to the measures adopted and applied by WTO Members, i.e. by their organs. Thus, the important question in this regards is whether the actions by private actors may nonetheless be considered as actions of WTO Members in the absence of explicit provisions on this respect in the GATT 1994. Moreover, the GATT 1994 contains some special rules on the attribution of behaviour of so-called "State Trading Enterprises" (STEs) to WTO Members. The following sections discuss the general issue of attribution of private conduct to WTO Members under the GATT 1994, as well as the more specific issue of attribution of STEs' conduct.

\subsection{General Approach to the Attribution of Private Conduct Under the GATT 1994}

The issue of attribution of private actions to WTO Members under the GATT 1994, as discussed in Section 3.1.2, could indeed be viewed as forming a part of the personal scope of application of the GATT 1994. The present Section further elaborates on the third issue raised in Section 3.1.2, namely when private conduct may be attributable to a WTO Member under the GATT 1994.

The issue of attribution under the GATT has arisen several times before GATT and WTO dispute settlement panels. ${ }^{377}$ The renowned Japan - Semi-Conductors dispute considered by a GATT Panel was concerned with the actions by the Japanese semi-conductor industry, but where the Japanese government was involved "behind the scene". In this dispute the EU challenged the voluntary export restraints imposed by the Japanese industry on the exports of semi-conductors to the US, following the informal pressures by the US industry and the US government. ${ }^{378}$ Japan argued that the measure was only a private self-enforced measure and was thus not challengeable under the GATT in general or its Article XI:1 in particular. ${ }^{379}$ The Panel disagreed and after reviewing the measures at hand finally came to the following conclusions:

All these factors led the Panel to conclude that an administrative structure had been created by the Government of Japan which

377 See: Rex J. Zedalis, "When Do the Activities of Private Parties Trigger WTO Rules?”, Journal of International Economic Law, 10(2), 2007, pp. 340 - 437; Petros C. Mavroidis, Trade in Goods. The GATT and the Other WTO Agreements Regulating Trade in Goods, OUP, Oxford, 2012, pp. 71 - 72.

378 See: GATT Panel Report, Japan-Semi-Conductors, paras. 33, 49.

379 See: GATT Panel Report, Japan - Semi-Conductors, para. 102. 
operated to exert maximum possible pressure on the private sector to cease exporting at prices below company-specific costs. [...] The Panel considered that the complex of measures exhibited the rationale as well as the essential elements of a formal system of export control. The only distinction in this case was the absence of formal legally binding obligations in respect of exportation or sale for export of semi-conductors. However, the Panel concluded that this amounted to a difference in form rather than substance because the measures were operated in a manner equivalent to mandatory requirements. ${ }^{380}$

Thus, the voluntary private export restrictions on the export of semi-conductors were attributed to Japan; and Japan was found to be in violation of Article XI: 1 of the GATT. ${ }^{381}$

A similar line of argumentation was followed by the GATT Panel in EEC - Dessert Apples. In this case the Panel considered two systems of regulation of prices on apples existing on the European Economic Community (EEC, now EU) common market: direct buying-in of apples by authorities of EEC Member State and withdrawals of product from the market by producer groups (i.e. private actors). The Panel finally concluded that both the buying-in and the withdrawal systems established for apples in the EEC shall be regarded as measures attributable to the EEC for the purposes of Article XI of the GATT. ${ }^{382}$ In this respect the Panel noted:

$[\ldots]$ the EEC internal regime for apples was a hybrid one, which combined elements of public and private responsibility. Legally there were two possible systems, direct buying-in of apples by Member State authorities and withdrawals by producer groups. Under the system of withdrawals by producer groups, which was the EEC's preferred option, the operational involvement of public authorities was indirect. ${ }^{383}$

Later, after the establishment of the WTO, the GATT case law discussed above was referred to by the Panel in Japan - Film, when the Panel again had to deal with the issue of attribution of private actions to WTO Members under the GATT 1994. The Panel generally observed in this respect:

Our review of GATT jurisprudence [...] teaches that where administrative guidance creates incentives or disincentives largely dependent upon governmental action for private parties

380 GATT Panel Report, Japan-Semi-Conductors, para. 117.

381 See: GATT Panel Report, Japan-Semi-Conductors, para. 132.

382 GATT Panel Report, EEC - Dessert Apples, para. 12.9.

383 GATT Panel Report, EEC - Dessert Apples, para. 12.9. 
to act in a particular manner, it may be considered a governmental measure. $^{384}$

In this dispute the US challenged three broad categories of measures claimed to be applied by Japan: 1. distribution measures, which allegedly encouraged and facilitated the creation of a market structure for photographic film and paper in which imports were excluded from traditional distribution channels; 2. restrictions on large retail stores, which allegedly restricted the growth of an alternative distribution channel for imported film; and 3. promotion measures, which allegedly disadvantaged imports by restricting the use of sales promotion techniques. The US alleged that these measures, individually and collectively, were inconsistent with GATT Article XXIII:1(b) (so-called "non-violation complaints") and with GATT Article III:4 (national treatment obligation). ${ }^{385}$

The Panel dealing with the US claims considered whether the actions of private enterprises in Japan, allegedly restricting the distribution and marketing of imported film products, could be attributed to Japan. The Panel first noted that "the WTO Agreement is an international agreement, in respect of which only national governments and separate customs territories are directly subject to obligations"; and therefore "it follows by implication that the term measure in Article XXIII:1(b) and Article 26.1 of the DSU, as elsewhere in the WTO Agreement, refers only to policies or actions of governments, not those of private parties" ${ }^{386}$ However, after considering the relevant preceding GATT cases, as discussed above, the Panel made the following renowned statement:

These past GATT cases demonstrate that the fact that an action is taken by private parties does not rule out the possibility that it may be deemed to be governmental if there is sufficient government involvement with it. It is difficult to establish brightline rules in this regard, however. Thus, that possibility will need to be examined on a case-by-case basis. ${ }^{387}$

Indeed, this observation of the Panel deserves particular attention. It seems reasonable to assume that government intervention into or incentives for private behaviour must be considered for the purposes of attribution of this behaviour in the context of the overall regulatory environment of a particular WTO Member. And since there are no WTO Members with exactly the same regulatory systems and traditions, it is hardly possible to establish general rules or criteria for the attribution of private behaviour which

\footnotetext{
384 Panel Report, Japan - Film, para. 10.45.

385 See: Panel Report, Japan - Film, paras. 10.22 - 10.24.

386 Panel Report, Japan - Film, para. 10.52.

387 Panel Report, Japan-Film, para. 10.56.
} 
would be applicable in all types of situations. In this regard, the evaluation of the governmental involvement or incentives may be and shall be accomplished only on a case-by-case basis and through the prism of regulatory traditions and the environment of each particular WTO Member.

Furthermore, while considering the particular measures allegedly taken by Japan, the Panel found that a number of Japan's governmental reports, manuals and surveys contained merely general policy recommendations and were often directed at the government rather than trade operators. Thus, the Panel concluded that they did not provide meaningful incentives or disincentives for the behaviour of private actors. ${ }^{388}$ At the same time, a number of Japanese acts were found by the Panel to provide such incentives or disincentives and could therefore be regarded as "measures" within the meaning of the GATT 1994. ${ }^{389}$ However, in the end the Panel concluded that the US failed to demonstrate that Japan's measures nullified or impaired benefits accruing to the US within the meaning of the GATT Article XXIII:1(b), or accorded less favourable treatment to imported photographic film and paper within the meaning of the GATT Article III:4. ${ }^{390}$

It is also worth noting that if the private conduct does not receive meaningful governmental involvement or incentives, it may not be attributed to a WTO Member. In this respect, one may recall the statement by the Appellate Body in Korea - Various Measures on Beef quoted above that private behaviour, if it "is not imposed directly or indirectly by law or governmental regulation, but is rather solely the result of private entrepreneurs acting on their own calculations of comparative costs and benefits", may not constitute a violation of the GATT Article III: $4 .{ }^{391}$ Similarly, and more recently, the Panel in China-Publications and Audiovisual Products did not find a violation of the GATT Article III:4 with respect to the distribution duopoly for film products in China. This was because the US (a complainant) failed to demonstrate that the distribution duopoly was created, either de facto or de jure, by China's rules and regulations. According to the Panel:

In other words, the United States has not established that the distribution duopoly is attributable to China. As the duopoly is not attributable to China it is not a "measure" of another Member

Sandford, “The (Untapped) Potential of WTO Rules to Discipline Private TradeLaw, 56/08, Geneva, July, 15-17, 2008, pp. 23-24.

391 Appellate Body Report, Korea - Various Measures on Beef, para. 149. See also Section 3.1.2.1 of the present Chapter. 
that can be challenged before the WTO dispute settlement system..$^{392}$

Thus, arguably, the practice of GATT and WTO panels on the attribution of private actions to WTO Members under the GATT in general followed an analogous approach to the one established by the general rules of customary international law on attribution as reflected in the ILC Articles on State Responsibility. Just like Article 8 of the ILC Articles requires the direction or control exercised by a State over private actors for the attribution of their conduct to it, GATT and WTO panels required the existence of sufficient nexus between the private conduct and a WTO Member, i.e. the existence of sufficient governmental intervention or incentives provided to support the private conduct. ${ }^{393}$ And like the ICJ under the rules of general customary law, GATT and WTO panels concluded that attribution under the GATT could be accomplished only on a case-by-case basis depending on particular circumstances taken in the context of a regulatory environment of a WTO Member.

However, what might appear to be different is the character of the nexus between a government and the private conduct required for the attribution in the context of the general customary international law and WTO law. It is also worth noting in this respect that the WTO Appellate Body has not taken the opportunity as yet to provide authoritative clarifications or guidelines on this complex and controversial issue under the GATT 1994.

\subsection{Attribution of Conduct of State Trading Enterprises Under the GATT 1994}

The text of the GATT 1994 contains one particular example of explicit attribution of non-governmental actions to WTO Members. GATT Article XVII is specially devoted to the behaviour of STEs; and paragraphs (a) - (c) of Article XVII:1 provide in this respect:

(a) Each contracting party undertakes that if it establishes or maintains a State enterprise, wherever located, or grants to any enterprise, formally or in effect, exclusive or special privileges, ${ }^{*}$ such enterprise shall, in its purchases or sales involving either imports or exports, act in a manner consistent with the general principles of non-discriminatory treatment prescribed in this Agreement for governmental measures affecting imports or exports by private traders.

392 Panel Report, China-Publications and Audiovisual Products, para. 7.1693.

393 See: Rex J. Zedalis, "When Do the Activities of Private Parties Trigger WTO Rules?”, Journal of International Economic Law, 10(2), 2007, p. 358. 
(b) The provisions of subparagraph (a) of this paragraph shall be understood to require that such enterprises shall, having due regard to the other provisions of this Agreement, make any such purchases or sales solely in accordance with commercial considerations, ${ }^{*}$ including price, quality, availability, marketability, transportation and other conditions of purchase or sale, and shall afford the enterprises of the other contracting parties adequate opportunity, in accordance with customary business practice, to compete for participation in such purchases or sales.

(c) No contracting party shall prevent any enterprise (whether or not an enterprise described in subparagraph $(a)$ of this paragraph) under its jurisdiction from acting in accordance with the principles of subparagraphs $(a)$ and $(b)$ of this paragraph. ${ }^{394}$

STEs may indeed not only be closely affiliated with WTO Members' governments, but may also perform certain governmental functions. On such occasions the relevant activities of STEs could undoubtedly be attributable to WTO Members as the conduct of State organs or the conduct of persons or entities exercising elements of governmental authority. ${ }^{395}$ Arguably, however, the language of Article XVII addresses the wider range of enterprises, including those which enjoy "exclusive or special privileges" granted by a government.

At the same time, the language of Article XVII seems also to imply the limitations on the scope of the entities regarded as STEs within the meaning of the Article: not every non-governmental entity owned or controlled by the government of a WTO Member could be recognised as an STE. An enterprise qualifies as an STE only if it serves as an agent of governmental policy or enjoys the "exclusive or special privileges". This approach is also acknowledged in the Uruguay Round Understanding on the Interpretation of Article XVII of the GATT 1994, which requires the notification of WTO Members' STEs through the WTO Secretariat. An STE is defined in Section 1 of the Understanding as:

Governmental and non-governmental enterprises, including marketing boards, which have been granted exclusive or special rights or privileges, including statutory or constitutional powers, in the exercise of which they influence through their purchases or sales the level or direction of imports or exports.

394 Ad Article XVII further clarifies the meaning and the status of certain terms under Article XVII, such as Marketing Boards which do or do not purchase or sell products; governmental measures imposed to insure standards of quality and efficiency, etc.

395 As this is provided in Articles 4 and 5 of the ILC Articles on State Responsibility discussed above. 
From this definition it seems that the potential for attribution of private actions to WTO Members under Article XVII of the GATT 1994 is quite limited. ${ }^{396}$ In fact, the Article attributes the actions of private entities to Members only if these entities constitute STEs, i.e. enterprises, which are granted "exclusive or special rights or privileges, including statutory or constitutional powers".

Not surprisingly, the WTO dispute settlement practice followed the same approach. The provisions of Article XVII have been examined by the Panels and the Appellate Body in Canada - Wheat Exports and Grain Imports and in Korea - Various Measures on Beef. The dispute Canada - Wheat Exports and Grain Imports, among other issues, involved the socalled Canadian Wheat Board (CWB) Export Regime which, according to the claims of the US (a complainant), violated the provisions of Article XVII of the GATT 1994. The Panel noted that there was no disagreement between the Parties on whether the Canadian CWB constituted an STE within the meaning of Article XVII. The Panel thus agreed that the CWB is an STE, since " $[t]$ here is no doubt that at least the CWB's exclusive right to sell Western Canadian wheat for export constitutes an "exclusive or special privilege" within the meaning of Article XVII:1(a)" ${ }^{397}$

However, the Panel further concluded that the US had not managed to establish that the Canadian CWB Export Regime resulted in a violation of the general principles of non-discriminatory treatment under the GATT 1994 and thus no violation of Article XVII was found. ${ }^{398}$ These findings were upheld on appeal by the Appellate Body. ${ }^{399}$ The Appellate Body, in its findings, further explained that Article XVII:1(a) of the GATT "sets out an obligation of non-discrimination" and that Article XVII:1(b) "clarifies the scope of that obligation". ${ }^{400}$ Therefore, in this respect and according to the Appellate Body, "panels must identify the differential treatment alleged to be discriminatory under subparagraph (a) in order to ensure that they are undertaking a proper inquiry under subparagraph (b)". ${ }^{401}$

Finally, with regard to the requirement for STEs to act "solely in accordance with commercial considerations", the Appellate Body noted:

396 See: Jan Bohanes, Iain Sandford, "The (Untapped) Potential of WTO Rules to Discipline Private Trade-Restrictive Conduct”, Inaugural Conference, Society of International Economic Law, 56/08, Geneva, July, 15-17, 2008, para. 52.

397 Panel Report, Canada - Wheat Exports and Grain Imports, para. 6.108.

398 See: Panel Report, Canada - Wheat Exports and Grain Imports, paras. 6.151, 7.4(a).

399 See: Appellate Body Report, Canada - Wheat Exports and Grain Imports, para. 214(a):V.

400 Appellate Body Report, Canada-Wheat Exports and Grain Imports, para. 100.

401 Appellate Body Report, Canada - Wheat Exports and Grain Imports, para. 111. 
[...] a panel inquiring whether an STE has acted solely in accordance with commercial considerations must undertake this inquiry with respect to the market(s) in which the STE is alleged to be engaging in discriminatory conduct. Subparagraph (b) does not give panels a mandate to engage in a broader inquiry into whether, in the abstract, STEs are acting "commercially". The disciplines of Article XVII: 1 are aimed at preventing certain types of discriminatory behaviour. We see no basis for interpreting that provision as imposing comprehensive competition-law-type obligations on STEs, as the United States would have us do. ${ }^{402}$

Thus, the Appellate Body upheld the Panel's interpretation of Article XVII:1(b) that the provisions of this Article are applicable to an STE only if it acts as an "agent" of a WTO Member, i.e. if it has been granted exclusive or special rights or privileges, for example, related to the purchase or sale of products. And in this respect, according to Article XVII:1, an STE, while purchasing or selling products, must ensure non-discriminatory treatment of their counteragents - as a rule, commercial enterprises. However, neither WTO Members, nor their STEs per se are obliged according to Article XVII to ensure equal competitive opportunities for the "competitors" of STEs, i.e. the enterprises buying or selling the same products. ${ }^{403}$ In fact, otherwise the mere existence of STEs, which as a rule enjoy exclusive or special rights or privileges in comparison with their competitors, would arguably be illegal under Article XVII:1 of the GATT 1994.

In Korea - Various Measures on Beef the Panel considered the actions of the Korean Livestock Products Marketing Organization (LPMO), a state trading agency, which handled the import of a significant percentage of beef into Korea, set a daily minimum acceptable price, and delegated the sale and auction of that beef, most typically, to the National Livestock Cooperatives Federation (NLCF). The Panel attributed the conduct of the LPMO directly to Korea and found that certain aspects of the LPMO distribution system violated Articles II:1(a), III:4, XI:1 of the GATT 1994.404 Interestingly, however, the Panel also noted that the LPMO was an STE notified by Korea and thus, in addition, found a violation of Article XVII:1(a) by Korea by stating:

Should the LPMO/NCLF not be viewed as having full control over the distribution of its 30 per cent share of Korea's import quota, the Panel considers that, when it delayed its sales of imported beef into the Korean market while having important stocks, the LPMO was not acting "in a manner consistent with the

\footnotetext{
402 Appellate Body Report, Canada - Wheat Exports and Grain Imports, para. 145.

403 See: Appellate Body Report, Canada - Wheat Exports and Grain Imports, paras. $148-151,161,214$.

404 Panel Report, Korea - Various Measures on Beef, paras. 769, 845.
} 
general principles of non-discriminatory treatment prescribed in this Agreement for governmental measures affecting imports or exports by private traders" (Article XVII:1(a)). ${ }^{405}$

Thus, according to Article XVII of the GATT 1994, certain conduct of STEs could be attributed to WTO Members. Arguably such conduct may also include the development or application of standards which affect imports or exports by private traders. However, as has been explained above, an STE within the meaning of Article XVII may be qualified as such only if it serves as an agent of governmental policy or enjoys certain exclusive or special privileges. Taking this into consideration, it seems that a standard adopted and applied by an STE would belong to the public domain rather than to the private one. Accordingly, Article XVII of the GATT 1994 appears to be not very useful with respect to the regulation of private-sector standards.

\subsubsection{Practice on the Attribution of Private Conduct Under Certain Other WTO Agreements}

The GATT is not the only WTO agreement under which the issue of attribution of private conduct to WTO Members has arisen in WTO dispute settlement practice. This complex issue, to a certain extent, was considered by WTO panels and the Appellate Body in a number of disputes under the rules of the WTO SCM Agreement and the Agreement on Agriculture. The following sections discuss the relevant provisions of these Agreements, as well as the relevant findings in the course of the WTO dispute settlement. Although provisions of both these Agreements generally do not fall immediately into the scope of the present study dealing with private-sector standards as technical barriers to international trade in goods, ${ }^{406}$ the following discussion may provide a broader picture and a deeper insight into the rules and practices on attribution of private conduct to Members in the WTO.

\subsection{Attribution of Private Conduct Under the SCM Agreement}

In the SCM Agreement, the provisions relevant for the issue of attribution of private actions to WTO Members may be found in its Article 1.1(a)(1). Article 1.1(a)(1), for the purposes of the definition of a subsidy, explains when a "financial contribution" is considered to be made by a government or any "public body" of a WTO Member. In particular, the relevant part of Article 1.1(a)(1) provides:

405 Panel Report, Korea - Various Measures on Beef, paras. 763, 769. These findings of the Panel were not appealed.

406 On the scope of the present study and the relevant WTO agreements, see Section 1.4 of Chapter I and Section 2.3.4.1 of Chapter II of the present study. 


\section{Article 1. Definition of a Subsidy}

1.1 For the purpose of this Agreement, a subsidy shall be deemed to exist if:

(a)(1) there is a financial contribution by a government or any public body within the territory of a Member (referred to in this Agreement as "government"), i.e. where:

[...] (iv) a government makes payments to a funding mechanism, or entrusts or directs a private body to carry out one or more of the type of functions illustrated in (i) to (iii) above which would normally be vested in the government and the practice, in no real sense, differs from practices normally followed by governments;

In the WTO dispute settlement practice under Article 1.1(a)(1) of the SCM Agreement, the issue of attribution of non-governmental actions to a WTO Member (if the term "governmental" is interpreted in a narrow sense to cover only de jure governmental bodies) first arose in the context of the definition of the term "public body" in this Article. In US - Anti-Dumping and Countervailing Duties (China), the Appellate Body considered whether the Chinese State-owned enterprise (SOE) input producers and the Stateowned commercial banks (SOCBs) were "public bodies" within the meaning of Article 1.1(a)(1).

The Appellate Body noted a clear distinction between a "public body" referred to in Article 1.1(a)(1) and a "private body" referred to in subparagraph (iv) of the same Article, "because the term "private body" describes something that is not "a government or any public body" ". ${ }^{407}$ It further acknowledged that the ownership of an enterprise by a government may indeed be one of the elements of the evidence proving the control exercised by the government over an enterprise. However, according to the Appellate Body, the "control of an entity by a government is, in itself, not sufficient to establish that an entity is a public body". ${ }^{408}$ The Appellate Body further explained in this respect:

We see the concept of "public body" as sharing certain attributes with the concept of "government". A public body within the meaning of Article 1.1.(a)(1) of the SCM Agreement must be an entity that possesses, exercises or is vested with governmental authority. Yet, just as no two governments are exactly alike, the precise contours and characteristics of a public body are bound to differ from entity to entity, State to State, and case to case.

407 Appellate Body Report, US - Anti-Dumping and Countervailing Duties (China), para. 291. See also: Panel Report, US - Export Restraints, para. 8.49.

408 Appellate Body Report, US - Anti-Dumping and Countervailing Duties (China), para. 320. 
Panels or investigating authorities confronted with the question of whether conduct falling within the scope of Article 1.1.(a)(1) is that of a public body will be in a position to answer that question only by conducting a proper evaluation of the core features of the entity concerned, and its relationship with government in the narrow sense. ${ }^{409}$

Therefore, the Appellate Body reversed the findings of the Panel that the term "public body" in the SCM Agreement means "any entity controlled by a government". ${ }^{410}$ It also found that the US Department of Commerce (DOC) acted inconsistently with the SCM Agreement by making conclusions that the Chinese SOE input producers were "public bodies" only on the basis of their State ownership. ${ }^{411}$ On the other hand, however, the Appellate Body did not find inconsistency with the SCM Agreement in the determination made by the US DOC that the Chinese SOCBs acted as "public bodies" since they provided "public loans" on more favourable conditions not based on commercial considerations. In this respect, the Appellate Body observed that the determination by the DOC in relation to the SOCBs was based on quite broader considerations than in the case with the SOE; and "these considerations, taken together, demonstrate that the US DOC's public body determination with respect to SOCBs was supported by evidence on the record that these SOCBs exercise governmental functions on behalf of the Chinese Government". ${ }^{412}$

Thus, as under the general customary international law rules on attribution reflected in the ILC Articles, under the SCM Agreement the fact that an entity is owned or otherwise controlled by a WTO Member does not directly mean that the behaviour of such an entity must be attributable to the Member. The State-owned or controlled entity must be vested with elements of governmental authority in order to constitute a "public body" according to the SCM Agreement. This reasoning in fact is in line with the logic of Article XVII:1 of the GATT 1994 with respect to STEs, as has been described above: WTO Members bear responsibility for actions of STEs

409 Appellate Body Report, US - Anti-Dumping and Countervailing Duties (China), para. 317.

410 See: Appellate Body Report, US - Anti-Dumping and Countervailing Duties (China), para. 322. This finding thus also rejected the approach (analogous to the one taken by the Panel in the present case) adopted by the Panel in Panel Report, KoreaCommercial Vessels, paras. 7.50, 7.352.

411 See: Appellate Body Report, US - Anti-Dumping and Countervailing Duties (China), paras. 340, $346-347$.

412 Appellate Body Report, US - Anti-Dumping and Countervailing Duties (China), para. 355. 
only if the latter are granted "statutory or constitutional powers" or "exclusive or special rights or privileges". ${ }^{413}$

Second, the issue of attribution of non-governmental actions to WTO Members arises under Article 1.1(a)(1) of the SCM Agreement in the context of its subparagraph (iv), cited above, which refers to the occasions when a "private body" is "entrusted" or "directed" by a WTO Member to perform appropriate functions related to the provision of subsidies. In US - Softwood Lumber IV, the Appellate Body discussed a wide range of transactions which fall within the meaning of the "financial contribution" in Article 1.1(a)(1), as outlined in subparagraphs (i) - (iv) of this Article. With respect to subparagraph (iv) the Appellate Body noted:

Paragraph (iv) of Article 1.1(a)(1) recognizes that paragraphs (i) - (iii) could be circumvented by a government making payments to a funding mechanism or through entrusting or directing a private body to make a financial contribution. It accordingly specifies that these kinds of actions are financial contributions as well. ${ }^{414}$

Thus, under the SCM Agreement, the actions of a "private body" are attributable to a WTO Member if the later "entrusts or directs" the private body to provide subsidies, or creates other funding mechanisms with the participation of private actors. Otherwise WTO Members would be able to circumvent the provisions of the SCM Agreement by hiding behind a "private veil" in providing subsidies. Such an approach is also in line with the rules of the general customary international law on the attribution of conduct to States as reflected in the ILC Articles and discussed before.

It is fair to say therefore that, as in the case with Article XVII of the GATT 1994, the options for attribution of private actions to WTO Members under Article 1.1(a)(1)(iv) of the SCM Agreement seem to be quite limited. This in fact was quite clearly explained by the Appellate Body in US - Countervailing Duty Investigation on DRAMS. According to the Appellate Body, "situations involving exclusively private conduct - that is, conduct that is not in some way attributable to a government or public body - cannot constitute a "financial contribution" for purposes of determining

413 See the working definition of an STE in Section 1of the Uruguay Round Understanding on the Interpretation of Article XVII of the GATT 1994.

${ }^{414}$ Appellate Body Report, US - Softwood Lumber IV, para. 52. See also: Appellate Body Report, US - Countervailing Duty Investigation on DRAMS, para. 113. See also: Jan Bohanes, Iain Sandford, "The (Untapped) Potential of WTO Rules to Discipline Private Trade-Restrictive Conduct”, Inaugural Conference, Society of International Economic Law, 56/08, Geneva, July, 15-17, 2008, pp. 10 - 11. 
the existence of a subsidy under the SCM Agreement". ${ }^{415}$ The Appellate Body further pointed out in this regard:

In other words, paragraph (iv) covers situations where a private body is being used as a proxy by the government to carry out one of the types of functions listed in paragraphs (i) through (iii). Seen in this light, the terms "entrusts" and "directs" in paragraph (iv) identify the instances where seemingly private conduct may be attributable to a government for purposes of determining whether there has been a financial contribution within the meaning of the SCM Agreement. ${ }^{416}$

Therefore, according to the Appellate Body, the terms "to entrust" and "to direct" are key for the proper interpretation of Article 1.1(a)(1)(iv) of the SCM Agreement. ${ }^{417}$ After clarifying the meaning of these terms, the Appellate Body observed that "Article 1.1(a)(1)(iv) requires the participation of the government, albeit indirectly" and therefore agreed with Korea that "there must be a demonstrable link between the government and the conduct of the private body". ${ }^{418}$ However, in addition the Appellate Body further noted:

It follows, therefore, that not all government acts necessarily amount to entrustment or direction. We note that both the United States and Korea agree that "mere policy pronouncements" by a government would not, by themselves, constitute entrustment or direction for purposes of Article 1.1(a)(1)(iv).181 Furthermore, entrustment and direction - through the giving of responsibility to or exercise of authority over a private body - imply a more active role than mere acts of encouragement. ${ }^{419}$

Finally, in considering the meaning and the scope of Article 1.1(a)(1)(iv) of the SCM Agreement, the Appellate Body summarized:

In sum, we are of the view that, pursuant to paragraph (iv), "entrustment" occurs where a government gives responsibility

415 Appellate Body Report, US - Countervailing Duty Investigation on DRAMS, para. 107.

416 Appellate Body Report, US - Countervailing Duty Investigation on DRAMS, para. 108.

417 Appellate Body Report, US - Countervailing Duty Investigation on DRAMS, paras. 109 - 111. See also: Panel Report, US - Export Restraints, para. 8.29.

418 Appellate Body Report, US - Countervailing Duty Investigation on DRAMS, para. 112. In several previous cases the Panels found that under Article 1.1(a)(1) (iv) "the action of the government must contain a notion of delegation"; see: Panel Report, US - Export Restraints, paras. 8.28 - 8.30, Panel Report, Korea-Commercial Vessels, para. 7.367.

419 Appellate Body Report, US - Countervailing Duty Investigation on DRAMS, para. 114. See also: Panel Report, US - Export Restraints, para. 8.31. 
to a private body, and "direction" refers to situations where the government exercises its authority over a private body. In both instances, the government uses a private body as proxy to effectuate one of the types of financial contributions listed in paragraphs (i) through (iii). It may be difficult to identify precisely, in the abstract, the types of government actions that constitute entrustment or direction and those that do not. The particular label used to describe the governmental action is not necessarily dispositive. Indeed, as Korea acknowledges, in some circumstances, "guidance" by a government can constitute direction. In most cases, one would expect entrustment or direction of a private body to involve some form of threat or inducement which could, in turn, serve as evidence of entrustment or direction. The determination of entrustment or direction will hinge on the particular facts of the case. ${ }^{420}$

Thus, Article 1.1(a)(1)(iv) of the SCM Agreement is aimed at addressing the situations where a WTO Member uses a private body merely as a "proxy" in pursuing governmental policies on providing subsidies. Whether this is the case may be determined on a case-by-case basis depending on particular circumstances. ${ }^{421}$

\subsection{Attribution of Private Conduct \\ Under the Agreement on Agriculture}

The WTO Agreement on Agriculture also contains a provision relevant for the attribution of certain private actions to WTO Members. In particular, Article 9.1(c) of the Agreement provides that export subsidies, which are subject to reduction commitments, include:

payments on the export of an agricultural product that are financed by virtue of governmental action, whether or not a charge on the public account is involved, including payments that are financed from the proceeds of a levy imposed on the agricultural product concerned or on an agricultural product from which the exported product is derived.

420 Appellate Body Report, US - Countervailing Duty Investigation on DRAMS, para. 116. Also in Korea-Commercial Vessels the Panel observed that an act of delegation or command by a WTO Member "could be explicit or implicit, formal or informal”; see: Panel Report, Korea-Commercial Vessels, para. 7.370.

421 For example, in Korea-Commercial Vessels the Panel based on the circumstances of the case at hand found that the private creditors participating in the restructuring of the Korean ship building industry "were not entrusted or directed to do so, such that their participation does not constitute a "financial contribution" covered by the SCM Agreement”; see: Panel Report, Korea-Commercial Vessels, para. 7.426. 
As can be seen, this provision covers a subsidy for which direct contribution by a government is not necessary, since no "charge on the public account" is required. In particular, as has been confirmed by the WTO dispute settlement practice, this provision is aimed at targeting the export subsidies provided from various producers' funds or other private funds, or the export subsidies resulting from cross-subsidization, if the provision of such subsidies is somehow "facilitated" by a government.

For example, in Canada - Dairy (Article 21.5 - New Zealand and US II) the US and New Zealand (complainants) argued that Canada provided export subsidies to its dairy processors in the form of cheap "commercial export milk", delivered to the processors by milk producers under the condition of exporting the processed dairy products. ${ }^{422}$ The complainants claimed that this was an export subsidy within the meaning of Article 9.1(c) of the Agreement on Agriculture and that this subsidy was in excess of Canada's commitment levels. The Appellate Body upheld the Panel's findings that the provision of the "cheap milk" under the condition of export of processed products was indeed an export subsidy within the meaning of Article 9.1(c), since the price of the provided milk was significantly below the industry-wide average costs of milk production. ${ }^{423}$

The Appellate Body also considered the requirement that the subsidy payment must be "financed by virtue of governmental action". In this regard, it observed:

[...] the governmental action may be a single act or omission, or a series of acts or omissions. We observe that Article 9.1(c) does not require that payments be financed by virtue of government "mandate", or other "direction". Although the word "action" certainly covers situations where government mandates or directs that payments be made, it also covers other situations where no such compulsion is involved. ${ }^{424}$

According to the Appellate Body, the words "by virtue of" express the relationship, i.e. the "nexus" or "link", between "governmental action" and the "financing" of payments for the purpose of Article 9.1(c). ${ }^{425}$ Moreover, the text of the Article indicates that the "financing" needs only to be "by

422 This measure was a result of modification by Canada of its original measure, where the "cheap milk" was provided by Canada's provincial milk marketing boards, which was found to be in violation if the Agreement on Agriculture; see: Appellate Body Report, Canada-Dairy, para. 144.

423 See: Appellate Body Report, Canada-Dairy (Article 21.5 - New Zealand and US II), paras. 98, 121, 155.

424 Appellate Body Report, Canada-Dairy (Article 21.5 - New Zealand and US II), paras. $127-128$.

425 See: Appellate Body Report, Canada - Dairy (Article 21.5 - New Zealand and US II), para. 130. 
virtue of governmental action", rather than "by government"; and this demonstrates that "payments may be financed by virtue of governmental action even though significant aspects of the financing might not involve government". ${ }^{426}$ The Appellate Body came to the following conclusions:

Accordingly, even if government does not fund the payments itself, it must play a sufficiently important part in the process by which a private party funds "payments", such that the requisite nexus exists between "governmental action" and "financing". ${ }^{427}$

Turning to the facts of the case at hand, the Appellate Body finally concluded that the "requisite nexus" between the "governmental action" and the "financing" existed in the situation at hand. This was the case because the Canadian milk producers were effectively reimbursed for the losses incurred due to the cheap sale prices to the dairy processors for export through the system of domestic subsidies and high market prices for milk, established and maintained by the government. ${ }^{428}$

Analogous conclusions were also arrived at by the Panel and the Appellate Body in another case, EC - Export Subsidies on Sugar. In this case the EU imposed the requirement on sugar producers to export sugar produced in excess of determined quota. The producers of sugar in the EU exported sugar below the average costs of its production, but were effectively reimbursed for the losses by subsidies and high prices on sugar maintained within the EU. The Appellate Body upheld the findings of the Panel that the production of sugar in the EU received a "payment on the export financed by virtue of governmental action" under Article 9.1(c) of the Agreement on Agriculture, and that the "financing" occurred in the form of transfers of financial resources through the cross-subsidization resulting from the operation of the EU sugar regime. ${ }^{429}$

Thus, the interpretation of the relevant provisions of the WTO Agreement on Agriculture adopted in the course of the WTO dispute settlement practice is, in principle, in line with the approach taken under the GATT 1994 and the SCM Agreement. In particular, the sufficient "nex$u s$ " or "link" is required between private actions and a government for the

426 Appellate Body Report, Canada-Dairy (Article 21.5 - New Zealand and US II), para. 132; quoting Appellate Body Report, Canada-Dairy (Article 21.5 - New Zealand and US), para. 114.

${ }^{427}$ Appellate Body Report, Canada-Dairy (Article 21.5 - New Zealand and US II), para. 133.

428 In other words, there was cross-subsidisation of diary and milk industries. See: Appellate Body Report, Canada-Dairy (Article 21.5 - New Zealand and US II), paras. $149-154$.

429 Appellate Body Report, EC - Export Subsidies on Sugar, paras. 250, 270, 278. 
attribution of private conduct to a WTO Member. ${ }^{430}$ The question remains, however, when and under which circumstances such nexus or link will be sufficient for the attribution of conduct to a WTO Member. It seems that the answer can only be given on a case-by-case basis and depending on particular circumstances.

\subsection{Relevant Rules of the GATT 1994}

The GATT 1994 contains a number of important rules relevant for the regulation of technical barriers to international trade in goods. Thus, in principle, these obligations might appear to be relevant with respect to the development, adoption and application of private-sector standards as well. This, of course, is under the condition that such conduct would fall into the scope of application of these relevant GATT provisions, as has been discussed above. The relevant rules of the GATT 1994 are the following:

- non-discrimination obligations: most-favoured-nation (MFN) and national treatment;

- rules on the publication and administration of trade laws and regulations;

- the elimination of quantitative restrictions on the importation or exportation of products;

- general exceptions from the GATT obligations; and

- non-violation and situation complaints.

The following sections provide the general overview of these important disciplines of the GATT 1994. ${ }^{431}$

430 It seems that a similar approach to the attribution of private conduct to WTO Members is also adopted in the text of the GATS with respect to trade in services. In particular, Article I:3(a)(ii) provides that, for the purposes of the GATS, "measures by Members" include measures taken by "non-governmental bodies in the exercise of powers delegated by central, regional or local governments or authorities".

431 For a more detailed analysis of some of these GATT disciplines see, for example: Peter Van den Bossche, Werner Zdouc, The Law and Policy of the World Trade Organization. Text, Cases and Materials, 3d Edition, CUP, 2013, pp. 315 - 414, $479-513$ and 543-582; Kevin Kennedy, “GATT 1994”, at: Patrick F.J. Macrory, The World Trade Organization: Legal, Economic and Political Analysis, 1 Springer [etc.], New York, 2005, pp. 89 - 186; Rüdiger Wolfrum, Peter-Tobias Stoll, Anja Seibert-Fohr, WTO: Technical Barriers and SPS Measures, Nijhoff, Leiden, 2007; pp. 2 - 166; Gabrielle Marceau, Joel P. Trachtman, “The Technical Barrier to Trade Agreement, the Sanitary and Phytosanitary Measures Agreement, and the General Agreement on Tariffs and Trade: A Map of the World Trade Organization Law of Domestic Regulation of Goods”, Journal of World Trade, 36(5), 2002, pp. 816 - 860; Gabrielle Marceau, Joel P. Trachtman, "A Map of the World Trade Organization Law of Domestic Regulation of Goods: The Technical Barriers to Trade Agreement, the Sanitary and Phytosanitary Measures Agreement, and the General 


\subsubsection{Non-Discrimination Obligations: Most-Favoured-Nation and National Treatment}

The non-discrimination disciplines form the core group of obligations of the GATT 1994. These disciplines include the MFN and the national treatment obligations imposed on WTO Members. Both obligations, according to the Appellate Body, require equality of competitive opportunities for the products concerned. The Appellate Body briefly described the essence of these obligations as follows:

Finally, we observe that, notwithstanding the textual differences between Articles I:1 and III:4, each provision is concerned, fundamentally, with prohibiting discriminatory measures by requiring, in the context of Article I:1, equality of competitive opportunities for like imported products from all Members, and, in the context of Article III:4, equality of competitive opportunities for imported products and like domestic products. It is for this reason that neither Article I:1 nor Article III:4 require a demonstration of the actual trade effects of a specific measure. $^{432}$

\subsubsection{Essence of MFN Treatment Obligation}

The MFN treatment obligation of WTO Members with respect to imported and exported products is prescribed in Article I:1 of the GATT 1994. The text of Articles I:1 reads as follows:

With respect to customs duties and charges of any kind imposed on or in connection with importation or exportation or imposed on the international transfer of payments for imports or exports, and with respect to the method of levying such duties and charges, and with respect to all rules and formalities in connection with importation and exportation, and with respect to all matters referred to in paragraphs 2 and 4 of Article III, any advantage,

Agreement on Tariffs and Trade”, Journal of World Trade, 48(2), 2014, pp. 351-432; Krista Schefer, Social Regulation in the WTO. Trade Policy and International Legal Development, Edward Elgar, Cheltenham, UK, 2010, pp. 99 - 128; Stefan Zleptnig, Non-Economic Objectives in WTO Law. Justification Provisions of GATT, GATS, SPS and TBT Agreements, Vol. 1, Martinus Nijhoff Publishers, Leiden - Boston, 2010, pp. 125 - 330; Lorand Bartels, "Article XX of GATT and the Problem of Extraterritorial Jurisdiction. The Case of Trade Measures for the Protection of Human Rights “, Journal of World Trade, 36(2), 2002, p. 353 - 403; Petros C.

Mavroidis, Trade in Goods. The GATT and the Other WTO Agreements Regulating Trade in Goods, OUP, Oxford, 2012, pp. 56 - 381; Thomas Cottier and Petros C. Mavroidis, Regulatory Barrier and the Principle of Non-Discrimination in World Trade Law, The University of Michigan Press, 2000.

432 Appellate Body Reports, EC - Seal Products, para. 5.82. 
favour, privilege or immunity granted by any contracting party to any product originating in or destined for any other country shall be accorded immediately and unconditionally to the like product originating in or destined for the territories of all other contracting parties.

Considering the text of Article I:1, the Appellate Body explained that "Article I: 1 thus prohibits discrimination among like imported products originating in, or destined for, different countries" and, in so doing, "protects expectations of equal competitive opportunities for like imported products from all Members". 433

The MFN obligation has been described as a "corner stone of the GATT" and as "one of the pillars of the WTO trading system". ${ }^{434}$ Indeed, the importance of the MFN obligation for the WTO system has been emphasized by the Appellate Body, describing it as "both central and essential to assuring the success of a global rules-based system for trade in goods". ${ }^{435}$

However, the process of proliferation of custom unions, free trade agreements and other preferential agreements and arrangements to a large extent undermined the universality of the MFN treatment, since nowadays a large share of the world trade is conducted not on a MFN basis. Indeed, the Report “The Future of the WTO” prepared in 2004 for the WTO Director General noted in this respect with a lot of concern:

Certainly, much trade between the major economies is still conducted on an MFN basis. However, what has been termed the "spaghetti bowl" of customs unions, common markets, regional and bilateral free trade areas, preferences and an endless assortment of miscellaneous trade deals has almost reached the point where MFN treatment is exceptional treatment. Certainly the term might now be better defined as LFN, Least-Favoured-Nation treatment. ${ }^{436}$

433 Appellate Body Reports, EC - Seal Products, para. 5.87, referring to Appellate Body Report, Canada - Autos, para. 84; and Panel Reports, US - COOL, para. 7.571.

434 See: Appellate Body Reports, EC - Seal Products, para. 5.86, referring to Appellate Body Report, EC - Tariff Preferences, para. 101, Appellate Body Report, Canada - Autos, para. 69; and Appellate Body Report, US - Section 211 Appropriations Act, para. 297. See also: Peter Van den Bossche, Werner Zdouc, The Law and Policy of the World Trade Organization. Text, Cases and Materials, 3d Edition, CUP, 2013, pp. 317 - 318; Kevin Kennedy, “GATT 1994”, at: Patrick F.J. Macrory, The World Trade Organization: Legal, Economic and Political Analysis, 1 Springer [etc.], New York, 2005, p. 100.

435 Appellate Body Report, US - Section 211 Appropriations Act, para. 297.

436 "The Future of the WTO: Addressing Institutional Challenges in the New Millennium", Report by the Consultative Board to the Director-General Supachai Panitchpakdi, WTO, 2004, para. 60. Since the Consultative Board was chaired by Peter Sutherland, the Report is frequently called as the "Sutherland Report". 
Nonetheless, the MFN treatment remains one of the principal obligations of the WTO system. ${ }^{437}$ In this respect, Article I:1 of the GATT 1994 is aimed at prohibiting discrimination and ensuring equal competitive opportunities for "like products" originating in or destined for different WTO Members. Article I:1 thus applies to both imported and exported goods.

The MFN treatment obligation in the GATT 1994 concerns a wide range of measures adopted and applied by WTO Members. According to the text of Article I:1, such measures may include custom duties and other charges imposed in connection with the importation or exportation of products, internal taxes (as referred to in Article III:2), and internal regulations affecting the sale and distribution of products (as referred to in Article III:4). Thus, the rules of Article I: 1 cover both border measures and internal measures of WTO Members. Indeed, as has been noted by Peter van den Bossche:

Generally, there has been little debate about the kind of measures covered by Article I:1. Both panels and the Appellate Body have recognised that Article I: 1 covers a broad range of measures. ${ }^{438}$

Based on the text of Article I:1, the MFN obligation consists out of two main elements: 1. the products "originating in or designed for" different WTO Members are the "like products"; and 2. "any advantage" granted to one such a "like product" "shall be accorded immediately and unconditionally" to the other "like product". ${ }^{439}$ These elements of the MFN obligation under Article I: 1 will be addressed in the subsequent sections of the present Chapter.

\subsubsection{Essence of National Treatment Obligation}

Article III of the GATT 1994 prescribes the national treatment obligation with respect to internal taxes and regulations imposed by WTO Members. The relevant paragraphs of Article III read as follows:

See also: Peter Van den Bossche, Werner Zdouc, The Law and Policy of the World Trade Organization. Text, Cases and Materials, 3d Edition, CUP, 2013, p. 318.

437 See: Peter Van den Bossche, Werner Zdouc, The Law and Policy of the World Trade Organization. Text, Cases and Materials, 3d Edition, CUP, 2013, p. 318; Kevin Kennedy, "GATT 1994", at: Patrick F.J. Macrory, The World Trade Organization: Legal, Economic and Political Analysis, 1 Springer [etc.], New York, 2005, p. 102.

438 Peter Van den Bossche, Werner Zdouc, The Law and Policy of the World Trade Organization. Text, Cases and Materials, 3d Edition, CUP, 2013, p. 321.

439 The Appellate Body in EC - Seal Products further subdivided these two elements and distinguished four elements to be demonstrated in order to establish an inconsistency with Article I:1 of the GATT 1994; see: Appellate Body Reports, EC-Seal Products, para. 5.86. 
1. The contracting parties recognize that internal taxes and other internal charges, and laws, regulations and requirements affecting the internal sale, offering for sale, purchase, transportation, distribution or use of products, and internal quantitative regulations requiring the mixture, processing or use of products in specified amounts or proportions, should not be applied to imported or domestic products so as to afford protection to domestic production.

2. The products of the territory of any contracting party imported into the territory of any other contracting party shall not be subject, directly or indirectly, to internal taxes or other internal charges of any kind in excess of those applied, directly or indirectly, to like domestic products. Moreover, no contracting party shall otherwise apply internal taxes or other internal charges to imported or domestic products in a manner contrary to the principles set forth in paragraph 1 .

3. $[\ldots]$

4. The products of the territory of any contracting party imported into the territory of any other contracting party shall be accorded treatment no less favourable than that accorded to like products of national origin in respect of all laws, regulations and requirements affecting their internal sale, offering for sale, purchase, transportation, distribution or use. The provisions of this paragraph shall not prevent the application of differential internal transportation charges which are based exclusively on the economic operation of the means of transport and not on the nationality of the product.

Article III thus prohibits the protection of domestic products and the discrimination of imported products once they have been cleared by customs. This indeed would prevent WTO Members from undermining their tariff commitments undertaken under Article II of the GATT 1994. For example, in Japan - Alcoholic Beverages II the Appellate Body explained the purpose of Article III as follows:

[...] Article III obliges Members of the WTO to provide equality of competitive conditions for imported products in relation to domestic products. "[T]he intention of the drafters of the Agreement was clearly to treat the imported products in the same way as the like domestic products once they had been cleared through the customs. Otherwise, indirect protection could be given". ${ }^{40}$

440 Appellate Body Report, Japan - Alcoholic Beverages II, p. 109, quoting GATT Panel Report, Italy - Agricultural Machinery, para. 11. 
Article III is only applicable to internal measures: internal taxes and regulations. However, due to the considerations of efficiency and convenience, the internal measures are frequently enforced at the border with respect to imported products. This sometimes makes the distinguishing between the measures covered by Article III and the other measures (such as custom duties addresses in Article II and quantitative restrictions addressed in Article XI:1) a hard task to accomplish. ${ }^{441}$ In this respect, Ad Articles III contains some important explanations:

Any internal tax or other internal charge, or any law, regulation or requirement of the kind referred to in paragraph 1 which applies to an imported product and to the like domestic product and is collected or enforced in the case of the imported product at the time or point of importation, is nevertheless to be regarded as an internal tax or other internal charge, or a law, regulation or requirement of the kind referred to in paragraph 1, and is accordingly subject to the provisions of Article III.

Thus, in principle, it seems that if the importation of a product is banned because it fails to comply, for instance, with domestic public health, consumer safety or environmental requirements, such a measure shall be examined under the provisions of Article III:4. ${ }^{42}$ For example, in EC - Asbestos, the Panel and the Appellate Body examined the EU regulation banning the use of asbestos and materials containing asbestos fibres under the provisions of Article III:4 and refused to consider it under Article XI:1 of the GATT $1994 .{ }^{443}$

However, in certain situations, the issue may appear to be more complicated and it is not entirely clear where the border lies between a product ban prohibited by Article XI: 1 and the application of an internal regulation under Article III:4. In this regard, as will be discussed in Section 3.3.6 of

441 For further discussion of the obligations under Article XI of the GATT 1994, see Section 3.3.3 of the present Chapter.

${ }^{442}$ See: GATT Panel Report, Canada - FIRA, para. 514. See also: Rüdiger Wolfrum, Peter-Tobias Stoll, Anja Seibert-Fohr, WTO: Technical Barriers and SPS Measures, Nijhoff, Leiden, 2007, p. 10; Peter Van den Bossche, Werner Zdouc, The Law and Policy of the World Trade Organization. Text, Cases and Materials, 3d Edition, CUP, 2013, p. 354.

443 See: Panel Report, EC - Asbestos, para. 8.100; Appellate Body Report, EC - Asbestos, para. 192. Asbestos and asbestos fibres are widely recognized to be cancerogenic and dangerous for human health. The Panel initially found a violation of Article III: 4 of the GATT 1994 but then found it to be justified under Article XX's general exceptions. The Appellate Body, however, reversed these findings and ruled that the EU did not violate Article III:4. See also: R. Howse and E. Turk, "The WTO Impact on Internal Regulations. A Case Study of the Canada - EC Asbestos Dispute", at: G. Bermann, P. Mavroidis (eds.), Trade and Human Health and Safety, CUP, 2006. 
the present Chapter, the issue of the relationship between Article III:4 and Article XI:1 arose also in connection with the application of PPM-based measures. For instance, in US - Tuna (Mexico, unadopted) and US - Tuna (EEC, unadopted), the GATT Panels held that the US rules prohibiting the importation of the tuna fished not in accordance with the US dolphin-safe requirements were not covered by Article III:4 and constituted an importation ban proscribed by Article XI:1. ${ }^{444}$ A similar approach was, to a large extent, taken later by the Panel in US - Shrimps, where the Panel found that the US ban on the importation of shrimps harvested in a turtle unfriendly manner (without use of TEDs) violated the rules of Article XI:1.445

Interestingly, in another case, India - Autos, the Panel noted that in exceptional circumstances there may be "a potential for overlap between the two provisions" and that Articles III and XI may be applicable simultaneously to the same measure. ${ }^{446}$ In the view of the Panel:

For example, an internal tax, or a product standard conditioning the sale of the imported but not of the like domestic product, could nonetheless "affect" the conditions of the imported product on the market and could be a source of less favourable treatment. Similarly, the fact that a requirement is imposed as a condition on importation is not necessarily in itself an obstacle to its falling within the scope of Article III: $4 .{ }^{447}$

The first paragraph of Article III establishes the general principle that the measures adopted and applied by WTO Members shall not be applied "so as to afford protection to domestic products". As has been noted by the Appellate Body, this general principle "informs the rest of Article III", ${ }_{448}$ and is further elaborated in paragraphs 2 and 4 of Article III. In particular, Article III:2 prescribes the national treatment obligation with respect to "internal taxes or other internal charges" applied to imported products. Article III:4 provides for the national treatment obligation regarding "all laws, regulations and requirements" affecting the sale and distribution of imported products.

As has been discussed in Chapter II, private-sector standards, as well as standards in general, address characteristics of products or their PPMs. They are, as a rule, not aimed at prescribing taxes or charges to be paid in

444 See: GATT Panel Report, US - Tuna (Mexico, unadopted), para. 7.1; GATT Panel Report, US - Tuna (EEC, unadopted), para. 6.1. See also Section 3.3.6 of the present Chapter.

445 See: Panel Report, US - Shrimp, para. 8.1. The findings of the Panel with respect to the violation of Article XI:1 were not appealed.

446 Panel Report, India - Autos, para. 7.224.

${ }_{447}$ Panel Report, India - Autos, para. 7.306.

448 Appellate Body Report, Japan - Alcoholic Beverages II, p. 111. 
connection with the sale or distribution of products. ${ }^{449}$ Accordingly, the provisions of Article III:2 are not really relevant with respect to the issues addressed in the present study. Thus, in this and the following sections, the discussion will focus only on provisions of Article III:4 - national treatment with respect to laws and regulations affecting international trade in goods.

Article III:4 deals with "all laws, regulations and requirements" affecting international trade in goods. Generally, panels and the Appellate Body interpreted the scope of application of Article III:4 broadly, to cover all possible regulatory requirements which may modify competitive conditions in a market. In this respect, the GATT Panel in Italy - Agricultural Machinery pointed out:

The selection of the word "affecting" would imply, in the opinion of the Panel, that the drafters of the Article intended to cover in paragraph 4 not only laws and regulations which directly govern the conditions of sale or purchase but also any laws or regulations which might adversely modify the conditions of competition between the domestic and imported products on the internal market. ${ }^{450}$

In the GATT and WTO dispute settlement practice, Article III:4 was recognized to cover, for instance, procedural rules on the enforcement of substantive legal provision, import licensing requirements, bans on the advertising of products, minimum price requirements, etc. ${ }^{451}$

In Canada - Autos an interesting issue was considered by the Panel which might be directly relevant with respect to the prospects of the application of Article III:4 to private-sector standards: whether actions of private parties could be regarded as "laws, regulations and requirements" within the meaning of Article III:4. In this regard, one of the measures at issue was certain commitments by Canadian car manufactures communicated in their letters to the Canadian government. The Panel concluded that such commitments could be regarded as "requirements" and observed:

449 In fact, regulations may, for example, also prescribe fines or other monetary penalties for non-compliance with their requirements. However, such fines or penalties, as a rule, may not be qualified as the duties or charges meant in Article III: 2 because they do not constitute the objective of the regulations per se and serve merely as a means for their enforcement.

450 GATT Panel Report, Italy - Agricultural Machinery, para. 12. The importance of the word "affecting" in the text of Article III: 4 was also later emphasized by the Appellate Body in Appellate Body Report, US - FSC (Article 21.5 - EC), para. 208.

451 See respectively: GATT Panel Report, US - Section 337 Tariff Act, para. 5.10; Appellate Body Report, EC - Bananas III, para. 211; GATT Panel Report, Thailand-Cigarettes, para. 77; GATT Panel Report, Canada-Provincial Liquor Boards (US), para.5.30. 
To qualify a private action as a "requirement" within the meaning of Article III:4 means that in relation to that action a Member is to provide no less favourable treatment to imported products than to domestic products.

A determination of whether private action amounts to a "requirement" under Article III:4 must therefore necessarily rest on a finding that there is a nexus between that action and the action of a government such that the government must be held responsible for that action. [...] The word "requirements" in its ordinary meaning and in light of its context in Article III:4 clearly implies government action involving a demand, request or the imposition of a condition but in our view this term does not carry a particular connotation with respect to the legal form in which such government action is taken. In this respect, we consider that, in applying the concept of "requirements" in Article III:4 to situations involving actions by private parties, it is necessary to take into account that there is a broad variety of forms of government action that can be effective in influencing the conduct of private parties. ${ }^{452}$

Thus, a private action could be regarded as a "requirement" within the meaning of Article III:4 only if there is a sufficient nexus (e.g. link) between the private action and the government of a WTO Member. ${ }^{453}$ Such a nexus may be in place, for instance, if a government grants a meaningful advantage for performing certain actions by private parties. This approach is indeed entirely in line with the practice of attribution of private conduct to WTO Members under the GATT 1994, as has been discussed above. ${ }^{454}$

In addition to the criterion that the measure at issue is a "law, regulation, or requirement affecting the internal sale, offering for sale, purchase,

452 Panel Report, Canada-Autos, paras. 10.106 - 10.107. The Panel also noted that the issue was previously addressed by the GATT Panels in Canada-FIRA and EEC - Parts and Components. In Canada - FIRA the GATT Panel concluded that purchase undertakings concluded between foreign investors and the Canadian government were legally enforceable private contractual obligations which, however, were not allowed to negatively affect the rights of WTO Members under Article III:4. Similarly, in EEC - Parts and Components, the GATT Panel concluded that a "requirement" within the meaning of Article III:4 was in place because the acceptance of certain undertakings by private parties was encouraged through granting an advantage by the government. See: GATT Panel Report, CanadaFIRA, paras. 5.4 - 5.6; EEC - Parts and Components, para. 5.21.

453 In this regard, for instance, see also the conclusions of the Appellate Body and the GATT Panel with respect to the dual distribution system for beef in Korea and voluntary export restraints on semi-conductors in Japan, as discussed in Sections 3.1.2.1 and 3.2.2.1.1 of the present Chapter: Appellate Body Report, KoreaVarious Measures on Beef, para. 149; GATT Panel Report, Japan-Semi-Conductors, para. 117.

${ }^{454}$ See Section 3.2.2.1.1 of the present Chapter. 
transportation, distribution, or use" of the products at issue, the national treatment obligation in Article III:4 consists of two other elements: 1. an imported product and a domestic product are "like products"; and 2. the imported product "shall be accorded treatment no less favourable" than the treatment enjoyed by the "like" domestic product. ${ }^{455}$ These elements of the national treatment obligation under Article III:4, as well as the relevant elements of the MFN obligation discussed in Section 3.3.1.1 above, will be addressed in the following sections of the present Chapter.

\subsubsection{3 "Like Products" in Articles I:1 and III:4}

Both Articles I:1 and III:4 of the GATT 1994 may be applicable to a situation at hand only if the products under consideration are "like". It has been generally accepted that the concept of "like products" may have a different scope depending on the context of a particular provision where it is used. ${ }^{456}$ In this respect, the Appellate Body in Japan - Alcoholic Beverages II compared the concept of likeness with the image of an accordion, which "stretches and squeezes in different places as different provisions of the WTO Agreement are applied". ${ }^{457}$ For example, Article III:2 of the GATT 1994 contains two sentences: the first dealing with "like products" and the second dealing with directly competitive or substitutable products. This context of Article III:2 brought the Appellate Body to the conclusion that the concept of "likeness" in the first sentence of Article III: 2 shall be construed much more narrowly in comparison with the concept of "likeness" in Article III:4. ${ }^{458}$

Generally, the concept of "likeness" in the aforementioned provisions of the GATT 1994 deals with the competitive relationship between products. For example, in EC - Asbestos, the Appellate Body explained the following with respect to the meaning of "likeness" in Article III:4:

455 See: Appellate Body Reports, EC - Seal Products, para. 5.99, referring to Appellate Body Report, Thailand-Cigarettes (Philippines), para. 127; and Appellate Body Report, Korea - Various Measures on Beef, para. 133.

456 See: Peter Van den Bossche, Werner Zdouc, The Law and Policy of the World Trade Organization. Text, Cases and Materials, 3d Edition, CUP, 2013, p. 326; Rüdiger Wolfrum, Peter-Tobias Stoll, Anja Seibert-Fohr, WTO: Technical Barriers and SPS Measures, Nijhoff, Leiden, 2007, pp. 14 - 15; Gabrielle Marceau, Joel P. Trachtman, "The Technical Barrier to Trade Agreement, the Sanitary and Phytosanitary Measures Agreement, and the General Agreement on Tariffs and Trade: A Map of the World Trade Organization Law of Domestic Regulation of Goods", Journal of World Trade, 36(5), 2002, pp. 818 - 819. See also: Gabrielle Marceau, Joel P. Trachtman, "A Map of the World Trade Organization Law of Domestic Regulation of Goods: The Technical Barriers to Trade Agreement, the Sanitary and Phytosanitary Measures Agreement, and the General Agreement on Tariffs and Trade", Journal of World Trade, 48(2), 2014, pp. 351-432.

457 Appellate Body Report, Japan - Alcoholic Beverages II, p. 114.

458 See: Appellate Body Report, EC - Asbestos, paras. 94 - 96. 
As products that are in a competitive relationship in the marketplace could be affected through treatment of imports "less favourable" than the treatment accorded to domestic products, it follows that the word "like" in Article III:4 is to be interpreted to apply to products that are in such a competitive relationship. Thus, a determination of "likeness" under Article III:4 is, fundamentally, a determination about the nature and extent of a competitive relationship between and among products. ${ }^{459}$

In dispute settlement practice, panels and the Appellate Body have developed four important criteria for analysing the competitive relationship between the products and determining whether products are "like" in the context of the relevant GATT provision: 1 . product characteristics; 2. product end-use; 3. consumers' tastes and habits; and 4. product tariff classification. ${ }^{460}$ In EC - Asbestos, however, the Appellate Body clearly pointed out that these general criteria merely "provide a framework for analyzing the "likeness" of particular products on a case-by-case basis" and that they are "simply tools to assist in the task of sorting and examining the relevant evidence". ${ }^{461}$ Thus, the four criteria are aimed at assisting in the evaluation of all pertinent evidence addressing different aspects of the products involved. ${ }^{462}$

It is worth noting, however, that not all possible factors are in fact relevant for the determination of "likeness" of products under the appropriate provisions of the GATT 1994. In this regard, the GATT Panel in US - Taxes on Automobiles (unadopted) tried to introduce the so-called "aimand-effect" test into the process of determination of products' "likeness", which per se had nothing to do with the competitive relationship between products. According to the GATT Panel, the "likeness" of products had to be examined in the light of the aims and effects of a measure: whether the less favourable treatment resulted from the regulatory distinction aimed at the protection of domestic products. ${ }^{463} \mathrm{~A}$ similar approach was adopted by

459 Appellate Body Report, EC - Asbestos, para. 99.

460 See: Appellate Body Report, EC - Asbestos, para. 101; Appellate Body Report, Japan - Alcoholic Beverages II, p.113 - 114; Panel Report, US - Gasoline, para. 6.8; GATT Panel Report, Spain - Unroasted Coffee, paras. 4.6 - 4.9; GATT Panel Report, EEC - Animal Feed Proteins, para 4.2; GATT Panel Report, Japan-Alcoholic Beverages I, para. 5.6. Originally, the first three criteria were suggested by the GATT Contracting Parties in 1970 Working Party Report, Border Tax Adjustments, BISD 18S/97, para 18. The fourth criterion was developed by the GATT Panels in: GATT Panel Report, EEC - Animal Feed Proteins, para. 4.2; GATT Panel Report, Japan - Alcoholic Beverages I, para. 5.6.

461 Appellate Body Report, EC - Asbestos, para. 102.

462 See: Appellate Body Report, EC - Asbestos, para. 102.

463 See: GATT Panel Report, US - Taxes on Automobiles (unadopted), paras. 5.12 5.15. The GATT Panel Report, however, has never been adopted by Contracting 
another GATT Panel in US - Malt Beverages, when the Panel considered the regulatory intent in determining whether low-alcohol beer is "like" high alcohol beer within the meaning of Article III:4 of the GATT. ${ }^{464}$ However, this approach was later clearly rejected by the Panel and the Appellate Body in Japan - Alcoholic Beverages II and in other subsequent cases. The Panel gave multiple reasons for rejecting the "aim-and-effect" test, including the multiplicity of possible aims of a measure, the weight of the burden of proof for a complaining Member, and the possible redundancy of the Article XX's general exceptions under such an approach. ${ }^{465}$

Finally, it is also worth briefly discussing the role of npr-PPMs with respect to the determination of products' "likeness" under the relevant GATT provisions.466 Originally, under the GATT 1947, it had been decided several times by GATT panels that npr-PPMs are irrelevant for the "likeness" test. For example, according to the GATT Panel in US - Malt Beverages, the fact that the products were produced by large or small firms (npr-PPM issue) was irrelevant for the determination of "likeness" of their products within the meaning of GATT Article III:2.467 Similarly, in US Tuna (Mexico, unadopted), the GATT Panel decided that the issue whether tuna was fished with a dolphin-safe method did not have any consequences for analysing the "likeness" of tuna products under Article III:4. In particular, the Panel explained:

Article III:4 calls for a comparison of the treatment of imported tuna as a product with that of domestic tuna as a product. Regulations governing the taking of dolphins incidental to the taking of tuna could not possibly affect tuna as a product. Article III:4 therefore obliges the United States to accord treatment to Mexican tuna no less favourable than that accorded to United

Parties. The dispute arose out of complaints of the EU concerning the additional luxury tax applied by the US on cars with a cost exceeding $30000 \$$. The Panel came to the conclusion that the EU had not demonstrated that the taxation aimed at or resulted in protectionism or discrimination of the cars from EC. And, in casu, since the luxury tax "was not implemented so as to afford protection to the domestic production of automobiles", in this case the cars with the price over and below 30 $000 \$$ were not found to be "like products" within the meaning of Article III: 2 of the GATT 1947.

464 See: GATT Panel Report, US - Malt Beverages, para. 5.71.

465 See: Panel Report, Japan - Alcoholic Beverages II, paras. 6.16 - 6.17; Appellate Body Report, Japan - Alcoholic Beverages II, p. 115. See also, for example, US - Gasoline, para.6.9. For more information on the issue see: Peter Van den Bossche, Werner Zdouc, The Law and Policy of the World Trade Organization. Text, Cases and Materials, 3d Edition, CUP, 2013, pp. 366 - 368 and $392-393$.

466 For the discussion on different kinds of PPMs, including npr-PPMs, see Section 3.3.6 of the present Chapter.

467 See: GATT Panel Report, US - Malt Beverages, para. 5.19. 
States tuna, whether or not the incidental taking of dolphins by Mexican vessels corresponds to that of United States vessels. ${ }^{468}$

However, it seems reasonable to assume that the npr-PPMs, in principle, may have a serious impact on consumer tastes and habits concerning products. And in this regard, arguably, the consideration of npr-PPMs could be brought into the "likeness" test. ${ }^{469}$ For example, it seems justified to argue that, nowadays, for many consumers on European markets, chocolate produced with and without the use of forced child labour is not "alike"; and diamonds mined in the zones of armed conflicts in Africa with systematic violations of human rights are not "like" other diamonds.

Such an approach indeed seems to fit quite harmoniously into the existing WTO dispute settlement jurisprudence. For example, in EC-Asbestos, the Appellate Body considered the "likeness" of the products containing cancerogenic chrysotile asbestos fibres and containing a substitute - PCG fibres. Although the matter at hand did in fact not touch on the npr-PPMs issue and was mainly concerned with the physical characteristics of the products, the Appellate Body put a lot of emphasis on the criterion of consumers' tastes and habits regarding the products. According to the Appellate Body, "[c]onsumer perceptions may similarly influence - modify or even render obsolete - traditional uses of the products". ${ }^{470}$ The Appellate Body thus observed:

Furthermore, in a case such as this, where the fibres are physically very different, a panel cannot conclude that they are "like products" if it does not examine evidence relating to consumers' tastes and habits. In such a situation, if there is no inquiry into this aspect of the nature and extent of the competitive relationship between the products, there is no basis for overcoming the inference, drawn from the different physical properties of the products, that the products are not "like".

In this case especially, we are also persuaded that evidence relating to consumers' tastes and habits would establish that the health risks associated with chrysotile asbestos fibres influence consumers' behaviour with respect to the different fibres at issue. ${ }^{471}$

As has been noted in Section 2.3.2.5.1 of Chapter II, the use of npr-PPM based criteria is becoming more and more popular in private-sector

\footnotetext{
468 GATT Panel Report, US - Tuna (Mexico, unadopted), para. 5.15.

469 See: Peter Van den Bossche, Werner Zdouc, The Law and Policy of the World Trade Organization. Text, Cases and Materials, 3d Edition, CUP, 2013, p. 393.

470 Appellate Body Report, EC - Asbestos, para. 102.

471 Appellate Body Report, EC - Asbestos, paras. 121 - 122.
} 
standards, as well as in public standards and regulations. One fascinating example in this respect is the Kimberley Process - the internationally accepted system of certification of diamonds aimed at the reduction of trade in so-called "blood diamonds" - diamonds mined (mostly in Africa) with forced labour and used to finance armed conflicts. ${ }^{472}$ However, it is quite interesting that the Kimberley Process is, so to speak, "legalised" within the WTO system through a waiver adopted by the WTO General Council under Articles IV:2 and IX:3 of the WTO Agreement. ${ }^{473}$ It is not clear, however, whether the approach currently adopted in the WTO implies that without the wavier the measures WTO Members would take in the context of the Kimberley Process constitute a discrimination between "like" diamonds from different countries. It is also quite interesting to note that the Kimberley Process waiver is granted only for the measures "necessary to prohibit the import of rough diamonds" and only with respect to Articles I:1, XI:1 and XIII: 1 of the GATT 1994, and not with respect to the national treatment obligation of Article III:4. ${ }^{474}$

\subsubsection{Any Advantage "Accorded Immediately and Unconditionally" in Article I:1}

First, according to the text of Article I:1, a measure of a WTO Member is supposed to grant "any advantage, favour, privilege or immunity" to "to any product originating in or destined for any other country". Since Article I:1 refers to "any advantage", it is not surprising that the term "advantage" received quite broad interpretation in the WTO dispute settlement practice. In Canada - Autos the Appellate Body pointed out in this regard:

The words of Article I:1 refer not to some advantages granted "with respect to" the subjects that fall within the defined scope of the Article, but to "any advantage"; not to some products, but to "any product"; and not to like products from some other Members, but to like products originating in or destined for "all other" Members. ${ }^{475}$

Second, such "any advantage, favour, privilege or immunity" must be "accorded immediately and unconditionally" to "like products" of other WTO

472 For more information on the Kimberley Process see, for example:

http://www.kimberleyprocess.com/web/kimberley-process/kp-basics

(last visited January 15, 2015).

473 The waiver was recently extended until the end of 2018; see: Extension of Waiver Concerning Kimberley Process Certification Scheme for Rough Diamonds, Decision of the WTO General Council, WT/L/876, Geneva, 14 December 2012.

474 See: Extension of Waiver Concerning Kimberley Process Certification Scheme for Rough Diamonds, Decision of the WTO General Council, WT/L/876, Geneva, 14 December 2012, paras. 1 and 2.

475 Appellate Body Report, Canada-Autos, para. 79. 
Members. Thus, according to the MFN treatment obligation, products from all WTO Members must be able to enjoy the same advantages granted to the like products from any other country, without delay and subject to no conditions. This obligation is also applicable if the "advantage" is granted to products from a country that is a non-Member of the WTO.

In Indonesia - Autos, the Panel took a broad approach to the interpretation of the term "unconditionally" in Article I: 1 and stated that "any advantage" (custom duty and tax benefits for auto parts in that case) could not be made conditional on any criteria that are "not related to the imported product itself". 476 Similarly, the Panel in EC - Tariff Preferences decided to adhere to the ordinary meaning of the term "unconditionally" that is "not limited by or subject to any conditions".477 However, in Canada - Autos, the Panel seems to have adopted a narrower interpretation and concluded that the determination of the "unconditionality" in Article I:1 "depends upon whether or not such conditions discriminate with respect to the origin of products". ${ }^{478}$ In particular, the Panel reasoned as following:

An advantage can be granted subject to conditions without necessarily implying that it is not accorded "unconditionally" to the like product of other Members. More specifically, the fact that conditions attached to such an advantage are not related to the imported product itself does not necessarily imply that such conditions are discriminatory with respect to the origin of imported products. We therefore do not believe that, as argued by Japan, the word "unconditionally" in Article I:1 must be interpreted to mean that making an advantage conditional on criteria not related to the imported product itself is per se inconsistent with Article I:1, irrespective of whether and how such criteria relate to the origin of the imported products. ${ }^{479}$

The meaning of the relevant provisions in Article I: 1 has been further clarified in the recent ruling of the Appellate body in EC - Seal Products. The Appellate Body first noted that, according to the text of Article I:1, "any advantage granted by a Member to imported products must be made available

476 Panel Report, Indonesia - Autos, para. 14.143.

477 Panel Report, EC - Tariff Preferences, para. 7.59. A similar broad approach to the interpretation of the term "unconditionally" was followed by the GATT Panels in GATT Panel Report, Belgium - Family Allowances and GATT Panel Report, EEC - Imports of Beef.

478 Panel Report, Canada-Autos, para. 10.29.

479 Panel Report, Canada-Autos, para. 10.24. The similar narrower approach later was supported by the Panels in Panel Report, Colombia - Ports of Entry, paras. 7.362 - 7.366 and Panel Report, US - Poultry (China), paras. 7.437 - 7.441. 
"unconditionally", or without conditions, to like imported products from all Members" ${ }^{480}$ Nevertheless, the Appellate Body then observed:

However, as Article I:1 is concerned, fundamentally, with protecting expectations of equal competitive opportunities for like imported products from all Members, it does not follow that Article I:1 prohibits a Member from attaching any conditions to the granting of an "advantage" within the meaning of Article I:1. Instead, it prohibits those conditions that have a detrimental impact on the competitive opportunities for like imported products from any Member. Conversely, Article I:1 permits regulatory distinctions to be drawn between like imported products, provided that such distinctions do not result in a detrimental impact on the competitive opportunities for like imported products from any Member. ${ }^{481}$

Thus, according to the Appellate Body, Article I:1 of the GATT 1994 prohibits only those conditions with respect to granting an "advantage", that have a detrimental impact on the competitive opportunities for like imported products. It follows that Article I:1 is applicable to both de jure and de facto types of discrimination, since a measure which "on its face" is formulated as being origin-neutral may in fact appear to be discriminatory. This was also confirmed by the Panel and the Appellate Body in Canada-Autos when they rejected Canada's argument that Article I: 1 was only applicable to origin-based measures. ${ }^{482}$

\subsubsection{5 "Treatment No Less Favourable" in Article III:4}

Article III:4 requires that imported products shall be accorded "treatment no less favourable" than the treatment accorded to "like" domestic products. Indeed, this requirement reflects the general objective of Article III to prohibit protectionism and to ensure the "effective equality of opportunities for imported products to compete with like domestic products". ${ }^{483}$ As has been noted by the Appellate Body in EC - Asbestos in this regard:

\footnotetext{
480 Appellate Body Reports, EC - Seal Products, para. 5.88.

481 Appellate Body Reports, EC - Seal Products, para. 5.88

482 See: Appellate Body Report, Canada-Autos, para. 78. The measure at issue in this case was Canada's import duty reductions for certain automobile manufacturers. Although the measure itself did not specify the countries of origin of products, de facto the measure provided an advantage to products from certain WTO Members where the relevant manufacturers were based. See also: L. Ehring, "De Facto Discrimination in World Trade Law. National and Most-Favoured-Nation Treatment - or Equal Treatment?”, Journal of World Trade, 36(5), 2002.

483 See: Appellate Body Reports, EC - Seal Products, para. 5.101, referring to Appellate Body Report, US - Clove Cigarettes, para. 176; GATT Panel Report, US - Section 337 Tariff Act, para. 5.10; Appellate Body Report, China-Publications and Audiovisual Products, para. 305; Appellate Body Report, Korea - Various Measures on
} 
A complaining Member must still establish that the measure accords to the group of "like" imported products "less favourable treatment" than it accords to the group of "like" domestic products. The term "less favourable treatment" expresses the general principle, in Article III:1, that internal regulations "should not be applied ... so as to afford protection to domestic production". If there is "less favourable treatment" of the group of "like" imported products, there is, conversely, "protection" of the group of "like" domestic products. ${ }^{484}$

It is worth noting, however, that the requirement of "no less favourable" treatment in the text of Article III:4 does not mean that the treatment of imported and domestic products must be exactly the same. For instance, in Korea - Various Measures on Beef, the Panel came to the conclusion that "[a] ny regulatory distinction that is based exclusively on criteria relating to the nationality or the origin of the products is incompatible with Article III" ${ }^{485}$ The Appellate Body disagreed with this sweeping statement and explained:

A measure that provides treatment to imported products that is different from that accorded to like domestic products is not necessarily inconsistent with Article III:4, as long as the treatment provided by the measure is "no less favourable". According "treatment no less favourable" means, as we have previously said, according conditions of competition no less favourable to the imported product than to the like domestic product $[\ldots]$

A formal difference in treatment between imported and like domestic products is thus neither necessary, nor sufficient, to show a violation of Article III:4. Whether or not imported products are treated "less favourably" than like domestic products should be assessed instead by examining whether a measure modifies the conditions of competition in the relevant market to the detriment of imported products. ${ }^{486}$

In its explanations, the Appellate Body also referred to the statement by the GATT Panel in US - Section 337 Tariff Act that:

Beef, paras. 135 and 136; Appellate Body Report, Thailand-Cigarettes (Philippines), para. 126; Appellate Body Report, Japan - Alcoholic Beverages II, p. 16. See also: GATT Panel Report, US - Malt Beverages, para. 5.30; Panel Report, US - Gasoline, para. 6.10.

484 Appellate Body Report, EC - Asbestos, para. 100.

485 Panel Report, Korea - Various Measures on Beef, para. 627.

486 Appellate Body Report, Korea - Various Measures on Beef, paras. 135, 137. See also: Appellate Body Reports, EC - Seal Products, para. 5.101. Furthermore, in Thailand - Cigarettes (Philippines) the Appellate Body observed that the mere existence of an additional requirement for imported products, in principle, does not immediately mean that the products are treated less favourably; Appellate Body Report, Thailand - Cigarettes (Philippines), para. 130. 
[...] it also has to be recognised that there may be cases where the application of formally identical legal provisions would in practice accord less favourable treatment to imported products and a contracting party might thus have to apply different legal provisions to imported products to ensure that the treatment accorded them is in fact no less favourable. ${ }^{487}$

Such an approach was also shared by the Panel in Dominican Republic Import and Sale of Cigarettes, where the Panel considered the requirements of the Dominican Republic to affix tax stamps to all (both imported and domestically produced) cigarette packages. In particular, the Panel observed:

In this respect, the Panel finds that, although the tax stamp requirement is applied in a formally equal manner to domestic and imported cigarettes, it does modify the conditions of competition in the marketplace to the detriment of imports. The tax stamp requirement imposes additional processes and costs on imported products. It also leads to imported cigarettes being presented to final consumers in a less appealing manner.

The Panel notes that, in this case, the differences in the conditions between imported and domestic products mean that the Dominican Republic should not apply the tax stamp requirement in a formally identical manner that does not take those differences into account, since this would, in practice, accord less favourable treatment to imported products. On the contrary, the Dominican Republic could have chosen to apply the requirement in a different manner to imported products, to ensure that the treatment accorded to them is de facto not less favourable. ${ }^{488}$

Thus, on the one hand, a mere difference in treatment of imported and domestic "like" products is not sufficient to demonstrate that the imported product is accorded less favourable treatment. However, on the other hand, formally identical regulatory requirements may also result in less favourable treatment of imported products. ${ }^{489}$ In this regard, Article III:4 clearly covers both de jure and de facto types of discrimination. ${ }^{490}$

With respect to private-sector standards, of course, in case such a standard could be regarded as a "measure" attributable to a WTO Member under the GATT 1994, the MFN and national treatment obligations would mean

487 GATT Panel Report, US - Section 337 Tariff Act, para. 5.11. See also: Appellate Body Report, Korea - Various Measures on Beef, para. 136.

488 Panel Report, Dominican Republic-Import and Sale of Cigarettes, paras. 7.196 -7.197 .

489 See: Appellate Body Reports, EC - Seal Products, para. 5.108.

490 For explanations about the difference between de jure and de facto types of discrimination, see Section 3.3.1.4 of the present Chapter. 
that the standard may not either treat the products of one Member less favourably than like products of an importing Member (national treatment), or fail to accord immediately and unconditionally the same advantages as accorded to like products from other countries (MFN treatment). For example, if a standard establishes the rules for certification and labelling of national or certain foreign tuna products as "dolphin safe" (fished without killing or injuring dolphins), the same opportunity for certification and labelling shall be provided for tuna products from other WTO Members and under non-discriminatory conditions.

\subsubsection{Rules on the Publication and Administration of Trade Laws and Regulations}

Article X of the GATT 1994 imposes obligations on WTO Members with respect to the publication and administration of their trade laws and regulations. The relevant parts of Article $\mathrm{X}$ read as follows:

1. Laws, regulations, judicial decisions and administrative rulings of general application, made effective by any contracting party, pertaining to the classification or the valuation of products for customs purposes, or to rates of duty, taxes or other charges, or to requirements, restrictions or prohibitions on imports or exports or on the transfer of payments therefor, or affecting their sale, distribution, transportation, insurance, warehousing inspection, exhibition, processing, mixing or other use, shall be published promptly in such a manner as to enable governments and traders to become acquainted with them. Agreements affecting international trade policy which are in force between the government or a governmental agency of any contracting party and the government or governmental agency of any other contracting party shall also be published. The provisions of this paragraph shall not require any contracting party to disclose confidential information which would impede law enforcement or otherwise be contrary to the public interest or would prejudice the legitimate commercial interests of particular enterprises, public or private.

2. No measure of general application taken by any contracting party effecting an advance in a rate of duty or other charge on imports under an established and uniform practice, or imposing a new or more burdensome requirement, restriction or prohibition on imports, or on the transfer of payments therefor, shall be enforced before such measure has been officially published. 
3 (a) Each contracting party shall administer in a uniform, impartial and reasonable manner all its laws, regulations, decisions and rulings of the kind described in paragraph 1 of this Article.

These obligations of Article $\mathrm{X}$ are important for ensuring transparency and fairness of application of trade rules adopted and applied by WTO Members. The Panel, in EC-Selected Custom Matters, noted in this regard:

The title as well as the content of the various provisions of Article $\mathrm{X}$ of the GATT 1994 indicate that that Article, at least in part, is aimed at ensuring that due process is accorded to traders when they import or export. ${ }^{491}$

Article X applies to a wide range of measures of general application "that have the potential to affect trade and traders". ${ }^{492}$ For example, in Thailand - Cigarettes (Philippines), the Panel found that the general methodology for customs valuation adopted in Thailand qualified as the laws and regulations of the general application under Article X:1. ${ }^{493}$ Similarly, in US - COOL, the Panel agreed with the parties to the dispute that the US country of origin labelling (COOL) measure fell within the category of the measures referenced in Articles X:1 and X:3 of the GATT $1994 .^{494}$

However, notably the provisions of Article $\mathrm{X}$ are only applicable to measures of general application, which were described by the Appellate Body in US - Underwear as those affecting "an unidentified number of economic operators". ${ }^{495}$ In this regard, the Appellate Body in EC - Poultry agreed with the Panel that individual decisions, such as "licences issued to a specific company or applied to a specific shipment", could not be regarded as a measure "of general application" within the meaning of Article X:1. ${ }^{496}$ Nonetheless, interestingly, in Japan - Film, the Panel noted that "inasmuch as the Article X:1 requirement applies to all administrative rulings of general application, it also should extend to administrative rulings in individual cases where such rulings establish or revise principles or criteria applicable in future cases". ${ }^{497}$

With respect to private-sector standards, of course, the provisions of Article X of the GATT 1994 are relevant only to the extent that these

491 Panel Report, EC - Selected Custom Matters, para. 7.107.

492 See: Panel Report, EC - IT Products, para. 7.1026, Panel Reports, China - Raw Materials, para. 7.803.

493 See: Panel Report, Thailand - Cigarettes (Philippines), paras. 7.773, 7.779- 7.780.

494 See: Panel Reports, US - COOL, paras. 7.814-7.815.

495 See: Appellate Body Report, US - Underwear, p. 29.

496 See: Appellate Body Report, EC - Poultry, para. 113; Panel Report, EC - Poultry, para. 269.

497 Pane Report, Japan - Film, para. 10.388. 
standards may qualify as "laws, regulations, judicial decisions and administrative rulings of general application" within the meaning of Article X:1. As has been discussed in Section 2.1.1.1 of Chapter II of the present study, a standard is generally defined as a document adopted by a "recognized body" that provides for "common and repeated use" rules, guidelines or characteristics. Arguably, based on this definition, it may be concluded that standards, and private-sector standards in particular, fulfil the criterion of being a measure "of general application" under Article X:1. However, another issue is whether private-sector standards may be regarded as "laws" and "regulations" "made effective" by a WTO Member within the meaning of Article X:1. ${ }^{498}$

On the one hand, the terms "laws" and "regulations" appear to be more specific in comparison with the term "measure" used through the GATT 1994. On the other hand, however, Article X:1 refers to laws and regulations "made effective" by a WTO Member (i.e. it does not specifically require that the laws and regulations shall be "adopted" by a WTO Member). This seems to give additional flexibility so that it might be argued that private-sector standards may fall under Article X:1 if they are "made effective" by a Member. In any case, in line with the discussion in Sections 3.1.1, 3.1.2 and 3.2.2 above, perhaps it would be incorrect to conclude generally that the documents bearing the name "standard", including private-sector standards, may never qualify as "laws" and "regulations" "made effective" by WTO Members within the meaning of Article X:1 of the GATT 1994. The consideration of this issue will depend on the content of these documents, as well as on the amount of involvement or incentives provided by a government for their implementation.

The following sections discuss, in more detail, the obligations of WTO Members to publish their trade laws and regulations, as well as the obligations to administer such laws and regulations in a "uniform, impartial and reasonable manner".

\subsubsection{Publication of Trade Laws and Regulations}

As can be seen from the text of Article X of the GATT 1994 quoted above, the obligations of WTO Members with regard to the publication of their trade laws and regulations are prescribed in its paragraphs 1 and 2. Article $\mathrm{X}: 1$ requires that the laws and regulations are published promptly in order to "enable governments and traders to become acquainted with them". Furthermore, Article X:2 of the GATT 1994 prohibits the enforcement of

498 It seems to be quite obvious that private-sector standards may not be viewed as "judicial decisions and administrative rulings" within the meaning of Article X of the GATT 1994. 
the measure of general application "before such measure has been officially published".

In the WTO dispute settlement practice a number of panels found the behaviour of WTO Members inconsistent with the rules of Article X:1 if they failed to publish their trade laws and regulations. For example, the Panel in China - Raw Materials concluded that China violated Article X:1 because it failed to promptly publish its decision not to authorize an export quota for zinc. ${ }^{499}$ In EC - IT Products, the Panel considered two possible "publications" of the Explanatory Notes to the Combined Nomenclature (CNEN) claimed to be exercised by the EU: 1. publication in the EU Official Journal at least eight months after the rules were made effective; 2. publication on the EU Comitology website. The Panel finally found that, in the first case, the publication was not "prompt" within the meaning of Article X:I, and in the second case - not "in such a manner as to enable governments and traders to become acquainted" with the measures at issue. ${ }^{500}$ Furthermore, the Panel in EC - IT Products also established a violation of Article X:2, as the EU enforced an amendment to the CNEN before they were properly published. ${ }^{501}$ The Panel further noted with regard to the scope of Article X:2 that this Article "refers simply to "measure" and hence encompasses an even broader category - namely, any act or omission by a WTO Member". ${ }^{502}$

Generally, the role and objective of Article X:2 has been clarified by the Appellate Body in US - Underwear through the following observation:

Article X:2, General Agreement, may be seen to embody a principle of fundamental importance - that of promoting full disclosure of governmental acts affecting Members and private persons and enterprises, whether of domestic or foreign nationality. The relevant policy principle is widely known as the principle of transparency and has obviously due process dimensions. The essential implication is that Members and other persons affected, or likely to be affected, by governmental measures imposing restraints, requirements and other burdens, should have a reasonable opportunity to acquire authentic information about such measures and accordingly to protect and adjust their activities or alternatively to seek modification of such measures. ${ }^{503}$

\footnotetext{
499 Panel Reports, China-Raw Materials, para. 7.807

500 See: Panel Report, EC - IT Products, para. 7.1088.

501 See: Panel Report, EC - IT Products, para. 7.1135.

502 Panel Report, EC - IT Products, para. 7.1097.

503 Appellate Body Report, US - Underwear, p. 29. See also: Appellate Body Report, US - Countervailing and Anti-Dumping Measures (China), para. 4.66.
} 
In US - Countervailing and Anti-Dumping Measures (China), the Appellate Body further developed its clarifications concerning the function and the scope of application of Article X:2. According to the Appellate Body, "[b] $y$ requiring that certain measures of general application are published promptly and that they are not enforced before their publication, Articles $\mathrm{X}: 1$ and $\mathrm{X}: 2$ are meant to ensure that traders are made aware of measures that may have an impact on them, so that they have time to become acquainted with, and to adapt to, the new measures". ${ }^{504}$ The Appellate Body further explained:

The function of Article X:2 of ensuring transparency and protecting traders' expectations as to the publication and enforcement of certain measures is relevant to the interpretation of the obligations contained in this provision. The fact that Article $\mathrm{X}: 2$ applies only to measures that increase duties or charges or impose new or more burdensome requirements, restrictions, or prohibitions is consistent with the due process function of this provision. The transparency and due process functions of Article $\mathrm{X}: 2$ also inform the identification of the baseline of comparison to determine whether a measure of general application effects an advance in a rate of duty or imposes a new or more burdensome requirement. ${ }^{505}$

According to the Appellate Body, the "baseline of comparison" is used to determine whether a measure of general application affects an advance in a rate of duty or imposes a new or more burdensome requirement. ${ }^{506} \mathrm{In}$ other words, "the language in Article X:2 that refers to an advance in a rate of duty and a new or more burdensome requirement implies a comparison between the measure that is alleged to be increasing a rate of duty or imposing a new or more burdensome requirement and a relevant baseline, which is normally to be found in published measures of general application". ${ }^{507}$ Thus, in order to identify this "baseline of comparison", it is necessary "to ascertain the meaning of the published measure of general application under municipal law" ${ }^{508}$ The Appellate Body then noted that the elements to be examined in ascertaining the meaning of municipal law will vary from

504 Appellate Body Report, US - Countervailing and Anti-Dumping Measures (China), para. 4.65.

505 Appellate Body Report, US - Countervailing and Anti-Dumping Measures (China), para. 4.67.

506 See: Appellate Body Report, US - Countervailing and Anti-Dumping Measures (China), para. 4.67.

507 Appellate Body Report, US - Countervailing and Anti-Dumping Measures (China), para. 4.96.

508 Appellate Body Report, US - Countervailing and Anti-Dumping Measures (China), para. 4.97. 
case to case. ${ }^{509}$ According to the Appellate Body, this process implies "a holistic assessment of all relevant elements, starting with the text of the law and including, but not limited to, relevant practices of administering agencies". ${ }^{510}$

Thus, coming back to the discussion concerning private-sector standards, if it is established that the requirements of a certain private-sector standard could be attributed to a WTO Member and constitute a trade law or regulation of the Member within the meaning of Article X of the GATT 1994, the Member would, arguably, be obliged to ensure the prompt publication of these requirements under Articles X:1 and X:2 before their enforcement. However, considering the variety and diversity of private-sector standards operational in markets nowadays, it is hardly possible to expect that WTO Members would be able to ensure the publication of the standards which were developed, adopted and applied without their involvement, and which they could even be unaware of. Thus, again, the presence of sufficient governmental involvement or incentives for the development, adoption and application of a standard play a key role in the determination of the scope of the publication requirements under Article X of the GATT 1994.

\subsubsection{Administration of Trade Laws and Regulations}

Article X:3(a) of the GATT 1994 obliges WTO Members to administer all their trade laws and regulations in a "uniform, impartial and reasonable manner". In US - Shrimp, the Appellate Body generally observed with respect to Article X:3 that it "establishes certain minimum standards for transparency and procedural fairness in the administration of trade regulations". ${ }^{511}$

Article X:3(a) is thus applicable to the "administration" of trade laws and regulations and not to the trade laws and regulations per se. In this regard, the Panel in EC - Selected Custom Matters arrived at the conclusion that "the text of Article X:3(a) does not contemplate the possibility that laws and regulations can simultaneously qualify as laws, regulations, judicial decisions, and administrative rulings of the kind described in Article X:1 of the GATT 1994 and as acts of administration within the meaning of Article X:3(a)" ${ }^{512}$ However, the Appellate Body reversed this rather sweeping conclusion and observed that "the possibility of challenging under

509 Appellate Body Report, US - Countervailing and Anti-Dumping Measures (China), para. 4.100, referring to Appellate Body Report, US - Carbon Steel, para. 157.

510 Appellate Body Report, US - Countervailing and Anti-Dumping Measures (China), para. 4.101.

511 Appellate Body Report, US - Shrimp, para. 183.

512 Appellate Body Report, EC - Selected Custom Matters, para. 191. See also: Panel Report, EC - Selected Custom Matters, para. 7.119. 
Article X:3(a) the substantive content of a legal instrument that regulates the administration of a legal instrument of the kind described in Article X:1 cannot be excluded". ${ }^{513}$

Other important issues which arose in EC - Selected Custom Matters were the meanings of the terms "administer" and "uniform" in Article $\mathrm{X}: 3(\mathrm{a})$. In this regard, the Appellate Body upheld the Panel's ruling that the term "administer" may include "administrative processes that put into effect the legal instruments of the kind described in Article X:1" ${ }^{514}$ The Appellate Body also observed that Article X:3(a) does not require uniformity of administrative processes; and a complainant has to show how and why such processes "necessarily lead to a lack of uniform, impartial, or reasonable administration of a legal instrument" ${ }^{515}$ According to the Appellate Body:
[...] the term "administer" in Article X:3(a) refers to putting into practical effect, or applying, a legal instrument of the kind described in Article X:1. Thus, under Article X:3(a), it is the application of a legal instrument of the kind described in Article $\mathrm{X}: 1$ that is required to be uniform, but not the processes leading to administrative decisions, or the tools that might be used in the exercise of administration. ${ }^{516}$

The issue concerning whether a WTO Member may challenge the substance of a measure under Article X was addressed by the Panel in Argentina - Hides and Leather. The Panel came to the conclusion that this is certainly possible. However, according to the Panel, the relevant question in this regard "is whether the substance of such a measure is administrative in nature or, instead, involves substantive issues more properly dealt with under other provisions of the GATT 1994". ${ }^{517}$

In Thailand - Cigarettes (Philippines), the Panel further noted that "Article X:3(a) sets out three distinct and legally independent obligations - an obligation to administer laws and regulations in a uniform, impartial and reasonable manner". ${ }^{518}$ These three requirements are independent and WTO Members are obliged to comply with each of them; and, in casu, a violation of any of these three requirements would constitute a violation of Article X:3(a)..$^{519}$ The "uniform" administration was defined as something "of one unchanging form, character", something that "stays the same

\footnotetext{
513 Appellate Body Report, EC - Selected Custom Matters, para. 217.

514 Appellate Body Report, EC - Selected Custom Matters, para. 227.

515 Appellate Body Report, EC - Selected Custom Matters, paras. 226 - 227.

516 Appellate Body Report, EC - Selected Custom Matters, para. 224.

517 Panel Report, Argentina-Hides and Leather, para. 11.70.

518 Panel Report, Thailand-Cigarettes (Philippines), para. 7.30.

519 See: Panel Report, Thailand-Cigarettes (Philippines), para. 7.867. See also: Panel Report, Argentina - Hides and Leather, para. 11.86;
} 
in different places or circumstances, or at different times"; the "“uniform administration" requires that Members ensure that their laws are applied consistently and predictably". 520 The "impartial" administration means "the application or implementation of the relevant laws and regulations in a fair, unbiased and unprejudiced manner". ${ }^{521}$ And "reasonable" administration is the administration "in accordance with reason", "not irrational or absurd". 522

Violations of Article X:3(a) of the GATT 1994 have been found in considerable number of disputes. For example, in EC-Selected Custom Matters, the Appellate Body upheld the conclusions of the Panel that the tariff classification of LCD monitors with digital video interface (DVI) exercised differently in different EU Member States amounted to the non-uniform administration of trade laws and regulations by the EU within the meaning of Article X:3(a). ${ }^{523}$ In Argentina - Hides and Leather the Panel found that Argentina violated Article X:3(a) by failing to administer its custom clearance procedures for bovine hides in an "impartial and reasonable manner". According to the Panel this was the case because the authorization of the presence of the tanning industry representatives during the export custom clearance procedures inherently entailed the threats of revealing confidential business information and putting pressure on bovine hide producers. ${ }^{524}$

More recently, in US - COOL, the Panel considered, under the rules of Article X:3(a), the letter by the US Secretary of Agriculture, Thomas J. Vilsack (Vilsack letter), which provided certain guidelines for meat producers with regard to the application of the COOL measure and suggested additional actions to the industry in this respect. The Panel ruled that, considering the circumstances, the Vilsack letter "was not "appropriate", and thus does not meet the requirement of reasonable administration of the COOL measure within the meaning of Article X:3(a)" . 525

The issue of uniform, impartial and reasonable administration is indeed relevant with respect to private-sector standards. As has been explained in Section 2.3.3.2 of Chapter II of the present study, possible abusive practices in the application of private-sector standards resulting in unjustified discrimination, disguised trade restrictions and the distortion of market

520 Panel Reports, US - COOL, para. 7.876; Panel Report, Argentina - Hides and Leather, para. 11.83.

521 Panel Report, Thailand-Cigarettes (Philippines), para. 7.899.

522 Panel Reports, US - COOL, para. 7.850; Panel Report, Dominican Republic-Import and Sale of Cigarettes, para. 7.385.

523 See: Appellate Body Report, EC - Selected Custom Matters, paras. 246 - 260; Panel Report, EC - Selected Custom Matters, paras. 7.294, 7.305.

524 See: Panel Report, Argentina - Hides and Leather, paras. 11.94, 11.100 - 11.101. For more information on this case see Section 3.1.2.2 of the present Chapter.

525 See: Panel Reports, US - COOL, paras. 7.863. 
competition, may not be excluded. Thus, in case a private-sector standard qualifies as a law or regulation attributable to a WTO Member within the meaning of Article X of the GATT 1994, the Member would thus be obliged under Article X:3(a) to ensure that such a standard is administered in a "uniform, impartial and reasonable manner".

\subsubsection{Elimination of Quantitative Restrictions on the Importation or Exportation of Products}

Article XI:1 prescribes a general prohibition for WTO Members to impose quantitative restrictions (QRs) on the import or export of products:

No prohibitions or restrictions other than duties, taxes or other charges, whether made effective through quotas, import or export licences or other measures, shall be instituted or maintained by any contracting party on the importation of any product of the territory of any other contracting party or on the exportation or sale for export of any product destined for the territory of any other contracting party.

Article XI:2 contains certain exceptions from the general prohibition of Article XI:1. With regard to the adoption and application of standards one relevant exception is provided in Article XI:2(b), which allows "[i]mport or export prohibitions or restrictions necessary to the application of standards or regulations for the classification, grading or marketing of commodities in international trade" ${ }^{526}$ Article XI:2(b) seems to contain the necessity requirement with respect to the export prohibitions and restrictions, which makes it similar, to some extent, to certain general exceptions prescribed in the GATT Article XX.527 This provision has, however, rarely been invoked in WTO dispute settlement practice; and even when it was invoked,

526 According to Arthur Appleton, "commodities" is "a term of art among trade lawyers", which "usually refers to food or metal products. Such products are frequently traded by investors". See: Arthur E. Appleton, "The Agreement on Technical Barriers to Trade", at: Patrick F.J. Macrory, The World Trade Organization: Legal, Economic and Political Analysis, 1 Springer [etc.], New York, 2005, p. 375. However, it is doubtful that this term in Article XI:2(b) limits the Article's application only to certain products, like food or metals. For example, in Canada - Herring and Salmon, the GATT Panel did not even consider the meaning of the term "commodities" while dealing with the applicability of this exception to the fish products concerned. See: GATT Panel Report, Canada-Herring and Salmon, paras. $4.2-4.3$.

527 See: Appellate Body Report, Argentina-Import Measures, para. 5.221. The Appellate Body, with reference to, among others, Articles XI:2(b) and XX of the GATT 1994, noted that "[f] or example, the scope of certain exclusions or exceptions is circumscribed with the imposition of certain conditions, often with reference to the concept of "necessity"“. 
this usually happened together with an invocation of the Article XX general exceptions. ${ }^{528}$

The rules of Article XI:1 in fact reflect the so-called "tariffs-only" approach, which departs from the point that custom tariffs (especially if they are significantly reduced) are much less detrimental to the liberalization of international trade than QRs. In this respect, for example, the Panel in Turkey - Textiles described the role and the context of Article XI:1 in the following way:

The prohibition on the use of quantitative restrictions forms one of the cornerstones of the GATT system. A basic principle of the GATT system is that tariffs are the preferred and acceptable form of protection.[...] The prohibition against quantitative restrictions is a reflection that tariffs are GATT's border protection "of choice". Quantitative restrictions impose absolute limits on imports, while tariffs do not. In contrast to MFN tariffs which permit the most efficient competitor to supply imports, quantitative restrictions usually have a trade distorting effect, their allocation can be problematic and their administration may not be transparent. ${ }^{529}$

As has been already noted, Article XI:1 covers both importation and exportation and thus provides protection not only for importers of foreign products, but also for exporters of domestic products. The text of Article XI:1 refers to "prohibitions" and "restrictions". It seems that the prohibitions imply a total ban on importation or exportation, while the restrictions cover all other measures which impede importation or exportation. ${ }^{530}$ Indeed, in China-Raw Materials, the Appellate Body observed:

The term "prohibition" is defined as a "legal ban on the trade or importation of a specified commodity". The second component of the phrase "[e]xport prohibitions or restrictions" is the noun "restriction", which is defined as "[a] thing which restricts someone or something, a limitation on action, a limiting condition or regulation", and thus refers generally to something that has a limiting effect. ${ }^{531}$

528 See, for example: GATT Panel Report, Canada-Herring and Salmon, paras. $4.2-4.7$. For more information on general exceptions under Article XX of the GATT 1994, see Section 3.3.4 of the present Chapter. Panel Report, Turkey - Textiles, para. 9.63.

530 See: Rüdiger Wolfrum, Peter-Tobias Stoll, Anja Seibert-Fohr, WTO: Technical Barriers and SPS Measures, Nijhoff, Leiden, 2007, p. 51.

531 Appellate Body Reports, China - Raw Materials, para. 319, quoting Shorter Oxford English Dictionary, 6th edn, W.R. Trumble, A. Stevenson (eds.) (Oxford University Press, 2007), Vol. 2, pp. 2363 and 2553. See also: Appellate Body Reports, Argentina-Import Measures, para. 5.217. 
Thus, the provisions of Article XI:1, are concerned with general product bans, quotas, restrictive import or export licensing, or other possible measures imposing QRs, whether of de jure or de facto nature. ${ }^{532}$ In this respect, in Argentina - Import Measures, the Appellate Body clarified that "[t]he use of the word "quantitative" in the title of Article XI of the GATT 1994 informs the interpretation of the words "restriction" and "prohibition" in Article XI:1, suggesting that the coverage of Article XI includes those prohibitions and restrictions that limit the quantity or amount of a product being imported or exported". ${ }^{533}$ According to the Appellate Body:

This provision, however, does not cover simply any restriction or prohibition. Rather, Article XI:1 refers to prohibitions or restrictions "on the importation ... or on the exportation or sale for export". Thus, in our view, not every condition or burden placed on importation or exportation will be inconsistent with Article XI, but only those that are limiting, that is, those that limit the importation or exportation of products. Moreover, this limitation need not be demonstrated by quantifying the effects of the measure at issue; rather, such limiting effects can be demonstrated through the design, architecture, and revealing structure of the measure at issue considered in its relevant context. ${ }^{534}$

The Appellate Body further noted that the expression "made effective through" in Article XI:1, which precedes the terms "quotas, import or export licences or other measures", suggests that "the scope of Article XI:1 covers measures through which a prohibition or restriction is produced or becomes operative". ${ }^{535}$

In addition, the Appellate Body explained:

As noted by the Panel, while the term "or other measures" suggests a broad coverage, the scope of application of Article XI:1 of the GATT 1994 is not unfettered. Article XI:1 itself

532 See: Panel Report, Argentina - Hides and Leather, paras. 11.17. In this case, the Panel found, however, that the EU had failed to prove that the authorized presence of the tanning industry representatives during custom clearance processes for export of bovine hides by their producers constituted a de facto QR; see: Panel Report, Argentina - Hides and Leather, para. 11.55. For more information concerning the case see also Section 3.1.2.2 of the present Chapter. In addition see also: Panel Report, India - Quantitative Restrictions , para. 11.17: GATT Panel Report, Japan - Semi-Conductors, paras. 105 - 109. See also: Petros C. Mavroidis, Trade in Goods. The GATT and the Other WTO Agreements Regulating Trade in Goods, OUP, Oxford, 2012, pp. 66- 70.

533 Appellate Body Reports, Argentina-Import Measures, para. 5.217, referring to Appellate Body Reports, China - Raw Materials, para. 320.

534 Appellate Body Reports, Argentina-Import Measures, para. 5.217.

535 Appellate Body Reports, Argentina-Import Measures, para. 5.218. 
explicitly excludes "duties, taxes and other charges" from its scope of application. Article XI:2 of the GATT 1994 further restricts the scope of application of Article XI:1 by providing that the provisions of Article XI:1 shall not extend to the areas listed in Article XI:2. ${ }^{536}$

Article XI:1 thus prohibits only certain, although a rather broad circle of border measures, and does not apply to custom duties, internal taxes or other charges. ${ }^{537}$ However, as has been observed, the border measures under Article XI:1 are not always easy to distinguish from internal regulations, which are enforced at the border. ${ }^{538}$

In the GATT and WTO dispute settlement practice there was quite a significant diversity of measures found to be inconsistent with the rules of Article XI:1. For instance, in US - Tuna (Mexico, unadopted) and US - Tuna (EEC, unadopted), the GATT Panels found that the US regulation prohibiting importation of tuna products fished with certain, as claimed, dolphin unsafe methods, violated Article XI:1. ${ }^{539}$ Similarly, in US - Shrimp, the Panel concluded that the US ban on the importation of shrimps harvested in a turtle unfriendly manner, i.e. without use of special turtle exclusion devises (TEDs), was in breach of Article XI:1. ${ }^{540}$ In EEC-Minimum Export Prices and Japan - Semi-Conductors the GATT Panels ruled that imposing minimum import and export prices constituted quantitative restrictions within the meaning of Article XI:1. ${ }^{541}$ The non-automatic import licensing system adopted in India was found to be in violation of Article XI:1 by the Panel in India - Quantitative Restrictions. ${ }^{542}$ The measure authorizing Colombian customs officials to restrict the points of entry of textile, apparel and footwear goods that arrived from Panama to only two ports (the

536 Appellate Body Reports, Argentina-Import Measures, para. 5.219, referring to Panel Reports, Argentina - Import Measures, paras. 6.246, 6.435, and 6.450

537 See: GATT Panel Report, Japan-Semi-Conductors, para. 104; Panel Report, India-Autos, para. 7.261. See also: Peter Van den Bossche, Werner Zdouc, The Law and Policy of the World Trade Organization. Text, Cases and Materials, 3 d Edition, CUP, 2013, p. 483.

538 In this respect, for more information on the relationship between Articles XI:1 and III:4, see Section 3.3.1.2 of the present Chapter.

539 See: GATT Panel Report, US - Tuna (Mexico, unadopted), para. 7.1; GATT Panel Report, US - Tuna (EEC, unadopted), para. 6.1. For more information on these cases see also Section 3.3.6 of the present Chapter.

540 See: Panel Report, US - Shrimp, para. 8.1.

541 See: GATT Panel Report, EEC - Minimum Export Prices, para. 4.14; GATT Panel Report, Japan - Semi-Conductors, para. 117. See also: Kevin Kennedy, "GATT 1994”, at: Patrick F.J. Macrory, The World Trade Organization: Legal, Economic and Political Analysis, 1 Springer [etc.], New York, 2005, p. 128.

542 See: Panel Report, India - Quantitative Restrictions, para. 5.130. 
Bogota airport and Barranquilla seaport) was found to be inconsistent with Article XI:1 by the Panel in Colombia - Ports of Entry. ${ }^{543}$

In one of the recent cases, China - Rare Earths, the Panel found that the export quotas applied by China to various forms of rare elements (so-called "rare earths"), tungsten and molybdenum were inconsistent with Article XI:1. ${ }^{544}$ In another recent case, Argentina-Import Measures, the Panel considered two types of trade-restrictive measures applied by Argentina: 1. the requirements that the economic operators undertake certain specific actions as part of a policy seeking to eliminate trade balance deficits and substitute imports for domestically-produced goods - the Restrictive TradeRelated Requirements (RTRRs); and 2. the very complex and burdensome procedure of obtaining an importation permission by an importer - filing the Advance Sworn Import Declaration (DJAI). The Panel found that both measures constituted restrictions on the importation of goods and were thus inconsistent with Article XI:1 of the GATT $1994^{545}$.

As has been noted, in addition to quotas and import or export licences, Article XI:1 also refers to "other measures" maintained by WTO Members. This makes the reach of this provision quite broad. In this regard, a measure imposing significant fines for actions in connection with the importation and exportation of products may fall into the scope of Article XI:1 as well. For example, in Brazil-Retreated Tyres, the EU (a complainant) argued that big fines imposed by the Brazilian government on the importation of retreated tyres and their marketing, transportation, storage, keeping or warehousing, constituted an enforcement of "restriction" on importation of retreated tyres within the meaning of Article XI:1. ${ }^{546}$ The Panel agreed with the EU and explained:

We are also of the view that what is important in considering whether a measure falls within the types of measures covered by Article XI:1 is the nature of the measure. In the present case, we note that the fines as a whole, including that on marketing, have the effect of penalizing the act of "importing" retreaded tyres by subjecting retreaded tyres already imported and existing in the Brazilian internal market to the prohibitively expensive rate of

${ }^{543}$ Panel Report, Colombia - Ports of Entry, para. 7.275. For some more examples see: Peter Van den Bossche, Werner Zdouc, The Law and Policy of the World Trade Organization. Text, Cases and Materials, 3d Edition, CUP, 2013, pp. 483 - 484.

${ }^{544}$ Panel Reports, China-Rare Earths, paras. 7.200 and 8.2. Similarly, in the earlier case against China, China-Raw Materials, the Panel found that the application of an export ban and export quotas to certain kinds of raw materials by China was inconsistent with Article XI:1 of the GATT 1994. See: Panel Reports, China - Raw Materials, paras. 8.3, 8.10 and 8.17, as modified by Appellate Body Reports, China - Raw Materials.

545 Panel Reports, Argentina - Import Measures, paras. 6.265 and 6.479.

546 See: Panel Report, Brazil-Retreated Tyres, paras. 7.361 and 7.368 . 
fines. To that extent, we consider that the fact that the fines are not administered at the border does not alter their nature as a restriction on importation within the meaning of Article XI:1. ${ }^{547}$

Moreover, as has been already described before, in Japan-Semi-Conductors, the GATT Panel considered the voluntary export restrains which operated through the actions of the relevant industry and were encouraged by the Japanese government. The Panel ruled that in the context of the Japanese legal system, this group of de jure non-mandatory measures constituted a "restriction" on exports in violation of Article XI:1, even in "the absence of formal legally binding obligations in respect of exportation or sale for export of semi-conductors". ${ }^{548}$

Considering the discussion above, it seems that Article XI:1, in appropriate circumstances, may appear to be relevant with respect to the regulation of private-sector standards. Indeed, as has been explained in Section 2.1.1.4 of Chapter II, a private-sector standard provides rules, guidelines or characteristics for products or PPMs. Article XI:1 of the GATT 1994 addresses the measures which prohibit or restrict the importation or exportation of products; and such prohibitions or restrictions, in principle, may be based on product characteristics or PPMs. However, as has been mentioned in Section 3.3.1.2 of the present Chapter, it might be difficult to draw a clear distinction, in this respect, between the relevance of Article XI:1 and Article III:4 (national treatment obligation in relation to internal regulations) of the GATT 1994. For example, in EC-Seal Products, the EU, due to moral and environmental reasons, imposed an import prohibition on seals and seal products, which was, however, qualified by a number of exceptions. The Panel found that the EU measure violated Article III:4 of the GATT 1994, because an exception from the ban granted to some EU seal products was not granted to the relevant products from Canada and Norway, thus allowing the less favourable treatment of the latter. ${ }^{549}$ The Panel, however, did not have to consider whether the EU Seal Regime as a whole had a restrictive impact on imported seal products in violation of Article XI:1 since this was not claimed by the complainants. ${ }^{550}$ Therefore, the important question about whether such a measure could be also considered under Article XI:1 of the GATT 1994 remains unanswered.

547 Panel Report, Brazil - Retreated Tyres, para. 7.372.

548 GATT Panel Report, Japan-Semi-Conductors, para. 108 - 132. For more information on this case see Sections 3.1.1 and 3.2.2.1.1 of the present Chapter.

549 See: Panel Reports, EC - Seal Products, paras. 7.608 - 7.609; these findings of the Panel were not appealed.

550 See: Panel Reports, EC - Seal Products, para. 7.658. In the Panel's understanding, the complainants rather contended that each exception from the prohibition resulted in a limiting effect on imports and thus violated Article XI:1. These findings of the Panel were not appealed. 


\subsubsection{General Exceptions From the GATT Obligations}

Article XX of the GATT 1994 provides for the general exceptions from the GATT obligations and reads in its relevant part as follows:

Subject to the requirement that such measures are not applied in a manner which would constitute a means of arbitrary or unjustifiable discrimination between countries where the same conditions prevail, or a disguised restriction on international trade, nothing in this Agreement shall be construed to prevent the adoption or enforcement by any contracting party of measures:

(a) necessary to protect public morals;

(b) necessary to protect human, animal or plant life or health; $[\ldots]$

(d) necessary to secure compliance with laws or regulations which are not inconsistent with the provisions of this Agreement, including those relating to customs enforcement, the enforcement of monopolies operated under paragraph 4 of Article II and Article XVII, the protection of patents, trade marks and copyrights, and the prevention of deceptive practices; $[\ldots]$

(f) imposed for the protection of national treasures of artistic, historic or archaeological value;

(g) relating to the conservation of exhaustible natural resources if such measures are made effective in conjunction with restrictions on domestic production or consumption; $[\ldots]^{551}$

The general exceptions of Article XX allow WTO Members to impose trade measures which would otherwise be inconsistent with the GATT 1994, in order to protect their important societal objectives, e.g. public health, or exhaustible natural resources. Article XX therefore serves as a tool for balancing trade- and non-trade-related values in measures adopted and applied by WTO Members. ${ }^{552}$ In this regard, as has been noted by the GATT Panel in US -Section 337 Tariff Act, the general exceptions of Article XX are

551 Other paragraphs of Article XX are less important and are indeed not relevant for the issue of regulation of private-sector standards. They are therefore not quoted here. See: Panel Reports, EC - Seal Products, paras. 7.660 - 7.663.

552 See: Peter Van den Bossche, Werner Zdouc, The Law and Policy of the World Trade Organization. Text, Cases and Materials, 3d Edition, CUP, 2013, p. 547; Stefan Zleptnig, Non-Economic Objectives in WTO Law. Justification Provisions of GATT, GATS, SPS and TBT Agreements, Vol. 1, Martinus Nijhoff Publishers, Leiden Boston, 2010, p. 125; Petros C. Mavroidis, Trade in Goods. The GATT and the Other WTO Agreements Regulating Trade in Goods, OUP, Oxford, 2012, pp. 325 - 326. 
"limited and conditional". ${ }^{553}$ Indeed, the exceptions are "limited" because their list in Article XX is a closed one, and no additional exceptions not specified in the Article may be invoked by WTO Members. Furthermore, the exceptions are "conditional" because they are subject to rather strict conditions imposed by the provisions of Article XX.

Finally, it is also worth noting that the status of the rules of Article XX as "exceptions" means that, in the WTO dispute settlement processes, it is the task of a respondent to invoke an exception out of the list and to meet the burden of proof that a measure is indeed justified under the exception. Generally, the approach to allocation of the burden of proof in the WTO dispute settlement process was developed by the Appellate Body in US Wool Shirts and Blouses. According to the Appellate Body:

\begin{abstract}
Also, it is a generally accepted canon of evidence in civil law, common law and, in fact, most jurisdictions, that the burden of proof rests upon the party, whether complaining or defending, who asserts the affirmative of a particular claim or defence. If that party adduces evidence sufficient to raise a presumption that what is claimed is true, the burden then shifts to the other party, who will fail unless it adduces sufficient evidence to rebut the presumption. ${ }^{554}$
\end{abstract}

According to this approach, as a rule, a complainant has the burden of raising a presumption of inconsistency or, in other words, making a prima facie case of the violation of a particular provision. Then the burden of proof shifts to a respondent who needs to provide sufficient evidence to rebut this presumption. Following this principle, after a violation of a substantive provision of the GATT has been established, the burden of proof shifts to a respondent to demonstrate that a measure is justified under the general exceptions of Article XX. ${ }^{555}$

In US - Shrimp, an interesting issue was raised with respect to the justification of a measure under Article XX: whether the Article may justify the measures of a WTO Member inducing other Members to adopt certain policies. The Panel came to the sweeping conclusions that the measures conditioning market access for a product "upon adoption by the exporting Member of certain policies" would undermine the security and predictability of the WTO system and, as such, could not be justified under Article XX. ${ }^{556}$ However, the Appellate Body strongly disagreed with such an approach and reversed the Panel's conclusions in this regard. In particular, it observed:

\footnotetext{
553 See: GATT Panel Report, US - Section 337 Tariff Act, para. 5.9

554 Appellate Report, US - Wool Shirts and Blouses, p. 14.

555 See: Appellate Body Reports, EC - Seal Products, para. 5.169.

556 See: Panel Report, US - Shrimp, para. 7.45.
} 
Paragraphs (a) to (j) comprise measures that are recognized as exceptions to substantive obligations established in the GATT 1994, because the domestic policies embodied in such measures have been recognized as important and legitimate in character. It is not necessary to assume that requiring from exporting countries compliance with, or adoption of, certain policies (although covered in principle by one or another of the exceptions) prescribed by the importing country, renders a measure a priori incapable of justification under Article XX. Such an interpretation renders most, if not all, of the specific exceptions of Article XX inutile, a result abhorrent to the principles of interpretation we are bound to apply. ${ }^{557}$

The text of Article XX may be subdivided into two parts: 1. paragraphs listing the specific exceptions; and 2. the chapeau providing certain requirements with respect to the entire list of exceptions. In US - Gasoline, the Appellate Body explained in this regard:

In order that the justifying protection of Article XX may be extended to it, the measure at issue must not only come under one or another of the particular exceptions - paragraphs (a) to (j) - listed under Article XX; it must also satisfy the requirements imposed by the opening clauses of Article XX. The analysis is, in other words, two-tiered: first, provisional justification by reason of characterization of the measure under XX $(\mathrm{g})$; second, further appraisal of the same measure under the introductory clauses of Article XX. ${ }^{558}$

Article XX therefore sets out a two-tier test in order to determine whether a measure, which is inconsistent with other GATT provisions, may nevertheless be justified under the general exceptions. First, it must be considered whether a measure is provisionally justified under a paragraph of Article XX listing a legitimate objective, which may be protected by a WTO Member. And second, a measure must be examined against the requirements of the chapeau of the Article. ${ }^{559}$ According to the Appellate Body, the chapeau of Article XX, "by its express terms addresses, not so much the questioned measure or its specific contents as such, but rather the

557 Appellate Body Report, US - Shrimp, para. 121.

558 Appellate Body Report, US - Gasoline, p. 22. See also: Appellate Body Report, US - Shrimp, para. 118; Appellate Body Report, Brazil - Retreated Tyres, para. 139.

559 See: Appellate Body Report, US - Gasoline, p. 22; p. 20; Appellate Body Report, US - Shrimp, paras. 119 and 120; Appellate Body Report, Brazil-Retreaded Tyres, para. 139; Appellate Body Reports, EC - Seal Products, para. 5.169; Panel Report, China - Publications and Audiovisual Products, para. 7.746; Appellate Body Reports, China-Rare Earths, para. 5.86. 
manner in which that measure is applied" ${ }^{560}$ And "[t]he general design of a measure, as distinguished from its application, is, however, to be examined "in the course of determining whether that measure falls within one or another of the paragraphs of Article XX following the chapeau". ${ }^{561}$ The Appellate Body further noted that the "task of interpreting the chapeau so as to prevent the abuse or misuse of the specific exemptions provided for in Article XX" would be rendered very difficult, if possible at all, unless the specific exception threatened with abuse is properly identified and examined. ${ }^{562}$ Concerning the provisional justification of a measure under one of the subparagraphs of Article XX of the GATT 1994, the Appellate Body recalled that the measure must "address the particular interest specified in that paragraph" and there must be "a sufficient nexus between the measure and the interest protected". ${ }^{563}$

The general exceptions provided in Article XX might be relevant for the regulation of private-sector standards in cases where a standard is attributable to a WTO Member and violates certain obligations of the GATT 1994. In such cases, provisions of such a standard could be justified under the rules of Article XX. Indeed, many private-sector standards claim to ensure the protection of important societal objectives, such as public health, environment and ethical or moral values. In this regard, a number of exceptions specified in Article XX seem to be relevant, namely: paragraph (a) dealing with protection of public morals; paragraph (b) dealing with protection of human, animal or plant life or health; paragraph (d) dealing with the measures necessary to secure compliance with laws or regulations, and paragraph $(\mathrm{g})$ dealing with the measures related to the conservation of exhaustible natural resources. Paragraph (f) justifies the measures imposed for the protection of national treasures of artistic, historic or archaeological value, i.e. subjects of national historical and cultural heritage, and has not been yet examined in detail in the WTO dispute settlement practice.

The next sections address the exceptions provided in paragraphs (a), (b), (d) and (g) in more detail, followed by an examination of the rules of the chapeau of Article XX.

560 Appellate Body Report, US - Gasoline, p. 22. See also: Appellate Body Report, US - Shrimp, para. 115.

561 See: Appellate Body Report, US - Shrimp, para. 116. See also: Panel Report, Brazil-Retreated Tyres, para. 7.107.

562 See: Appellate Body Report, US - Shrimp, para. 120.

563 See: Appellate Body Reports, China - Rare Earths, para. 5.87; referring to Appellate Body Reports, EC - Seal Products, para. 5.169 and Appellate Body Report, US - Gambling, para. 292. 


\subsubsection{Measures Necessary to Protect Public Morals}

The exception of Article XX(a) deals with measures necessary to protect public morals. Therefore, for a measure to be justified under Article XX(a), the measure, first, must be aimed at the protection of the "public morals" of a WTO Member; and, second, it must be "necessary" in order to exercise such a protection. ${ }^{564}$

The morality, however, appears to depend on the beliefs of a particular society and, as such, may differ from WTO Member to WTO Member. ${ }^{565}$ This indeed has been noted by the Panel in China - Publications and Audiovisual Products. The Panel noted that Article XX(a) of the GATT 1994 uses the same concept of "public morals" as the corresponding provision of the GATS - Article XIV(a). ${ }^{566}$ This concept in Article XVI(a) of the GATS has been examined by the Panel in US - Gambling, which noted that "the term "public morals" denotes standards of right and wrong conduct maintained by or on behalf of a community or nation". ${ }^{567}$ The Panel further observed that "the content of these concepts for Members can vary in time and space, depending upon a range of factors, including prevailing social, cultural, ethical and religious values". ${ }^{568}$ The Members thus "should be given some scope to define and apply for themselves the concepts of "public morals" $[\ldots]$ in their respective territories, according to their own systems and scales of values". ${ }^{569}$

With respect to the term "to protect" used in Article XX(a) of the GATT 1994, the Appellate Body in EC - Seal Products observed that this term "is used in three subparagraphs of Article XX that concern the "protection" of different non-economic interests and concerns", namely, paragraphs (a), (b) and (f) of Article XX. According to the Appellate Body, for example, the protection of human, animal, or plant life or health under Article XX(b)

564 See: Panel Report, China-Publications and Audiovisual Products, paras. 7.758 - 7.781; Appellate Body Reports, EC - Seal Products, para. 5.169.

565 See: Stefan Zleptnig, Non-Economic Objectives in WTO Law. Justification Provisions of GATT, GATS, SPS and TBT Agreements, Vol. 1, Martinus Nijhoff Publishers, Leiden - Boston, 2010, pp. 128 - 142. For the discussion on the issue of "necessity" see Section 3.3.4.2 of the present Chapter.

566 Panel Report, China-Publications and Audiovisual Products, para. 7.759.

567 Panel Report, US - Gambling, para. 6.465; Appellate Body Report, US - Gambling, para. 299; Panel Report, China-Publications and Audiovisual Products, para. 7.759.

568 Panel Report, US - Gambling, para. 6.461; Panel Report, China-Publications and Audiovisual Products, para. 7.759.

569 Panel Report, US - Gambling, para. 6.461; Panel Report, China-Publications and Audiovisual Products, para. 7.759. See also: Appellate Body Reports, EC - Seal Products, para. 5.199. 
may imply a particular focus on the protection from or against certain dangers or risks. ${ }^{570}$ Nonetheless, the Appellate Body further concluded:

However, the notion of risk in the context of Article XX(b) is difficult to reconcile with the subject matter of protection under Article XX(a), namely, public morals. While the focus on the dangers or risks to human, animal, or plant life or health in the context of Article XX(b) may lend itself to scientific or other methods of inquiry, such risk-assessment methods do not appear to be of much assistance or relevance in identifying and assessing public morals. ${ }^{571}$

The Appellate Body therefore ruled that the term "to protect", when used in relation to "public morals" under Article XX(a), did not require the Panel to identify the existence of a risk to EU public moral concerns regarding seal welfare. ${ }^{572}$ For this reason, and taking into account the meaning of the concept of "public morals" as discussed above, the Appellate Body also concluded that a panel is not required to identify the exact content of the public morals standard at issue for the purposes of an analysis under Article XX(a).$^{573}$ Finally, the Appellate Body further observed that, even if the EU had the same moral concerns regarding seal welfare and the welfare of other animals, the EU was not required by Article XX(a) to address such public moral concerns in the same way. ${ }^{574}$

The concept of "necessity" under Article XX(a), i.e. whether a measure is "necessary" for the protection of public morals, has been interpreted by panels and the Appellate Body following the same approach as developed under paragraphs (b) and (d) of Article XX; it will be discussed in more detail in Section 3.3.4.2 hereafter. In a nutshell, the necessity analysis involves a process of "weighing and balancing" a series of factors, including the importance of the objective, the contribution of the measure to that objective, and the trade-restrictiveness of the measure. ${ }^{575}$ The Appellate Body has also explained that "in most cases, a comparison between the challenged measure and possible alternatives should then be undertaken". ${ }^{576}$ In this

570 Appellate Body Reports, EC - Seal Products, para. 5.197, referring to Panel Report, $E C$ - Asbestos, para. 8.170. For further discussion of the exception provided in Article XX(b) of the GATT 1994 see Section 3.3.4.2 of the present Chapter.

571 Appellate Body Reports, EC - Seal Products, para. 5.198.

572 Appellate Body Reports, EC - Seal Products, para. 5.198.

573 Appellate Body Reports, EC - Seal Products, para. 5.199.

574 Appellate Body Reports, EC - Seal Products, para. 5.200.

575 Appellate Body Reports, EC - Seal Products, para. 5.169, referring to Appellate Body Report, Korea - Various Measures on Beef, para. 164; Appellate Body Report, US - Gambling, para. 306; Appellate Body Report, Brazil-Retreaded Tyres, para. 182.

576 Appellate Body Reports, EC - Seal Products, para. 5.169, referring to Appellate 
process " $[\mathrm{t}]$ he burden of proving that a measure is "necessary to protect public morals" within the meaning of Article XX(a) resides with the responding party, although a complaining party must identify any alternative measures that, in its view, the responding party should have taken". ${ }^{577}$

The protection of public morals seems to be an important objective of laws and regulations adopted by many WTO Members. This objective serves as a basis for such trade-restrictive measures as the prohibition of importation and sales of alcoholic beverages and swine meat in many Muslim countries, bans on gambling and gambling machines and the prohibition of pornographic materials. This objective may also be invoked, for example, in cases of a ban imposed on products produced with child labour or serious violations of human rights. ${ }^{578}$

However, to date, the justification provided in Article XX(a) of the GATT 1994 has been examined only in two disputes. In China - Publications and Audiovisual Products, the Appellate Body upheld most of the Panel's findings that China's restrictions on the importation and distribution of publications and audiovisual products, namely a content review mechanism and importation only by approved entities, was not necessary for the protection of public morals in China and was therefore not provisionally justified under Article XX(a) ${ }^{579}$ In the second case, EC - Seal Products, the Appellate Body, on the other hand, upheld the Panel's findings that the EU ban on the importation of seal products was necessary to protect public morals within the meaning of Article XX(a). ${ }^{580}$

The objective of the protection of public morals is clearly relevant with respect to private-sector standards; indeed, quite a few such standards and labelling schemes, e.g. GLOBALG.A.P. and FLO, address this type of objective to greater or lesser degree. ${ }^{581}$ However, the important question which arises in this respect is whether the application of a private-sector standard is really "necessary" for the protection of particular public moral

Body Report, US - Gambling, para. 307; Appellate Body Report, Korea - Various Measures on Beef, para. 166; Appellate Body Report, US - Tuna II (Mexico), para. 321. See also: Appellate Body Report, China-Publications and Audiovisual Products, paras. $318-319$.

577 Appellate Body Reports, EC - Seal Products, para. 5.169, referring to Appellate Body Report, US - Gambling, paras. 309 - 311. See also: Appellate Body Report, China - Publications and Audiovisual Products, para. 289.

578 For more examples see: Peter Van den Bossche, Werner Zdouc, The Law and Policy of the World Trade Organization. Text, Cases and Materials, 3d Edition, CUP, 2013, p. 571.

579 See: Appellate Body Report, China - Publications and Audiovisual Products, paras. $336-337$.

580 See: Appellate Body Reports, EC - Seal Products, paras. 5.289 - 5.290.

581 For further discussion about objectives of private-sector standards see Section 2.2.5 of Chapter II. 
values within the meaning of Article XX(a) of the GATT 1994. The concept of "necessity" and the necessity test are described in more detail in the following Section.

\subsubsection{Measures Necessary to Protect Life or Health}

The exception of Article XX(b) addresses measures "necessary to protect human, animal or plant life or health". In US - Gasoline, the Panel distinguished between two elements which must be fulfilled for a measure to be provisionally justified under Article XX(b). These two elements form the two-tier test under Article XX(b) and were described by the Panel as follows:

(a) the policy in respect of the measures for which the provision is invoked falls within the range of policies designed to protect human, animal or plant life or health; and

(b) the inconsistent measure for which the exception is invoked is necessary to fulfil the policy objective. ${ }^{582}$

The first element deals with determining whether a measure at issue is really designed to protect the specified objectives, i.e. whether it is appropriate to address the relevant risks. This determination usually does not raise significant problems in practice. For example, the Panel in Brazil-Retreated Tyres concluded that:

[..] Brazil has demonstrated the existence of risks to animal and plant life or health in relation to toxic emissions caused by tyre fires. It also finds that risks to animal life or health posed by at least one mosquito-borne disease (dengue) exist in connection with the accumulation of waste tyres. ${ }^{583}$

The Panel also found that "Brazil's policy of reducing exposure to the risks to human, animal or plant life or health arising from the accumulation of waste tyres falls within the range of policies covered by Article XX(b)". ${ }^{584}$ Interestingly, the Panel further noted that Article XX(b), in principle, may cover measures adopted for environmental purposes; however Brazil had to "establish the existence not just of risks to "the environment" generally, but specifically of risks to animal or plant life or health". ${ }^{585}$

On the other hand, in EC - Tariff Preferences for example, the Panel came to the opposite conclusions with regard to the additional tariff preferences

582 Panel Report, US - Gasoline, para. 6.20. See also: Panel Report,

Brazil-Retreated Tyres, para. 7.40.

583 Panel Report, Brazil-Retreated Tyres, para. 7.93.

584 Panel Report, Brazil - Retreated Tyres, para. 7.102.

585 Panel Report, Brazil-Retreated Tyres, para. 7.46. 
granted by the EU under its Drug Arrangements and the Generalized System of Preferences. In particular, the Panel ruled that "the policy reflected in the Drug Arrangements is not one designed for the purpose of protecting human life or health in the European Communities, and, therefore, the Drug Arrangements are not a measure for the purposes of protecting human life or health under Article XX(b) of the GATT 1994" ${ }_{586}$

The second element of the two-tier test under Article XX(b) is definitely more complex than the first one and involves the determination of the "necessity" of a measure at hand, i.e. the necessity test. The concept of necessity is also present in the exception of Article XX(d). With regard to the latter provision, the Appellate Body clarified in Korea - Various Measures on Beef that:

$[\ldots]$ the term "necessary" refers, in our view, to a range of degrees of necessity. At one end of this continuum lies "necessary" understood as "indispensable"; at the other end, is "necessary" taken to mean as "making a contribution to." We consider that a "necessary" measure is, in this continuum, located significantly closer to the pole of "indispensable" than to the opposite pole of simply "making a contribution to". ${ }^{587}$

The Appellate Body further explained that this concept "involves in every case a process of weighing and balancing a series of factors which prominently include the contribution made by the compliance measure to the enforcement of the law or regulation at issue, the importance of the common interests or values protected by that law or regulation, and the accompanying impact of the law or regulation on imports or exports". ${ }^{588}$ Thus, according to the Appellate Body, the "weighing and balancing" process entails that:

The more vital or important those common interests or values are, the easier it would be to accept as "necessary" a measure designed as an enforcement instrument. ${ }^{589}$

586 Panel Report, EC - Tariff Preferences, para. 7.210.

587 Appellate Body Report, Korea - Various Measures on Beef, para. 161. See also: Appellate Body Report, Brazil - Retreated Tyres, para. 141.

588 Appellate Body Report, Korea - Various Measures on Beef, para. 164.

See also: Appellate Body Report, EC - Asbestos, para. 172; Appellate Body Report, US - Gambling, para. 306; Appellate Body Report, Dominican Republic - Import and Sale of Cigarettes, para. 70; Panel Report, Brazil - Retreated Tyres, para. 7.104; Appellate Body Report, Brazil - Retreated Tyres, para. 142; Panel Reports, China-Raw Materials, paras. 7.480 - 7.481.

589 Appellate Body Report, Korea - Various Measures on Beef, para. 162. See also: Appellate Body Report, EC - Asbestos, para. 172; Panel Reports, China-Raw Materials, para. 7.482. 
In the process of "weighing and balancing" these factors, panels and the Appellate Body suggested that a comparison be made between a challenged measure and possible less trade-restrictive alternatives:

The weighing and balancing process of these three factors also informs the determination whether a WTO-consistent alternative measure which the Member concerned could reasonably be expected to employ is available, or whether a less WTO-inconsistent measure is reasonably available. ${ }^{590}$

A possible less trade-restrictive alternative is, as can be seen, one that is "reasonably" available for a WTO Member. In this regard, as has been pointed out by the Panel in US - Gasoline, an alternative measure did not cease to be "reasonably" available simply because the alternative involved certain administrative difficulties for a Member. ${ }^{591}$ However, an alternative measure must be able to address the risk and achieve the level of health protection chosen by a WTO Member. For example, in EC - Asbestos, the Appellate Body, upon suggestion by Canada (the complainant), considered the "controlled use" of asbestos as an alternative measure to the total ban of asbestos. The Appellate Body upheld the ruling of the Panel that this alternative was not "reasonably" available since it did not achieve the level of health protection chosen by the EU and in fact involved a continuation of the very risk the EU sought to halt. ${ }^{592}$

Similarly, in Brazil - Retreated Tyres, the Appellate Body rejected two types of alternatives to Brazil's ban on the importation of retreated tyres, which were suggested by the EU (the complainant): 1 . measures to reduce the number of waste tyres accumulating in Brazil; and 2. measures or practices to improve the management of waste tyres in Brazil. ${ }^{593}$ In this regard, the Appellate Body agreed with the Panel that the proposed alternative measures, some of which were already in place, were not as effective as the import ban in reducing the risks arising from the accumulation of waste

590 Appellate Body Report, Dominican Republic - Import and Sale of Cigarettes, para. 70. See also: Appellate Body Report, Korea - Various Measures on Beef, paras. 165 - 166; Appellate Body Report, US - Gambling, paras. 306 - 308; Appellate Body Report, EC - Asbestos, para. 169; GATT Panel Report, US - Section 337 Tariff Act, para. 5.26; Panel Report, Brazil-Retreated Tyres, para. 7.104. It is the task of a complainant to suggest alternative measures, which are reasonably available; see: Appellate Body Report, Brazil-Retreated Tyres, para. 156; Appellate Body Report, US - Gambling, paras. 311. See also: Jan Neumann, Elisabeth Turk, "Necessity Revisited: Proportionality in World Trade Organization Law After Korea - Beef, EC - Asbestos and EC - Sardines”, Journal of World Trade, 37(1), 2003, pp. $210-212$.

591 See: Panel Report, US - Gasoline, paras. 6.26 - 6.28; Appellate Body Report, EC-Asbestos, para. 169.

592 See: Appellate Body Report, EC - Asbestos, paras. 174 -175.

593 See: Appellate Body Report, Brazil - Retreated Tyres, para. 157. 
tyres. Brazil's measure was thus found to be necessary for the achievement of the specified objectives and, hence, provisionally justified under Article $\mathrm{XX}(\mathrm{b}) .{ }^{594}$

It seems that the private-sector standards adopted and applied without meaningful governmental involvement or incentives hardly fit into the concept of necessity analysis developed by WTO panels and the Appellate Body, which is discussed above. First of all, a private entity developing a private-sector standard may base it on its own interests or on the interests of certain group of actors, e.g. the interests of industry or buyers. Thus, such private-sector standards would not be aimed at the protection of "common interests or values" of a society ${ }^{595}$ (this is, however, not to say that private-sector standards, in principle, may not be aimed at the protection of common interests or values; in fact, many private-sector standards, such as the FSC, the MSC, the Fair Trade labelling, etc., have such an objective). Second, the implementation of a private-sector standard adopted and applied without meaningful governmental involvement or incentives is voluntary (both de jure and de facto) for market players. In this light the determination whether an alternative less trade-restrictive measure is reasonably available for a WTO Member (and not a private actor) would, arguably, hardly make any sense, unless the development and application of the private-sector standard receives meaningful governmental support, transforming it into the measure of the WTO Member.

\subsubsection{Measures Necessary to Secure Compliance With Laws or Regulations}

Article XX(d) provides an exception with respect to the measures "necessary to secure compliance with laws or regulations which are not inconsistent with the provisions" of the GATT 1994. Thus, for a measure to be justified, Article XX(d) sets out the two-tier test, which was explained by the Appellate Body in Korea - Various Measures on Beef as follows:

For a measure, otherwise inconsistent with GATT 1994, to be justified provisionally under paragraph (d) of Article XX, two elements must be shown. First, the measure must be one designed to "secure compliance" with laws or regulations that are not themselves inconsistent with some provision of the GATT 1994. Second, the measure must be "necessary" to secure such compliance. A Member who invokes Article XX(d) as a justification has the burden of demonstrating that these two requirements are met. ${ }^{596}$

594 See: Appellate Body Report, Brazil - Retreated Tyres, paras. 175, 183.

595 Appellate Body Report, Korea - Various Measures on Beef, para. 164.

596 Appellate Body Report, Korea - Various Measures on Beef, para. 157. See also: 
With respect to the first element of the two-tier test, the Panel in US Gasoline explained that a measure designed to "secure compliance", as a rule, must constitute "an enforcement mechanism" for another GATT consistent measure. ${ }^{597}$ The Appellate Body in Mexico - Taxes on Soft Drinks further clarified the first element of the test. In this case the Appellate Body considered the meaning of the terms "laws or regulations" in Article XX(d). Mexico (the respondent) asserted that its measure was necessary in order to ensure the compliance of the US with its obligations under the North American Free Trade Agreement (NAFTA). Thus, the issue was whether Article XX(d) may cover and justify the measures adopted by WTO Members in order to "persuade" other Members to comply with their international obligations. The Panel found negatively on this issue and ruled that Article XX(d) may apply only to domestic laws or regulations. ${ }^{598}$ The Appellate Body agreed with the Panel and explained:

We agree with the United States that one does not immediately think about international law when confronted with the term "laws" in the plural. Domestic legislative or regulatory acts sometimes may be intended to implement an international agreement. In such situations, the origin of the rule is international, but the implementing instrument is a domestic law or regulation. In our view, the terms "laws or regulations" refer to rules that form part of the domestic legal system of a WTO Member. Thus, the "laws or regulations" with which the Member invoking Article XX(d) may seek to secure compliance do not include obligations of another WTO Member under an international agreement. ${ }^{599}$

The Appellate Body further substantiated such an interpretation through the "illustrative list" of measures provided in Article XX(d), which includes laws or regulations "relating to customs enforcement, the enforcement of monopolies operated under paragraph 4 of Article II and Article XVII, the protection of patents, trade marks and copyrights", etc. According to the Appellate Body, "[t]hese matters are typically the subject of domestic laws or regulations". ${ }^{600}$ The Appellate Body then observed that the terms "to

Appellate Body Report, Dominican Republic - Import and Sale of Cigarettes, para. 65; Appellate Body Report, US - Gasoline, pp. 22-23; Appellate Body Report, US - Wool Shirts and Blouses, pp. 14-16; GATT Panel Report, US - Section 337 Tariff Act, para. 5.27.

597 See: Panel Report, US - Gasoline, para. 6.33. The Panel therefore concluded that the US baseline establishment methods were discriminatory for foreign gasoline and "were not the type of measures with which Article XX(d) was concerned".

598 See: Panel Report, Mexico - Taxes on Soft Drinks, para. 8.181.

599 Appellate Body Report, Mexico - Taxes on Soft Drinks, para. 69.

600 Appellate Body Report, Mexico - Taxes on Soft Drinks, para. 70. 
secure compliance" in Article XX(d) "relate to the design of the measures sought to be justified" ${ }^{601}$ It further explained in this respect:

In our view, a measure can be said to be designed "to secure compliance" even if the measure cannot be guaranteed to achieve its result with absolute certainty. Nor do we consider that the "use of coercion" is a necessary component of a measure designed "to secure compliance". Rather, Article XX(d) requires that the design of the measure contribute "to secur[ing] compliance with laws or regulations which are not inconsistent with the provisions of" the GATT $1994 .{ }^{602}$

The second element of the two-tier test under Article XX(d) - the "necessity" requirement - has, to large extent, been interpreted in the same way as the "necessity" requirement under Article XX(b) ${ }^{603}$

Private-sector standards may indeed frequently be aimed at securing compliance with governmental laws or regulations. For example, the private "Dolphin Safe" labelling scheme for tuna products developed and administered by the US-based NGO Earth Island Institute, ${ }^{604}$ is apparently aimed at the protection of dolphins, which are also protected according to the US legislation and other international agreements. However, as has been noted in Section 3.3.4.2, considering the structure of the "necessity test" developed by the Appellate Body, the issues of necessity with respect to a private-sector standard seems to be closely linked with the issue of attribution of such a standard to a WTO Member. Indeed, determining whether an alternative less trade-restrictive measure is reasonably available for a WTO Member would be hardly possible unless the development and application of a private-sector standard receives meaningful governmental involvement or incentives.

\subsubsection{Measures Relating to the Conservation of Exhaustible Natural Resources}

Article XX(g) provides for the exception with respect to the measures "relating to the conservation of exhaustible natural resources". Based on the text of Article XX (g), the analysis under this Article consists of a three-tier test with the following elements:

- resources at issue must be "exhaustible natural resources";

- a measure must "relate to conservation" of such resources; and

601 Appellate Body Report, Mexico - Taxes on Soft Drinks, para. 72.

602 Appellate Body Report, Mexico - Taxes on Soft Drinks, para. 74. See also: Panel Report, Mexico - Taxes on Soft Drinks, para. 8.178.

${ }_{603}$ See Section 3.3.4.2 of the present Chapter.

604 See: http://www.earthisland.org/dolphinSafeTuna/consumer/index.html (last visited January 15, 2015). 
- a measure must be "made effective in conjunction with restrictions on domestic production or consumption".

With respect to the first element of the test, in US - Shrimp the issue arose whether endangered animal species, such as sea turtles, may qualify as "exhaustible natural resources" within the meaning of Article XX(g). In this regard, the complainants argued that Article XX(g) refers only to "finite resources such as minerals, rather than biological or renewable resources" ${ }^{605}$ The Appellate Body disagreed with the complainants and held that:

Textually, Article $\mathrm{XX}(\mathrm{g})$ is not limited to the conservation of "mineral” or "non-living" natural resources. The complainants' principal argument is rooted in the notion that "living" natural resources are "renewable" and therefore cannot be "exhaustible" natural resources. We do not believe that "exhaustible" natural resources and "renewable" natural resources are mutually exclusive. One lesson that modern biological sciences teach us is that living species, though in principle, capable of reproduction and, in that sense, "renewable", are in certain circumstances indeed susceptible of depletion, exhaustion and extinction, frequently because of human activities. Living resources are just as "finite" as petroleum, iron ore and other non-living resources.

The words of Article XX(g), "exhaustible natural resources", were actually crafted more than 50 years ago. They must be read by a treaty interpreter in the light of contemporary concerns of the community of nations about the protection and conservation of the environment. While Article XX was not modified in the Uruguay Round, the preamble attached to the WTO Agreement shows that the signatories to that Agreement were, in 1994, fully aware of the importance and legitimacy of environmental protection as a goal of national and international policy. [...]

From the perspective embodied in the preamble of the WTO Agreement, we note that the generic term "natural resources" in Article XX $(\mathrm{g})$ is not "static" in its content or reference but is rather "by definition, evolutionary". ${ }^{606}$

605 Panel Report, US - Shrimp, para. 3.237; Appellate Body Report, US - Shrimp, para. 127. For brief overview of the US - Shrimp case see: Krista Schefer, Social Regulation in the WTO. Trade Policy and International Legal Development, Edward Elgar, Cheltenham, UK, 2010, pp. 187 - 191.

606 Appellate Body Report, US - Shrimp, paras. 128 - 130. The Appellate Body also noted two previous GATT Panel Reports where fish was found to be an exhaustible natural resource; see: GATT Panel Report, US - Canadian Tuna, para. 4.9; GATT Panel Report, Canada - Herring and Salmon, para. 4.4. See also: Appellate Body Reports, China-Rare Earths, para. 5.89. 
Thus, the Appellate Body employed the "evolutionary" approach to the interpretation of the relevant terms in Article XX(g) and concluded that sea turtles could indeed be regarded as "exhaustible natural resources". Also in an earlier case, US - Gasoline, the Appellate Body agreed with the Panel that clean air could constitute an "exhaustible natural resource" within the meaning of Article XX(b). ${ }^{607}$

Another interesting issue which arose in US - Shrimp was whether the rules of Article XX (g) have jurisdictional limitations, i.e. whether the US, under the provisions of this Article, was allowed to protect "exhaustible natural resources" located outside of its territory and jurisdiction. The Appellate Body observed, however, that in the case at hand it was unnecessary to take a position on this controversial issue, since sea turtles were migratory species and could well be found within the US jurisdiction. Thus, the Appellate Body concluded that "in the specific circumstances of the case before us, there is a sufficient nexus between the migratory and endangered marine populations involved and the United States for purposes of Article XX $(\mathrm{g})$ " ${ }^{608}$ The issue of jurisdictional limitations of measures is therefore indeed relevant with respect to private-sector standards, which often pursue extraterritorial objectives, e.g. the worldwide protection of endangered species of flora or fauna, environmental protection or protection of human rights.

With respect to the second element of the three-tier test under Article XX (g), the Appellate Body in US - Gasoline pointed out that the term "related" in the Article refers to a "substantial relationship" between the measure and the "conservation of exhaustible natural resources". In particular, this may imply that a measure is "primarily aimed" at the conservation. ${ }^{609}$ Similarly, in US - Shrimp, the Appellate Body ruled that the relationship

607 See: Appellate Body Report, US - Gasoline, pp. 14, 19

608 Appellate Body Report, US - Shrimp, para. 133. It is also worth noting that in EC-Tariff Preferences the Panel, while considering the EU tariff preferences for certain countries under Article XX(b) of the GATT 1994, observed that it "finds nothing linking the preferences to the protection of human life or health in the European Communities". The Panel thus seemed to have implied that the EU measures could be provisionally justified under Article XX(b) only if it perused the objectives within the EU. See: Panel Report, EC - Tariff Preferences, para. 7.202. See also: Lorand Bartels, "Article XX of GATT and the Problem of Extraterritorial Jurisdiction. The Case of Trade Measures for the Protection of Human Rights ", Journal of World Trade, 36(2), 2002, pp. 358 - 359.

609 See: Appellate Body Report, US - Gasoline, pp. 18 - 19. The Appellate Body thus held that the US baseline establishment rules for gasoline were "primarily aimed" at the conservation of clean air. The Appellate Body also referred in this respect to the previous ruling by the GATT Panel in GATT Panel Report, Canada-Herring and Salmon, para. 4.6. See also: Appellate Body Report, US - Shrimp, para. 136. 
between the US measure and the goal of protection of sea turtles was a "substantial" and "observably a close and real one". ${ }^{610}$

In China-Rare Earths, the Appellate Body noted the ordinary meaning of the term "conservation", that is "the preservation of the environment, especially of natural resources". ${ }^{611}$ The Appellate Body also explained:

It seems to us that, for the purposes of Article XX(g), the precise contours of the word "conservation" can only be fully understood in the context of the exhaustible natural resource at issue in a given dispute. For example, "conservation" in the context of an exhaustible mineral resource may entail preservation through a reduction in the pace of its extraction, or by stopping its extraction altogether. In respect of the "conservation" of a living natural resource, such as a species facing the threat of extinction, the word may encompass not only limiting or halting the activities creating the danger of extinction, but also facilitating the replenishment of that endangered species. ${ }^{612}$

The third element of the test under Article XX(g) has been interpreted by the Appellate Body as the requirement of "even-handedness" of a measure. In US - Gasoline, the Appellate Body observed in this regard:

[...] we believe that the clause "if such measures are made effective in conjunction with restrictions on domestic product or consumption" is appropriately read as a requirement that the measures concerned impose restrictions, not just in respect of imported gasoline but also with respect to domestic gasoline. The clause is a requirement of even-handedness in the imposition of restrictions, in the name of conservation, upon the production or consumption of exhaustible natural resources. ${ }^{613}$

In addition, the Appellate Body further clarified with respect to the nature of such "even-handedness":

[...] if no restrictions on domestically-produced like products are imposed at all, and all limitations are placed upon imported products alone, the measure cannot be accepted as primarily or even substantially designed for implementing conservationist

610 Appellate Body Report, US - Shrimp, para. 141. See also: Appellate Body Reports, China-Raw Materials, para. 355; Appellate Body Reports, China-Rare Earths, para. 5.90.

611 See: Appellate Body Reports, China-Rare Earths, para. 5.89; referring to Appellate Body Reports, China - Raw Materials, para. 355, quoting Shorter Oxford English Dictionary, 6th edn, A. Stevenson (ed.) (Oxford University Press, 2007), Vol. 1, p. 496.

612 Appellate Body Reports, China - Rare Earths, para. 5.89.

613 Appellate Body Report, US - Gasoline, pp. 20 - 21. See also: Appellate Body Report, US - Shrimp, para. 143. 
goals. The measure would simply be naked discrimination for protecting locally-produced goods. ${ }^{614}$

The meanings of the phrase "made effective in conjunction with restrictions on domestic production or consumption" in Article XX(g) of the GATT 1994 was further clarified by the Appellate Body in China - Raw Materials as follows:

The word "effective" as relating to a legal instrument is defined as "in operation at a given time". We consider that the term "made effective", when used in connection with a legal instrument, describes measures brought into operation, adopted, or applied. The Spanish and French equivalents of "made effective" - namely "se apliquen" and "sont appliquées"—confirm this understanding of "made effective". The term "in conjunction" is defined as "together, jointly, (with)". Accordingly, the trade restriction must operate jointly with the restrictions on domestic production or consumption. Article XX $(\mathrm{g})$ thus permits trade measures relating to the conservation of exhaustible natural resources when such trade measures work together with restrictions on domestic production or consumption, which operate so as to conserve an exhaustible natural resource. By its terms, Article XX(g) does not contain an additional requirement that the conservation measure be primarily aimed at making effective the restrictions on domestic production or consumption. ${ }^{615}$

Therefore, it seems that, according to the Appellate Body, although Article $\mathrm{XX}(\mathrm{g})$ does not necessarily require "a trade restriction must be aimed at ensuring the effectiveness of domestic restrictions", ${ }^{616}$ Article XX(g) may never provisionally justify a de jure discriminatory measure. In China-Rare Earths the Appellate Body observed in this respect:

Thus, the requirement that restrictions be made effective "in conjunction" suggests that, in their joint operation towards a conservation objective, such restrictions limit not only international trade, but must also limit domestic production or consumption. Moreover, in order to comply with the "made effective" element of the second clause of Article XX(g), it would not be sufficient for domestic production or consumption to be subject to a possible limitation at some undefined point in the future. Rather, a Member must impose a "real" restriction

614 Appellate Body Report, US - Gasoline, p. 21.

615 Appellate Body Reports, China-Raw Materials, para. 356. See also: Appellate Body Reports, China-Rare Earths, paras. 5.92 and 5.93.

616 Appellate Body Reports, China-Raw Materials, para. 360. 
on domestic production or consumption that reinforces and complements the restriction on international trade. ${ }^{617}$

The Appellate Body then summarised the meaning of the provisions of Article $\mathrm{XX}(\mathrm{g})$ in the following way:

In sum, Article XX $(\mathrm{g})$ permits the adoption or enforcement of trade measures that have "a close and genuine relationship of ends and means" to the conservation of exhaustible natural resources, when such trade measures are brought into operation, adopted, or applied and "work together with restrictions on domestic production or consumption, which operate so as to conserve an exhaustible natural resource". In order to justify a measure pursuant to Article XX(g), a WTO Member must show that it satisfies all the requirements set out in that provision. Indeed, the text of Article XX(g), particularly its use of the conjunctive "if", suggests a holistic assessment of its component elements, as the Panel rightly recognized. ${ }^{618}$

It worth noting that the exception of Article XX $(\mathrm{g})$ appears to be quite suitable for the justification of application of private-sector standards with environmental objectives. Indeed, Article XX $(\mathrm{g})$ does not require that the application of a private-sector standard shall be necessary for protection of the objective, and the genuine and close relationship between the measure and the objective is sufficient. Arguably, many environmental privatesector standards (of course, only if they are found to constitute a measure attributable to a Member under the GATT 1994) could fulfil this criterion, as well as the criterion of "even-handedness", and would thus be provisionally justified under Article XX(g). The question which arises then would be - whether they comply with the strict requirements of the chapeau of Article XX.

\subsubsection{Chapeau of Article XX}

The chapeau of Article XX of the GATT 1994 contains the strict requirements constituting the second part of the two-tier test under the Article. According to the Appellate Body, "the chapeau by its express terms addresses, not so much the questioned measure or its specific contents as such, but rather the manner in which that measure is applied". ${ }^{619}$ In this regard, the

${ }_{617}$ Appellate Body Reports, China-Rare Earths, para. 5.92.

618 Appellate Body Reports, China-Rare Earths, para. 5.94; referring to Appellate Body Report, US - Shrimp, para. 136; Appellate Body Reports, China-Raw Materials, paras. 355 and 356; Panel Reports, China-Rare Earths, para. 7.240.

619 Appellate Body Report, US - Gasoline, p. 22; Appellate Body Reports, EC - Seal Products, para. 5.302. See also: Rüdiger Wolfrum, Peter-Tobias Stoll, Anja SeibertFohr, WTO: Technical Barriers and SPS Measures, Nijhoff, Leiden, 2007, pp. 75 - 76. 
purpose of the chapeau is to ensure that the particular exceptions of Article XX "are not to be abused or misused" and "must be applied reasonably, with due regard both to the legal duties of the party claiming the exception and the legal rights of the other parties concerned" ${ }^{620}$ According to the Appellate Body, whether a measure is applied in a particular manner "can most often be discerned from the design, the architecture, and the revealing structure of a measure". ${ }^{621}$ In US - Gasoline, the Appellate Body also ruled that the burden of proof to demonstrate that a measure complies with the requirements of the chapeau lies on a Member invoking an exception of Article XX to justify its measure. ${ }^{622}$

In US - Shrimp, the Appellate Body further explained that "the language of the chapeau makes clear that each of the exceptions in paragraphs (a) to (j) of Article XX is a limited and conditional exception from the substantive obligations contained in the other provisions of the GATT 1994", and that the chapeau is in fact an "expression of the principle of good faith" . ${ }^{623}$ Thus, the Appellate Body observed:

The task of interpreting and applying the chapeau is, hence, essentially the delicate one of locating and marking out a line of equilibrium between the right of a Member to invoke an exception under Article XX and the rights of the other Members under varying substantive provisions (e.g., Article XI) of the GATT 1994, so that neither of the competing rights will cancel out the other and thereby distort and nullify or impair the balance of rights and obligations constructed by the Members themselves in that Agreement. The location of the line of equilibrium, as expressed in the chapeau, is not fixed and unchanging; the line moves as the kind and the shape of the measures at stake vary and as the facts making up specific cases differ. ${ }^{624}$

The requirements of the chapeau of Article XX focus primarily on the application of a measure in order to ensure that the exceptions are used in good faith and do not constitute the means of circumvention of the GATT obligations. ${ }^{625}$ In this regard, "the function of the chapeau is the prevention

620 Appellate Body Report, US - Gasoline, p. 22. See also: Appellate Body Report, US - Shrimp, para. 156; Appellate Body Report, Brazil - Retreated Tyres, paras. 215, 224; Appellate Body Reports, EC - Seal Products, para. 5.297.

${ }_{621}$ Appellate Body Reports, EC - Seal Products, para. 5.302; referring to Appellate Body Report, Japan - Alcoholic Beverages II, p. 29.

${ }^{622}$ Appellate Body Report, US - Gasoline, pp. 22 - 23. See also: Appellate Body Reports, EC - Seal Products, para. 5.297.

623 Appellate Body Report, US - Shrimp, paras. 157 - 158.

${ }^{624}$ Appellate Body Report, US - Shrimp, para. 159. See also: Appellate Body Report, Brazil-Retreated Tyres, para. 224.

${ }^{625}$ See: Appellate Body Report, Brazil - Retreated Tyres, para. 215. 
of abuse of the exceptions specified in the paragraphs of Article XX" ${ }^{626}$ The function of the chapeau is thus "to maintain the equilibrium between the obligations under the GATT 1994 and the exceptions provided under each subparagraph of Article XX" ${ }^{627}$

In particular, the chapeau of Article XX prohibits for a measure to be applied in a manner which constitutes:

- arbitrary or unjustifiable discrimination between countries where the same conditions prevail; or

- a disguised restriction on international trade.

In US - Shrimp, the Appellate Body distinguished three elements with regard to the first prohibition of the chapeau of Article XX:

First, the application of the measure must result in discrimination.

[...] Second, the discrimination must be arbitrary or unjustifiable in character. [...] Third, this discrimination must occur between countries where the same conditions prevail. ${ }^{628}$

The Appellate Body noted in US - Gasoline that the discrimination meant in the chapeau of Article XX is different from the discrimination prohibited by other substantive obligations of the GATT 1994, e.g. Article III:4. Hence, the chapeau does not proscribe all types of discrimination, but only "arbitrary or unjustifiable" ones. ${ }^{629}$ According to the Appellate Body, "[t] his does not mean, however, that the circumstances that bring about the discrimination that is to be examined under the chapeau cannot be the same as those that led to the finding of a violation of a substantive provision of the GATT 1994". ${ }^{630}$

Furthermore, in EC - Seal Products, the Appellate Body noted that " $[\mathrm{t}]$ he examination of whether a measure is applied in a manner that would constitute a means of "arbitrary or unjustifiable discrimination between countries where the same conditions prevail" necessitates an assessment of whether the "conditions" prevailing in the countries between which the

626 Appellate Body Report, Brazil - Retreated Tyres, para. 224.

627 Appellate Body Reports, EC - Seal Products, para. 5.301.

${ }^{628}$ Appellate Body Report, US - Shrimp, para. 150.

629 See: Appellate Body Report, US - Gasoline, p. 23; Appellate Body Report, US - Shrimp, para. 150; Appellate Body Reports, EC - Seal Products, para. 5.298. See also: Peter Van den Bossche, Werner Zdouc, The Law and Policy of the World Trade Organization. Text, Cases and Materials, 3d Edition, CUP, 2013, p. 574; Stefan Zleptnig, Non-Economic Objectives in WTO Law. Justification Provisions of GATT, GATS, SPS and TBT Agreements, Vol. 1, Martinus Nijhoff Publishers, Leiden Boston, 2010, pp. $278-279$.

630 Appellate Body Reports, EC - Seal Products, para. 5.298; referring to Appellate Body Report, US - Gasoline, pp. 28-29. 
measure allegedly discriminates are "the same" “. ${ }^{631}$ After considering the ordinary meanings of the term "condition", the Appellate Body explained:

The term "conditions" could thus potentially encompass a number of circumstances facing a country. In order further to define and circumscribe the meaning of the term "conditions", the treaty interpreter should therefore seek guidance from the specific context in which that term appears in the chapeau. As we see it, only "conditions" that are relevant for the purpose of establishing arbitrary or unjustifiable discrimination in the light of the specific character of the measure at issue and the circumstances of a particular case should be considered under the chapeau. The question is thus whether the conditions prevailing in different countries are relevantly "the same". ${ }^{632}$

Following this approach the Appellate Body, in US - Shrimp, found that the US measure imposing an importation ban on shrimps, harvested without the use of turtle exclusion devices (TEDs), constituted the "unjustifiable" discrimination within the meaning of the chapeau of Article XX. According to the Appellate Body this was the case because:

The actual application of the measure, through the implementation of the 1996 Guidelines and the regulatory practice of administrators, requires other WTO Members to adopt a regulatory program that is not merely comparable, but rather essentially the same, as that applied to the United States shrimp trawl vessels. Thus, the effect of the application of Section 609 is to establish a rigid and unbending standard by which United States officials determine whether or not countries will be certified, thus granting or refusing other countries the right to export shrimp to the United States.[...]

However, it is not acceptable, in international trade relations, for one WTO Member to use an economic embargo to require other Members to adopt essentially the same comprehensive regulatory program, to achieve a certain policy goal, as that in force within that Member's territory, without taking into consideration different conditions which may occur in the territories of those other Members. ${ }^{633}$

In addition, as has also been pointed out by the Appellate Body, the issue of the protection of endangered species, such as sea turtles, "demands

631 Appellate Body Reports, EC - Seal Products, para. 5.299.

632 Appellate Body Reports, EC - Seal Products, para. 5.299; referring to Appellate Body Report, US - Shrimp, para. 120.

633 Appellate Body Report, US - Shrimp, paras. 163 - 164. See also: Appellate Body Reports, EC - Seal Products, para. 5.305. 
concerted and cooperative efforts on the part of the many countries whose waters are traversed in the course of recurrent sea turtle migrations". ${ }^{634}$ The US, however, failed "to engage the appellees, as well as other Members exporting shrimp to the United States, in serious, across the-board negotiations with the objective of concluding bilateral or multilateral agreements for the protection and conservation of sea turtles, before enforcing the import prohibition against the shrimp exports of those other Member" ${ }^{635}$ This point in fact appears to be quite problematic with respect to privatesector standards, which very often deal with issues demanding "cooperative efforts on the part of the many countries". However, it is doubtful that an inclusion of such an issue into a private-sector standard adopted and applied within certain WTO Member, should necessarily trigger across the-board negotiations between this and other Members unless, of course, the adoption and application of such a standard receives substantial governmental support or incentives.

Moreover, the Appellate Body further found that the US measure also constituted the "arbitrary" discrimination within the meaning of chapeau of Article XX:

We have already observed that Section 609, in its application, imposes a single, rigid and unbending requirement that countries applying for certification under Section 609(b)(2)(A) and (B) adopt a comprehensive regulatory program that is essentially the same as the United States' program, without inquiring into the appropriateness of that program for the conditions prevailing in the exporting countries. Furthermore, there is little or no flexibility in how officials make the determination for certification pursuant to these provisions. In our view, this rigidity and inflexibility also constitute "arbitrary discrimination" within the meaning of the chapeau. ${ }^{636}$

In order to implement the rulings of the Appellate Body, the US took a number of steps to modify its measure and to make it more flexible even though the US did not lift the ban per se on the importation of shrimps harvested in the sea turtle unfriendly manner. Malaysia was dissatisfied with such an implementation and brought the complaint under Article 21.5 of the DSU. The Panel, and then the Appellate Body, ruled, however, that the US efforts were sufficient and that the measure was brought into compliance with the chapeau of Article XX. In view of the Appellate Body, the US measure must allow for the adoption of the turtle protection programs "comparable in

634 Appellate Body Report, US - Shrimp, para. 168.

635 Appellate Body Report, US - Shrimp, para. 166. See also: Appellate Body Reports, EC-Seal Products, para. 5.305.

636 Appellate Body Report, US - Shrimp, para. 177. 
effectiveness" to the US program, and must be sufficiently flexible in order to take into account the specific conditions prevailing in other WTO Members, including Malaysia. ${ }^{637}$ The Appellate Body thus observed:

As we see it, the Panel correctly reasoned and concluded that conditioning market access on the adoption of a programme comparable in effectiveness, allows for sufficient flexibility in the application of the measure so as to avoid "arbitrary or unjustifiable discrimination". ${ }^{638}$

The Appellate Body further upheld the findings of the Panel that "in view of the serious, good faith efforts made by the United States to negotiate an international agreement" with respect to actions on the protection of sea turtles, the US measure was "applied in a manner that no longer constitutes a means of unjustifiable or arbitrary discrimination". ${ }^{639}$

In another relevant case, Brazil - Retreated Tyres, the Appellate Body considered the exemption from the import ban on retreated tyres granted by Brazil to the countries of the Mercado Común del Sur (MERCOSUR) in order to comply with the appropriate ruling by the MERCOSUR tribunal. The Appellate Body, when examined this exemption under the provisions of the chapeau of Article XX, concluded that the exemption, although was not "capricious" or "random", still constituted arbitrary or unjustifiable discrimination and explained this as follows:

Acts implementing a decision of a judicial or quasi-judicial body - such as the MERCOSUR arbitral tribunal - can hardly be characterized as a decision that is "capricious" or "random". However, discrimination can result from a rational decision or behaviour, and still be "arbitrary or unjustifiable", because it is explained by a rationale that bears no relationship to the objective of a measure provisionally justified under one of the paragraphs of Article XX, or goes against that objective. ${ }^{640}$

The Appellate Body also observed that it had "difficulty understanding how discrimination might be viewed as complying with the chapeau of Article $\mathrm{XX}$ when the alleged rationale for discriminating does not relate to the pursuit of or would go against the objective that was provisionally found to justify a measure under a paragraph of Article XX" ${ }^{641}$

The second requirement of the chapeau that a measure shall not be applied in a manner constituting "a disguised restriction on international

\footnotetext{
637 Appellate Body Report, US - Shrimp (Article 21.5 - Malaysia), paras. 148 - 152.

638 Appellate Body Report, US - Shrimp (Article 21.5 - Malaysia), para. 144.

639 Appellate Body Report, US - Shrimp (Article 21.5 - Malaysia), para. 134.

${ }^{640}$ Appellate Body Report, Brazil - Retreated Tyres, para. 232.

${ }^{641}$ Appellate Body Report, Brazil-Retreated Tyres, para. 227. See also: Appellate Body Reports, EC - Seal Products, para. 5.306.
} 
trade" has been interpreted by the Appellate Body in US - Gasoline. The Appellate Body described the meaning of the requirement in the following way:

"Arbitrary discrimination”, "unjustifiable discrimination" and "disguised restriction" on international trade may, accordingly, be read side-by-side; they impart meaning to one another. It is clear to us that "disguised restriction" includes disguised discrimination in international trade. It is equally clear that concealed or unannounced restriction or discrimination in international trade does not exhaust the meaning of "disguised restriction." We consider that "disguised restriction", whatever else it covers, may properly be read as embracing restrictions amounting to arbitrary or unjustifiable discrimination in international trade taken under the guise of a measure formally within the terms of an exception listed in Article XX. ${ }^{642}$

Generally it seems that the second requirement of the chapeau prohibiting "disguised restrictions" has not been addressed in the course of the WTO dispute settlement practice as thoroughly as the first requirement. Arguably, this is because, in practice, panels and the Appellate Body, after finding "arbitrary or unjustifiable discrimination", did not consider this really necessary to explore in detail the application of the second requirement to a measure at hand. ${ }^{643}$ However, it is quite clear that a measure resulting in "arbitrary or unjustifiable discrimination" does not necessarily result in "disguised restriction", and vice-versa.

Thus, the application of private-sector standards, if violating substantive provisions of the GATT 1994, may be justified under general exceptions of Article XX only if their application does not constitute arbitrary or unjustifiable discrimination or disguised restriction on international trade. These requirements will, in all likelihood, not be fulfilled if provisions or the manner of application of a private-sector standard have a hidden protectionist motive.

\subsubsection{Non-Violation and Situation Complaints}

Article XXIII:1 of the GATT 1994 provides for the possibility for a WTO Member to bring a complaint against another Member in case if any benefits accrued to the complaining Members are nullified or impaired without a violation of a particular GATT provision. The text of Article XXIII:1 in its relevant part reads as follows:

${ }_{642}$ Appellate Body Report, US - Gasoline, p. 25.

${ }^{643}$ See, for example, in this regard: Appellate Body Report, US - Shrimp, para. 184. 
If any contracting party should consider that any benefit accruing to it directly or indirectly under this Agreement is being nullified or impaired or that the attainment of any objective of the Agreement is being impeded as the result of [...]

(b) the application by another contracting party of any measure, whether or not it conflicts with the provisions of this Agreement, or

(c) the existence of any other situation,

Subparagraph (b) of Article XXIII: 1 thus provides the legal basis for the socalled "non-violation" complaints, and subparagraph (c) - for the so-called "situation" complaints. ${ }^{644}$ The rules and procedures with respect to the non-violation and the situation complaints are also reflected and further developed in Articles 26.1 and 26.2 of the DSU respectively. The non-violation claims have rarely been invoked in the GATT and WTO dispute settlement processes, and the situation claims have never been invoked at all. It is not surprising therefore that the Appellate Body referred to the nonviolation complaints as a "rather unusual remedy". ${ }^{645}$ In EEC-Oilseeds, the GATT Panel outlined the purpose of this remedy in the following way:

The idea underlying [the provisions of Article XXIII:1(b)] is that the improved competitive opportunities that can legitimately be expected from a tariff concession can be frustrated not only by measures proscribed by the General Agreement but also by measures consistent with that Agreement. In order to encourage contracting parties to make tariff concessions they must therefore be given a right of redress when a reciprocal concession is impaired by another contracting party as a result of the application of any measure, whether or not it conflicts with the General Agreement. ${ }^{646}$

In EC - Asbestos, the Appellate Body quoted the statement by the Panel in Japan - Film that the remedy in Article XXIII:1(b) "should be approached with caution and should remain an exceptional remedy". ${ }^{647}$ According to the Panel, "[t]he reason for this caution is straightforward. Members negotiate the rules that they agree to follow and only exceptionally would expect to be challenged for actions not in contravention of those rules". ${ }^{648}$

${ }^{644}$ See: Peter Van den Bossche, Werner Zdouc, The Law and Policy of the World Trade Organization. Text, Cases and Materials, 3d Edition, CUP, 2013, pp. 174-175.

645 See: Appellate Body Report, EC - Asbestos, para. 185.

${ }^{646}$ GATT Panel Report, EEC - Oilseeds I, para. 144. See also: Appellate Body Report, EC-Asbestos, para. 185.

${ }^{647}$ Appellate Body Report, EC - Asbestos, para. 186; Panel Report, Japan - Film, para. 10.37. See also: Panel Reports, US - COOL, para. 7.901.

${ }_{648}$ Panel Report, Japan - Film, para. 10.36; Appellate Body Report, EC - Asbestos, 
Although the claims under Article XXIII:1(b) are generally called "nonviolation" claims, the Appellate Body, in EC - Asbestos, based on the reading of the text of the Article, upheld the ruling of the Panel that "a measure may, at one and the same time, be inconsistent with, or in breach of, a provision of the GATT 1994 and, nonetheless, give rise to a cause of action under Article XXIII:1(b)" ${ }^{649}$ The burden of proof to demonstrate that there is a "nullification or impairment" with respect to the non-violation complaints, according to Article XXIII:1(b), clearly lies on a complainant. ${ }^{650}$

Based on the text of Article XXIII:1(b), the Panel in Japan - Film developed a three-pronged test for non-violation claims, described as follows:

The text of Article XXIII:1(b) establishes three elements that a complaining party must demonstrate in order to make out a cognizable claim under Article XXIII:1(b): (1) application of a measure by a WTO Member; (2) a benefit accruing under the relevant agreement; and (3) nullification or impairment of the benefit as the result of the application of the measure. ${ }^{651}$

With regard to the first criterion, the Panel in Japan - Film ruled that the term "measure" in Article XXIII:1(b) shall be construed quite broadly and include a non-binding government action having effects similar to a binding one, and a private action if there is sufficient government involvement in it. ${ }^{652}$ Also, according to the Panel, the non-violation remedy is limited to "measures that are currently being applied". ${ }^{653}$ The second criterion primarily deals with the "legitimate expectations of improved market-access opportunities arising out of relevant tariff concessions" ${ }^{654}$ Finally, with respect to the third criterion, the Panel in Japan - Film observed that:

para. 186. See also: Panel Reports, US - COOL, para. 7.900.

649 Appellate Body Report, EC - Asbestos, para. 187. See also: Panel Report, EC - Asbestos, paras. 8.263; Panel Report, Japan - Film, para. 10.50. However, according to the Panel in US - COOL, compliance with a substantive provision of WTO law (in cases where a violation of such a provision has been found) may "remove the basis of the complainants' non-violation claims of nullification or impairment”. See: Panel Reports, US - COOL, para. 7.907; GATT Panel Report, EEC - Oilseeds I, para. 142.

650 See: Panel Report, EC - Asbestos, paras. 8.275 - 8.278; Panel Report, Japan - Film, paras. $10.28-10.32$.

651 Panel Report, Japan - Film, para. 10.41. See also: Panel Reports, US - COOL, para. 7.890 .

652 See: Panel Report, Japan - Film, paras. 10.43 - 10.60. For more information about the relevant issues considered by the Panel in this respect, see Sections 3.1.1 and 3.2.2.1.1 of the present Chapter. Similarly, the Panel in EC - Asbestos concluded that a "measure" within the meaning of Article XXIII:1(b) exists in the case at hand; see: Panel Report, EC - Asbestos, para. 8.284.

653 Panel Report, Japan - Film, para. 10.57.

${ }^{654}$ Panel Report, Japan - Film, para. 10.61. Also, for instance, in EC - Asbestos the 
[...] it must be demonstrated that the competitive position of the imported products subject to and benefitting from a relevant market access (tariff) concession is being upset by ("nullified or impaired ... as the result of") the application of a measure not reasonably anticipated. ${ }^{655}$

Similarly, in EC - Asbestos, the Panel pointed out that Canada's measure "must have had the effect of upsetting the competitive relationship between Canadian asbestos and products containing it, on the one hand, and substitute fibres and products containing them, on the other". ${ }^{656}$

Generally, in the GATT and WTO dispute settlement practice, the provisions of Article XXIII:1(b) have been interpreted so restrictively that serious doubts arise that these provisions are practically useful. Theoretically it seems that the "situation" complaints appear to be quite suitable for addressing private-sector standards as this sort of complaints under Article XXIII:1 does not require that a measure be adopted by a WTO Member (i.e. that it is attributable to the Member). Thus, it appears that there may be certain leeway for the accommodation of private-sector standards through the provisions of Article XXIII:1 of the GATT 1994. However, considering the very careful approach to the application of these provisions in the GATT and the WTO dispute settlement history, it seems to be doubtful that this is a realistic option. In this regard, it is also worth noting certain special procedures and remedies provided with respect to non-violation and situation complaints in Article 26 of the DSU. For non-violation complaints these procedures and remedies include the presentation of a detailed justification supporting the complaint, absence of the obligation to withdraw the measure for a respondent, and compensation as a part of the final settlement of the dispute.

\subsubsection{Processes and Production Methods Under the GATT 1994}

Provisions of the GATT 1994, among other important matters, are applicable to technical barriers in international trade in goods. In this respect, GATT provisions primarily address measures of WTO Members based on characteristics of goods, e.g. their physical and consumer qualities, appearance, content, etc. However, already in dispute settlement practice under

Panel observed that "at the conclusion of the Uruguay Round Canada could reasonably have anticipated that France might, in the short term, adopt more restrictive measures on the use of asbestos"; see: Panel Report, EC - Asbestos, para. 8.300.

655 Panel Report, Japan-Film, para. 10.82.

${ }_{656}$ Panel Report, EC - Asbestos, para. 8.288. 
the GATT 1947, the important and controversial issue had arisen whether the GATT provisions allow for adopting measures which present requirements to PPMs. ${ }^{657}$

This issue has indeed been controversial historically and highly sensitive for many WTO Members, because the use of PPM-based requirements may, in practice, frequently mean the protection of societal objectives located outside of the territory of a Member imposing a measure. This, in turn, may be viewed by WTO Members as a threat to their own regulatory autonomy and sovereignty. Moreover, the use of PPM-based requirements may result in the protection of domestic industry against cheap imports produced under social and environmental conditions no longer allowed in the country of importation, thus taking away from the exporting countries what they may consider to be a competitive advantage. Therefore, PPM-based requirements have a potential to be seriously trade-restrictive, since producers abroad have to adjust their production facilities to foreign regulatory requirements, which might also significantly differ from WTO Member to Member.

As has been explained in Section 2.3.2.5.1 of Chapter II, private-sector standards in many instances contain PPM-based requirements. Thus, the issue of applicability of GATT provisions to PPMs is quite relevant with respect to the implications of the GATT 1994 for the legal regulation of private-sector standards.

Generally PPMs may be classified into two categories: "product related PPMs" (or incorporated PPMs) and "non-product related PPMs" (npr-PPMs or unincorporated PPM). Related PPMs are closely related to the characteristics of a final product and may be traced to the qualities of a product per se. For example, if there is a direct dependency between the amount of pesticides used during the growing of certain vegetables and the final pesticide residue in these vegetables, a requirement for the amount of pesticides used during the growing process would be a requirement for a related PPM. On the other hand, npr-PPMs do not have any effect on the final characteristics of a product. For instance, a carpet produced with the use of child labour might not be materially any different from a carpet produced by adult workers; and the requirement that no child labour shall be used in the process of carpet production would thus be a requirement for a npr-PPM.

Measures adopted and applied by WTO Members may include nprPPM-based requirements solely or in addition to product-based requirements. In fact, a large majority of governmental or private eco-labelling and ethical labelling schemes are based on npr-PPM criteria. In this respect,

657 See: Christiane R. Conrad, Process and Production Methods (PPMs) in WTO Law. Interfacing Trade and Social Goals, CUP, 2011, pp. 11 - 13. 
some examples of npr-PPM-based requirements related to the protection of ecological objectives may be also found in the GATT and the WTO dispute settlement practice: the US - Tuna (Mexico, unadopted), the US - Tuna (EEC, unadopted), the US - Shrimp and the US - Tuna II (Mexico) cases. These cases dealt with US measures restricting or affecting the importation and marketing of certain sea products (tuna and shrimps) based on the method of fishing or harvesting used - whether the method was safe for dolphins or sea turtles. ${ }^{658}$

Generally, npr-PPM-based measures may be considered in the context of such provisions of the GATT 1994 as Articles I (MFN), III (national treatment), XI (prohibition of quantitative restrictions) and XX (general exceptions) ${ }^{659}$ Under the GATT 1947, prior to the conclusion of the Uruguay Round, it seems that there was a certain level of understanding among a number of GATT Contracting Parties, especially developing countries, that mandatory npr-PPM-based measures would violate the substantive obligations of the GATT and could thus hardly be justified under the general exceptions of Article XX. This understanding was mainly based on the two GATT Panel reports in US - Tuna (Mexico, unadopted) and US - Tuna (EEC, unadopted), although both reports were never adopted by the GATT Contracting Parties due to the requirement of consensus. The cases were brought by Mexico and by the EU in relation to the US legislative import ban on tuna that had been fished in a manner which, according to the US view, resulted in the incidental killing of dolphins. The Panels found that the US measure did not apply to "a product as such", but applied to the product's PPM. According to the Panels, such a measure was not covered by GATT Article III, constituted a product importation ban prohibited by Article XI and, in principle, could not be justified under the GATT Article XX general exceptions ${ }^{600}$ It is interesting to note, however, that this was found only with respect to the US mandatory regulation effectively banning certain tuna products from the US market. In the US - Tuna (Mexico, unadopted) case, the Panel also very briefly examined the voluntary product

658 See: GATT Panel Report, US - Tuna (Mexico, unadopted); GATT Panel Report, US - Tuna (EEC, unadopted); Panel and Appellate Body Reports, US - Shrimp; Panel and Appellate Body Reports, US - Tuna II (Mexico), For more examples of different types of PPMs see: Peter Van den Bossche, Werner Zdouc, The Law and Policy of the World Trade Organization. Text, Cases and Materials, 3d Edition, CUP, 2013, pp. 854 - 855; Rüdiger Wolfrum, Peter-Tobias Stoll, Anja Seibert-Fohr, WTO: Technical Barriers and SPS Measures, Nijhoff, Leiden, 2007, pp. 195 - 196; Manoj Joshi, "Are Eco-labels Consistent with World Trade Organization Agreements?", Journal of World Trade, 38(1), 2004, p.74.

${ }^{659}$ For more discussion with respect to the meaning and the content of these obligations, see Sections 3.3.1 - 3.3.4 of the present Chapter.

660 See: GATT Panel Report, US - Tuna (Mexico, unadopted), para. 7.1; GATT Panel Report, US - Tuna (EEC, unadopted), para. 6.1. 
labelling scheme with the "Dolphin Safe" label established by the US government, and did not find an inconsistency with the GATT 1947 at that time. ${ }^{661}$

Later, after the completion of the Uruguay Round and the establishment of the WTO, the ruling of the Appellate Body in US - Shrimp changed the general understanding in this regard to a certain extent. The Appellate Body found that the US npr-PPM-based requirement to harvest shrimps in a turtle friendly manner (using so-called turtle exclusion device (TED)), while it constituted a product ban in violation of Article XI:1 of the GATT 1994, under certain conditions could still be justified under the general exceptions of Article XX. In particular, in US - Shrimp the Appellate Body concluded that the US measure was provisionally justified as it was indeed related to the "conservation of exhaustible natural resources" within the meaning of Article XX (g) of the GATT $1994 .{ }^{662}$ However, the measure was found to be inconsistent with the requirements of the chapeau of Article XX constituting unjustifiable and arbitrary discrimination. ${ }^{663}$

Consequently, the US, while implementing the recommendations of the Appellate Body, did not repeal the npr-PPM-based ban on shrimps. Instead, the US took efforts to satisfy the requirements of the chapeau of Article XX through making the requirements more flexible and undertaking serious, good faith efforts to negotiate and conclude a multilateral sea turtle conservation agreement with interested States. ${ }^{664}$ Malaysia considered these efforts to be insufficient and brought the case under Article 21.5 of the DSU claiming that the US did not comply with the ruling of the Appellate Body. However, the Article 21.5 Panel recognized the US efforts to be sufficient in order to satisfy the requirements of the chapeau, and these conclusions were then upheld by the Appellate Body. ${ }^{665}$

Thus, it appears that measures addressing npr-PPMs may, in principle, be GATT consistent, and at least such measures are capable of being justified under Article XX of the GATT 1994 so long as the appropriate strict conditions of this Article are fulfilled. Therefore, if a private-sector standard contains npr-PPM-based requirements, it does not automatically mean that such requirements will always be in violation of the GATT 1994 assuming, of course, that a particular provision of the GATT 1994 would be applicable to the standard at hand.

\footnotetext{
661 See: GATT Panel Report, US - Tuna (Mexico, unadopted), paras. 5.41 - 5.44.

662 See: Appellate Body Report, US - Shrimp, para. 142.

663 See: Appellate Body Report, US - Shrimp, paras. 176, 184.

664 See: Appellate Body Report, US - Shrimp (Article 21.5 - Malaysia), paras. 5 -7, 115.

665 See: Appellate Body Report, US - Shrimp (Article 21.5 - Malaysia), paras. 134, 148, 152.
} 


\subsection{Summary and Conclusions}

The GATT 1994 establishes the general legal framework for the measures of WTO Members affecting international trade, including technical barriers in international trade in goods. In the WTO dispute settlement practice it has been recognised that there is no clear cut distinction between mandatory and voluntary measures and that the GATT 1994, under certain conditions, may cover both. What really matters is the effects that such measures have on competitive opportunities of products on markets of WTO Members. Accordingly, it seems that the forms of technical barriers to trade covered by the GATT 1994 may, in principle, include both mandatory regulations and de jure voluntary standards, adopted and enforced with significant involvement of WTO Members.

With respect to technical barriers to trade in goods, the relevant requirements of the GATT 1994 include the prohibition of discrimination between foreign "like" products (MFN treatment, Article I); the prohibition of discrimination between national and foreign "like" or directly competitive and substitutable products (national treatment, Article III); the prohibition of quantitative restrictions for import or export (Article XI), transparency, uniformity, impartiality and reasonableness in the administration of trade laws, regulations and decisions (Article X). The possibility of so-called "non-violation complaints" of WTO Members under Article XIII:1(b) may, arguably, also be relevant in this respect. Article XX provides for the justification of trade restrictions imposed to protect public health, morals, exhaustible natural resources, etc. According to the chapeau of Article XX, such trade restrictions may not constitute arbitrary or unjustifiable discrimination, or disguised restrictions on international trade.

There is quite an extensive dispute settlement case law interpreting and applying many of these provisions, and a lot of relevant information in this respect may be found in dispute settlement reports of panels or the Appellate Body, as well as in WTO law text books. However, in the context of the present study, the most relevant question to be answered is whether and to what extent these disciplines of the GATT 1994 may be applicable to the development, adoption and application of private-sector standards. Because the development, adoption and application of private-sector standards is a form of private conduct, the question stated above indeed forms part of a more general issue - whether and under what conditions the GATT 1994 is applicable to private conduct.

Generally, provisions of the GATT 1994 apply to measures employed by WTO Members. WTO Members are thus undoubtedly fully responsible under WTO agreements for their own governmental measures which may underpin private behaviour. Indeed, governmental measures may seriously affect the competitive opportunities in a market and force (or provide 
meaningful incentives for) private actors to act in certain ways. Such governmental measures per se may well constitute violations of appropriate provisions of WTO agreements.

However, the question remains whether, under certain conditions, private conduct may be directly attributable to a WTO Member, i.e. regarded as the conduct of the Member per se. The GATT 1994 itself does not generally clarify which measures are to be regarded as those of the Members. In other words, the GATT does not contain its own general norms on the attribution of acts to WTO Members. Since, as has been rightly noted by the Appellate Body, the GATT rules are "not to be read in clinical isolation from public international law", ${ }^{666}$ the general customary international law rules on the attribution of acts to States may appear to be quite relevant in this respect. These customary international law rules are reflected in many provisions of the ILC Articles on State Responsibility. Arguably, these rules shall apply also within the WTO legal system, including the GATT 1994, unless the norms of WTO law contain special and different rules, which would then constitute lex specialis in relation to the rules of general customary international law. According to the ILC Articles, States are responsible for the measures adopted or enforced by their organs and persons or entities exercising elements of governmental authority. Furthermore, acts or omissions may be attributable to a State in cases where the measure is adopted by other persons and entities acting under the direction or control of a State, or if a State acknowledged and adopted this measure as its own. ${ }^{667}$ However, remarkably, the international courts and tribunals, such as the ICJ and the ICTY, established rather high standards of control to be exercised by a State over private actors for the attribution of their conduct to it - "effective" and "overall" control tests. ${ }^{668}$

In principle it seems that the approach to the attribution of private actions to WTO Members taken in the WTO dispute settlement practice under the GATT 1994 and some other WTO agreements is in line with the general rules of customary international law on the attribution of acts to States. ${ }^{669}$ In fact, similarly to the ILC Articles, GATT or WTO panels and the Appellate Body required the existence of appropriate and sufficient

666 Appellate Body Report, US - Gasoline, p. 17.

667 See: Articles on Responsibility of States for Internationally Wrongful Acts, ILC, UN Doc. A/56/10, 2001, Articles 4, 5, 8, 11.

668 See, for example: Military and Paramilitary Activities in and against Nicaragua (Nicaragua v. United States of America), Merits, ICJ Reports 1986, paras. 109 and 115; Case IT-94-1-A, Prosecutor v. Tadić, Appeals Chamber, 15 July 1999, paras. 117,145 .

669 See: Santiago Villalpando, "Attribution of Conduct to the State: How Rules of State Responsibility May Be Applied Within the WTO Dispute Settlement System”, Journal of International Economic Law, 5(2), 2002, pp. 407 - 408. 
nexus between the government of a WTO Member and the private conduct for the attribution of the latter to the former. In particular, as has been described above, in several cases considered under the GATT, panels ruled that there are no "bright line rules" allowing for the automatic exclusion of the acts of private parties from the scope of application of the GATT 1994. Accordingly, private conduct may be attributed to WTO Members if there is sufficient governmental involvement in or incentives for the conduct, which shall be evaluated on a case-by-case basis. ${ }^{670}$ Similarly, under more specific provisions of Article XVII:1 of the GATT 1994 devoted to the issues of responsibility of WTO Members for conduct of their STEs, such STEs are meant to enjoy the "exclusive or special rights or privileges, including statutory or constitutional powers" granted to them by Members' governments. ${ }^{671}$

Similarly, according to the dispute settlement practice under the WTO SCM Agreement, a "financial contribution" is recognized as a subsidy if paid by a "private body" entrusted or directed to do so by the government of a WTO Member (such a private body is then merely used as a "proxy" for carrying out governmental actions). ${ }^{672}$ Analogously, under the WTO Agreement on Agriculture, the Appellate Body required for attribution of a subsidy to a WTO Member that the government of the Member "play a sufficiently important part" in the process of subsidization, "such that the requisite nexus exists" between a governmental action and a financial contribution. ${ }^{673}$ However, according to the Appellate Body, the existence of such a nexus does not necessary imply that a "government mandates or directs" payments of subsidies. ${ }^{674}$

Arguably, all these examples of attribution of conduct to WTO Members under WTO law are in line with the general rules of customary international law on the attribution of private conduct to States provided in the ILC Articles. However, it seems that the high standards of control (i.e.

670 See: Panel Report, Japan - Film, para. 10.56. See also: GATT Panel Report, Japan - Semi-Conductors, para. 108; GATT Panel Report, Japan-Agricultural Products I, para. 5.4.1.4.

671 See: Uruguay Round Understanding on the Interpretation of Article XVII of the GATT 1994, Sec. 1. See also: Panel Report, Canada - Wheat Exports and Grain Imports, para. 6.108.

672 See: SCM Agreement, Article 1.1(a)(1). See also, for instance: Appellate Body Report, US - Anti-Dumping and Countervailing Duties (China), paras. 317 - 322; Appellate Body Report, US - Softwood Lumber IV, para. 52; Appellate Body Report, US - Countervailing Duty Investigation on DRAMS, paras. $108-11$.

673 See: Appellate Body Report, Canada - Dairy (Article 21.5 - New Zealand and US II), para. 133. See also: Appellate Body Report, EC - Export Subsidies on Sugar, paras. 250, 270, 278.

674 See: Appellate Body Report, Canada - Dairy (Article 21.5 - New Zealand and US II), paras. $127-128$. 
"effective" and "overall" control) required by the ICJ and the ICTY in the context of State responsibility for genocide and individual criminal responsibility for the gravest international crimes might appear to be inappropriate for the WTO, which mainly deals with issues of international trade and commerce. In fact, it seems that in the WTO context, the "control test" may be more relaxed. However, WTO panels and the Appellate Body will, most likely, not easily assume the responsibility of WTO Members for conduct of private actors without convincing evidence of the sufficient nexus between a private action and a Member. The burden of proof to establish such a nexus in the WTO dispute settlement process lies on the complainant and, arguably, is quite difficult to fulfil.

Thus, considering this approach to the attribution of private conduct to WTO Members under the GATT 1994 and some other WTO agreements, it seems that the key provisions of the GATT 1994 discussed in this Chapter may be applicable to private-sector standards only if there is a sufficient nexus between the standard and the government of a WTO Member. In particular, this could be the case due to sufficient governmental involvement in or incentives for the development, adoption and application of a private-sector standard. Establishing the existence of such sufficient governmental involvement or incentives before WTO panels or and the Appellate Body will be a decisive step to be fulfilled by a complainant. On the other hand, it seems justified to conclude that the GATT 1994 may not be applicable to "purely" private-sector standards which are developed, adopted and applied without any meaningful governmental involvement or incentives. 


\section{CHAPTER IV \\ PRIVATE-SECTOR STANDARDS AND THE TBT AGREEMENT ${ }^{675}$}

he TBT Agreement could be regarded as the most relevant among
all WTO agreements for the regulation of private-sector standards. As has been already discussed in Chapter II, private-sector standards may present non-tariff barriers to international trade. ${ }^{676}$ And in fact the TBT Agreement is specially designed to address a specific type of non-tariff barriers - technical barriers to trade in the form of technical regulations, standards and conformity assessment procedures. The TBT Agreement is a multilateral agreement adopted as part of the "package" of the Uruguay Round and is contained in Annex 1A to the WTO Agreement.

The TBT Agreement was in fact not created completely from scratch and has a predecessor - the Agreement on Technical Barriers to Trade, frequently referred to as the Tokyo Round Standards Code. ${ }^{677}$ The Standards Code was adopted in 1979 as a result of the Tokyo Round of trade negotiations and was a plurilateral agreement, i.e. it was binding only on 43 out of more than 100 GATT Contracting Parties, primarily developed and advanced developing countries, which opted to join it. ${ }^{678}$ The Standards Code applied to mandatory "technical regulations" and voluntary "standards", which were both defined as types of "technical specifications". ${ }^{679}$ Basically, it contained the same obligations for Contracting Parties with respect to technical regulations and standards. In particular, Article 2 of the Standards

675 This Chapter is based on: Arkady Kudryavtsev, "The TBT Agreement in Context", Chapter 2, Research Handbook on the WTO and Technical Barriers to Trade, eds.

Tracey Epps and Michael J. Trebilcock, Edward Elgar, 2013.

676 See Sections 2.3.3.2 and 2.3.4.1 of Chapter II.

677 See: Tokyo Round Agreement on Technical Barriers to Trade, BISD 26th Supp, 1980, 8.

678 See: Gabrielle Marceau, Joel P. Trachtman, "The Technical Barrier to Trade Agreement, the Sanitary and Phytosanitary Measures Agreement, and the General Agreement on Tariffs and Trade: A Map of the World Trade Organization Law of Domestic Regulation of Goods”, Journal of World Trade, 36(5), 2002, p. 814. See also: Gabrielle Marceau, Joel P. Trachtman, "A Map of the World Trade Organization Law of Domestic Regulation of Goods: The Technical Barriers to Trade Agreement, the Sanitary and Phytosanitary Measures Agreement, and the General Agreement on Tariffs and Trade”, Journal of World Trade, 48(2), 2014, pp. 351-432; Arthur E. Appleton, "The Agreement on Technical Barriers to Trade”, at: Patrick F.J. Macrory, The World Trade Organization: Legal, Economic and Political Analysis, 1 Springer [etc.], New York, 2005, p. 376; Terence .P. Stewart, The GATT Uruguay Round. A Negotiating History (1986-1992), Vol. 1, Kluwer Law and Taxation Publishers, Denver. Boston, 1993, pp. 1067 - 1068.

679 See: Tokyo Round Agreement on Technical Barriers to Trade, BISD 26th Supp, 1980, 8 , Annex 1 , sections $1-3$. 
Code prohibited the discrimination of foreign products and imposed MFN and national treatment obligations in this respect and also forbade the creation of unnecessary obstacles to international trade through technical barriers. It also contained rules on the harmonization of technical regulations and standards based on provisions of international standards, and provided rules on publication, notification and access to information with respect to the relevant documents. ${ }^{680}$ The Code also distinguished, and dealt separately with, conformity determination processes and certification systems. ${ }^{681}$ In fact, several provisions of the Tokyo Round Standards Code became a basis for respective provisions in the current TBT Agreement.

However, in the decade following the Tokyo Round, consensus emerged among the Contracting Parties that the rules of the Tokyo Round Standards Code were insufficient in dealing with the proliferating technical barriers to trade. Especially the disciplining of technical regulations and standards in the field of food and agricultural products raised many concerns among the Contracting Parties. ${ }^{622}$ First of all, the regime of the Standards Code was seriously fragmented, as it applied only to a limited number of the GATT Contracting Parties. Second, as with the GATT 1947, the enforcement of the Code through the GATT dispute settlement system could be problematic due to the positive consensus requirement for the establishment of panels and the adoption of their reports, and also due to the absence of an appellate instance to ensure uniformity in the Code's application.

Thus, through incorporation into the Uruguay Round "package" of the new TBT Agreement and the SPS Agreement, compulsory for all WTO Members, the GATT Contracting Parties (who became WTO Members, after the WTO Agreement came into force on 1 January 1995) recognized the importance of the technical barriers to international trade and the increasing need for their regulation by WTO law. ${ }^{683}$

680 See: Ibid., Articles $2.1-2.8$.

681 See: Ibid., Articles 5 and 7.

682 See: Donna Roberts, "Preliminary Assessment of the Effects of the WTO Agreement on Sanitary and Phytosanitary Trade Regulations”, Journal of International Economic Law, 1(2), 1998, p. 380; Gabrielle Marceau, Joel P. Trachtman, "The Technical Barrier to Trade Agreement, the Sanitary and Phytosanitary Measures Agreement, and the General Agreement on Tariffs and Trade: A Map of the World Trade Organization Law of Domestic Regulation of Goods”, Journal of World Trade, 36(5), 2002, p. 814. See also: Gabrielle Marceau, Joel P. Trachtman, "A Map of the World Trade Organization Law of Domestic Regulation of Goods: The Technical Barriers to Trade Agreement, the Sanitary and Phytosanitary Measures Agreement, and the General Agreement on Tariffs and Trade”, Journal of World Trade, 48(2), 2014, pp. 351-432.

683 See: Jan McDonald, "Domestic Regulation, Harmonization, and Technical Barriers to Trade”, World Trade Review, 4(2), 2005, p. 251; Veijo Heiskanen, "The Regulatory Philosophy of International Trade Law”, Journal of World Trade, 38(1), 2004 , pp. $5-7$. 
The present Chapter deals primarily with the provisions of the TBT Agreement, which may appear to be relevant for the regulation of the development, adoption and application of private-sector standards. ${ }^{684}$ First, the Chapter discusses the scope of application of the TBT Agreement with the aim of identifying to what extent this scope may incorporate private-sector standards. In this regard, particular attention is paid to the definitions of the measures covered by the TBT Agreement and to the range of bodies or entities able to adopt such measures. Second, the Chapter addresses certain provisions of the TBT Agreement, prescribing specific obligations for WTO Members with respect to the actions of non-governmental bodies or entities in order to identify the scope of these obligations and their possible implications for regulation of private-sector standards. Finally, the Chapter discusses the key substantive obligations of WTO Members under the TBT Agreement with respect to technical regulations, standards and conformity assessment procedures. This is followed by conclusions concerning the relevance and appropriateness of these obligations with regard to disciplining the development, adoption and application of private-sector standards.

\subsection{Scope of Application of the TBT Agreement}

The scope of application of the TBT Agreement includes technical regulations, standards and conformity assessment procedures adopted and applied by appropriate bodies. Therefore, the applicability of the TBT Agreement to a particular measure depends on a number of factors. First, the TBT Agreement covers only certain types of measures, which form the material scope of application of the Agreement. Second, the TBT Agreement has personal scope of application related to the types of entities whose behaviours are regulated by the Agreement. Finally, the TBT Agreement, as well as any other international agreement, is applicable to

684 For a detailed discussion on the other norms and issues of the TBT Agreement, as well as for a general overview of the TBT Agreement see: Peter Van den Bossche, Denise Prévost, Mariëlle Matthee, "WTO Rules on Technical Barriers to Trade", Maastricht, 2005-6; Peter Van den Bossche, Werner Zdouc, The Law and Policy of the World Trade Organization. Text, Cases and Materials, 3d Edition, CUP, 2013, pp. 850 - 889; Rüdiger Wolfrum, Peter-Tobias Stoll, Anja Seibert-Fohr, WTO: Technical Barriers and SPS Measures, Nijhoff, Leiden, 2007, pp. 167 - 364; Arthur E. Appleton, "The Agreement on Technical Barriers to Trade", at: Patrick F.J. Macrory, The World Trade Organization: Legal, Economic and Political Analysis, 1 Springer [etc.], New York, 2005, p. 371; James H. Mathis, "The WTO Agreement on Technical Barriers to Trade", Consumer Policy Review, 16(1), 2006, p. 16; Norbert L. W. Wilson, "Clarifying the Alphabet Soup of the TBT and the SPS in the WTO”, Drake Journal of Agricultural Law, 8, 2003, p. 703. 
acts performed within appropriate timeframes, thus having its temporal scope of application. ${ }^{685}$

\subsubsection{Material Scope of Application of the TBT Agreement}

As has been noted by the Appellate Body in EC - Asbestos, the TBT Agreement is applicable to a "limited class of measures". ${ }^{686}$ These measures are technical regulations, standards and conformity assessment procedures as defined in Annex 1 to the TBT Agreement. Article 1.3 of the Agreement further provides that such measures may cover any kinds of goods, including industrial and agricultural products. In addition, according to Article 1.6 of the TBT Agreement, the technical regulations, standards and conformity assessment procedures referred to in the Agreement also include any material amendments or additions hereto.

The definitions of technical regulation, standard and conformity assessment procedure, as well as the definition of other terms provided in Annex 1 of the TBT Agreement, play a decisive role for determining the material scope of the TBT Agreement and for the interpretation of the Agreement's provisions. However, not all the terms, which might be relevant in the context of the Agreement, are defined in Annex 1. In this respect, the first paragraph of Annex 1 provides that the terms not covered by the list of definitions in the Annex must have the same meaning as in the ISO/IEC Guide 2: 1991, General Terms and Their Definitions Concerning Standardization and Related Activities, taking into account that services are not covered by the TBT Agreement. ${ }^{687}$ Moreover, Article 1.1 of the TBT Agreement provides that the general terms for standardization and conformity assessment procedures "shall normally have the same meaning given to them by definitions adopted within the United Nations system and by international standardizing bodies" with due regard to their context, as well as to the object and purpose of the TBT Agreement.

The following sections discuss the scope and meaning of the definitions of technical regulation, standard and conformity assessment procedure

685 For similar classification of the scope of application of the TBT Agreement see: Peter Van den Bossche, Werner Zdouc, The Law and Policy of the World Trade Organization. Text, Cases and Materials, 3d Edition, CUP, 2013, pp. 852 - 861. For the analogous classification with respect to the scope of application of the GATT 1994, see Section 3.1 of Chapter III. See: Appellate Body Report, EC - Asbestos, para. 80.

687 The ISO/IEC Guide 2 provides general terms and definitions concerning standardization and related activities. The ISO/IEC Guide 2: 1991 was reviewed twice in 1996 and 2004 by the ISO, and currently it is replaced by the ISO/IEC Guide 2:2004 - the last edition of the Guide. For more information about the ISO/ IEC Guide 2, see Section 2.1.1.1 of Chapter II. 
under the TBT Agreement with the aim of identifying whether and to what extent these definitions may cover private-sector standards.

\subsubsection{Technical Regulation}

Annex 1.1 to the TBT Agreement provides for the following definition of technical regulation:

\section{Technical regulation}

Document whichlays down productcharacteristics or their related processes and production methods, including the applicable administrative provisions, with which compliance is mandatory. It may also include or deal exclusively with terminology, symbols, packaging, marking or labelling requirements as they apply to a product, process or production method.

Interpreting this definition, the Appellate Body, first in EC - Asbestos and then in EC - Sardines, developed a three-tier test containing three essential requirements, which must be met by a measure for it to qualify as a technical regulation within the meaning of the TBT Agreement. These requirements are:

- the measure must be applicable to an identifiable product or group of products;

- the measure must lay down product characteristics or their related PPMs, including the applicable administrative provisions; and

- compliance with the measure must be mandatory. ${ }^{68}$

According to the Appellate Body, in order to identify whether these three requirements are met, the measure must be "examined as a whole" ${ }^{899}$ and

688 See: Appellate Body Report, EC - Asbestos, paras. 66 - 70; Appellate Body Report, EC - Sardines, para. 176. This three-tier test was also applied in the later TBT cases: Panel Report, US - Clove Cigarettes, paras. 7.23 - 7.25; Appellate Body Report, US - Tuna II (Mexico), paras. 183 - 185; Panel Reports, US COOL, paras. 7.144 - 7.148; Appellate Body Reports, EC - Seal Products, para. 5.10. For more information on the tree-tire test for technical regulation, see also: Arkady Kudryavtsev, "The TBT Agreement in Context”, at: Tracey Epps, Michael J. Trebilcock, Research Handbook on the WTO and Technical Barriers to Trade, Edward Elgar, Cheltenham, UK, 2013, pp. 27 - 33; Rüdiger Wolfrum, Peter-Tobias Stoll, Anja Seibert-Fohr, WTO: Technical Barriers and SPS Measures, Nijhoff, Leiden, 2007, pp. 187 - 190; Jan McDonald, "Domestic Regulation, Harmonization, and Technical Barriers to Trade”, World Trade Review, 4(2), 2005, pp. 253 - 254; Peter Van den Bossche, Werner Zdouc, The Law and Policy of the World Trade Organization. Text, Cases and Materials, 3d Edition, CUP, 2013, pp. 856 - 857; James H. Mathis, "WTO Panel Report, European Communities - Trade Description of Sardines, WT/DS231/R, 29 May 2002”, Legal Issues of Economic Integration, 29(3), 2002.

689 Appellate Body Report, EC - Asbestos, para. 64, Appellate Body Report, EC Sardines, paras. $192-193$. 
"in the light of the characteristics of the measure at issue and the circumstances of the case".${ }^{600}$ This approach has particular importance as it rejects the mere formalistic evaluation of the characteristics of measures and implies the determination of the status of a measure in the broad context of its design and application in a domestic legal system.

First, as was stated by the Appellate Body in EC - Asbestos, a "“technical regulation" must be applicable to an identifiable product, or group of products. Otherwise, enforcement of the regulation will be practically impossible". ${ }^{991}$ However, this requirement does not demand that the product must be necessarily directly named or otherwise "expressly" identified in a technical regulation. ${ }^{692}$ In this respect the Appellate Body further clarified:

Although the TBT Agreement clearly applies to "products" generally, nothing in the text of that Agreement suggests that those products need to be named or otherwise expressly identified in a "technical regulation". Moreover, there may be perfectly sound administrative reasons for formulating a "technical regulation" in a way that does not expressly identify products by name, but simply makes them identifiable - for instance, through the "characteristic" that is the subject of regulation. ${ }^{693}$

Similarly, in EC-Sardines, the Appellate Body found that the EU Regulation applied to the identifiable product - Sardinops sagox, although this fish species was not mentioned in the text of the Regulation per se. The EU Regulation was applicable to the identifiable product because it effectively prohibited Sardinops sagox to be identified and marketed as "sardines" on EU market. ${ }^{694}$ Furthermore, the identifiable group of products may be quite broad. For example, the Panel in EC - Trade Marks and Geographical Indications ruled that the identifiable group of products included all the products covered by the EU Regulation on the protection of geographical indications and designations of origin. ${ }^{695}$ Thus, arguably, even if a mandatory labelling requirement imposed on the majority of products sold on a

\footnotetext{
690 Appellate Body Report, US - Tuna II (Mexico), paras. 188.

691 Appellate Body Report, EC - Asbestos, para. 70.

692 Although in many cases a technical regulation may expressly identify a product, e.g. the US's regulation identified cigarettes in US - Clove Cigarettes, as was acknowledged by the Panel; see: Panel Report, US - Clove Cigarettes, paras. 7.27 -7.28 .

693 Appellate Body Report, EC - Asbestos, para. 70.

694 See: Appellate Body Report, EC - Sardines, para. 184.

695 See: Panel Report, EC - Trademarks and Geographical Indications (Australia), para. 7.457 .
} 
domestic market of a WTO Member, this measure could still be regarded as applicable to an identifiable group of products. ${ }^{696}$

Second, a technical regulation must lay down product characteristics, ${ }^{697}$ and according to the statement of the Appellate Body cited above, these are the product characteristics that usually make the product identifiable. ${ }^{698}$ The ordinary meaning of the term "product characteristics" is clarified by the Appellate Body through reference to its synonyms: "“features", "qualities", "attributes", or other "distinguishing marks" of a product"; "[s] uch "characteristics" might relate, inter alia, to a product's composition, size, shape, colour, texture, hardness, tensile, strength, flammability, conductivity, density, or viscosity". ${ }^{699}$

In this regard, it seems that the prescription of the product characteristics shall be distinguished from the product ban. In EC - Asbestos, the Appellate Body considered whether the prohibition imposed on asbestos fibres due to public health reasons may be qualified as a technical regulation within the meaning of the TBT Agreement. It eventually found that the prohibition of this material as such does not constitute a technical regulation because it "does not, in itself, prescribe or impose any "characteristics" on asbestos fibres, but simply bans them in their natural state" ${ }^{700}$ However, the measures employed by the EU were aimed at prohibiting asbestos fibres not only in their pure form, but also to prohibit products containing asbestos fibres. And in this regard, the Appellate Body concluded that the requirement for the products not to contain asbestos constituted the prescription of the characteristic for the identifiable group of products. Therefore, the EU measure was qualified as the technical regulation within the meaning of the TBT Agreement. ${ }^{701}$ Such an approach has been further reiterated by the Panel and the Appellate Body in EC - Seal Products. The Panel noted that the EU measure banning the importation and sale of seals and seal products accompanied with a number of exceptions (EU Seal Regime), both allow and prohibit the placing of seal products in the market. ${ }^{702}$ The Appellate

696 See: Rüdiger Wolfrum, Peter-Tobias Stoll, Anja Seibert-Fohr, WTO: Technical Barriers and SPS Measures, Nijhoff, Leiden, 2007, p. 188.

697 Concerning the possibility for a technical regulation to lay down different types of PPMs, see Section 4.1.1.4 of the present Chapter.

698 See: Appellate Body Report, EC - Asbestos, para. 70.

699 Appellate Body Report, EC - Asbestos, para. 67. See also: Appellate Body Reports, EC-Seal Products, para. 5.11.

700 Appellate Body Report, EC - Asbestos, para. 71. See also: Panel Reports, EC - Seal Products, paras. 7.99 and 7.104; Appellate Body Reports, EC - Seal Products, para. 5.25 .

701 See: Appellate Body Report, EC - Asbestos, paras. 72 -75. See also: Panel Reports, EC - Seal Products, para. 7.104; Appellate Body Reports, EC - Seal Products, para. 5.25 .

702 See: Panel Reports, EC - Seal Products, para. 7.54. See also: Appellate Body 
Body observed that " $[t]$ he Panel therefore correctly considered that the EU Seal Regime does not constitute a "total" or "general" ban on seal products, but instead "consists of both prohibitive and permissive components and should be examined as such". ${ }^{703}$

According to the Appellate Body in EC - Asbestos, product characteristics may be laid down by a technical regulation in positive or negative form, i.e. the technical regulation may require that a product shall have or shall not have certain characteristics. ${ }^{704}$ In addition, one shall not be confused by the plural form of the word "characteristics" in the definition of technical regulation in Annex 1 of the TBT Agreement. A technical regulation "may be confined to laying down only one or a few "product characteristics" ". ${ }^{705}$ The Appellate Body came to this conclusion due to the use of the words "exclusively" and the conjunction "or" in the second sentence of the definition of technical regulation, dealing with "terminology, symbols, packaging, marking or labelling requirements" ${ }^{706}$

Thus, in the view of the Appellate Body, both sentences of the definition of technical regulation in the TBT Agreement are interconnected and inform the meaning of each other. In this regard, according to the reasoning of the Appellate Body, the second sentence provides particular examples of "product characteristics" (i.e. "terminology, symbols, packaging, marking or labelling requirements"). And therefore the term "product characteristics", in the view of the Appellate Body, addresses not only the intrinsic qualities of a product, but also its "related characteristics", "such as the means of identification, the presentation and the appearance of a product". ${ }^{707}$

This approach was reiterated by the Appellate Body in EC - Sardines, where the EU unsuccessfully tried to draw a distinction between the labelling and "naming" of products; "naming", it was claimed, did not lay down product characteristics, and therefore could not be covered by the definition of technical regulation. The Appellate Body rejected this argument and, with the reference to its previous ruling in EC - Asbestos, stated that

Reports, EC - Seal Products, para. 5.17.

703 Appellate Body Reports, EC - Seal Products, para. 5.17; referring to Panel Reports, EC-Seal Products, para. 7.54.

704 See: Appellate Body Report, EC - Asbestos, para. 69. See also: Panel Report, US - Clove Cigarettes, paras. 7.31-7.36.

705 Appellate Body Report, EC - Asbestos, para. 67.

706 See: Appellate Body Report, EC - Asbestos, para. 67.

707 Appellate Body Report, EC - Asbestos, para. 67. See also: Tania Voon, Andrew Mitchell, Catherine Gascoigne, "Consumer Information, Consumer Preferences and Product Labels under the TBT Agreement”, at: Tracey Epps, Michael J.

Trebilcock, Research Handbook on the WTO and Technical Barriers to Trade, Edward Elgar, Cheltenham, UK, 2013, pp. 456 - 458. 
requirements on the name of a product (i.e. on the "means of identification") constituted requirements on "product characteristics". ${ }^{708}$ Moreover, in another dispute, EC - Trade Marks and Geographical Indications, the Panel also followed this line of argumentation and observed with regard to the EU requirements on geographical indications on products that:

The issue is not whether the content of the label refers to a product characteristic: the label on a product is a product characteristic. ${ }^{709}$

The term "labelling requirements" in the second sentence of the definition of technical regulation was further clarified later by the Appellate Body in the US - Tuna II (Mexico) case as referring "to provisions that set out criteria or conditions to be fulfilled in order to use a particular label". ${ }^{710}$

The meaning and scope of the terms "product characteristics" and "related processes and production methods" in the first sentence of the definition of technical regulation provided in Annex 1.1 of the TBT Agreement was recently examined by the Panel and the Appellate Body in EC - Seal Products. The Panel decided that the EU measure banning the importation and sales of seals and seal products, accompanied with a number of exceptions, constituted a technical regulation within the meaning of the TBT Agreement, because it fulfilled all three requirements provided in the definition in Annex 1.1. ${ }^{711}$ In particular, regarding the issue of whether the EU measure lays down product characteristics, the Panel noted that the measure also makes an exception with regard to the importation and / or placing in the market of seal products in three situations, namely when they result from Inuit or other indigenous communities (IC) hunts, marine resource management (MRM) hunts, or in the case of imports by travellers. ${ }^{712}$ With reference to the ruling of the Appellate Body in EC - Asbestos, the Panel then concluded that "the prohibition on seal-containing products under the EU Seal Regime lays down a product characteristic in the negative form by requiring that all products not contain seal". ${ }^{713}$ The Panel also found that "the EU Seal Regime sets out, through its exceptions, the "applicable administrative provisions with which compliance is mandatory" for products with certain objective "characteristics”“ .714

\footnotetext{
708 See: Appellate Body Report, EC - Sardines, paras. 187 - 193.

709 Panel Report, EC - Trademarks and Geographical Indications (Australia), para. 7.449.

710 Appellate Body Report, US - Tuna II (Mexico), para. 186.

711 See: Panel Reports, EC - Seal Products, para. 7.125.

712 Panel Reports, EC - Seal Products, para. 7.105.

${ }_{713}$ Panel Reports, EC - Seal Products, para. 7.106. The Panel referred to the Appellate Body Report, EC - Asbestos, paras. 67 and 71.

714 Panel Reports, EC - Seal Products, para. 7.108.
} 
These findings of the Panel were, however, reversed by the Appellate Body. ${ }^{715}$ The Appellate Body first referred to its prior statements that "a determination of whether a measure constitutes a technical regulation "must be made in the light of the characteristics of the measure at issue and the circumstances of the case" "; and that "this analysis should give particular weight to the "integral and essential" aspects of the measure." ${ }^{\prime 16}$ The Appellate Body then observed:

Although a measure that comprises, among other elements, a prohibition of seal-containing products may include a component that appears to prescribe product characteristics, we consider the Panel to have erred, to the extent it reached a final conclusion as to the legal character of the measure on the basis of an examination of the aspect of the EU Seal Regime that sets out a "prohibition on seal-containing products" taken alone. The Panel could not have properly reached a conclusion as to the legal character of the measure at issue without analysing the weight and relevance of the essential and integral elements of the measure as an integrated whole. ${ }^{717}$

While examining prohibitive and permissive elements of the EU measure, the Appellate Body noted that the Panel's analysis gives the impression that the Panel treated the identity of the hunter, the type of hunt, and the purpose of the hunt as "product characteristics" within the meaning of Annex 1.1. ${ }^{718}$ The Appellate Body found that the Panel erred in this regard and further explained:

We see no basis in the text of Annex 1.1, or in prior Appellate Body reports, to suggest that the identity of the hunter, the type of hunt, or the purpose of the hunt could be viewed as product characteristics. Nor do we see a basis to find that the market access conditions under the exceptions to the EU Seal Regime exhibit features setting out product characteristics. ${ }^{719}$

According to the Appellate Body, "[u]nlike the measure at issue in EC Asbestos, the EU Seal Regime does not prohibit (or permit) the importation or placing on the EU market of products depending on whether or not they

715 Appellate Body Reports, EC - Seal Products, para. 5.59.

716 Appellate Body Reports, EC - Seal Products, para. 5.19, referring to Appellate Body Report, US - Tuna II (Mexico), para. 188; and Appellate Body Report, EC-Asbestos, para. 72.

717 Appellate Body Reports, EC - Seal Products, para. 5.29.

718 Appellate Body Reports, EC - Seal Products, para. 5.45, referring to Panel Reports, EC-Seal Products, para. 7.110. In particular, the Appellate Body observed that the Panel referred to these factors as "objectively definable features" of seal products that "lay down particular 'characteristics' of the final products".

719 Appellate Body Reports, EC - Seal Products, para. 5.45. 
contain seal as an input". ${ }^{720}$ This is because the measure conditions market access on the type and purpose of the seal hunt, and the identity of the hunter - the criteria, which do not constitute product characteristics. ${ }^{721}$

Finally, the Appellate Body further observed that " $[t]$ o the extent the measure prohibits the placing on the EU market of seal-containing products, it could be seen as imposing certain "objective features, qualities or characteristics" on all products by providing that they may not contain seal". ${ }^{722}$ However, the Appellate Body viewed this aspect of the EU measure as an ancillary one and was "not persuaded" that it constituted the main feature of the measure at issue. ${ }^{723}$ The Appellate Body then declined to complete the legal analysis and to determine whether the EU measure lays out "related PPMs" as provided in the first sentence of the definition of technical regulation in Annex 1.1 of the TBT Agreement. The reasons for this were that the meaning of the phrase "their related PPMs" had not yet been examined in the WTO dispute settlement practice, and the complainants did not sufficiently develop the argumentation in their submissions in this regard..$^{724}$

Thus, according to the approach adopted by the Appellate Body, the "product characteristics" and "related PPMs", referred to in the first sentence of the definition of technical regulation in Annex 1.1 of the TBT Agreement, should be clearly distinguished.

The third, and very important criterion for a technical regulation, is that compliance with it must be mandatory. Indeed, the mandatory character of a technical regulation is the main, if not the only, factor which makes it different from a standard, as defined in Annex 1.2 to the TBT Agreement. ${ }^{725}$ The Appellate Body, in EC - Asbestos, clarified the meaning of the term "mandatory" in the following way:

A "technical regulation" must, in other words, regulate the "characteristics" of products in a binding or compulsory fashion. It follows that, with respect to products, a "technical regulation" has the effect of prescribing or imposing one or more "characteristics" - "features", "qualities", "attributes", or other "distinguishing mark". 726

\footnotetext{
720 Appellate Body Reports, EC - Seal Products, para. 5.54.

721 Appellate Body Reports, EC - Seal Products, para. 5.55.

722 Appellate Body Reports, EC - Seal Products, para. 5.58.

723 Appellate Body Reports, EC - Seal Products, paras. 5.57 - 5.58.

724 Appellate Body Reports, EC - Seal Products, paras. 5.68 - 5.69

725 For a detailed discussion on the definition of "standard" according to Annex 1 of the TBT Agreement, see the following Section 4.1.1.2 of the present Chapter.

726 Appellate Body Report, EC - Asbestos, para. 68.
} 
Based on this approach, the Appellate Body concluded that the measures, set out in the administrative provisions of the French Decree banning the products containing asbestos fibres, are "mandatory" within the meaning of the definition of technical regulation in the TBT Agreement. ${ }^{727}$

In the more recent US - Tuna II (Mexico) case, the Panel, and then on appeal the Appellate Body, examined the criterion of the mandatory character with respect to labelling requirements for tuna products. The US (the respondent) adopted a set of measures providing for the conditions under which tuna products sold in the US could be labelled as "dolphin safe". Mexico (the complainant) argued that this complex of measures must be qualified as a technical regulation within the meaning of the TBT Agreement as it effectively prohibited the labelling of tuna products as "dolphin safe" if the specified conditions were not met. The US objected, arguing that the measure was non-mandatory since it did not prohibit the selling of tuna products which failed to meet the criteria for the "dolphin safe" labelling on the US market. The Panel disagreed with the US and accepted the arguments of Mexico, and these findings were then upheld by the Appellate Body. ${ }^{728}$

The Appellate Body first noted that "[ $t]$ he fact that "labelling requirements" may consist of criteria or conditions that must be complied with in order to use a particular label does not imply therefore that the measure is for that reason alone a "technical regulation" within the meaning of Annex 1.1" ${ }^{729}$ According to the Appellate Body, the "determination of whether a particular measure constitutes a technical regulation must be made in the light of the characteristics of the measure at issue and the circumstances of the case". ${ }^{730}$ The Appellate Body further explained:

In some cases, this may be a relatively straightforward exercise. In others, the task of the panel may be more complex. Certain features exhibited by a measure may be common to both technical regulations falling within the scope of Article 2 of the TBT Agreement and, for example, standards falling under Article 4 of that Agreement. Both types of measure could, for instance, contain conditions that must be met in order to use a label. In both cases, those conditions could be "compulsory" or "binding"

See: Appellate Body Report, EC - Asbestos, paras. $74-75$.

728

See: Panel Report, US - Tuna II (Mexico), paras. 7.22, 7.142 - 7.145. Appellate Body Report, US - Tuna II (Mexico), paras. 191 - 199. The Panel report, in its paras. $7.146-7.188$, contains the separate opinion of one of the panellists who disagreed with the Panel's conclusions that the US measure constituted a technical regulation under the TBT Agreement.

729 Appellate Body Report, US - Tuna II (Mexico), para. 187.

730 Appellate Body Report, US - Tuna II (Mexico), para. 188; referring to Appellate Body Report, EC - Asbestos, para. 64; and Appellate Body Report, EC - Sardines, paras. $192-193$. 
and "enforceable". Such characteristics, taken alone, cannot therefore be dispositive of the proper legal characterization of the measure under the TBT Agreement. Instead, it will be necessary to consider additional characteristics of the measure in order to determine the disciplines to which it is subject under that Agreement. ${ }^{731}$

The Appellate Body then enumerated the "additional characteristics" which may be considered in the process of determining whether a particular measure constitutes a technical regulation, namely: 1 . whether the measure consists of a law or a regulation enacted by a WTO Member; 2 . whether it prescribes or prohibits particular conduct; 3 . whether it sets out specific requirements that constitute the sole means of addressing a particular matter; and 4 . the nature of the matter addressed by the measure. ${ }^{732}$ After considering the relevant characteristics of the US measure, the Appellate Body finally concluded that "the measure at issue establishes a single definition of "dolphin-safe" and treats any statement on a tuna product regarding "dolphin-safety" that does not meet the conditions of the measure as a deceptive practice or act". ${ }^{733}$ Moreover, in refuting the US arguments the Appellate Body explained:

The text of Annex 1.1 to the TBT Agreement does not use the words "market" or "territory". Nor does it indicate that a labelling requirement is "mandatory" only if there is a requirement to use a particular label in order to place a product for sale on the market. To us, the mere fact that there is no requirement to use a particular label in order to place a product for sale on the market does not preclude a finding that a measure constitutes a "technical regulation" within the meaning of Annex 1.1.734

Indeed, the definition of technical regulation in Annex 1 of the TBT Agreement does not specify particular methods through which the measure shall be made mandatory. The most direct way to impose mandatory technical regulation is through the appropriate legal requirements, i.e. mandatory de jure. However, even a recommendatory or voluntary measure may become de facto mandatory due to governmental support or incentives for its adoption and / or implementation. The approach adopted by the Appellate Body that a measure must be examined as a whole and in light

731 Appellate Body Report, US - Tuna II (Mexico), para. 188; referring to Appellate Body Reports, China - Auto Parts, para. 171.

732 See: Appellate Body Report, US - Tuna II (Mexico), paras. 188. See also: Peter Van den Bossche, Werner Zdouc, The Law and Policy of the World Trade Organization. Text, Cases and Materials, 3d Edition, CUP, 2013, p. 859.

733 Appellate Body Report, US - Tuna II (Mexico), para. 195.

734 Appellate Body Report, US - Tuna II (Mexico), para. 196. 
of the circumstances, as described above, seems to suggest that a de jure voluntary measure could qualify as a technical regulation under the TBT Agreement, if the amount of governmental support or incentives is sufficient in order to make it de facto mandatory and, of course, if other relevant requirements are met. In fact, concluding otherwise would allow WTO Members to avoid the disciplines of the TBT Agreement by using "soft" and recommendatory language in their legislation, but enforcing such rules in a "highly persuasive" manner. Thus, in principle, even the measures formally adopted as voluntary standards could be regarded as technical regulations within the meaning of the TBT Agreement if their adoption and / or application received substantial governmental support or incentives, sufficient for making them mandatory de facto in the market of a WTO Member. ${ }^{735}$ Arguably, this conclusion is valid with respect to private-sector standards as well.

Such an approach was further confirmed by the Panel in US - COOL. In this case, the complaint was brought by Canada and Mexico concerning a complex system of country of origin labelling (COOL) for certain meat products adopted by the US which, according to the complainants, discriminated their exports. The Panel found that the US COOL measure per se satisfied all three relevant criteria discussed above and constituted a technical regulation within the meaning of Annex 1 of the TBT Agreement. ${ }^{736}$ However, the Panel found otherwise with respect to the letter sent to industry representatives by the US Secretary of Agriculture, Thomas J. Vilsack (Vilsack letter) suggesting three additional voluntary practices to be followed by the industry. On the one hand, the Panel agreed with the complainants that although the Vilsack letter was not mandatory de jure, it remained to be examined "whether compliance with the Vilsack letter may be considered de facto mandatory". ${ }^{737}$ On the other hand, however, the Panel observed that there was no compelling evidence provided by the complainants demonstrating that the voluntary recommendations provided in the letter "materialized" into meaningful governmental pressure or incentives. As a result, it finally concluded that the complainants did not demonstrate that compliance with the Vilsack letter was mandatory within the meaning of TBT Agreement Annex 1.1. ${ }^{738}$

735 In this regard, interestingly, the predecessor of the TBT Agreement, the Tokyo TBT Agreement, in the Explanatory Note to the definition of a technical regulation, provided that "this definition covers also a standard of which the application has been made mandatory not by separate regulation but by virtue of a general law".

See: Tokyo Round Agreement on Technical Barriers to Trade, BISD 26th Supp, 1980, 8, Annex 1. See also on the issue: R. W. Middleton, "The GATT Standards Code", Journal of World Trade Law, 14, 1980, pp. $201-203$.

736 See: Panel Reports, US - COOL, paras. 7.216 - 7.217.

737 See: Panel Reports, US - COOL, paras. 7.175 - 7.176.

738 See: Panel Reports, US - COOL, paras. 7.179, 7.184- 7.196. The findings of the 
Private-sector standards are voluntary de jure by definition because they are adopted and applied by private entities. ${ }^{739}$ Arguably, however, they may become mandatory de facto in a market of a WTO Member in two types of situations. ${ }^{740}$ First, this may happen due to significant governmental support or incentives for the adoption and / or application of a private-sector standard. Such governmental support or incentives may, for example, include tax or other benefits for compliance with requirements of a privatesector standard, presumption of compliance with governmental requirements, etc. ${ }^{741}$ Considering the approach taken by WTO panels and the Appellate Body discussed above, it seems that a private-sector standard may be found to constitute a technical regulation within the meaning of the TBT Agreement only if the support or incentives provided by a government are sufficient for rendering the standard (or certain requirement thereof) mandatory de facto. The determination in this respect may, of course, be made only on a case-by-case basis and in the context of the domestic regulatory environment of a particular WTO Member. This is indeed in line with the approach adopted by the WTO dispute settlement practice under the GATT, as discussed in Chapter III. ${ }^{72}$

Panel were not appealed. The Panel, however, also later found that through the issuance of the Vilsack letter, the US failed to administer its COOL measure in a reasonable manner and was thus in violation of Article X:3(a) of the GATT 1994; see: Panel Reports, US - COOL, para. 7.864. See also Section 3.3.2.2 of Chapter III.

739 This is, of course, excluding situations where the provisions of a private-sector standard are inserted into the text of a mandatory regulation or incorporated into a governmental regulation by reference. In such a case the provisions of the standard would be mandated de jure. However, the provisions of the standards would then stop to be private by nature and become a part of a mandatory governmental legislation. See: Jan Bohanes, Iain Sandford, "The (Untapped) Potential of WTO Rules to Discipline Private Trade-Restrictive Conduct”, Inaugural Conference, Society of International Economic Law, 56/08, Geneva, July, 15-17, 2008, paras. $62-63$.

740 See Section 2.3.3.2 of Chapter II. See also: Private Standards and the SPS Agreement. Note by the Secretariat, WTO, SPS Committee, G/SPS/GEN/746, Geneva, 24 January 2007, paras. 3 - 10; Samir R. Gandhi, "Voluntary Environmental Standards: The Interplay Between Private Initiatives, Trade Rules and the Global Decision-Making Process", 3rd Global Administrative Law Seminar, Viterbo, June 15-16, 2007, pp. 2 - 4; Grace Chia-Hui Lee, "Private Food Standards and Their Impacts on Developing Countries", European Commission DG Trade Unit G2, Brussels, 2006, pp. 8-14.

741 See: Samir R. Gandhi, "Regulating the Use of Voluntary Environmental Standards Within the World Trade Organization Legal Regime: Making a Case for Developing Countries", Journal of World Trade, 39(5), 2005, p. 875; Erik P. Bartenhagen, "The Intersection of trade and the Environment: An Examination of the Impact of the TBT Agreement on Eco-labeling Programs", Virginia Environmental Law Journal, 17, 1997, p. 63; Rüdiger Wolfrum, Peter-Tobias Stoll, Anja Seibert-Fohr, WTO: Technical Barriers and SPS Measures, Nijhoff, Leiden, 2007, pp. 190 - 191.

${ }^{742}$ See Section 3.1.1 of Chapter III. 
Second, private-sector standards may become de facto mandatory without governmental support or incentives through their wide scale application in the market of a WTO Member. ${ }^{743}$ In this respect, a standard may be applied voluntarily by a large majority of market players due to their own business decisions. It may also be applied by a company or group of companies controlling a market, i.e. in case of monopolies or industry cartels. Arguably, however, it seems quite unlikely that such de facto mandatory private-sector standards, which are not subject to meaningful governmental involvement or incentives, could qualify as technical regulations within the meaning of the TBT Agreement. First of all, as has been noted, the term "mandatory" in the definition of technical regulation has been interpreted by the Appellate Body to mean the prescription of product characteristics "in a binding or compulsory fashion". ${ }^{74}$ This phrasing seems to relate to the modes of governmental influence and enforcement of a measure and could hardly be interpreted to address the voluntary application of a standard, even if it is widespread. Second, the recognition that such a standard is "mandatory" within the meaning of the definition of technical regulation would, arguably, deny the meaning of another measure covered by the TBT Agreement - the voluntary "standard" ${ }^{745}$ Having said this, it is worth noting, however, that according to the approach of the Panel and the Appellate Body in US - Tuna II (Mexico), the term "mandatory" in the definition of technical regulation does not necessarily mean the outright denial of market access for a product at issue if it does not comply. In other words, the prescription of product characteristic or rules for use of a particular label in a technical regulation shall be "mandatory" only, and not necessarily "mandatory for sale of a product".

The conclusions above, however, could be disputable if a standard is adopted and / or applied by a monopoly or a cartel established by a government of a WTO Member. However, in most cases such monopolies or cartels would constitute STEs enjoying exclusive or special rights or privileges granted by a government. Such situations would thus, most likely, be more appropriately captured by the specific rules of Article XVII:1 of the GATT

743 This is indeed the main argument of the countries complaining about traderestrictive effects of private-sector standards; see: Private Voluntary Standards and Developing Country Market Access: Preliminary Results. Communication from OECD, Linda Fulponi, WTO, SPS Committee, G/SPS/GEN/763, Geneva, 27 February 2007, para. 1; Stephen Clapp, "Private Sector Standards Seen Harming Developing Countries", Food Chemical News, 49(33), 2007, p. 16; Private Voluntary Standards within the WTO Multilateral Framework: Submission by the United Kingdom. A report prepared by Digby Gascoine and O'Connor and Company, WTO, SPS Committee, G/SPS/GEN/802, Geneva, 9 October 2007, p. 35.

744 Appellate Body Report, EC - Asbestos, para. 68.

${ }^{745}$ For discussion of the definition of standard in the TBT Agreement, see Section 4.1.1.2 of the present Chapter. 
1994, devoted to the STEs, although the rules of the TBT Agreement and of the GATT 1994 in fact are not mutually exclusive. ${ }^{76}$

Thus, it seems that similarly to the approach taken under the GATT on the distinction of mandatory and voluntary measures, ${ }^{747}$ the existence and amount of governmental involvement or incentives is decisive for the qualification of a de jure non-mandatory measure as a de facto mandatory technical regulation under the TBT Agreement.

\subsubsection{Standard}

Annex 1.2 to the TBT Agreement contains the following definition of standard:

\section{Standard}

Document approved by a recognized body, that provides, for common and repeated use, rules, guidelines or characteristics for products or related processes and production methods, with which compliance is not mandatory. It may also include or deal exclusively with terminology, symbols, packaging, marking or labelling requirements as they apply to a product, process or production method.

The definition of standard has not as yet been thoroughly interpreted in the WTO dispute settlement practice. ${ }^{748}$ In US - Tuna II (Mexico), the Appellate Body noted with respect to the second sentences of the definitions of technical regulation and standard in paragraphs 1 and 2 of Annex 1, that their language is identical. In principle, “"terminology”, "symbols”, "packaging”, "marking", and "labelling requirements" may thus be the subject-matter of both technical regulations and standards". ${ }^{79}$

It is also worth noting that the ISO/IEC Guide 2, whose definitions are applicable for the terms used in the TBT Agreement unless the Agreement

746 For more information about Article XVII:1 of the GATT 1994, see Section 3.2.2.1.2 of Chapter III. See also on the issue: Jan Bohanes, Iain Sandford, "The (Untapped) Potential of WTO Rules to Discipline Private Trade-Restrictive Conduct”, Inaugural Conference, Society of International Economic Law, 56/08, Geneva, July, 15-17, 2008, paras. $47-57$.

${ }^{747}$ For more information about the dispute settlement practice on the distinction of mandatory and voluntary measures under the GATT 1994, see Section 3.1.1 of Chapter III.

748 See: Arthur E. Appleton, "The Agreement on Technical Barriers to Trade", at: Patrick F.J. Macrory, The World Trade Organization: Legal, Economic and Political Analysis, 1 Springer [etc.], New York, 2005, p. 379; Arkady Kudryavtsev, "The TBT Agreement in Context”, at: Tracey Epps, Michael J. Trebilcock, Research Handbook on the WTO and Technical Barriers to Trade, Edward Elgar, Cheltenham, UK, 2013, p. 33.

749 Appellate Body Report, US - Tuna II (Mexico), para. 187. 
contains diverging definitions ${ }^{750}$ provides that a standard is a "document, established by consensus and approved by recognized body", thus requiring decision-making by consensus. ${ }^{71}$ However, the Explanatory Note to the definition of standard in Annex 1.2 of the TBT Agreement clarifies that the TBT Agreement "covers also documents which are not based on consensus". The fact that a standard shall not necessarily be adopted by consensus in order to qualify as such under the TBT Agreement was also confirmed by the Panel and the Appellate Body in EC - Sardines. ${ }^{752}$

Due to the similarities in the structure and wording of the definitions of standard and technical regulation, it may be assumed that some criteria are common for both definitions. First, a standard as well as a technical regulation is a "document", i.e. it must exist in written form. ${ }^{753}$ Second, a standard, like a technical regulation within the meaning of the TBT Agreement, is a document, which shall:

- apply to an identifiable product or group of products; and

- provide for product characteristics or related PPMs.

It is very likely that these criteria would be interpreted in the same way as analogous criteria with respect to technical regulations, as discussed in the previous Section. ${ }^{754}$ However, the definition of standard also contains certain important elements which make it different from the definition of technical regulation:

- compliance with a standard must be not

mandatory, i.e. it must be voluntary;

- in addition to product characteristics or PPMs, a standard may provide "rules" and "guidelines";

- rules, guidelines or characteristics for products or PPMs must be provided by a standard "for common and repeated use"; and

- a standard must be "approved by a recognized body".

The distinction between a standard and a technical regulation is indeed essential in the context of the TBT Agreement, since the Agreement contains different sets of rules for these two types of measures. ${ }^{75}$ In this regard, the

750 See the first paragraph of Annex 1 of the TBT Agreement.

751 See: ISO/IEC Guide 2: 2004, Standardization and Related Activities - General Vocabulary, definition 3.2; see also: Appellate Body Report, EC-Sardines, para. 225.

752 See: Panel Report, EC - Sardines, para. 7.90; Appellate Body Report, EC - Sardines, para. 227.

753 Arthur E. Appleton, "Supermarket Labels and the TBT Agreement: "Mind the Gap”“, Business Law Brief, 4, Fall 2007. p. 12.

754 Concerning the possibility for a standard to lay down different types of PPMs, see Section 4.1.1.4 of the present Chapter.

755 Articles 2 and 3 of the TBT Agreement prescribe the obligations with respect to 
decisive criterion which marks the difference between the definitions of standard and technical regulation in the TBT Agreement is that compliance with first is not mandatory. ${ }^{756}$ Standards may be adopted by governmental and non-governmental standardizing bodies and, contrary to a technical regulation, it shall not "regulate the product in a binding or compulsory fashion" ${ }^{757}$. For example, the voluntary documents specifying product characteristics and labelling rules approved by the American National Standards Institute (ANSI) in the United States, or by the European Committee for Electrotechnical Standardization (CENELEC) in the EU, may be regarded as standards within the meaning of the TBT Agreement. ${ }^{758}$

However, as has been noted, standards frequently seem to not be fully voluntary de facto. ${ }^{759}$ Some standards are in fact applied by business actors so widely that, in practice, this turns the compliance with requirements of such standards into a mandatory condition for real market access. The importers then have to comply with requirements of such standards in order to ensure the needed volumes of sales or even in order to be able to sell their products at all. ${ }^{760}$ Accordingly, although standards are voluntary, they may still present considerable barriers for international trade. This, perhaps, was the main reason for their inclusion into the scope of application of the TBT Agreement.

As has been also noted before, the distinction between mandatory and voluntary measures is not always clear. Governments may sometimes

technical regulations and Article 4, with the Code of Good Practices in Annex 3, prescribes obligations with respect to standards. For more information about main substantive obligations according to the TBT Agreement, see Section 4.3 of the present Chapter.

756 See: Arthur E. Appleton, "The Agreement on Technical Barriers to Trade", at: Patrick F.J. Macrory, The World Trade Organization: Legal, Economic and Political Analysis, 1 Springer [etc.], New York, 2005, p. 379; Jan McDonald, "Domestic Regulation, Harmonization, and Technical Barriers to Trade", World Trade Review, 4(2), 2005, p. 253; Arkady Kudryavtsev, "The TBT Agreement in Context", at: Tracey Epps, Michael J. Trebilcock, Research Handbook on the WTO and Technical Barriers to Trade, Edward Elgar, Cheltenham, UK, 2013, pp. $34-35$.

757 Appellate Body Report, EC - Asbestos, para. 68.

758 The examples are cited from: Rüdiger Wolfrum, Peter-Tobias Stoll, Anja SeibertFohr, WTO: Technical Barriers and SPS Measures, Nijhoff, Leiden, 2007, p. 190; Peter Van den Bossche, Werner Zdouc, The Law and Policy of the World Trade Organization. Text, Cases and Materials, 3d Edition, CUP, 2013, p. 853.

759 See: Spencer Henson, "The Role of Public and Private Standards in Regulating International Food Markets”, Food Regulation and Trade: Institutional Framework, Concepts of Analysis and Empirical Evidence, IATRC, Bonn, Germany, May 28-30, 2006, pp. 3 - 4.

760 See: Peter Van den Bossche, Werner Zdouc, The Law and Policy of the World Trade Organization. Text, Cases and Materials, 3d Edition, CUP, 2013, p. 853; Rüdiger Wolfrum, Peter-Tobias Stoll, Anja Seibert-Fohr, WTO: Technical Barriers and SPS Measures, Nijhoff, Leiden, 2007, p. 190. 
choose not to require mandatory compliance with a measure straightforwardly. Instead, they may provide certain weaker or stronger incentives for compliance with a formally voluntary measure. In such situations determining whether a measure is mandatory or voluntary may be done only on a case-by-case basis depending on the regulatory environment of a WTO Member and the level of governmental involvement or incentives, i.e. whether the incentives provided by a government for the implementation of a measure are sufficient in order to render this measure de facto mandatory. ${ }^{761}$

According to the definition, a standard may provide for "rules" and "guidelines" in addition to product characteristics or PPMs. It is not clear, however, whether this wording adds anything to the requirement of laying down product characteristics or PPMs, common to the definitions of both technical regulation and standard. In principle it might be argued that rules and guidelines for products may address not only product characteristics or PPMs, but also contain any other relevant requirements, for example requirements to a product's use, disposal, utilization after use, etc. Under such an interpretation, the definition of standard would appear broader to some extent than the definition of technical regulation. However, due to the absence of the clarifications from the WTO dispute settlement practice on this matter it is difficult to make well founded conclusions in this respect. ${ }^{762}$

Moreover, a standard shall provide rules, guidelines or characteristics for products or PPMs "for common and repeated use". This wording seems to imply that a standard must be developed and adopted with the aim of its wide and multiple applications and thus it shall most probably be developed not solely for the internal purposes of a single entity. In this respect, private-sector standards adopted and applied by retailers, manufacturers or any other commercial companies solely for their own commercial activities may, arguably, not be regarded as adopted "for common and repeated use" ${ }^{763}$ On the other hand, if a private-sector standard is developed and re-

${ }^{761}$ See previous Section 4.1.1.1 of the present Chapter and Section 3.1.1 of Chapter III.

762 In fact, this difference in wording of the definitions of standard and technical regulation in the TBT Agreement have not received a lot of attention in the literature; many of the authors are of the opinion, however, that the voluntary character is the main, if not the only, difference between "standard" and "technical regulation" according to the TBT Agreement. See: Arthur E. Appleton, "The Agreement on Technical Barriers to Trade”, at: Patrick F.J. Macrory, The World Trade Organization: Legal, Economic and Political Analysis, 1 Springer [etc.], New York, 2005, p. 379; Jan McDonald, "Domestic Regulation, Harmonization, and Technical Barriers to Trade”, World Trade Review, 4(2), 2005, p. 253; Rüdiger Wolfrum, Peter-Tobias Stoll, Anja Seibert-Fohr, WTO: Technical Barriers and SPS Measures, Nijhoff, Leiden, 2007, p. 190.

763 See: Arthur E. Appleton, "Supermarket Labels and the TBT Agreement: "Mind the 
peatedly applied to products from many different suppliers by a commercial corporation, which occupies a substantial share of a market, it is still possible to speak about "common and repeated" application of the standard, notwithstanding its adoption solely for the purposes of one entity.

It is interesting to note, in this regard, that the predecessor of the TBT Agreement, namely the Tokyo Standards Code, contained the following clarification in the Explanatory Note to the definition of standard: "This definition does not cover technical specifications prepared by an individual company for its own production or consumption requirements". ${ }^{764}$ This clarification has, however, not been included into the text of Annex 1 of the TBT Agreement during the Uruguay Round negotiations. ${ }^{765}$ In any case, it seems that, in practice, a standard shall not only be meant for "common and repeated use", but must also be used commonly and repeatedly in a market. Otherwise its existence would, arguably, not raise any meaningful trade concerns for exporters and WTO Members. Indeed, it is logical to assume that a standard, in general, and due to its voluntary character, will create significant problems for the exports of WTO Members only if it is widely applied in a particular market, and is not forgotten "under the dust of a library shelf", so to speak.

Finally, according to its definition, a standard shall be "approved by a recognized body". The TBT Agreement, however, does not clarify what exactly this criterion implies. In this regard, Article 4 and the Code of Good Practice in Annex 3 of the TBT Agreement use another term, "standardizing body", though the TBT Agreement itself does not define this important term. ${ }^{766}$ Annex 1 of the Tokyo Standards Code contained the following definition of standardizing body: "A governmental or non-governmental body, one of whose recognized activities is in the field of standardization". This definition was not incorporated into the text of the TBT Agreement, probably because the ISO/IEC Guide 2, referred to in Annex 1 of the TBT

Gap”“, Business Law Brief, 4, Fall 2007, p. 12.

764 Annex 1 of Tokyo Round Agreement on Technical Barriers to Trade, BISD 26th Supp, $1980,8$.

765 See: Negotiating History of the Coverage of the Agreement on Technical Barriers to Trade with Regard to Labelling Requirements, Voluntary Standards and Production Methods Unrelated to Product Characteristics. Note by Secretariat, TBT Committee, CTE, WT/CTE/W/10, G/TBT/W/11, Geneva, 29 August 1995, para. XLV. See also: Private Voluntary Standards within the WTO Multilateral Framework: Submission by the United Kingdom. A report prepared by Digby Gascoine and O'Connor and Company, WTO, SPS Committee, G/SPS/GEN/802, Geneva, 9 October 2007, pp. $74-76$.

766 This is the case notwithstanding the fact that the TBT Agreement uses the term "standardizing body" more than 55 times, see: Arthur E. Appleton, "Supermarket Labels and the TBT Agreement: "Mind the Gap”“, Business Law Brief, 4, Fall 2007, p. 12. 
Agreement, contains a similar definition. ${ }^{767}$ According to the ISO/IEC Guide 2, a standardizing body is a "body that has recognized activities in standardization" ${ }^{768}$

A number of important questions arise in this regard: 1 . by whom must the body be "recognized" in order to adopt standards within the meaning of the TBT Agreement?; 2. should this be a "recognition" by the government of a WTO Member and / or by market players through the wide scale application of a standard in a market?; 3 . what exactly does the act of such a "recognition" mean, e.g. does it imply the presence of a certain amount of governmental involvement or support for the adoption and / or application of a standard?; 4. could NGOs who develop and adopt private-sector standards, such as GLOBALG.A.P., the FLO and the MSC, be regarded as the "recognized" bodies within the meaning of the definition of standard in the TBT Agreement?; and 5. should the "recognized" standardizing body have standardization as its core activity in order to be regarded as such under the TBT Agreement, or the "recognized" standardizing bodies under the Agreement may also include commercial companies or NGOs that have standard-setting as an ancillary activity? ${ }^{769}$

These questions are not easy to answer. Some of them have been touched upon by the Appellate Body in the US - Tuna II (Mexico) case, although in the context of considering the meaning and the scope of the term "international standard" and "international standardizing body" in the TBT Agreement. ${ }^{770}$ According to the Appellate Body, Members' participation in the standardizing activities of a body, as well as the acceptance of standards adopted by a body, could be regarded as evidence that the standardizing body is "recognized". Moreover, even if a body adopts a single standard, which is widely recognized and accepted, it may be regarded as a "recognized standardizing body" under the TBT Agreement. ${ }^{71}$

767 See: Negotiating History of the Coverage of the Agreement on Technical Barriers to Trade with Regard to Labelling Requirements, Voluntary Standards and Production Methods Unrelated to Product Characteristics. Note by Secretariat, TBT Committee, CTE, WT/CTE/W/10, G/TBT/W/11, Geneva, 29 August 1995, para. XLVIII.

${ }^{768}$ ISO/IEC Guide 2: 2004, Standardization and Related Activities - General Vocabulary, definition 4.3. See also Section 2.1.1.4 of Chapter II.

769 See: Tomasz Wlostowski, "Selected Observations on Regulation of Private Standards by the WTO”, Polish Yearbook of International Law, XXX, 2010, pp. $220-221$

770 According to the TBT Agreement, however, an "international standard" is arguably still a type of a standard and, as such, must satisfy the criteria applicable to the latter. For a detailed discussion on the obligations of harmonization based on international standards, see Section 4.3.3 of the present Chapter.

771 See: Appellate Body Report, US - Tuna II (Mexico), paras. 390 - 394. 
It is worth noting that the definition of standard in the TBT Agreement uses the term "body", and not the term "entity" - arguably a more general term. In principle, the term "body" may be construed to refer to some sort of specialized organ of a WTO Member; however, broader interpretations seem to be legitimate as well. For example, one of the relevant definitions in the Oxford English Dictionary defines the term "body" as is "[a] number of persons taken collectively, usually as united and organized in a common cause or for common action, as for deliberation, government, business; a society, association, league, fraternity". ${ }^{772}$ The Oxford English Dictionary also contains the range of meanings of the term "to recognize", e.g. "[t]o accept the authority, validity, or legitimacy of", and "[t]o acknowledge, consider, or accept (a person or thing) as or to be something". ${ }^{773}$

In principle, nothing in the definition of standard in Annex 1 or in any other provision of the TBT Agreement directly suggests that the "recognized" standardizing body must have standardization as its core activity, although, arguably, usually this is indeed the case. However, the core activities of entities according to their articles of association or other internal documents are in fact a purely internal matter of these entities, while the term "recognized body" seems to have a more external connotation, i.e. recognized in the eyes of somebody. Of course, an entity may or may not consider itself to be a "recognized" standardizing body, but this shall not prevent the test against some objective criteria in order to exclude the opportunities for the circumvention of obligations under the TBT Agreement with respect to such standardizing bodies.

This issue is quite relevant regarding the prospects for regulating private-sector standards by the rules of the TBT Agreement. In particular, the question is whether standardizing NGOs, industry associations or even big commercial corporations could be regarded as the "recognized" standardizing bodies within the meaning of the TBT Agreement. For example, Jan Bohanes and Iain Sandford note the following concerning this debate:

Among the questions raised as part of this debate is whether, for instance, large retailers (supermarket chains) like Tesco that have formulated product and production process standards for their sourcing decisions can fall under the term "non-governmental standardizing body". We consider this unlikely because, in general, supermarket chains do not have recognized activities in standardization. Indeed, based on the traditional textual approach to interpretation, a WTO panel or the Appellate Body would likely enquire, inter alia, whether one of the core activities

772 Oxford English Dictionary Online, see: http://dictionary.oed.com (last visited January 15, 2015).

773 Oxford English Dictionary Online, see: http://dictionary.oed.com (last visited January 15, 2015). 
of the "body" at issue is acknowledged to be the preparation and issuance of standards. This has not traditionally been the case for a supermarket chain. However, certain private standards that have been promulgated by EurepGAP, which is an industry association, and not a single company like Tesco, have given rise to discussions in WTO Committees. At least some WTO Members appear to take the view that sectoral industry associations constitute "non-governmental standardizing bodies" under the TBT Agreement. Examples are the Australia Gas Association and Japan Iron and Steel Federation (JISF). ${ }^{774}$

In fact, one of the important issues with regard to the term "recognized body" in the TBT Agreement is by whom such a body shall be "recognized". ${ }^{775}$ As has been explained, WTO law, and the TBT Agreement in particular, prescribes rights and obligations only for WTO Members and, as such, only WTO Members may be held responsible for violations of its provisions. ${ }^{776}$ This might suggest that a WTO Member shall bear responsibility for the activities of a standardizing body, whether governmental or non-governmental, only if this body is "recognized" by a WTO Member itself, i.e. by its governmental or other public organs. These organs may be administrative, executive, legislative or judicial, i.e. any organ of a WTO Member whose actions are attributable to the Member.

However, then this raises questions regarding which acts by organs of WTO Members might constitute such a "recognition" of a standardizing body: request or authorization of the development and adoption of a standard, participation in standard-setting processes, references to a standard in governmental normative acts, and / or support or incentives for the application of a standard. In this regard, the controversial issue is whether the financing of a standard-setting organization by a government may be evidence of the "recognition" of the organization by a WTO Member. The answer seems to be negative, as long as such financing is not accompanied by meaningful governmental involvement into the standard-setting activities of the organization, or by governmental incentives for the application of adopted standards. Indeed, the funding of a standard-setting organization by a government taken alone, may hardly constitute exhaustive evidence of the organization's “recognition" by a WTO Member.

In any case, due to the differences in the regulatory traditions of various WTO Members it seems impossible to develop a general test in this respect.

${ }^{774}$ Jan Bohanes, Iain Sandford, "The (Untapped) Potential of WTO Rules to Discipline Private Trade-Restrictive Conduct”, Inaugural Conference, Society of International Economic Law, 56/08, Geneva, July, 15-17, 2008, para. 125.

775 See: Ibid., para. 122.

776 See Section 1.2 of Chapter I, Section 2.3.4.1 of Chapter II and Section 3.1.2 of Chapter III. 
This issue therefore shall be decided on a case-by-case basis. However, it seems safe to say that at least NSBs of WTO Members, whether of governmental or non-governmental nature (such as the South African Bureau of Standards (SABS) or the American National Standards Institute (ANSI)), shall be regarded as the "recognised" standardizing bodies within the meaning of the TBT Agreement. ${ }^{777}$

The approach that a non-governmental standardizing body shall be "recognized" by the governmental authorities of a WTO Member is clearly not really favourable with respect to the legal regulation by the TBT Agreement of so-called "purely" private-sector standards adopted and / or applied without meaningful governmental involvement or incentives. If there is no sufficient evidence of governmental "recognition", a non-governmental entity which adopted a standard could not be regarded as a "recognized" standardizing body within the meaning of the Agreement. Consequently, private-sector standards adopted by such entities would not be "standards" within the meaning of the TBT Agreement, and thus they would not be subjects of its relevant disciplines. This conclusion seems justified in light of the fact that it is hardly possible to hold WTO Member responsible for conduct which they did not control or support, and might even be unaware of. Such an approach would therefore "provide a certain symmetry between the state's obligations, and the ambit of the state's control". ${ }^{778}$

Another possible approach to the interpretation of the term "recognized body" in the definition of standard is the "recognition" by a market (i.e. by market players) of a WTO Member. ${ }^{779}$ This may entail the consideration of two relevant factors: 1 . how widely various interested stakeholders are involved in the standard-setting processes of a standard developer; and 2. how widely a standard adopted by a standardizing organization is applied in a market of a WTO Member. Under such an approach, the wide scale application of a standard would serve as evidence of the recognition of its "author" by market players and, if the application of a standard is sufficiently widespread in the market of a WTO Member, the organization which adopted the standard would be considered to be the "recognized body". This approach to the interpretation of the term "recognized body" in the definition of standard indeed seems to be "friendlier" with respect to the prospects for regulating private-sector standards by the TBT Agreement. If a private entity with wide participation of stakeholders adopted a standard which, in turn, is widely applied in a market, this entity would be regarded

777 For more examples and information about NSBs, see Section 2.2.4.3.3 of Chapter II.

778 Jan Bohanes, Iain Sandford, "The (Untapped) Potential of WTO Rules to Discipline Private Trade-Restrictive Conduct”, Inaugural Conference, Society of International Economic Law, 56/08, Geneva, July, 15-17, 2008, para. 122.

779 See: Ibid., para. 122. 
as the "recognized body". A private-sector standard adopted by such an entity would therefore be a standard within the meaning of Annex 1 of the TBT Agreement.

On the one hand, this line of reasoning could, arguably, promote the effectiveness of the relevant rules of the TBT Agreement by dealing with the real trade effects of private-sector standards and trade concerns raised by certain WTO Members in this regard. ${ }^{780}$ On the other hand, such an approach to the interpretation of the term "recognized body" on the basis of the "recognition" by a market and market players, may entail some significant problems. First, it seems difficult, if possible at all, to develop some sort of test on how widely the relevant stakeholders should be involved in standardizing processes and how common the application of a privatesector standard should be in a market. Second, the question arises whether it would be fair and realistic to require WTO Members to bear responsibility under the TBT Agreement for something they do not actually participate in, control, encourage or support, i.e. for something they did not "recognize". ${ }^{781}$

Moreover, in principle, both interpretative approaches to the term "recognized body" in the definition of standard could be merged. Under such an interpretation a standard within the meaning of the TBT Agreement shall be "recognised" by both governmental authorities of a WTO Member and by market players. On the one hand, such a two-tier approach would be quite restrictive with regard to the possibility of regulating private-sector standards by the TBT Agreement, as many such standards would be then not covered by the definition of standard in the TBT Agreement. On the other hand, however, it also seems quite practical as WTO Members would, first, be responsible only for the bodies they actually "recognized" and, second, only for widely applied standards that are able to create significant negative trade effects. ${ }^{782}$

780 See: Private Industry Standards. Communication from Saint Vincent and the Grenadines, WTO, SPS Committee, G/SPS/GEN/766, 28 February 2007; Private and Commercial Standards. Statement by Ecuador at the Meeting of 27 - 28 June 2007, WTO, SPS Committee, G/SPS/GEN/792, Geneva, circulated on 5 July 2007; Private Standards and the SPS Agreement. Note by the Secretariat, WTO, SPS Committee, G/SPS/GEN/746, Geneva, 24 January 2007, para. 9.

See also: "Private Standards Are a Mixed Blessing, Committee Hears", WTO News Items, March 2007, available at: https://www.wto.org/english/news_e/news07_e/ sps_28feb_1march07_e.htm (last visited January 15, 2015).

781 For a more detailed discussion on the positive and negative obligations of WTO Members with respect to governmental and non-governmental bodies, see Section 4.2 of the present Chapter.

782 It is worth noting, however, that an actual trade effect is not usually a criterion for the application of WTO rules and a potential trade-restrictive effect may thus be sufficient. Nonetheless it would, arguably, be surprising if a WTO dispute could arise with respect to a private-sector standard which nobody knows and nobody 
In this regard it is interesting to note that an even more restrictive approach is offered by Arthur Appleton who proposes six criteria for qualifying an entity as a "recognized" standardizing body within the meaning of the TBT Agreement:

[...] a panel is likely to determine whether the entity is: (i) recognized by one or more WTO Members as a standardization body, (ii) involved with the activities of international standardization organizations (ISO, IEC, etc.), (iii) open to involvement from other WTO Members, and (iv) has accepted the Code. It will also determine (v) whether any WTO Members apply "standards" promulgated by the entity, and (vi) if the aim of its "standards" further a legitimate objective within TBT Article 2.2. ${ }^{.83}$

It seems that many of the mentioned characteristics might be relevant in determining whether an entity could be regarded as a "recognized" standardizing body. However, it is noteworthy that the text of the TBT Agreement per se does not impose all these complex requirements.

\subsubsection{Conformity Assessment Procedures}

Conformity assessment procedures are the third type of measures regulated by the TBT Agreement. According to the definition in Annex 1.3 to the TBT Agreement, conformity assessment procedures are:

Any procedure used, directly or indirectly, to determine that relevant requirements in technical regulations or standards are fulfilled.

Thus, conformity assessment procedures serve to verify and assess the compliance of products or PPMs with the requirements presented by technical regulations or standards. The Explanatory Note to the definition of conformity assessment procedures further clarifies:

Conformity assessment procedures include, inter alia, procedures for sampling, testing and inspection; evaluation, verification and assurance of conformity; registration, accreditation and approval as well as their combinations.

Thus, under the TBT Agreement, the term "conformity assessment procedures" is understood broadly to include all kinds of procedures in which the compliance of products with technical regulations or standards is

applies.

783 See: Arthur E. Appleton, "Supermarket Labels and the TBT Agreement: "Mind the Gap”“, Business Law Brief, 4, Fall 2007, p. 12. For more information about the Code of Good Practice and obligations under Article 2.2 of the TBT Agreement, see Section 4.3.2 of the present Chapter. 
assessed. ${ }^{784}$ The Explanatory Note does not directly mention another important type of conformity assessment procedure - "certification". As has been mentioned in Chapter II, certification usually consists of a combination of procedures which may include sampling, testing, inspection, etc. There is thus no doubt that certification is covered by the definition of conformity assessment procedure in the TBT Agreement. ${ }^{785}$ Also, as was explained in Chapter II, conformity assessment procedures may in principle belong to three possible types: first-party assessment (self-declaration claims), second-party assessment and third-party assessment. Since certification, as a rule, is performed by an independent third party, it usually belongs to the third-party assessment type. ${ }^{786}$ It is also worth noting that the TBT Agreement clearly does not deal with the conformity assessment procedures performed by a producer with respect to its own products, i.e. firstparty assessment or self-declaration claims such as quality control. Indeed, such self-control by producers may not create technical barriers to trade and, as a rule, contributes to ensuring the safety and quality of products.

According to the TBT Agreement, conformity assessment procedures are a separate type of measure, different from technical regulations and standards. In EC - Trademarks and Geographical Indications, Australia argued that the requirements for product labelling and for structures of inspection groups for the registration of geographical indications according to the EU regulation both constituted technical regulations within the meaning of the TBT Agreement. The Panel agreed with Australia concerning the labelling requirements and disagreed concerning the structures of inspection groups. The latter, according to the Panel, were conformity assessment procedures. ${ }^{787}$ The Panel provided the following clarifications concerning the scope and definition of conformity assessment procedures:

784 See: World Trade Report. Exploring the Links Between Trade, Standards and the WTO, WTO, 2005, p. 97.

785 Interestingly, the Tokyo Round Standards Code distinguished between conformity assessment procedures and "certification systems", subjecting them to regulation by different articles, see: Tokyo Round Agreement on Technical Barriers to Trade, BISD 26th Supp, 1980, 8, Articles 5 -9. In the TBT Agreement there is no such a distinction.

786 For more information on the types of conformity assessment procedures, see Section 2.2.9 of Chapter II. See also: World Trade Report. Exploring the Links Between Trade, Standards and the WTO, WTO, 2005, p. 97 - 100; see also: Rüdiger Wolfrum, Peter-Tobias Stoll, Anja Seibert-Fohr, WTO: Technical Barriers and SPS Measures, Nijhoff, Leiden, 2007, pp. 193 - 194; Arthur E. Appleton, "Conformity Assessment Procedures”, at: Tracey Epps, Michael J. Trebilcock, Research Handbook on the WTO and Technical Barriers to Trade, Edward Elgar, Cheltenham, UK, 2013, pp. $81-119$.

787 See: Panel Report, EC - Trademarks and Geographical Indications (Australia), paras. $7.459,7.514-7.515$. 
This definition shows that "conformity assessment procedures" assess conformity with "technical regulations" and "standards". This suggests that they are not only distinct from one other, but mutually exclusive. Whilst a single measure can combine both a technical regulation and a procedure to assess conformity with that technical regulation, it would be an odd result if a conformity assessment procedure could fall within the definition of a technical regulation as well. ${ }^{788}$

The Panel further noted that standards and technical regulations on the one hand, and conformity assessment procedures on the other, are subject to different rules of the TBT Agreement: technical regulations and standards are regulated by Articles 2 to 4, and conformity assessment procedures by Articles 5 to 9 . It would therefore be unreasonable to merge the scope of these terms and apply the different rules of the TBT Agreement cumulatively. According to the Panel, the Explanatory Note to the definition of conformity assessment procedure explicitly refers to "procedures for ... inspections", and this suggests that the requirements for inspection procedures, including inspection structures, may not be viewed as technical regulations under the TBT Agreement. ${ }^{789}$

The definition of conformity assessment procedures explicitly refers to a technical regulation and a standard. It thus seems fair to conclude that the answer to the question about whether conformity assessment procedures for private-sector standards are disciplined by the TBT Agreement largely depends on the relationships between private-sector standards and the terms "technical regulation" and "standard" in the TBT Agreement. If a private-sector standard may be qualified as a technical regulation or a standard within the meaning of the TBT Agreement, the conformity assessment procedures under such a private-sector standard would, arguably, also be covered by the TBT Agreement.

\subsubsection{Processes and Production Methods Under the TBT Agreement}

PPMs are mentioned in the definitions of both standard and technical regulation in the TBT Agreement. In particular, the first sentence of the definition of technical regulation in Annex 1 of the TBT Agreement provides that a technical regulation may, besides product characteristics, also address "their related process and production methods". Similarly, according to

788 Panel Report, EC - Trademarks and Geographical Indications (Australia), para. 7.512.

789 Panel Report, EC - Trademarks and Geographical Indications (Australia), para. 7.513 - 7.514. See also on the issue: Peter Van den Bossche, Werner Zdouc, The Law and Policy of the World Trade Organization. Text, Cases and Materials, 3d Edition, CUP, 2013, pp. 857 - 858; Rüdiger Wolfrum, Peter-Tobias Stoll, Anja Seibert-Fohr, WTO: Technical Barriers and SPS Measures, Nijhoff, Leiden, 2007, pp. $194-195$. 
the first sentence of the definition of standard in Annex 1, a standard may provide for "related process and production methods". ${ }^{790}$ Furthermore, the second sentences of both the definitions of standard and technical regulation in Annex 1 provide that both these types of documents may deal with "terminology, symbols, packaging, marking or labelling requirements as they apply to a product, process or production method". ${ }^{791}$

There is no definition of PPM in the TBT Agreement. In the course of the Uruguay Round negotiations, the draft definition for PPM was proposed by the United States; however, it did not receive meaningful support from other negotiators and was not included in the final text of the TBT Agreement. ${ }^{792}$ The proposed definition of PPM was formulated as follows:

Process or Production Method (PPM):

One or more planned actions in a series of conditions or operations (e.g. mechanical, electrical, chemical, inspection, test) by means of which a material or product advances from one stage to its final state. PPMs include conditions of growth as well as controlled treatments that subject materials or products to the influence of one or more types of energy (e.g. human, animal, mechanical, electrical, chemical, thermal) as required to achieve a desired reaction, change, result or performance. ${ }^{793}$

Interestingly, the predecessor of the TBT Agreement, namely the Tokyo Round Standards Code, dealt with technical specifications, technical regulations and standards related only to products. On the one hand, this could suggest that all kinds of PPMs were excluded from the scope of

790 As one may notice, in the definition of technical regulation the term "related process and production methods" is qualified by the word "their", while in the definition of standard it is not. It is unlikely, however, that this signifies any substantive difference in the meanings of the two definitions.

791 As can be seen, there is a small difference in the references to the PPMs between the first and the second sentences in the definitions of both standard and technical regulation in Annex 1 of the TBT Agreement. In the first sentence it reads "process and production method", in the second - "process or production method". However, this difference appears to be minor and merely accidental. Thus, the abbreviation "PPM" is used with respect to both sentences. See: Arkady Kudryavtsev, "The TBT Agreement in Context", at: Tracey Epps, Michael J. Trebilcock, Research Handbook on the WTO and Technical Barriers to Trade, Edward Elgar, Cheltenham, UK, 2013, pp. $40-42$.

792 Document TBT/M/30 and 31, as referred in: Negotiating History of the Coverage of the Agreement on Technical Barriers to Trade with Regard to Labelling Requirements, Voluntary Standards and Production Methods Unrelated to Product Characteristics. Note by Secretariat, TBT Committee, CTE, WT/CTE/W/10, G/ TBT/W/11, Geneva, 29 August 1995, para. CXXV.

793 TBT/W/108/Add.1, as referred to in: Ibid., para. CXXV. 
the Standards Code. ${ }^{794}$ On the other hand, however, Article 14.25 of the Standards Code provided that the dispute settlement procedures set out in the Code could be used "in cases where a Party considers that obligations under this Agreement are being circumvented by the drafting of requirements in terms of processes and production methods rather than in terms of characteristics of products". Taking into account this wording, different points of view were expressed by the GATT Contracting Parties: one - that the measures addressing PPMs were covered and generally prohibited by the Standards Code; and another - that the measures addressing PPMs, although generally were not covered by the Agreement, could be prohibited in case of the circumvention of the other provisions of the Standards Code..$^{795}$

794 See: Tokyo Round Agreement on Technical Barriers to Trade, BISD 26th Supp, 1980, 8, Explanatory Note to the definition of technical specification in Annex 1. One of the first drafts of the Tokyo Standards Code (March 1975) provided that a technical specification "includes, where applicable, test methods, and specifications concerning testing, packaging, marking or labelling to the extent that they affect products rather than processes". Later this limitation with respect to the "processes" was omitted and, upon proposal by the United States, the following wording was included in the draft in May 1976: "For the purposes of this Code "technical specifications" includes processes and production methods insofar as they are necessary to achieve the final product desired". In the definitions in the final text of the Standards Code all references to PPMs were omitted. See: Negotiating History of the Coverage of the Agreement on Technical Barriers to Trade with Regard to Labelling Requirements, Voluntary Standards and Production Methods Unrelated to Product Characteristics. Note by Secretariat, TBT Committee, CTE, WT/CTE/W/10, G/TBT/W/11, Geneva, 29 August 1995, paras. XXVIII, XXIX, CVII - CIX; see also: Terence .P. Stewart, The GATT Uruguay Round. A Negotiating History (1986 - 1992), Vol. 1, Kluwer Law and Taxation Publishers, Denver. Boston, 1993, pp. $1086-1087$.

795 "There was a widely held view that Article $14.25 \mathrm{did}$ not provide a suitable basis for further pursuing the extension of the coverage of the Agreement to include PPM-based measures. It was noted that its operation had proved unsatisfactory because of a lack of agreement among Parties on its application." See: Negotiating History of the Coverage of the Agreement on Technical Barriers to Trade with Regard to Labelling Requirements, Voluntary Standards and Production Methods Unrelated to Product Characteristics. Note by Secretariat, TBT Committee, CTE, WT/CTE/W/10, G/TBT/W/11, Geneva, 29 August 1995, para. CXXIII. See also: Terence .P. Stewart, The GATT Uruguay Round. A Negotiating History (1986 1992), Vol. 1, Kluwer Law and Taxation Publishers, Denver. Boston, 1993. p. 1087; Gabrielle Marceau, Joel P. Trachtman, "The Technical Barrier to Trade Agreement, the Sanitary and Phytosanitary Measures Agreement, and the General Agreement on Tariffs and Trade: A Map of the World Trade Organization Law of Domestic Regulation of Goods”, Journal of World Trade, 36(5), 2002, p. 860. See also: Gabrielle Marceau, Joel P. Trachtman, "A Map of the World Trade Organization Law of Domestic Regulation of Goods: The Technical Barriers to Trade Agreement, the Sanitary and Phytosanitary Measures Agreement, and the General Agreement on Tariffs and Trade", Journal of World Trade, 48(2), 2014, pp. 351-432. 
Considering the definitions of standard and technical regulation in Annex 1 of the current TBT Agreement, the first sentences of both definitions refer only to related PPMs, while the second sentences of the same definitions do not specify which type/s of PPM is / are meant. The important question is thus: what types of PPMs are covered by the TBT Agreement, i.e. are these only related PPMs, or npr-PPMs as well? 796 This question is important with respect to the issue of applicability of the TBT Agreement to private-sector standards because private-sector standards frequently contain PPM-based requirements, as has been mentioned.797 Moreover, some private-sector standards are based solely on npr-PPMs; for example the "greenhouse emission" and "air miles" labelling used by big British retail consortiums Tesco and Marks \& Spencer aimed at informing consumers about amount of carbon emission released into the atmosphere during the production process.798 Many private eco-labelling schemes are based on so-called life-cycle analysis (LCA), which implies the complex analysis of the environmental impact of a product during all stages of production, processing and consumption (i.e. "from cradle to grave") 799 and therefore usually includes many npr-PPM-based criteria.800

\subsection{Negotiation History of the TBT Agreement and PPMs}

The negotiation history of the TBT Agreement, as well as the text of the definitions of standard and technical regulation in Annex 1 of the TBT

796 For more information with respect to the types of PPMs see Section 3.3.6 of Chapter III.

797 See Section 2.3.2.5.1 of Chapter II.

798 For more information on Tesco carbon labelling scheme see: http://www.tesco. com/greenerliving/what_we_are_doing/carbon_labelling.page? (last visited January 15, 2015); on labelling of airfreighted food by Marks \& Spencer see: "How We Do Business Report 2009”, p.23, available at: http://corporate.marksandspencer. com/page.aspx?pointerid=ad6248969dcf4934b8c4a57934935baf (last visited January 15, 2015); see also: Arthur E. Appleton, "Supermarket Labels and the TBT Agreement: "Mind the Gap”“, Business Law Brief, 4, Fall 2007, p. 10.

799 See on LCA: "Eco-Labeling Standards, Green Procurement and the WTO: Significance for World Bank Borrowers", Center for International Environmental Law, Washington, DC, Geneva, Switzerland, March, 2005, p. 4; Samuel N. Lind, "Eco-Labels and International Trade Law: Avoiding Trade Violations while Regulating the Environment", International Legal Perspectives, 8, 1996, pp. 133 - 134. See also: B. Phillips, T. Ward, et al., Eco-Labelling in Fisheries. What Is It All about?, Blackwell Science, 2003; H. Ward, "Trade and Environment Issues in Voluntary Eco-Labelling and Life Cycle Analysis”, RECIEL, 6(2), 1997.

800 The examples of LCA-based eco-labelling schemes are Nordic Swan, German Blue Angel and Eco Seal, the EU Flower, see: Labelling for Environmental Purposes. Submission by the European Communities under Paragraph 32(iii), WTO, Committee on Trade and Environment, WT/CTE/W/225, 6 March 2003, para. 23; Richard Bonsi, A. L. Hammett, Bob Smith, "Eco-Labels and International Trade: Problems and Situations”, Journal of World Trade, 42(3), 2008, pp. 411 - 412. 
Agreement, demonstrates that related PPMs are undoubtedly included in the scope of the TBT Agreement. ${ }^{801}$ This is indeed not disputed by WTO Members and WTO law experts. However, the issue of disciplining nprPPM-based requirements of WTO Members by the TBT Agreement was one of the most controversial issues during the process of negotiating the Agreement. And today, as will be discussed hereafter, certain aspects of this issue remain uncertain due to the lack of consensus among WTO Members on the matter, and due to the absence of direct clarifications by WTO panels and the Appellate Body. ${ }^{802}$

As has been pointed out, the definitions of technical regulation and standard in their first sentences refer only to related PPMs. In principle, this might suggest that the standards and technical regulations addressing nprPPMs-based issues do not fall within the scope of the TBT Agreement. The negotiation history of the TBT Agreement in the course of the Uruguay Round indeed indicates that a considerable number of negotiating Parties intended to exclude npr-PPMs from the scope of the TBT Agreement. ${ }^{803}$

At first, during the early stage of the Uruguay Round negotiations, some developed countries came up with proposals to include measures addressing all types of PPMs into the scope of application of the TBT Agreement in order to enhance its effectiveness. For example, the United States argued that: "[1]ack of full coverage of PPMs seriously weakened the effectiveness of the Agreement by excluding a growing body of regulations from

801 Negotiating History of the Coverage of the Agreement on Technical Barriers to Trade with Regard to Labelling Requirements, Voluntary Standards and Production Methods Unrelated to Product Characteristics. Note by Secretariat, TBT Committee, CTE, WT/CTE/W/10, G/TBT/W/11, Geneva, 29 August 1995, para. III; see also: Course on Dispute Settlement. World Trade Organization. 3.10. Technical Barriers to Trade, UNCTAD, New York and Geneva, 2003, p. 9; Rüdiger Wolfrum, Peter-Tobias Stoll, Anja Seibert-Fohr, WTO: Technical Barriers and SPS Measures, Nijhoff, Leiden, 2007, p.196; Manoj Joshi, "Are Eco-labels Consistent with World Trade Organization Agreements?", Journal of World Trade, 38(1), 2004, p. 74 .

802 See: Negotiating History of the Coverage of the Agreement on Technical Barriers to Trade with Regard to Labelling Requirements, Voluntary Standards and Production Methods Unrelated to Product Characteristics. Note by Secretariat, TBT Committee, CTE, WT/CTE/W/10, G/TBT/W/11, Geneva, 29 August 1995, para. III; see also: Erik P. Bartenhagen, "The Intersection of trade and the Environment: An Examination of the Impact of the TBT Agreement on Eco-labeling Programs", Virginia Environmental Law Journal, 17, 1997, pp. 73 - 76.

803 Manoj Joshi, "Are Eco-labels Consistent with World Trade Organization Agreements?”, Journal of World Trade, 38(1), 2004, pp. 74 - 75; Richard Bonsi, A. L. Hammett, Bob Smith, "Eco-Labels and International Trade: Problems and Situations", Journal of World Trade, 42(3), 2008, p. 416; Processes and Production Methods (PPMs): Conceptual Framework and Considerations on Use of PPMBased Trade Measures, OECD, OCDE/GD(97)137, Paris, 1997, p. 49. 
its disciplines" ${ }^{804}$ The main intention in this respect was "not to discourage the use of PPMs but rather to eliminate potential trade barriers to both industrial and agricultural trade posed by PPM-based requirements" ${ }^{805}$ However, at the same time, another developed country, New-Zealand, proposed to apply the TBT Agreement only to the measures addressing product related PPMs ${ }^{806}$ Generally, as has been noted by Gabrielle Marceau and Joel Trachtman:

Early debate during the Uruguay Round about the definition of technical barriers to trade were motivated by a desire to include process and production methods within the disciplines of the TBT Agreement, in order to prevent them from becoming barriers to trade. ${ }^{807}$

The proposals to include npr-PPM-based requirements into the scope of application of the TBT Agreement made in the course of the Uruguay Round negotiations met with considerable resistance from certain developing countries who saw this as an attempt to "legalize" the npr-PPM-based restrictions on trade. ${ }^{808}$ The draft text of the TBT Agreement submitted to the Brussels Ministerial Conference in 1990 did, however, in addition to product characteristics, contain the reference to PPMs in the definitions of standard and technical regulation without clarifying the types of PPMs covered.

Later, however, during informal consultations in October 1991, Mexico proposed to clarify the coverage of PPMs in the TBT Agreement by inserting the word "related" before the references to PPMs in the definitions of

804 MTN.GNG/NG8/6,as referred in: Negotiating History of the Coverage of the Agreement on Technical Barriers to Trade with Regard to Labelling Requirements, Voluntary Standards and Production Methods Unrelated to Product Characteristics. Note by Secretariat, TBT Committee, CTE, WT/CTE/W/10, G/ TBT/W/11, Geneva, 29 August 1995, para. CXXI

805 Ibid.

806 Ibid., para. CXXI.

807 Gabrielle Marceau, Joel P. Trachtman, "The Technical Barrier to Trade Agreement, the Sanitary and Phytosanitary Measures Agreement, and the General Agreement on Tariffs and Trade: A Map of the World Trade Organization Law of Domestic Regulation of Goods”, Journal of World Trade, 36(5), 2002, p. 860. See also: Gabrielle Marceau, Joel P. Trachtman, "A Map of the World Trade Organization Law of Domestic Regulation of Goods: The Technical Barriers to Trade Agreement, the Sanitary and Phytosanitary Measures Agreement, and the General Agreement on Tariffs and Trade", Journal of World Trade, 48(2), 2014, pp. 351-432.

808 Indeed, the Preamble to the TBT Agreement provides that "no country should be prevented from taking measures" in order to protect certain important legitimate objectives. See also: Jan McDonald, "Domestic Regulation, Harmonization, and Technical Barriers to Trade”, World Trade Review, 4(2), 2005, p. 255; Manoj Joshi, "Are Eco-labels Consistent with World Trade Organization Agreements?", Journal of World Trade, 38(1), 2004, p. 75. 
standard and technical regulation. Mexico explained that the intention was to exclude explicitly the measures addressing npr-PPMs from the scope of the TBT Agreement. This proposal was accepted by other Parties; however the word "related" finally appeared only in the first sentences of the definitions of standard and technical regulation in Annex 1 of the TBT Agreement, while the second sentences of the definitions were not changed. ${ }^{809}$ Mexico was still satisfied with this outcome because, in its view, the second sentence in the definitions of standard and technical regulation was merely "illustrative of the first". ${ }^{810}$ However, another view was expressed by Finland, supported by the United States and European Communities, who argued that the second sentence in the definitions was to be regarded "as additional to the first and not merely illustrative" - the approach evidenced by the usage of the word "also" in the second sentence. ${ }^{811}$

Thus, arguably, the wording of the relevant provisions of the TBT Agreement and the negotiation history of the Agreement demonstrate that the status of the npr-PPM-based requirements under the Agreement is rather uncertain. On the one hand, npr-PPMs are apparently excluded from the first sentences of the definitions of technical regulation and standard dealing with the requirements to product characteristics per se. On the other hand, the second sentences of the definitions dealing with product packaging marking or labelling seems to cover all types of PPMs.

After the completion of the Uruguay Round and the adoption of the TBT Agreement, the issue of the npr-PPM-based marking and labelling received particular attention in the context of eco-labelling schemes which are frequently based on the LCA and contain many npr-PPM-based criteria. The TBT Committee, and especially the Committee on Trade and Environment (CTE) established by the Ministerial Decision on Trade and Environment 1994, became the main venues for debate on eco-labelling and its regulation by WTO law.

European Communities, Switzerland and Canada expressed the views that eco-labelling based on npr-PPM requirements, whether mandatory or voluntary, may be covered by the TBT Agreement in order to increase the transparency of administrating such eco-labelling, limit its trade-restrictive effects, and to promote environmentally-friendly policies. ${ }^{812}$ Many devel-

809 Negotiating History of the Coverage of the Agreement on Technical Barriers to Trade with Regard to Labelling Requirements, Voluntary Standards and Production Methods Unrelated to Product Characteristics. Note by Secretariat, TBT Committee, CTE, WT/CTE/W/10, G/TBT/W/11, Geneva, 29 August 1995, para. CXLVI.

810 Ibid., para. XXI.

811 Ibid., para. XX.

812 See: Submission by Canada in the CTE, WT/CTE/W/38, 22 July 1996, WT/ CTE/W/21, 21 February 1996, as referred in: Manoj Joshi, “Are Eco-labels 
oping countries were strongly opposed to this proposal and argued that the negotiation history of the TBT Agreement demonstrated that all types of npr-PPM-based measures were excluded from the scope of application of the TBT Agreement and, as such, had to be examined under the GATT $1994 .{ }^{813}$ Some developed countries, e.g. the US and New Zealand, also expressed views against the coverage of the npr-PPM-based eco-labelling by the scope of TBT Agreement due to possible adverse implications of the labelling for the increased production of genetically modified products. Moreover, Canada later withdrew its initial proposal to include npr-PPMbased eco-labelling in the scope of the application of the TBT Agreement due to the same reason. ${ }^{814}$

Interestingly, in 2003, the EU and Switzerland made submissions to the CTE and the TBT Committee expressing the view that eco-labelling based on the LCA approach is legitimate according to the TBT Agreement and that the emphasis in the discussion shall be directed to the issues of compliance with particular provisions of the TBT Agreement and technical assistance for developing countries. ${ }^{815}$ However, these proposals were opposed

Consistent with World Trade Organization Agreements?”, Journal of World Trade, 38(1), 2004, p. 81.

813 For more information about the regulation of npr-PPM-based measures under the GATT see Section 3.3.6 of Chapter III. See also: Gabrielle Marceau, Joel P. Trachtman, "The Technical Barrier to Trade Agreement, the Sanitary and Phytosanitary Measures Agreement, and the General Agreement on Tariffs and Trade: A Map of the World Trade Organization Law of Domestic Regulation of Goods”, Journal of World Trade, 36(5), 2002 p. 861; Gabrielle Marceau, Joel P. Trachtman, “A Map of the World Trade Organization Law of Domestic Regulation of Goods: The Technical Barriers to Trade Agreement, the Sanitary and Phytosanitary Measures Agreement, and the General Agreement on Tariffs and Trade", Journal of World Trade, 48(2), 2014, pp. 351-432; Manoj Joshi, "Are Ecolabels Consistent with World Trade Organization Agreements?”, Journal of World Trade, 38(1), 2004, p.81. Interestingly, some developing countries, e.g. Indonesia and Malaysia, argued that, generally, voluntary standards and mandatory technical regulations, if based on npr-PPM requirements, would violate both the TBT Agreement and the GATT 1994.

814 Manoj Joshi, "Are Eco-labels Consistent with World Trade Organization Agreements?”, Journal of World Trade, 38(1), 2004, pp. 82 - 83.

815 In particular, the EU submitted: "The use of voluntary eco-labelling schemes based on a life-cycle approach is legitimate within the rights and obligations of the WTO Agreements. The use of relevant international standards when preparing, adopting and applying such schemes further ensures that such schemes do not become unnecessary barriers to international trade"; see: Labelling for Environmental Purposes. Submission by the European Communities under Paragraph 32(iii), WTO, Committee on Trade and Environment, WT/CTE/W/225, 6 March 2003, para. 28(c). See also: Marking and Labelling Requirements. Submission from Switzerland, WTO, Committee on Trade and Environment, TBT Committee, WT/ CTE/W/192, G/TBT/W/162, Geneva, 19 June 2001, paras. 27 - 28. 
by almost all non-European countries. ${ }^{816}$ The efforts of the EU to raise the issue of consistency of the LCA-based eco-labelling schemes with the TBT Agreement also failed at the 2003 Cancun Ministerial Conference due to strong opposition. ${ }^{817}$

On the other hand, WTO Members managed to reach an agreement in 2002 concerning the proposal to increase the transparency of the nprPPM-based labelling schemes regardless whether they are covered by the TBT Agreement or not. Thus, the following decision was adopted by the TBT Committee with regard to the notification requirements for technical regulations according to Article 2.9 of the TBT Agreement:

In conformity with Article 2.9 of the Agreement, Members are obliged to notify all mandatory labelling requirements that are not based substantially on a relevant international standard and that may have a significant effect on the trade of other Members. That obligation is not dependent upon the kind of information which is provided on the label, whether it is in the nature of a technical specification or not. ${ }^{818}$

During the first triennial review of the TBT Agreement a similar decision was adopted concerning voluntary standards that, "without prejudice to the views of Members concerning the coverage and application of the Agreement, the obligation to publish notices of draft standards containing voluntary labelling requirements under paragraph $\mathrm{L}$ of the Code is not dependent upon the kind of information provided on the label". 819

816 For example, many developing countries expressed a negative attitude towards npr-PPM-based labelling schemes notified by Belgium and the Netherlands. See the TBT Committee discussion concerning the Belgian "social responsibility product" labelling scheme and the Dutch labelling for timber products: Minutes of the Meeting Held on 30 March 2001, TBT Committee, G/TBT/M/23, Geneva, 8 May 2001, paras. 9 - 28. See also in: Gabrielle Marceau, Joel P. Trachtman, "The Technical Barrier to Trade Agreement, the Sanitary and Phytosanitary Measures Agreement, and the General Agreement on Tariffs and Trade: A Map of the World Trade Organization Law of Domestic Regulation of Goods”, Journal of World Trade, 36(5), 2002, p. 861; Gabrielle Marceau, Joel P. Trachtman, "A Map of the World Trade Organization Law of Domestic Regulation of Goods: The Technical Barriers to Trade Agreement, the Sanitary and Phytosanitary Measures Agreement, and the General Agreement on Tariffs and Trade", Journal of World Trade, 48(2), 2014, pp. 351-432; T. Hock, "The Role of Eco-Labels in International Trade: Can Timber Certification Be Implemented as a Means to Slowing Deforestation?”, Colorado Journal of International Environmental Law and Policy, 12, 2001.

817 See: Manoj Joshi, "Are Eco-labels Consistent with World Trade Organization Agreements?”, Journal of World Trade, 38(1), 2004, pp. 84-85.

818 See: Decisions and Recommendations Adopted by the Committee since 1 January 1995. Note by the Secretariat, TBT Committee, G/TBT/1/Rev.12, Geneva, 21 January 2015, p. 22.

819 First Triennial Review of the Operation and Implementation of the Agreement on 
In practice, due to the high sensitivity of npr-PPM-based measures for WTO Members, some developed countries decided to refrain from using certain npr-PPM-based requirements and labelling schemes. This was at least the case with respect to the proposed mandatory measures which are usually more trade-restrictive than the voluntary ones. For example, in 1992 Austria considered adopting legislation on mandatory eco-labelling and additional tariffs for tropical timber, because tropical forests were presumed to be managed unsustainably. Later, however, under pressure from Indonesia, Malaysia and other countries of the Association of Southeast Asian Nations (ASEAN), Austria decided to amend the proposed legislation in order to transform the mandatory labelling scheme into a voluntary and non-discriminatory one, where a label could be granted to all timber from sustainably managed forests. ${ }^{820}$ One of the main reasons for this decision by Austria was possible inconsistency of the measure with the GATT 1947 and, probably, also potentially with the TBT Agreement, which was under negotiation at that time. In 1992 - 1993 the Netherlands planned to adopt a ban on timber from unsustainably managed forests but due to the same reasons finally decided to substitute it with a voluntary labelling scheme. $^{821}$

It is worth noting, however, that, as has been discussed in Section 4.1.1.1 above, in the light of the later rulings of the Panel and the Appellate Body in US - Tuna II (Mexico), it appears that a voluntary labelling scheme under certain conditions may still constitute a technical regulation within the meaning of the TBT Agreement.

\subsection{Dispute Settlement Practice Under the TBT Agreement and PPMs}

The scope of the measures covered by the definition of technical regulation in the TBT Agreement was considered for the first time by the Appellate Body in EC - Asbestos. The Appellate Body recognized the close relationship between the first and the second sentences of the definition, because the second sentence simply "gives certain examples of "product characteristics”", which are referred to in the first sentence. ${ }^{822}$ Thus, from this perspective, it is not really relevant what kind of information the marking or labelling provides, nor whether it is related to product characteristics or

Technical Barriers to Trade, TBT Committee, G/TBT/5, Geneva, November 1997, para. 12. See also: Decisions and Recommendations Adopted by the Committee since 1 January 1995. Note by the Secretariat, TBT Committee, G/TBT/1/Rev.12, Geneva, 21 January 2015, p. 29.

820 Surya P. Subedi, "Balancing International Trade with Environmental Protection: International Legal Aspects of Eco-labels", Brooklyn Journal of International Law, 25,1999 , pp. $391-393$.

821 Ibid., pp. 395 - 398.

822 See: Appellate Body Report, EC - Asbestos, para. 67. 
npr-PPMs. What is relevant, is - packaging and the marking or labelling of products as these constitute "product characteristics", because they are applied (i.e. "attached") to a product and thus are covered by the definition of technical regulation provided that all other appropriate criteria are met. ${ }^{823}$ This approach, developed by the Appellate Body, was later applied by the Panel in EC - Trade Marks and Geographical Indications, when the Panel ruled:

The issue is not whether the content of the label refers to a product characteristic: the label on a product is a product characteristic $[\ldots]$ In summary, a document that lays down a requirement that a product label must contain a particular detail, in fact, lays down a product characteristic". 824

More recently, the matter was again addressed by the Panel and the Appellate Body in US - Tuna II (Mexico) which, to large extent, confirmed the previously adopted approach. In US - Tuna II (Mexico), the Panel examined the US "dolphin safe" labelling requirements for tuna products, based on the npr-PPM criteria of fishing processes. Among other issues, the Panel had to determine whether the US labelling rules fall within the scope of the second sentence of the definition of technical regulation in Annex 1.1 of the TBT Agreement and thus constitute a technical regulation under the Agreement. The Panel held that:

In the present case, the US dolphin-safe labelling provisions define the conditions that must be met in order to bear a "dolphinsafe" label. In so doing, they "convey criteria to be fulfilled" in order to qualify for such label. They therefore lay down "labelling requirements" within the meaning of Annex 1.1. ${ }^{825}$

The Panel further noted that the US did not contest that their "dolphin safe" labelling requirements apply to "a product, namely tuna products", and accordingly, the Panel was "satisfied that the measures at issue lay down labelling requirements, as they apply to a product, process or production method and that the subject-matter of the measures therefore falls within the scope of the second sentence of Annex 1.1" ${ }^{826}$ This particular issue was not appealed before the Appellate Body; however, the Appellate Body upheld the Panel's overall determination that the US "dolphin safe" labelling

823 See: Jan McDonald, "Domestic Regulation, Harmonization, and Technical Barriers to Trade”, World Trade Review, 4(2), 2005; Peter Van den Bossche, Werner Zdouc, The Law and Policy of the World Trade Organization. Text, Cases and Materials, 3d Edition, CUP, 2013, pp. $855-856$.

${ }^{824}$ Panel Report, EC - Trademarks and Geographical Indications (Australia), paras. 7.449, 7.451.

825 Panel Report, US - Tuna II (Mexico), para. 7.76.

826 Panel Report, US - Tuna II (Mexico), para. 7.78. 
rules constituted a technical regulation within the meaning of Annex 1.1 of the TBT Agreement. ${ }^{827}$

Therefore, based on WTO case law, which is although quite limited, it seems justified to conclude that npr-PPM-based packaging, marking and labelling requirements are covered by the definitions of technical regulation and standard in the TBT Agreement and thus fall within its scope of application. However, based on the plain reading of the text of the first sentences of the definitions, as well as on the negotiating history of the TBT Agreement, ${ }^{828}$ the opposite may be concluded with respect to npr-PPMbased requirements to products (other than marking and labelling). Such a situation may seem quite paradoxical. On the one hand, for instance, if a document prescribes npr-PPM-based requirements, compliance with which is communicated to a consumer through the appropriate labelling on a product, such a document could be qualified as a "standard" or a "technical regulation" under the TBT Agreement. On the other hand, if the same requirements are imposed without labelling, the document could not be regarded as one of the measures covered by the Agreement.

It remains to be seen how this paradoxical situation will be dealt with by the Appellate Body in the course of the WTO dispute settlement. ${ }^{829}$ On the one hand, it could be easy to adhere to the language of the definitions of standard and technical regulation in the TBT Agreement, and to conclude that only npr-PPM-based marking or labelling is covered (the second sentences of the definitions), while npr-PPM-based product requirements are not (the first sentences of the definitions). For private-sector standards such an approach would in fact mean that all npr-PPM-based product requirements of these standards would fall outside the scope of application of the TBT Agreement. On the other hand, such an approach would, arguably, hardly contribute to the consistency and effectiveness of the regulation of technical barriers to trade by WTO law, especially if npr-PPM-based product requirements become a predominant type of technical barriers to trade in the future. Indeed, under such an approach, and considering the tendency of the regulatory shift to process-based criteria as discussed in Section 2.3.2.5.1 of Chapter II, the TBT Agreement may well become an agreement just on some, very limited number of technical barriers to trade.

827 See: Appellate Body Report, US - Tuna II (Mexico), para. 199.

828 The negotiating history of the TBT Agreement may be relevant as a "supplementary means of interpretation" of the TBT Agreement according to Article 32 of the Vienna Convention on the Law of Treaties 1969 (VCLT).

829 Indeed, as has been explained in Section 4.1.1.1 of the present Chapter, in ECSeal Products the Appellate Body declined to complete the legal analysis in order to determine whether the EU measure laid out "related PPMs" as provided in the first sentence of the definition of technical regulation in Annex 1.1 of the TBT Agreement. See: Appellate Body Reports, EC - Seal Products, paras. 5.68 - 5.69. 
In any case, it seems that if the Appellate Body does adopt the approach discussed above, this would not really be a misfortune for the regulation of technical barriers to trade, as the relevant disciplines of the GATT 1994, as described in Section 3.3 of Chapter III, could still be applicable to the measures at issue.

\subsubsection{Relationship of the TBT Agreement With Other WTO Agreements}

The scope of application of the TBT Agreement is also dependent on its relationships with other WTO multilateral and plurilateral agreements. The TBT Agreement contains several relevant provisions in this regard. In general, the relationships of the TBT Agreement with other WTO agreements could be classified into two groups:

- Exclusive application, i.e. the application of another WTO agreement excludes the application of the TBT Agreement.

- Co-regulation, i.e. the TBT Agreement may be applied simultaneously with another WTO agreement to the same measure. ${ }^{830}$

The present Section briefly examines the relationship between the TBT Agreement and other relevant WTO agreements, particularly its relationship with the GATS, the Agreement on Government Procurement (GPA), the SPS Agreement and the GATT 1994.

\subsubsection{Relationship With the GATS}

The text of the TBT Agreement per se does not directly provide that the technical barriers to trade in services are excluded from its scope. However, the first paragraph of Annex 1 of the Agreement refers to definitions of the terms in the ISO/IEC Guide 2:1991, which shall apply to the terms used in the Agreement "taking into account that services are excluded from the coverage of this Agreement". Also, as has been mentioned, the TBT Agreement is placed in Annex 1A of the WTO Agreement "Multilateral Agreements on Trade in Goods", while the Agreement dealing specifically with services, the General Agreement on Trade in Services (GATS) is located in the separate Annex 1B.

All these clearly indicate that technical barriers in services are not covered by the TBT Agreement. The GATS, in its Articles I:2 and I:3, defines trade in services through four modes of supply ${ }^{831}$ and excludes from its

830 See: Arkady Kudryavtsev, “The TBT Agreement in Context”, at: Tracey Epps, Michael J. Trebilcock, Research Handbook on the WTO and Technical Barriers to Trade, Edward Elgar, Cheltenham, UK, 2013, p. 48.

831 These are the cross border mode of supply, the consumption abroad mode, the commercial presence mode and presence of natural persons mode; see Article I:2(a) 
scope the "services supplied in the exercise of governmental authority". However, sometimes it may be quite difficult to draw a clear distinction between trade in goods and trade in services, such as when the provision of goods and services is considerably interconnected. For instance, energy supply could arguably be regarded both as the supply of a good and the provision of a service. Another example is the regulation of retail services which may negatively affect trade in goods as well. Thus, arguably, the TBT Agreement may still be applicable cumulatively with the GATS to the same measure if the measure affects not only trade in services, but also trade in goods.

\subsubsection{Relationship With the Agreement on Government Procurement}

According to Article 1.4 of the TBT Agreement "[p]urchasing specifications prepared by governmental bodies for production or consumption requirements of governmental bodies" are not covered by the TBT Agreement and are regulated by the Agreement on Government Procurement (GPA) to the extent of its coverage. According to its Article I:1, the GPA "applies to any law, regulation, procedure or practice regarding any procurement" by governmental bodies enlisted by each Party in Appendix I. ${ }^{832}$ In fact, government procurement constitutes quite a significant share of the trade in goods comprising, on average, about $10-15$ per cent of the national GDP of WTO Members. ${ }^{833}$ Thus, Article 1.4 excludes this significant share from the scope of application of the TBT Agreement in favour of the GPA. This limitation of the scope of the TBT Agreement exists regardless whether a particular WTO Member participates in the GPA or not.

Thus, for instance, if the government of a WTO Member decides to procure for its own needs only those timber products which are certified and labelled under the FSC labelling scheme, the TBT Agreement would not apply to such practices.

- (d) of the GATS. See also: Peter Van den Bossche, Werner Zdouc, The Law and Policy of the World Trade Organization. Text, Cases and Materials, 3d Edition, CUP, 2013, pp. $339-340$.

832 As has been discussed in Section 2.3.4.1 of Chapter II, the GPA 1994 was renegotiated in 2012 and the revised GPA entered into force on 6 April 2014 for the first ten parties (constituting two-thirds of the parties to the GPA), which have accepted the Protocol of Amendment of the GPA. The revised GPA, in its Article II:1, provides that the "Agreement applies to any measure regarding covered procurement, whether or not it is conducted exclusively or partially by electronic means".

833 See: Peter Van den Bossche, Denise Prévost, Mariëlle Matthee, "WTO Rules on Technical Barriers to Trade", Maastricht, 2005-6, p. 13. 


\subsubsection{Relationship With the SPS Agreement}

Article 1.5 of the TBT Agreement provides that provisions of the Agreement do not apply to sanitary and phytosanitary measures (SPS measures) as defined in the SPS Agreement. Annex A(1) of the SPS Agreement defines an SPS measure as any measure adopted and applied by a WTO Member to protect specified objectives, i.e. the protection of human, animal or plant life or health from pests, diseases and disease-causing organisms, foodborne risks, and the prevention or limitation of other damage from the establishment and spread of pests. The second part of the definition provides that SPS measures "include all relevant laws, decrees, regulations, requirements and procedures". 834

In principle, an SPS measure may, according to the SPS Agreement, be viewed as a type of technical barrier to trade adopted in a particular form and with a particular purpose; the SPS Agreement is thus specially designed to regulate this quite narrow type of technical barriers. The TBT Agreement explicitly excludes from its scope SPS measures, qualified as such under the SPS Agreement. Therefore, the rules of the SPS Agreement may be viewed as constituting a lex specialis in relation to the rules of the TBT Agreement. ${ }^{835}$ At the same time, according to Article 1.4 of the SPS Agreement, nothing in that Agreement affects the rights and obligations of WTO Members under the TBT Agreement to the extent that a measure is not covered by the SPS Agreement.

This approach was applied by the Panels in EC - Hormones, where the US and Canada claimed that the EU ban on hormone-treated meat products violates the provisions of both the SPS Agreement and the TBT Agreement. The Panels referred to Article 1.5 of the TBT Agreement and found that, since the measure qualified as an SPS measure under the SPS Agreement, the TBT Agreement could not apply. ${ }^{836}$

834 See definition 1 in Annex A of the SPS Agreement. For more information about the definition of an SPS measure, see Section 5.1.1.1 of Chapter V.

835 See: Rüdiger Wolfrum, Peter-Tobias Stoll, Anja Seibert-Fohr, WTO: Technical Barriers and SPS Measures, Nijhoff, Leiden, 2007, p. 185. Indeed, an SPS measure, as defined in the SPS Agreement, would, on many occasions, constitute a "technical regulation" or, more arguably, a "standard" under the TBT Agreement. However, it seems that this is not always the case to the extent that an SPS measure under the SPS Agreement may cover a simple product importation ban, while a technical regulation under the TBT Agreement may not unless it entails a prescription of product characteristics. See Section 4.1.1.1 of the present Chapter and Appellate Body Report, EC - Asbestos, para. 71. For more information concerning the definition of an SPS measure under the SPS Agreement, see Section 5.1.1.1 of Chapter V.

836 See: Panel Report, EC - Hormones (US), para. 8.29; Panel Report, EC - Hormones (Canada), para. 8.32. 
However, the relationship between these two Agreements is not always as simple as it seems. In EC - Approval and Marketing of Biotech Products, the Panel encountered a situation when a single EU measure was adopted for multiple purposes which, arguably, included SPS and non-SPS-related ones. The Panel observed:

Hence, we consider that to the extent the requirement in the consolidated law is applied for one of the purposes enumerated in Annex A(1), it may be properly viewed as a measure which falls to be assessed under the SPS Agreement; to the extent it is applied for a purpose which is not covered by Annex A(1), it may be viewed as a separate measure which falls to be assessed under a WTO agreement other than the SPS Agreement..$^{837}$

Thus, according to the view of the Panel, Article 1.5 of the TBT Agreement does not exclude from the scope of application of the Agreement a measure covered by the SPS Agreement "to the extent it embodies a non-SPS measure". ${ }^{838}$ In other words, a single requirement may have multiple purposes and therefore may embody both SPS and non-SPS measures. There may thus, in principle, be situations when even a single measure adopted with multiple purposes falls within the scope of application of both the TBT Agreement and the SPS Agreement. Indeed, the reasoning of the Panel in this respect looks quite convincing considering the fact that, in real life, many measures may be targeted for the protection of several important societal objectives, which are covered by different WTO agreements.

Requirements of private-sector standards may be multiple, complex and serve various objectives. Thus, depending on their objectives, different requirements of private-sector standards might fall within the scope of either the TBT Agreement or the SPS Agreement or, in some cases, of the both Agreements simultaneously. This is, of course, presuming that such standards fulfil other relevant criteria set out by these Agreements.

\subsubsection{Relationship With the GATT 1994}

In contrast to the direct references to the SPS Agreement and the GPA, the TBT Agreement does not contain specific provisions concerning its relationship with the GATT 1994. The issue of the relationship between the TBT Agreement and the GATT 1994 was considered by the Panel in EC-Asbestos, where the Panel ruled that both Agreements may be applied

837 Panel Report, EC - Approval and Marketing of Biotech Products, para. 7.165.

838 Panel Report, EC - Approval and Marketing of Biotech Products, para. 7.167. Even though the Panel found that both the SPS Agreement and the TBT Agreement are applicable to certain measures of the EU, it decided to exercise judicial economy with respect to the claims under the TBT Agreement, since several violations of the SPS Agreement by the EU were found. 
cumulatively to a measure. However, according to the Panel, the issue of consistency with the TBT Agreement must be examined first, as the TBT Agreement deals "specifically, and in detail" with technical barriers to trade. ${ }^{839}$ On appeal, the Appellate Body confirmed the Panel's ruling concerning the cumulative application of both Agreements and stated:

We observe that, although the TBT Agreement is intended to "further the objectives of GATT 1994", it does so through a specialized legal regime that applies solely to a limited class of measures. For these measures, the TBT Agreement imposes obligations on Members that seem to be different from, and additional to, the obligations imposed on Members under the GATT $1994 .{ }^{840}$

The issue concerning which of the Agreements, namely the TBT Agreement or the GATT 1994, must be examined first with respect to a measure, was also considered by the Panel in EC - Sardines. The Panel, with reference to the prior findings of the Appellate Body in EC - Bananas III, pointed out:

The Appellate Body suggests that where two agreements apply simultaneously, a panel should normally consider the more specific agreement before the more general agreement. ${ }^{841}$

The Panel further noted that, "[a]rguably, the TBT Agreement deals "specifically, and in detail" with technical regulations", and, in any case, there is no "error of law" to start the analysis of legality of the measures taken by the EU with the norms of the TBT Agreement before the norms of the GATT $1994 .{ }^{842}$ Eventually the entire dispute was decided only on the basis of the TBT Agreement, since the complainant requested to consider its claims under the GATT 1994 only if no violations of the TBT Agreement would be found. Thus, after finding a violation of Article 2.4 of the TBT Agreement, the Panel decided to exercise judicial economy over the GATT claims. ${ }^{843}$

However, if a complainant insists on the examination of the relevant claims under both the TBT Agreement and the GATT 1994, a panel is obliged to do so in the appropriate circumstances. In this respect, more

839 Panel Report, EC - Asbestos, para. 8.16.

840 Appellate Body Report, EC - Asbestos, para. 80. The Appellate Body, although, reversed the decision of the Panel not to examine the EU measure against the rules of the TBT Agreement.

${ }^{841}$ Panel Report, EC - Sardines, para. 7.15. See also: Appellate Body Report, EC Bananas III, para. 204.

${ }^{842}$ See: Panel Report, EC - Sardines, paras. 7.16 - 7.17. More generally on this issue: Appellate Body Report, EC - Bananas III, para. 204; Appellate Body Report, US FSC, para. 89.

843 See: Panel Report, EC - Sardines, paras. 7.147 - 7.152. 
recently in US - Tuna II (Mexico), the Panel assumed that the provisions of Article 2.1 of the TBT Agreement and Articles I:1 and III:4 of the GATT 1994 are "substantially the same" and exercised judicial economy with respect to the GATT claims. ${ }^{844}$ On appeal the Appellate Body, however, ruled that this assumption was incorrect and that the Panel exercised "false judicial economy". ${ }^{845}$

Finally, it is worth noting that, according to the General Interpretative Note to Annex 1A of the WTO Agreement, in case of conflict between the GATT 1994 and any other WTO agreement on trade in goods, ${ }^{846}$ the provisions of such an other agreement shall prevail. Taking into account the observation of the Appellate Body in EC - Asbestos quoted above, that the TBT Agreement is intended to "further the objectives of the GATT 1994", it is quite difficult to imagine a situation of direct conflict between the provisions of these two Agreements. ${ }^{847}$

Indeed, the occurrence of such a situation seems quite unlikely. First of all, general international law prescribes the presumption against conflicting treaty interpretation which in fact has been already applied in the WTO dispute settlement practice by panels and the Appellate Body. ${ }^{848}$ Second, the Appellate Body adopted a rather narrow approach to the concept of "conflict", defining it as "a situation where adherence to one provision will lead

844 See: Panel Report, US - Tuna II (Mexico), para. 7.748; Appellate Body Report, US Tuna II (Mexico), para. 405.

845 See: Appellate Body Report, US - Tuna II (Mexico), para. 405.

846 The Appellate Body defined the situation of conflict between provisions as "a situation where adherence to the one provision will lead to a violation of the other provision"; see: Appellate Body Report, Guatemala - Cement I, para. 65.

847 See: Peter Van den Bossche, Denise Prévost, Mariëlle Matthee, "WTO Rules on Technical Barriers to Trade", Maastricht, 2005-6, p. 14.

848 As has been held by the Panel in Indonesia - Autos: "[ $t]$ his presumption is especially relevant in the WTO context since all WTO agreements, including GATT 1994 which was modified by Understandings when judged necessary, were negotiated at the same time, by the same Members and in the same forum”, see: Panel Report, Indonesia-Autos, para. 14.28. See also, for example, Appellate Body Report, Canada-Periodicals, para. 19; Appellate Body Report, EC - Bananas III, paras. $219-222$. For further information on the presumption against conflicting treaty interpretation in general international law and WTO law see: Denise Prévost, Balancing Trade and Health in the SPS Agreement: The Development Dimension, Wolf Legal Publishers, Nijmegen, 2009, p. 566; Gabrielle Marceau, Joel P. Trachtman, "The Technical Barrier to Trade Agreement, the Sanitary and Phytosanitary Measures Agreement, and the General Agreement on Tariffs and Trade: A Map of the World Trade Organization Law of Domestic Regulation of Goods", Journal of World Trade, 36(5), 2002, p. 868; Gabrielle Marceau, Joel P. Trachtman, "A Map of the World Trade Organization Law of Domestic Regulation of Goods: The Technical Barriers to Trade Agreement, the Sanitary and Phytosanitary Measures Agreement, and the General Agreement on Tariffs and Trade", Journal of World Trade, 48(2), 2014, pp. 351-432. 
to a violation of another provision". ${ }^{849}$ Thus, according to this approach, a mere situation when a measure consistent with the TBT Agreement violates the GATT 1994 may not be regarded as a conflict. This is at least the case if the TBT Agreement does not explicitly authorize the measure ${ }^{850}$ However, if the situation of a conflict does arise, then more specific provisions of the TBT Agreement would prevail over provisions of the GATT 1994.

\subsubsection{Personal Scope of Application of the TBT Agreement}

The TBT Agreement imposes obligations in relation to standards, technical regulations and conformity assessment procedures which are adopted or applied by appropriate persons, i.e. certain types of bodies. These bodies may be governmental, non-governmental or regional. The governmental bodies in Annex 1 of the TBT Agreement are classified into central governmental and local governmental bodies. In this regard, private-sector standards may be disciplined by the rules of the TBT Agreement only in case of attribution of the development, adoption and / or application of such standards to a WTO Member, or if the personal scope of application of the TBT Agreement under certain circumstances may otherwise include private standard-setting entities. ${ }^{851}$

The TBT Agreement contains definitions of several types of regulatory bodies, activities of which are addressed by Agreement's provisions.

\subsubsection{Central and Local Governmental Bodies}

A central governmental body of a WTO Member is defined in Annex 1.6 of the TBT Agreement as:

Central government, its ministries and departments or any body subject to the control of the central government in respect of the activity in question.

849 Appellate Body Report, Guatemala - Cement I, para. 65.

850 Indeed, the Panel in EC - Bananas III interpreted the General Interpretative Note to Annex $1 \mathrm{~A}$ to cover two types of conflicts: 1 . the situation when the obligations are mutually exclusive: one agreement obliges to do something, which is prohibited by another agreement; and 2. the situation when one agreement prohibits something which is explicitly authorised by another agreement; see: Panel Report, EC - Bananas III, para. 7.159. Such a broader understanding of "conflict", which incorporates the situations of the second type, is also advocated by some scholars. In the view of Joost Pauwelyn this may allow better consistency and balance in application of WTO agreements; see: Joost Pauwelyn, "Cross-Agreement Complaints before the Appellate Body: A Case Study of the EC-Asbestos Dispute”, World Trade Review, 1, 2002, p. 78.

851 See: Arkady Kudryavtsev, "The TBT Agreement in Context”, at: Tracey Epps, Michael J. Trebilcock, Research Handbook on the WTO and Technical Barriers to Trade, Edward Elgar, Cheltenham, UK, 2013, pp. $73-75$. 
Annex 1.7 to the TBT Agreement provides for the definition of a local governmental body, which is:

Government other than a central government (e.g. states, provinces, Länder, cantons, municipalities, etc.), its ministries or departments or any body subject to the control of such a government in respect of the activity in question.

As is apparent from the definition, the term "local governmental body" within the meaning of the TBT Agreement, may be applicable not only to governmental bodies of constituent territories in federal States, but also to municipal or other local authorities in any WTO Member. In fact, provincial, municipal and other local authorities in many countries enjoy significant political, administrative and financial independence from central government. ${ }^{852}$ It seems that the TBT Agreement, by differentiating local governmental bodies from central governmental bodies, aims to take this into account.

Both the definitions of central governmental body and local governmental body also refer to any other body subject to their control. Thus, it seems reasonable to assume that, in principle, even non-governmental bodies or entities under certain conditions may appear to constitute governmental bodies under the TBT Agreement, i.e. if such bodies or entities are controlled by the local or central governmental organs of a WTO Member. The TBT Agreement does not provide further clarifications concerning the nature of such control. In fact, this approach is in line with the customary international law rules on the attribution of actions to States reflected in the ILC Articles on States Responsibility, which were discussed in Chapter III. ${ }^{853}$

However, considering that the TBT Agreement also specifically addresses measures adopted and applied by non-governmental bodies, it seems that the level of control referred to in the definitions of governmental bodies shall be construed as rather high. In other words, on the one hand, it seems that even non-governmental bodies under the TBT Agreement could be regarded as central or local governmental bodies if their conduct is attributable to such governmental bodies. On the other hand, the fact that the TBT Agreement also specifically addresses the conduct of

852 Indeed, this may be true not only for governmental authorities of states in a federation, but also for local and municipal authorities in unitary countries. For example, see: European Charter of Local Self-Government 1985 adopted under the auspice of the Council of Europe, Articles 3 and 4.

853 In particular, the relevant rules are Articles 4, 5 and 8, Articles on Responsibility of States for Internationally Wrongful Acts, ILC, UN Doc. A/56/10, 2001. For more information, see Section 3.2.1 of Chapter III. 
non-governmental bodies of WTO Members has its own implications and deserves special attention..$^{85}$

\subsubsection{Non-Governmental Bodies}

A non-governmental body is defined in Annex 1.8 of the TBT Agreement rather broadly as:

Body other than a central government body or a local government body, including a non-governmental body which has legal power to enforce a technical regulation.

Indeed, the definition of non-governmental body is formulated very broadly by merely specifying which bodies may not be regarded as non-governmental ones. The definition covers those non-governmental bodies which are legally empowered to enforce mandatory technical regulations. However, the use of the word "including" in the definition seems to indicate that the scope of the term "non-governmental body" under the TBT Agreement is not limited only to such a kind of non-governmental body. ${ }^{85}$

First of all, by addressing this type of body, the TBT Agreement "recognizes the vital role many non-governmental entities (national standardizing institutes are often privately organized and incorporated) play in various countries in shaping, developing, and implementing technical regulations and standards" ${ }^{856}$ In fact, as has been noted in Chapter II, the NSBs of quite a number of countries are incorporated as private non-profit organizations. ${ }^{857}$ Obviously, if a national body of a WTO Member, which develops

854 See: Santiago Villalpando, "Attribution of Conduct to the State: How Rules of State Responsibility May Be Applied Within the WTO Dispute Settlement System”, Journal of International Economic Law, 5(2), 2002, p. 407. For a detailed discussion on obligations of the WTO Members with respect to conduct of non-governmental bodies, see Section 4.2 of the present Chapter.

855 However, some authors seem to understand the plain reading of the definition's text more restrictively. For example, Joanne Scott argues that in the TBT Agreement, the non-governmental bodies "are defined by reference to the legal power of bodies to enforce technical regulations which are, by definition, mandatory"; see: Joanne Scott, The WTO Agreement on Sanitary and Phytosanitary Measures. A Commentary, Oxford University Press, Oxford, 2007, pp. 32 - 33.

856 Rüdiger Wolfrum, Peter-Tobias Stoll, Anja Seibert-Fohr, WTO: Technical Barriers and SPS Measures, Nijhoff, Leiden, 2007, p. 208. Prominent examples of nongovernmental NSBs are Deutsches Institut fur Normung e.V. (DIN) in Germany, the American National Standards Institute (ANSI) in the US, the British Standards Institution (BSI) in the UK and the Netherlands Standardization Institute (NEN) in the Netherlands. All these NSBs are established as NGOs.

857 Prominent examples of non-governmental NSBs are Deutsches Institut fur Normung e.V. (DIN) in Germany, the American National Standards Institute (ANSI) in the US, the British Standards Institution (BSI) in the UK and the Netherlands Standardization Institute (NEN) in the Netherlands. All these NSBs are established as NGOs. See also Section 2.2.4.3.3 of Chapter II. 
and adopts technical regulations or standards, is incorporated as an NGO, this shall not allow the Member to circumvent the disciplines of the TBT Agreement. However, the important question which arises in this regard is whether the term "non-governmental body" in the TBT Agreement covers only NSBs and other non-governmental entities performing public regulatory functions; or if this term may also cover NGOs or even commercial enterprises developing and adopting private-sector standards? ${ }^{858}$

The answer seems to depend on many factors and could be given only on a case-by-case basis. On the one hand, as has already been noted, the definitions of central and local governmental bodies also refer to the bodies controlled by governments. Therefore, it seems that the meaning of the term "non-governmental body" in the TBT Agreement should cover something other than NGOs controlled or directed by WTO Members (i.e. by their government). On the other hand, and in light of the approach taken in the dispute settlement practice under the GATT and some other WTO agreements discussed in Chapter III, it is likely that the existence of an appropriate nexus between a non-governmental entity (and / or its measure) and a WTO Member is required for responsibility of the Member for activities of the entity. ${ }^{859}$ Such a nexus may be reflected in governmental involvement, or support or incentives provided to a non-governmental measure at issue. Thus, the answer to the question stated above will probably be negative with respect to the "purely" private-sector standards which were adopted and applied by non-governmental entities without any meaningful governmental involvement or incentives.

\subsubsection{Regional Bodies}

Finally, the TBT Agreement recognizes that technical barriers may also be adopted at a regional level for several WTO Members. Thus, Annex 1.5 to the TBT Agreement contains the following definition of regional body or system:

Body or system whose membership is open to the relevant bodies of only some of the Members.

Examples of such regional bodies or systems are provided in the Explanatory Note to the definition of central governmental body in Annex 1.6 of the TBT Agreement with regard to the European Communities. According to the Explanatory Note, in general, the EU shall be subject to the provisions of the TBT Agreement devoted to central governmental bodies. However,

858 See: Alessandra Arcuri, “The TBT Agreement and Private Standards", at: Tracey Epps, Michael J. Trebilcock, Research Handbook on the WTO and Technical Barriers to Trade, Edward Elgar, Cheltenham, UK, 2013, pp. 504-505.

859 For more information, see Section 3.2.2 of Chapter III. 
regional bodies or systems may also be established within the EU and their activities shall then be regulated by the provisions of the TBT Agreement applicable to such kind of bodies or systems.

Pursuant to the definition, the regional body, within the meaning of the TBT Agreement, may be open to "relevant bodies" of only some WTO Members. The TBT Agreement does not provide further explanations on which bodies of WTO Members may be regarded as "relevant" in this regard. One possible option is that these shall be the bodies specially authorized by WTO Members to participate in a regional body. Another option may offer the broader understanding, namely that these are the regulatory or standard-setting entities renowned on domestic level, whether of governmental or non-governmental nature, which independently decide to participate in the activities of a regional body. However, considering the fact that the participating "relevant bodies" are, by definition, those of WTO Members, the first option seems to be more probable.

In this regard, it is interesting to note the clear difference in the understanding of the terms "regional body" in the TBT Agreement and "regional authorities" in the GATT 1994. According to the definition of regional body in the TBT Agreement, such a body comprises participants - i.e. "relevant bodies" - of some WTO Members. Thus, it is presumed that, due to jurisdictional limitations, WTO Members usually may not exercise full control over the regional bodies, but may do so only with respect to their participating "relevant bodies". On the contrary, Article XXIV:12 of the GATT 1994 provides that each WTO Member "shall take such reasonable measures as may be available to it to ensure observance of the provisions of this Agreement by the regional and local governments and authorities within its territories". Therefore, it seems that under the GATT 1994 it is meant that regional authorities must be situated within Member territories. ${ }^{860}$

The important question arising in the regard is whether a regional standard-setting NGO developing and adopting private-sector standards for regional use could be regarded as a "regional body or system" within the meaning of the TBT Agreement? It seems that the answer to this question may be given on a case-by-case basis and depends on, among other factors, the membership of the regional NGO. The answer will probably be negative if the participants of the regional NGO are not authorized by WTO Members to represent their interests in the standardizing activities of such an NGO. Moreover, the NGOs, which develop private-sector standards and start as national or regional organizations, very often tend to expand

860 This approach to understanding "regional authorities" is reiterated in Article XXIV:12, para. 13 of the Understanding of the Interpretation of Article XXIV of the GATT 1994 and Article 22.9 of the DSU. Moreover, the GATS, according to its Article I:3(a), seems to share the approach of the GATT 1994 with regard to the meaning of the terms "regional governments and authorities". 
and claim to become international, i.e. open for worldwide membership and not only for the membership within a certain region or country. EUREPG.A.P., for example, evolved rather quickly into GLOBALG.A.P., and the BRC standards originally designed mainly for the UK market gradually became BRC Global Standards. ${ }^{861}$

\subsubsection{Temporal Scope of Application of the TBT Agreement}

The TBT Agreement has its temporal limits of application. Generally, as provided in Article 28 of the Vienna Convention on the Law of Treaties 1969 (VCLT), a treaty may not be applied retroactively, unless the treaty itself provides otherwise:

Unless a different intention appears from the treaty or is otherwise established, its provisions do not bind a party in relation to any act or fact which took place or any situation which ceased to exist before the date of the entry into force of the treaty with respect to that party.

The text of the TBT Agreement does not provide that it may be applied to any situations or facts which "cease to exist". The TBT Agreement therefore does not generally have retroactive force and is applicable only to standards, technical regulations and conformity assessment procedures, which are applied after 1 January 1995 - the date when the TBT Agreement came into force. However, this does not mean that the TBT Agreement may not apply to the measures which were adopted before 1 January 1995 but remain in force after this date, since these measures did not "cease to exist" within the meaning of Article 28 of the VCLT. This was confirmed by the Panel and the Appellate Body in EC - Sardines, where the issue arose about whether the TBT Agreement (and in particular its Article 2.4 prescribing the harmonization of technical regulations with international standards) may be applicable to an EU Regulation adopted before 1 January 1995, but which remained in force at the time of the dispute. The Panel answered affirmatively and stated:

...the EC Regulation is a "situation or measure that did not cease to exist" and the TBT Agreement does not reveal a contrary intention to limit the temporal application of the TBT Agreement to measures adopted after 1 January 1995... Therefore, Article 2.4 of the TBT Agreement applies to measures that were adopted before 1 January 1995 but which have not ceased to exist. ${ }^{862}$

861 For more information in this regard, see Section 2.2.3.2.2.3 of Chapter II.

862 Panel Report, EC - Sardines, paras. 7.59 - 7.60. 
This conclusion was upheld by the Appellate Body, ${ }^{863}$ which in its support also cited Article XVI:4 of the WTO Agreement:

Each Member shall ensure the conformity of its laws, regulations and administrative procedures with its obligations as provided in the annexed Agreements.

These conclusions of the Appellate Body are of great significance. In practice they mean that WTO Members are obliged to check and revise their "active" standards and technical regulations adopted before the TBT Agreement came into force, on the subject of their conformity with the rules of the Agreement. The same would be relevant for private-sector standards in case they are covered by the TBT Agreement. WTO Members would then have been obliged to take appropriate measures to ensure that private standard-setting organizations revise their "active" standards so as to bring them into compliance with the provisions of the TBT Agreement after the latter came into force. Arguably this would indeed be a rather difficult task to accomplish in cases where a WTO Member was not involved or did not provide meaningful incentives for the development, adoption and application of a private-sector standard.

Finally, it is worth noting that the temporal scope of the TBT Agreement also seems to be relevant in the context of the attribution of a private standard-setting behaviour to a WTO Member. If the adoption and application of a private-sector standard received significant governmental incentives, it is important whether these incentives were provided only before the TBT Agreement came into force, or whether they are still in place thereafter. In this respect, the development and application of a private-sector standard could arguably be attributed to a WTO Member under the TBT Agreement only if such private conduct received governmental support or incentives after 1 January 1995.

\subsection{Obligations of WTO Members With Respect to Different Types of Bodies}

With respect to central governmental bodies, the TBT Agreement requires WTO Members "to ensure" that these bodies are in compliance with the provisions of the Agreement, and with provisions of the Code of Good Practice if the matter concerns standards. ${ }^{864}$ The actions of the

863 See: Appellate Body Report, EC - Sardines, paras. 213, 216

864 See, for example: Articles 2.1, 2.2, 4.1, 5.1, 5.8 of the TBT Agreement. For 
central governmental bodies of WTO Members thus entail, as a rule, the direct and full responsibility of the Members. However, the obligations of WTO Members with respect to local governmental, regional and nongovernmental bodies are phrased differently in the TBT Agreement. These obligations take both a positive and negative form and may be classified as follows:

- positive obligations to take available reasonable measures in order to ensure that local governmental, non-governmental and regional bodies comply with provisions of the TBT Agreement; and

- negative obligations to refrain from taking measures which require or encourage local governmental, non-governmental and regional bodies to act inconsistently with provisions of the TBT Agreement. ${ }^{865}$

These obligations of WTO Members with respect to local governmental, regional and non-governmental bodies are provided separately in different provisions of the TBT Agreement dealing with standards, technical regulations and conformity assessment procedures. Article 4 of the TBT Agreement deals with the preparation, adoption and application of standards by (in addition to central governmental bodies) local governmental, non-governmental and regional bodies; Article 3 addresses the preparation, adoption and application of technical regulation by local governmental and non-governmental bodies; Articles 7 and 8 regulate the use of conformity assessment procedures by local governmental and non-governmental bodies respectively. In addition, Article 9 of the TBT Agreement provides for the obligation of WTO Members with respect to international and regional systems for conformity assessment.

The sections below discuss these two types of obligations with respect to the relevant bodies. The discussion is quite relevant with respect to the issues of disciplining private-sector standards under the TBT Agreement. Indeed, if private-sector standards developed and adopted by standardizing NGOs are covered by the scope of application of the TBT Agreement, the question that arises then is what shall be done by WTO Members under the Agreement with respect to such NGOs and their standards.

information about the main obligations to be complied with by central governmental bodies of WTO Members, see Section 4.3 of the present Chapter. See: Rüdiger Wolfrum, Peter-Tobias Stoll, Anja Seibert-Fohr, WTO: Technical Barriers and SPS Measures, Nijhoff, Leiden, 2007, p. 238; Arkady Kudryavtsev, "The TBT Agreement in Context", at: Tracey Epps, Michael J. Trebilcock, Research Handbook on the WTO and Technical Barriers to Trade, Edward Elgar, Cheltenham, UK, 2013, pp. 75 - 78; Alessandra Arcuri, "The TBT Agreement and Private Standards”, at: Tracey Epps, Michael J. Trebilcock, Research Handbook on the WTO and Technical Barriers to Trade, Edward Elgar, Cheltenham, UK, 2013, pp. 499 -501 . 


\subsubsection{Positive Obligations}

The TBT Agreement prescribes, in different provisions, positive obligations with respect to technical regulations, standards and conformity assessment procedures adopted / operated by local governmental, regional and non-governmental bodies.

\subsubsection{Positive Obligations With Respect to Technical Regulations}

Article 3 of the TBT Agreement specifies the obligations of WTO Members with respect to the preparation, adoption and application of technical regulations by local governmental and non-governmental bodies. According to Article 3.1:

Members shall take such reasonable measures as may be available to them to ensure compliance by such bodies with the provisions of Article 2, with the exception of the obligation to notify as referred to in paragraphs 9.2 and 10.1 of Article 2.

Article 2 of the TBT Agreement deals with the obligations of WTO Members in relation to the preparation, adoption and application of technical regulations by central governmental bodies, as will be discussed in more detail in Section 1.3 of the present Chapter. According to Article 3, WTO Members are obliged to take available "reasonable measures" in order to ensure that the behaviour of local governmental and non-governmental bodies in the course of the preparation, adoption and application of technical regulations meets the requirements set for central governmental bodies. This is, however, qualified by an exception from the obligation to notify other Members through the WTO Secretariat about technical regulations with significant trade effects which were prepared or adopted not in accordance with the content of the relevant international standard, or where the relevant international standard does not exist. ${ }^{866}$

At the same time, Article 3.5 of the TBT Agreement further provides that:

Members are fully responsible under this Agreement for the observance of all provisions of Article 2. Members shall formulate and implement positive measures and mechanisms in

866 See Articles 2.9.2 and 2.10.1 of the TBT Agreement. It is worth noting that Article 3.2 of the TBT Agreement differentiates the local governmental bodies "on the level directly below that of the central government in Members". For technical regulations prepared and adopted by this type of local governmental body, the WTO Members "shall ensure" notification of other WTO Members according to Articles 2.9.2 and 2.10.1 of the TBT Agreement, unless they duplicate the technical regulations of central governmental bodies, which have already been notified. 
support of the observance of the provisions of Article 2 by other than central government bodies.

Thus, according to Articles 3.1 and 3.5 of the TBT Agreement, WTO Members are fully responsible for compliance with the requirements specified in Article 2 of the Agreement by their central governmental bodies. With respect to the other bodies, namely local governmental and nongovernmental bodies, Members are obliged to take available "reasonable" measures in order to ensure that the technical regulations adopted by such bodies comply with Article 2. In this respect, Members "shall formulate and implement positive measures and mechanisms". It is not quite clear, however, whether the obligations to take available "reasonable" measures and to "formulate and implement positive measures and mechanisms" would, in practice, mean less responsibility for WTO Members regarding the conduct of their local governmental and non-governmental bodies. This issue is discussed in more detail in Section 4.2.1.4.

\subsubsection{Positive Obligations With Respect to Standards}

A similar obligation to take available "reasonable" measures is prescribed in Article 4.1 of the TBT Agreement with respect to the standards developed and adopted by local governmental, non-governmental and regional standardizing bodies. According to Article 4.1 WTO Members shall:

take such reasonable measures as may be available to them to ensure that local government and non-governmental standardizing bodies within their territories, as well as regional standardizing bodies of which they or one or more bodies within their territories are members, accept and comply with this Code of Good Practice.

The Code of Good Practice for the Preparation, Adoption and Application of Standard (Code of Good Practice) is attached to the TBT Agreement in its Annex 3; it specifies certain rules which standardizing bodies shall follow in the course of their standard-setting activities. ${ }^{867}$ The obligations of WTO Members with respect to local governmental, non-governmental and regional standardizing bodies are therefore formulated differently in comparison with the obligations concerning central governmental bodies: WTO Members "shall ensure" the acceptance of and compliance with the Code of Good Practice by central governmental standardizing bodies. In addition, Article 4.1 further provides that even if a standardizing body has not accepted the Code of Good Practice, the obligations of a WTO

867 For more information about the obligations of standardizing bodies according to the Code of Good Practice, see Section 4.3 of the present Chapter. 
Member in relation to the compliance of that standardizing body with the rules of the Code of Good Practice "shall apply irrespective" of this fact.

Furthermore, Article 4.2 of the TBT Agreement establishes a presumption of compliance by the standardizing bodies with the principles of the TBT Agreement, if these standardizing bodies accept and comply with the Code of Good Practice.

\subsubsection{Positive Obligations With Respect to Conformity Assessment Procedures}

The obligations of WTO Members in relation to the procedures for assessment and conformity operated by non-governmental bodies are specified in Article 8 of the TBT Agreement. According to the first sentence of Article 8.1:

Members shall take such reasonable measures as may be available to them to ensure that non-governmental bodies within their territories which operate conformity assessment procedures comply with the provisions of Articles 5 and 6, with the exception of the obligation to notify proposed conformity assessment procedures.

Articles 5 and 6 of the TBT Agreement provide for the obligations of WTO Members in relation to the operation of conformity assessment procedures by central governmental bodies. ${ }^{868}$ WTO Members shall thus take available "reasonable" measures in order to ensure that non-governmental bodies, during the administration of conformity assessment procedures, fulfil the same obligations as prescribed for central governmental bodies, with the exception of the obligation to notify other Members of the proposed conformity assessment procedures. In addition, Article 8.2 clarifies the conditions under which WTO Members may rely on conformity assessment procedures operated by non-governmental bodies by providing that:

Members shall ensure that their central government bodies rely on conformity assessment procedures operated by nongovernmental bodies only if these latter bodies comply with the provisions of Articles 5 and 6, with the exception of the obligation to notify proposed conformity assessment procedures.

Article 7 of the TBT Agreement contains the obligations of WTO Members related to the conformity assessment procedures operated by local governmental bodies which are, to a large extent, formulated in the same manner as

868 For more information about the obligations of WTO Members with respect to operation of conformity assessment procedures by central governmental bodies, see Section 4.3 of the present Chapter. 
the obligations with respect to non-governmental bodies. ${ }^{869}$ Interestingly, the TBT Agreement, in its Article 9, further lays down separate rules for "international and regional systems" regarding conformity assessment, although they are somewhat analogous to the ones prescribed in respect of non-governmental bodies. According to Article 9.1, in cases when "a positive assurance of conformity with a technical regulation or standard is required", WTO Members are required to, "wherever practicable, formulate and adopt international systems for conformity assessment and become members thereof or participate therein". Article 9.2 further provides that:

Members shall take such reasonable measures as may be available to them to ensure that international and regional systems for conformity assessment in which relevant bodies within their territories are members or participants comply with the provisions of Articles 5 and 6.

Finally, as in the case with conformity assessment procedures operated by non-governmental bodies, Article 9.3 prescribes that the central governmental bodies of WTO Members are allowed to "rely on international and regional conformity assessment systems only to the extent that these systems comply with the provisions of Articles 5 and 6, as applicable". In fact, this type of requirement is in line with the general rules of international law on State responsibility as reflected in the ILC Articles on State Responsibility. In particular, if a WTO Member relies on the conformity assessment procedures operated by non-governmental, regional or international bodies or systems, this may be regarded as acknowledgment of the conduct of these bodies or systems as a Member's own within the meaning of Article 11 of the ILC Articles. ${ }^{870}$

\subsubsection{Available "Reasonable" Measures}

The obligations of WTO Members to take available "reasonable" measures with respect to the relevant bodies have not as yet been interpreted in WTO dispute settlement practice. Therefore, it remains quite unclear what these obligations entail for WTO Members. Which "reasonable" measures shall be available to WTO Members? Whether WTO Members, under the TBT

869 It is worth noting that Article 7.2 of the TBT Agreement also differentiates the local governmental bodies "on the level directly below that of the central government in Members" from other local governmental bodies. For conformity assessment procedures operated by this type of local governmental body, WTO Members "shall ensure" notification of other WTO Members according to Articles 5.6.2 and 5.7.1 of the TBT Agreement unless they duplicate the conditions of conformity assessment procedures of central governmental bodies which have been already notified.

870 For more information about Article 11 of the ILC Articles on State Responsibility, see Section 3.2.1.2 of Chapter III. 
Agreement, have some sort of "due diligence" obligation to discipline the relevant behaviour of certain non-governmental entities, including those developing and adopting private-sector standards? And if so, does the obligation to take available "reasonable" measures with respect to the appropriate bodies or entities constitute an obligation of conduct, or an obligation of result? These questions are indeed difficult to answer. It seems that the relevant criteria of these obligations, namely "availability" and "reasonableness" of a measure, are interconnected. In fact, the reasonableness of a measure may be identified by considering the issue in terms of its availability; and vice versa, the availability of a measure depends on evaluating to what extent it is reasonable. ${ }^{871}$

In this regard, Digby Gascione proposes a number of examples of reasonable measures to be taken by WTO Members with respect to private standard-setting organizations: disseminating information, developing and circulating national policy, dialogue with such organizations and entering into a memoranda of understanding with them, and providing financial incentives to encourage their compliance with good practices. However, these are only a few examples of possible reasonable measures which could be available to WTO Members. It is clearly impossible to come up with an exhaustive and conclusive list of such measures. ${ }^{872}$

In principle, two approaches may be considered for interpreting the obligation to take available "reasonable" measures; i.e. this obligation may be regarded as an obligation of conduct or as an obligation of result. According to the approach of obligation of conduct, only the conduct of central

871 Many authors do not in fact discuss the criteria of "reasonableness" and "availability" separately; see for example: Jan Bohanes, Iain Sandford, "The (Untapped) Potential of WTO Rules to Discipline Private Trade-Restrictive Conduct”, Inaugural Conference, Society of International Economic Law, 56/08, Geneva, July, 15-17, 2008, paras. 130 - 132; Samir R. Gandhi, "Voluntary Environmental Standards: The Interplay Between Private Initiatives, Trade Rules and the Global Decision-Making Process”, 3rd Global Administrative Law Seminar, Viterbo, June 15-16, 2007, p. 18; Private Voluntary Standards within the WTO Multilateral Framework: Submission by the United Kingdom. A report prepared by Digby Gascoine and O'Connor and Company, WTO, SPS Committee, G/SPS/GEN/802, Geneva, 9 October 2007, pp. 32 - 33, 76 - 77. However, some authors choose to consider these criteria separately: Rüdiger Wolfrum, Peter-Tobias Stoll, Anja Seibert-Fohr, WTO: Technical Barriers and SPS Measures, Nijhoff, Leiden, 2007 , pp. $256-257$.

872 See: Private Voluntary Standards within the WTO Multilateral Framework: Submission by the United Kingdom. A report prepared by Digby Gascoine and O'Connor and Company, WTO, SPS Committee, G/SPS/GEN/802, Geneva, 9 October 2007, paras. 11, 66. See also: Denise Prévost, Balancing Trade and Health in the SPS Agreement: The Development Dimension, Wolf Legal Publishers, Nijmegen, 2009. p. 548. 
governmental bodies would be directly attributable to WTO Members under the TBT Agreement. With respect to all other bodies (local governmental, non-governmental, regional), WTO Members would only have an appropriate "due diligence" or "best efforts" obligation to take available "reasonable" measures. ${ }^{873}$ Under such an approach it follows that WTO Members might be not responsible for violations of the rules of the TBT Agreement, provided that they have indeed taken available "reasonable" measures with regard to the appropriate bodies. ${ }^{874}$ This approach could, arguably, provide some flexibility concerning the obligations of WTO Members under the TBT Agreement with respect to such bodies.

Generally, obligations of conduct are not uncommon in international law. For instance, the ICJ pointed out that the obligation to prevent genocide according to the Genocide Convention was clearly an obligation of conduct and not one of result. ${ }^{875}$ Other examples of obligations of conduct confirmed by the ICJ are the duty to negotiate in good faith generally and, in particular, the duty to negotiate the delimitation of continental shelf according to the customary international law rules. ${ }^{876}$ However, the

873 See: Rüdiger Wolfrum, Peter-Tobias Stoll, Anja Seibert-Fohr, WTO: Technical Barriers and SPS Measures, Nijhoff, Leiden, 2007, p. 238; Samir R. Gandhi, "Voluntary Environmental Standards: The Interplay Between Private Initiatives, Trade Rules and the Global Decision-Making Process", 3rd Global Administrative Law Seminar, Viterbo, June 15-16, 2007, p. 17.

874 See: Jan Bohanes, Iain Sandford, "The (Untapped) Potential of WTO Rules to Discipline Private Trade-Restrictive Conduct”, Inaugural Conference, Society of International Economic Law, 56/08, Geneva, July, 15-17, 2008, para. 129.

875 See: Convention on the Prevention and Punishment of the Crime of Genocide, 78 U.N.T.S. 277, adopted 1 January 1948, Article 1. See also: Case Concerning the Application of the Convention on the Prevention and Punishment of the Crime of Genocide (Bosnia and Herzegovina v. Serbia and Montenegro), Merits, ICJ Reports 2007, para. 430. In addition, the Court noted: "the Genocide Convention is not the only international instrument providing for an obligation on the States parties to it to take certain steps to prevent the acts it seeks to prohibit. Many other instruments include a similar obligation, in various forms: see, for example, the Convention against Torture and Other Cruel, Inhuman or Degrading Treatment or Punishment of 10 December 1984 (Article 2); the Convention on the Prevention and Punishment of Crimes against Internationally Protected Persons, Including Diplomatic Agents, of 14 December 1973 (Article 4); the Convention on the Safety of United Nations and Associated Personnel of 9 December 1994 (Article 11); the International Convention on the Suppression of Terrorist Bombings of 15 December 1997 (Article 15)". However, "[t] he decision of the Court does not, in this case, purport to establish a general jurisprudence applicable to all cases where a treaty instrument, or other binding legal norm, includes an obligation for States to prevent certain acts". See: Ibid., para. 429.

876 See: North Sea Continental Shelf, Judgment, I.C.J. Reports 1969, para. 85: "the parties are under an obligation to enter into negotiations with a view to arriving at an agreement, and not merely to go through a forma 1 process of negotiation $[\ldots]$; they are under an obligation so to conduct themselves that the negotiations are meaningful, which will not be the case when either of them insists upon its 
interesting feature of the "obligation of conduct" approach in the context of the relevant provisions of the TBT Agreement, is that such obligations would not be substantive per se, and would be prescribed generally with respect to only certain types of bodies, i.e. local governmental, regional and non-governmental ones. Only the conduct of central governmental bodies could thus be directly attributable to WTO Members. Such an approach would therefore constitute a deviation from customary rules on the international responsibility of States as reflected in the ILC Articles, according to which a State is equally responsible for the acts of all types of its organs, "whatever position it holds in the organization of the State, and whatever its character as an organ of the central government or of a territorial unit of the State" 877 .

The approach of obligation of result puts the emphasis on the results of the measure adopted or applied by the relevant body. It entails that WTO Members, in addition to taking available "reasonable" measures in relation to local governmental, regional and non-governmental bodies, are still obliged to achieve positive results, equivalent to the ones prescribed by the TBT Agreement for central governmental bodies. Arguably, this approach found its reflection in Article 14.4 of the TBT Agreement, which seems to attribute the results of the actions by the relevant bodies to WTO Members in the context of the WTO dispute settlement process. In particular, Article 14.4 provides that:

The dispute settlement provisions set out above can be invoked in cases where a Member considers that another Member has not achieved satisfactory results under Articles 3, 4, 7, 8 and 9 and its trade interests are significantly affected. In this respect, such results shall be equivalent to those as if the body in question were a Member.

Article 14.4 therefore places the emphasis on a result to be achieved by WTO Members in disciplining the conduct of the relevant bodies. It is not quite clear, however, what the "satisfactory results under Articles 3, 4, 7, 8 and 9" would be within the meaning of this provision of the TBT Agreement. Article 14.4 of the TBT Agreement seems to recognize that when an obligation imposed by the Agreement is not respected by a relevant body within the territory of a WTO Member, the failure or the results of such a failure would then be attributed to the Member concerned, i.e.

own position without contemplating any modification of it”. See also: Gabč́kovo-

Nagymaros Project (Hungary v. Slovakia), Judgment, I.C.J. Reports 1997, paras. 139 -142 .

877 Articles on Responsibility of States for Internationally Wrongful Acts, ILC, UN Doc. A/56/10, 2001, Article 4. For more information about customary law rules on attribution of conduct to States as reflected in the ILC Articles, see Section 3.2.1 of Chapter III. 
- "such results shall be equivalent to those as if the body in question were a Member". Under the TBT Agreement a WTO Member might thus arguably be sued on two fronts:

- attribution of the results of actions or inactions of the relevant bodies directly to a WTO Member pursuant to the provision of Article 14.4; and

- violation of Members' own obligations under Articles 3, 4 or 8 of the TBT Agreement, i.e. failure to take available "reasonable measures" to ensure that the relevant body respects the rules of the TBT Agreement.

However, it is also possible to conceive of a different way of interpreting the provisions of Article 14.4. In fact, Article 14.4 refers to dispute settlement and, basically, only sets out the conditions for the purposes of invocation of the dispute settlement provisions. In this regard, Article 14.4 does not provide that a WTO Members shall definitely be found responsible if the "satisfactory results", "equivalent to those as if the body in question were a Member", are not achieved. Moreover, the second sentence of Article 14.4 provides that the results must be "equivalent" and not necessarily identical to the results achieved "if the body in question were a Member". This, arguably, may also allow for a certain amount of flexibility in the process of evaluation. ${ }^{878}$ It seems thus that the provisions of Article 14.4 do not provide conclusive evidence that the TBT Agreement prescribes an obligation of result for WTO Members in relation to the conduct of their local governmental, non-governmental and regional bodies.

The problem with an "obligation of result" approach to the obligations of WTO Members, regarding the relevant bodies, is that it does not allow for much flexibility. WTO Members would be equally and fully responsible for the conduct of all their governmental and non-governmental bodies with respect to the development, adoption and application of technical regulations, standards and operation of conformity assessment procedures. The unique feature of the TBT Agreement is that it explicitly covers not only mandatory and more trade-restrictive measures, i.e. technical regulations, but also voluntary ones, i.e. standards, which, arguably, tend to be less trade-restrictive than mandatory measures. Thus, it seems appropriate to allow for a certain amount of flexibility with regard to the obligations of WTO Members concerning different bodies developing and adopting the different types of measures. Moreover, interestingly, under the "obligation of result" approach and according to Article 9.2 of the TBT Agreement, WTO Members would be directly and fully responsible for the relevant conduct of the international and regional systems of conformity assessment. However, it is doubtful that this would be practically possible, as such

878 See: Jan Bohanes, Iain Sandford, "The (Untapped) Potential of WTO Rules to Discipline Private Trade-Restrictive Conduct”, Inaugural Conference, Society of International Economic Law, 56/08, Geneva, July, 15-17, 2008, para. 135. 
conduct usually may not be controlled by a single WTO Member. Finally, such an approach would disregard the clear differences in the formulations of the obligations of WTO Members with respect to their central governmental bodies and the other types of bodies in the TBT Agreement. ${ }^{879}$

In fact, during the Uruguay Round negotiations on the TBT Agreement, the negotiating parties distinguished between two levels of obligations under the Agreement. The first level obligations were formulated using the words "shall ensure", while the second level obligations "were specified in terms of "best efforts" " 880 which requires the disciplining of conduct of the bodies by available "reasonable" measures. It seems that such a distinction was introduced because "[o]ne of the main concerns during the negotiations was the question of balance of rights and obligations amongst the signatories" ${ }^{881}$ Although, there were quite a number of discussions among the negotiating parties with different proposals concerning the types of the bodies to be covered by the second level "best efforts" obligations, the final outcome was that the first level obligations in the TBT Agreement were prescribed only with respect to central governmental bodies. ${ }^{882}$ Indeed, the choice of the second level obligations for all other bodies could probably be explained by the need for flexibility in the application of the TBT Agreement to the varying conditions of different WTO Members and for the avoidance of a "one-size-fits-all" approach.

879 See: Ibid., para. 130.

880 See: Negotiating History of the Coverage of the Agreement on Technical Barriers to Trade with Regard to Labelling Requirements, Voluntary Standards and Production Methods Unrelated to Product Characteristics. Note by Secretariat, TBT Committee, CTE, WT/CTE/W/10, G/TBT/W/11, Geneva, 29 August 1995, paras. LI, LVI, LXXI, LXXIX, C; see also: Private Voluntary Standards within the WTO Multilateral Framework: Submission by the United Kingdom. A report prepared by Digby Gascoine and O'Connor and Company, WTO, SPS Committee, G/SPS/ GEN/802, Geneva, 9 October 2007, pp. $77-78$.

881 Private Voluntary Standards within the WTO Multilateral Framework: Submission by the United Kingdom. A report prepared by Digby Gascoine and O'Connor and Company, WTO, SPS Committee, G/SPS/GEN/802, Geneva, 9 October 2007, pp. $74-75$.

882 Michael Koebele and Gordon LaFortune note that the "[r]elated [a]ttempts of the EC to impose stricter responsibility at least with respect to local governmental bodies failed"; see: Rüdiger Wolfrum, Peter-Tobias Stoll, Anja Seibert-Fohr, WTO: Technical Barriers and SPS Measures, Nijhoff, Leiden, 2007, p. 257, footnote 41; referring to: Terence .P. Stewart, The GATT Uruguay Round. A Negotiating History (1986 - 1992), Vol. 1, Kluwer Law and Taxation Publishers, Denver. Boston, 1993, p. 1078; Negotiating History of the Coverage of the Agreement on Technical Barriers to Trade with Regard to Labelling Requirements, Voluntary Standards and Production Methods Unrelated to Product Characteristics. Note by Secretariat, TBT Committee, CTE, WT/CTE/W/10, G/TBT/W/11, Geneva, 29 August 1995, paras. III(b), LIII, LXXI, LXXII, XCVIII - C. 
The term "reasonable" may indeed allow for considerable flexibility. For example, the Appellate Body has interpreted the term "reasonable" in the context of the references to "reasonable period" and "reasonable time" in the Anti-Dumping Agreement in the following way: 883

The word "reasonable" implies a degree of flexibility that involves consideration of all of the circumstances of a particular case. What is "reasonable" in one set of circumstances may prove to be less than "reasonable" in different circumstances. This suggests that what constitutes a reasonable period or a reasonable time, under Article 6.8 and Annex II of the Anti-Dumping Agreement, should be defined on a case-by-case basis, in the light of the specific circumstances of each investigation. ${ }^{884}$

It is also worth noting that that the obligations of WTO Members to take available "reasonable" measures, besides the TBT Agreement, may be found in some other WTO agreements. Article I:3 of the GATS prescribes such obligations with respect to "regional and local governments and authorities", as well as "non-governmental bodies"; Article 13 of the SPS Agreement - in relation to "non-governmental entities ..., as well as regional bodies"; 885 Article XXIV:12 of the GATT 1994 - in relation to "regional and local governments and authorities"; and Article 22.9 of the DSU - with respect to "regional or local governments or authorities". For example, Article 22.9 of the DSU provides:

The dispute settlement provisions of the covered agreements may be invoked in respect of measures affecting their observance taken by regional or local governments or authorities within the territory of a Member. When the DSB has ruled that a provision of a covered agreement has not been observed, the responsible Member shall take such reasonable measures as may be available to it to ensure its observance.

In Article XXIV:12 of the GATT 1994 the obligations of WTO Members with respect to regional and local authorities are formulated in the following way:

Each contracting party shall take such reasonable measures as may be available to it to ensure observance of the provisions of this Agreement by the regional and local governments and authorities within its territories.

883 See: Agreement on Implementation of Article VI of the GATT 1994 (AntiDumping Agreement), Article 6.8, para 1 of Annex II.

884 Appellate Body Report, US - Hot-Rolled Steel, para. 84.

885 For more information about the provisions of Article 13 of the SPS Agreement see Section 5.2 of Chapter V. 
The Understanding on the Interpretation of Article XXIV of the GATT 1994 (Understanding on Article XXIV), in its paragraph 13, further clarifies that:

Each Member is fully responsible under GATT 1994 for the observance of all provisions of GATT 1994, and shall take such reasonable measures as may be available to it to ensure such observance by regional and local governments and authorities within its territory.

Historically, Article XXIV:12 of the GATT 1994 represents the so-called "federal clause" and "had been included into the GATT to accommodate the need of federal states, such as the United States or Australia, which in some areas may face significant hurdles within their federal structure to the full implementation of international law". ${ }^{886}$ The meaning of Article XXIV:12 was considered by the Panel in EC - Selected Customs Matters, where the EU tried to invoke this Article as a defence limiting their obligations to administer their customs laws in a uniform way under the GATT Article X:3(a). ${ }^{887}$ The Panel, with the reference to the aforementioned provisions of the Understanding on Article XXIV, noted:

Article XXIV:12 of the GATT 1994 is drafted as a positive obligation rather than as a defence. More specifically, the use of the word "shall" in Article XXIV:12 of the GATT 1994 indicates that that Article imposes an obligation on Members to take all reasonable measures to ensure that local authorities comply with WTO obligations. This would tend to indicate that Article XXIV:12 of the GATT 1994 cannot be relied upon to attenuate nor to derogate from the provisions of the GATT 1994 (including Article X:3(a) of the GATT 1994), to which Article XXIV:12 of the GATT 1994 refers. ${ }^{888}$

The Panel further concluded that Article XXIV:12 of the GATT 1994 "does not constitute an exception nor a derogation from the obligation of uniform administration in Article X:3(a) of the GATT 1994. Therefore, Article XXIV:12 of the GATT 1994 has no impact upon our examination of the United States' claims under Article X:3(a) of the GATT 1994" ${ }^{889}$ Thus,

Rüdiger Wolfrum, Peter-Tobias Stoll, Anja Seibert-Fohr, WTO: Technical Barriers and SPS Measures, Nijhoff, Leiden, 2007, p. 255; see also: Edward T. Hayes,

"Changing Notions of Sovereignty and Federalism in the International Economic System: A Reassessment of WTO Regulation of Federal States and the Regional and Local Governments Within Their Territories", Northwestern Journal of International Law and Business, 25(1), 2004, pp. 21 - 25.

887 For more information about Article X:3(a) of the GATT 1994 see Section 3.3.2.2 of Chapter III.

888 Panel Report, EC - Selected Customs Matters, para. 7.144.

889 Panel Report, EC - Selected Customs Matters, para. 7.145 
in this ruling, the Panel seems to have taken the approach of obligation of result in relation to Article XXIV:12 of the GATT 1994.

In the case discussed above, the EU, in its argumentation concerning Article XXIV:12, referred to another GATT Panel decision in Canada Gold Coins (unadopted) which, in view of the EU, reflected their position concerning the interpretation of the Article. In this case, Canada tried to invoke Article XXIV:12 as a defence for a violation of Article III:2 of the GATT (national treatment obligation on internal taxation) claimed by South Africa. In particular, the dispute concerned the discriminatory application of the retail sales tax by Canadian province Ontario.

First, the Panel observed that the GATT Article XXIV:12 has the "function of allowing federal States to accede to the General Agreement without having to change the federal distribution of competence", and therefore "Canada had to be given the benefit of the doubt and that Article XXIV:12 had to be deemed to be applicable to the Ontario measure" ${ }^{890}$ Further, the Panel referred to paragraph 1 of Addendum to Article III of the GATT, which provides the following clarifications on the understanding of the term "reasonable measures" in Article XXIV:12 for the purposes of Article III of the GATT: 891

The term "reasonable measures" in the last-mentioned paragraph would not require, for example, the repeal of existing national legislation authorizing local governments to impose internal taxes which, although technically inconsistent with the letter of Article III, are not in fact inconsistent with its spirit, if such repeal would result in a serious financial hardship for the local governments or authorities concerned. With regard to taxation by local governments or authorities which is inconsistent with both the letter and spirit of Article III, the term "reasonable measures" would permit a contracting party to eliminate the inconsistent taxation gradually over a transition period, if abrupt action would create serious administrative and financial difficulties.

Thus, on the basis of this interpretative note to Article III of the GATT, the Panel came to the following conclusion:

The basic principle embodied in this note is, in the view of the Panel, that in determining which measures to secure the observance of the provisions of the General Agreement are "reasonable" within the meaning of Article XXIV:12, the consequences of their non-observance by the local government

890 GATT Panel Report, Canada - Gold Coins (unadopted), para. 58.

891 GATT Panel Report, Canada-Gold Coins (unadopted), para. 69. 
for trade relations with other contracting parties are to be weighed against the domestic difficulties of securing observance. ${ }^{892}$

The GATT Panel thus seems to have considered the obligation of Article XXIV:12 to take "reasonable measures" in relation to local governmental authorities as the obligation of conduct and recommended to Canada to "continue to take such reasonable measures as are available to it to secure the observance of Article III: 2 by the province of Ontario in accordance with Article XXIV:12”. Interestingly, however, the Panel still obliged Canada to "compensate South Africa for the competitive opportunities lost as a result of the Ontario measure until its efforts in accordance with Article XXIV:12 have secured the withdrawal of the measure". ${ }^{893}$ The final result was thus not substantially different from the result in the first case discussed above.

A similar approach was followed by the GATT Panel in Canada Provincial Liquor Boards (EEC), where the Panel observed:

Canada had taken the position that the only authority that could judge whether all reasonable measures had been taken under Article XXIV:12 was in this case the Canadian government. While noting that in the final analysis it was the contracting party concerned that would be the judge as to whether or not specific measures could be taken, the Panel concluded that Canada would have to demonstrate to the CONTRACTING PARTIES that it had taken all reasonable measures available and that it would then be for the CONTRACTING PARTIES to decide whether Canada had met its obligations under Article XXIV:12. ${ }^{894}$

The Panel concluded "that the measures taken by the Government of Canada were clearly not all the reasonable measures as might be available to it to ensure observance of the provisions of the General Agreement". However, in the circumstances of the case, "the Government of Canada should be given a reasonable period of time to take such measures" ${ }^{895}$ In the later revision of this case, in Canada-Provincial Liquor Boards (US), the GATT Panel reiterated again that Canada had to demonstrate that "it had taken all reasonable measures available with respect to the different practices which the Panel had found to be contrary to the General Agreement. The Panel considered that, for this purpose, Canada would have to show that it had made a serious, persistent and convincing effort to secure

\footnotetext{
892 GATT Panel Report, Canada-Gold Coins (unadopted), para. 69.

893 GATT Panel Report, Canada-Gold Coins (unadopted), para. 72.

894 GATT Panel Report, Canada-Provincial Liquor Boards (EEC), para. 4.34.

895 GATT Panel Report, Canada-Provincial Liquor Boards (EEC), para. 4.35
} 
compliance". ${ }^{896}$ The Panel, however, came to the conclusion that Canada failed to do so. ${ }^{897}$

Furthermore, in US - Malt Beverages, the GATT Panel "noted from the drafting history of Article XXIV:12 that this provision was designed to apply only to those measures by regional or local governments or authorities which the central government cannot control because they fall outside its jurisdiction under the constitutional distribution of powers". ${ }^{898}$ The Panel further observed:

...the qualification in Article XXIV:12 of the obligation to implement the provisions of the General Agreement grants a special right to federal states without giving an offsetting privilege to unitary states, and has to be construed narrowly so as to avoid undue imbalances in rights and obligations between contracting parties with unitary and federal constitutions. The abovementioned interpretation - according to which Article XXIV:12 applies only to measures by regional or local authorities which the central government cannot control under the constitutional distribution of powers - meets the constitutional difficulties which central governments may have in ensuring the observance of the provisions of the General Agreement by regional and local authorities, but minimizes the risk that such difficulties lead to imbalances in the rights and obligations of contracting parties. ${ }^{89}$

The Panel finally concluded that the US had, in this case, not demonstrated that the GATT obligations could not be observed "by the United States as a result of its federal constitutional structure". ${ }^{900}$

Thus, in most of the dispute settlement practice under the GATT Article XXIV:12, its provisions with respect to the obligation to take available "reasonable" measures in relation to the "regional and local governments and authorities" were interpreted as an obligation of result or, at the very least, as something close to such an obligation. Indeed, as was noted by Santiago Villalpando, Article XXIV:12 of the GATT "does not exclude in any way the attribution to the State of the conduct of local authorities, since the Member's responsibility is thereby explicitly reaffirmed". ${ }^{901}$ Moreover, according to Edward Hayes, "there is no question that federal GATT/WTO Members remain fully responsible for the actions of their component

\footnotetext{
896 GATT Panel Report, Canada-Provincial Liquor Boards (US), para. 5.37.

897 GATT Panel Report, Canada-Provincial Liquor Boards (US), para. 5.37.

898 GATT Panel Report, US - Malt Beverages, para. 5.79

899 GATT Panel Report, US - Malt Beverages, para. 5.79.

900 GATT Panel Report, US - Malt Beverages, para. 5.80.

901 Santiago Villalpando, "Attribution of Conduct to the State: How Rules of State Responsibility May Be Applied Within the WTO Dispute Settlement System", Journal of International Economic Law, 5(2), 2002, p. 402.
} 
governmental units". ${ }^{902}$ At the same time, however, in Canada-Gold Coins (unadopted), the GATT Panel pointed out the option of weighing the traderestrictive consequences of a measure against the domestic difficulties in securing observance of the relevant rules by the "regional and local governments and authorities". 903

It is doubtful that the practice under the GATT approach could be fully transposed into the context of the TBT Agreement with respect to the relevant types of bodies. However, it seems reasonable to argue that, considering customary law rules on State responsibility, as well as the general practice of attribution of conduct to WTO Members as has been discussed in Chapter III, ${ }^{904}$ the "obligation of result" approach would be more appropriate under the TBT Agreement with respect to the mandatory technical regulations adopted by local governmental and non-governmental bodies controlled by government. However, the same rather rigid interpretation of the obligations to take available "reasonable" measures might not be suitable with respect to voluntary standards adopted by non-governmental or regional bodies, as referred to in Article 4 of the TBT Agreement. In other words, it appears that the closer the relevant body is affiliated with a government, and the more compulsory the measure adopted and applied by such a body is, the more "reasonable" the measures available to a Member shall be with respect to this body and, accordingly, the closer this obligation will be to an obligation of result.

However, the text of the TBT Agreement does not make a distinction in this regard. According to Articles 3.1, 4.1, 7.1 and 8.1 of the TBT Agreement, WTO Members are similarly obliged to take available "reasonable" measures with respect to both local governmental and non-governmental bodies, as well as with respect to technical regulations, standards and conformity assessment procedures. A possible way to approach this could thus be generally regarding the obligations of WTO Members to take available "reasonable" measures with respect to the appropriate bodies as obligations of conduct which, in particular circumstances, depending on the measure and the body at issue, may de facto become very close and similar to the obligations of result. Such an interpretation would provide sufficient flexibility for the TBT Agreement in dealing with different types of bodies which develop, adopt and apply standards, technical regulations and

902 Edward T. Hayes, "Changing Notions of Sovereignty and Federalism in the International Economic System: A Reassessment of WTO Regulation of Federal States and the Regional and Local Governments Within Their Territories", Northwestern Journal of International Law and Business, 25(1), 2004, p. 20. See also: Denise Prévost, Balancing Trade and Health in the SPS Agreement: The Development Dimension, Wolf Legal Publishers, Nijmegen, 2009, p. 536.

903 GATT Panel Report, Canada - Gold Coins (unadopted), para. 69.

904 See Section 3.2 of Chapter III. 
conformity assessment procedures. ${ }^{905}$ Indeed, it seems more appropriate to determine whether a certain measure is "available" and "reasonable" for a WTO Members on a case-by-case basis. ${ }^{906}$ A measure which is "available" and "reasonable" for disciplining mandatory technical regulations might not be "available" and "reasonable" for voluntary standards. Similarly, the available "reasonable" measures for disciplining the conduct of local governmental bodies might not be such for disciplining the conduct of nongovernmental and regional bodies.

Of course, the use of the "obligations of conduct" approach in the context of the TBT Agreement would not mean that a result of a conduct is not important. In fact, the result is essential. Arguably, it is only in rather exceptional cases that WTO Members should be allowed to justify nonachievement of satisfactory results in disciplining the activities of their local governmental and non-governmental bodies by the lack of available "reasonable" measures, and if the trade interests of the other WTO Members were seriously affected. In a WTO dispute it seems that the burden of proof in order to show that a WTO Member has failed to take all available "reasonable" measures lies on a complaining Member. ${ }^{907}$ It would therefore be reasonable to expect that, at least in relation to mandatory technical regulations, the threshold of making a prima facie case should not be high ${ }^{908}$ However, the result in this regard is only one important factor in determining whether the obligations of a WTO Member to take available "reasonable" measures were fulfilled. Other relevant factors might include the level of governmental involvement or incentives provided for a measure, the type and characteristics of the body adopting a measure, the character of a measure and its trade-restrictive or discriminatory effects, the resources and regulatory capacity of a WTO Member, and the practices of other WTO Members with regard to similar measures.

905 See: Jan Bohanes, Iain Sandford, "The (Untapped) Potential of WTO Rules to Discipline Private Trade-Restrictive Conduct”, Inaugural Conference, Society of International Economic Law, 56/08, Geneva, July, 15-17, 2008, paras. 130 -133. See: Rüdiger Wolfrum, Peter-Tobias Stoll, Anja Seibert-Fohr, WTO: Technical Barriers and SPS Measures, Nijhoff, Leiden, 2007, p. 239.

907 Indeed, "the burden of proof rests upon the party, whether complaining or defending, who asserts the affirmative of a particular claim or defence. If that party adduces evidence sufficient to raise a presumption that what is claimed is true, the burden then shifts to the other party, who will fail unless it adduces sufficient evidence to rebut the presumption"; see: Appellate Body Report, US - Wool Shirts and Blouses, p. 335; see also: Appellate Body Report, EC - Sardines, para. 270.

908 It is submitted that even for standards according to Article 4 of the TBT Agreement "the threshold of a prima facie case should be relatively low as the defending party is in a more appropriate position to judge and present its internal legal system with respect to reasonable and available measures"; see: Rüdiger Wolfrum, Peter-Tobias Stoll, Anja Seibert-Fohr, WTO: Technical Barriers and SPS Measures, Nijhoff, Leiden, 2007, p. 258. 
Thus, concluding this discussion, it seems that, on the one hand, the appropriate provisions of Articles 3, 4 and 8 of the TBT Agreement are aimed at allowing for more flexibility for WTO Members with respect to their local governmental and non-governmental bodies. That is, the Members are only required to take "such reasonable measures as may be available to them" in order to ensure compliance of such bodies with the rules of the TBT Agreement. On the other hand, it is not clear how much flexibility these provisions of the TBT Agreement may actually allow for WTO Members in practice. Arguably, more flexibility should be given with respect to voluntary standards than with respect to mandatory technical regulations. Similarly, more flexibility should also be given to the measures adopted by non-governmental bodies than the measures adopted by local governmental bodies. However, considering the text of Article 14.4 of the TBT Agreement, as well as the practice of attribution of conduct to WTO Members under other WTO agreements, it seems that the flexibility will be quite limited, if existing at all, at least with respect to more trade-restrictive measures, such as mandatory technical regulations. In this regard, WTO Members will most likely be fully and directly responsible for the conduct of their local governmental bodies. They will also be fully and directly responsible for the conduct of non-governmental bodies or entities if there is a sufficient nexus between the conduct and their governments, i.e. sufficient governmental involvement or incentives for a measure.

\subsubsection{Negative Obligations}

The TBT Agreement also imposes negative obligations for WTO Members to abstain from requiring or encouraging local governmental, non-governmental and regional bodies to violate the provisions of the Agreement. Thus, with respect to the technical regulations adopted by local governmental and non-governmental bodies, Article 3.4 of the TBT Agreement requires that:

Members shall not take measures which require or encourage local government bodies or non-governmental bodies within their territories to act in a manner inconsistent with the provisions of Article 2.

Similarly, in relation to the standards adopted by local governmental, nongovernmental and regional standardizing bodies, the third sentence of Article 4.1 of the TBT Agreement provides that:

In addition, Members shall not take measures which have the effect of, directly or indirectly, requiring or encouraging such standardizing bodies to act in a manner inconsistent with the Code of Good Practice. 
Finally, the analogous negative obligations of WTO Members are also prescribed in the TBT Agreement for the relevant bodies operating conformity assessment procedures. In particular, Article 7.4 provides for such obligations with respect to local governmental bodies operating conformity assessment procedures; Article 8.1, second sentence, - for non-governmental bodies; and Article 9.2, second sentence, - for international and regional systems of conformity assessment.

This type of obligation of WTO Members in the TBT Agreement has not as yet been interpreted in the WTO dispute settlement process. These provisions seem to constitute specific requirements in the form of the prohibition of certain behaviours of WTO Members, i.e. requiring or encouraging the appropriate wrongful conduct with respect to local governmental, regional and non-governmental bodies ${ }^{909}$ However, it is not really clear whether a Member shall be responsible for the inconsistent conduct of local, regional and non-governmental bodies per se (i.e. if the conduct shall be attributed to the Member), or if it shall only be responsible for "requiring" or "encouraging" such conduct. It seems that the text of the TBT Agreement leaves both options available.

With respect to private-sector standards, the "requiring and encouraging" of non-governmental standardizing bodies to act inconsistently with the TBT Agreement could in fact constitute a form of governmental incentives or support for the development, adoption or application of such a standards. Arguably the "requiring and encouraging" could thus be the reason for the attribution of a standard to a WTO Member, as well as be the grounds for the responsibility of a Member for the act of "requiring and encouraging" perse.

\subsection{Main Disciplines of the TBT Agreement}

The TBT Agreement prescribes a number of important obligations for WTO Members with respect to the technical regulations and standards they develop, adopt and apply, and the conformity assessment procedures they operate. Although the obligations of WTO Members with respect to their technical regulations, standards and conformity assessment procedures are prescribed by different provisions of the TBT Agreement, these obligations are based on common principles ${ }^{910}$ and may be classified in the following groups:

909 See: Ibid., p. 259.

910 See: Arthur E. Appleton, “The Agreement on Technical Barriers to Trade”, at: Patrick F.J. Macrory, The World Trade Organization: Legal, Economic and Political Analysis, 1 Springer [etc.], New York, 2005, p. 388; Course on Dispute Settlement. World Trade Organization. 3.10. Technical Barriers to Trade, UNCTAD, New York 
- MFN and national treatment obligations;

- the prohibition of unnecessary obstacles to trade;

- harmonization with relevant international standards; and

- other obligations, including equivalence and mutual recognition, transparency and notification.

In case the scope of application of the TBT Agreement covers certain private-sector standards, some of these obligations may appear to be relevant with regard to the disciplining of such standards. The present Section briefly discusses these obligations as applicable to technical regulations, standards and conformity assessment procedures. ${ }^{911}$

\subsubsection{MFN and National Treatment Obligations}

The TBT Agreement contains the MFN and national treatment obligations in relation to the preparation, adoption and application of standards, technical regulations and conformity assessment procedures by WTO Members. ${ }^{912}$ The MFN and national treatment obligations of WTO Members in relation to technical regulations are prescribed in Article 2.1 of the TBT Agreement, which reads:

Members shall ensure that in respect of technical regulations, products imported from the territory of any Member shall be accorded treatment no less favourable than that accorded to like products of national origin and to like products originating in any other country.

The analogous MFN and national treatment obligations are prescribed in paragraph D of Annex 3 of the TBT Agreement (Code of Good Practice) with respect to the preparation, adoption and application of standards, ${ }^{913}$

and Geneva, 2003, p. 19.

911 For more information about the key disciplines of the TBT Agreement see, for example: Peter Van den Bossche, Werner Zdouc, The Law and Policy of the World Trade Organization. Text, Cases and Materials, 3d Edition, CUP, 2013, pp. 863 - 886; Arthur E. Appleton, "The Agreement on Technical Barriers to Trade", at: Patrick F.J. Macrory, The World Trade Organization: Legal, Economic and Political Analysis, 1 Springer [etc.], New York, 2005; Rüdiger Wolfrum, Peter-Tobias Stoll, Anja Seibert-Fohr, WTO: Technical Barriers and SPS Measures, Nijhoff, Leiden, 2007; Petros C. Mavroidis, Trade in Goods. The GATT and the Other WTO Agreements Regulating Trade in Goods, OUP, Oxford, 2012, pp. 670 - 706; Arkady Kudryavtsev, "The TBT Agreement in Context", at: Tracey Epps, Michael J. Trebilcock, Research Handbook on the WTO and Technical Barriers to Trade, Edward Elgar, Cheltenham, UK, 2013, pp. $54-73$.

912 For the description of the MFN and national treatment obligations under the GATT 1994, see Section 3.3.1 of Chapter III.

913 Paragraph D of the Code of Good practice reads: "In respect of standards, the standardizing body shall accord treatment to products originating in the territory of 
and, in Article 5.1.1, with respect to the operation of conformity assessment procedures. ${ }^{914}$

The national treatment obligation under Article 2.1 was, for the first time, examined by the Panel and the Appellate Body in US - Clove Cigarettes. The Appellate Body first observed that "[f] or a violation of the national treatment obligation in Article 2.1 to be established, three elements must be satisfied: (i) the measure at issue must be a technical regulation; (ii) the imported and domestic products at issue must be like products; and (iii) the treatment accorded to imported products must be less favourable than that accorded to like domestic products". ${ }^{915}$ It also further noted that the language of the national treatment obligation of Article 2.1 "closely resembles" the language of GATT Article III:4 and that Article III:4 could therefore be regarded as a "relevant context for the interpretation of the national treatment obligation of Article 2.1" ${ }^{916}$ In this respect, according to the findings of the Appellate Body, "the determination of likeness under Article 2.1 of the TBT Agreement, as well as under Article III:4 of the GATT 1994, is a determination about the nature and extent of a competitive relationship between and among the products at issue". ${ }^{917}$

The competitive relationship between the products under Article 2.1, as well as under GATT Article III:4, is determined through the examination of a number of relevant criteria of "likeness": (i) product characteristics; (ii) product end-use; (iii) consumers' tastes and habits; and (iv) product tariff classification. ${ }^{918}$ The Appellate Body thus disagreed with and reversed the findings of the Panel that "the text and context of the TBT Agreement support an interpretation of the concept of "likeness" in Article 2.1 of the TBT Agreement that focuses on the legitimate objectives and purposes of the

any other Member of the WTO no less favourable than that accorded to like products of national origin and to like products originating in any other country".

914 According to Article 5.1.1, WTO Members shall ensure that "conformity assessment procedures are prepared, adopted and applied so as to grant access for suppliers of like products originating in the territories of other Members under conditions no less favourable than those accorded to suppliers of like products of national origin or originating in any other country, in a comparable situation[...]".

915 Appellate Body Report, US - Clove Cigarettes, para. 87.

916 Appellate Body Report, US - Clove Cigarettes, paras. 99 - 100.

917 Appellate Body Report, US - Clove Cigarettes, para. 120.

918 See: Appellate Body Report, US - Clove Cigarettes, para. 104; Report, Panel Report, US - Clove Cigarettes, para. 7.244; Appellate Body Report, EC - Asbestos, para. 101. See also: Appellate Body Report, Japan - Alcoholic Beverages II, pp. 20 - 21; Panel Report, US - Gasoline, para. 6.8. In particular, the first three criteria were set by the GATT Contracting Parties in 1970 Working Party Report, Border Tax Adjustments, BISD 18S/97, para 18. The fourth criterion was developed by the GATT Panels in: GATT Panel Report, EEC - Animal Feed Proteins, para. 4.2; GATT Panel Report, Japan - Alcoholic Beverages I, para. 5.6. For more information about the "likeness" test under Article I and III of the GATT 1994 see Section 3.3.1.3 of Chapter III. 
technical regulation, rather than on the competitive relationship between and among the products". ${ }^{919}$ According to the Appellate Body, "regulatory concerns underlying technical regulations may play a role in the determination of likeness" to the extent they influence the competitive relationship between the products determined according to the criteria of "likeness". ${ }^{920}$ Thus, based on the "likeness" criteria, the Appellate Body, "albeit for different reasons," upheld the Panel's findings that clove and menthol cigarettes were like products within the meaning of Article 2.1 of the TBT Agreement. ${ }^{921}$

With respect to the issue of whether there is "less favourable treatment" of the like products, the Appellate Body noted in US - Clove Cigarettes that:

[...] the object and purpose of the TBT Agreement is to strike a balance between, on the one hand, the objective of trade liberalization and, on the other hand, Members' right to regulate. This object and purpose therefore suggests that Article 2.1 should not be interpreted as prohibiting any detrimental impact on competitive opportunities for imports in cases where such detrimental impact on imports stems exclusively from legitimate regulatory distinctions. ${ }^{922}$

According to the Appellate Body, Article 2.1 prohibits "both de jure and de facto discrimination against imported products, while at the same time permitting detrimental impact on competitive opportunities for imports that stems exclusively from legitimate regulatory distinctions". ${ }^{923}$ Therefore, as has been further explained by the Appellate Body:

$[\ldots]$ a panel must further analyze whether the detrimental impact on imports stems exclusively from a legitimate regulatory distinction rather than reflecting discrimination against the group of imported products. In making this determination, a panel must carefully scrutinize the particular circumstances of the case, that is, the design, architecture, revealing structure, operation, and application of the technical regulation at issue, and, in particular, whether that technical regulation is evenhanded, in order to determine whether it discriminates against the group of imported products. ${ }^{924}$

\footnotetext{
919 Appellate Body Report, US - Clove Cigarettes, para. 112.

920 Appellate Body Report, US - Clove Cigarettes, para. 120.

921 See: Appellate Body Report, US - Clove Cigarettes, para. 160; Panel Report, US Clove Cigarettes, para. 7.248.

922 Appellate Body Report, US - Clove Cigarettes, para. 174.

923 Appellate Body Report, US - Clove Cigarettes, para. 175.

924 Appellate Body Report, US - Clove Cigarettes, para. 182.
} 
After examining the measure at hand, the Appellate Body finally concluded that the US did not demonstrate that the exemption of menthol cigarettes from the ban on flavoured cigarettes, which resulted in a detrimental impact on competitive opportunities for imported clove cigarettes, stemmed from a "legitimate regulatory distinction". ${ }^{925}$ It therefore agreed with the Panel that the US ban on clove cigarettes treated clove cigarettes from Indonesia "less favourably" in comparison with the like domestic products and was thus in violation of Article 2.1 of the TBT Agreement. ${ }^{926}$

In another TBT case, US - Tuna II (Mexico), the Panel agreed with Mexico (the complainant) that tuna caught in Mexico is "like" the tuna caught in the US. ${ }^{927}$ However, the Panel further concluded that it "was not persuaded" that that the US "dolphin-safe" labelling regulation afforded less favourable treatment to Mexican tuna products within the meaning of Article 2.1. ${ }^{928}$ The Appellate Body reversed the Panel's conclusions with respect to "less favourable treatment" and found that the US was in violation of Article 2.1. ${ }^{929}$ In particular, the Appellate Body ruled that the US "dolphin safe" labelling scheme discriminated against Mexican tuna products since it modified the conditions of market competition to the detriment of such products. It also found that the US did not demonstrate that the detrimental impact on Mexican tuna products "stems exclusively from a legitimate regulatory distinction" ${ }^{930}$ In particular, according to the Appellate Body, the US measure was not "even-handed in the relevant respects", because it did not address the issue of mortality of dolphins during tuna fishing processes outside the Eastern Tropical Pacific Ocean (ETP). ${ }^{931}$

In US - COOL, the Panel and the Appellate Body considered whether the US very complex country of origin labelling rules for meat products (COOL measure) was consistent with the rules of Article 2.1. The Appellate Body, with reference to its decisions in the cases described above, reaffirmed that "an analysis of less favourable treatment involves an assessment of whether the technical regulation at issue modifies the conditions of competition in the relevant market to the detriment of the group of imported products vis-à-vis the group of like domestic products". ${ }^{932}$ The Appellate Body then observed that technical regulations are such measures which, by their nature, aim to establish distinctions between products based on their characteristics or PPMs. Article 2.1 therefore should not be read to prohibit

\footnotetext{
925 Appellate Body Report, US - Clove Cigarettes, para. 225.

926 Appellate Body Report, US - Clove Cigarettes, para. 226.

927 See: Panel Report, US - Tuna II (Mexico), para. 7.251.

928 See: Panel Report, US - Tuna II (Mexico), para. 7.374.

929 Appellate Body Report, US - Tuna II (Mexico), para. 299.

930 Appellate Body Report, US - Tuna II (Mexico), paras. 240, 297, 299.

931 See: Appellate Body Report, US - Tuna II (Mexico), para. 297.

932 Appellate Body Reports, US - COOL, paras. 268 - 270.
} 
such distinctions. According to the Appellate Body, a measure modifies the conditions of competition if there is "a "genuine relationship" between the measure at issue and the adverse impact on competitive opportunities for imported products". ${ }^{933}$ The Appellate Body further explained:

In each case, the relevant question is whether it is the governmental measure at issue that "affects the conditions under which like goods, domestic and imported, compete in the market within a Member's territory". While a measure may not require certain treatment of imports, it may nevertheless create incentives for market participants to behave in certain ways, and thereby treat imported products less favourably. However, changes in the competitive conditions in a marketplace that are "not imposed directly or indirectly by law or governmental regulation, but [are] rather solely the result of private entrepreneurs acting on their own calculations of comparative costs and benefits", cannot be the basis for a finding that a measure treats imported products less favourably than domestic like products. In every case, it is the effect of the measure on the competitive opportunities in the market that is relevant to an assessment of whether a challenged measure has a detrimental impact on imported products. ${ }^{934}$

The Appellate Body further reiterated that the determination of the adverse impact on competitive opportunities is "not dispositive of a violation of Article 2.1", because not all detrimental impacts on competitive opportunities result in "less favourable treatment". A measure does not violate Article 2.1 if the detrimental impact "stems exclusively from a legitimate regulatory distinction", and the measure is "designed and applied in an even-handed manner". 935 The Appellate Body also observed, regarding the detrimental impact caused by the decisions of private actors, that:

We further emphasize that, while detrimental effects caused solely by the decisions of private actors cannot support a finding of inconsistency with Article 2.1, the fact that private actors are free to make various decisions in order to comply with a measure does not preclude a finding of inconsistency. Rather, where private actors are induced or encouraged to take certain decisions because of the incentives created by a measure, those decisions are not "independent" of that measure. As the Appellate Body noted, the "intervention of some element of private choice does not relieve [a Member] of responsibility ... for the resulting establishment of competitive conditions less favourable for the

See: Appellate Body Reports, US - COOL, para. 268.

934 Appellate Body Reports, US - COOL, para. 270. See also: Appellate Body Report, Korea-Various Measures on Beef, para. 149; as discussed in Section 3.1.2.1 of Chapter III.

935 See: Appellate Body Reports, US - COOL, para. 271. 
imported product than for the domestic product”, and thus does not preclude a finding that the measure provides less favourable treatment. ${ }^{936}$

According to the Appellate Body, a measure may lack even-handedness "for example, because it is designed or applied in a manner that constitutes a means of arbitrary or unjustifiable discrimination, and thus reflects discrimination in violation of Article 2.1 of the TBT Agreement" ${ }^{937}$ After the detailed examination of the US COOL measure and the Panel's findings, the Appellate Body observed the following:

In sum, our examination of the COOL measure under Article 2.1 reveals that its recordkeeping and verification requirements impose a disproportionate burden on upstream producers and processors, because the level of information conveyed to consumers through the mandatory labelling requirements is far less detailed and accurate than the information required to be tracked and transmitted by these producers and processors. It is these same recordkeeping and verification requirements that "necessitate" segregation, meaning that their associated compliance costs are higher for entities that process livestock of different origins. Given that the least costly way of complying with these requirements is to rely exclusively on domestic livestock, the COOL measure creates an incentive for US producers to use exclusively domestic livestock and thus has a detrimental impact on the competitive opportunities of imported livestock. Furthermore, the recordkeeping and verification requirements imposed on upstream producers and processors cannot be explained by the need to convey to consumers information regarding the countries where livestock were born, raised, and slaughtered, because the detailed information required to be tracked and transmitted by those producers is not necessarily conveyed to consumers through the labels prescribed under the COOL measure. ${ }^{938}$

Based on these findings, the Appellate Body concluded "that the regulatory distinctions imposed by the COOL measure amount to arbitrary and unjustifiable discrimination against imported livestock, such that they cannot be said to be applied in an even-handed manner". ${ }^{939}$ Accordingly, it found "that the detrimental impact on imported livestock does not stem

936 Appellate Body Reports, US - COOL, para. 291; referring to Appellate Body

Report, Korea - Various Measures on Beef, para. 146.

937 Appellate Body Reports, US - COOL, para. 340.

938 Appellate Body Reports, US - COOL, para. 349.

939 Appellate Body Reports, US - COOL, para. 349. 
exclusively from a legitimate regulatory distinction but, instead, reflects discrimination in violation of Article 2.1 of the TBT Agreement" ${ }^{940}$

Thus, it appears that, in its legal analysis under Article 2.1 of the TBT Agreement, the Appellate Body emphasized the right of WTO Members to regulate, as well as the admissibility of detrimental impacts on the competitive opportunities of products if this impact stems exclusively from a legitimate regulatory distinction made by Members. Therefore, in light of the approach taken by the Appellate Body, it seems that a private measure (including a private-sector standard) may not constitute a violation of Article 2.1 of the TBT Agreement if it results merely out of free private conduct based on entrepreneurial considerations and there are no meaningful governmental incentives for such conduct. Arguably, however, if the behaviour of private entities with respect to the development, adoption and application of private-sector standards is significantly influenced by governmental involvement or incentives, WTO Members are obliged to ensure (or take available and reasonable measures to ensure) that provisions of such standards do not discriminate against foreign products.

\subsubsection{Prohibition of Unnecessary Obstacles to Trade}

Article 2.2 of the TBT Agreement provides that "Members shall ensure that technical regulations are not prepared, adopted or applied with a view to or with the effect of creating unnecessary obstacles to international trade". The analogous obligations prohibiting the creation of unnecessary obstacles to trade are prescribed with respect to standards in paragraph $\mathrm{E}$ of Annex 3 of the Code of Goode Practice, and with respect to conformity assessment procedures in Article 5.1.2 of the TBT Agreement. ${ }^{941}$

Article 2.2 further contains the following explanations in relation to technical regulations:

For this purpose, technical regulations shall not be more traderestrictive than necessary to fulfil a legitimate objective, taking account of the risks non-fulfilment would create. Such legitimate objectives are, inter alia: national security requirements; the prevention of deceptive practices; protection of human health or safety, animal or plant life or health, or the environment. In assessing such risks, relevant elements of consideration are, inter alia: available scientific and technical information, related processing technology or intended end-uses of products. ${ }^{942}$

940 Appellate Body Reports, US - COOL, para. 349.

941 The prohibition of unnecessary obstacles to trade with respect to conformity assessment procedures is further clarified in detail in provisions of Article 5.2 of the TBT Agreement.

942 A similar rule is also prescribed in the second sentence of Article 5.1.2 of the TBT 
Thus, according to Article 2.2 of the TBT Agreement, technical regulations may create obstacles to international trade only in order to pursue appropriate legitimate policy objectives, some of which are listed in the Article. The use of the term "inter alia" before the enumeration of the legitimate objectives indicates that the list of legitimate policy objectives in Article 2.2 is not exhaustive, and WTO Members may pursue other legitimate policy objectives, e.g. the protection of human rights, minimal labour standards, public morals, consumer information, etc. ${ }^{943}$ Indeed, the protection of such objectives is frequently the purpose of private-sector standards. However, it is less clear whether such objectives, as the protection of a firm's reputation or the interoperability of product, could be regarded as legitimate within the meaning of Article 2.2.

The provisions of Article 2.2 were, for the first time, examined by the Panel in US - Clove Cigarettes. The Panel noted that "Article 2.2 appears to call for a two-step analysis", i.e. "a technical regulation must: (i) pursue a "legitimate objective"; and (ii) not be more trade-restrictive than "necessary" to fulfil that legitimate objective (taking into account the risks nonfulfilment would create)" ${ }^{944}$ With respect to the first criterion, the Panel recognized that the goal of the US measure banning the manufacturing and sale of clove cigarettes was "to reduce youth smoking", i.e. protection of human health, which is the one the legitimate objectives explicitly mentioned in Article 2.2. ${ }^{945}$ Therefore, the Panel concluded that Indonesia failed to demonstrate that the aims of the US measure were illegitimate. ${ }^{946}$

With respect to the second criterion that a measure is not more trade-restrictive than necessary, the Panel noted that the wording of the second sentence of Article 2.2 is "very similar" to Article XX(b) of the GATT 1994. ${ }^{947}$ The Panel therefore agreed to consider the relevant jurisprudence under Article XX(b) in order to interpret the second sentence of Article 2.2 of the

Agreement for conformity assessment procedures: "This means, inter alia, that conformity assessment procedures shall not be more strict or be applied more strictly than is necessary to give the importing Member adequate confidence that products conform with the applicable technical regulations or standards, taking account of the risks non-conformity would create".

943 See: Rüdiger Wolfrum, Peter-Tobias Stoll, Anja Seibert-Fohr, WTO: Technical Barriers and SPS Measures, Nijhoff, Leiden, 2007, pp. 219 - 220; Jan Neumann, Elisabeth Turk, "Necessity Revisited: Proportionality in World Trade Organization Law After Korea - Beef, EC - Asbestos and EC - Sardines", Journal of World Trade, 37(1), 2003, p. 218.

944 Panel Report, US - Clove Cigarettes, para. 7.333.

945 Panel Report, US - Clove Cigarettes, paras. 7.343 - 7.347.

946 Panel Report, US - Clove Cigarettes, para. 7.350.

947 Panel Report, US - Clove Cigarettes, para. 7.360; the Panel referred to the similar statement in Panel Report, EC - Asbestos, para. 8.55. For more information about Article XX(b) of the GATT 1994 see Section 3.3.4.2 of Chapter III. 
TBT Agreement, although it clarified at the same time that it was not going to transpose this jurisprudence into Article 2.2 "in its entirety" ${ }^{948}$ After careful consideration of the US measure and the circumstances of the case the Panel reached the conclusion that "Indonesia has failed to demonstrate that the ban on clove cigarettes $[. .$.$] is more trade-restrictive than necessary$ to fulfil the legitimate objective of reducing youth smoking, taking account of the risks non fulfilment would create" ${ }^{949}$ In particular, according to the Panel, Indonesia failed to demonstrate that the ban on clove cigarettes: (i) "exceeds the "level of protection" sought by the United States"; and (ii) "makes no "material contribution" to the objective of reducing youth smoking". ${ }^{950}$ The Panel also found that the alternative less trade-restrictive measures identified by Indonesia would not "make an "equivalent" contribution to the achievement of the objective, at the level of protection sought" by the US. ${ }^{951}$ These findings of the Panel were not appealed.

In another case, US - Tuna II (Mexico), the Panel, and then upon appeal the Appellate Body, examined the US "dolphin safe" labelling rules against the requirements of Article 2.2 of the TBT Agreement. The Appellate Body subdivided the text of Article 2.2 into several elements, namely: "legitimate objective", "fulfilment", "not ... more trade-restrictive than necessary" and "taking account of the risks non-fulfilment would create". ${ }^{952}$ The Appellate Body confirmed that the list of the legitimate objectives in Article 2.2 is an open one, and that it is for a panel to assess what the objective of a technical regulation at issue is and whether this objective is a legitimate one. ${ }^{953}$ Assessing the term "fulfil", the Appellate Body clarified that, in this regard, a panel "must seek to ascertain to what degree, if at all, the challenged technical regulation, as written and applied, actually contributes to the legitimate objective pursued by the Member". ${ }^{954}$

With respect to the third phrase identified by the Appellate Body, it explained that "a comparison with reasonably available alternative measures is a conceptual tool for the purpose of ascertaining whether a challenged measure is more trade restrictive than necessary". ${ }^{955}$ Finally, according to the Appellate Body, the reference to the "risks of non-fulfilment" in Article 2.2 "suggests that the comparison of the challenged measure with a possible alternative measure should be made in the light of the nature of the risks at issue and the gravity of the consequences that would arise from

948 See: Panel Report, US - Clove Cigarettes, para. 7.369.

949 Panel Report, US - Clove Cigarettes, para. 7.432.

950 Panel Report, US - Clove Cigarettes, paras. 7.378, 7.417.

951 Panel Report, US - Clove Cigarettes, para. 7.424.

952 Appellate Body Report, US - Tuna II (Mexico), para. 312, 322.

953 Appellate Body Report, US - Tuna II (Mexico), paras. 313 - 314.

954 Appellate Body Report, US - Tuna II (Mexico), para. 317.

955 Appellate Body Report, US - Tuna II (Mexico), para. 320. 
non-fulfilment of the legitimate objective", which also "suggests a further element of weighing and balancing". ${ }^{956}$

After considering these elements of Article 2.2, the Appellate Body turned to examine the findings of the Panel in this respect. The Panel in this case held that the US measure "can only partially ensure that consumers are informed about whether tuna was caught by using a method that adversely affects dolphins" ${ }^{957}$ It also found that Mexico successfully identified a less trade-restrictive alternative for the US measure capable of achieving the same objective, namely the coexistence of the US and the AIDCP provisions on "dolphin safe" labelling. ${ }^{958}$ The Appellate Body disagreed with the Panel that the less trade-restrictive alternative proposed by Mexico would contribute to the US's legitimate objective "to the same extent" as the existing US "dolphin-safe" labelling provisions. ${ }^{959}$ Based on this, the Appellate Body concluded that "the Panel's comparison and analysis is flawed and cannot stand" and thus reversed the Panel's findings that the measure at issue was inconsistent with Article 2.2 of the TBT Agreement. ${ }^{960}$ The Appellate Body, however, was subsequently unable to complete the legal analysis on whether the US measure at issue was or was not inconsistent with Article 2.2 of the TBT Agreement. ${ }^{961}$

Finally, in the US - COOL case, the Appellate Body reaffirmed the structure of analysis followed by it in US - Tuna II (Mexico). First, the Appellate Body upheld the Panel's findings that the US COOL measure had a legitimate objective within the meaning of Article 2.2, i.e. providing information to consumers about the origin of meat products. ${ }^{962}$ However, the Appellate Body then found that the Panel erred in finding that "the COOL measure does not fulfil the identified objective within the meaning of Article 2.2 because it fails to convey meaningful origin information to consumers" and therefore reversed the Panel's finding that the COOL measure was inconsistent with Article 2.2 of the TBT Agreement. ${ }^{963}$ At the same time, however, the Appellate Body was unable to complete the legal analysis with respect to Article 2.2 "due to the absence of relevant factual findings by the Panel, and of sufficient undisputed facts on the record" ${ }^{964}$

\footnotetext{
956 Appellate Body Report, US - Tuna II (Mexico), para. 321.

957 Panel Report, US - Tuna II (Mexico), para. 7.563

958 Panel Report, US - Tuna II (Mexico), para. 7.573

959 See: Appellate Body Report, US - Tuna II (Mexico), para. 330.

960 Appellate Body Report, US - Tuna II (Mexico), para. 331.

961 See: Appellate Body Report, US - Tuna II (Mexico), paras. 334 - 342.

962 See: Appellate Body Reports, US - COOL, paras. 433 and 453.

963 See: Appellate Body Reports, US - COOL, para. 468.

964 See: Appellate Body Reports, US - COOL, para. 491.
} 
Interestingly, no violations of Article 2.2 of the TBT Agreement have, thus far, been found in the WTO dispute settlement practice. In fact, it seems that the restrictive interpretation given by the Appellate Body to the provisions of this Article makes it very difficult - if at all possible - to prove violations of these provisions in practice. Since this seems to be the case even with respect to governmental measures, perhaps, this would be even more so with respect to non-governmental measures. Moreover, as has been argued in 3.3.4.2 of Chapter III, the private-sector standards adopted and applied without meaningful governmental involvement or incentives would hardly fit into the concept of the necessity test developed by WTO panels and the Appellate Body. In fact, a considerable number of privatesector standards is developed, adopted and applied by private actors in order to ensure additional guarantees (i.e. the guarantees not ensured by governmental regulation) with respect to the quality of products, environmental protection, the protection of moral values, etc. Accordingly, such private-sector standards may go beyond something which is "necessary" for the protection of the claimed objectives and may therefore be more trade-restrictive than necessary. It is thus doubtful that the provisions of Article 2.2 could have a lot of relevance for the regulation of private-sector standards.

\subsubsection{Harmonization Based on Relevant International Standards}

The harmonization of the measures used by WTO Members, based on the provisions of relevant international standards, is one of the key requirements of the TBT Agreement. Indeed, as has rightly been submitted, "[h]armonisation around international standards diminishes the trade-restrictive effect of technical barriers to trade by minimising the variety of requirements that exporters have to meet in their different export markets". ${ }^{965}$ Therefore, WTO Members are required by the TBT Agreement to base their technical regulations and standards on the relevant international standards. In particular, Article 2.4 provides the following obligations with respect to technical regulations:

Where technical regulations are required and relevant international standards exist or their completion is imminent, Members shall use them, or the relevant parts of them, as a basis for their technical regulations except when such

965 Peter Van den Bossche, Werner Zdouc, The Law and Policy of the World Trade Organization. Text, Cases and Materials, 3d Edition, CUP, 2013, p. 878. See also: Markus Wagner, "International Standards”, at: Tracey Epps, Michael J. Trebilcock, Research Handbook on the WTO and Technical Barriers to Trade, Edward Elgar, Cheltenham, UK, 2013, pp. $240-245$. 
international standards or relevant parts would be an ineffective or inappropriate means for the fulfilment of the legitimate objectives pursued, for instance because of fundamental climatic or geographical factors or fundamental technological problems.

The analogous obligations are prescribed with respect to standards in paragraph F of the Code of Good Practice ${ }^{966}$ and in Article 5.4 with respect to conformity assessment procedures. ${ }^{967}$ Moreover, with the view to harmonizing standards, technical regulations and conformity procedures, Members and their standardizing bodies are required by the TBT Agreement to "play a full part, within the limits of their resources, in the preparation by appropriate international standardizing bodies of international standards" for the relevant products or subject matter. ${ }^{968}$

In order to encourage harmonization based on international standards, Article 2.5 grants a so-called "safe harbour" for the technical regulations which are adopted for an objective explicitly mentioned in Article 2.2 and "in accordance with relevant international standards", ${ }^{969}$ by providing, in its second sentence, the rebuttable presumption that such technical regulations do not "create an unnecessary obstacle to international trade".

One of the key issues under Article 2.4 is thus when and under what conditions a standard adopted by a standard-setting organization could be regarded as an "international standard" within the meaning of the TBT Agreement. The Agreement itself does not contain the definition of an international standard, although it would seem that, under the Agreement, an international standard shall at least satisfy the criteria of the general definition of a standard as has been discussed in Section 4.1.1.2 above, i.e. it shall be a "[d] ocument approved by a recognized body, that provides, for

966 Para. F of the Code of Good Practice reads: "Where international standards exist or their completion is imminent, the standardizing body shall use them, or the relevant parts of them, as a basis for the standards it develops, except where such international standards or relevant parts would be ineffective or inappropriate, for instance, because of an insufficient level of protection or fundamental climatic or geographical factors or fundamental technological problems".

967 Article 5.4 of the TBT Agreement requires WTO Members to ensure that their central governmental bodies use "relevant guides or recommendations issued by international standardizing bodies" "as a basis for their conformity assessment procedures" unless "such guides or recommendations $[\ldots]$ are inappropriate".

968 See: Article 2.6 of the TBT Agreement with respect to technical regulations, Article 5.5 - conformity assessment procedures, para. G (first sentence) of Annex 3 - standards.

969 See: James H. Mathis, “The WTO Agreement on Technical Barriers to Trade”, Consumer Policy Review, 16(1), 2006, p. 17; Markus Wagner, "International Standards”, at: Tracey Epps, Michael J. Trebilcock, Research Handbook on the WTO and Technical Barriers to Trade, Edward Elgar, Cheltenham, UK, 2013, p. 254. 
common and repeated use, rules, guidelines or characteristics [...]" ${ }^{970}$ It is also reasonable to assume that an international standard is a standard adopted by an "international body or system", which is defined in Annex 1.4 of the TBT Agreement as:

Body or system whose membership is open to the relevant bodies of at least all Members.

It is worth noting that, generally, international standards adopted by "international bodies or systems" play quite a different role in the context of the TBT Agreement in comparison with other measures addressed by the Agreement. International standards are in fact not disciplined by the TBT Agreement; rather this is the other way around - international standards serve as a normative basis for disciplining technical regulations, standards and conformity assessment procedures adopted and operated by WTO Members. According to the definition of an "international body or system", a body - in order to be recognized as an international one within the meaning of the TBT Agreement - shall be open for participation to all WTO Members without limitations. However, this does not mean that the membership of such a body shall necessarily encompass all WTO Membership; every WTO Member must merely have an opportunity to join the body.

The provisions of Article 2.4 were, for the first time, examined by the Panel and the Appellate Body in EC-Sardines. In this case, Peru brought the claim against the EU Regulation which effectively prohibited the marketing of Peruvian Sardinops sagax under the name "sardines" on the European market. ${ }^{971}$ In particular, Peru complained that the EU Regulation, being a technical regulation within the meaning of the TBT Agreement, was not based on the relevant international standards as prescribed by Article 2.4 of the TBT Agreement. The relevant international standard was claimed to be the CODEX-STAN 94 adopted by the Codex - an international foodstandards-setting body established by FAO and WHO. ${ }^{972}$

The Panel confirmed that the Codex could indeed be regarded as an "international body or system" within the meaning of the TBT Agreement and stated that:

According to Rule 1 of the Statutes and Rules of Procedures of the Codex Alimentarius Commission, "[m]embership of the

970 See: Petros C. Mavroidis, Trade in Goods. The GATT and the Other WTO Agreements Regulating Trade in Goods, OUP, Oxford, 2012, pp. 678 - 679. See also: Markus Wagner, "International Standards", at: Tracey Epps, Michael J. Trebilcock, Research Handbook on the WTO and Technical Barriers to Trade, Edward Elgar, Cheltenham, UK, 2013, pp. $249-253$.

971 See: Panel Report, EC - Sardines; Appellate Body Report, EC - Sardines.

972 For more information about the Codex Alimentarius Commission see Section 2.2.4.3.1 of Chapter II. 
joint FAO/WHO Codex Alimentarius Commission ... is open to all Member Nations and Associate Members of the FAO and/or WHO. As membership to the Codex Alimentarius Commission is open to all WTO Members, it is an international body within the meaning of annex 1.4 of the TBT Agreement. ${ }^{973}$

The EU argued that the CODEX-STAN 94 standard adopted by the Codex could not be regarded as the relevant international standard within the meaning of Article 2.4 for two reasons. First, according to the EU, only standards adopted by international bodies by consensus could be regarded as "relevant international standards" under Article 2.4 of the TBT Agreement, and it was not established by the complainant that the CODEXSTAN 94 had been adopted by consensus. Second, the EU argued that the CODEX-STAN 94 could not be recognized as a "relevant" standard for the EU Regulation as its product coverage was different and broader than the one of the Regulation. ${ }^{974}$ The Appellate Body dismissed both arguments of the EU. With respect to the first contention of the EU, the Appellate Body referred to the Explanatory Note to paragraph 2 of Annex 1 of the TBT Agreement, which provides that:

Standards prepared by the international standardization community are based on consensus. This Agreement covers also documents that are not based on consensus.

The Appellate Body thus upheld the ruling of the Panel that the term "international standard" in the TBT Agreement also includes the documents adopted without requirement of consensus. And, in any case, the EU also did not demonstrate that the CODEX-STAN 94 was adopted without consensus. ${ }^{975}$

With respect to the second contention of the EU, the Appellate Body referred to the ordinary meaning of the term "relevant", namely "bearing on or relating to the matter in hand; pertinent" ${ }^{\prime 976}$, and concluded that the CODEX-STAN 94 was indeed relevant for the EU Regulation since, among other fish species, it did cover Sardina pilchardus and Sardinops sagax, which were addressed by the relevant provisions of the EU Regulation. ${ }^{977}$

973 Panel Report, EC - Sardines, para. 7.66. The Panel also noted in the footnote 74 to the same paragraph of the Report that "Codex Alimentarius Commission is explicitly referred to in Article 3.4 of the SPS Agreement." In fact, the EU did not "contest the status of the Codex Alimentarius Commission as an international standardization body for the purposes of the TBT Agreement”. See also: Appellate Body Report, EC - Sardines, paras. $217-218$.

974 See: Appellate Body Report, EC - Sardines, para. 218.

975 See: Appellate Body Report, EC - Sardines, paras. 219-227.

976 Appellate Body Report, EC - Sardines, para. 229.

977 See: Appellate Body Report, EC - Sardines, paras. 231 - 233. 
The meaning and the scope of the terms "international standard" and "international body or system" in the TBT Agreement was further elaborated by the Panel and the Appellate Body in US - Tuna II (Mexico). The Appellate Body pointed out that the definition of standard in the TBT Agreement and the definition of standardizing body in the ISO/IEC Guide 2: $1991^{978}$ both refer to a "recognized" body with respect to its activities in standardization. ${ }^{979}$ Then, after noting the definition of international body or system in Annex 1.4 of the TBT Agreement, the Appellate Body concluded that, according to the Agreement, an international standard is a standard approved by an "international standardizing body"; that is, "a body that has recognized activities in standardization and whose membership is open to the relevant bodies of at least all Members". ${ }^{980}$

The Appellate Body then turned to the examination of the concept of "recognition" and concluded that this concept "would appear to require, at a minimum, that WTO Members are aware, or have reason to expect, that the international body in question is engaged in standardization activities". ${ }^{981}$ With respect to the concept of "openness", the Appellate Body considered the relevance of the TBT Committee Decision on Principles for the Development of International Standard ${ }^{982}$ for the interpretation of appropriate provisions of the TBT Agreement. Interestingly, it found that the content of the Decision is indeed relevant for the interpretation of the appropriate provisions of Article 2.4 and could be regarded as a "subsequent agreement" within the meaning of Article 31(3)(a) of the VCLT. ${ }^{983}$ Based on the provisions of the TBT Agreement and the Decision, the Appellate Body further noted that a body, in order to be regarded as an "international standardizing body" within the meaning of the TBT Agreement, must be open to all WTO Members "at every stage of standards development" and "on a non-discriminatory basis". ${ }^{984}$

978 The ISO/IEC Guide 2: 1991 defines standardizing body as a "body that has recognized activities in standardization"; see: ISO/IEC Guide 2: 1991, General Terms and Their Definitions Concerning Standardization and Related Activities, sec. 4.3. See also Section 2.1.1.4 of Chapter II.

979 See: Appellate Body Report, US - Tuna II (Mexico), para. 357.

980 Appellate Body Report, US - Tuna II (Mexico), para. 359.

981 Appellate Body Report, US - Tuna II (Mexico), para. 362.

982 See: Decision of the Committee on Principles for the Development of International Standards, Guides and Recommendations with relation to Articles 2, 5 and Annex 3 of the Agreement, in Decisions and Recommendations adopted by the WTO Committee on Technical Barriers to Trade since 1 January 1995, G/TBT/1/Rev.10, 9 June 2011, pp. 46-48.

983 See: Appellate Body Report, US - Tuna II (Mexico), para. 372. According to Article 31(3)(a) of the VCLT "any subsequent agreement between the parties regarding the interpretation of the treaty or the application of its provisions" may be taken into account in the process of treaty interpretation

984 See: Appellate Body Report, US - Tuna II (Mexico), paras. 374 - 375. 
The Appellate Body finally found that the Agreement on the International Dolphin Conservation Program (AIDCP) could not be regarded as an international standardizing body within the meaning of the TBT Agreement as it was not open to all WTO Members. This was because, in the view of the Appellate Body, the accession to the AIDCP required a formal invitation which was not an automatic formality and had to be adopted by consensus of the existing Parties to the Agreement. ${ }^{985}$

Furthermore, Article 2.4 of the TBT Agreement requires that a relevant international standard must be used "as a basis" for the technical regulations of WTO Members. This requirement was interpreted by the Appellate Body in EC - Sardines when it had to determine whether the EU Regulation was based on the CODEX-STAN 94, which was found to be the relevant international standard. The Appellate Body, with reference to the case law under Article 3.1 of the SPS Agreement (EC - Hormones), stated that "“based on" does not mean the same thing as "conform to" ", and a "thing is commonly said to be "based on" another thing when the former "stands" or is "founded" or "built" upon or "is supported by" the latter". 986 The Appellate Body further refused to go deeper into the discussion on the meaning of the terms "basis" and "based on", and pointed out that, in any case, for a technical regulation to be based on a relevant international standard, the regulation should, at least, not contradict the relevant international standard. ${ }^{987}$ The EU Regulation was, however, manifestly in contradiction with the CODEX-STAN 94, since it prohibited labelling Sardinops sagax as "sardines" on the European market, while the CODEX-STAN 94 clearly provided that this type of fish could be labelled as "X Sardines", where $\mathrm{X}$ was the name of a country, geographic area or species. ${ }^{988}$ Thus, the Appellate Body upheld the findings of the Panel that the EU Regulation violated Article 2.4 of the TBT Agreement. ${ }^{989}$

According to Article 2.4 of the TBT Agreement, technical regulations must be based on relevant international standards unless these standards or their relevant parts "would be an ineffective or inappropriate means for the fulfilment of the legitimate objectives pursued". In EC - Sardines, the EU argued that the CODEX-STAN 94 was ineffective and inappropriate

985 See: Appellate Body Report, US - Tuna II (Mexico), paras. 398 - 399. The Appellate Body therefore reversed the prior findings of the Panel to the opposite.

986 See: Appellate Body Report, EC - Sardines, para. 242; Panel Report, EC - Sardines, para. 7.110. See also: Appellate Body Report, EC - Hormones, paras. 163, 166.

987 See: Appellate Body Report, EC - Sardines, para. 248.

988 See: Appellate Body Report, EC - Sardines, paras. 239, 257.

989 See: Panel Report, EC - Sardines, para. 7.139; Appellate Body Report, EC Sardines, para. 315. See also: Harm Schepel, "Private Regulators in Law", at: Joost Pauwelyn, Ramses A. Wessel, Jan Wouters, Informal International Lawmaking, OUP, Oxford, 2012, pp. $363-364$. 
for using it as a basis for their technical regulation. The Panel found that it was the task of the EU (the respondent) to prove this and that it had failed to do so. As one of the arguments for such an allocation of burden of proof, the Panel referred to the possible inability of Peru (the complainant) to independently "spell out" the "legitimate objectives" of the EU Regulation. ${ }^{990}$ The Appellate Body reversed the ruling of the Panel with regard to the burden of proof because there was no "“general rule-exception" relationship between the first and the second parts of Article 2.4" ${ }^{991}$ In response to the reasoning of the Panel mentioned above, the Appellate Body emphasized the importance of the first sentence of Article 2.5 which obliges WTO Members to provide explanations on their technical regulations and stated that:

A complainant may obtain relevant information about a technical regulation from a respondent under Article 2.5 of the TBT Agreement, which establishes a compulsory mechanism requiring the supplying of information by the regulating Member. ${ }^{992}$

The Appellate Body thus ruled that the burden of proof lay with the complainant to demonstrate that the CODEX-STAN 94 was indeed effective and appropriate for the technical regulation of the EU, and that this task was successfully accomplished by Peru. ${ }^{993}$

In the process of the legal analysis, the Appellate Body also examined the meanings of the terms "ineffective or inappropriate" and "legitimate objectives" in Article 2.4 of the TBT Agreement. It upheld the conclusions of the Panel that:

...the term "ineffective or inappropriate means" refers to two questions - the question of the effectiveness of the measure and the question of the appropriateness of the measure - and that these two questions, although closely related, are different in nature...

Thus, in the context of Article 2.4, an ineffective means is a means which does not have the function of accomplishing the legitimate objective pursued, whereas an inappropriate means is a means which is not specially suitable for the fulfilment of the legitimate objective pursued. ... The question of effectiveness bears upon the results of the means employed, whereas the

990 Panel Report, EC - Sardines, paras. 7.50 - 7.51.

991 Appellate Body Report, EC - Sardines, para. 275. In reasoning the Appellate Body referred to its previous finding on relationship between Articles 3.1 and 3.3 of the SPS Agreement in EC - Hormones, see: Appellate Body Report, EC - Sardines, paras. 271 - 275; see also: Appellate Body Report, EC - Hormones, paras. 104, 109.

992 Appellate Body Report, EC - Sardines, para. 277.

993 Appellate Body Report, EC - Sardines, paras. 275, 287. 
question of appropriateness relates more to the nature of the means employed. ${ }^{994}$

The criterion of "effectiveness" therefore deals with the capacity of a measure to fulfil pursued legitimate objectives, while the criterion of "appropriateness" deals with the suitability of the measure to fulfil these objectives. ${ }^{995}$ With regard to the meaning of the term "legitimate objectives" in Article 2.4, the Appellate Body confirmed the ruling of the Panel that this term "must be interpreted in the context of Article 2.2", which also refers to "legitimate objectives" and "includes a description of what the nature of some such objectives can be". ${ }^{996}$

In another case, US - COOL, the Panel considered another Codex standard, the CODEX-STAN 1-1985, with respect to the claims under Article 2.4. It found that although the CODEX-STAN 1-1985 was an international standard within the meaning of Article 2.4, it was "ineffective" and "inappropriate" to fulfil the specific objective defined by the US in its COOL measure. ${ }^{997}$ According to the Panel, the provisions of the CODEXSTAN 1-1985 were based on the "principle of substantial transformation" and confer the origin of a food product exclusively to the country where the processing of food took place. Therefore, in the Panel's view, "the exact information that the United States wants to provide to consumers" (the information about the origin of livestock for meat products) could not be conveyed through the CODEX-STAN 1-1985. 998

The relevance of the harmonization obligations in the TBT Agreement for the issue of legal regulation of private-sector standards is not straightforward. On the one hand, those private-sector standards which are adopted or applied with significant governmental involvement or incentives under appropriate conditions shall be subject to these obligations as WTO Members shall not be allowed to avoid their obligations under the TBT Agreement using the so-called "private veil". However, it is doubtful that these obligations are appropriate for regulating "purely" privatesector standards adopted and applied without meaningful governmental involvement or incentives. In fact, the very purpose of many private-sector standards is to respond to consumer demands and pursue a higher level

994 Appellate Body Report, EC - Sardines, para. 285, citing Panel Report, EC Sardines, para. 7.116.

995 See: Arthur E. Appleton, “The Agreement on Technical Barriers to Trade”, at: Patrick F.J. Macrory, The World Trade Organization: Legal, Economic and Political Analysis, 1 Springer [etc.], New York, 2005, pp. 398 - 399.

996 Appellate Body Report, EC - Sardines, para. 286, citing Panel Report, EC Sardines, para. 7.118.

997 See: Panel Reports, US - COOL, paras. 7.735 - 7.736.

998 See: Panel Reports, US - COOL, paras. $7.733-7.734$. 
of protection of important societal objectives than the levels established in international standards, or to pursue the protection of such objectives through different means. Moreover, private-sector standards might address highly controversial issues, both from scientific and political points of view. This might not allow the adoption of new international standards on these issues or updating the existing ones. Imposing the obligation of harmonization with regard to such private-sector standards would therefore equate to prohibiting their existence.

Another interesting question which may arise with regard to the obligations of Article 2.4 and private-sector standards is whether a private-sector standard adopted by an international NGO under certain circumstances could be regarded as an international standard within the meaning of the Article. In other words, may WTO Members be required under the TBT Agreement to harmonize their measures based on the provisions of an international private-sector standard? On the one hand, it seems reasonable to argue that the "international body or system" capable of developing and adopting the international standards within the meaning of the TBT Agreement is primarily meant to cover international intergovernmental standardizing organizations, in which all or majority of WTO Members are represented. However, on the other hand, a general answer to this question could hardly be provided, because the form of incorporation of a standardsetting entity (i.e. governmental or non-governmental form) is, arguably, only one factor which may be considered in this regard. Other relevant factors may include the characteristics of an organization (e.g. international NGO), such as its membership, openness to new members, rules and procedures for standard-setting, and involvement of WTO Members in standardizing activities. Like this is indeed the case, for example, with the ISO, ${ }^{999}$ an international standard-setting organization may be incorporated as an international NGO open to all WTO Members. The Members could then participate in such an organization either through their governmental bodies, or through specially authorised non-governmental entities (e.g. NSBs, which have a non-governmental nature in some countries).

In many cases, it seems that with regard to international NGOs, the "problematic" criterion might be not their "openness" for all WTO Members, but rather their "recognition", i.e. their status as "recognized" international standardizing bodies within the meaning of the TBT Agreement. Indeed, many international NGOs, such as GLOBALG.A.P., the FSC, the MSC, the FLO, etc. claim to be open for a wide range of interested stakeholders which, in principle, might include WTO Members as well. ${ }^{1000}$ However, it is

999 The ISO in fact constitutes a hybrid public-private organization. For more information about the ISO and its membership, see Section 2.2.4.3.1 of Chapter II.

1000 For more information about such international standard-setting NGOs, see 
doubtful that such international NGOs may qualify as "international bodies or systems" capable of developing and adopting international standards within the meaning of Article 2.4, in the absence of clear evidence of their "recognition" by many WTO Members and the international community as a whole. ${ }^{1001}$ Such "recognition" may be evidenced by, for example, participation in their standardizing activities of a wide range of stakeholders, including many NSBs or other relevant bodies of WTO Members; acceptance, approval and application of their standards by such stakeholders; etc. Indeed, this conclusion appears to be quite reasonable in light of legally binding and enforceable nature of the obligations of harmonization under Article 2.4 of the TBT Agreement.

\subsubsection{Other Obligations}

In addition to the obligations described above, the TBT Agreement contains certain other obligations with respect to the development, adoption and application of technical regulations and standards, as well as the operation of conformity assessment procedures. These obligations relate to:

- equivalence and mutual recognition;

- specification of product requirements in terms of performance; and

- transparency and notification. ${ }^{1002}$

Indeed, some of these obligations (e.g. transparency and notification), if applicable to private-sector standards, could have far-reaching consequences for the scope of the rights and obligations of WTO Members. The present Section briefly examines the relevant provisions of the TBT Agreement.

Section 2.2.3.2 of Chapter II.

1001 It is interesting to see that some international standardizing NGOs, such as the FSC and the ISEAL Alliance, sometimes argue that their standards could indeed be regarded as "international standards" within the meaning of the TBT Agreement. The reason for such statements could be the attempts to promote the wide scale application of their standards. However, it should not be forgotten that, under the TBT Agreement, WTO Members would then be obliged to base their national measures on the provisions of such standards, which is hardly a realistic option. See, for example: Referencing International Standards in Government Procurement. International Standards and Technical Barriers to Trade. Legal Opinion Summaries, ISEAL Alliance, CIEL, Switzerland, United Kingdom, July, 2006, pp. $1-2,8-12$, available at: http://www.fsc-deutschland.de/infocenter/ docs/info/studien/iseal_01.pdf (last visited January 15, 2015).

1002 For more information see also: Peter Van den Bossche, Werner Zdouc, The Law and Policy of the World Trade Organization. Text, Cases and Materials, 3d Edition, CUP, 2013, p. 883. 


\subsubsection{Equivalence and Mutual Recognition}

According to Article 2.7 of the TBT Agreement, WTO Members are required to "give positive consideration" to foreign technical regulations with the view to recognize them as equivalent to their own regulations, if such foreign regulations "adequately fulfil" the relevant objectives.

Similar requirements of recognition of equivalence of conformity assessment procedures are prescribed in Article 6.1 of the TBT Agreement. According to the Article, WTO Members "shall ensure that results of conformity assessment procedures on other Members are accepted", even if such procedures are different, but able to provide an equivalent assurance of conformity. Members are encouraged to engage in mutual consultations and negotiations with respect to the mutual recognition of conformity assessment procedures, as well as to conclude agreements in this regard. Furthermore, in the process of mutual recognition of equivalence of conformity assessment procedures, the accreditation and compliance with relevant guidelines and recommendations approved by international standardizing bodies shall be taken into account. WTO Members therefore are encouraged to participate in the adoption and functioning of international systems for conformity assessment. ${ }^{1003}$

Apparently, the aforementioned wording of the obligation of equivalence and mutual recognition with respect to technical regulations and conformity assessment procedures leave a lot of room for discretion from WTO Members. This results in them hardly being legally enforceable through the WTO dispute settlement system. And in any case, the TBT Agreement does not contain the rules on equivalence and the mutual recognition for standards. As has been discussed in 2.3.4 of Chapter II, the recognition of equivalence of standards is performed by the appropriate standard-setting entities through the process called "benchmarking". It might be the case therefore that the TBT Agreement follows this approach and views the recognition of equivalence with respect to standards as a prerogative of standard-setting bodies, and not of WTO Members. It is, as a result, doubtful that the rules of the TBT Agreement on equivalence and mutual recognition may have considerable relevance for the regulation of private-sector standards.

\subsubsection{Product Requirements in Terms of Performance}

Article 2.8 of the TBT Agreement provides that "[w]herever appropriate, Members shall specify technical regulations based on product requirements in terms of performance rather than design or descriptive characteristics". A similar preference in favour of product requirements in terms

1003 See: Articles 6.1.1, 9.1 of the TBT Agreement. 
of performance is established for standards in paragraph I of the Code of Goode Practice. ${ }^{1004}$ These provisions of the TBT Agreement presume that requirements on design and the descriptive characteristics of products have a more trade-restrictive nature than the requirements on product performance.

The provisions of Article 2.8 of the TBT Agreement have been examined by the Panel in US - Clove Cigarettes. In this case, Indonesia (a complainant) asserted that the US measure prohibiting the production and sale of clove cigarettes, first, lacked the specificity required by Article 2.8 and, second, failed to specify the ban on clove cigarettes "in terms of performance, rather than design or descriptive characteristics" ${ }^{1005}$ With respect to the first issue, the Panel concluded that Article 2.8 by itself "does not oblige Members to provide "a certain level of specificity" in their technical regulations". ${ }^{1006}$ Concerning the second issue, the Panel noted the importance of the wording "whether appropriate" in the beginning of Article 2.8 and finally found that "Indonesia has not demonstrated that it would be "appropriate" to formulate the [US] technical regulation [...] in terms of "performance"“. 1007

Generally, no violations of Article 2.8 of the TBT Agreement (with respect to technical regulations) and of the relevant provision of the Code of Good Practice (with respect to standards) have thus far been found in the WTO dispute settlement practice. Therefore, considering the approach to the nature of these provisions adopted by the Panel in US - Clove Cigarettes, it seems that even with regard to governmental technical regulations and standards, the regulatory role of these provisions is quite limited. This is perhaps even truer in relation to the regulation of private-sector standards.

\subsubsection{Transparency and Notification}

The TBT Agreement contains a number of requirements with respect to transparency and the notification of technical regulations and standards. ${ }^{1008}$ According to Article 2.9 (with its subparagraphs 1-4), WTO Members are obliged to publish a notice about the development of a technical regulation at an early stage, to notify other Members through the WTO Secretariat

1004 Para. I of the Code of Goode Practice reads: "Wherever appropriate, the standardizing body shall specify standards based on product requirements in terms of performance rather than design or descriptive characteristics".

1005 See: Panel Report, US - Clove Cigarettes, paras. 7.464 -7.465, 7.468 - 7.471.

1006 Panel Report, US - Clove Cigarettes, para. 7.484.

1007 Panel Report, US - Clove Cigarettes, paras. 7.485, 7.497.

1008 For more information about transparency obligations under the TBT Agreement, see: Denise Prévost, “Transparency Obligations under the TBT Agreement”, at: Tracey Epps, Michael J. Trebilcock, Research Handbook on the WTO and Technical Barriers to Trade, Edward Elgar, Cheltenham, UK, 2013, pp. 120 - 163. 
about certain main characteristics of a draft technical regulation, to provide copies of the draft to other Members upon their requests, and to allow for a reasonable period of time for their comments. This, however, is relevant only for those draft technical regulations which are "not in accordance with the technical content of relevant international standard", or where "a relevant international standard does not exist". ${ }^{1009}$

Article 2.10 further provides that WTO Members, in the case of certain urgent problems, such as problems of security, health and environmental protection, may omit the steps specified in Article 2.9, provided that they still accomplish these steps after the adoption of the needed technical regulation. It is worth noting, however, with respect to private-sector standards that these standards do not normally deal specifically with urgent problems or situations of the kinds specified above, because governments would usually act on such occasions.

The provisions of the TBT Agreement, with respect to the notification of technical regulations, have been examined by the Panel in US - Clove Cigarettes. The Panel concluded that the US failed to comply with TBT Agreement Article 2.9.2 "in the absence of a notification to WTO Members through the Secretariat of the products to be covered by the proposed Section 907(a)(1)(A), together with a brief indication of its objective and rationale, at an early appropriate stage, i.e., when amendments and comments were still possible". ${ }^{1010}$ The Panel also found that Article 2.10 of the TBT Agreement was not applicable to the situation at hand due to the absence of any evidence of the existence of urgent problems related to safety, health, environmental protection or national security. ${ }^{1011}$

In addition, Articles 2.11 and 2.12 of the TBT Agreement require the prompt publication of adopted technical regulations and a "reasonable interval" between their publication and entry into force in order to allow time for producers to adjust. According to paragraph 5.2 of the Doha Ministerial Decision on Implementation-Related Issues and Concerns adopted in 2001, "the phrase "reasonable interval" shall be understood to mean normally a period of not less than 6 months, except when this would be ineffective in fulfilling the legitimate objectives pursued". ${ }^{1012}$ In US - Clove Cigarettes the Panel, and then on appeal the Appellate Body, found this provision of the Doha Ministerial Decision to constitute a subsequent agreement between

\footnotetext{
1009 See: Article 2.9 of the TBT Agreement.

1010 Panel Report, US - Clove Cigarettes, para. 7.550.

1011 See: Panel Report, US - Clove Cigarettes, para. 7.507.

1012 Implementation-Related Issues and Concerns, Decision of 14 November 2001, Doha, Ministerial Conference, WT/MIN(01)/17, 20 November 2001, para. 5.2. See also: Decisions and Recommendations adopted by the WTO Committee on Technical Barriers to Trade since 1 January 1995, G/TBT/1/Rev.10, 9 June 2011, section IV, para. 8, p. 26.
} 
the parties on the interpretation of the term "reasonable interval" in Article 2.12 of the TBT Agreement within the meaning of Article 31(3)(a) of the VCLT. ${ }^{1013}$ As a result, the US was found to be in violation of Article 2.12 of the TBT Agreement for failing to allow for at least 6 months between the publication of their measure and its entry into force. ${ }^{1014}$

Furthermore, pursuant to Article 10.1, WTO Members are obliged to establish enquiry points which shall be able "to answer all reasonable enquiries" from the other WTO Members or interested parties concerning standards, technical regulations and conformity assessment procedures applied on their territory. The provisions on transparency and notification, analogous to those described above, are also prescribed with regard to standards ${ }^{1015}$ and conformity assessment procedures. ${ }^{1016}$

The Code of Good Practice in Annex 3 of the TBT Agreement contains a number of requirements for standardizing bodies in order to ensure transparency of the standards developed, adopted and applied by such bodies. According to paragraph J of the Code of Good Practice, standardizing bodies are obliged to publish their work program in national or regional publications of standardizing activities with specifications of their contact details, standards under the process of development, and information about the standards adopted in the preceding period. The titles of specific draft standards shall, upon request, be provided in three languages: English, French and Spanish. The published work program shall, for each standard, indicate its classification according to the ISONET rules ${ }^{1017}$, stage of development, and "any international standard taken as a basis". ${ }^{1018}$ The standardizing bodies shall also notify their work program before it is published to ISO/IEC Information Centre in Geneva directly or through the relevant national member or affiliate of ISONET. Such a notification must contain

1013 Panel Report, US - Clove Cigarettes, para. 7.576; Appellate Body Report, US Clove Cigarettes, para. 268.

1014 Panel Report, US - Clove Cigarettes, para. 7.595; Appellate Body Report, US Clove Cigarettes, para. 297.

1015 See: paras. J- Q of the Code of Good Practice, Annex 3 of the TBT Agreement. According to para. J of the Code standardizing bodies shall also notify their work programs to ISO/IEC Information Centre in Geneva.

1016 See: Articles 5.6, 5.7, 5.8 and 5.9 of the TBT Agreement.

1017 "ISONET - the ISO Information Network - is an agreement between standardizing bodies to combine their efforts in order to make information on standards, technical regulations and related matters readily available whenever it is required... ISONET is a network comprised of the national standards information centres and it constitutes the links between them. It includes also the ISO/IEC Information Centre in Geneva and a few international members that have similar responsibilities for providing information at international level"; see: http://www. wssn.net/WSSN/RefDocs/isonetdir/index.html (last visited January 15, 2015).

1018 Para. J of the Code of Good Practice, Annex 3 of the TBT Agreement. 
the specifications of the relevant details, including details of a standardizing body and its work program, details of the publication where the work program was published, its price and the place where it can be obtained.

Furthermore, " $[t]$ he national member of ISO/IEC shall make every effort to become ISONET member", "to acquire the most advanced membership", or to be represented by another body. "Other standardizing bodies shall make every effort to associate themselves with the ISONET member" ${ }^{1019}$ A standardizing body must provide 60 days before the adoption of standards for the submission of comments on draft standards by any interested party, unless a shorter period is necessary in connection with urgent safety, health or environmental threats. The notice about the start of the term for comments on a standard shall be put into the publication of work program, as described above, and shall provide explanations on deviations from the relevant international standard if such deviations take place. ${ }^{1020}$ The copy of the draft standard must be promptly provided upon request of interested parties and the related fees shall be non-discriminatory and reflect the real costs of the delivery. ${ }^{1021}$ The received comments shall be taken into account by a standardizing body. If comments requesting the response were received from other standardizing bodies which accepted the Code of Good Practice, a prompt response shall be given with the relevant clarifications, including explanations on the need for deviations from the relevant international standard. ${ }^{1022}$

Compliance with these provisions of the Code of Good Practice is indeed important for ensuring the transparency and predictability of the standard-setting work of standardizing bodies. Arguably, this would also be true with respect to the work of private entities developing and adopting private-sector standards. However, it is unlikely that WTO Members could be obliged to take available reasonable measures to ensure that the private entities, which develop and adopt private-sector standards in their territories and do not receive any governmental support or incentives, fulfil these comprehensive requirements of the Code. Indeed, if a government does not provide any support or incentives to a private standard-setting entity (and might, as such, even be unaware of its standard-setting activities), it is hardly possible to argue that any reasonable measures are available to it in this regard. For the same reason, it is also doubtful that the enquiry points established by WTO Members would be able "to answer all reasonable enquiries" from interested parties concerning the private-sector standards operational on Member territories which are not subject to any

\footnotetext{
1019 Para. K of the Code of Good Practice, Annex 3 of the TBT Agreement.

1020 Para. L of the Code of Good Practice, Annex 3 of the TBT Agreement.

1021 Para. M of the Code of Good Practice, Annex 3 of the TBT Agreement.

1022 Para. N of the Code of Good Practice, Annex 3 of the TBT Agreement.
} 
governmental involvement or incentives. In fact, it seems that the term "reasonable" per se in the wording of these provisions refers to something which should, at least, be practically feasible. However, if the standardsetting work of a private entity (or application of the adopted standards) does receive meaningful governmental support or incentives, it is, arguably, justified to submit that certain reasonable measures shall be available to a WTO Member in this regard.

\subsubsection{TBT Agreement and Developing Country Members}

The TBT Agreement, as well as many other WTO agreements, aims to take into account the special needs of developing countries, and especially of the least-developed ones.

\subsubsection{Technical Assistance}

According to Article 11 of the TBT Agreement, WTO Members shall, upon request from other WTO Members, especially developing country Members, provide technical assistance and advice concerning their technical regulations, standards and conformity assessment procedures. They are also obliged to take available reasonable measures to ensure that such assistance or advice is provided by the regulatory bodies within their territories. The assistance and advice may be granted with respect to:

- the establishment of national standardizing or regulatory bodies and bodies for the assessment of conformity with standards and technical regulations; ${ }^{1023}$

- participation in international standardizing bodies; ${ }^{1024}$

- access to systems of conformity assessment operated within a WTO Member; ${ }^{1025}$ and

- the establishment of an institutional and legal framework for membership or participation in international or regional systems of conformity assessment. ${ }^{1026}$

Pursuant to Article 11.8, in providing advice and technical assistance, priority shall be given to the needs of least-developed country Members. However, it is important to note that, as a rule, technical assistance or advice must be provided "on mutually agreed terms and conditions". ${ }^{1027}$ Thus, although the technical assistance provisions of the TBT Agreement are formulated in a mandatory fashion, with the use of the word "shall",

\footnotetext{
1023 See: Articles 11.2, 11.3, 11.4 of the TBT Agreement.

1024 See: Article 11.2 of the TBT Agreement.

1025 See: Article 11.5 of the TBT Agreement

1026 See: Articles 11.6, 11.7 of the TBT Agreement.

1027 See, for example: Articles 11.4, 11.5, 11.6 of the TBT Agreement.
} 
the character and the amount of assistance to be provided largely depends on the "good will" of WTO Members. This is perhaps even truer with regard to private-sector standards adopted and applied without the meaningful governmental involvement or incentives, i.e. WTO Members are free to provide technical assistance regarding these standards, but it remains at their discretion whether to do so or not.

\subsubsection{Special and Differential Treatment}

Article 12 of the TBT Agreement recognizes "that developing country Members may face special problems [...] in the field of preparation and application of standards, technical regulations and conformity assessment procedures". ${ }^{1028}$ Developed country Members are therefore obliged "to take into account the special development, financial and trade needs of developing country Members" ${ }^{1029}$ and to provide special and differential treatment (SDT) to them. Such treatment includes:

- ensuring that unnecessary obstacles for exports from developing country Members do not exist;

- exemptions from obligations to use relevant international standards as a basis for measures, if these standards do not allow for the preservation of indigenous technologies and productions methods, or do not meet development needs;

- taking available reasonable measures to ensure that international standardizing bodies and the international systems for conformity assessment give due regard to the problems of developing country Members, and prepare international standards for products which are of special interest to such Members; and

- the TBT Committee, upon appropriate request, is able to grant time-limited exceptions from the obligations under the TBT Agreement to developing country Members if they are not able to comply with these obligations.

The provisions of Article 12 are quite broadly formulated and it is not clear which benefits exactly developing countries may receive according to these provisions. ${ }^{1030}$ In US - Clove Cigarettes, Indonesia claimed that the US technical regulation violated Article 12.3 of the TBT Agreement "because the ban on clove cigarettes created an unnecessary barrier to exports from a developing country". ${ }^{1031}$ The Panel disagreed with the arguments of Indonesia that Article 12.3 embodies an obligation of result which prohibits the creation of unnecessary obstacles to exports from developing countries. In

\footnotetext{
1028 Article 12.8 of the TBT Agreement.

1029 Article 12.2 of the TBT Agreement.

1030 See: Arthur E. Appleton, "The Agreement on Technical Barriers to Trade", at: Patrick F.J. Macrory, The World Trade Organization: Legal, Economic and Political Analysis, 1 Springer [etc.], New York, 2005, pp. 403 - 404.

1031 Panel Report, US - Clove Cigarettes, para. 7.576
} 
the Panel's view, the Article rather requires to "take account of the special development, financial and trade needs of developing country Members", and also provides appropriate guidance on how this should be done. ${ }^{1032}$ The Panel further noted that "a requirement to exclude a product that is harmful to human health from a ban, solely on the grounds that the product is produced and exported by a developing country, would limit Members' ability to regulate for public health purposes". ${ }^{1033}$ Therefore, the Panel finally concluded that Indonesia did not demonstrate that the US failed to take account of Indonesia's special financial, trade and development needs and that no violations of Article 12.3 were thus found. ${ }^{1034}$

Thus, it seems to be quite difficult to operationalize the SDT provisions of Article 12 of the TBT Agreement, even with respect to the actions by governmental or other public bodies. Arguably, this would be even more difficult with respect to private-sector standards. Governments would then be obliged to ensure that private entities, which adopt and apply such standards, provide the SDT to producers from developing countries in accordance with the relevant provisions of the TBT Agreement. This hardly seems a possible task to accomplish if a government was not involved in the development, adoption and application of a private-sector standard. However, if governmental involvement or incentives are provided for the development, adoption and application of a private-sector standard, this standard could be attributed to a WTO Member, and it will be for the Member then to provide the SDT in this regard.

\subsection{Summary and Conclusions}

The TBT Agreement is intended to "further the objectives of GATT $1994 " 1035$ and to elaborate the disciplines on the technical barriers to trade in goods. In particular, it applies to such types of technical barriers to trade as technical regulations, standards and conformity assessment procedures (procedures aimed at verifying compliance with requirements of technical regulations and standards). ${ }^{1036} \mathrm{~A}$ technical regulation is defined in Annex

1032 See: Panel Report, US - Clove Cigarettes, para. 7.617. See also the analogous conclusions by the Panel in Panel Reports, US - COOL, paras. 7.763 - 7.766.

1033 Panel Report, US - Clove Cigarettes, para. 7.647

1034 See:Panel Report, US - Clove Cigarettes, paras. 7.648 - 7.649. See also the analogous conclusions by the Panel with respect to the relevant claims of Mexico concerning the US COOL measure: Panel Reports, US - COOL, paras. 7.799 -7.803 .

1035 See: Appellate Body Report, EC - Asbestos, para. 80.

1036 See: Norbert L. W. Wilson, "Clarifying the Alphabet Soup of the TBT and the SPS in the WTO”, Drake Journal of Agricultural Law, 8, 2003, pp. $704-706$. 
1 to the TBT Agreement as a mandatory measure specified in a document laying down product characteristics, which may also include terminology, packaging, marking or labelling requirements and PPMs. A standard is defined in quite similar terms, but only as a voluntary measure prescribed in a document approved by a recognized body for common and repeated use.

Technical regulations and standards may be adopted, and conformity assessment procedures performed, by different types of bodies, including central or local governmental and non-governmental bodies. A non-governmental body is defined rather broadly in Annex 1 of the TBT Agreement as a body "other than a central government body or a local government body" ${ }^{1037}$ In addition, as has been mentioned before, a standard, according to its definition in Annex 1, shall be approved by a "recognized body". However, what constitutes such a "recognition" and by whom a body must be "recognized" (i.e. by governmental agencies, markets, society, etc.), is not further explicated. The unique feature of the TBT Agreement is thus that it is clearly applicable to voluntary measures, which may be developed and adopted by non-governmental "recognized" bodies.

The TBT Agreement clearly recognizes that WTO Members have the inherent right to protect their important societal objectives. This inherent right of Members, however, is subject to rather strict requirements. In this regard, the Agreement contains a number of important obligations for WTO Members. The articles of the Agreement per se prescribe the disciplines with respect to technical regulations and conformity assessment procedures. The disciplines, with respect to standards, are provided in Annex 3 of the TBT Agreement - the Code of Good Practice for the Preparation, Adoption and Application of Standards. However, the requirements of the Code of Good Practice for standards are, to large extent, quite similar to those prescribed for technical regulations and conformity assessment procedures. These requirements include the MFN and national treatment obligations, ${ }^{1038}$ the prohibition of creating unnecessary obstacles to trade, ${ }^{1039}$ harmonization with relevant international standards, ${ }^{1040}$ avoidance of duplications in standard-setting work, equivalence and mutual recognition (although prescribed only for technical regulations and

1037 See: Annex 1 of the TBT Agreement, Definition 8.

1038 See: Article 2.1 (for technical regulations), Para. D of the Code of Good Practice (for standards) and Article 5.1.1 (for conformity assessment procedures) of the TBT Agreement

1039 See: Articles 2.2, 2.3 (for technical regulations), Para. E of the Code of Good Practice (for standards) and Article 5.1.2 (for conformity assessment procedures) of the TBT Agreement,

1040 See: Articles 2.4, 2.5 (for technical regulations), para. F of the Code of Good Practice (for standards) and Article 5.4 (for conformity assessment procedures) of the TBT Agreement 
conformity assessment procedures), transparency and notification, ${ }^{1041}$ and technical assistance. ${ }^{1042}$

The TBT Agreement is aimed at striking a proper balance between the liberalization of international trade and the protection of legitimate societal objectives by WTO Members, and, in this regard, it furthers the objectives of the GATT 1994 and its Article XX in particular. In the end, it is the WTO panels and the Appellate Body who have to rule in each particular case whether and how a measure of a WTO Member fits into the subtle balance of trade and non-trade values established by the TBT Agreement. In this respect, a lot of caution is, undoubtedly, necessary in the interpretation of the Agreement's provisions. If the provisions are interpreted excessively strictly, this may substantially limit the "policy space" of WTO Members in the performance of their rights and duties to protect important societal objectives. However, if the provisions of the TBT Agreement are interpreted excessively laxly, this may result in disguised protectionism and discrimination against foreign products. Both deviations may appear deeply dissatisfactory for the WTO Members concerned.

It is perhaps due to this political sensitivity and the controversial character of the issues involved that there was, until recently, only a small number of dispute settlement cases involving the provisions of the TBT Agreement. As a result, many important provisions of the Agreement remain unexamined by the WTO panels and the Appellate Body. However, in the last several years a number of new TBT cases were brought to the WTO dispute settlement system, in which WTO panels and the Appellate Body had a chance, on some occasions for the first time, to express their views related to the interpretation of certain key provisions of the TBT Agreement.

The guidelines provided by the panels, and especially by the Appellate Body, in these recent cases are very important and useful, and thus deserve thorough examination. In different countries the issues of environmental protection, climate change, public health and morals receive more and more public attention, pushing governmental and non-governmental actors to adopt complex rules addressing these problems. Thus, as the role of technical barriers to trade increases, more TBT disputes will, arguably, come to be resolved by the WTO dispute settlement system. This makes the research related to the role of the TBT Agreement with respect to public and private conduct creating technical barriers to trade even more relevant nowadays.

1041 See: Articles 2.7 - 2.12 (for technical regulations), paras. H - J of the Code of Good Practice (for standards) and Articles 6.1 (for conformity assessment procedures), Article 10.1 of the TBT Agreement.

1042 See: Article 11 of the TBT Agreement. 
Regarding the issue of disciplining private standard-setting activities, it appears that it is, generally, based on the approach to the attribution of private conduct to WTO Members adopted under the GATT 1994 and certain other WTO agreements. The TBT Agreement may thus apply to privatesector standards if their development, adoption and application are subject to substantial governmental involvement or incentives. ${ }^{1043}$ A private-sector standard may, in such as case, be attributable to a WTO Member.

However, the TBT Agreement also contains a number of special obligations with respect to certain types of bodies, which include non-governmental bodies. WTO Members are obliged to take available "reasonable" measures in order to ensure that the non-governmental bodies developing and adopting technical regulations and standards comply with the requirements of the Agreement (Annex 3, Code of Good Practice in relation to standards). WTO Members are also required to refrain from requiring or encouraging these bodies to behave inconsistently with the rules of the TBT Agreement. ${ }^{1044}$ It is not fully clear, however, what the meaning and the scope is of the obligation to take available and reasonable measures, and which particular actions it requires from the Members, if any. Some questions to be answered in this regard are: 1 . whether this obligation is that of a result or that of conduct; 2 . whether and to what extent these obligations may extend to private standard-setting entities adopting private-sector standards; and 3. which "reasonable" measures are available to WTO Members in this respect.

It seems reasonable to argue that the obligation to take available "reasonable" measures is aimed at allowing a certain amount of flexibility for WTO Members with respect to their non-governmental bodies or entities, depending on the level of the particular Member's development and technical feasibility. In this context, these provisions may be interpreted as an obligation of conduct and not of result. However, it is also reasonable to argue that the Members shall be obliged to take measures only with respect to those non-governmental entities or bodies which they "recognize" as standardizing bodies and thus meaningfully support or encourage in their standard-setting activities or the application of their standards in a market. This is, of course, assuming that the term "recognized body" in the definition of standard in Annex 1 of the TBT Agreement implies the necessary recognition by a government, and not by a market or a society alone. These conclusions, in principle, would be in line with the requirements of governmental involvement or incentives under the GATT 1994 for the attribution of acts to a WTO Member, as was described in Chapter III. ${ }^{1045}$

1043 See: Section 3.2.2 of Chapter III.

1044 See: Articles 3.1, 3.2, 4.1 of the TBT Agreement.

1045 See Section 3.2.2.1 of Chapter III. See also: Alessandra Arcuri, "The TBT 
From this approach, the amount of reasonable measures available to a WTO Member for disciplining private-sector standards would depend mainly on two factors: 1 . the level of the Member's development and technical feasibility, and 2. the amount of governmental involvement or incentives provided for the development, adoption and application of a private-sector standard. The following diagram attempts to demonstrate the possible relationship between the obligations of WTO Members to take available and reasonable measures under the TBT Agreement, and the level of governmental involvement or incentives provided for the development, adoption or application of standards and technical regulations by non-governmental bodies or entities. ${ }^{1046}$

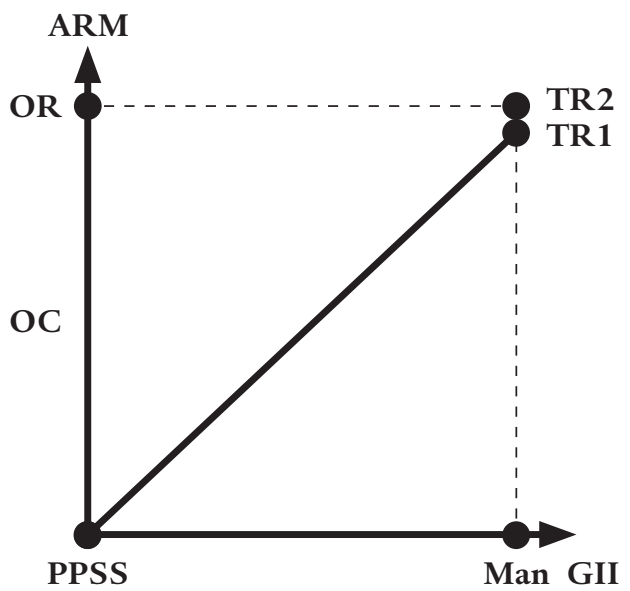

\section{Legend:}

ARM available and reasonable measures to be taken by WTO Members

GII governmental involvement or incentives

PPSS "purely" private-sector standards

Man the mandatory character of the measures
TR1 technical regulations adopted by local governmental and non-governmental bodies

TR2 technical regulations adopted by central governmental bodies;

OR obligation of result

OC obligation of conduct

Agreement and Private Standards”, at: Tracey Epps, Michael J. Trebilcock, Research Handbook on the WTO and Technical Barriers to Trade, Edward Elgar, Cheltenham, UK, 2013, pp. $497-498$.

1046 It is worth noting, however, that this diagram presents a simplified picture. Its only aim indeed is to show visually what possible relations between the specified factors look like. It obviously does not take into account the many other factors which may play a role in the case-by-case determination of the amount of available and reasonable measures required to be taken by the WTO Member, e.g. the trade-restrictiveness of a measure, availability of alternatives, and particular characteristics of the bodies adopting the measures. 
As can be seen from the diagram, private-sector standards adopted without any governmental involvement or incentives do not require any available reasonable measures to be taken by WTO Members according to the TBT Agreement. However, an increase in governmental involvement or incentives for the development, adoption and application of a measure also results in an increase in the level of obligation of WTO Members to discipline such a measure. Mandatory technical regulations present the highest level of governmental incentives. Therefore, with respect to the technical regulations adopted by central governmental authorities, WTO Members have an obligation of result to ensure that the requirements of the TBT Agreement are complied with. For technical regulations adopted by local governmental and non-governmental bodies receiving a high level of governmental support or incentives, obligations of WTO Members come very close to being that of result, but may still be regarded as obligations of conduct.

Such an approach also seems to suggest a relatively restrictive interpretation of the terms "technical regulation", "standard" and "non-governmental body" in the TBT Agreement, preventing them from capturing "purely" private-sector standards that are developed, adopted and applied without meaningful governmental involvement or incentives. Indeed, it would perhaps be unfair and unrealistic to oblige WTO Members to ensure that all non-governmental standard-setting entities on their territory, including those which they did not support and might, as a result, not even be aware of, comply with the strict disciplines of the TBT Agreement. One important question that arises with respect to such an approach is: if the governmental incentives for the adoption and application of private-sector standards are a prerequisite for WTO Members having the relevant obligations in their regard (i.e. making them attributable to WTO Members), why does the need exist to provide two additional types of obligations with respect to non-governmental bodies in the TBT Agreement (these were described above as positive obligations to take available "reasonable" measures, and negative obligations to abstain from "requiring or encouraging")? Do the specific obligations with respect to non-governmental bodies under the TBT Agreement add something extra to the personal scope of the application of the Agreement, which is already delineated by the general rules on attribution of private measures to WTO Members?

These questions are not easy to answer. On the one hand, the TBT Agreement, as a treaty, should be interpreted in a way which gives effective meaning to all its provisions. On the other hand, as has been discussed before, WTO Members could hardly be held responsible for the standardsetting activities of all non-governmental entities on their territory; and certain level of governmental involvement or incentives for such activities shall be a prerequisite for the responsibility of Members. 
Nonetheless, the author is of the view that these two arguments could, in principle, be reconciled with each other. In fact, the specific obligations with respect to non-governmental bodies under the TBT Agreement arguably fulfil a number of purposes: 1 . emphasising the importance of the role that non-governmental bodies may have with respect to the development, adoption and application of technical regulations and standards, as well as the administration of conformity assessment procedures; and 2. providing appropriate flexibility with respect to the responsibility of WTO Members for non-governmental technical regulations and standards to WTO Members. In other words, as has been illustrated in the diagram above, the more governmental involvement or incentives are provided in support of activities of a non-governmental entity, the more reasonable measures shall be available to a WTO Member to discipline such activities. However, under this approach, a certain meaningful level of governmental involvement or incentives is still necessary for the responsibility of WTO Members regarding private standard-setting activities. WTO Members are thus not obliged to ensure compliance with the TBT Agreement of "purely" private-sector standards which are adopted and applied without governmental support. 


\section{CHAPTER V \\ PRIVATE-SECTOR STANDARDS \\ AND THE SPS AGREEMENT}

B esides the GATT 1994 and the TBT Agreement, the WTO regulatory framework contains another multilateral agreement, namely the SPS Agreement, which might be directly relevant for the regulation of privatesector standards in trade in goods. This Agreement is included into Annex 1A, "Multilateral Agreements on Trade in Goods", of the Marrakesh Agreement establishing the WTO. ${ }^{1047}$ The SPS Agreement therefore forms an integral part of the single undertaking resulting from the Uruguay Round and is mandatory for all Members of the WTO.

The SPS Agreement deals with the specific type of technical barriers to trade identified as "sanitary and phytosanitary measures" (SPS measures). These are the measures aimed at the protection of human, animal or plant life and health from food-borne risks or from risks related to the spread of pests and diseases. ${ }^{1048}$ During the Uruguay Round negotiations it was clearly accepted that the SPS measures may be legitimately adopted and enforced by WTO Members to protect their relevant policy objectives. At the same time it was widely recognized that these measures may actually or potentially create significant restrictive effects on the international trade in goods, and especially in one of the most sensitive areas of trade, namely trade in agriculture. The important issue for the negotiating parties was thus reaching and maintaining the appropriate balance between two important tasks: the liberalization of international agricultural trade and the protection of public health. ${ }^{1049}$

As has been discussed in Chapter IV, the earlier adopted Tokyo Round TBT Agreement 1979 (or, as it is frequently called, the Tokyo Round

1047 See: The Results of the Uruguay Round of Multilatreral Trade Negotiations. The Legal Texts., WTO, 1995.

1048 See: Annex 1.1 of the SPS Agreement. See also: Peter Van den Bossche, Werner Zdouc, The Law and Policy of the World Trade Organization. Text, Cases and Materials, 3d Edition, CUP, 2013, pp. 896-897.

1049 For more information see: Denise Prévost, Balancing Trade and Health in the SPS Agreement: The Development Dimension, Wolf Legal Publishers, Nijmegen, 2009, pp. 481 - 515; Denise Prévost, Peter Van den Bossche, "The Agreement on the Application of Sanitary and Phytosanitary Meaures", at: Patrick F.J. Macrory, The World Trade Organization: Legal, Economic and Political Analysis, 1 Springer [etc.], New York, 2005, pp. 233 - 234; Joanne Scott, The WTO Agreement on Sanitary and Phytosanitary Measures. A Commentary, Oxford University Press, Oxford, 2007, pp. 1 - 6; Tracey Epps, International Trade and Health Protection. A Critical Assessment of the WTO's SPS Agreement, Edward Elgar, Cheltenham, UK, 2008, pp. $28-32$. 
Standards Code) was regarded as unsuccessful in this regard, not only because this was a plurilateral agreement, but also because it was not specific enough. ${ }^{1050}$ Thus, during the Uruguay Round, the parties negotiated the SPS Agreement as a separate multilateral agreement dealing specifically with SPS measures. ${ }^{1051}$ The intent of WTO Members of balancing the important policy objectives found its reflection in the first paragraph of the preamble of the SPS Agreement:

Reaffirming that no Member should be prevented from adopting or enforcing measures necessary to protect human, animal or plant life or health, subject to the requirement that these measures are not applied in a manner which would constitute a means of arbitrary or unjustifiable discrimination between Members where the same conditions prevail or a disguised restriction on international trade.

In fact, the SPS Agreement is conceived as the further elaboration of the Article XX(b) exception in the GATT 1994 authorizing measures "necessary to protect human, animal or plant life and health". This is clearly pointed out in the preamble to the SPS Agreement:

Desiring therefore to elaborate rules for the application of the provisions of GATT 1994 which relate to the use of sanitary or phytosanitary measures, in particular the provisions of Article XX(b).

1050 See: Tokyo Round Agreement on Technical Barriers to Trade, BISD 26th Supp, 1980, 8. The Tokyo Standards Code was a predecessor of the TBT Agreement, and although it had similar structure as the TBT Agreement, it was rather general in its nature. In particular, the Standards Code dealt with technical specifications, technical regulations and standards. For more information with regard to the Tokyo Standards Code, see the introduction to Chapter IV.

1051 For more information about negotiating history of the SPS Agreement see, for example: Denise Prévost, Balancing Trade and Health in the SPS Agreement: The Development Dimension, Wolf Legal Publishers, Nijmegen, 2009, pp. 451 - 480, 561; Denise Prévost, Peter Van den Bossche, "The Agreement on the Application of Sanitary and Phytosanitary Meaures”, at: Patrick F.J. Macrory, The World Trade Organization: Legal, Economic and Political Analysis, 1 Springer [etc.], New York, 2005, p. 238; Stefan Zleptnig, Non-Economic Objectives in WTO Law. Justification Provisions of GATT, GATS, SPS and TBT Agreements, Vol. 1, Martinus Nijhoff Publishers, Leiden - Boston, 2010, p. 332; Gabrielle Marceau, Joel P. Trachtman, "The Technical Barrier to Trade Agreement, the Sanitary and Phytosanitary Measures Agreement, and the General Agreement on Tariffs and Trade: A Map of the World Trade Organization Law of Domestic Regulation of Goods", Journal of World Trade, 36(5), 2002, pp. 813 - 815; Gabrielle Marceau, Joel P. Trachtman, "A Map of the World Trade Organization Law of Domestic Regulation of Goods: The Technical Barriers to Trade Agreement, the Sanitary and Phytosanitary Measures Agreement, and the General Agreement on Tariffs and Trade”, Journal of World Trade, 48(2), 2014, pp. 351-432. 
As has been expounded, ${ }^{1052}$ private standard-setting activities did not, initially, often concern SPS matters and dealt primarily with issues of product quality or environmental, moral or ethical objectives. However, due to the development of international trade, accompanied by widely publicized food and non-food product safety scandals, product safety became an important and popular subject for private standard-setting as well. Nowadays a lot of private-sector standards, among other relevant matters, address such SPS issues as maximum residue limits (MRLs) of pesticides or other chemicals, genetic modification and hormone residues in food products, etc. The examples of private-sector standards addressing, among others, SPS issues are GLOBALG.A.P. and BRC. ${ }^{1053}$ Many private-sector standards for food products are very complex and may include both SPS and non-SPS related matters. In principle, however, it is possible that a private-sector standard might be devoted to only one SPS-related issue, or several of them. ${ }^{1054}$ The SPS Agreement, as will be later explained in more detail, regulates SPS measures adopted and applied by appropriate bodies or entities of WTO Members. The SPS Agreement can therefore certainly be considered as one of the relevant WTO agreements with respect to the issue of regulating private-sector standards within the WTO legal framework. This is, of course, only true for those private-sector standards which contain SPSrelated requirements.

The present Chapter shall discuss the possibility of applying the SPS Agreement to private-sector standards. In this respect, one of the most important issues is the scope of the SPS Agreement, i.e. what kind of measures the Agreement is applicable to and whether such measures may include private-sector standards. To address this, Section 5.1 of the present Chapter is devoted to the material, personal and temporal scopes of application of the SPS Agreement, as well as the relationship of this Agreement with other WTO agreements. In other words, this Section will address questions such as: 1 . what is the form and nature of an SPS measure under the SPS Agreement?; 2. which entities may adopt these measures?; and 3. to what extent might the SPS Agreement cover private-sector standards?

\footnotetext{
1052 See Section 2.3.2 of Chapter II.

1053 For more information about these and other relevant private-sector standards, see Section 2.2.3.2 of Chapter II.

1054 For more information about the issues addressed by private-sector standards, see Section 2.2.5 of Chapter II. See also, for example: Denise Prévost, Balancing Trade and Health in the SPS Agreement: The Development Dimension, Wolf Legal Publishers, Nijmegen, 2009, pp. 138 - 141; Private Voluntary Standards within the WTO Multilateral Framework: Submission by the United Kingdom. A report prepared by Digby Gascoine and O'Connor and Company, WTO, SPS Committee, G/SPS/GEN/802, Geneva, 9 October 2007, pp. $14-16$.
} 
As has been already explained, ${ }^{1055}$ private-sector standards are, by definition, adopted by non-governmental (i.e. private) entities. Yet in the WTO it is the Members (i.e. States, SCTs and the EU) who are responsible for compliance with the provisions of the WTO agreements. ${ }^{1056}$ The application of the SPS Agreement to private-sector standards would thus mean that WTO Members bear certain due diligence obligations to discipline the activities of private standard-setting and conformity assessment organizations and to bring them in compliance with the SPS Agreement. This may also mean that WTO Members have the obligation not to rely on the services of private standardizing organizations and conformity assessors, unless these entities comply with the requirements set out in the Agreement. ${ }^{1057}$ Section 5.2 of the present Chapter discusses the duties of WTO Members with respect to non-governmental entities, regional and (collaterally) local bodies under the relevant provisions of the SPS Agreement. It also provides a brief outline of the work on private-sector standards undertaken at the WTO within the SPS Committee which became an important forum for deliberations between WTO Members on this controversial issue.

Finally, Section 5.3 of this Chapter explains the substantive obligations of WTO Members with respect to the preparation, adoption and application of their SPS measures. In fact, these disciplines would be applicable to private-sector standards only in cases where such standards qualify as SPS measures under the SPS Agreement. The discussion of the substantial requirements of the SPS Agreement is aimed at identifying whether these rules are actually suitable for the regulation of private-sector standards.

1055 See Section 2.3.4.1 of Chapter II.

1056 See: Peter Van den Bossche, Werner Zdouc, The Law and Policy of the World Trade Organization. Text, Cases and Materials, 3d Edition, CUP, 2013, pp. 104 - 109; Denise Prévost, Balancing Trade and Health in the SPS Agreement: The Development Dimension, Wolf Legal Publishers, Nijmegen, 2009, p. 541.

1057 See: Private Voluntary Standards within the WTO Multilateral Framework: Submission by the United Kingdom. A report prepared by Digby Gascoine and O'Connor and Company, WTO, SPS Committee, G/SPS/GEN/802, Geneva, 9 October 2007, pp. 21 - 23; Jan Bohanes, Iain Sandford, "The (Untapped) Potential of WTO Rules to Discipline Private Trade-Restrictive Conduct", Inaugural Conference, Society of International Economic Law, 56/08, Geneva, July, 1517, 2008, pp. 24 - 27; Rex J. Zedalis, "When Do the Activities of Private Parties Trigger WTO Rules?”, Journal of International Economic Law, 10(2), 2007, pp. 335 - 362; Samir R. Gandhi, "Voluntary Environmental Standards: The Interplay Between Private Initiatives, Trade Rules and the Global Decision-Making Process”, 3rd Global Administrative Law Seminar, Viterbo, June 15-16, 2007, pp. 12 - 13; Santiago Villalpando, "Attribution of Conduct to the State: How Rules of State Responsibility May Be Applied Within the WTO Dispute Settlement System”, Journal of International Economic Law, 5(2), 2002. pp. 393 - 420. 


\subsection{Scope of Application of the SPS Agreement}

The scope of the SPS Agreement may be subdivided into three components, namely material scope, personal scope and temporal scope. ${ }^{1058}$ The material scope of the SPS Agreement defines the types of measures that are covered by the SPS Agreement, i.e. what the substance (purposes, typical characteristics) of an "SPS measure" is under the Agreement. The personal scope addresses the types of bodies and entities which may develop, adopt and apply SPS measures falling within the scope of the Agreement. Finally, the temporal scope answers the question about when an SPS measure must be adopted or applied in order to be covered by the SPS Agreement. Furthermore, the discussion of the relationship between the SPS Agreement and other relevant WTO agreements (such as the TBT Agreement and the GATT 1994) is supposed to assist with the proper understanding of the scope of the SPS Agreement.

All of these aspects regarding the scope of application of the SPS Agreement seem to be important for identifying whether a certain privatesector standard may be covered by the rules of the SPS Agreement.

\subsubsection{Material Scope of Application of the SPS Agreement}

The material scope of application of the SPS Agreement is prescribed in Article 1.1 of the Agreement:

This Agreement applies to all sanitary and phytosanitary measures which may, directly or indirectly, affect international trade.

In order to be covered by the SPS Agreement, a measure thus must: 1. fall under the definition of an SPS measure in the Agreement, and 2. affect international trade, directly or indirectly. These two components will be discussed in the following two sub-sections.

\subsubsection{Definition of an SPS Measure}

Annex A "Definitions" of the SPS Agreement defines an SPS measure in paragraph 1 as:

1058 The material scope of application is also frequently called the "substantive" scope; see: Peter Van den Bossche, Denise Prévost, Mariëlle Matthee, "WTO Rules on Technical Barriers to Trade”, Maastricht, 2005-6, pp. 28 - 30; Denise Prévost, Peter Van den Bossche, "The Agreement on the Application of Sanitary and Phytosanitary Meaures”, at: Patrick F.J. Macrory, The World Trade Organization: Legal, Economic and Political Analysis, 1 Springer [etc.], New York, 2005, pp. 244 - 250; Denise Prévost, Balancing Trade and Health in the SPS Agreement: The Development Dimension, Wolf Legal Publishers, Nijmegen, 2009, 515 - 516. 
Any measure applied:

(a) to protect animal or plant life or health within the territory of the Member from risks arising from the entry, establishment or spread of pests, diseases, disease-carrying organisms or disease-causing organisms;

(b) to protect human or animal life or health within the territory of the Member from risks arising from additives, contaminants, toxins or disease-causing organisms in foods, beverages or feedstuffs;

(c) to protect human life or health within the territory of the Member from risks arising from diseases carried by animals, plants or products thereof, or from the entry, establishment or spread of pests; or

(d) to prevent or limit other damage within the territory of the Member from the entry, establishment or spread of pests.

Sanitary or phytosanitary measures include all relevant laws, decrees, regulations, requirements and procedures including, inter alia, end product criteria; processes and production methods; testing, inspection, certification and approval procedures; quarantine treatments including relevant requirements associated with the transport of animals or plants, or with the materials necessary for their survival during transport; provisions on relevant statistical methods, sampling procedures and methods of risk assessment; and packaging and labelling requirements directly related to food safety.

The definition of an SPS measure is formulated quite broadly which leaves a lot of room for interpretation. ${ }^{1059}$ Interestingly, it has not been examined and interpreted comprehensively by the panels and the Appellate Body for more than a decade after the adoption of the SPS Agreement. ${ }^{1060}$ In fact, in the first disputes under the SPS Agreement, the parties to these disputes did not contest that the measures at issue were SPS measures. As has been correctly noted by the Panel in US - Poultry (China), "determining whether the measure at issue is an SPS measure has been straightforward" in the

1059 Moreover, according to Joanne Scott "[t]he concept of an SPS measure, as defined, is deeply ambiguous"; see: Joanne Scott, The WTO Agreement on Sanitary and Phytosanitary Measures. A Commentary, Oxford University Press, Oxford, 2007, p. 13.

1060 See: Lukasz Gruszczynski, Regulating Health and Environmental Risks under WTO Law. A Critical Analysis of the SPS Agreement, Oxford University Press, Oxford, 2010, p. 53. See also: Denise Prévost, Balancing Trade and Health in the SPS Agreement: The Development Dimension, Wolf Legal Publishers, Nijmegen, 2009, p. 520 . 
early SPS disputes. ${ }^{1061}$ This was the case until 2006 when the definition of an SPS measure was examined in detail for the first time by the Panel Report in EC - Approval and Marketing of Biotech Products. ${ }^{1062}$ In several later disputes the definition of an SPS measure was further interpreted and clarified by the panels ${ }^{1063}$ and, finally, by the Appellate Body in 2010. ${ }^{1064}$

According to the text of the definition in Annex A, in order to qualify as an SPS measure, a measure must: 1. be aimed at the fulfilment of one or several objectives enumerated in subparagraphs (a) - (d); and 2. satisfy other substantive criteria set out in the last paragraph of the definition. ${ }^{1065}$ These two groups of criteria are examined below.

\subsection{Purpose of an SPS Measure}

The purpose of a measure is the decisive criterion which distinguishes SPS measures from all other kinds of measures regulated by WTO agreements. As has been correctly emphasized by the Panel in Australia - Apples, "purpose, as set out in subparagraphs (a)-(d), is an essential criterion for assessing whether a measure amounts to an SPS measure under Annex A(1)" ${ }^{1066}$ The list of possible objectives of an SPS measure in Annex A to the SPS Agreement is therefore an exhaustive one and is specially designed to limit the application of the SPS Agreement to a specific category of measures. ${ }^{1067}$ These objectives of an SPS measure may be summarized as follows:

1061 Panel Report, US - Poultry (China), para. 7.84. The examples of such first SPSrelated disputes are provided in the footnote 268 to this para. 7.84: "Panel Report, EC-Hormones, para. 8.22 (where the panel saw no need to further examine if the measures were "applied to protect human ... life or health" because both parties agreed that the EC measures were "sanitary measures"); Panel Report, Australia Salmon, para. 8.30 (noting that the parties agreed that the measures fell under the SPS Agreement and that the main issue was whether they were applied to serve the purposes outlined in either Annex A(1)(a) or Annex A(1)(b)); Panel Report, Japan - Agricultural Products II, para. 8.12 (where the panel noted that the parties agreed that the measures at issue were SPS measures); Panel Report, Japan-Apples, para. 8.9 (where the panel noted that the parties agreed that the measures at issue were SPS measures)".

1062 See: Panel Report, EC - Approval and Marketing of Biotech Products, paras. 7.147 7.433; see also: Panel Report, US - Poultry (China), para. 7.85.

1063 See: Panel Reports, US/Canada - Continued Suspension, paras. 7.428 - 7.434/ paras. 7.419 - 7.425; Panel Report, US - Poultry (China), paras. 7.80 - 7.124; Panel Report, Australia-Apples, paras. 7.113-7.187.

1064 See: Appellate Body Report, Australia - Apples, paras. 165 - 184.

1065 See: Panel Report, EC - Approval and Marketing of Biotech Products, para. 7.149; Panel Report, US - Poultry (China), para. 7.102; Panel Report, Australia - Apples, paras. 7.118 - 7.119; Appellate Body Report, Australia - Apples, paras. 172 - 175.

1066 Panel Report, Australia-Apples, para. 7.118.

1067 See: Denise Prévost, Balancing Trade and Health in the SPS Agreement: The Development Dimension, Wolf Legal Publishers, Nijmegen, 2009, p. 517. 
- the protection of human, animal or plant life or health from pests, diseases and disease-causing organisms;

- the protection of human or animal life or health from foodborne risks, e.g. the presence of contaminants, additives, toxins and disease-causing organisms in food and beverages;

- the prevention or limitation of other damage from establishment and spread of pests. ${ }^{1068}$

The footnote to the entire Annex A further clarifies that, in all the definitions of the SPS Agreement, the terms "plant" and "animal" include objects of wild flora and fauna respectively, such as fish and forests. The term "pests" includes weeds, and the term "contaminants" may include pesticides or drug residues and other extraneous matters. This clarification demonstrates that the product coverage of the SPS Agreement is neither limited to the agricultural products covered by the WTO Agreement on Agriculture, ${ }^{1069}$ nor solely to agricultural products in general. The SPS Agreement is also applicable to products of wild fauna and flora, and various industrial products which may carry pests or diseases.

However, it is worth noting that, according to the SPS Agreement, an SPS measure shall be aimed at addressing the specific kinds of health or life risks as described above and not other kinds of health-related risks. For example, health risks from toxic plastic (e.g. in child toys), materials containing asbestos fibres and low quality computer monitors are not covered by the definition of an SPS measure according to the SPS Agreement. Moreover, and particularly with regard to food products, SPS measures must be aimed at dealing with safety issues ("protection of life or health"). The SPS Agreement thus does not cover the measures, or parts of the measures, addressing the issues of food quality, as far as a food product is considered to be safe (for instance, the regulation of organic food, food nutrition indicators, etc.). ${ }^{1070}$

Subparagraphs (a) - (d) of Annex A(1) provide that an SPS measure adopted by a WTO Member shall protect life or health, or prevent or limit other damage "within the territory of the Member". Arguably, this means that the SPS Agreement does not cover extra-territorial measures not related to the internal SPS protection of a WTO Member. In other words, an SPS measure, under the SPS Agreement, may not include a measure

1068 See: Peter Van den Bossche, Werner Zdouc, The Law and Policy of the World Trade Organization. Text, Cases and Materials, 3d Edition, CUP, 2013, pp. 896 - 897.

1069 The Agreement on Agriculture, in its Annex 1, contains the list of the covered agricultural products which, for instance, includes diary and meat products, raw cotton and essential oils, but does not include such products as fish and timber.

1070 See: Denise Prévost, Balancing Trade and Health in the SPS Agreement: The Development Dimension, Wolf Legal Publishers, Nijmegen, 2009, p. 517. 
targeted solely for the protection of life and health abroad. ${ }^{1071}$ However, SPS measures, although targeted for protection within the territories of Members, usually have important implications for producers abroad as the producers have to comply with the SPS requirements of an importing country and thus have to adjust their production methods or processes accordingly. Moreover, producers from one WTO Member often have to admit certification experts from another WTO Member in order to verify compliance of their production facilities with the appropriate foreign SPS requirements for the importation of their products.

The issue of territorial application of an SPS measure is closely related to another, yet separate, issue of PPMs and their coverage by the SPS Agreement. The second paragraph of the definition of an SPS measure in Annex A(1), among other examples of issues to be addressed by an SPS measure, explicitly refers to PPMs. Indeed, nowadays many governmental or non-governmental regulations and standards devoted to product safety address processes of production, which may take place both domestically and abroad. For example, the HACCP analysis, dealing with the minimization of risks in each vulnerable production stage, is commonly found in various industry spheres. ${ }^{1072}$ This is the case particularly in agricultural production where HACCP-based system-wide approaches, such as prefarm-gate and from-farm-to-fork, are widely used. ${ }^{1073}$ Even though process requirements are usually targeted at production processes abroad, in the SPS context they are, as a rule, aimed at the prevention or minimization of SPS risks "back home", i.e. risks related to the introduction of a foreign product to a domestic market. It would thus seem that the HACCP analysis

1071 See: Joanne Scott, The WTO Agreement on Sanitary and Phytosanitary Measures. A Commentary, Oxford University Press, Oxford, 2007, pp. 11 - 12. For more discussion on this issue see also, for example: Denise Prévost, Balancing Trade and Health in the SPS Agreement: The Development Dimension, Wolf Legal Publishers, Nijmegen, 2009, p. 528; Gabrielle Marceau, Joel P. Trachtman, “The Technical Barrier to Trade Agreement, the Sanitary and Phytosanitary Measures Agreement, and the General Agreement on Tariffs and Trade: A Map of the World Trade Organization Law of Domestic Regulation of Goods", Journal of World Trade, 36(5), 2002, p. 862; Gabrielle Marceau, Joel P. Trachtman, "A Map of the World Trade Organization Law of Domestic Regulation of Goods: The Technical Barriers to Trade Agreement, the Sanitary and Phytosanitary Measures Agreement, and the General Agreement on Tariffs and Trade”, Journal of World Trade, 48(2), 2014, pp. 351-432.

1072 For more information about the HACCP analysis see Section 2.3.2.5.1 of Chapter II.

1073 The regulation of production processes is frequently viewed as more effective in terms of risks management and control costs. Indeed, products sampling and testing may be expensive and cover a very limited share of a product consignment, while the control of production processes may create a much higher certainty. 
and similar process-based requirements in the SPS sphere could be viewed as product-related PPMs. ${ }^{1074}$

The objectives of an SPS measure, as described above, are directly relevant with respect to issues regarding the regulation of private-sector standards by the SPS Agreement. In order to qualify as an SPS measure under the SPS Agreement, a private-sector standard must, first of all, be aimed at the protection of life and health (as well as at the prevention or limitation of "other damage") from the specified risks. Moreover, the provisions of a private-sector standard shall be aimed at SPS protection within the territory of a WTO Member where it is applied.

The definition of an SPS measure in the SPS Agreement provides that a measure must be "applied to protect", or "applied to prevent". Of course it is, in the first place, a prerogative of a WTO Member to explain the objectives of its measure, i.e. whether they are SPS-related or not. However, full reliance on such explanations would sometimes entail unfair results. WTO Members would then be able to avoid judicial scrutiny under the SPS Agreement by providing "artificial" non-SPS-related objectives and concealing the real ones. This can, of course, not be allowed; and WTO panels and the Appellate Body, in the process of examining the objectives of a measure, take into consideration not only the objectives claimed directly by a WTO Member, but also all circumstances surrounding the adoption and application of a measure. In Australia - Apples the Appellate Body explained in this regard:

We note, in addition, that the word "applied" points to the application of the measure and, thus, suggests that the relationship of the measure and one of the objectives listed in Annex A(1) must be manifest in the measure itself or otherwise evident from the circumstances related to the application of the measure. This suggests that the purpose of a measure is to be ascertained on the basis of objective considerations. ${ }^{1075}$

The Appellate Body further noted that such an approach is indeed in line with the practice under the GATT 1994 where the purposes of a measure

1074 For more information about types of PPM and their regulation, see Section 3.3.6 of Chapter III and Section 4.1.1.4 of Chapter IV. See also: Christiane R. Conrad, Process and Production Methods (PPMs) in WTO Law. Interfacing Trade and Social Goals, CUP, 2011, pp. $420-421$.

1075 Appellate Body Report, Australia - Apples, para. 172; see also: Panel Report, Australia-Salmon, para.8.34; Appellate Body Report, Australia-Salmon, para. 200. In EC - Approval and Marketing of Biotech Products the Panel during examining the goals of the EU measures pointed to the "rational relationship" which must exist between a measure as such and its stated objective; see: Panel Report, EC - Approval and Marketing of Biotech Products, para. 7.2558. 
are determined based on its overall design, structure and architecture, ${ }^{1076}$ and finally concluded that:

Whether a measure is "applied ... to protect" in the sense of Annex $\mathrm{A}(1)$ (a) must be ascertained not only from the objectives of the measure as expressed by the responding party, but also from the text and structure of the relevant measure, its surrounding regulatory context, and the way in which it is designed and applied. For any given measure to fall within the scope of Annex $\mathrm{A}(1)(\mathrm{a})$, scrutiny of such circumstances must reveal a clear and objective relationship between that measure and the specific purposes enumerated in Annex A(1)(a). ${ }^{1077}$

To date, in the majority of SPS disputes, the determination of the purposes of a measure has been quite straightforward and based on the stated and intended objectives of a measure. For example, in EC - Hormones, all the parties agreed that the ban on hormone-treated meat was introduced by the EU with the objectives covered by subparagraph (b) of Annex A(1). ${ }^{1078}$ In Australia - Salmon, Australia did not contest that the ban on the importation of salmon from Canada (the complainant) and other countries was implemented within the quarantine regime and with SPS-related objectives. Australia submitted that the goals of its measure are covered by both subparagraph (a) and (b), while Canada argued that only subparagraph (a) was relevant. The Panel agreed with Canada and concluded:

We are of the view that, even though both definitions of a "sanitary measure" invoked by Australia might be applicable to the measure in dispute, the objectives for which that measure is being applied are more appropriately covered by the definition in paragraph 1(a). These objectives have been clearly expressed by Australia on several occasions. ${ }^{1079}$

Interestingly, in one of the relatively recent cases resolved by the Panel under the SPS Agreement, US - Poultry (China), the measure at issue had a budgetary character. Section 727 of the US Agencies Appropriations Act (AAA) of 2009 as enacted by the US Congress, provided that:

1076 The Appellate Body referred to "the design, the architecture and the revealing structure of a measure" when determining whether the Japanese tax measure was applied so "as to afford protection" under Article III:2 of the GATT 1994; see: Appellate Body Report, Japan - Alcoholic Beverages II, p.29. See also: Appellate Body Report, Chile - Alcoholic Beverages, paras. 71 - 72; Panel Report, CanadaPeriodicals, para.5.38; Panel Report, Korea-Alcoholic Beverages, para. 10.101.

1077 Appellate Body Report, Australia-Apples, para. 173.

1078 See: Panel Report, EC - Hormones (US), para. 8.21; Panel Report, EC - Hormones (Canada), para. 8.24.

1079 Panel Report, Australia-Salmon, para. 8.34. 
None of the funds made available in this Act may be used to establish or implement a rule allowing poultry products to be imported into the United States from the People's Republic of China. ${ }^{1080}$

This budgetary provision was adopted notwithstanding the fact that the import of poultry products from China had earlier been authorised by the relevant US authorities under the conditions of equivalence determination and the certification of production facilities. The explanatory statement accompanying Section 727 of the Act expressed the concerns of the US Congress with regard to the "contaminated foods from China" and, particularly, poultry products. ${ }^{1081}$ The Panel concluded that this budgetary measure was in fact adopted for SPS purposes:

In the Panel's view, Section 727 was enacted for the purpose of protecting human and animal life and health from the risk posed by the prospect of the importation of contaminated poultry products from China. Accordingly, the Panel concludes that Section 727 is a measure applied for the purpose set forth in Annex A(1)(b). ${ }^{1082}$

The provisions regarding the objectives of an SPS measure in subparagraphs (a) - (d) of Annex A(1) were examined thoroughly by the Panel for the first time in EC - Approval and Marketing of Biotech Products. The case was initiated by the US, Canada and Argentina with regard to the EU system of premarketing approval of biotech products, i.e. products consisting of GMOs. ${ }^{1083}$ However, this system of approval per se was not challenged by the complainants. ${ }^{1084}$ The three types of challenged EU measures were: the EU alleged a de facto moratorium on the approval of new biotech products; certain measures of the EU with respect to the approval of particular biotech products (product specific measures); and the bans imposed by six Member States of the EU on a number of biotech products which had already received premarketing approval at EU level (EU Members' safeguard measures). ${ }^{1085}$

\footnotetext{
1080 Panel Report, US - Poultry (China), para. 2.2.

1081 See: Panel Report, US - Poultry (China), paras. 2.3 - 2.32.

1082 Panel Report, US - Poultry (China), para. 7.115.

1083 This system was adopted and maintained according to the Council Directive 90/220/EEC and, subsequently, according to the Directive 2001/18/EC concerning the deliberate release of biotech products into environments and, according to the Regulation 258/97 of the European Parliament and the Council, concerning novel foods and novel food ingredients.

1084 This is most likely the case because the complainants themselves, as well as many other WTO Members, have their own domestic system of premarketing approval of different products, such as chemicals, drugs, etc.

1085 See: Panel Report, EC - Approval and Marketing of Biotech Products. Of course, this
} 
In considering the dispute, the Panel had to determine whether these three types of measures constituted SPS measures under the SPS Agreement. It was thus necessary to identify whether these measures were used for the purposes enumerated in subparagraphs (a) - (d) of Annex $\mathrm{A}(1)$. In the process of determination, the Panel had to engage in interesting discussions related to the interpretation of these provisions of the SPS Agreement in terms of their applicability to GMOs. ${ }^{1086}$ In particular, for example, the Panel considered whether the term "animal or plant life or health" in subparagraph (a) included the life or health of micro-organisms, which comprise a part of all ecosystems and which could be affected by the introduction of GMOs. This question was answered positively by the Panel. ${ }^{1087}$ Referring to the same subparagraph of the definition of an SPS measure, the Panel concluded that the term "pests" covers cultivated GM plants if they grow in undesired places, or cross-breed with other plants and introduce undesired traits, like pesticide resistance or increased fertility. Moreover, the phrase "“'establishment or spread of pests”, according to the Panel, includes the process of spreading of an already existing pest to new territories after cross-breeding with GMOs and gaining more

is a rather simplified description of the circumstances of the case. EC - Approval and Marketing of Biotech Products may be regarded as one of the most complicated WTO disputes. This is reflected in the unprecedented size of the Panel Report which comprises almost 900 pages. For more information on the case and GMOs, see: Christiane R. Conrad, "PPMs, the EC-Biotech Dispute and Applicability of the SPS Agreement: Are the Panel's Findings Built on Shaky Ground?”, Research Paper No. 8-06, Hebrew University, Jerusalem, August 2006; Denise Prévost, "Opening Pandora's Box: The Panel's Findings in the EC - Biotech Products Dispute”, Legal Issues of Economic Integration, 34(1), 2007, pp. 67 - 101; Tracey Epps, International Trade and Health Protection. A Critical Assessment of the WTO's SPS Agreement, Edward Elgar, Cheltenham, UK, 2008, pp. 218 - 222; Lukasz Gruszczynski, Regulating Health and Environmental Risks under WTO Law. A Critical Analysis of the SPS Agreement, Oxford University Press, Oxford, 2010, pp. 53 - 62; Stuart Smyth, Peter W.B. Phillips, William A. Kerr, "Global Governance Quandaries Regarding Transformative Technologies for Bioproducts, Crops, and Foods", Journal of World Trade, 43(6), 2009, pp. 1299 - 1323.

1086 Interestingly, in this case the Panel used a rather unusual methodology. Instead of taking each measure (or part of the measure) and examining it in terms of the subparagraph (a) - (d) to which it may correspond, the Panel examined the provisions of each subparagraph in order to identify whether it fits into the purposes of the EU measures. Such an approach may have been prompted by the high complexity of the measures which, as was finally ruled by the Panel, included all the objectives enumerated in subparagraphs (a) - (d). See: Christiane R. Conrad, "PPMs, the EC-Biotech Dispute and Applicability of the SPS Agreement: Are the Panel's Findings Built on Shaky Ground?", Research Paper No. 8-06, Hebrew University, Jerusalem, August 2006; see also: Denise Prévost, Balancing Trade and Health in the SPS Agreement: The Development Dimension, Wolf Legal Publishers, Nijmegen, 2009, p. 521.

1087 See: Panel Report, EC - Approval and Marketing of Biotech Products, paras. 7.219 -7.220 . 
resistance. ${ }^{1088}$ Under subparagraph (b), the Panel ruled that the term "food, beverages or feedstuffs" does not only cover food and drink products intended for consumption by humans or animals, but also everything that may be eaten in principle, including undesired GM crops. Under the same paragraph the term "additives" was interpreted to include genetic modification (added genes), and the term "contaminants" was interpreted to encompass the organic mass produced by GMOs. ${ }^{1089}$ Under subparagraph (c), the Panel found that "pests", within the meaning of the subparagraph, need not definitely be living and may also encompass harvested plants, which may potentially cause allergenic effects during harvesting, transportation or processing. ${ }^{1090}$

Even more interesting and debatable were the Panel's findings with respect to subparagraph (d). The Panel concluded that the term "other damage" in this subparagraph could include not only direct economic and material damages, but also ecological damage to the environment, including non-living components thereof, such as biodiversity, geochemical cycles, carbon and nitrogen recycling, etc. ${ }^{1091}$ In concluding this, the Panel arguably adopted quite an expansive interpretation of subparagraph (d), thus enabling the SPS Agreement to cover a range of measures aimed at the protection of the environment. These conclusions are indeed quite controversial. In particular, as has been argued by the respondent (the EU) in this case, such a broad interpretation of subparagraph (d) may go against the negotiating history of the SPS Agreement. ${ }^{1092}$ Moreover, such an approach seems to blur the distinction between an SPS measure under the SPS Agreement and the measures covered by the TBT Agreement, e.g. a technical regulation. ${ }^{1093}$

1088 See: Panel Report, EC - Approval and Marketing of Biotech Products, paras. 7.232 -7.244 .

1089 See: Panel Report, EC - Approval and Marketing of Biotech Products, paras. 7.292 7. 313 .

1090 See: Panel Report, EC - Approval and Marketing of Biotech Products, para. 7.351.

1091 See: Panel Report, EC - Approval and Marketing of Biotech Products, paras. 7.369 -7.373 .

1092 The EU pointed out that, during negotiations on the SPS Agreement, discussions took place whether to include environmental protection into the list of possible objectives of an SPS measure. The final outcome was the omission of the text which expressly included such objectives; see: Panel Report, EC - Approval and Marketing of Biotech Products, para. 7.199.

1093 Indeed, Article 2.2 of the TBT Agreement mentions the protection of the environment as one of the possible legitimate objectives for technical regulations. Protection of the environment is also referred to in the Preamble of the TBT Agreement. For more information about the measures covered by the TBT Agreement and about its Article 2.2, see Sections 4.1.1 and 4.3.2 of Chapter IV. 
As a result of such a broad interpretation, the Panel found that almost all of the objectives of European legislation on approval and marketing of biotech products were covered by subparagraphs (a) - (d) of the definition of an SPS measure. ${ }^{1094}$ Only with respect to the EU Regulation concerning novel foods and food ingredients did it determine that two out of three objectives of this Regulation fell outside of the SPS Agreement. ${ }^{1095}$

This broad approach to the interpretation of the objectives of an SPS measure under subparagraphs (a) - (d) is met with a certain amount of criticism in the relevant literature. ${ }^{1096}$ For example, it has been argued that the Panel "went beyond the internationally-agreed upon definitions of the pertinent terms developed by the relevant international standard-setting bodies referred to in the SPS Agreement". ${ }^{1097}$ Instead, the Panel often used the ordinary meanings of the terms taken from a dictionary. ${ }^{1098}$ It could therefore be argued that the Panel did not follow the general rules on treaty interpretation as provided in Article 31 of the VCLT that, although the words of a treaty must be interpreted according to their ordinary meaning, they

1094 Interestingly, in EC - Approval and Marketing of Biotech Products, the Panel decided to cover all of subparagraphs from (a) to (d) of Annex A(1) in its analysis. It would seem that the Panel wanted to put as many arguments forward as it could to demonstrate the SPS nature of the European measures with respect to biotech products. In this regard, for example, the Panel in Australia - Salmon chose to deal only with subparagraph (a) as it was more appropriate to cover the measure at issue, although subparagraph (b) was found to be relevant as well. See: Panel Report, Australia - Salmon, para. 8.34, as discussed above.

1095 These two objectives were to prevent the misleading of consumers with regard to biotech products and to ensure that such products are not nutritiously disadvantageous. The third objective of ensuring the safety of biotech products for consumers was found to be within the scope of an SPS measure under the SPS Agreement; see: Panel Report, EC - Approval and Marketing of Biotech Products, paras. $7.415-7.416$.

1096 For example, see: Joanne Scott, The WTO Agreement on Sanitary and Phytosanitary Measures. A Commentary, Oxford University Press, Oxford, 2007, pp. 14-16; Christiane R. Conrad, "PPMs, the EC-Biotech Dispute and Applicability of the SPS Agreement: Are the Panel's Findings Built on Shaky Ground?", Research Paper No. 8-06, Hebrew University, Jerusalem, August 2006, p. 10 - 21; Denise Prévost, Balancing Trade and Health in the SPS Agreement: The Development Dimension, Wolf Legal Publishers, Nijmegen, 2009, pp. 522 - 528; Jacqueline Peel, "A GMO by Any Other Name ... Might Be an SPS Risk!: Implications of Expanding the Scope of the WTO Sanitary and Phytosanitary Measures Agreement”, European Journal of International Law, 17(5), 2007, pp. 1015 - 1018.

1097 Denise Prévost, Balancing Trade and Health in the SPS Agreement: The Development Dimension, Wolf Legal Publishers, Nijmegen, 2009, p. 522. See also: Denise Prévost, "Opening Pandora's Box: The Panel's Findings in the EC - Biotech Products Dispute”, Legal Issues of Economic Integration, 34(1), 2007, p. 75.

1098 For example, Lukas z Cruszczynski writes about Panel's "over-reliance on the dictionary meaning of the terms”; see: Lukasz Gruszczynski, Regulating Health and Environmental Risks under WTO Law. A Critical Analysis of the SPS Agreement, Oxford University Press, Oxford, 2010, p. 61. 
should be taken in their context and in the light of the object and purpose of the treaty. ${ }^{1099}$ Indeed, the SPS Agreement, according to its negotiation history, is intended to deal with a limited set of measures. ${ }^{1100}$ Traditionally, SPS measures are aimed at dealing with the specific health risks related to food or the spread of pests and diseases. The risks related to the broad range of ecological and environmental issues, such as biodiversity and geochemistry, were, arguably, not intended to be included into the scope of the SPS Agreement. It is doubtful that the specific and strict scientific disciplines of the SPS Agreement are appropriate for the regulation of such a broad set of issues.

It would seem, then, that the delimitation of the possible goals of an SPS measure under the SPS Agreement (and therefore the delimitation of the scope of application of the SPS Agreement as such) appears to be one of the challenges for the functioning of the Agreement in future. With the development of science and technology, and with the increasing anthropogenic impact on nature with production processes and novel substances, this issue has become very complex. In such matters as, for example, the introduction of GMOs, cloning, and global warming, the possible environmental and ecological risks may also materialize as risks to particular ecosystems which include particular species of animals and plants. This may also entail substantial and direct economic damages for WTO Members in such spheres as, for instance, tourism and agriculture.

It will thus be for the WTO panels and the Appellate Body to decide, based on the circumstances of each particular case, whether certain measures may be covered by the definition of an SPS measure according to the SPS Agreement. The main issue in this regard seems to be whether a measure is sufficiently related to the objectives specified in subparagraphs (a) (d) (i.e. aimed at these objectives); or whether this relationship, if exists at

1099 See: Denise Prévost, Balancing Trade and Health in the SPS Agreement: The Development Dimension, Wolf Legal Publishers, Nijmegen, 2009, pp. 522 - 523; Christiane R. Conrad, "PPMs, the EC-Biotech Dispute and Applicability of the SPS Agreement: Are the Panel's Findings Built on Shaky Ground?”, Research Paper No. 8-06, Hebrew University, Jerusalem, August 2006, pp. 18 - 19.

1100 Jacqueline Peel, "A GMO by Any Other Name ... Might Be an SPS Risk!: Implications of Expanding the Scope of the WTO Sanitary and Phytosanitary Measures Agreement", European Journal of International Law, 17(5), 2007. See also: Doaa Abdel Motaal, "The "Multilateral Scientific Consensus" and the World Trade Organization", Journal of World Trade, 38(5), 2004, p. 856; Laurence Boisson de Chazournes, Makane Moïse Mbengue, "GMOs and Trade: Issues at Stake in the EC Biotech Dispute", Review of European Community and International Environmental Law, 13(3), 2004, p. 295; Denise Prévost, Balancing Trade and Health in the SPS Agreement: The Development Dimension, Wolf Legal Publishers, Nijmegen, 2009, p. 525; Lukasz Gruszczynski, Regulating Health and Environmental Risks under WTO Law. A Critical Analysis of the SPS Agreement, Oxford University Press, Oxford, 2010, pp. 56 - 57. 
all, is too remote. The future will reveal whether a clearer test in this respect will be developed by the WTO dispute settlement system.

\subsection{Other Substantive Criteria for an SPS Measure}

Besides being aimed at the specified objectives, an SPS measure must also fulfil other appropriate substantive criteria. These criteria are provided in the second paragraph of the definition of an SPS measure in Annex A(1), according to which SPS measures shall "include all relevant laws, decrees, regulations, requirements and procedures". The text of the second paragraph further provides an open illustrative list ${ }^{1101}$ of the measures and types of issues that they may address, e.g. end product criteria, processes and production methods, testing, inspection, certification, packaging and labelling requirements, etc. This list demonstrates that the scope of an SPS measure may include a broad range of legal, procedural, administrative and technical rules.

The meaning of the second paragraph of the definition of an SPS measure was examined in detail for the first time in EC-Approval and Marketing of Biotech Products. The Panel determined that there were, generally, three elements of an SPS measure according to the definition. Thus, in addition to 1. the purpose of a measure as enumerated in subparagraphs (a) - (d), an SPS measure must satisfy the criteria of: 2. the legal form of the measure ("all relevant laws, decrees, regulations"), and 3. the nature of the measure ("requirements and procedures including [specified examples]"). According to the Panel, all three elements had to be in place in order to establish that a measure at hand was an SPS measure. ${ }^{1102}$

With respect to the second element, the form, the Panel recognized its broad character, which could include a variety of possible types of measures. It noted that, due to the use of the word "include", "the reference to "laws, decrees [and] regulations" should not be taken to prescribe a particular legal form". ${ }^{103}$ The Panel found that all three types of the EU measures (de facto moratorium, the EU product specific measures and the EU Member States' safeguard measures) fulfilled this second criterion of the form. ${ }^{1104}$

However, a different conclusion was made with respect to the third element, the nature of a measure, which the Panel regarded as a key element for

1101 This is demonstrated by use of the terms "including" and "inter alia".

1102 See: Panel Report, EC - Approval and Marketing of Biotech Products, para. 7.149.

1103 Panel Report, EC - Approval and Marketing of Biotech Products, paras. 7.422 -7.423 .

1104 See: Panel Report, EC - Approval and Marketing of Biotech Products, paras. 7.423, $7.2598-7.2913$. 
the analysis. ${ }^{1105}$ In this regard, the Panel found that the EU de facto moratorium on the approval of biotech products, as well as its product specific measures, were not "requirements" or "procedures" as provided in the second paragraph of the definition of Annex A(1). ${ }^{1106}$ Instead, the Panel qualified them as the "application" of approval procedures which were not covered by the definition of an SPS measure. ${ }^{1107}$ Thus, according to the Panel's final findings, such an "application" was captured by Annex C of the SPS Agreement, "Control, Inspection and Approval Procedures". ${ }^{1108}$ The Panel therefore concluded that the de facto moratorium and the EU product specific measures failed to meet the third criterion of the nature of a measure, and were not SPS measures within the meaning of the SPS Agreement.

Only with respect to the nine safeguard measures applied by the EU Member States did the Panel find that they qualified as SPS measures under the SPS Agreement. In this regard, the Panel noted that the safeguard measures imposed a ban on the importation of certain biotech products which shall be regarded as a "requirement" within the meaning of the second paragraph of Annex A(1):

Furthermore, in respect of the nature of SPS measures, we have indicated earlier that the reference in the same paragraph to "requirements" is broad and unqualified. Hence, both an authorization to market a particular product and a ban on the marketing of a particular product may be considered as "requirements". The second example would constitute a negative requirement. ${ }^{1109}$

1105 See: Panel Report, EC - Approval and Marketing of Biotech Products, para. 7.1338.

1106 See: Panel Report, EC - Approval and Marketing of Biotech Products, paras. 7.1338 -7.1378 .

1107 The Panel rejected the arguments that the failure to consider the new applications for approval of biotech products constitutes a de facto ban on these products. It also disagreed with the argument that this failure could be regarded as a "procedure" within the meaning of the second paragraph of the definition of an SPS measure. The Panel noted that the pre-marketing approval system itself constituted a provisional ban on the biotech products which were not approved. Thus, the Panel viewed the de facto moratorium and the EU product specific measures as a decision to delay the final approval of biotech products. See: Panel Report, EC - Approval and Marketing of Biotech Products, paras. 7.1690 - 7.1697 (with regard to the US arguments), 7.1701 - 7.1704 (with regard to the Canada's arguments), 7.1711 7.1712 (with regard to the Argentina's arguments).

1108 The Panel finally found that the de facto moratorium and the product specific measures were inconsistent with the obligations under Annex C(1)(a) to undertake and complete the approval procedures "without undue delay", and thus also inconsistent with Article 8 of the SPS Agreement, which mandates Annex C, see: Panel Report, EC - Approval and Marketing of Biotech Products, paras. 8.34(a), 8.38(a).

1109 Panel Report, EC - Approval and Marketing of Biotech Products, para. 7.2597. It is interesting to compare these conclusions of the Panel with the ruling of the 
The approach taken by the Panel was "somewhat surprising". ${ }^{1110}$ In particular, the distinction between the form and nature of an SPS measure does not follow from the text in the SPS Agreement, i.e. the terms "all relevant laws, decrees, regulations, requirements and procedures" are not divided into two groups by a conjunction or otherwise. Moreover, it seems that the imposition of the nature requirement encompassing only the "requirements and procedures" could, arguably, allow WTO Members to avoid the disciplines of the SPS Agreement through the use of various "creative" practices, including moratoriums, the non-implementation of laws and procedures, etc. Finally, the conclusions of the Panel with respect to the nature criterion, arguably, did not logically correspond to the structure and scope of the SPS Agreement. The Panel finally found, with regard to the EU de facto moratorium and product specific measures, that these measures violated the provisions of Annex C, "Control, Inspection and Approval Procedures", and in particular its paragraph 1(a) obliging Members to undertake and complete the approval procedures "without undue delay". Annex C is incorporated into the SPS Agreement through Article 8 and may be applicable only to SPS measures and, moreover, only to a specific type of SPS measure, namely "control, inspection and approval procedures". Therefore, it was quite odd for the Panel to make the findings concerning the "undue delay" without determining first that the measure at issue actually was an SPS measure.

Although the approach to include the determination of both the form and nature of an SPS measure was initially followed by the two panels, ${ }^{1111}$ this approach was, rightly, abandoned in the subsequent rulings of panels and the Appellate Body. In Australia - Apples, the Panel noted that "the second paragraph of Annex A(1) sets out elements of the definition of SPS measures by providing examples". ${ }^{112}$ According to the Panel, the list of examples of the "relevant laws, decrees, regulations, requirements and procedures" should be regarded as purely illustrative, broad and non-exhaustive. ${ }^{1113}$ The

Appellate Body in EC - Asbestos, that a product ban as such does not constitute a technical regulation under the TBT Agreement as it does not specify product characteristics; see: Appellate Body Report, EC - Asbestos, para. 71. See also Section 4.1.1.1 of Chapter IV.

1110 Joanne Scott, The WTO Agreement on Sanitary and Phytosanitary Measures. A Commentary, Oxford University Press, Oxford, 2007. See also: Denise Prévost, "Opening Pandora's Box: The Panel's Findings in the EC - Biotech Products Dispute”, Legal Issues of Economic Integration, 34(1), 2007, pp. 75 - 76; Denise Prévost, Balancing Trade and Health in the SPS Agreement: The Development Dimension, Wolf Legal Publishers, Nijmegen, 2009, pp. 529 - 530.

1111 These two panels were basically established for the same case, see: Panel Report, Canada-Continued Suspension, para. 7.420; Panel Report, US - Continued Suspension, para. 7.429.

1112 Panel Report, Australia - Apples, para. 7.144.

1113 See: Panel Report, Australia - Apples, para. 7.151. 
Panel finally concluded that there is no clear reason for distinguishing between the form and the nature of a measure when interpreting the definition of an SPS measure:

In sum, the form and nature elements in the definition of SPS measures in Annex A(1) are both broad, and they are closely connected to each other. ${ }^{1114}$

This conclusion was confirmed by the Appellate Body, which upheld the analysis of the Panel and stated:

The use of both "including" and "inter alia" emphasizes that the list is only indicative. The list itself covers a broad range of measures that are identified with varying degrees of specificity. To us, it is a list of examples of measures that may fall within the definition of an SPS measure, provided always that the measure manifests a clear and objective relationship with (is "applied" for) at least one of the purposes set out in subparagraphs (a) through (d). ${ }^{1115}$

In US - Poultry (China) the Panel also disagreed with the separate treatment of the form and the nature criteria of an SPS measure undertaken in EC - Approval and Marketing of Biotech Products ${ }^{1116}$. The Panel came to the following conclusions:

In our view, the nature of a measure is an intrinsic element of its form. Therefore, reading the second part of Annex A(1) as a whole, means that an examination of whether a measure is of the type set forth in Annex A(1) will encompass an holistic examination of the measure, including, both its form and nature. ${ }^{1117}$

\subsection{SPS Measures: Voluntary vs. Mandatory}

The distinct application of the form and the nature criteria, as well as the restrictive interpretation of the definition of an SPS measure based on the nature criterion, has been ruled out by the latest decisions of panels and the Appellate Body. However, the interpretation of the second paragraph of Annex A(1) still leaves a number of unanswered questions. It is clear that the illustrative list of SPS measures in this paragraph is an open one and has a broad character. The question therefore is: does it contain any specific criteria for an SPS measure at all? For example, does it contain the criterion

\footnotetext{
1114 Panel Report, Australia-Apples, para. 7.153.

1115 Appellate Body Report, Australia-Apples, para. 176.

1116 See: Panel Report, US - Poultry (China), paras. 7.99 - 7.100

1117 Panel Report, US - Poultry (China), para. 7.101.
} 
that a measure shall be mandatory for compliance? Does an SPS measure under the SPS Agreement cover provisions of soft-law, codes of practices, voluntary labelling schemes and standards, whether governmental or nongovernmental? Or does the SPS Agreement cover only mandatory measures, such as laws, regulations, and rules of procedure? Moreover, even if the SPS Agreement only extends to mandatory measures, does this mean that SPS measures must be mandatory de jure, or may they also be mandatory de facto due to governmental support or incentives, or perhaps even due to free market forces, e.g. the demands of business entities in supply chains or the demands of consumers? These questions are very relevant with respect to SPS-related standards in general, and private-sector standards in particular.

These questions are not easy to answer. As has been discussed in Chapter IV, the TBT Agreement explicitly covers "standards", which are defined as the documents "with which compliance is not mandatory". ${ }^{1118}$ On the contrary, the SPS Agreement does not address voluntary measures separately. ${ }^{1119}$ Moreover, the differences in the wording of the definition of a standard in the TBT Agreement and the definition of an SPS measure in the SPS Agreement, are clearly noticeable. While the definition of a standard in the TBT Agreement refers to a "document $[\ldots]$ that provides $[\ldots]$ rules, guidelines or characteristics for products or related processes and production methods", the definition of an SPS measure refers to "all relevant laws, decrees, regulations, requirements and procedures". Such wording in the definition of an SPS measure in Annex A(1) of the SPS Agreement seems to have the connotation of a mandatory type of measure (i.e. mandatory either in law, or in practice due to substantial governmental incentives). In fact, the Oxford English Dictionary defines the terms used in the definition of an SPS measure as binding to a certain degree and as having an authoritative character. ${ }^{1120}$

The negotiation history of the SPS Agreement does not provide much information in this regard either. During the Uruguay Round negotiations,

1118 See the definition of standard in Annex 1(2) of the TBT Agreement; see also Section 4.1.1.2 of Chapter IV.

1119 See: Petros C. Mavroidis, Trade in Goods. The GATT and the Other WTO Agreements Regulating Trade in Goods, OUP, Oxford, 2012, p. 709.

${ }_{1120}$ Law - the body of rules, whether proceeding from formal enactment or from custom, which a particular state or community recognizes as binding on its members or subjects. Decree - an ordinance or edict set forth by the civil or other authority; an authoritative decision having the force of law. Regulation - a rule or principle governing behaviour or practice; esp. such a directive established and maintained by an authority. Procedure - the fact or manner of proceeding with any action... Also: the established or prescribed way of doing something. See: Oxford English Dictionary Online, available at: http://www.oed.com (last visited January $15,2015)$. 
the negotiating parties were mainly concerned with binding governmental SPS measures which served as barriers to the importation or marketing of products. Arguably, voluntary measures in the SPS sphere, such as privatesector standards, were not widespread at that time and, as such, did not present a serious concern. ${ }^{1121}$ However, this fact per se may indicate that an SPS measure under the SPS Agreement was originally not meant to cover those measures which are voluntary both in law and in practice. ${ }^{1122}$

It seems that one of the relatively recent cases, Australia - Apples, may, to certain extent, be useful in this regard. The case was brought to the WTO by New Zealand concerning Australia's quarantine measures on the importation of apples from New Zealand. The 16 Australian measures at issue were aimed at preventing the introduction of fire blight, European canker and the apple leafcurling midge into Australian territory. These measures were provided in Australia's Final Import Risk Analysis Report for Apples (IRA) from New Zealand prepared by an independent commission and issued by the Australian State agency, Biosecurity Australia. ${ }^{1123}$ The IRA Report as such had a recommendatory character. However, because the Report was incorporated into the official and mandatory memorandum on the Australian bio-security policy, the Panel concluded that the IRA Report shall be regarded as a "regulation" within the meaning of the definition of an SPS measure:

The above also demonstrates that Australia's policy for the importation of apples from New Zealand, including the IRA, was adopted in an official manner, within the framework, and on the basis of, established legal instruments. In particular, the IRA was issued by the "Chief Executive of Biosecurity Australia", a "part of the Commonwealth Department of Agriculture, Fisheries and Forestry - Australia", and under the seal of the Australian Government...

All these characteristics accord a significant degree of legal formality to the IRA and liken it to a "regulation" under Annex $A(1)$, even if the IRA is not formally termed as such and even though it only "recommends" measures. Through Biosecurity Australia Policy Memorandum 2007/7, and by virtue of the more

1121 See: Private Voluntary Standards within the WTO Multilateral Framework: Submission by the United Kingdom. A report prepared by Digby Gascoine and O'Connor and Company, WTO, SPS Committee, G/SPS/GEN/802, Geneva, 9 October 2007, para. 25.

1122 This point of view seems to be shared by Joanne Scott, who writes: "For the SPS Agreement $[\ldots]$ genuinely voluntary measures would anyway fall outside the scope of the agreement"; see: Joanne Scott, The WTO Agreement on Sanitary and Phytosanitary Measures. A Commentary, Oxford University Press, Oxford, 2007, pp. 33, 34 .

1123 See: Panel Report, Australia - Apples, paras. 2.26 - 2.33. 
general legal framework referenced in the IRA, the measures recommended by the IRA have become part of Australia's applicable and enforceable legal "policy for the importation of apples from New Zealand". ${ }^{124}$

The Panel also agreed with the argument of New Zealand that "each of the 16 measures requires New Zealand or its apple producers, packing houses and traders to do something as a condition for New Zealand apples to have access to the Australian market". ${ }^{1125}$ In its analysis, the Panel placed some emphasis on the implementation of the IRA Report into Australia's legislative framework, which made it binding. ${ }^{1126}$ Thus, the reasoning of the Panel seems to hint at the fact that a purely "recommendatory" measure, both in law and in practice, would hardly qualify as an SPS measure under the SPS Agreement.

In an earlier case resolved under the provisions of the SPS Agreement, Japan-Agricultural Products II, Japan did not contest the assertions of the US that certain Japanese plant protection rules constituted SPS measures within the meaning of the SPS Agreement. ${ }^{1127}$ Interestingly, however, these rules included two de jure non-mandatory documents devoted to varietal testing requirements and fumigation developed by the Japanese governmental authorities, called "Experimental Guides". ${ }^{1128}$ However, the issue of the non-mandatory character of one of the Experimental Guides came up in the determination of whether the Guide could be qualified as an "SPS regulation"1129 under Annex B(1) of the SPS Agreement, "Transparency of Sanitary and Phytosanitary Regulations". Japan argued that the Experimental Guide was not a legally mandatory measure and could therefore not be regarded as an SPS regulation. ${ }^{1130}$ The Panel disagreed and noted:

Even though the varietal testing requirement is not mandatory in that exporting countries can demonstrate quarantine efficiency by other means - in our view, it does constitute a "phytosanitary

\footnotetext{
1124 Panel Report, Australia - Apples, paras. 7.157 - 7.158.

1125 Panel Report, Australia - Apples, paras. 7.161 - 7.163.

1126 This aspect of the Panel's reasoning was not appealed by Australia. However, in general the Appellate Body upheld the conclusions of the Panel that Australia's measures were SPS measures under the SPS Agreement; see: Appellate Body Report, Australia-Apples, paras. 170 - 184.

1127 See: Panel Report, Japan - Agricultural Products II, para. 8.12.

1128 See: Panel Report, Japan - Agricultural Products II, paras. 2.23 - 2.24, 8.3.

1129 Undoubtedly, the SPS regulation is a type of the SPS measure within the meaning of the SPS Agreement. For more information about the definition of the SPS regulation and the obligations regarding transparency according to Annex B of the SPS Agreement, see Section 5.3.5.3 of the present Chapter.

1130 See: Panel Report, Japan - Agricultural Products II, para. 8.106.
} 
regulation" subject to the publication requirement in Annex B. The footnote to paragraph 1 of Annex B refers in general terms to "phytosanitary measures such as laws, decrees or ordinances". Nowhere does the wording of this paragraph require such measures to be mandatory or legally enforceable. Moreover, Paragraph 1 of Annex A to the SPS Agreement makes clear that "phytosanitary measures include all relevant laws, decrees, regulations, requirements and procedures". It does not, in turn, require that such measures be mandatory or legally enforceable. The interpretation that measures need not be mandatory to be subject to WTO disciplines is confirmed by the context of the relevant SPS provisions, a context which includes provisions of other WTO agreements and the way these provisions define "measure", "requirement" or "restriction", as interpreted in GATT and WTO jurisprudence. This context indicates that a non-mandatory government measure is also subject to WTO provisions in the event compliance with this measure is necessary to obtain an advantage from the government or, in other words, if sufficient incentives or disincentives exist for that measure to be abided by. ${ }^{1131}$

The Panel finally concluded that Japan violated the provisions of Annex $\mathrm{B}(1)$ by not publishing the Experimental Guide with varietal testing requirements. These conclusions of the Panel were later appealed by Japan and upheld by the Appellate Body. ${ }^{1132}$

In reaching its conclusions in Japan-Agricultural Products II, the Panel referred to the context of the relevant SPS provisions which, according to the Panel, included other WTO agreements and the relevant GATT and WTO jurisprudence, i.e. cases resolved under the GATT 1947 and 1994, such as Japan-Film, Japan - Semi-Conductors, EEC - Parts and Components. ${ }^{1133}$ As has been explained in Section 3.1.1 of Chapter III, similarly to the SPS Agreement, the GATT 1994 does not clearly provide for whether it covers only mandatory measures, or voluntary ones as well. And in this regard, the GATT and the WTO panels clarified that it is not possible to make a bright line distinction between mandatory and voluntary measures which would be suitable for all kinds of situations. Such a decision may be and shall be based on the circumstances of each particular case, including the regulatory environment of a particular WTO Member involved. In fact, a legally voluntary measure may become more or less de facto mandatory due to sufficient governmental involvement or incentives provided for its adoption

1131 Panel Report, Japan - Agricultural Products II, para. 8.111.

1132 See: Panel Report, Japan - Agricultural Products II, paras. 8.114- 8.115; See: Appellate Body Report, Japan - Agricultural Products II, paras. 105 - 108.

1133 See: Panel Report, Japan - Agricultural Products II, para. 8.111, footnote 346. 
and implementation. ${ }^{1134}$ The relevant conclusions of the Panel in Japan Agricultural Products II are therefore fully in line with the relevant WTO dispute settlement jurisprudence under the GATT.

Such an approach, of course, has important consequences for the issue of application of the SPS Agreement to such voluntary measures as standards in general, and private-sector standards in particular. Even with respect to public standards (e.g. those adopted by officially recognized NSBs which have a governmental or non-governmental nature), it seems that the mere fact that these standards were developed and adopted by governmental or other public institutions will not suffice. ${ }^{1135}$ Arguably, the sufficient level of governmental involvement or incentives, whether in law or in practice, for the application and implementation of such standards (thus, rendering them de facto mandatory) will be necessary in order to qualify the provisions of these standards as SPS measures. This seems to be true also with respect to private-sector standards developed and adopted by private entities. Arguably, the "purely" private-sector standards adopted and applied without meaningful governmental involvement or incentives could therefore not be regarded as SPS measures under the SPS Agreement. According to such an approach, the argument that a private-sector standard may appear to become de facto mandatory due to demands by a majority of market players, would not work unless it is established that sufficient governmental involvement or incentives for such demands were provided.

Indeed, making the distinction between mandatory SPS measures and voluntary measures may prove to be more complicated in cases of product labelling. In fact, the second paragraph of the definition of an SPS measure in Annex A(1) provides that "packaging and labelling requirements directly related to food safety" may constitute an SPS measure. This, at least, is quite clear with respect to mandatory SPS-related labelling requirements. At the same time, it seems that, in line with the discussion above, "purely" voluntary labelling recommendations provided for SPS-related reasons may not be regarded as SPS measures. However, and especially in case of marking or labelling, it is necessary to distinguish between the "voluntary" or "mandatory" character of a measure and the possibility of importing and marketing a product. In this respect, as has been explained by the Appellate

1134 See: GATT Panel Report, Japan - Agricultural Products I, p. 242; GATT Panel Report, Canada-FIRA, para. 5.4; GATT Panel Report, EEC -- Parts and Components, para. 5.21; GATT Panel Report, Japan - Semi-Conductors, paras. 102 - 117, 154 - 155; Panel Report, Japan - Film, paras. 10.43 - 10.51. For more information see also Section 3.1.1 of Chapter III.

1135 Indeed, as has been noted by the Panel Japan-Film, "it is also true that not every utterance by a government official or study prepared by a non-governmental body at the request of the government or with some degree of government support can be viewed as a measure of a Member government"; see: Panel report, Japan-Film, para. 10.43 . 
Body in US - Tuna II (Mexico) in the context of considering the definition of a technical regulation under the TBT Agreement, the "voluntary" or "mandatory" character of a measure is not determined by whether or not the product may be placed for sale on a particular market. ${ }^{1136}$ By analogy with the circumstances of US - Tuna II (Mexico), ${ }^{1137}$ it is possible that together with an SPS-related labelling scheme, which is not mandatory for marketing of a product, a WTO Member may introduce certain rules enforcing such a scheme and prohibiting the usage of alternative or similar labelling. For example, a governmental regulation may prohibit the use of labels claiming "good for your health" for food products containing GMOs and allowing this prerogative only for products without GMOs and certified under this labelling scheme. Thus, although such a regulation does not prohibit the marketing of products containing GMOs per se, it would establish the mandatory criteria for using the label and could, as a result, be treated as an SPS measure adopted and applied by a WTO Member.

In concluding the discussion of the definition of an SPS measure in the SPS Agreement, it could be observed that the definition of an SPS measure, taken together with the dispute settlement practice in this regard, seems to be rather unfavourable for the possibility of coverage of private-sector standards by the SPS Agreement. This at least seems to be the case if such standards are fully voluntary for market players and are thus adopted and applied without meaningful governmental involvement or incentives.

\subsubsection{Measures Affecting International Trade}

According to its Article 1.1, the SPS Agreement is applicable only to the SPS measures "which may, directly or indirectly, affect international trade". The wording of this requirement appears to be very broad and is unlikely to substantially limit the scope of application of the SPS Agreement. As has been noted by the Panel in EC-Approval and Marketing of Biotech Products, "it is not necessary to demonstrate that an SPS measure has an actual effect on trade"; it is only required that an SPS measure actually or potentially affects international trade. ${ }^{1138}$ An SPS measure may affect international trade "directly or indirectly", which might not be clearly distinguishable on many occasions. For example, in US - Poultry (China), the Panel, while

\footnotetext{
1136 See: Appellate Body Report, US - Tuna II (Mexico), para. 196.

1137 In US - Tuna II (Mexico), the Panel and the Appellate Body considered the US measures providing for the conditions, under which tuna products sold in the US could be labelled as "dolphin safe" and which prohibited all other labels claiming "dolphin safety" of tuna products. For more information about US - Tuna II (Mexico) and the mandatory character of a technical regulation under the TBT Agreement, see Section 4.1.1.1 of Chapter IV.

1138 Panel Report, EC - Approval and Marketing of Biotech Products, para. 7.435. See also: Panel Report, US - Poultry (China), para. 7.89.
} 
considering the US budgetary measure prohibiting public expenditure on the approval of importation of Chinese poultry, concluded that:

In the Panel's view, Section 727 did affect international trade because it prohibited the FSIS from using appropriated funds for the establishment and implementation of a rule allowing the importation of poultry products from China. Whether a measure affects international trade directly or indirectly depends on how one views it. The Panel notes that regardless of whether one considers the effect of Section 727 as direct or indirect, the effect of the measure was such that while it was in force poultry exports from China to the United States could not commence. Therefore, Section 727 directly or indirectly affected international trade in poultry products. ${ }^{1139}$

In practice, WTO Members usually decide to spend their resources on the WTO dispute settlement process if their trade interests are somehow affected. Thus, no wonder that in all the WTO disputes concerning the provisions of the SPS Agreement so far, a measure qualified as an SPS measure was also recognized to affect international trade. However, this does not mean that an SPS measure without effects on international trade does not, in principle, exist. Hygienic requirements to small-scale vendors of food products may, arguably, be regarded as an example of a measure not affecting international trade. ${ }^{1140}$

This criterion may have certain implications for the treatment of private-sector standards under the SPS Agreement. Arguably, it may exclude some local or company standards from the scope of application of the SPS Agreement. However, as has been argued in Chapter II, the last decade saw the significant internationalization of private-sector standard-setting. Industry and company standards are also frequently applied internationally to imported products and / or foreign producers or suppliers. ${ }^{1141}$ As a

1139 Panel Report, US - Poultry (China), para. 7.123.

1140 The example is taken from: Peter Van den Bossche, Werner Zdouc, The Law and Policy of the World Trade Organization. Text, Cases and Materials, 3d Edition, CUP, 2013, p. 900. See also: Denise Prévost, Balancing Trade and Health in the SPS Agreement: The Development Dimension, Wolf Legal Publishers, Nijmegen, 2009, p. 533. Joanne Scott in this respect draws the parallel with the concept of "selling arrangements" (e.g. shop opening hours, special requirements to qualify for selling particular products) developed in the EU by the European Court of Justice. According to the Cases C-267-268/91 Keck \& Mithouard, selling arrangements, if not discriminatory, are not deemed to hinder trade within the EU. See: Joanne Scott, The WTO Agreement on Sanitary and Phytosanitary Measures. A Commentary, Oxford University Press, Oxford, 2007, p. 26.

1141 For example, EUREPG.A.P. evolved into GLOBALG.A.P.; the BRC started to develop global standards; such NGOs as the MSC and the FSC target their standards to international markets; large retailers, such as Tesco, Marks \& Spencer, Carrefour and many other TNCs apply their own standards to their international 
result, many private-sector standards would be able to meet this requirement of the SPS Agreement.

\subsubsection{Relationship With the GATT 1994}

The scope of application of the SPS Agreement depends also on its relationship with other WTO agreements. Such a relationship, in principle, may have two formats: 1 . exclusive application of one agreement and 2. coregulation by both agreements, which may be applicable simultaneously to a measure. ${ }^{1142}$ Among the WTO agreements there are two other agreements addressing the issues of technical barriers to trade - the GATT 1994 and the TBT Agreement. Therefore, the relationship of the SPS Agreement with these two Agreements is the most relevant in the context of the present study. The relationship between the SPS Agreement and the TBT Agreement has been already discussed quite thoroughly in Section 4.1.2.3 of Chapter IV. The present Section therefore explains the relationship between the SPS Agreement and the GATT 1994.

The GATT 1994 is generally applicable to all types of measures which affect the trade in goods and is structurally different from both the SPS Agreement and the TBT Agreement. As has been described in Chapter III, the GATT 1994 contains general obligations of WTO Members and the appropriate provisions with exceptions from these obligations. Subparagraph (b) of the GATT Article XX (General Exceptions) provides for the justification of the measures "necessary to protect human, animal or plant life or health". As has been mentioned in the beginning of the present Chapter, the SPS Agreement, according to the last paragraph of its preamble, is designed to further "elaborate" these rules of the GATT 1994.

However, the SPS Agreement may not be treated as a mere elaboration of the GATT Article XX(b) exception. In fact, it is an independent Agreement containing several separate and additional obligations for WTO Members, such as the harmonization of measures with international standards, and basing measures on scientific principles and risk assessment. This approach to the status of the SPS Agreement was confirmed by the Panels in EC - Hormones. ${ }^{1143}$ In these cases, the EU argued that the SPS Agreement could be applicable only after finding a violation under the substantive provisions of the GATT 1994 (Articles I, III or XI). Thus, according to the arguments of the EU, the SPS Agreement could be applicable only together with Article XX(b) of the GATT 1994 and in the context of the general ex-

supply chains. For more information on this issue, see Section 2.2.3.2.2.3 of Chapter II.

1142 See Section 4.1.2 of Chapter IV.

1143 See: Panel Report, EC - Hormones (US), paras. 8.31 - 8.42; Panel Report, EC Hormones (Canada), paras. 8.34-8.45. 
ceptions from the substantive provisions of the GATT $1994 .{ }^{1144}$ The Panels rejected these arguments and stated:

Many provisions of the SPS Agreement impose "substantive" obligations which go significantly beyond and are additional to the requirements for invocation of Article XX(b). These obligations are, inter alia, imposed to "further the use of harmonized sanitary and phytosanitary measures between Members" and to "improve the human health, animal health and phytosanitary situation in all Members". They are not imposed, as is the case of the obligations imposed by Article XX(b) of GATT, to justify a violation of another GATT obligation (such as a violation of the non-discrimination obligations of Articles I or III). ${ }^{1145}$

The Panels further noted the fundamental difference in the general approach adopted in Article XX(b) of the GATT 1994 and the approach adopted in the SPS Agreement:

Article $\mathrm{XX}(\mathrm{b})$, which is not limited to sanitary or phytosanitary measures, provides for a general exception which can be invoked to justify any violation of another GATT provision. The SPS Agreement, on the other hand, provides for specific obligations to be met in order for a Member to enact or maintain specific types of measures, namely sanitary and phytosanitary measures. ${ }^{146}$

The SPS Agreement thus constitutes an autonomous set of rules providing for substantive and specific rights and obligations, which are additional to those of the GATT 1994. The relationship between the SPS Agreement and the GATT 1994 may therefore be characterized as the one of co-regulation, i.e. both agreements may apply simultaneously to the same measure. Indeed, since the SPS Agreement is more specific and contains additional obligations, a measure may still breach the provisions of the Agreement even if it complies with requirements of the GATT 1994. In this regard, the SPS Agreement constitutes the lex specialis in relation to the GATT 1994. ${ }^{1147}$ That is why the WTO panels decided to first examine the claims

1144 See: Panel Report, EC - Hormones (US), para. 4.4; Panel Report, EC - Hormones (Canada), para. 4.3.

1145 Panel Report, EC - Hormones (US), para. 8.38; Panel Report, EC - Hormones (Canada), para. 8.41. These findings of the Panels, perhaps, looked convincing enough and therefore were no appealed by the EU.

1146 Panel Report, EC - Hormones (US), para. 8.39; Panel Report, EC - Hormones (Canada), para. 8.42.

1147 In fact, this was directly stated by the Panel in US - Poultry (China); see: Panel Report, US - Poultry (China), para. 7.66. In the absence of conflict, the application of lex specialis does not exclude the application of lex generalis. Lex specialis, however, is usually examined first and prevails in the case of conflict. For more information, see: Gabrielle Marceau, Joel P. Trachtman, “The Technical Barrier to 
concerning the provisions of the SPS Agreement in disputes dealing with both Agreements. For example, in Australia - Salmon, the Panel observed:

We note, moreover, that (1) the SPS Agreement specifically addresses the type of measure in dispute, and (2) we will in any case need to examine the SPS Agreement, whether or not we find a GATT violation (since GATT consistency is nowhere presumed to constitute consistency with the SPS Agreement). In order to conduct our consideration of this dispute in the most efficient manner, we shall, therefore, first address the claims made by Canada under the SPS Agreement before addressing those put forward under GATT 1994 . $^{1148}$

Moreover, unlike the TBT Agreement, the SPS Agreement contains a presumption of consistency of a measure with the GATT 1994 if it complies with the requirements of the SPS Agreement. Article 2.4 of the SPS Agreement provides:

Sanitary or phytosanitary measures which conform to the relevant provisions of this Agreement shall be presumed to be in accordance with the obligations of the Members under the provisions of GATT 1994 which relate to the use of sanitary or phytosanitary measures, in particular the provisions of Article XX(b).

This provision does not, however, preclude the examination of a measure against the requirements of the GATT 1994 which has already been found to be inconsistent with the rules of the SPS Agreement. It also does not establish the rule that a measure inconsistent with the SPS Agreement must necessarily be inconsistent with rules of the GATT 1994, although it will likely be in many cases. Furthermore, it is not clear whether such a presumption of consistency with the GATT 1994 is a rebuttable one or not. There is no clear ruling on this issue in WTO case law, although in one of the cases, US - Poultry (China), the Panel seems to assume that this presumption is irrebuttable by noting:

Trade Agreement, the Sanitary and Phytosanitary Measures Agreement, and the General Agreement on Tariffs and Trade: A Map of the World Trade Organization Law of Domestic Regulation of Goods", Journal of World Trade, 36(5), 2002, pp. 869 - 870; Gabrielle Marceau, Joel P. Trachtman, "A Map of the World Trade Organization Law of Domestic Regulation of Goods: The Technical Barriers to Trade Agreement, the Sanitary and Phytosanitary Measures Agreement, and the General Agreement on Tariffs and Trade", Journal of World Trade, 48(2), 2014, pp. 351-432; Denise Prévost, Balancing Trade and Health in the SPS Agreement: The Development Dimension, Wolf Legal Publishers, Nijmegen, 2009, p. 569.

1148 Panel Report, Australia - Salmon, para. 8.39. See also: Panel Report, EC Hormones (US), para. 8.42; Panel Report, EC - Hormones (Canada), para. 8.45; Panel Report, US - Poultry (China), paras. 7.65 - 7.67. 
Therefore, if the Panel were to find that Section 727 is an SPS measure, a finding that it is not inconsistent with the SPS Agreement, would yield a presumption that Section 727 is in accordance with Article XX(b) of the GATT 1994. Accordingly, the Panel would not need to consider the GATT claims because the measure would be presumed to be consistent with Article $\mathrm{XX}(\mathrm{b})$.

In the literature on this subject, there are different points of views on this issue. Some authors argue that the presumption must be irrebuttable in order to avoid imposing a double burden of obligations on WTO Members according to both Agreements. ${ }^{1149}$ Others argue that there might be a possibility to rebut the presumption of conformity with the GATT 1994 and that, in principle, a measure consistent with the SPS Agreement may still appear to be inconsistent with Article XX(b) of the GATT 1994. ${ }^{1150}$ If the presumption is rebuttable, it may also result in shifting the burden of proof under Article XX of the GATT 1994 from a respondent to a complainant. ${ }^{1151}$

1149 See: Denise Prévost, Balancing Trade and Health in the SPS Agreement: The Development Dimension, Wolf Legal Publishers, Nijmegen, 2009, pp. 567 - 569; Lukasz Gruszczynski, Regulating Health and Environmental Risks under WTO Law. A Critical Analysis of the SPS Agreement, Oxford University Press, Oxford, 2010, pp. $70-71$.

1150 Joanne Scott argues that a similar presumption (only with respect to SPS measures conforming with international standards) may be found in Article 3.2 of the SPS Agreement; this presumption was found by the Appellate Body to be susceptible to rebuttal in EC - Hormones; see: Joanne Scott, The WTO Agreement on Sanitary and Phytosanitary Measures. A Commentary, Oxford University Press, Oxford, 2007, p. 28. See also: Lukasz Gruszczynski, Regulating Health and Environmental Risks under WTO Law. A Critical Analysis of the SPS Agreement, Oxford University Press, Oxford, 2010, p. 70; Gabrielle Marceau, Joel P. Trachtman, "The Technical Barrier to Trade Agreement, the Sanitary and Phytosanitary Measures Agreement, and the General Agreement on Tariffs and Trade: A Map of the World Trade Organization Law of Domestic Regulation of Goods”, Journal of World Trade, 36(5), 2002, p. 871; Gabrielle Marceau, Joel P. Trachtman, "A Map of the World Trade Organization Law of Domestic Regulation of Goods: The Technical Barriers to Trade Agreement, the Sanitary and Phytosanitary Measures Agreement, and the General Agreement on Tariffs and Trade”, Journal of World Trade, 48(2), 2014, pp. 351-432.

1151 Article XX of the GATT 1994 may be invoked to justify violations of substantive obligations of the GATT 1994 which have been successfully proven by the complainant. Thus, as a rule, the respondent bears the burden of proof under Article XX. For more information on Article XX of the GATT 1994, see Section 3.3.4 of Chapter III. For the relevant discussion in SPS context, see also: Gabrielle Marceau, Joel P. Trachtman, "The Technical Barrier to Trade Agreement, the Sanitary and Phytosanitary Measures Agreement, and the General Agreement on Tariffs and Trade: A Map of the World Trade Organization Law of Domestic Regulation of Goods”, Journal of World Trade, 36(5), 2002, p. 871; Gabrielle Marceau, Joel P. Trachtman, "A Map of the World Trade Organization Law of 
It seems that the literal meaning of the term "presumed", used in the wording of Article 2.4 of the SPS Agreement, usually implies something which may be rebutted. Indeed, if the presumption is meant to be irrebuttable, it would be more appropriate to use such wording as, for example, "shall be regarded to be in accordance with the obligations ..." Thus, the plain reading of the text of the SPS Agreement arguably does not support the idea about the irrebuttable nature of the presumption. However, in dispute settlement practice this might appear to be otherwise as WTO panels and the Appellate Body would strive to interpret both Agreements in a harmonious way. This will probably result in a very high threshold of proof for rebutting the presumption, the overcoming of which will be very difficult or even virtually impossible in practice.

As has been noted in Section 4.1.2.4 of Chapter IV, the General Interpretative Note to Annex 1A of the WTO Agreement provides that rules of more specialized agreements in trade in goods shall prevail over the GATT rules in case of a conflict. The provisions of the SPS Agreement would therefore prevail over conflicting provisions of the GATT 1994. In any case, as has been said, it is reasonable to assume that the WTO dispute settlement system will do its outmost to prevent conflicting interpretations of the Agreements. In this regard, the approach of harmonious interpretation of both Agreements seems to be the most suitable one. Such an approach may prevent not only direct conflicts in the interpretation of the Agreements, but also the findings that a measure violates the GATT 1994 while being consistent with the SPS Agreement. ${ }^{1152}$

The approach of harmonious interpretation of the SPS Agreement and the GATT 1994 has in fact already been applied by the Panel in US - Poultry (China). Contrary to a few preceding SPS cases, after finding violations of the SPS Agreement by the US, the Panel did not exercise judicial economy with respect to China's complaints on violations of the GATT 1994. After deciding that the US breached Articles 2.2, 2.3, 5.1, 5.2, 5.5 and 8 of the SPS Agreement, the Panel concluded that "it would be appropriate" to rule

Domestic Regulation of Goods: The Technical Barriers to Trade Agreement, the Sanitary and Phytosanitary Measures Agreement, and the General Agreement on Tariffs and Trade", Journal of World Trade, 48(2), 2014, pp. 351-432; Denise Prévost, "Opening Pandora's Box: The Panel's Findings in the EC - Biotech Products Dispute", Legal Issues of Economic Integration, 34(1), 2007, p. 567.

1152 See: Denise Prévost, Balancing Trade and Health in the SPS Agreement: The Development Dimension, Wolf Legal Publishers, Nijmegen, 2009, p. 568; Stefan Zleptnig, Non-Economic Objectives in WTO Law. Justification Provisions of GATT, GATS, SPS and TBT Agreements, Vol. 1, Martinus Nijhoff Publishers, Leiden - Boston, 2010, p. 339; Joanne Scott, The WTO Agreement on Sanitary and Phytosanitary Measures. A Commentary, Oxford University Press, Oxford, 2007, pp. $28-29$. 
on the claims under Articles I and XI of the GATT $1994 .{ }^{1153}$ It finally found that these Articles of the GATT 1994 were violated by the US measures as well. ${ }^{1154}$ The Panel thus confirmed that the relationship between the SPS Agreement and the GATT 1994 is one of the co-regulation. After the US tried to invoke Article XX(b) of the GATT 1994 in justification of the violations, the Panel noted:

We therefore conclude that the SPS Agreement elaborates and thus explains the provisions of Article XX(b) in further detail when dealing with SPS measures. In the Panel's view, this interpretation gives meaning to both Article XX(b) of the GATT 1994 and the SPS Agreement in a harmonious manner. ${ }^{1155}$

The Panel further found that "where [...] an SPS measure has been found inconsistent with provisions of the SPS Agreement such as Articles 2 and 5, the disciplines of Article XX(b) cannot be applied so as to justify such a measure". ${ }^{1156}$ This statement by the Panel appears to be a rather sweeping one. First of all, it does not seem to be based on the text of the SPS Agreement, because Article 2.4 of the Agreement, as was discussed above, contains only the presumption of consistency and not vice versa, i.e. the presumption of inconsistency. Moreover, as has been explained, the Panel in EC-Hormones expounded that the rules of the SPS Agreement set out new disciplines, and thus constitute something more than a mere elaboration of Article XX(b) of the GATT 1994. ${ }^{1157}$

A private-sector standard dealing with SPS matters could thus, in principle, be examined against both the SPS Agreement and the GATT 1994. The examination under the SPS Agreement will be carried out first. In cases where it is established that a standard falls within the scope of the SPS Agreement, and if no inconsistencies with the SPS Agreement were found, the standard will benefit from the presumption of consistency with the GATT 1994. Arguably, such a presumption will be difficult, if possible, to rebut.

\subsubsection{Personal Scope of Application of the SPS Agreement}

The personal scope of application of the SPS Agreement defines which actors are involved in the development, adoption and / or enforcement of SPS measures under the Agreement. In particular, the question is whether,

\footnotetext{
1153 See: Panel Report, US - Poultry (China), paras. 7.399, 7.455.

1154 See: Panel Report, US - Poultry (China), para. 8.3.

1155 Panel Report, US - Poultry (China), para. 7.479.

1156 Panel Report, US - Poultry (China), para. 7.482.

1157 Panel Report, EC - Hormones (US), para. 8.38; Panel Report, EC - Hormones (Canada), para. 8.41. These findings of the Panel were not appealed.
} 
according to the SPS Agreement, these actors include only governmental bodies (or non-governmental bodies entrusted with the performance of governmental tasks), or whether they may also include certain private entities. This is indeed a very important issue to properly understand whether, and to what extent, the SPS Agreement is relevant for the regulation of such private measures as private-sector standards.

The definition of an SPS measure in Annex A of the SPS Agreement does not specify the types of entities or bodies which may adopt or enforce SPS measures. Thus, as in the case with the GATT 1994, the general customary rules of international law on state responsibility might be relevant with regard to the issue of attribution of SPS measures to WTO Members. ${ }^{158}$ As has been discussed in Chapter III, the ILC Articles on State Responsibility contain the norms on the attribution of conduct to States, some of which are widely recognized to be a restatement of customary norms of international law. ${ }^{1159}$ In accordance with the ILC Articles, WTO Members are responsible for the SPS measures adopted and applied by their organs and persons or entities exercising elements of governmental authority. ${ }^{1160}$ With respect to the SPS Agreement, for instance in EC-Approval and Marketing of Biotech Products, the Panel ruled that the EU general de facto moratorium in approval of biotech products constitutes a measure attributable to the EU under the Agreement. According to the Panel, this was the case since the "common plan or course of actions" was followed by the EU Commission and a group of five EU Member States which were recognized to be the organs of the EU under international law. ${ }^{1161}$ The Panel also referred to the previous Appellate Body decision in US - Corrosion-Resistant Steel Sunset Review, noting "that a measure of a Member can only be challenged if the measure is attributable to that Member". ${ }^{1162}$

1158 Indeed, panels and the Appellate Body clearly stated that the norms of WTO law are not "to be read in clinical isolation from public international law"; see: Appellate Body Report, US - Gasoline, p. 17. For more information, see Section 3.2.1 of Chapter III.

1159 Some of the ILC Articles may also represent the progressive development of international law; for more information on the ILC Articles, see Section 3.2.1 of Chapter III. See also: Rüdiger Wolfrum, "State Responsibility for Private Actors: An Old Problem of Renewed Relevance", at: Maurizio Ragazzi, International Responsibility Today: Essays in Memory of Oscar Schachter, Martinus Nijhoff Publisher, Leiden, 2005; Santiago Villalpando, "Attribution of Conduct to the State: How Rules of State Responsibility May Be Applied Within the WTO Dispute Settlement System”, Journal of International Economic Law, 5(2), 2002.

1160 See: Articles 4, 5 of the ILC Articles on State Responsibility.

1161 See: Panel Report, EC - Approval and Marketing of Biotech Products, para. 7.1294. See also: Denise Prévost, Balancing Trade and Health in the SPS Agreement: The Development Dimension, Wolf Legal Publishers, Nijmegen, 2009, p. 541.

1162 Panel Report, EC - Approval and Marketing of Biotech Products, para. 7.1294. The Panel seem to refer mistakenly to US - Corrosion Resistant Steel Sunset Review as 
Moreover, according to the ILC Articles on State Responsibility, an SPS measure may be attributable to a WTO Member if a measure is adopted by other persons and entities acting under the direction or control of the WTO Member, or if the Member acknowledged and adopted this measure as its own. ${ }^{1163}$ As has been discussed in Section 3.2.2.1.1 of Chapter III, the jurisprudence under the GATT 1994 followed an analogous approach to large extent. According to the ruling of the Panel in Japan - Film, "past GATT cases demonstrate that the fact that an action is taken by private parties does not rule out the possibility that it may be deemed to be governmental if there is sufficient government involvement with it". ${ }^{1164}$ Thus, as was further noted by the Panel, there are no "bright-line rules" in this respect and the decision on attribution must be made on a case-by-case basis depending on the level of governmental involvement or incentives. ${ }^{1165}$ It would perhaps be appropriate to follow the same approach under the SPS Agreement. ${ }^{1166}$ The level of governmental involvement or incentives will therefore play an important role not only for identifying a measure as a mandatory or voluntary one, as has been explained in Section 5.1.1.1.3 of the present Chapter, but also regarding the attribution of a measure to a WTO Member.

The fact that the SPS Agreement is applicable to SPS measures attributable to WTO Members is also reflected in the wording of many important disciplines of the SPS Agreement, as will be discussed in Section 5.3. For instance, Article 2.1 refers to the right of Members to take SPS measures, and Articles 2.3, 3.1, 5.1, 6.1, 7 refer to "their" SPS measures, i.e. the measures of WTO Members. It is important to note, however, that the SPS Agreement does mention, in its Article 13, that the actors developing,

US - Carbon Steel. However, interestingly, the Appellate Body in US - Corrosion Resistant Steel Sunset Review did not formulate this in the way suggested by the Panel. The Appellate Body in fact noted that "[i]n principle, any act or omission attributable to a WTO Member can be a measure of that Member for purposes of dispute settlement proceedings"; see: Appellate Body Report, US - CorrosionResistant Steel Sunset Review, para. 81.

1163 See: Articles 8, 11 of the ILC Articles on State Responsibility.

1164 Panel Report, Japan - Film, para. 10.56, see also paras 10.54-10.55. The GATT cases which the Panel referred to are Japan - Semi-Conductors and EEC - Dessert Apples; see: GATT Panel Report, Japan-Semi-Conductors, para. 102; GATT Panel Report, EEC-Dessert Apples, p. 126. For more information on these cases and the attribution of private behaviour to WTO Members under the GATT 1994 see Section 3.2.2.1.1 of Chapter III.

1165 Panel Report, Japan-Film, para. 10.56. See also: Samir R. Gandhi, "Regulating the Use of Voluntary Environmental Standards Within the World Trade Organization Legal Regime: Making a Case for Developing Countries”, Journal of World Trade, 39(5), 2005, pp. $866-867$.

1166 For example, the appropriateness of such an approach was admitted by Joanne Scott in: Joanne Scott, The WTO Agreement on Sanitary and Phytosanitary Measures. A Commentary, Oxford University Press, Oxford, 2007, p. 25. 
adopting or applying SPS measures may include "non-governmental-entities" and "regional bodies". In particular, Article 13 of the Agreement specifies a number of obligations of WTO Members with respect to such entities and bodies, which reads as follows:

Members are fully responsible under this Agreement for the observance of all obligations set forth herein. Members shall formulate and implement positive measures and mechanisms in support of the observance of the provisions of this Agreement by other than central government bodies. Members shall take such reasonable measures as may be available to them to ensure that non-governmental entities within their territories, as well as regional bodies in which relevant entities within their territories are members, comply with the relevant provisions of this Agreement. In addition, Members shall not take measures which have the effect of, directly or indirectly, requiring or encouraging such regional or non-governmental entities, or local governmental bodies, to act in a manner inconsistent with the provisions of this Agreement. Members shall ensure that they rely on the services of non-governmental entities for implementing sanitary or phytosanitary measures only if these entities comply with the provisions of this Agreement.

Although the SPS Agreement refers to "non-governmental entities" and "regional bodies" it does not, contrary to the TBT Agreement, contain the definitions of these terms. ${ }^{1167}$ Moreover, it is not really clear why the term "non-governmental entity" is used in the SPS Agreement, while in the TBT Agreement the term "non-governmental body" is used. This difference is, most likely, purely accidental and probably arose due to the separate drafting processes of the texts by different working groups. Indeed, it seems unlikely that this minor mismatch in the use of the terms entails substantial differences in their meanings.

With respect to the term "regional body", the SPS Agreement also does not explain what kinds of "relevant entities" from Member territories may participate in such bodies. Thus, it is not clear whether the regional bodies may include any regional private standardizing organization in which private standardizing entities from different WTO Members participate. The "relevant entities" from WTO Members meant to participate in the regional bodies are, most likely, their NSBs, as WTO Members can hardly bear obligations to influence the activities of regional bodies if they are not meaningfully involved into activities of those bodies. ${ }^{1168}$

1167 For the discussion of the relevant definitions in the TBT Agreement, see Section 4.1.3 of Chapter IV.

1168 Similarly to the TBT Agreement, the meaning of the term "regional body" in the SPS Agreement seems to be quite different from the meaning of the terms 
In fact, it is not clear from the wording of Article 13 of the SPS Agreement what types of private entities the term "non-governmental entities" is supposed to cover. Does this term include only those private entities whose activities may be attributable to WTO Members due to a sufficient level of governmental involvement or incentives for such activities? Such an interpretation may, however, render the content of Article 13 of the SPS Agreement superfluous as the relevant acts of such entities would, in any case, be attributable to WTO Members according to the customary rules of international law on State responsibility, as has been discussed above. Another approach to the interpretation of the term "non-governmental entity" is that it covers other private entities which develop, adopt or apply SPS measures without governmental involvement or incentives sufficient for the attribution of the measures to WTO Members. However, the problem that then arises is determining what the criteria are for identifying such private entities, which WTO Members shall be responsible for. This is clearly the key issue with regard to the prospect of regulation of private-sector standards by the SPS Agreement. The crucial question in this respect is whether the term "non-governmental entities" in Article 13 may cover private entities adopting private-sector standards.

It seems that during the negotiations of the SPS Agreement, SPS-related private-sector standards were not really common, and the SPS regulation was regarded as the prerogative of States. As has been observed by Digby Gascoine, who served as one of negotiators of the SPS Agreement:

The SPS and TBT Agreements were negotiated in the Uruguay Round, between 1986 and 1994. While private voluntary standards were extensively in use before and during this period, safety standards were typically considered to be a matter for action by governments in the form of technical regulations (in the terminology of the TBT Agreement) or sanitary measures (in the terminology of the SPS Agreement). The taking up of consumer concerns about animal welfare, environmental, occupational health and safety and consumer safety aspects of foods, for example, in private voluntary standards is a phenomenon that largely post-dates the negotiation of the SPS and TBT Agreements; and it is a development that parallels the rapid increase of market penetration by very large supermarket chains ("multiples" in UK terms). In the recollection of two individuals who were centrally involved in the negotiations that produced the SPS Agreement, the possible application of the Agreement to private voluntary standards was never mentioned

"regional governments and authorities" in the GATT Article XXIV:12 and the GATS Article I:3(a), since the "regional governments and authorities" are supposed to be established within the territories of the WTO Members. For more information, see Section 4.1.3.3 of Chapter IV. 
either in formal negotiating meetings or in informal discussions. As discussed further below, the reference to "non-governmental entities" in Article 13 of the Agreement did not, therefore, specifically contemplate the application of the SPS Agreement to the development of private voluntary standards or conformity assessment against such standards. ${ }^{1169}$

It would seem therefore that, at least originally, the negotiated text of the SPS Agreement, and its Article 13 in particular, was not meant to cover private entities, which do not exercise any elements of governmental authority or act without significant governmental involvement or incentives.

However, the situation regarding SPS regulation has changed significantly since the time when the SPS Agreement was negotiated. The role of private-sector standards in the sphere of food safety and quality has risen during the last decade. Indeed, as has been argued, compliance with private-sector standards applied to agricultural and food products in many developed countries became a necessary condition for market access. ${ }^{1170}$ According to the OECD Report devoted to effects of private standards on agro-food systems, and prepared by Linda Fulponi:

Ensuring food safety is considered a basic requirement to doing business in the food sector. Over $85 \%$ of the retailers reported that their required standard is higher than that of the government and about half reported that they were significantly higher [.... This result is attributed to both the safety and quality management protocols adopted and the additional firm specific requirements applied. The latter may include expanded lists of possible allergens, contaminants, packaging materials and care in transport, storage and distribution procedures. ${ }^{1171}$

1169 The "two individuals who were centrally involved in the negotiations that produced the SPS Agreement" are Digby Gascoine himself, who represented Australia through the negotiations, and Gretchen Stanton, "who chaired almost all of the negotiating meetings"; see: Private Voluntary Standards within the WTO Multilateral Framework: Submission by the United Kingdom. A report prepared by Digby Gascoine and O'Connor and Company, WTO, SPS Committee, G/SPS/ GEN/802, Geneva, 9 October 2007, para. 25.

1170 The WTO Secretariat noted in this respect: "Thus the choice of whether or not to comply with a voluntary standard becomes a choice between compliance or exit from the market. In this way, the distinction between private voluntary standards and mandatory "official" or "public" requirements can blur". See: Private Standards and the SPS Agreement. Note by the Secretariat, WTO, SPS Committee, G/SPS/ GEN/746, Geneva, 24 January 2007, para. 9.

1171 Linda Fulponi, "Final Report on Private Standards and the Shaping of the AgroFood System”, AGR/CA/APM(2006)9/FINAL, OECD, Working Party on Agricultural Policies and Markets, July 2006, para. 50. 
As a matter of fact, trade in food and agricultural products are very important for developing countries. For many developing countries, agricultural products constitute the main share of their exports. At the same time, producers from developing countries may have significant difficulties with meeting the requirements of private-sector standards, or with the process of verification of compliance with such standards. This may be the case due to the very limited access to financial or scientific resources, the lack of technical capacity, high costs of certification and an absence of real price benefits for compliance with a standard. Moreover, the requirements of private-sector standards may be not well-suited for local or traditional methods of production. As has been noted by Denise Prévost, "[s]everal empirical studies have been carried out that confirm the significant impact of private sector standards on the agri-food sector in general, and on developing-country producers in particular". ${ }^{1172}$

Thus, even if private-sector standards were not meant to be covered by the SPS Agreement during the negotiations, due to the importance of the issue one may argue in favour of an "evolutionary" approach to the interpretation of the relevant terms in the SPS Agreement. ${ }^{1173}$ In fact, nothing in the text of the SPS Agreement directly precludes the broad interpretation of the term "non-governmental entities" to cover private standardizing entities and private entities performing conformity assessment. ${ }^{1174}$ Several authors

1172 Denise Prévost, Balancing Trade and Health in the SPS Agreement: The Development Dimension, Wolf Legal Publishers, Nijmegen, 2009, p. 539. See also such studies as: Linda Fulponi, "Final Report on Private Standards and the Shaping of the Agro-Food System”, AGR/CA/APM(2006)9/FINAL, OECD, Working Party on Agricultural Policies and Markets, July 2006; Grace Chia-Hui Lee, "Private Food Standards and Their Impacts on Developing Countries”, European Commission DG Trade Unit G2, Brussels, 2006; Spencer Henson, John Humphrey, “The Impacts of Private Food Safety Standards on the Food Chain and on Public Standard-Setting Processes", Codex thirty-second Session, FAO, WHO, Codex Alimentarius Commission, Rome, May 2009; Steven Jaffee, Spencer Henson, "Standards and Agro-Food Exports from Developing Countries: Rebalancing the Debate", Policy Research Working Paper 3348, World Bank, June 2004; John Humphrey, "Private Standards, Small Farmers and Donor Policy: EUREPGAP in Kenya”, IDS WORKING PAPER 308, Institute of Development Studies, University of Sussex, Brighton, UK, July 2008; etc.

1173 For example, as has been already discussed in Section 3.3.4.4 of Chapter III, the "evolutionary" approach to treaty interpretation was already employed by the Appellate Body under the GATT 1994 Article XX (g) with respect to "conservation of exhaustible natural resources".

1174 For example, Denise Prévost notes that, due to the important role of private-sector standards in the agri-food sphere today, the "good faith" approach to interpretation of the SPS Agreement might call for an evolutionary interpretation of Article 13. Dr. Prévost further argues that such a broad interpretation "seems justifiable" due to the ordinary meaning of the terms of Article 13; see: Denise Prévost, Balancing Trade and Health in the SPS Agreement: The Development Dimension, Wolf Legal Publishers, Nijmegen, 2009, pp. 545 - 546. 
have in fact expressed support for a broad interpretation of the term "nongovernmental entity" in Article 13, ${ }^{1175}$ although it seems unlikely that such an interpretation is really feasible in the context of the SPS Agreement. Indeed, as has been mentioned above, under such an approach the problem of objective criteria for the identification of private entities covered by this term would arise. As has been demonstrated in Section 2.3.1 Chapter II, the "world" of private standard-setting entities is a very diverse and dynamic one; such entities are created, transformed and disappear every day. Governments may frequently be uninvolved in these processes, and may even be unaware of them. The governments, with their limited roles and capacities, could therefore hardly be expected to bear responsibility for the SPS-related activities of every private entity on their territories.

One possible solution for this problem could be the reading of Article 13 of the SPS Agreement as requiring WTO Members to adopt legislation (i.e. "reasonable measures as may be available to them") to regulate the conduct of private entities active on their territories in SPS-related standard-setting. It could be even argued that Members may be able to do more with regard to private entities than with regard to sub-federal entities, where the constitutional division of powers may limit what a Member can do. However, it seems that such an approach, if adopted with respect to private standard-setting entities whose relevant conduct is not subject to any meaningful governmental support or incentives, would hardly fit into the conceptual framework of the SPS Agreement. As has been described in Section 5.1.1.1 of the present Chapter, the SPS Agreement, including its Article 13, is only applicable to SPS measures as defined in Annex A(1) of the SPS Agreement. Accordingly, in order to fall under the disciplines of Article 13 of the SPS Agreement, a standard adopted by a private entity shall satisfy the criteria of the definition of an SPS measure provided in Annex A(1). In this respect, in Section 5.1.1.1.3 above, after considering the relevant GATT and the WTO dispute settlement practice, it has been argued that for an SPS measure to be recognised as such under the SPS Agreement, it must not be fully voluntary due to meaningful governmental involvement or incentives for its adoption and application. It has been also concluded that private conduct which is not subject to any governmental

1175 See: Jan Bohanes, Iain Sandford, "The (Untapped) Potential of WTO Rules to Discipline Private Trade-Restrictive Conduct”, Inaugural Conference, Society of International Economic Law, 56/08, Geneva, July, 15-17, 2008, pp. 37 - 38; Private Voluntary Standards within the WTO Multilateral Framework: Submission by the United Kingdom. A report prepared by Digby Gascoine and O'Connor and Company, WTO, SPS Committee, G/SPS/GEN/802, Geneva, 9 October 2007, pp. 53 - 54; Impact of Private Food Standards in the Southern Cone: Financial Costs and Legal Implications. Communication from the Inter-American Institute for Cooperation on Agriculture (IICA), WTO, SPS Committee, G/SPS/GEN/1100, Geneva, 27 June 2011, para. 27. 
involvement or incentives, could hardly qualify as an SPS measure under the SPS Agreement. Indeed, the considerations provided above lead some authors to argue that the relevant provisions of Article 13 would "make sense" only if they are applicable to something other than an SPS measure of WTO Members as defined in the SPS Agreement. In particular, Joanne Scott pointed out that:

It is only possible to make sense of this second obligation if it is read as imposing an obligation on Members in relation to non-governmental bodies, even when these non-governmental bodies are promulgating SPS requirements which do not meet the definition of a measure under the agreement because of their non-government origins. ${ }^{1176}$

Moreover, it is also unclear what the content of such legislation adopted by WTO Members would have to be with respect to private standard-setting conduct, if this conduct is not subject to any meaningful governmental involvement or incentives. In fact, at least in countries with free market economies, the governments are quite limited in terms of what they can do with respect to the regulation of private conduct based on legitimate entrepreneurial objectives. In this regard, the governmental regulatory role could hardly extend much further than the protection of important societal objectives, i.e. in case of the SPS Agreement, the protection of human, animal or plant life or health, or the prevention or limitation of other relevant damage, as provided in the definition of an SPS measure in Annex A(1).

Another possible solution would be to interpret the term "non-governmental entities" so that it covers only those private entities which receive meaningful governmental involvement or incentives. Under this approach WTO Members may, and shall, take available "reasonable measures" under Article 13 only with respect to non-governmental entities whose activities they meaningfully support or encourage. The issue of whether the governmental support or incentives for an SPS measure is "meaningful enough" is to be decided on a case-by-case basis depending on particular circumstances.

In any case, in order to reach well founded conclusions in this regard, the scope of the terms in Article 13 must be evaluated in the context of the entire Agreement, including its substantive obligations. Section 5.2 of the present Chapter thus discusses in detail the obligations of WTO Members with respect to "non-governmental entities" and "regional bodies" under Article 13 of the SPS Agreement. Section 5.3 then addresses the most

1176 Joanne Scott, The WTO Agreement on Sanitary and Phytosanitary Measures. A Commentary, Oxford University Press, Oxford, 2007, p. 34. 
important substantive obligations of the SPS Agreement with respect to SPS measures developed, adopted and applied by the Members.

\subsubsection{Temporal Scope of Application of the SPS Agreement}

As with any international agreement, the SPS Agreement has temporal limitations for its application. As such, the SPS Agreement may cover all the SPS measures which were adopted and applied by WTO Members after the Agreement entered into force on 1 January 1995. However, what about an SPS measure adopted before this date? As has been explained in Chapter IV concerning the temporal application of the TBT Agreement, Article 28 of the VCLT provides that treaties, as a rule, do not have a retroactive effect with respect to "any situation which ceased to exist before the date of the entry into force of the treaty", "[u]nless a different intention appears from the treaty". ${ }^{1177}$

As is the case with the TBT Agreement, the text of the SPS Agreement does not contain provisions giving the Agreement retroactive force. The SPS Agreement thus clearly does not apply to expired SPS measures which "ceased to exist". However, another relevant and very important issue is whether the SPS Agreement may cover SPS measures which were adopted and applied before its entry into force, but which continue to exist after this date. The matter was considered by the Panels and the Appellate Body in $E C$ - Hormones. The EU argued that since its measure was adopted and entered into force before 1 January 1995, the SPS Agreement may not apply. Based on Article 28 of the VCLT, the Panels and the Appellate Body ruled to the contrary, finding that if such an "old" measure is still in force, it falls within the temporal scope of the SPS Agreement. ${ }^{1178}$ In particular, the Appellate Body stated:

We agree with the Panel that the SPS Agreement would apply to situations or measures that did not cease to exist, such as the 1981 and 1988 Directives, unless the SPS Agreement reveals a contrary intention. We also agree with the Panel that the SPS Agreement does not reveal such an intention. The SPS Agreement does not contain any provision limiting the temporal application of the SPS Agreement, or of any provision thereof, to SPS measures adopted after 1 January 1995. In the absence of

\footnotetext{
1177 See Section 4.1.4 of Chapter IV.

1178 See: Panel Report, EC - Hormones (US), para. 8.26; Panel Report, EC - Hormones (Canada), para. 8.29; Appellate Body Report, EC - Hormones, paras. 128 - 130. These conclusions are analogous to those with respect to the temporal scope of the TBT Agreement in EC - Sardines. In EC - Sardines the Panel in its reasoning even referred to the previous similar findings in EC - Hormones; see: Panel Report, EC Sardines, paras. 7.59 - 7.60; see also: Appellate Body Report, EC - Sardines, paras. 213, 216. See also Section 4.1.4 of Chapter IV.
} 
such a provision, it cannot be assumed that central provisions of the SPS Agreement, such as Articles 5.1 and 5.5, do not apply to measures which were enacted before 1995 but which continue to be in force thereafter. ${ }^{1179}$

The Appellate Body further referred to the relevance of Article XVI:4 of the WTO Agreement in this regard, which provides that each WTO Member is obliged to ensure the conformity of their legislation with the requirements of WTO agreements. It also noted that, “[u]nlike the GATT 1947, the WTO Agreement was accepted definitively by Members, and therefore, there are no longer "existing legislation" exceptions (so-called "grandfather rights")". ${ }^{1180}$

With regard to the issue of disciplining private-sector standards, the temporal scope of application of the SPS Agreement means that the Agreement may not apply to the facts of the adoption and application of standards which took place before 1 January 1995 . However, if a privatesector standard adopted before 1 January 1995 is still applied after this date (especially if this is due to sufficient governmental involvement or incentives), such a standard would be within the temporal scope of application of the SPS Agreement. ${ }^{1181}$

1179 Appellate Body Report, EC - Hormones, para. 128.

1180 Appellate Body Report, EC - Hormones, para. 128. The Appellate Body also noted that this might be one of the reasons why, under Article 14 of the SPS Agreement, the least-developed countries and other developing countries are allowed "to delay implementation of the provisions of that Agreement for a period of five and two years, respectively, following the date of entry into force of the WTO Agreement. Developing country Members may only delay application of the provisions of that Agreement where such application is prevented by lack of technical expertise, technical infrastructure or resources”. See: Appellate Body Report, EC-Hormones, para. 128, footnote 99. See also Section 3.1.3 of Chapter III and Section 4.1.4 of Chapter IV.

1181 The Appellate Body also noted that this might be one of the reasons why, under Article 14 of the SPS Agreement, the least-developed countries and other developing countries are allowed "to delay implementation of the provisions of that Agreement for a period of five and two years, respectively, following the date of entry into force of the WTO Agreement. Developing country Members may only delay application of the provisions of that Agreement where such application is prevented by lack of technical expertise, technical infrastructure or resources". See: Appellate Body Report, EC - Hormones, para. 128, footnote 99. 


\subsection{Obligations of WTO Members With Respect to Different Types of Bodies}

In the WTO framework, only Members (i.e. States, SCTs and the EU) may have rights and obligations under the provisions of WTO law. Thus, with regard to private-sector standards, the issue is not whether private entities, such as industry associations, NGOs, supermarket chains or multinational corporations, may be bound directly by the SPS Agreement. As has been discussed in previous chapters, in principle, under the WTO legal framework, there are two possible ways in which private conduct may entail responsibility of WTO Members. First, private behaviour may be attributable to a WTO Member according to the general customary international law rules on the attribution of conduct to States. Second, a WTO agreement may contain special provisions imposing obligations on WTO Members to discipline private behaviour. As has been outlined before, the SPS Agreement does indeed contain some relevant special provisions in Article 13, namely the rules concerning the obligations of WTO Members with respect to non-governmental entities, local and regional bodies. ${ }^{1182}$ This sort of obligations with respect to specific entities in WTO agreements is frequently called the "second level" obligations of WTO Members. ${ }^{1183}$

The rules of Article 13, to a large extent, are formulated similarly to the obligation of WTO Members under the TBT Agreement with respect to non-governmental, local and regional bodies. ${ }^{1184}$ In a nutshell, Article 13 includes two types of obligations in relation to the relevant entities and bodies: 1 . positive obligations of WTO Members to take available reasonable measures in order to ensure that the relevant entities and bodies comply with the provisions of the SPS Agreement; and 2. negative obligations prohibiting WTO Members to encourage and rely on the activities of the bodies and entities if these activities are inconsistent with the SPS Agreement. The scope of these obligations and their meaning for WTO Members is somewhat obscure, however, as the provisions of Article 13 have not as yet been thoroughly interpreted in the course of WTO dispute settlement practice. Indeed, as has been noted by Joanne Scott, "Article 13 of the SPS Agreement is one of the most intricate in the entire agreement". ${ }^{1185}$ The fol-

1182 For the full text of Article 13 of the SPS Agreement, see Section 5.1.3 of the present Chapter.

1183 See: Denise Prévost, Balancing Trade and Health in the SPS Agreement: The Development Dimension, Wolf Legal Publishers, Nijmegen, 2009, p. 550.

1184 See Section 4.2 of Chapter IV.

1185 Joanne Scott, The WTO Agreement on Sanitary and Phytosanitary Measures. A Commentary, Oxford University Press, Oxford, 2007, p. 30. See also: Tomasz Wlostowski, "Selected Observations on Regulation of Private Standards by the WTO”, Polish Yearbook of International Law, XXX, 2010. P. 224. 
lowing two sections will discuss the two groups of obligations prescribed in Article 13 of the SPS Agreement in more detail.

\subsubsection{Positive Obligations}

The first two sentences of Article 13 provide that WTO Members are "fully responsible" under the SPS Agreement "for the observance of all obligations set forth herein", and that WTO Members are obliged to "formulate and implement positive measures and mechanisms" to ensure that bodies, other than central governmental bodies, comply with the provisions of the SPS Agreement. Similar provisions on the full responsibility of WTO Members with respect to the bodies other than central governmental bodies may be found in Article 3.5 of the TBT Agreement concerning technical regulations, and in Article XXIV:12, paragraph 13 of the Understanding of the Interpretation of Article XXIV of the GATT 1994, with respect to local and regional bodies. ${ }^{1186}$

However, from the wording of Article 13 of the SPS Agreement it is not entirely clear what WTO Members are fully responsible for, i.e. for observance of the entire SPS Agreement, or only for observance of the provisions of Article 13. In other words, the question is whether, under Article 13, WTO Members are "fully responsible" for the conduct of non-governmental entities, local and regional bodies and their compliance with the SPS Agreement, which would be the obligation of result; or if Members, with respect to such entities and bodies, are only "fully responsible" for fulfilling certain "due diligence" obligations prescribed in Article 13, which would be the obligation of conduct.

It seems that the "obligation of result" approach was chosen with respect to Article 13 by the Panel in Australia - Salmon (Article 21.5 Canada), which is thus far the only case where the Article has been considered. However, the Panel considered Article 13 only with regard to the local governmental body of Australia, namely the government of Tasmania, the Australian island and a state within the Commonwealth of Australia. The dispute involved the ban on importation of salmon imposed by the Tasmanian local government. The Panel concluded that "the Tasmanian ban is to be regarded as a measure taken by Australia, in the sense that it is a measure for which Australia, under both general international law and relevant WTO provisions, is responsible". ${ }^{1187}$ Explaining this conclusion the

1186 Article XXIV:12, paragraph 13 of the Understanding of the Interpretation of Article XXIV of the GATT 1994 provides that "[e]ach Member is fully responsible under GATT 1994 for the observance of all provisions of GATT 1994".

1187 Panel Report, Australia-Salmon (Article 21.5 - Canada), para. 7.12. These conclusions of the Panel do indeed reflect the general rules of international law and the rules of WTO Law. In particular, the Panel also referred to the provisions 
Panel, among other arguments, referred to the first two sentences of Article 13 of the SPS Agreement:

As recognized by Australia in its letter of 9 December 1999, the Tasmanian measures "could be characterized as ... measures taken by 'other than a central government body' in the sense of Article 13 of the SPS Agreement, and would constitute measures 'taken by a regional government' within Australia's territory, in the sense of Article 22.9 of the DSU". Article 13 of the SPS Agreement provides unambiguously that: (1) "Members are fully responsible under [the SPS] Agreement for the observance of all obligations set forth herein"; and (2) "Members shall formulate and implement positive measures and mechanisms in support of the observance of the provisions of this Agreement by other than central government bodies". Reading these two obligations together, in light of Article 1.1 of the SPS Agreement referred to earlier, we consider that sanitary measures taken by the Government of Tasmania, being an "other than central government" body as recognized by Australia, are subject to the SPS Agreement and fall under the responsibility of Australia as WTO Member when it comes to their observance of SPS obligations. ${ }^{1188}$

In addition, Canada claimed that Australia failed to implement "positive measures" with respect to the local authorities of Tasmania and thus violated the second sentence of Article 13 of the SPS Agreement. The Panel, however, refused to rule on this issue and stated that the claim was not

of Article 27 of the VCLT, providing that a party to a treaty may not invoke the provisions of its internal law (obviously, including the provisions on its governance structure) to justify violations of a treaty. Furthermore, Article 29 of the VCLT is also relevant in this respect since it provides that "a treaty is binding upon each party in respect of its entire territory", "[u]nless a different intention appears form the treaty or is otherwise established". The same principle is reflected in Article XXIV: 12 of the Understanding of the Interpretation of Article XXIV of the GATT 1994. According to paragraph 13 of Article XXIV:12 of the Understanding, "[e] ach Member is fully responsible under GATT 1994 for the observance of all provisions of GATT 1994". Thus, in the WTO, it is a well established principle that WTO Members are directly and fully responsible not only for the act or omissions of their central governmental bodies, but also for the acts or omissions of their local authorities. The same is true with respect to the SPS Agreement.

1188 Panel Report, Australia-Salmon (Article 21.5 - Canada), para. 7.13. Article 22.9 of the DSU (referred to in the excerpt) provides: "The dispute settlement provisions of the covered agreements may be invoked in respect of measures affecting their observance taken by regional or local governments or authorities within the territory of a Member”. Literally the same provisions concerning the invocation of the dispute settlement rules are specified in 14 (first sentence) of Article XXIV:12 of the Understanding of the Interpretation of Article XXIV of the GATT 1994. 
substantiated by the complainant. ${ }^{1189}$ It thus remains unclear whether the second sentence of Article 13 prescribes any additional and substantive obligations for WTO Members, although the sentence is formulated in a binding fashion using the verb "shall". Joanne Scott, for example, writes in this respect that " $[\mathrm{t}]$ here is nothing to suggest that these obligations are anything but autonomous and capable in themselves of grounding an action in the WTO". ${ }^{1190}$

Another important positive obligation of WTO Members is prescribed in the third sentence of Article 13 of the SPS Agreement. WTO Members are obliged to take "reasonable" measures available to them in order to ensure that non-governmental entities within their territories, and regional bodies in which their relevant entities are members, comply with the SPS Agreement. These provisions of Article 13 raise a number of questions. What do the "reasonable" measures available to WTO Members include? Do the "reasonable" measures constitute a kind of "positive measure" to be taken by the Members according to the second sentence of Article 13? Is this an obligation of contact or an obligation of result?

Indeed, the wording for the third sentence of Article 13 of the SPS Agreement is quite similar to the wording of the relevant provisions of the TBT Agreement. As has been discussed in Chapter IV, the TBT Agreement provides for the obligations of WTO Members to take available "reasonable" measures with respect to three types of bodies: non-governmental, regional and local. ${ }^{1191}$ It is interesting to note, however, that the similar obligations under Article 13 of the SPS Agreement extend only to nongovernmental entities and regional bodies, leaving out local bodies. The reasons for this difference in the rules of the TBT Agreement and the SPS Agreement are not really clear. It is likely that the difference has purely a technical nature and arose due to the separate drafting and negotiation processes of the Agreements within the working groups on the TBT and the SPS matters.

As has been discussed in detail in Section 4.2.1.4 of Chapter IV, Article XXIV:12 of the GATT 1994 provides for similar obligations of WTO Members to take available "reasonable" measures with respect to "'the regional and local governments and authorities within its territories". The dispute settlement under the GATT 1947, as a rule, interpreted this obligation strictly, practically entailing the full responsibility of the GATT Contracting Parties for the acts and omissions of their federal constituencies

1189 Panel Report, Australia-Salmon (Article 21.5-Canada), para. 7.162.

1190 See: Joanne Scott, The WTO Agreement on Sanitary and Phytosanitary Measures. A Commentary, Oxford University Press, Oxford, 2007, pp. 31 - 32.

1191 See Section 4.1.3 of Chapter IV. 
or other local authorities. ${ }^{1192}$ In the GATT case, Canada-Provincial Liquor Boards (EEC), it was only admitted that the GATT Contracting Parties could require a reasonable period of time to ensure the revision of local GATT inconsistent laws and regulations by their local authorities. ${ }^{1193}$ After the establishment of the WTO and the adoption of such agreements as the Understanding of the Interpretation of Article XXIV of the GATT 1994 and the DSU, all remaining doubts with respect to the full responsibility of WTO Members for acts or omissions of local authorities disappeared. Due to a number of provisions of the Understanding and the DSU discussed in Chapter IV ${ }^{1194}$, it was recognized that WTO Members are fully responsible for the acts of their local authorities, and that Article XXIV:12 of the GATT 1994 does not provide for any exceptions in this regard. ${ }^{1195}$

The very similar obligations of WTO Members under the TBT Agreement to take available "reasonable" measures with regard to technical regulations, standards and conformity assessment procedures adopted by non-governmental, regional and local bodies, were thoroughly discussed in Section 4.2.1 of Chapter IV. Perhaps, this discussion is relevant regarding the third sentence in Article 13 of the SPS Agreement as well. As has been suggested with respect to the relevant provisions of the TBT Agreement, the obligation to take available "reasonable" measures could be interpreted as an obligation of conduct (and not as one of result), which would provide the necessary flexibility to the appropriate provisions. In the dispute settlement process the issue could therefore be considered on a case-by-case basis in the light of attendant circumstances. ${ }^{1196}$

As in the relevant obligations of the TBT Agreement, according to the third sentence of Article 13, WTO Members shall take available "reasonable" measures only with respect to non-governmental entities situated "within their territories". Moreover, this obligation of Article 13 extends

1192 See: GATT Panel Report, Canada-Gold Coins (unadopted), paras. 69 - 72; GATT Panel Report, Canada - Provincial Liquor Boards (EEC), paras. 4.34-4.35; GATT Panel Report, Canada - Provincial Liquor Boards (US), para. 5.37; GATT Panel Report, US - Malt Beverages, paras. 5.79 - 8.80. For more information, see Section 4.2.1.4 of Chapter IV.

1193 See: GATT Panel Report, Canada-Provincial Liquor Boards (EEC), para. 4.35.

1194 See paras. 13, 14 of the Understanding of the Interpretation of Article XXIV of the GATT 1994 and Article 22.9 of the DSU. For more information, see Section 4.2.1.4 of Chapter IV.

1195 As has been stated by the Panel in EC - Selected Customs Matters, "Article XXIV:12 of the GATT 1994 cannot be relied upon to attenuate nor to derogate from the provisions of the GATT 1994"; see: Panel Report, EC-Selected Customs Matters, para. 7.144.

1196 For more discussion on interpretation of the term "reasonable measures" within the context of Article 13 of the SPS Agreement see also: Denise Prévost, Balancing Trade and Health in the SPS Agreement: The Development Dimension, Wolf Legal Publishers, Nijmegen, 2009, pp. $546-549$. 
only to those regional bodies "in which relevant entities within their territories are members". Thus, Article 13 clearly recognizes the jurisdictional limitations of WTO Members. It is also clear that a regional body, according to Article 13 does not, as a rule, fall under the full jurisdictional control of a particular WTO Member, as the decision-making process in such a body would depend on "relevant entities" from several countries (whether WTO Members or not). Indeed, WTO Members are only practically able to exercise control over their own "relevant entities" participating in a regional body and, as a rule, not an entire regional body. This could, arguably, serve as logical confirmation that the obligation of WTO Members to take available "reasonable" measures is an obligation of conduct, since achieving a guaranteed result with regard to a regional body in each and every case would be hardly possible.

Thus, it seems that the obligation of WTO Members to take available "reasonable" measures with regard to the relevant entities and bodies shall be interpreted as an obligation of conduct or, in other words, as an obligation of good, or maybe even, best effort. The determination of whether a WTO Member complies with this obligation would entail an evaluation of all relevant factors, including: 1. the level of influence a government may exercise or exercises over a body or entity; 2 . the role of a body or entity in the development, adoption and enforcement of SPS measures; and 3. the overall regulatory environment of a WTO Member, including its legal system, regulatory approach and capacity, etc.

However, at the same time, it seems that the reasoning concerning the meaning of the obligation to take available "reasonable" measures under the TBT Agreement, as described in Section 4.2.1 of Chapter IV, might not be fully suitable with respect to the SPS Agreement. This is due to differences in the scopes and contexts of these Agreements. First, the TBT Agreement is explicitly applicable to voluntary measures, i.e. standards, while the SPS Agreement does not specifically address such measures. As has been discussed in Section 5.1.1.1.3 of the present Chapter, the SPS Agreement could hardly be applicable to voluntary measures, such as standards, whether governmental or non-governmental, if the implementation thereof does not receive meaningful governmental support or incentives. Second, the TBT Agreement, in its Annex 3, contains a separate set of obligations formulated specially with respect to (voluntary) standards, known as the Code of Good Practice. The SPS Agreement does not contain a similar set of rules specially designed for voluntary measures.

Taking this into account, as has been noted in Section 5.1.3 it could, in principle, be argued that the third sentence of Article 13 of the SPS Agreement shall be understood as requiring WTO Members to adopt legislation to regulate the conduct of private entities active on their territories in SPS-related standard-setting. However, as has been also pointed out, 
certain problematic aspects arise in the correlation between the definition of an SPS measure under the SPS Agreement and the content of Article 13 with respect to private conduct which is not subject to any meaningful governmental support or incentives. In particular, in order to fall under the disciplines of Article 13 of the SPS Agreement, the conduct of a private entity shall satisfy the criteria of the definition of an SPS measure provided in Annex A(1). In this respect, as has been argued in Section 5.1.1.1.3 of the present Chapter, an SPS measure must not be fully voluntary due to some meaningful governmental involvement or incentives for its adoption and application in order for it to be recognised as an SPS measure under the SPS Agreement. Accordingly, a private act which is not subject to any governmental involvement or incentives could hardly qualify as an SPS measure under the SPS Agreement. This understanding is indeed in line with the approach adopted under the GATT 1994 as discussed in Section 3.2.2.1.1 of Chapter III which states that certain nexus must exist between a private measure and a WTO Member for responsibility of the Member.

Moreover, as was also pointed out in Section 5.1.3, it is not really clear what WTO Members could, in principle, do with respect to the free market behaviour of private entities adopting or applying private-sector standards. Governments in fact do have certain instruments enabling them to regulate and limit the freedom of private entrepreneurial behaviour, which include the rules on market competition and consumer protection. However, considering the objectives of the SPS Agreement and the nature of its main disciplines as shall be discussed in Section 5.3, it is unlikely that WTO Members may be obliged to have and use such instruments according to the rules of the third sentence of Article 13 of the SPS Agreement.

Thus, to summarize, it is unlikely that WTO Members are obliged under the third sentence of Article 13 of the SPS Agreement to take available "reasonable" measures (whether this includes the adoption of the appropriate legislation or something else) with respect to private conduct that is not subject to any governmental involvement or incentives.

It is worth noting, however, that the definition of an SPS measure in Annex A(1) of the SPS Agreement per se does not contain the requirement that an SPS measure should be one of a WTO Member, i.e. attributable to the Member. Taking this into account, it could also be argued that an SPS measure, under the SPS Agreement, may be developed, adopted and applied by non-governmental entities with a meaningful level of governmental involvement or incentives. This, nonetheless, does not necessarily imply or require the attribution of the measure to a WTO Member. Taking this into consideration, the third sentence of Article 13 of the SPS Agreement seems to provide for more flexibility with respect to the responsibility of WTO Members for the conduct of non-governmental entities, depending on the level of governmental involvement or incentives provided for this conduct. 
In this regard, the third sentence of Article 13 prescribes the obligation of conduct for WTO Members, namely the obligation to take available "reasonable" measures with respect to the behaviour of non-governmental entities whose relevant conduct receives meaningful governmental support or incentives. Similarly to the approach under the TBT Agreement proposed in Chapter IV, ${ }^{1197}$ this obligation of conduct could be viewed from the following perspective: the more governmental involvement or incentives provided by a Member for the behaviour of a private entity, the more "reasonable" measures shall be available to the Member for disciplining this behaviour. In other words, the relevant provisions of Article 13 arguably play an important role by providing more options with respect to the responsibility of WTO Members for non-governmental conduct in addition to the two "straightforward" options, i.e. either full responsibility or no responsibility at all.

Moreover, it is worth noting that the third sentence of Article 13 requires WTO Members to take available "reasonable" measures to ensure the compliance of non-governmental entities and regional bodies with "the relevant provisions" of the SPS Agreement. It would appear therefore that a non-governmental measure shall be examined under the substantive provisions of the SPS Agreement prior to or together with the determination under the third sentence of Article 13 of the Agreement.

Thus, if an SPS-related private-sector standard is adopted and applied by a non-governmental entity with meaningful support or incentives provided by a WTO Member, the Member is obliged to take available "reasonable" measures with respect to this conduct, if it is inconsistent with the substantive provisions of the SPS Agreement. In this regard, as is proposed with respect to the relevant obligations of the TBT Agreement and illustrated in the diagram in Sections 4.2.1.4 and 4.4 of Chapter IV, the more governmental involvement or incentives are provided by the Member for the adoption and application of a standard, the more "reasonable" measures shall be available to the Member for disciplining this behaviour. In cases where governmental involvement or the incentives provided by a WTO Member for the adoption and application of a standard are really substantial, the obligation of conduct to take available "reasonable" measures may be viewed as something very close, if not identical, to an obligation of result. The standard, in such a case, is virtually attributable to the Member which is obliged to ensure the compliance of the standard with the disciplines of the SPS Agreement.

Finally, it should be pointed out that the approach proposed above implies that, for a WTO Member to be responsible, the governmental support or incentives provided with respect to the adoption and application of a

1197 See Sections 4.2.1.4 and 4.4 of Chapter IV. 
private-sector standard must be governmental and meaningful. Accordingly, the market conjuncture and normal business practices influencing the free entrepreneurial behaviour of business actors would hardly be sufficient. Arguably, the same would apply in a case where minor influence is exercised by a government in relation to a private standard-setting entity; for instance, in case of unconditional financing, or providing premises or other useful facilities by a government.

The last sentence of Article 13 of the SPS Agreement provides that WTO Members, for the implementation of their SPS measures, shall "rely on the services of non-governmental entities [...] only if these entities comply with the provisions of this Agreement". It is worth noting in this regard that since the services of non-governmental entities may be relied on for the purposes of implementing SPS measures, this obligation concerns perhaps mainly conformity assessment procedures performed by such entities. ${ }^{1198}$ Indeed, as has been noted in Chapter IV, a very similar obligation may also be found in the TBT Agreement and also only with regard to non-governmental bodies performing conformity assessment procedures. ${ }^{1199}$

The use of private entities in the performance of conformity assessment procedures might indeed be a rather attractive option for governments and may allow better efficiency and professionalism in exercising theses procedures. And in itself such a practice shall not constitute anything illegal. However, if a government entrusts certain functions to a private entity, this may not be used by the government to avoid responsibility for the improper performance of those functions. Thus, these important provisions in both the TBT Agreement and the SPS Agreement reflect the understanding that if a government of a WTO Member delegates the implementation or enforcement of its measure to a private entity, the Member will be responsible for the conduct of this entity. Similarly, if due to delegation by a governmental authority, a private-sector standard is applied in a more or less mandatory fashion through the services of a non-governmental entity, a WTO Member may be held responsible for the violations of substantive obligations of the SPS Agreement in conjunction with the last sentence of Article 13.

\subsubsection{Negative Obligations}

The fourth sentence of Article 13 of the SPS Agreement provides that WTO Members "shall not take measures which have the effect of, directly

1198 As has been noted in Section 5.1.1.1.2 of the present Chapter, according to the definition of an SPS measure in Annex A of the SPS Agreement, conformity assessment procedures as such constitute the form of an SPS measure.

1199 See Articles 8.2 and 9.3 of the TBT Agreement. See also Section 4.2.1.3 of Chapter IV. 
or indirectly, requiring or encouraging ... regional or non-governmental entities, or local governmental bodies, to act in a manner inconsistent with the provisions of this Agreement". This is the negative obligation for WTO Members in that they have to refrain from certain actions, i.e. "requiring or encouraging". As has been described in Section 4.2.2 of Chapter IV, very similar negative obligations may be found in the TBT Agreement. ${ }^{1200}$ In fact, as has been noted with respect to the analogous negative obligations of the TBT Agreement, the "requiring or encouraging" and the reliance "on the services of non-governmental entities", may in principle constitute the forms of governmental involvement or incentives necessary for the attribution of a private act to a WTO Member.

This has been already reflected in the dispute settlement practice under the GATT 1994. For example, as was discussed in more detail in Section 3.2.2.1.1 of Chapter III, in Japan - Film, the US argued that some Japanese measures encouraging certain private behaviour (e.g. the behaviour of retailers), de facto effectively disadvantaged imported photographic film and paper on the Japanese market. The Panel recognized that private acts may be attributed to WTO Members if there is a sufficient level of governmental involvement or incentives. However, the Panel finally concluded that the US failed to demonstrate that this was the case in the situation at hand. ${ }^{1201}$ In another relevant case resolved under the GATT 1994, Korea - Various Measures on Beef, Korea introduced a mandatory dual retail system for domestic and imported beef products, according to which Korean meat products vendors were forced to make a choice to sell either domestic or foreign beef products. Quite predictably, the vendors reacted to this measure by refusing to sell imported beef. The Panel and the Appellate Body found that the Korean measures effectively encouraged or even forced private firms in Korea to treat foreign beef products unfavourably in violation of the national treatment obligation under Article III:4 of the GATT 1994. ${ }^{1202}$

As in the case with the relevant provisions of the TBT Agreement, ${ }^{1203}$ it is, however, not really clear whether, under these provisions of Article 13 of the SPS Agreement, a WTO Member shall be responsible for the violation of substantive provisions of the Agreement resulting from "requiring or encouraging" due to the attribution of wrongful conduct to the Member.

1200 See: TBT Agreement, Article 3.4 with respect to technical regulations, Article 4.1 with respect to standards, Articles 7.4, 8.1, 9.2 with respect to conformity assessment procedures. See also Section 4.2.2 of Chapter IV.

1201 See: Panel Report, Japan - Film, paras. 2.7 - 2.10, 10.56, 10.402 - 10.404. See also Section 3.2.2.1.1 of Chapter III.

1202 See: Panel Report, Korea - Various Measures on Beef, paras. 633 - 639 as upheld in Appellate Body Report, Korea - Various Measures on Beef, paras. 141 - 151, 186. See also Section 3.1.2.1 of Chapter III

1203 See Section 4.2.2 of Chapter IV. 
Or whether the Member, under Article 13, shall only be responsible for the "requiring or encouraging" per se? Similarly to the TBT Agreement, it seems that both options could be feasible under the SPS Agreement. In fact, this is also in line with the discussion above concerning the interpretation of the third sentence of Article 13 which provides for the obligations of WTO Members to take available "reasonable" measures regarding the conduct of non-governmental entities.

Thus, with respect to private-sector standards, if such a standard receives a substantial amount of governmental "requiring or encouraging" for its development, adoption and application, this standard may be regarded as an SPS measure attributable to a WTO Member under the SPS Agreement. The Member may therefore be held responsible if the measure breaches any particular substantive obligations of the Agreement; a violation of the fourth sentence of Article 13 may be found in conjunction with such a breach. If the development, adoption and application of a privatesector standard receives only some meaningful governmental "requiring or encouraging" which is insufficient for its attribution to a WTO Member, the standard may also be recognized as an SPS measure within the meaning of the SPS Agreement. And the Member will be thus responsible under Article 13 for the "requiring or encouraging" of the conduct inconsistent with substantive provisions of the SPS Agreement.

\subsubsection{Work of the SPS Committee With Respect to Article 13 of the SPS Agreement and Private-Sector Standards}

The role and meaning of Article 13 of the SPS Agreement, as well as its implications for the regulation of private-sector standards has become an important subject for discussions in the WTO Committee on Sanitary and Phytosanitary Measures, commonly referred to as the SPS Committee. The Committee is established according to Article 12 of the SPS Agreement; it consists of the representatives of WTO Members and adopts its decisions by consensus. One of the main tasks of the SPS Committee is "to provide a regular forum for consultations" between WTO Members on SPS matters. ${ }^{1204}$ From this perspective, the Committee serves as a forum for the exchange of the information, consultations and negotiations between WTO Members. In particular, this is also a place for addressing specific trade concerns in SPS matters brought to the Committee by the Members in attempts to resolve these concerns on mutually agreeable terms. Another function of the SPS Committee is to further the implementation of the SPS

1204 See: Article 12.1 of the SPS Agreement. See also: Y. Naiki, “Accountability and Legitimacy in Global Health and Safety Governance: The World Trade organization, the SPS Committee, and International Standard-Setting Organizations”, Journal of World Trade, 43(6), 2009. 
Agreement through the adoption of the recommendations, and making binding clarifications and decisions on the interpretation of the Agreement.

Finally, according to Article 12, the SPS Committee "shall maintain close contact with the relevant international organizations" in the field of the SPS protection, particularly with the main international standardizing organizations. In doing this, the Committee participates in the identification of international standards, guidelines or recommendations in the SPS area important for international trade, and monitors the process of international harmonization under such international standards, guidelines or recommendations. ${ }^{1205}$

It is interesting to note that the SPS Committee (and not so much the TBT Committee, although it is the TBT Agreement which directly and explicitly addresses such voluntary measures as standards) became the forum for discussions on the effects of private-sector standards on the international trade in goods and the role of WTO law (particularly, the SPS Agreement) in addressing these standards. This is perhaps the case because private-sector standards in the area of food safety and quality are widely applied nowadays by food producers, processors and retailers, especially in the markets of the developed countries. ${ }^{1206}$ At the same time, agricultural goods, and food products in particular, have historically been an essential and predominant part of the exports of many developing countries. It therefore seems that private-sector standards in this area are frequently regarded by the developing countries to be the most detrimental for their trade interests.

The issue of the effects of private-sector standards on the international trade in goods was first brought to the WTO in 2005 by Saint Vincent and Grenadines. During the meeting of the SPS Committee Saint Vincent and Grenadines raised its concerns about the impact of the private standard scheme EUREPG.A.P. (now GLOBALG.A.P.) which was applied by major supermarket chains in the UK to its exports of bananas. According to Saint Vincent and Grenadines, compliance with this private standard scheme (including the SPS requirements thereof) effectively became a condition for market access in the UK for fresh fruit and vegetables. ${ }^{1207}$ The request was

\footnotetext{
1205 See: Articles 12.2 - 12.4 of the SPS Agreement.

1206 For example, in the EU the private-sector standards, like GLOBALG.A.P., BRC Global Standard for Food Safety or smaller private standards schemes, are applied by the majority of supermarket chains. For more information see Section 2.3.1 of Chapter II.

1207 See: Summary of the Meeting Held on 29-30 June 2005. Note by the Secretariat. Revision, WTO, SPS Committee, G/SPS/R/37/Rev.1, Geneva, 18 August 2005, para. 16. See also: Private Standards and the SPS Agreement. Note by the Secretariat, WTO, SPS Committee, G/SPS/GEN/746, Geneva, 24 January 2007, para. 1
} 
supported by Jamaica which claimed to face similar problems with respect to EUREPG.A.P. The EU responded that EUREPG.A.P. was a private consortium representing the interests of retailers and could therefore not be regarded as a body of the EU. According to the EU, under no conditions could the requirements presented by EUREPG.A.P. be regarded as those imposed by the EU. ${ }^{1208}$

Another critical statement was further made by Argentina. As has been observed by the WTO Secretariat in a summary of the SPS Committee discussions, Argentina claimed that:

If the private sector was going to have unnecessarily restrictive standards affecting trade and countries had no forum where to advocate some rationalization of these standards, twenty years of discussions in international fora would have been wasted. The representative of Argentina was convinced that the rational and legal aspects of these kinds of regulations had to be addressed. ${ }^{1209}$

Since then, discussions on private-sector standards in the WTO have mostly been conducted within the SPS Committee. Among the concerns that some members expressed with respect to the SPS-related private standards, are:

- the standards are not always based on science;

- they deviate from international standards or from official governmental requirements;

- there is a large number of them and they lack harmonization;

- high costs of certification;

- the lack of transparency, as well as consultation or systems for appealing private standard-setting;

- they prescribe how measures should be applied rather than what the outcome should be; and

- they pose disproportionate burdens on small- and mediumsized producers and exporters in developing countries. ${ }^{1210}$

1208 See: Summary of the Meeting Held on 29-30 June 2005. Note by the Secretariat. Revision, WTO, SPS Committee, G/SPS/R/37/Rev.1, Geneva, 18 August 2005, paras. $17-19$.

1209 Ibid., para. 20. See also: Jan Wouters, Axel Marx, Nicolas Hachez, "Private Standards, Global Governance and International Trade: The Case of Global Food Safety Governance", at: Axel Marx, Miet Maertens, Johan Swinnen, Jan Wouters, Private Standards and Global Governance. Economic, Legal and Political Perspectives, Edward Elgar, Cheltenham, UK, 2012, pp. 269 - 270.

1210 See: Report of the Ad Hoc Working Group on SPS-Related Private Standards to the SPS Committee, WTO, SPS Committee, G/SPS/W/256, Geneva, 3 March 2011, para. 24. See also: "Members Take First Steps on Private Standards in Food Safety, Animal Plant Health”, March 30 - 31, 2011, WTO News Items 2011, available at: http://www.wto.org/english/news_e/news11_e/sps_30mar11_e.htm 
Some WTO Members have also referred to the benefits generated by private-sector standards:

- they help suppliers comply with national and international standards when they prescribe how those standards should be met;

- they promote best practices and improved productivity;

- they give brands a better reputation and help suppliers have access to markets and credit; and

- they address emerging risks in a rapid manner, filling gaps, and make it easier for international standards to eventually be adopted. ${ }^{1211}$

For the past few years, the Secretariat of the WTO released several reports and notes on private standards, prepared by the Secretariat itself, WTO Members, and international organizations like UNCTAD, OECD, and IICA (Inter-American Institute for Cooperation on Agriculture) ${ }^{1212}$ These reports and notes addressed the concerns raised by Members with respect to private-sector standards, the effects of these standards on international trade, the implications of the WTO legal regime for private standard-setting, and other relevant issues. Many of these documents also identified the division between the opinions of WTO Members regarding the effects of private-sector standards and their legal regulation. In particular, the meaning and the scope of the relevant provisions of the SPS Agreement has long

(last visited January 15, 2015).

1211 See: Ibid., para. 25. See also: "Members Take First Steps on Private Standards in Food Safety, Animal Plant Health”, March 30 - 31, 2011, WTO News Items 2011, available at: http://www.wto.org/english/news_e/news11_e/sps_30mar11_e.htm (last visited January 15, 2015).

1212 See, for example: Private Standards and the SPS Agreement. Note by the Secretariat, WTO, SPS Committee, G/SPS/GEN/746, Geneva, 24 January 2007; Private Voluntary Standards within the WTO Multilateral Framework: Submission by the United Kingdom. A report prepared by Digby Gascoine and O'Connor and Company, WTO, SPS Committee, G/SPS/GEN/802, Geneva, 9 October 2007; Private Sector Standards and Developing Country Exports of Fresh Fruit and Vegetables. Communication from the United Nations Conference on Trade and Development (UNCTAD), WTO, SPS Committee, G/SPS/GEN/761, 26 February 2007; Private Voluntary Standards and Developing Country Market Access: Preliminary Results. Communication from OECD, Linda Fulponi, WTO, SPS Committee, G/SPS/GEN/763, Geneva, 27 February 2007; Documents and other Information on Private Standards. Note By Secretariat, WTO, Committee on Sanitary and Phytosanitary Measures, G/SPS/GEN/865, Geneva, 11 July 2008; Effects of SPS-Related Private Standards - Compilation of Replies. Note by the Secretariat, WTO, SPS Committee, G/SPS/GEN/932/Rev.1, Geneva, 10 December 2009; Voluntary Standards. Submission by Switzerland, WTO, SPS Committee, G/SPS/GEN/967, Geneva, 20 October 2009; Impact of Private Food Standards in the Southern Cone: Financial Costs and Legal Implications. Communication from the Inter-American Institute for Cooperation on Agriculture (IICA), WTO, SPS Committee, G/SPS/GEN/1100, Geneva, 27 June 2011; and other relevant documents. 
been debated in the SPS Committee. A number of developing countries suggested that the provisions of Article 13 obliges WTO Members to take available "reasonable" measures with respect to private-sector standards developed or applied within their territories in order to decrease their traderestrictive effects. ${ }^{1213}$ Other Members, mainly developed countries, disagreed and submitted that private-sector standards fall outside the scope of the SPS Agreement. ${ }^{1214}$ It has also been suggested that the SPS Committee could "analyse and propose reasonable measures that governments should take and suggest those that should be avoided" and thus should "begin drafting guidelines to encourage the application of Article 13". ${ }^{1215}$

In 2008 the Chairman of the SPS Committee circulated a number of questions to WTO Members in order "to solicit proposals regarding what the SPS Committee can and should do": 1. to reduce the negative effects that private SPS standards have on international trade, especially for developing countries; and 2. to enhance the potential benefits arising from private SPS standards for developing countries. ${ }^{1216}$ The responses received from 30 Members were summarized by the Secretariat and indicated a wide range of matters for consideration by the SPS Committee, including transparency, the harmonization of private-sector standards, their trade effects, and options for information exchange and technical assistance. ${ }^{1217}$

1213 See, for example: Samir R. Gandhi, "Voluntary Environmental Standards: The Interplay Between Private Initiatives, Trade Rules and the Global Decision-Making Process”, 3rd Global Administrative Law Seminar, Viterbo, June 15-16, 2007, pp. 15 - 16; Private Standards and the SPS Agreement. Note by the Secretariat, WTO, SPS Committee, G/SPS/GEN/746, Geneva, 24 January 2007, paras. 16 - 17; Impact of Private Food Standards in the Southern Cone: Financial Costs and Legal Implications. Communication from the Inter-American Institute for Cooperation on Agriculture (IICA), WTO, SPS Committee, G/SPS/GEN/1100, Geneva, 27 June 2011, paras. $6-27$.

1214 See: Makane Moïse Mbengue, "Private Standards and WTO Law", Bridges Trade BioRes Trade \& Environment Review, 5(1), Spring 2011, p. 11. See also, for example, Summary of the Meeting Held on 29-30 June 2005. Note by the Secretariat. Revision, WTO, SPS Committee, G/SPS/R/37/Rev.1, Geneva, 18 August 2005, paras. 16 - 20; Voluntary Standards. Submission by Switzerland, WTO, SPS Committee, G/SPS/GEN/967, Geneva, 20 October 2009

1215 Impact of Private Food Standards in the Southern Cone: Financial Costs and Legal Implications. Communication from the Inter-American Institute for Cooperation on Agriculture (IICA), WTO, SPS Committee, G/SPS/GEN/1100, Geneva, 27 June 2011, para. 27.

1216 Private Standards - Identifying Practical Actions for the SPS Committee Summary of Responses. Note by the Secretariat, WTO, SPS Committee, G/ SPS/W/230, 25 September 2008, para. 1. See also: Gretchen H. Stanton, "Food Safety-Related Private Standards: The WTO Perspective”, at: Axel Marx, Miet Maertens, Johan Swinnen, Jan Wouters, Private Standards and Global Governance. Economic, Legal and Political Perspectives, Edward Elgar, Cheltenham, UK, 2012, p. 245.

1217 See: Private Standards - Identifying Practical Actions for the SPS Committee 
In order to bring more structure and concrete examples into the discussion, the SPS Committee also decided in 2008 to undertake a threestep study on private standards led by an ad hoc working group. ${ }^{1218}$ As the first step, the WTO Secretariat prepared and circulated a questionnaire to Members on SPS-related private-sector standards operational in their markets, their trade effects, relevant costs involved, and other problems posed by these standards. ${ }^{1219}$ As the second step, the Secretariat prepared a report summarizing the information contained in 40 responses from 22 WTO Members, which was discussed during the SPS Committee meetings held in June and October 2009. ${ }^{1220}$ WTO Members expressed differing views with respect to the data in this report. While some Members regarded it as a useful basis for further deliberations in the SPS Committee, others complained about the accuracy of the provided data, the lack of specificity of certain responses, and their extension to non-SPS-related matters. ${ }^{1221}$

The third step included the preparation of the document identifying possible actions for WTO Members and the SPS Committee with respect to private standards. This was then submitted to the Members for review, discussed in the SPS Committee, and later revised several times, each time taking into account the suggestions of the Members. ${ }^{1222}$ In this document, the working group identified twelve possible actions with respect to private SPS-related standards: ${ }^{1223}$

- Summary of Responses. Note by the Secretariat, WTO, SPS Committee, G/ SPS/W/230, 25 September 2008

1218 See: Summary of the Meeting of 8-9 October 2008. Note by the Secretaria, WTO, SPS Committee, G/SPS/R/53, Geneva, 22 December 2008. See also: Possible Actions for the SPS Committee Regarding SPS-Related Private Standards. Note by the Secretariat, WTO, SPS Committee, G/SPS/W/247/Rev.3, Geneva, 11 October 2010, para. 2.

1219 See: Questionnaire on SPS-Related Private Standards. Note by the Secretariat, WTO, SPS Committee, G/SPS/W/232, Geneva, 8 December 2008.

1220 See: Effects of SPS-Related Private Standards - Compilation of Replies. Note by the Secretariat, WTO, SPS Committee, G/SPS/GEN/932/Rev.1, Geneva, 10 December 2009.

1221 See: Possible Actions for the SPS Committee Regarding SPS-Related Private Standards. Note by the Secretariat, WTO, SPS Committee, G/SPS/W/247/Rev.3, Geneva, 11 October 2010, para. 5.

1222 See: Possible Actions for the SPS Committee Regarding Private SPS Standards. Note by the Secretariat, WTO, SPS Committee, G/SPS/W/247, Geneva, 20 October 2009. See also: Possible Actions for the SPS Committee Regarding SPS-Related Private Standards. Note by the Secretariat, WTO, SPS Committee, G/SPS/W/247/ Rev.3, Geneva, 11 October 2010, para. 6.

1223 See: Possible Actions for the SPS Committee Regarding SPS-Related Private Standards. Note by the Secretariat, WTO, SPS Committee, G/SPS/W/247/Rev.3, Geneva, 11 October 2010, para. 8. 
Action 1: The SPS Committee should develop a working definition of SPS-related private standards and limit any discussions to these.

Action 2: The SPS Committee should regularly inform the Codex, OIE and IPPC regarding relevant developments in its consideration of SPS-related private standards, and should invite these organizations to likewise regularly inform the SPS Committee of relevant developments in their respective bodies.

Action 3: The SPS Committee invites the Secretariat to inform the Committee on developments in other WTO fora which could be of relevance for its discussions on SPS-related private standards.

Action 4: [Once a definition of SPS-related private standards is agreed upon (as per Action 1),] Members are encouraged to communicate with entities involved in such standards in their territories to sensitize them to the issues raised in the SPS Committee and underline the importance of following international standards established by the Codex, OIE and IPPC.

Action 5: The SPS Committee should explore the possibility of working with the Codex, OIE and IPPC to support the development and dissemination of promotional materials underlining the importance of international SPS standards.

Action 6: Members are encouraged to exchange relevant information regarding SPS-related private standards among themselves to enhance understanding and awareness on how these compare or relate to international standards and governmental regulations, without prejudice to the different views of Members regarding the scope of the SPS Agreement.

Action 7: The SPS Committee should provide a forum for the discussion of specific trade concerns related to SPS-related private standards.

Action 8: The SPS Committee should develop guidelines on the implementation of Article 13 of the SPS Agreement.

Action 9: The SPS Committee should develop a transparency mechanism regarding SPS-related private standards.

Action 10: The SPS Committee should develop a Code of Good Practice for the preparation, adoption and application of SPSrelated private standards.

Action 11: The SPS Committee should develop guidelines for the governments of WTO Members to liaise with entities involved in SPS-related private standards. 
Action 12: The SPS Committee should seek clarification as to whether the SPS Agreement applies to SPS-related private standards. ${ }^{1224}$

The list of possible actions includes a wide variety of actions and many of them entailed the divergent views of the members of the working group. For example, one interesting option is specified in Action 10 which proposes that a Code of Good Practice is created specifically for private-sector standards in the SPS area. During the discussion some of the working group members referred to the Code of Good Practice in Annex 3 of the TBT Agreement and favoured the adoption of a comparable document for the SPS Agreement as well. Other members of the group were of the view that the extension of the TBT Code of Good Practice to SPS matters could be another possible option, although some of them doubted that this Code could be applicable to private-sector standards at all. ${ }^{1225}$

In March 2011, upon discussion and consultations between its members, the ad hoc working group on SPS-related private standards prepared a Report in which it was proposed that the SPS Committee endorse six actions with respect to SPS-related private standards. ${ }^{1226}$ At the same time, the working group recognized the divergence of the views of WTO Members with respect to the applicability of the SPS Agreement to private-sector standards. Therefore, according to the Report, the "[e]ndorsement of these actions would be without prejudice to the views of Members regarding the scope of the SPS Agreement". ${ }^{1227}$

The proposed six actions included: 1 . the development of a working definition of an SPS-related private standard; 2. cooperation and exchange of information on relevant developments in their consideration of private standard issues with international standard-setting organizations, particularly, the Codex, the OIE and the IPPC; 3. getting information through the WTO Secretariat on the activities of the other WTO fora relevant for the issue of private standards; 4. encouraging WTO Members to liaise with private standard-setting organizations in their territories and communicating to them the issues raised in the SPS Committee; 5. the dissemination of materials underlining the importance of international standards; and 6 .

1224 Ibid., pp. $4-16$.

1225 See: Ibid., paras. 55 - 59. See also, for example, the summery of the discussion on developing the guidelines on liaising between the governments and the private standards-setting entities in the SPS area: Possible Actions for the SPS Committee Regarding SPS-Related Private Standards. Note by the Secretariat, WTO, SPS Committee, G/SPS/W/247/Rev.3, Geneva, 11 October 2010, paras. 60 - 63.

1226 See: Report of the Ad Hoc Working Group on SPS-Related Private Standards to the SPS Committee, WTO, SPS Committee, G/SPS/W/256, Geneva, 3 March 2011.

1227 Ibid., para. 9. 
encouraging the exchange of information between WTO Members with respect to SPS-related private standards. According to the report, the other six actions out of the twelve previously proposed by the working group were not recommended for the endorsement due to the absence of consensus by the group members. ${ }^{1228}$

At the meeting of the SPS Committee held on 30 - 31 March 2011, WTO Members agreed on five out of the six proposed actions. ${ }^{1229}$ The sixth action - encouraging the exchange of information concerning SPS-related private standards between WTO Members - did not find sufficient support in the SPS Committee. This seems again to be due to the difference in views concerning the scope of application of the SPS Agreement and its applicability to SPS-related private standards. In this regard, later, in June 2011, some of WTO Members proposed an alternative compromise wording of the sixth proposed action providing that WTO Members are encouraged to exchange information about SPS-related private standards "outside the formal and informal sessions of the SPS Committee". ${ }^{1230}$

The remaining seven actions, which have not been endorsed by the SPS Committee, are still under discussion. They "include possible further work in the WTO such as developing guidelines and codes of conduct and clarifying governments' legal obligations under the SPS Agreement - members views still differ on these". ${ }^{1231}$ The future will reveal whether the ongoing work and discussions in the SPS Committee on the issue of private standards will bring any positive results. What is quite clear, however, is that building a consensus among WTO Members on such complex and controversial issues is very difficult. ${ }^{1232}$

At the meeting of the SPS Committee held in October 2011, WTO Members were further invited to submit specific proposals on Action 1 (developing a working definition of an SPS-related private standard), as well as

\footnotetext{
1228 See: Ibid., para. 10.

1229 See: Actions Regarding SPS-Related Private Standards. Decision of the Committee, WTO, SPS Committee, G/SPS/55, Geneva, 6 April 2011

1230 Proposed Revisions to Action Six of the Report of the Ad Hoc Working Group on SPS-Related Private Standards (G/SPS/W/256), WTO, SPS Committee, G/ SPS/W/261, Geneva, 20 June 2011, para. 3.

1231 "Members Take First Steps on Private Standards in Food Safety, Animal Plant Health”, March 30 - 31, 2011, WTO News Items 2011, available at: http://www. wto.org/english/news_e/news11_e/sps_30mar11_e.htm (last visited January 15, 2015). See also: Report of the Ad Hoc Working Group on SPS-Related Private Standards to the SPS Committee, WTO, SPS Committee, G/SPS/W/256, Geneva, 3 March 2011, Annex I.

1232 See: Gretchen H. Stanton, "Food Safety-Related Private Standards: The WTO Perspective”, at: Axel Marx, Miet Maertens, Johan Swinnen, Jan Wouters, Private Standards and Global Governance. Economic, Legal and Political Perspectives, Edward Elgar, Cheltenham, UK, 2012, pp. $244-245$.
} 
proposals on the implementation of Actions 2 to 5, which were earlier endorsed by the Committee. Based on the proposals and the inputs received from the Members, the SPS Committee discussed a draft working definition of SPS-related private standards which was then twice revised taking into account further comments received from the Members. The text of the discussed draft definition as revised reads as follows:

SPS-related private standards are [voluntary, market] requirements which are [developed and/or] applied by [private] [non-governmental] entities [footnote 6] in order to protect human, animal or plant life or health."

OR

"SPS-related private standards are [voluntary, market] requirements which are [developed and/or] applied by [private] [non-governmental] entities [footnote 7], which may [directly or indirectly] affect international trade, and which relate to one of the following objectives:

(a) to protect animal or plant life or health [within the territory of the Member] from risks arising from the entry, establishment or spread of pests, diseases, disease-carrying organisms or disease-causing organisms;

(b) to protect human or animal life or health [within the territory of the Member] from risks arising from additives, contaminants, toxins or disease-causing organisms in foods, beverages or feedstuffs;

(c) to protect human life or health [within the territory of the Member] from risks arising from diseases carried by animals, plants or products thereof, or from the entry, establishment or spread of pests; and

(d) to prevent or limit other damage [within the territory of the Member] from the entry, establishment or spread of pests." ${ }^{1233}$

Footnotes 6 and 7 to this text further define a "non-governmental entity" as "any entity that does not possess, exercise, or is not vested with governmental authority. Non-governmental entities are private entities, including private sector bodies, companies, industrial organizations, enterprises and private standard-setting bodies". ${ }^{2234}$ The document prepared by the WTO

1233 Proposed Working Definition of SPS-Related Private Standards. Noted by the Secretariat, WTO, SPS Committee, G/SPS/W/265/Rev.2, Geneva, 28 September 2012, para. 5.

1234 Proposed Working Definition of SPS-Related Private Standards. Noted by the Secretariat, WTO, SPS Committee, G/SPS/W/265/Rev.2, Geneva, 28 September 2012, footnotes 6 and 7 . 
Secretariat also provided a number of the "additional elements to consider" with regard to the definition (see Appendix 1).

The discussions concerning the trade effects of private-sector standards and the actions proposed in this regard continued to be held in the SPS Committee. For example, Belize, in its communication to the SPS Committee, noted that "the proliferation of SPS-related private standards calls into question the relevance of competent authorities", as well as "the relevance of standard-setting organizations such as Codex". ${ }^{1235}$ China, with reference to Action 4 adopted by the SPS Committee's Decision on "Actions regarding SPS-related Private Standards" (Members are encouraged to communicate with entities involved in SPS-related private standards in their territories to sensitize them to the issues raised in the SPS Committee and underline the importance of international standards established by the Codex, the OIE and the IPPC), drew attention to the important principles elaborated in the Code of Good Practice of the TBT Agreement (Annex 3) and the Decision of the WTO TBT Committee on the "Six Principles" for the preparation of international standards. ${ }^{1236}$

In October 2013, China and New Zealand jointly proposed a new version of the definition of SPS-related private standards for consideration by the SPS Committee, which reads as follows:

An SPS-related private standard is a set of requirements of a non-governmental entity which are related to food safety, animal or plant life or health.*

*This working definition or any part of it shall be without prejudice to Members' rights and obligations under the WTO Agreement on the Application of Sanitary and Phytosanitary Measures. ${ }^{1237}$

Following the informal and formal meetings in October 2013, Members of the SPS Committee Members agreed to set up an "electronic working group" (e-WG), composed of Members who submitted specific and concrete proposals or comments on the definition tabled by China and New Zealand to the Secretariat by 8 November. It was also agreed that China and New Zealand would act as "co-stewards" and take the lead in developing a compromise working definition of SPS-related private standards. ${ }^{1238}$

1235 Concerns with Private and Commercial Standards. Communication from Belize, WTO, SPS Committee, G/SPS/GEN/1240, Geneva, 27 March 2013.

1236 Actions Regarding SPS-Related Private Standards. Communication from China, WTO, SPS Committee, G/SPS/GEN/1261, Geneva, 8 July 2013.

1237 Proposed Working Definition of an SPS-Related Private Standard. Submission by China and New Zealand, WTO, SPS Committee, G/SPS/W/272, Geneva, 8 October 2013, p. 1.

1238 See: Report of the Co-Stewards of the Private Standards E-Working Group on 
The comments were received by the Secretariat from 11 Members Argentina, Australia, Belize, Brazil, Burkina Faso, Canada, China, the European Union, Japan, Singapore and the United States. ${ }^{1239}$ The comments were reviewed by the e-WG which also emphasised that the group was developing a working definition, not a legal definition, and that such a definition would apply to SPS-related private standards, but not interpret the SPS Agreement or any of its words or provisions. ${ }^{1240}$

While certain progress was made on resolving differences in some elements of the definition, consensus was not reached on language for a working definition. The co-stewards, on their own responsibility and upon consultations with the e-WG members, suggested the following revised language of the definition for consideration by the SPS Committee:

"An SPS-related private standard is a written requirement or a set of written requirements of a non-governmental entity which are related to food safety, animal or plant life or health and for common and repeated use."

(Optional footnote: "This working definition or any part of it shall be without prejudice to the rights and obligations of Members under the WTO Agreement on the Application of Sanitary and Phytosanitary Measures or the views of Members on the scope of this Agreement.") ${ }^{1241}$

The co-stewards also explained the rationale for the elements of this working definition (see Appendix 2).

The SPS Committee then agreed that the e-WG would pursue its work based on the working definition of SPS-related private standards tabled by the e-WG co-stewards. ${ }^{1242}$ The Committee also discussed the existing definitions of private standards compiled in the Note prepared by the Secretariat (see Appendix 3). ${ }^{1243}$ After the receipt and the consideration of the new comments from the members of the e-WG, the co-stewards proposed the following revised working definition of SPS-related private standard:

"An SPS-related private standard is: A written requirement or condition, or a set of written requirements or conditions,

Action 1 (G/SPS/55). Submission by the Co-Stewards of the E-Working Group, WTO, SPS Committee, G/SPS/W/276, Geneva, 18 March 2014, para. 3.

1239 See: Ibid., para. 4.

1240 See: Ibid., para. 6.

1241 Ibid., para. 8.

1242 See: Existing Definitions of Private Standards in Other International Organizations. Note by the Secretariat. Revision, WTO, SPS Committee, G/SPS/ GEN/1334/Rev.1, Geneva, 5 August 2014, para. 1.5.

1243 See: Ibid., para. 1.4. 
related to food safety, or animal or plant life or health that may be used in commercial transactions and that is applied by a non-governmental entity that is not exercising governmental authority." 1244

The co-stewards further proposed that there be a statement in the decision document (rather than a footnote to the definition) that the definition is a working definition of an SPS-related private standard, is without prejudice to the rights and obligations of Members, and does not represent any views of Members on the scope of the Agreement with respect to private standards. ${ }^{1245}$

The e-WG continued its work on the working definition of an SPSrelated private standard. However, in March 2015, it communicated to the SPS Committee that despite the efforts made, the e-WG members could not reach consensus on the text for a working definition proposed by co-stewards. The e-WG observed that, in particular, it has reached an impasse with respect to the terms "requirement" and "non-governmental entity" due to the differences in views of its members (see Appendix 4). ${ }^{1246}$ Nonetheless, Action 1 (agreeing on a working definition of an SPS-related private standard) remains on the agenda of meetings of the SPS Committee, although the co-stewards suggested a "time out" in this regard, i.e. a cooling off period for all e-WG members to reflect further on this complex issue. ${ }^{1247}$

\subsection{Main Disciplines of the SPS Agreement}

The SPS Agreement contains a number of important rights and obligations of WTO Members with respect to the SPS measures they impose. In cases where a private-sector standard is recognized as an SPS measure of a Member (i.e. if it is covered by the scope of application of the SPS Agreement), the Member would be obliged to ensure that the provisions of this standard are in compliance with the relevant disciplines of the SPS

1244 Second Report of the Co-Stewards of the Private Standards E-Working Group on Action 1 (G/SPS/55). Submission by the Co-Stewards of the E-Working Group, WTO, SPS Committee, G/SPS/W/281, Geneva, 30 September 2014, para. 15.

1245 See: Ibid., para. 9.

1246 See: Report of the Co-Stewards of the Private Standards E-Working Group to the March 2015 Meeting of the SPS Committee on Action 1 (G/SPS/55). Submission by the Co-Stewards of the E-Working Group, WTO, SPS Committee, G/SPS/W/283, Geneva, 17 March 2015, para. 21.

1247 See: Ibid., para. 22. See also: "Food Safety Body Agrees to E-Working Group "Time Out" on Definition of Private Standards", March 26 - 27, 2015, WTO News Items 2015, available at: https://www.wto.org/english/news_e/news15_e/ sps_26mar15_e.htm (last visited April 1, 2015). 
Agreement; or, at the very least, as was discussed in Section 5.2.1, the Member will have to take available "reasonable" measures to ensure such compliance.

Therefore, in order to understand the possible implications of the SPS Agreement for the regulation of private-sector standards, it is further necessary to discuss the substantive disciplines of the SPS Agreement with respect to SPS measures. This discussion is useful not only in order to identify the possible substantive obligations of WTO Members with respect to private-sector standards under the SPS Agreement, but also to clarify whether the substantive disciplines of the SPS Agreement are in fact appropriate and useful for the regulation of private-sector standards.

\subsubsection{Right to Take SPS Measures and the Burden of Proof}

The SPS Agreement aims at balancing market access for imported food and agricultural products against the objective necessity to impose and apply SPS measures to protect public health by WTO Members. ${ }^{1248}$ Therefore, the SPS Agreement, in its Article 2.1, explicitly acknowledges the sovereign rights of WTO Members to take SPS measures necessary for the protection of human, animal or plant life or health. However, it is further required that such measures be consistent with the provisions of the SPS Agreement. On the one hand, Article 2.1 thus guarantees the sovereign right of Members to impose SPS measures limiting international trade, but, on the other hand, this right is limited by the many important and stringent disciplines of the SPS Agreement.

The recognized sovereign right of WTO Members to impose SPS measures has direct consequences for the allocation of burden of proof in dispute settlement under the SPS Agreement. Indeed, the allocations of burden of proof may play an important role in the dispute settlement under the SPS Agreement due to "the difficult and intricate factual issues involved". ${ }^{1249}$ As has been observed by the Panels in EC - Hormones:

Given the nature of disputes under the SPS Agreement, which imposes substantive and procedural requirements raising various, and in this case complex, issues of fact, the allocation of the burden of proof is of particular importance. ${ }^{1250}$

1248 See: Peter Van den Bossche, Werner Zdouc, The Law and Policy of the World Trade Organization. Text, Cases and Materials, 3d Edition, CUP, 2013, pp. 896 and 904.

1249 Denise Prévost, Balancing Trade and Health in the SPS Agreement: The Development Dimension, Wolf Legal Publishers, Nijmegen, 2009, p. 877.

1250 Panel Report, EC - Hormones (US), para. 8.48; Panel Report, EC - Hormones (Canada), para. 8.51. See also: Appellate Body Report, EC - Hormones, para. 97. 
As has been explained in Section 3.3.4 of Chapter III, under Article XX of the GATT 1994, and particularly under its paragraph (b) which addresses the justification of measures "necessary to protect human, animal or plant life or health", the burden of proof to establish that a measure meats the relevant criteria lies on a respondent. ${ }^{1251}$ However, in comparison with Article XX(b) of the GATT 1994, under the SPS Agreement the imposition of SPS measures aimed at the protection of human, animal or plant life or health, is treated as a substantive right of WTO Members and not as an exception. Therefore, in conformity with the general approach to the allocation of burden of proof in the WTO dispute settlement process, as described by the Appellate Body in US - Wool Shirts and Blouses ${ }^{1252}$, it is the task of a complainant under the SPS Agreement to make a prima facie case that certain provisions of the Agreement have been breached. This was first decided by the Appellate Body in EC - Hormones, which explained:

The initial burden lies on the complaining party, which must establish a prima facie case of inconsistency with a particular provision of the SPS Agreement on the part of the defending party, or more precisely, of its SPS measure or measures complained about. When that prima facie case is made, the burden of proof moves to the defending party, which must in turn counter or refute the claimed inconsistency. This seems straightforward enough and is in conformity with our ruling in United States Shirts and Blouses, which the Panel invokes and which embodies a rule applicable in any adversarial proceedings. ${ }^{1253}$

The Appellate Body thus reversed the findings of the Panels which allocated the "evidentiary burden" of proof under certain provisions of the SPS Agreement to a WTO Member imposing an SPS measure. ${ }^{1254}$ Thus, in

1251 See also: Joanne Scott, The WTO Agreement on Sanitary and Phytosanitary Measures. A Commentary, Oxford University Press, Oxford, 2007, p. 29; Denise Prévost, Balancing Trade and Health in the SPS Agreement: The Development Dimension, Wolf Legal Publishers, Nijmegen, 2009, p. 577.

1252 Appellate Report, US - Wool Shirts and Blouses, p. 14.

1253 Appellate Body Report, EC - Hormones, para. 98.

1254 The Panels came to these conclusions based on two main arguments. First, the wording of certain Articles in the SPS Agreement (e.g. Articles 2.2, 2.3, 5.1, 5.6) require that Members "shall ensure" compliance with specified obligations. Second, the Panels referred to provisions of Article 5.8 of the SPS Agreement that WTO Members are obliged to provide explanations regarding their SPS measures which constrains the exports of another Member or are not based on the relevant international standards. However, the Appellate Body ruled that the wording "shall ensure" does not have a logical connection with the issue of the allocation of burden of proof. It also concluded that the obligation to provide explanations under Article 5.8 does not address the burden of proof issues as it extends only to pre-dispute settlement negotiations. The information gained by a WTO Member from such explanations may in fact be used by the Member in a dispute settlement 
WTO dispute settlement, the SPS measures of WTO Members are generally presumed to be consistent with the disciplines of the SPS Agreement unless it is proven to be otherwise.

However, the allocation of the initial burden of proof under the SPS Agreement on a complaining Member does not exonerate a respondent from making its case and providing relevant evidence. ${ }^{1255}$ As has been further clarified by the Appellate Body in Japan - Apples:

That said, the Appellate Body's statement in EC-Hormones does not imply that the complaining party is responsible for providing proof of all facts raised in relation to the issue of determining whether a measure is consistent with a given provision of a covered agreement. In other words, although the complaining party bears the burden of proving its case, the responding party must prove the case it seeks to make in response. ${ }^{1256}$

It is worth noting that Article 2.1 of the SPS Agreement recognizes the right of WTO Members to take SPS measures and does not refer to such a right of non-governmental entities. This again appears to point to the need for a certain nexus to exist between a WTO Member and a measure adopted by a non-governmental entity for the measure to be regarded as an SPS measure under the SPS Agreement, i.e. the existence of meaningful governmental involvement or incentives for the development, adoption and application of the measure.

In any case, neither Article 2.1, nor any other provision of the SPS Agreement, prohibits non-governmental entities to develop, adopt and apply private-sector standards in the SPS sphere. Moreover, in cases where a private-sector standard is qualified as an SPS measure under the SPS Agreement, the right to develop and adopt such a standard would be generally presumed. Thus, it is quite clear that the SPS Agreement does not require or mandate the general limitations or prohibitions of private standard-setting activities in SPS areas to be exercised by WTO Members. If a private-sector standard could be qualified as an SPS measure, a Member would simply have to ensure its compliance with the relevant provisions of the Agreement. In WTO dispute settlement procedures, and with respect to such private-sector standards, the burden of proof would fall on the complaining Member. Arguably, this burden of proof would have to be quite substantial, because a complainant is to make a prima facie case not

in order to make a prima facie case. See: Appellate Body Report, EC - Hormones, paras. 99 - 105. See also: Panel Report, EC - Hormones (US), paras. 8.52 - 8.54; Panel Report, EC - Hormones (Canada), paras. 8.55 - 8.57.

1255 See: Denise Prévost, Balancing Trade and Health in the SPS Agreement: The Development Dimension, Wolf Legal Publishers, Nijmegen, 2009, p. 879.

1256 Appellate Body Report, Japan - Apples, para. 154. 
only with regard to a violation of particular substantive obligation under the SPS Agreement, but also concerning the existence of a sufficient nexus between a standard and a WTO Member, i.e. the presence of meaningful governmental involvement or incentives for the development, adoption and application of a private-sector standard.

\subsubsection{Basic Limitations on the Right to Take SPS Measures}

The right of WTO Members to adopt and maintain SPS measures is not unlimited. The SPS Agreement contains important limitations to this right. In this regard, basic limitations are prescribed in Article 2 of the Agreement, entitled "Basic Rights and Obligations". They comprise:

- necessity requirement;

- the use of scientific principles and evidence; and

- the prohibition of arbitrary or unjustifiable discrimination and disguised restrictions on trade.

\subsubsection{Necessity Requirement}

According to the first phrase of Article 2.2 of the SPS Agreement, "Members shall ensure that any sanitary or phytosanitary measure is applied only to the extent necessary to protect human, animal or plant life or health". This general requirement of the SPS Agreement has not as yet been thoroughly examined in WTO dispute settlement practice. In EC - Approval and Marketing of Biotech Products, Canada and Argentina claimed that the EU's de facto moratorium on the marketing approval of biotech products, product specific measures, and the safeguard measures of the EU Member States violated the necessity requirement of Article 2.2. However, the Panel did not consider these claims with respect to the de facto moratorium and the product specific measures as it did not qualify them as SPS measures. And with respect to the safeguard measures, the Panel exercised judicial economy after finding a violation of Article 5.1 of the SPS Agreement. ${ }^{1257}$

The necessity requirement in Article 2.2 of the SPS Agreement seems to be quite similar to the necessity requirements specified in the relevant subparagraphs of Article XX of the GATT 1994, e.g. subparagraphs (b) and (d). Accordingly, the necessity test developed by the WTO dispute settlement under these provisions of the GATT 1994 might be relevant for the interpretation of the necessity requirement in Article 2.2 of the SPS Agreement. It seems that, as with Article XX subparagraphs (b) and (d), such a necessity test would embody the "weighting and balancing" of three

1257 See: Panel Report, EC - Approval and Marketing of Biotech Products, paras. 7.1430 $-7.1434,7.1758-7.1759,7.3394$. 
elements against each other: the importance of a protected objective, the trade-restrictive character of a measure, and the contribution of a measure to the achievement of the identified objective. In addition, the examination of less trade-restrictive alternative measures which are reasonably available to achieve the same level of protection, could serve as a conceptual tool for determining the necessity of a measure. ${ }^{1258}$

However, if this test is to be used for the necessity provision in the SPS Agreement, it should perhaps be adapted to the context of the Agreement. ${ }^{1259}$ This seems to be particularly true with respect to the process of weighing the importance of a protected objective. ${ }^{1260}$ The SPS objectives and risks are generally regarded as very important and, as will be demonstrated hereafter, under the SPS Agreement, once an SPS risk is established by a WTO Member through scientific means, it is up to the Member to choose an appropriate level of protection addressing this risk. In this regard, Article 5.6 of the SPS Agreement presents related but more specific requirements for WTO Members to ensure that their SPS measures "are not more trade-restrictive than required" to achieve their chosen level of protection. According to WTO case law, the necessity requirement of Article 2.2 "informs" and "imparts meaning to" the provisions of Article 5.6. ${ }^{1261}$ It has been also pointed out by the panels and the Appellate Body that a violation of more the specific provisions of Article 5.6 will automatically entail a

1258 See: Appellate Body Report, Korea - Various Measures on Beef, paras. 162 - 166. For more information on the necessity test under Article XX of the GATT 1994 see Sections 3.3.4.1 and 3.3.4.2 of Chapter III.

1259 Indeed, caution needs to be exercised when transposing the interpretation of the provisions of the GATT 1994 to similar provisions of other WTO agreements. The differences in context, structure and purpose of the agreements may entail differences in the interpretation. See: Peter Van den Bossche, Werner Zdouc, The Law and Policy of the World Trade Organization. Text, Cases and Materials, 3d Edition, CUP, 2013, p. 863.

1260 Denise Prévost submits that the necessity test under Article XX(b) of the GATT 1994 contains "an element of strong proportionality test", which "involves an examination whether the trade-restrictive effects of the measure are disproportionate or excessive in relation to the importance of the objective it pursues". With respect to the necessity provisions of the SPS Agreement, Joanne Scott argues in favour of a "weak proportionality" requirement, which includes two elements of the necessity test and does not include the evaluation of the importance of a pursued SPS objective. See: Denise Prévost, Balancing Trade and Health in the SPS Agreement: The Development Dimension, Wolf Legal Publishers, Nijmegen, 2009, pp. 579, 580; Joanne Scott, The WTO Agreement on Sanitary and Phytosanitary Measures. A Commentary, Oxford University Press, Oxford, 2007, pp. $159-160$.

1261 See: Appellate Body Report, Australia - Apples, para. 339. For more information about the provisions of Article 5.6 of the SPS Agreement see Section 5.3.4.2.2 of the present Chapter. 
violation of the general necessity requirement of Article 2.2, but not necessarily vice versa. ${ }^{1262}$

The necessity requirement of Article 2.2 has thus a rather general nature; and this requirement is also reflected in some of the more specific provisions of the SPS Agreement, e.g. Article 5.6 mentioned above. That is why, in dispute settlement procedures, WTO Members preferred, as a rule, to base their claims on the more specific provisions of the SPS Agreement.

Would the necessity requirement be appropriate with respect to private-sector standards? Probably not really, and at least not for the standards which are adopted and applied without meaningful governmental involvement or incentives. Indeed, the SPS-related requirements of many privatesector standards are formulated not because of the recognized necessity to protect SPS objectives, but because of consumer beliefs and demands which are usually addressed by the business sector and not by a government. In this regard, it would perhaps be imprudent to prohibit business entities to meet the demands of consumers through the use of stringent SPS requirements under the pretext that these requirements are not evidently necessary to protect animal or human health.

\subsubsection{The Use of Scientific Principles and Evidence}

Article 2.2 of the SPS Agreement also presents the basic requirement for WTO Members to use scientific disciplines in the adoption and application of their SPS measures. According to the second part of Article 2.2, WTO Members shall ensure that any of their SPS measures "is based on scientific principles and is not maintained without sufficient scientific evidence, except as provided for in paragraph 7 of Article 5".

Article 5.7 of the SPS Agreement, referred to in the aforementioned provision, deals with situations when available and relevant scientific evidence are insufficient. ${ }^{1263}$ Indeed, governments sometimes have to be cautious and take preventive measures with respect to possible risks despite the insufficient scientific evidence available regarding the existence and likelihood of the risks. ${ }^{1264}$ Thus, Articles 2.2 and 5.7 take this into account and expressly allow for the imposition of provisional SPS measures under certain conditions. As has been noted by the Appellate Body in Japan Agricultural Products II:

1262 See: Panel Report, Australia - Apples, paras. 7.1404, 7.1409 - 7.1410; the issue was not appealed, but was collaterally upheld in Appellate Body Report, AustraliaApples, para. 340. See also: Appellate Body Report, Australia-Salmon, para. 213.

1263 For more information about Article 5.7 of the SPS Agreement, see Section 5.3.4.3 of the present Chapter.

1264 See: Peter Van den Bossche, Werner Zdouc, The Law and Policy of the World Trade Organization. Text, Cases and Materials, 3d Edition, CUP, 2013, p. 907. 
Finally, it is clear that Article 5.7 of the SPS Agreement, to which Article 2.2 explicitly refers, is part of the context of the latter provision and should be considered in the interpretation of the obligation not to maintain an SPS measure without sufficient scientific evidence. Article 5.7 allows Members to adopt provisional SPS measures "[i]n cases where relevant scientific evidence is insufficient" and certain other requirements are fulfilled. Article 5.7 operates as a qualified exemption from the obligation under Article 2.2 not to maintain SPS measures without sufficient scientific evidence. An overly broad and flexible interpretation of that obligation would render Article 5.7 meaningless. ${ }^{1265}$

Article 5.7 is thus not an exception to the requirements of Article 2.2 which can be only invoked in justification of a violation of these requirements; it is an autonomous right of WTO Members. Therefore, in principle, SPS measures which fall under Article 5.7 are excluded from the scope of application of scientific disciplines imposed by Article 2.2. The Panel, in EC - Approval and Marketing of Biotech Products, provided the following clarifications in this respect:

In concrete terms, characterizing Article 5.7 as a qualified right rather than an exception means that if a challenged SPS measure was adopted and is maintained consistently with the four cumulative requirements of Article 5.7, the situation is "as provided for in paragraph 7 of Article 5" (Article 2.2), and the obligation in Article 2.2 not to maintain SPS measures without sufficient scientific evidence is not applicable to the challenged measure. Conversely, if a challenged SPS measure is not consistent with one of the four requirements of Article 5.7, the situation is not "as provided for in paragraph 7 of Article 5" (Article 2.2), and the relevant obligation in Article 2.2 is applicable to the challenged measure, provided there are no other elements which render Article 2.2 inapplicable. ${ }^{1266}$

The requirement of Article 2.2 for WTO Members not to maintain SPS measures without sufficient scientific evidence raises the question: what is "sufficient scientific evidence"? The terms "scientific" and "evidence" in the context of Article 2.2 were first interpreted by the Panel in Japan-Apples. The Panel ruled that, for evidence to be considered "scientific", they must be gathered through scientific methods. ${ }^{1267}$ This presents "an approach that favours relying on scientifically produced evidence rather than on purely

\footnotetext{
1265 Appellate Body Report, Japan - Agricultural Products II, para. 80.

1266 Panel Report, EC - Approval and Marketing of Biotech Products, para. 7.2974.

1267 See: Panel Report, Japan-Apples, para. 8.92.
} 
circumstantial evidence". ${ }^{1268}$ According to the Panel, the term "evidence" also imposes certain limitation on the information which may be acceptable under Article 2.2. In particular, the Panel held:

Negotiators could have used the term "information", as in Article 5.7, if they considered that any material could be used. By using the term "scientific evidence", Article 2.2 excludes in essence not only insufficiently substantiated information, but also such things as a non-demonstrated hypothesis. ${ }^{269}$

The Panel further explained that both direct and indirect evidence may be equally considered, although they might have different "probative value", "since it is obvious that evidence which does not directly prove a fact might not have as much weight as evidence directly proving it, if it is available". ${ }^{1270}$ It was also noted that both the "quality and quantity of scientific evidence at issue is relevant". ${ }^{1271}$

With respect to the issue about when scientific evidence can be regarded as "sufficient", the Panel in Japan - Apples referred to the earlier ruling of the Appellate Body in Japan - Agricultural Products II. ${ }^{1272}$ The Appellate Body held that "sufficiency" constituted a relational concept, and that " [s] ufficiency' requires the existence of a sufficient or adequate 'rational relationship' between two elements, in casu, between the SPS measure and the scientific evidence". ${ }^{1273}$ The Appellate Body further concluded:

Whether there is a rational relationship between an SPS measure and the scientific evidence is to be determined on a case-by-case basis and will depend upon the particular circumstances of the case, including the characteristics of the measure at issue and the quality and quantity of the scientific evidence. ${ }^{1274}$

Thus, the determination about whether an SPS measure is maintained without sufficient scientific evidence will depend on the circumstances of each particular case, and WTO panels and the Appellate Body have some discretion in this regard.

In Japan - Apples, the Panel further elaborated on the concept of "sufficient scientific evidence". The Panel stated that scientific evidence is

1268 Panel Report, Japan-Apples, para. 8.95. This, however, was stated with respect to and in the context of comments of a particular expert.

1269 Panel Report, Japan-Apples, para. 8.93.

1270 Panel Report, Japan-Apples, para. 8.98.

1271 Panel Report, Japan-Apples, para. 8.170.

1272 See: Panel Report, Japan - Apples, paras. 8.100 - 8.101.

1273 Appellate Body Report, Japan - Agricultural Products II, para. 73.

1274 Appellate Body Report, Japan - Agricultural Products II, para. 84. 
"supposed to confirm the existence of a given risk". ${ }^{1275}$ It also introduced an element of proportionality in the "rational relationship" test. The Panel weighed the burdensome and rigorous requirements of the Japanese SPS measure preventing the transmission of fire blight through the importation of apples against the scientific evidence confirming that the risks were absent or negligible. ${ }^{1276}$ The Panel finally concluded that the SPS measure at issue was "clearly disproportionate to the risk identified on the basis of the scientific evidence available". ${ }^{277}$ For the Panel, such clear disproportion meant the absence of a "rational relationship" between the measure and the relevant sufficient evidence and therefore it held that the measure was maintained "without sufficient scientific evidence" contrary to the requirement of Article 2.2 of the SPS Agreement. ${ }^{1278}$ The Appellate Body abstained from taking a general view on the proportionality criterion in this context. It simply concluded that the "methodology adopted by the Panel was appropriate to the particular circumstances of the case before it". This does not, however, "exhaust the range of methodologies available to determine whether a measure is maintained 'without sufficient scientific evidence' within the meaning of Article 2.2”. 1279

The scientific disciplines of Article 2.2 are further elaborated in Articles 5.1 and 5.2 of the SPS Agreement which require that SPS measures must be based on risk assessment taking into account the available scientific evidence. ${ }^{1280}$ As has been stated by the Panels and the Appellate Body in EC - Hormones, "Article 5.1 may be viewed as a specific application of the basic obligations contained in Article 2.2 of the SPS Agreement". ${ }^{1281}$ The Appellate Body also emphasised that "Articles 2.2 and 5.1 should constantly be read together. Article 2.2 informs Article 5.1: the elements that define the basic obligation set out in Article 2.2 impart meaning to Article 5.1". ${ }^{1282}$

\footnotetext{
1275 Panel Report, Japan-Apples, para. 8.104.

1276 See: Panel Report, Japan - Apples, para. 8.169-8.197.

1277 Panel Report, Japan-Apples, para. 8.198. See also: Appellate Body Report, JapanApples, para. 163.

1278 See: Panel Report, Japan-Apples, para. 8.199. See also: Appellate Body Report, Japan-Apples, para. 163.

1279 Appellate Body Report, Japan-Apples, para. 164.

1280 See: Peter Van den Bossche, Werner Zdouc, The Law and Policy of the World Trade Organization. Text, Cases and Materials, 3d Edition, CUP, 2013, p. 908. For more information about Articles 5.1 and 5.2, see Section 5.3.4.1 of the present Chapter.

1281 Appellate Body Report, EC - Hormones, para. 180. See also: Panel Report, EC Hormones (Canada), para. 8.96; Panel Report, EC - Hormones (US), para. 8.93; Appellate Body Report, Canada-Continued Suspension, para. 526; Panel Report, Australia-Apples, para. 7.210.

1282 Appellate Body Report, EC - Hormones, para. 180. See also: Appellate Body Report, Canada-Continued Suspension, para. 526; Panel Report, AustraliaApples, para. 7.210.
} 
That is why, in a dispute settlement where a violation of the risk assessment obligation under Article 5.1 is found, panels do not usually engage in the detailed examination a measure under the relevant requirements of Article 2.2. They usually establish the violation of Article 2.2 "by implication", i.e. a violation of Article 5.1 always entails a violation of Article 2.2. ${ }^{1283}$ However, as has been confirmed in dispute settlement practice, Article 2.2 contains general and autonomous obligations which may, in principle, also be violated without a breach of Article 5.1. ${ }^{1284}$ But since Article 5.1, as well as other articles of the SPS Agreement, contains more specific provisions in comparison with Article 2.2, dispute settlement panels, as a rule, prefer to start their analysis with the more specific provisions. ${ }^{1285}$

With respect to the regulation of private-sector standards, the application of the general but quite rigorous requirements of Article 2.2 could have far-reaching consequences. SPS-related requirements of such private-sector standards are, in many instances, developed and applied by businesses due to SPS-related consumer demands which are not based on science, but on myths, cultural or religious beliefs, and superstitions or excessive precaution. Indeed, as is frequently argued, many private-sector standards present stricter SPS requirements than governmental rules and regulations which certainly need to be in compliance with the rules of Article 2.2 of the SPS Agreement. The SPS requirements of such private-sector standards are, frequently, neither based on scientific evidence, nor on "sufficient scientific evidence" within the meaning of Article 2.2. Thus, the application of the scientific disciplines of Article 2.2 to "purely" private-sector standards adopted without meaningful governmental involvement or incentives would, in practice, mean the prohibition of such private standard-setting in the area of SPS regulation.

1283 See: Panel Report, Australia - Apples, paras. 7.212, 7.906. See also: Panel Report, Australia - Salmon, para. 8.52; Appellate Body Report, Australia - Salmon, para. 138; Panel Report, EC - Approval and Marketing of Biotech Products, paras. 7.33937.3396; Panel Report, Australia - Salmon (Article 21.5 - Canada), paras. 7.83 7.85; Panel Report, US - Poultry (China), paras. 7.203 - 7.204.

1284 See: Appellate Body Report, Australia - Salmon, para. 138; Panel Report, Australia - Salmon, para. 8.52; Panel Report, US - Poultry (China), para. 7.168; Panel Report, Australia-Apples, para. 7.212.

1285 See: Panel Report, EC - Hormones (Canada), paras.8.96, 8.274; Panel Report, EC - Hormones (US), paras. 8.93, 8.271; Appellate Body Report, Australia-Salmon, para. 137; Panel Report, US - Poultry (China), para. 7.169; Panel Report, Australia - Apples, para. 7.215. However, in EC - Hormones, the Appellate Body stated that it was "surprised by the fact that the Panel did not begin its analysis of this whole case by focusing on Article 2", "an approach that appears logically attractive"; see: Appellate Body Report, EC - Hormones, para. 250. Some Panels also followed another approach by analyzing Article 2.2 first; see: Panel Report, Japan - Apples, paras. 8.199, 8.290; Panel Report, Japan - Apples (Article 21.5 - US), paras. 8.120, 8.157. 


\subsubsection{The Prohibition of Arbitrary or Unjustifiable Discrimination and Disguised Restrictions on Trade}

Article 2.3 of the SPS Agreement provides:

Members shall ensure that their sanitary and phytosanitary measures do not arbitrarily or unjustifiably discriminate between Members where identical or similar conditions prevail, including between their own territory and that of other Members. Sanitary and phytosanitary measures shall not be applied in a manner which would constitute a disguised restriction on international trade.

In Australia - Salmon, the Appellate Body noted the following with respect to Article 2.3:

This provision takes up obligations similar to those arising under Article I:1 and Article III:4 of the GATT 1994 and incorporates part of the "chapeau" to Article XX of the GATT 1994. Its fundamental importance in the context of the SPS Agreement is reflected in the first paragraph of the preamble of the SPS Agreement.

Indeed, the requirements of Article 2.3 regarding the prohibition of arbitrary or unjustifiable discrimination and disguised restriction on international trade are formulated quite similarly to the requirements of the chapeau of Article XX of the GATT 1994. Therefore, in principle, the WTO dispute settlement practice on the chapeau of Article XX may have direct relevance for the interpretation of Article 2.3 of the SPS Agreement. ${ }^{1286}$ However, as has been stated before, the application of interpretations of the GATT provisions for other WTO agreement shall be done with caution due to possible differences in structure, context, object and purpose of the agreements.

The provisions of Article 2.3 of the SPS Agreement have been interpreted by the Panel in Australia - Salmon (Article 21.5 - Canada). In this case, Canada claimed that Australian import requirements for salmonids were inconsistent with the first sentence of Article 2.3. The Panel held that the first sentence of Article 2.3 contains three elements, which are cumulative in nature:

1. the measure discriminates between the territories of Members other than the Member imposing the measure, or between the territory of the Member imposing the measure and that of another Member;

1286 For more information about the test developed under chapeau of Article XX of the GATT 1994, see Section 3.3.4.5 of Chapter III. 
2. the discrimination is arbitrary or unjustifiable; and

3. identical or similar conditions prevail in the territory of the Members compared. ${ }^{1287}$

With respect to the first element, the Panel concluded that, under the first sentence of Article 2.3, as well as under provisions of Article 5.5, a discrimination "may also include discrimination between different products, e.g. not only discrimination between Canadian salmon and New Zealand salmon, or Canadian salmon and Australian salmon; but also discrimination between Canadian salmon and Australian fish including non-salmonids, as referred to by Canada in this case". ${ }^{1288}$ The Panel thus found that the first element was fulfilled in the case at hand.

However, with respect to the two remaining elements, the Panel found otherwise and thus did not find any inconsistency with Article 2.3. ${ }^{1289} \mathrm{It}$ stated that Canada "has not met its burden of demonstrating that any discrimination made by Australia between these two categories of fish is 'arbitrary or unjustifiable' in the sense of the second element of Article 2.3, first sentence". ${ }^{1290}$ The Panel also noted "the substantial difference in disease status between Canada and Australia" and therefore did not agree that "identical or similar conditions prevail" in these countries. ${ }^{1291}$

The provisions of Article 2.3 are made more specific in Article 5.5 which prohibits an arbitrary or unjustifiable discrimination and disguised restrictions on international trade in the adoption and application of appropriate levels of protection against SPS risks in various situations. WTO panels and the Appellate Body recognized that, since Article 2.3 provides for basic obligations which are more specifically enunciated in Article 5.5, "a finding of a violation of Article 5.5 will necessarily imply a violation of Article 2.3". ${ }^{1292}$ However, it has also been recognized that not all violations of the general obligations of Article 2.3 are covered by violations of Article 5.5, and that Article 2.3 may be violated independently. ${ }^{1293}$ In such a case, a complainant has to substantiate its claims under Article 2.3 separately from

\footnotetext{
1287 Panel Report, Australia-Salmon (Article 21.5 - Canada), para. 7.111. See also: Panel Report, US - Poultry (China), para. 7.317.

1288 Panel Report, Australia-Salmon (Article 21.5 - Canada), para. 7.112.

1289 Panel Report, Australia - Salmon (Article 21.5 - Canada), para. 7.114.

1290 Panel Report, Australia - Salmon (Article 21.5 - Canada), para. 7.113.

1291 See: Panel Report, Australia-Salmon (Article 21.5 - Canada), para. 7.113.

1292 Appellate Body Report, Australia-Salmon, para. 252. See also: Panel Report, Australia-Salmon, para. 8.109; Panel Report, US - Poultry (China), para. 7.318; Panel Report, Australia-Apples, paras. 7.1092 - 7.1093.

1293 See: Panel Report, Australia - Salmon, para. 8.109; Appellate Body Report, Australia - Salmon, para. 252; Panel Report, US - Poultry (China), para. 7.318; Panel Report, Australia-Apples, paras. 7.1092 - 7.1093.
} 
the arguments under Article 5.5. For example, in Australia - Apples, New Zealand (the complainant) claimed violations of both Article 5.5 and, by implication, Article 2.3. Since the Panel did not find any inconsistency with the provisions of Article 5.5, it also rejected the claims under Article 2.3 because no specific arguments or evidence in this respect had been provided by the Complainant. ${ }^{1294}$

For private-sector standards, the requirements of Article 2.3 could, arguably, be quite problematic if these requirements were applicable to them. And this is not only due to the frequent lack of sufficient scientific evidence supporting SPS requirements of these standards, as has been mentioned before. Private-sector standards are frequently developed and applied in particular product sectors and for particular territories. They may be applied to certain kinds of territories or products and not to other kinds of territories or products. It seems hardly possible to oblige WTO Members to ensure that private-sector standards in their territories are always applied without arbitrary or unjustifiable discrimination of different products. It is thus doubtful that the rules of Article 2.3 would be appropriate, at least in cases of "purely" private-sector standards, whose adoption and application does not receive any meaningful governmental involvement or incentives.

\subsubsection{Promotion of Harmonization Based on International Standards}

Different WTO Members may have diverging SPS policies, which are largely dependent on the countries' geographical location, climate, level of development and welfare, perceptions of SPS risks, public SPS policies and societal demands. Such a divergence, when based on objective factors and scientific evidence, is perfectly normal and, perhaps, even necessary. Indeed, every WTO Member must be able to adopt and maintain those SPS measures which are appropriate and adequate for local conditions. At the same time, large differences in SPS policies and measures between countries present barriers to international trade, because foreign producers have to adjust to diverging SPS requirements applied in various countries. In order to decrease this sort of barriers, Article 3 of the SPS Agreement aims to increase the convergence of national SPS measures through harmonization ${ }^{1295}$ based on international standards. ${ }^{1296}$

\footnotetext{
1294 See: Panel Report, Australia - Apples, paras. 7.1094- 7.1095.

1295 In Annex A(2) of the SPS Agreement, harmonization is defined as " $[\mathrm{t}]$ he establishment, recognition and application of common sanitary and phytosanitary measures by different Members".

1296 Article 3 and other relevant provisions of the SPS Agreement refer to "international standards, guidelines or recommendations". For the sake of convenience the shorter term, "international standards", will be used with the same
} 
However, the encouragement of harmonization in the SPS Agreement is not unqualified and limited by the levels of SPS protection chosen by WTO Members. This is indeed reflected in the Preamble of the SPS Agreement, which provides:

Desiring to further the use of harmonized sanitary and phytosanitary measures between Members, on the basis of international standards, guidelines and recommendations developed by the relevant international organizations ... without requiring Members to change their appropriate level of protection of human, animal or plant life or health.

In this respect, the Appellate Body in EC - Hormones, explained the objectives of harmonization under Article 3 as follows:

In generalized terms, the object and purpose of Article 3 is to promote the harmonization of the SPS measures of Members on as wide a basis as possible, while recognizing and safeguarding, at the same time, the right and duty of Members to protect the life and health of their people. The ultimate goal of the harmonization of SPS measures is to prevent the use of such measures for arbitrary or unjustifiable discrimination between Members or as a disguised restriction on international trade, without preventing Members from adopting or enforcing measures which are both "necessary to protect" human life or health and "based on scientific principles", and without requiring them to change their appropriate level of protection. ${ }^{1297}$

According to Article 3 of the SPS Agreement, WTO Members may choose three alternative options with respect to the harmonization of their SPS measures around international standards:

- to base their SPS measures on existing international standards as provided in Article 3.1;

- to bring their SPS measures in conformity with international standards as provided in Article 3.2; or

- to introduce and maintain SPS measures resulting in a higher level of protection than prescribed in the relevant international standards as provided in Article 3.3.

\subsubsection{Relationship Between the Provisions of Article 3}

Article 3.1 of the SPS Agreement provides:

To harmonize sanitary and phytosanitary measures on as wide a basis as possible, Members shall base their sanitary or

1297 Appellate Body Report, EC - Hormones, para. 177. 
phytosanitary measures on international standards, guidelines or recommendations, where they exist, except as otherwise provided for in this Agreement, and in particular in paragraph 3.

Considering this wording of Article 3.1 in EC - Hormones, the Panels concluded that Article 3.3 forms an exception from of the general provisions of Article 3.1. ${ }^{1298}$ These conclusions were then reversed by the Appellate Body which ruled that Articles 3.1, 3.2 and 3.3 of the SPS Agreement present three alternative options equally available to WTO Members and there is no "general rule - exception" relationship between them. ${ }^{1299}$ This has direct implications for the allocation of burden of proof under Article 3. According to the Appellate Body, WTO Members may not be penalized in the form of reallocation of this burden for choosing any of the three options available under Article 3. And thus, similarly to other provisions of the SPS Agreement, the initial burden of proof under Articles 3.1, 3.2 and 3.3 rests on the complainant. ${ }^{1300}$

\subsubsection{International Standard Under the SPS Agreement}

As has been mentioned, the first option provided in Article 3.1 requires WTO Members to base their SPS measures on existing international standards except if a WTO Member decides to opt for a higher level of SPS protection according to the conditions of Article 3.3. According to Annex A(3) of the SPS Agreement, the "international standards, guidelines and recommendations" referred to in Article 3, are defined as standards adopted by certain international organizations. These are: the Codex, with respect to food safety issues; the OIE, ${ }^{1301}$ with respect to the issues of animal health; and the Secretariat of the International Plant Protection Convention (IPPC), in cooperation with regional organizations operation within the framework of the Convention, with respect to the issues of plant health. For matters not covered by the activities of the specified international organizations, the SPS Committee may identify other relevant international organizations open for membership to all WTO Members which may develop and adopt international standards within the meaning of the SPS Agreement. Thus far, the SPS Committee has not identified any ad-

1298 See: Panel Report, EC - Hormones (Canada), paras.8.60, 8.83 - 8.86; Panel Report, EC - Hormones (US), paras. 8.57, 8.80-8.83

1299 See: Appellate Body Report, EC - Hormones, paras. 158, 169.

1300 See: Appellate Body Report, EC - Hormones, paras. 104-109, 171. See also the general discussion on allocation of the burden of proof under the SPS Agreement in Section 5.3.1 of the present Chapter.

1301 As was explained in Section 2.2.4.3.1 of Chapter II, the International Office of Epizootics officially changed its name to the World Organization for Animal Health in May 2003. However, it still uses the historical acronym OIE. See the OIE website: http://www.oie.int/about-us (last visited January 15, 2015). 
ditional international organizations capable of adopting the international standards referred to in the SPS Agreement. ${ }^{1302}$

In addition, Article 3.4 of the SPS Agreement requires WTO Members to "play a full part, within the limits of their resources", in the activities of these international standard-setting organizations, i.e. "to promote within these organizations the development and periodic review of standards, guidelines and recommendations with respect to all aspects of sanitary and phytosanitary measures".

It is worth noting that, in comparison with the provisions on harmonization of the TBT Agreement, ${ }^{1303}$ the SPS Agreement presents a much clearer picture on what the term "international standard" means and which international organizations may adopt these standards. For example, standards adopted by an important international standard-setting organization such as the ISO would certainly not be regarded as "international standards" within the meaning of the SPS Agreement. This is at least the case until the SPS Committee officially identifies the ISO as an organization capable of adopting international standards within the meaning of the SPS Agreement. The situation is analogous with private standard-setting organizations. It is quite certain that private-sector standards developed and adopted by international NGOs or industry associations may not be regarded as "international standards" under the SPS Agreement. This is at least the case until the SPS Committee adopts an appropriate decision, though this seems unlikely given the fact that the consensus of all the WTO Members represented in the Committee would be required for the adoption of such a decision.

1302 For more information about these organizations, see: Alberto Alemanno, Trade in Food: Regulatory and Judicial Approaches in the EC and the WTO, Cameron May, London, 2007, pp. 261 - 272; Lukasz Gruszczynski, Regulating Health and Environmental Risks under WTO Law. A Critical Analysis of the SPS Agreement, Oxford University Press, Oxford, 2010, pp. 79 - 88; Joanne Scott, The WTO Agreement on Sanitary and Phytosanitary Measures. A Commentary, Oxford University Press, Oxford, 2007, pp. 246 - 250; Mariëlle D. Masson-Matthee, The Codex Alimentarius Commission and Its Standards, T.M.C. Asser Press, 2007, pp. 13 - 50. See also: M. M. Du, "Reducing Product Standards Heterogeneity Through International Standards in the WTO: How Far Across the River?", Journal of World Trade, 44(2), 2010; J. Ewers, "Dueling Risk Assessments: Why the WTO and CODEX Threaten U.S. Food Standards”, Environmental Law, 30, 2000.

1303 As has been discussed in Chapter IV, the TBT Agreement does not provide a list or examples of international organizations capable of developing "international standards" within the meaning of the Agreement, which must be used by WTO Members as a basis for harmonization. It only contains the criterion that the membership in such "international body or system" must be open to all WTO Members. For more information about the rules of the TBT Agreement on harmonization based on relevant international standards, see Section 4.3 .3 of Chapter IV. 


\subsubsection{Measures "Based on" and "Conforming to" International Standards}

Article 3.1 of the SPS Agreement provides the first option available to WTO Members to base their SPS measures on relevant international standards. The Appellate Body, in interpreting the provisions of Article 3.1, referred to the ordinary meaning of the term "based on" as provided in a dictionary and stated the following:

A thing is commonly said to be "based on" another thing when the former "stands" or is "founded" or "built" upon or "is supported by" the latter. ${ }^{1304}$

The second option, which is available to WTO Members, is conforming their SPS measures to international standards according to Article 3.2. According to the Appellate Body, this option is something quite different from the option of "basing" SPS measures on relevant international standards:

The reference of "conform to" is to "correspondence in form or manner", to "compliance with" or "acquiescence", to "follow[ing] in form or nature". A measure that "conforms to" and incorporates a Codex standard is, of course, "based on" that standard. A measure, however, based on the same standard might not conform to that standard, as where only some, not all, of the elements of the standard are incorporated into the measure. ${ }^{1305}$

The Appellate Body thus reversed the findings of the Panels that the options of "basing on" and "conform to" international standards in Articles 3.1 and 3.2 of the SPS Agreement shared the same meaning and stated:

To read Article 3.1 as requiring Members to harmonize their SPS measures by conforming those measures with international standards, guidelines and recommendations, in the here and now, is, in effect, to vest such international standards, guidelines and recommendations (which are by the terms of the Codex recommendatory in form and nature) with obligatory force and effect. The Panel's interpretation of Article 3.1 would, in other words, transform those standards, guidelines and recommendations into binding norms. But, as already noted, the SPS Agreement itself sets out no indication of any intent on

1304 Appellate Body Report, EC - Hormones, para. 163. This statement was also later referred to in EC - Sardines when interpreting a similar obligation of WTO Members under Article 2.4 of the TBT Agreement to use relevant international standards as a basis for their technical regulations. See: Panel Report, EC Sardines, para. 7.110; Appellate Body Report, EC - Sardines, para. 242; for more information see also Section 4.3.3 of Chapter IV.

1305 Appellate Body Report, EC - Hormones, para. 163. 
the part of the Members to do so. We cannot lightly assume that sovereign states intended to impose upon themselves the more onerous, rather than the less burdensome, obligation by mandating conformity or compliance with such standards, guidelines and recommendations. To sustain such an assumption and to warrant such a far-reaching interpretation, treaty language far more specific and compelling than that found in Article 3 of the SPS Agreement would be necessary. ${ }^{1306}$

The Appellate Body thus found that a measure conforming to an international standard "would embody the international standard completely and, for practical purposes, converts it into a municipal standard". ${ }^{1307}$ Accordingly, bringing SPS measures into conformity with international standards is only one of the options available to WTO Members in addition to the less burdensome option of basing their SPS measures on an international standard. And in this regard, the SPS Agreement clearly does not aim to transform non-binding norms of international standards into mandatory requirements. However, to make the option of conformity more attractive for WTO Members, Article 3.2 provides that SPS measures conforming to international standards "shall be deemed to be necessary to protect human, animal or plant life of health, and presumed to be consistent with the relevant provisions of this [SPS] Agreement and of GATT 1994”. Thus, WTO Members which decide to conform their SPS measures to international standards enjoy the benefit of presumption of consistency with the SPS Agreement and the GATT 1994, although according to the Appellate Body, this presumption is a rebuttable one. ${ }^{1308}$

The presumption of consistency with the relevant rules of the SPS Agreement is, however, not applicable if a WTO Member chooses the first option provided in Article 3.1. As has been noted by the Appellate Body:

Under Article 3.1 of the SPS Agreement, a Member may choose to establish an SPS measure that is based on the existing relevant international standard, guideline or recommendation. Such a measure may adopt some, not necessarily all, of the elements of the international standard. The Member imposing this measure does not benefit from the presumption of consistency set up in Article 3.2; but, as earlier observed, the Member is not penalized by exemption of a complaining Member from the normal burden of showing a prima facie case of inconsistency with Article 3.1 or

1306 Appellate Body Report, EC - Hormones, paras. 165, 166. See also: Panel Report, EC - Hormones (Canada), paras.8.75, 8.76; Panel Report, EC - Hormones (US), paras. 8.72, 8.73.

1307 Appellate Body Report, EC - Hormones, para. 170.

1308 See: Appellate Body Report, EC - Hormones, para. 170. 
any other relevant article of the SPS Agreement or of the GATT 1994. ${ }^{1309}$

\subsubsection{Higher Level of SPS Protection Than in an International Standard}

The third option, which is available to WTO Members as provided in Article 3.3 of the SPS Agreement, is to deviate from the norms of international standards by establishing a higher level of SPS protection than the level to be achieved if an SPS measure is based on an international standard. As has been noted above, the Appellate Body in EC - Hormones concluded that "this right of a Member to establish its own level of sanitary protection under Article 3.3 of the SPS Agreement is an autonomous right and not an "exception" from a "general obligation" under Article 3.1". ${ }^{1310}$

However, the right of WTO Members to deviate from the norms of international standards is not unqualified. Article 3.3 prescribes two alternative conditions for establishing the level of SPS protection higher than would be achieved according to the norms of international standards:

- there must be scientific justification for such higher level of SPS protection; according to the footnote to Article 3.3, the existence of scientific justification is determined "on the basis of an examination and evaluation of available scientific information in conformity with the relevant provisions of this [SPS] Agreement"; or

- the higher level of protection is determined in accordance with obligations of Articles $5.1-5.8$ of the SPS Agreement.

In addition, the last sentence of Article 3.3 provides the more general requirement that SPS measures which are not based on relevant international standards "shall not be inconsistent with any other provision of this [SPS] Agreement".

The difference between these two alternatives is not really clear. In this respect, as has been noted by the Appellate Body, "Article 3.3 is evidently not a model of clarity in drafting and communication". ${ }^{1311}$ It is clear, however, that both alternatives require compliance with the risk analysis obligations of Article 5 of the SPS Agreement, and the obligation of risk assessment under Article 5.1 in particular. In fact, as has been held by the Appellate Body in EC-Hormones:

First, the last sentence of Article 3.3 requires that "all measures which result in a [higher] level of ... protection", that is to say,

1309 Appellate Body Report, EC - Hormones, para. 171.

1310 Appellate Body Report, EC - Hormones, para. 172.

1311 Appellate Body Report, EC - Hormones, para. 175. 
measures falling within situation (a) as well as those falling within situation (b), be "not inconsistent with any other provision of [the SPS] Agreement". "Any other provision of this Agreement" textually includes Article 5. Secondly, the footnote to Article 3.3, while attached to the end of the first sentence, defines "scientific justification" as an "examination and evaluation of available scientific information in conformity with relevant provisions of this Agreement ...”. This examination and evaluation would appear to partake of the nature of the risk assessment required in Article 5.1 and defined in paragraph 4 of Annex A of the SPS Agreement. ${ }^{1312}$

The Appellate Body further noted with respect to the distinction between the two alternatives prescribed in Article 3.3:

We are not unaware that this finding tends to suggest that the distinction made in Article 3.3 between two situations may have very limited effects and may, to that extent, be more apparent than real. Its involved and layered language actually leaves us with no choice. ${ }^{1313}$

Thus, the Appellate Body concluded that although the EU established for itself a higher level of SPS protection than the one implied in the Codex standard (recognized to be the relevant international standard), the EU was still bound to comply with the risk analysis obligations under Article 5.1 of the SPS Agreement. ${ }^{1314}$ And since the EU was found to be in breach of the requirements of Article 5.1, the Appellate Body also concluded that the EU violated Article 3.3 of the SPS Agreement. ${ }^{1315}$

In general, the approach taken by the Appellate Body in the interpretation of Articles 3.1 - 3.3 may be characterized as very delicate and aimed at leaving a lot of policy space for WTO Members. The Appellate Body in fact stressed: "It is clear to us that harmonization of SPS measures of Members on the basis of international standards is projected in the Agreement, as a goal, yet to be realized in the future". ${ }^{1316}$ Hence, according to this interpretation, it seems that Article 3.1 per se could hardly be violated as WTO Members always have an option to opt for the alternative of Article 3.3 and thus deviate from an international standard. ${ }^{1317}$ Arguably, Article 3.3 may

\footnotetext{
1312 Appellate Body Report, EC - Hormones, para. 175.

1313 Appellate Body Report, EC - Hormones, para. 176.

1314 Appellate Body Report, EC - Hormones, para. 176.

1315 Appellate Body Report, EC - Hormones, para. 209.

1316 Appellate Body Report, EC - Hormones, para. 165.

1317 For example, Marielle D. Masson Matthee also asks the question whether such an interpretation has rendered Article 3.1 obsolete; see: Mariëlle D. Masson-Matthee, The Codex Alimentarius Commission and Its Standards, T.M.C. Asser Press, 2007, pp. $147-148$.
} 
be breached only together with other substantive provisions of the SPS Agreement, like risk analysis obligations under Article 5.1.

In this regard, it may be argued that the interpretation of Article 3.1 employed by the Appellate Body contradicts the plain reading of this Article which is formulated in a mandatory fashion and provides that WTO Members "shall base" their SPS measures on international standards. It seems to be more logical to view Article 3.3 as an exemption (not an exception though) from Article 3.1. ${ }^{1318}$ Indeed, Article 3.3 itself does not provide obligations for WTO Members; it only specifies the conditions under which Members may deviate from the harmonization of their SPS measures with international standards. If these conditions are not met, it would be reasonable to expect that the matter fall under the scope of Article 3.1. It is then the obligations of Article 3.1 which would be breached and not those of Article 3.3. However, due to the character of the Article 3.3 provisions, a breach of Article 3.1 would be usually found together with a violation of another substantive obligation of the SPS Agreement (like Article 5.1). This approach would place more emphasis on the importance of harmonization by framing it as a legally enforceable obligation under the SPS Agreement. Although, perhaps due to the political sensitivity of the matter, this was exactly what the Appellate Body tried to avoid. ${ }^{1319}$

Thus, the approach taken by the Appellate Body in the interpretation of the rules of Article 3 renders the harmonization under the SPS Agreement with international standards into a rather weak concept. According to this approach, rules on harmonization could hardly be viewed as independent and fully fledged obligations under the SPS Agreement. Accordingly, compared to the requirements of harmonization based on international standards as prescribed in the TBT Agreement, the "harmonization regime" of the SPS Agreement seems to be weaker, at least in the interpretation of this regime given by the Appellate Body. ${ }^{1320}$

1318 This would indeed be in line with the approach to the interpretation of the relationship between Articles 5.7 and 5.1; for more information concerning this relationship, see Section 5.3.4.3 of the present Chapter.

1319 Indeed, SPS matters (protection of human, animal or plant life of health) seems to be more sensitive for harmonization in comparison with many other areas of regulation. Countries are frequently reluctant to limit their "policy space" in this area through harmonization based on international standards. A forceful imposition of rigid harmonization may result in a paralysis in the standardizing work of international standard-setting organizations as governments would try to block the adoption of relevant international standards. The lack of consensus among scientists concerning controversial SPS issues may also prevent "achieving a greater uniformity in national health measures”; see: Denise Prévost, Peter Van den Bossche, "The Agreement on the Application of Sanitary and Phytosanitary Meaures", at: Patrick F.J. Macrory, The World Trade Organization: Legal, Economic and Political Analysis, 1 Springer [etc.], New York, 2005, p. 279.

1320 Indeed, in EC - Sardines, the Appellate Body held that Article 2.4 prescribes legally 
However, the rules of Article 3 on the harmonization of SPS measures must be viewed in the context of the entire SPS Agreement. In this respect, unless a measure conforms to an international standard according to Article 3.2, it still needs to comply with other obligations provided in the SPS Agreement, including its strict and quite burdensome risk analysis disciplines. This indeed has implications for the regulation of private-sector standards, of course, in cases where a particular standard qualifies as an SPS measure under the SPS Agreement. The harmonization with an international standard would not be a mandatory option with respect to such a standard. However, if the private-sector standard does not confirm to the international standard, it then have to comply with extensive risk analysis disciplines, as described in the following Section.

\subsubsection{Risk Analysis Disciplines and Provisional Measures}

As has been noted, according to Article 2.2 of the SPS Agreement, WTO Members are required to base their SPS measures on scientific principles and evidence. These requirements are further developed in the risk analysis rules provided in Articles 5.1 - 5.7 of the SPS Agreement. In fact, under the SPS Agreement, the analysis of SPS risks by WTO Members is the usual and necessary process before adoption or review of their SPS measures. In the context of the SPS Agreement, two components of the risk analysis may be distinguished: risk assessment and risk management.

Risk assessment is a scientific process of evaluation of a potential or likelihood that certain SPS risks may actually materialize. It is addressed in Articles 5.1 - 5.3 of the SPS Agreement, which obliges WTO Members to undertake risk analysis based on scientific disciplines. Risk management is predominantly a policy-based process of determination by a WTO Member of an appropriate level of protection against identified SPS risks and choice of SPS measure aimed at achieving this level of protection. ${ }^{1321}$ One aspect of risk management, namely the determination of an appropriate level of SPS protection, is addressed by Articles 5.4 and 5.5 of the SPS Agreement. Another aspect, namely choice of an SPS measure, is regulated by Articles 5.3 and 5.6 of the SPS Agreement. The distinction between risk assessment and risk management appears to be a useful tool for structuring

binding and enforceable obligations for WTO Members to use international standards as a basis for their technical regulations; for more information, see Section 4.3 .3 of Chapter IV.

1321 For more general information see: Matsuo Matsushita, Thomas J. Schoenbaum, Petros C. Mavroidis, The World Trade Organization. Law, Practice, and Policy, Oxford University Press, Oxford, 2003, pp. 494 - 496; Peter Van den Bossche, Werner Zdouc, The Law and Policy of the World Trade Organization. Text, Cases and Materials, 3d Edition, CUP, 2013, p. 914. 
the regulatory process in the SPS area. However, these two processes do not exist in isolation from each other and are interconnected.

Finally, Article 5.7 provides for an exemption from the obligation to base SPS measures on risk assessment and grants WTO Members the right to adopt provisional measures if risk assessment, within the meaning of Article 5.1, is not possible due to the insufficiency of relevant scientific evidence. However, this right of WTO Members to adopt provisional measures is subject to the specific conditions contained in Article 5.7 of the SPS Agreement.

The sections below will discuss the rules of the SPS Agreement on risk assessment, risk management and adoption of provisional SPS measures in more detail.

\subsubsection{Risk Assessment Obligations}

Article 5.1 of the SPS Agreement provides:

Members shall ensure that their sanitary or phytosanitary measures are based on an assessment, as appropriate to the circumstances, of the risks to human, animal or plant life or health, taking into account risk assessment techniques developed by the relevant international organizations.

Article 5.1 thus prescribes two obligations for WTO Members: 1. to have a "risk assessment" as appropriate to the circumstances before adoption or review of SPS measures; and 2. to base their SPS measures on the "risk assessment". Accordingly, as has been held by the Panel in EC - Approval and Marketing of Biotech Products, in order to examine an SPS measure against the requirements of Article 5.1, it is necessary to address two distinct issues:

(i) whether there is a "risk assessment" within the meaning of the SPS Agreement; and

(ii) whether the measure is "based on" this risk assessment. ${ }^{1322}$

\subsection{Nature of the Risk Assessment}

The SPS Agreement, in its Annex A(4), contains the following definition of a "risk assessment":

The evaluation of the likelihood of entry, establishment or spread of a pest or disease within the territory of an importing Member according to the sanitary or phytosanitary measures which might be applied, and of the associated potential biological and economic consequences; or the evaluation of the potential

1322 Panel Report, EC - Approval and Marketing of Biotech Products, para. 7.3019. See also: Panel Report, US - Poultry (China), para. 7.173. 
for adverse effects on human or animal health arising from the presence of additives, contaminants, toxins or disease-causing organisms in food, beverages or feedstuffs.

The definition distinguishes two types of risk assessment which have different characteristics. The first type of risk assessment is aimed at the prevention of risks from pests and diseases taking into account the characteristics of an SPS measure; it also includes the evaluation of potential biological and economical consequences. The second type is applicable to SPS measures aimed at the prevention of foodborne risks. The first type of risk assessment is designed for SPS measures aimed at the objectives specified in paragraphs (a), (c) and (d) of the definition of an SPS measure in Annex A(1) of the SPS Agreement. The second type is specially meant for paragraph (b) of the definition of an SPS measure. ${ }^{1323}$

As has been confirmed by the Appellate Body in Australia - Salmon, according to the definition, the first type of risk assessment shall:

1. identify the diseases [or pests] whose entry, establishment or spread a Member wants to prevent within its territory, as well as the potential biological and economic consequences associated with the entry, establishment or spread of these diseases [or pests];

2. evaluate the likelihood of entry, establishment or spread of these diseases [or pests], as well as the associated potential biological and economic consequences; and

3. evaluate the likelihood of entry, establishment or spread of these diseases [or pests] according to the SPS measures which might be applied. ${ }^{1324}$

The second type of risk assessment incorporates another set of requirements. According to the Panel in US - Poultry (China), this type of risk assessment shall:

(i) identify the additives, contaminants, toxins or disease-causing organisms in food, beverages or feedstuffs at issue (if any);

(ii) identify any possible adverse effect on human or animal health; and

1323 See: Panel Reports, Canada-Continued Suspension, para. 7.461; Panel Report, US - Poultry (China), para. 7.177.

1324 Appellate Body Report, Australia - Salmon, para. 121. See also: Panel Report, Australia - Salmon, para. 8.72; Panel Report, Australia - Salmon (Article 21.5 Canada), para. 7.41; Appellate Body Report, Japan - Agricultural Products II, para. 113. 
(iii) evaluate the potential for that adverse effect to arise from the presence of the identified additives, contaminants, toxins or disease-causing organisms in food, beverages or feedstuffs. ${ }^{1325}$

It is worth noting the differences between the two types of risk assessment. First, the characteristics of the first type of risk assessment include the evaluation of associated potential biological and economic consequences, while the second type does not contain such a requirement. Article 5.3 of the SPS Agreement clarifies that the relevant economic factors, which WTO Members must take into account in assessing the risks to animal or plant (but not human) life or health, are:1326

$[\ldots]$ the potential damage in terms of loss of production or sales in the event of the entry, establishment or spread of a pest or disease; the costs of control or eradication in the territory of the importing Member; and the relative cost-effectiveness of alternative approaches to limiting risks.

Second, the first type of risk assessment requires an evaluation of the "likelihood" of spread of pests or diseases, while the second type only refers to an evaluation of the "potential" that adverse effect may arise. As has been held by the Appellate Body in EC - Hormones, the meaning of the terms "likelihood" (or "probability") and "potential” are not the same, as “[p]robability' implies a higher degree or a threshold of potentiality or possibility". ${ }^{1327}$ This higher threshold of possibility for "likelihood" has been further explained by the Appellate Body in Australia-Salmon:

[...] we maintain that for a risk assessment to fall within the meaning of Article 5.1 and the first definition in paragraph 4 of Annex A, it is not sufficient that a risk assessment conclude that there is a possibility of entry, establishment or spread of diseases and associated biological and economic consequences. A proper risk assessment of this type must evaluate the "likelihood", i.e., the "probability", of entry, establishment or spread of diseases and associated biological and economic consequences as well

1325 Panel Report, US - Poultry (China), para. 7.178, referring to Panel Reports, Canada - Continued Suspension, para. 7.479. See also in this respect: Panel Report, ECHormones (US), para. 8.98; Panel Report, EC - Hormones (Canada), para. 8.101 as modified by Appellate Body Report, EC - Hormones, paras. 183 - 186; Peter Van den Bossche, Werner Zdouc, The Law and Policy of the World Trade Organization. Text, Cases and Materials, 3d Edition, CUP, 2013, pp. 915 - 916.

1326 The protection of human health obviously has a higher priority in the SPS Agreement than health of animals or plants. The drafters of the SPS Agreement did perhaps not consider it appropriate to require taking into account economic factors while assessing the risks to human health.

1327 Appellate Body Report, EC - Hormones, para. 184. 
as the "likelihood", i.e., "probability", of entry, establishment or spread of diseases according to the SPS measures which might be applied. ${ }^{1328}$

Third, the first type of risk assessment is required to evaluate the risks "according to the SPS measure which might be applied", while there is no such a requirement for the second type. In Japan - Apples, the Appellate Body upheld the conclusions of the Panel that this requirement suggests that consideration be given "at least to a potential range of relevant measures". ${ }^{1329}$ Thus, "a risk assessment should not be limited to an examination of the measure already in place or favoured by the importing Member". ${ }^{1330}$

Generally, the second type of risk assessment seems to be formulated in a less demanding fashion than the first one. This is perhaps the case because human health is presumed to be more likely endangered by foodborne risks.

Furthermore, some general guidelines and requirements with respect to both types of risk assessment have been developed in WTO case law. First, as has been noted by the Appellate Body, neither type of risk assessment is required "to establish a minimum magnitude of risk"; ${ }^{1331}$ i.e. there is no a requirement to show a certain minimal level of risks. A risk assessment does therefore not necessarily imply that risks must be quantified (e.g. in percentage); they "may be expressed either quantitatively or qualitatively". ${ }^{1332}$ Second, "the 'risk' evaluated in a risk assessment must be an ascertainable risk; theoretical uncertainty is "not the kind of risk which, under Article 5.1, is to be assessed". ${ }^{1333}$ Third, the Appellate Body emphasized that the risks to be addressed in the risk assessment are not only those ascertainable "in a science laboratory operating under strictly controlled conditions", but these are also the risks "in human societies as they actually exist [...] in the real world where people live and work and die". ${ }^{1334}$ Fourth, a risk assessment must be specific, i.e. it must identify specific risks presented by specific agents and be supported by specific scientific evidence. ${ }^{1335}$ It may

\footnotetext{
1328 Appellate Body Report, Australia-Salmon, para. 123.

1329 Appellate Body Report, Japan - Apples, para. 207; See also Panel Report, Japan - Apples, para. 8.285.

1330 Appellate Body Report, Japan - Apples, para. 208.

1331 Appellate Body Report, EC - Hormones, para. 186.

1332 Appellate Body Report, Australia-Salmon, para. 124.

1333 Appellate Body Report, Australia-Salmon, para. 125. See also: Appellate Body Report, EC - Hormones, para. 186; the Appellate Body admitted the note by the Panel that theoretical uncertainty, in principle, may always be present as science can never provide absolute certainty.

1334 Appellate Body Report, EC - Hormones, para. 187.

1335 See: Appellate Body Report, EC - Hormones, para. 200; Appellate Body Report, Japan-Apples, para. 204.
} 
not only point out hypothetical or general hazards. Fifth, Article 5.1 does not necessarily require that WTO Members conduct their own risk assessment. Instead, they may base their SPS measures on a risk assessment conducted by another Member or an international organization. ${ }^{1336}$ Sixth, a risk assessment must be objective and unprejudiced. As has been noted by the Appellate Body, it "should not be distorted by preconceived views on the nature and the content of the measure to be taken; nor should it develop into an exercise tailored to and carried out for the purpose of justifying decisions ex post facto". ${ }^{1337}$ Seventh, as has been noted by the Appellate Body, "while the correctness of the views need not have been accepted by the broader scientific community, the views must be considered to be legitimate science according to the standards of the relevant scientific community". ${ }^{1338}$

Finally, according to the Panel in EC - Approval and Marketing of Biotech Products, a risk assessment must be "appropriate to the circumstances". ${ }^{1339}$ This factor not only provides WTO Members with "a certain degree of flexibility in meeting the requirements of Article 5.1", ${ }^{1340}$ but also affects the relevance of the risk assessment in the sequence of time. Relevant circumstances may change over the time; for example new scientific evidence may become available, rendering existing risk assessments outdated and therefore irrelevant. ${ }^{1341}$ Thus, WTO Members are obliged to review previous risk assessments or undertake new ones, if necessary, due to the evolution of scientific evidence or other important changes of circumstances. ${ }^{1342}$

\footnotetext{
1336 See: Appellate Body Report, EC - Hormones, para. 190.

1337 Appellate Body Report, Japan - Apples, para. 208.

1338 Appellate Body Report, US/Canada - Continued Suspension, para. 591. See also: Appellate Body Report, Australia-Apples, para. 214.

1339 See: Panel Report, EC - Approval and Marketing of Biotech Products, paras. 7.3030 -7.3031 .

1340 Appellate Body Report, EC - Hormones, para. 129. See also: Panel Report, EC Approval and Marketing of Biotech Products, para. 7.3032.

1341 See: Panel Report, EC - Approval and Marketing of Biotech Products, paras. 7.3031 - 7.3034. The Panel therefore concluded that, under Article 5.1, a risk assessment must be "appropriate to the circumstances" not on the dates of adoption of an SPS measure, and not on the date of performance of the risk assessment, but on the date of a dispute, i.e. on the date of establishment of a WTO panel for resolution of the dispute. Thus, according to this interpretation, it was irrelevant for the Panel to consider whether certain scientific evidence available at the time of the dispute were actually existing and available on the dates of risk assessment or adoption of a measure.

1342 See: Panel Report, Japan - Apples, para. 7.12. According to the Panel, the risk assessment obligation must be read together with the requirement of Article 2.2 not to maintain SPS measures without sufficient scientific evidence. Therefore, "[i] $\mathrm{f}$ the scientific evidence evolves, this may be an indication that the risk assessment should be reviewed or a new assessment undertaken. [...] Even though new evidence may not always justify a new risk assessment".
} 
Article 5.1 of the SPS Agreement specifies that WTO Members must undertake a risk assessment which takes into account the techniques developed by relevant international organizations. Article 5.2 further provides other factors that Members shall take into account in performing risk assessment:

In the assessment of risks, Members shall take into account available scientific evidence; relevant processes and production methods; relevant inspection, sampling and testing methods; prevalence of specific diseases or pests; existence of pest- or disease-free areas; relevant ecological and environmental conditions; and quarantine or other treatment.

This, apparently, is an open list, which makes clear that a risk assessment within the meaning of the SPS Agreement is a process based not solely on pure science practiced in isolated laboratory conditions. The risk assessment may take into account factors of the real world, such as climatic conditions in a place of production and control methods, including even the risks of human mistakes. As has been already mentioned, in EC - Hormones the Appellate Body explained this in the following way:

Some of the kinds of factors listed in Article 5.2 such as "relevant processes and production methods" and "relevant inspection, sampling and testing methods" are not necessarily or wholly susceptible of investigation according to laboratory methods of, for example, biochemistry or pharmacology. Furthermore, there is nothing to indicate that the listing of factors that may be taken into account in a risk assessment of Article 5.2 was intended to be a closed list. It is essential to bear in mind that the risk that is to be evaluated in a risk assessment under Article 5.1 is not only risk ascertainable in a science laboratory operating under strictly controlled conditions, but also risk in human societies as they actually exist, in other words, the actual potential for adverse effects on human health in the real world where people live and work and die. ${ }^{1343}$

In dispute settlement, it is not for WTO panels or the Appellate Body to make their own scientific judgments or to determine whether a risk assessment undertaken by a WTO Member is correct. According to the Appellate Body in US/Canada - Continued Suspension, it shall rather be determined "whether that risk assessment is supported by coherent reasoning and respectable scientific evidence and is, in this sense, objectively justifiable". ${ }^{1344}$ In other words, according to the Appellate Body, in the dispute settle-

1343 Appellate Body Report, EC - Hormones, para. 187.

1344 Appellate Body Report, US/Canada-Continued Suspension, para. 590. See also: Appellate Body Report, Australia - Apples, para. 213. 
ment process it shall be verified whether a scientific basis underlying an SPS measure "comes from a respected and qualified source" and has "the necessary scientific and methodological rigour to be considered reputable science". ${ }^{1345}$

In Australia - Apples, the Appellate Body summarized the abovementioned findings and identified two aspects for the review of a risk assessment by the WTO dispute settlement under Article 5.1 of the SPS Agreement:

(i) a determination that the scientific basis of the risk assessment comes from a respected and qualified source and can accordingly be considered "legitimate science" according to the standards of the relevant scientific community; and

(ii) a determination that the reasoning of the risk assessor is objective and coherent and that, therefore, its conclusions find sufficient support in the underlying scientific basis. ${ }^{1346}$

Thus, under Article 5.1 of the SPS Agreement, there is no requirement that a scientific opinion must be predominant within a scientific community and shared by a majority of scientists. An adequate risk assessment may also be based by a WTO Member on a dissenting opinion (i.e. an opinion adhered to by a minority or even one scientist), presuming that this opinion is scientific in its nature, i.e. may be regarded as "legitimate science".

\subsection{SPS Measures Based on Risk Assessment}

As has been stated above, according to Article 5.1, SPS measures must be "based on" risk assessment. The Appellate Body interpreted the meaning of this requirement as an objective and rational relationship between a measure and a risk assessment. ${ }^{1347}$ As has been observed by the Appellate Body in EC-Hormones:

We believe that "based on" is appropriately taken to refer to a certain objective relationship between two elements, that is to say, to an objective situation that persists and is observable between an SPS measure and a risk assessment. ${ }^{1348}$

The Appellate Body further concluded that Article 5.1, read in conjunction with Article 2.2, requires that:

1345 Appellate Body Report, US/Canada - Continued Suspension, para. 591. See also: Appellate Body Report, Australia - Apples, para. 214.

1346 Appellate Body Report, Australia-Apples, para. 220.

1347 See: Appellate Body Report, EC - Hormones, paras. 189 - 193. See also: Appellate Body Report, Australia - Apples, paras. 210, 215, 219.

1348 Appellate Body Report, EC - Hormones, para. 189. 
$[\ldots]$ the results of the risk assessment must sufficiently warrant - that is to say, reasonably support - the SPS measure at stake. The requirement that an SPS measure be "based on" a risk assessment is a substantive requirement that there be a rational relationship between the measure and the risk assessment. ${ }^{1349}$

The Appellate Body thus rejected the interpretation adopted by the Panel that the requirement to base SPS measures on a risk assessment meant only that a risk assessment must be "taken into account" when imposing a measure. According to the Appellate Body, "taking into account", as has been construed by the Panel, refers "to some subjectivity which, at some time, may be present in particular individuals", while the term "based on" signifies an "objective relationship" between the two relevant elements. ${ }^{1350}$

Furthermore, in EC - Approval and Marketing of Biotech Products, the Panel clarified that a measure may not be regarded as based on a risk assessment if "these assessments reached a different overall conclusion" and if a WTO Member disagrees with some or all of the conclusions. In such cases, Members need to provide explanations "by reference to the existing assessment, how and why they assess the risks differently, and to provide their revised or supplemental assessment of the risks". ${ }^{1351}$

According to the Appellate Body, the determination about whether an SPS measure is based on risk assessment (i.e. a determination of the objective and rational relationship between a measure and a risk assessment) shall be conducted on a case-by case basis considering all the circumstances of a situation. Depending on the circumstances, WTO Members may, in principle, base their SPS measures not only on mainstream scientific opinions, but also on diverging scientific views. In EC - Hormones the Appellate Body observed in this respect:

Article 5.1 does not require that the risk assessment must necessarily embody only the view of a majority of the relevant scientific community. In some cases, the very existence of divergent views presented by qualified scientists who have investigated the particular issue at hand may indicate a state of scientific uncertainty. Sometimes the divergence may indicate a roughly equal balance of scientific opinion, which may itself be

\footnotetext{
1349 Appellate Body Report, EC - Hormones, para. 193.

1350 See: Appellate Body Report, EC - Hormones, para. 189. However, in the end the Appellate Body affirmed the ultimate findings of the Panel that the EU measure (import prohibition on hormone treated meat products) was not based on risk assessment within the meaning of Articles 5.1 and 5.2 of the SPS Agreement (and thus was inconsistent with Article 5.1), since "no risk assessment that reasonably supports or warrants the import prohibition embodied in the EC Directives was furnished to the Panel”. See: Appellate Body Report, EC - Hormones, para. 208.

1351 See: Panel Report, EC - Approval and Marketing of Biotech Products, para. 7.3062.
} 
a form of scientific uncertainty. In most cases, responsible and representative governments tend to base their legislative and administrative measures on "mainstream" scientific opinion. In other cases, equally responsible and representative governments may act in good faith on the basis of what, at a given time, may be a divergent opinion coming from qualified and respected sources. By itself, this does not necessarily signal the absence of a reasonable relationship between the SPS measure and the risk assessment, especially where the risk involved is life-threatening in character and is perceived to constitute a clear and imminent threat to public health and safety. Determination of the presence or absence of that relationship can only be done on a case-tocase basis, after account is taken of all considerations rationally bearing upon the issue of potential adverse health effects. ${ }^{1352}$

From the above discussion on the content of the risk assessment disciplines of the SPS Agreement, it is clear that these disciplines are rather complex and strict. Article 5.1 of the SPS Agreement requires solid scientific basis for the adoption and maintenance of SPS measures; abstract assumptions and precautions due to consumer concerns would be insufficient in this regard. In this regard, the risk assessment disciplines of Article 5.1 would be particularly problematic with respect to private-sector standards, should they be recognized as SPS measures under the SPS Agreement. Indeed, as has been explained in Section 5.3.2.2 of the present Chapter, SPS requirements of private-sector standards are, in many instances, developed, adopted and applied due to consumer demands which are not based on science. Meanwhile, such standards usually present stricter SPS requirements than governmental rules and regulations. It would thus seem reasonable to suppose that many, if not the majority of SPS-related private-sector standards, should they be qualified as SPS measures under the SPS Agreement, would not be in compliance with the rules of Article 5.1.

\subsubsection{Risk Management}

As has been mentioned before, risk management is a policy-based decisionmaking process. It includes two elements: 1. a determination of the level of SPS protection, which a WTO Member regards as appropriate for its territory; and 2. a decision on a measure to be applied by a Member in order to achieve the chosen level of protection. These decisions are usually based both on the available scientific information and public health policy of WTO Members. Public health policies of the Members depend on their geographical conditions, traditions, societal values and other relevant factors. Indeed, because WTO Members may have differing socio-economic,

1352 Appellate Body Report, EC - Hormones, para. 194. 
geographical conditions and public health policies, the SPS Agreement allows substantial discretion to Members in their choices of the levels of SPS protection and in their choices of SPS measures. Nevertheless, the SPS Agreement still prescribes important legal disciplines in order to ensure that this leeway for discretion is not abused, and also that the trade-restrictive effects of SPS measures are minimized.

\subsection{Choice of Appropriate Level of Protection}

The first element of the risk assessment entails a determination of the "appropriate level of SPS protection", which is defined in Annex A(5) of the SPS Agreement as:

The level of protection deemed appropriate by the Member establishing a sanitary or phytosanitary measure to protect human, animal or plant life or health within its territory.

The definition clearly acknowledges the freedom of WTO Members to choose the level of SPS protection they deem appropriate. Therefore, if the presence of SPS risks is reliably established through the risk assessment process, WTO Members have the discretion to determine the level of protection suitable for them. This may even be a "zero risk" level of SPS protection. ${ }^{1353}$

There are two provisions in the SPS Agreement that deal with determining the appropriate level of protection by WTO Members. The first is specified in Article 5.4 which provides that: "Members should, when determining the appropriate level of sanitary or phytosanitary protection, take into account the objective of minimizing negative trade effects". The use of the verb "should" (and not "shall") indicates that Article 5.4 is hortative in nature and, as such, does not impose mandatory obligations on WTO Members. ${ }^{1354}$ Indeed, requiring WTO Members to choose the least trade-restrictive level of SPS protection would contradict the abovementioned principle specified in Annex A(5) of the SPS Agreement that WTO Members are free to choose their appropriate level of protection. Needless to say, this would substantially limit a "policy space" for WTO Members to pursue their health policy objectives which, undoubtedly, would be unacceptable for many Members.

The second provision is specified in Article 5.5 which reads, in its relevant part:

With the objective of achieving consistency in the application of the concept of appropriate level of sanitary or phytosanitary

1353 See: Appellate Body Report, Australia - Salmon, para. 125.

1354 See: Peter Van den Bossche, Werner Zdouc, The Law and Policy of the World Trade Organization. Text, Cases and Materials, 3d Edition, CUP, 2013, p. 921. 
protection against risks to human life or health, or to animal and plant life or health, each Member shall avoid arbitrary or unjustifiable distinctions in the levels it considers to be appropriate in different situations, if such distinctions result in discrimination or a disguised restriction on international trade.

As has been explained before, this provision of Article 5.5 forms a specific enunciation in relation to the general prohibition of arbitrary or unjustifiable discrimination and disguised restrictions on international trade prescribed in Article 2.3 of the SPS Agreement. A violation of Article 5.5 will therefore necessarily entail a violation of Article 2.3, but not necessarily vice versa. ${ }^{1355}$

From the text of the relevant provision of Article 5.5 two elements can be distinguished:

- the objective - achieving consistency in the application of the concept of appropriate level of SPS protection; and

- the obligation - to avoid arbitrary or unjustifiable distinctions in these levels in different situations if such distinctions result in discrimination or disguised restrictions on international trade.

With respect to the objective of achieving consistency, the Appellate Body in EC - Hormones pointed out: "Clearly, the desired consistency is defined as a goal to be achieved in the future". ${ }^{1356}$ The Appellate Body thus agreed with the conclusions of the Panels that "the statement of that goal does not establish a legal obligation of consistency of appropriate levels of protection". ${ }^{1357}$ The Appellate Body further concluded that the goal, as such, is not set as an absolute or perfect consistency, because governments may establish their levels of protection on an ad hoc basis, taking into account various risks arising over different periods of time. Thus, only arbitrary or unjustifiable inconsistency must be avoided under to Article 5.5. ${ }^{1358}$

In order to establish a violation of Article 5.5 three distinct and cumulative requirements must be met:

- the Member has adopted its own appropriate levels of SPS protection in several different situations;

- these levels of SPS protection demonstrate arbitrary or unjustifiable distinctions (i.e. differences) in their treatment of different situations; and

- the arbitrary or unjustifiable distinctions result in discrimination or disguised restrictions on international trade. ${ }^{1359}$

\footnotetext{
1355 See Section 5.3.2.3 of the present Chapter.

1356 Appellate Body Report, EC - Hormones, para. 213.

1357 Appellate Body Report, EC - Hormones, para. 213.

1358 See: Appellate Body Report, EC - Hormones, para. 213.

1359 See: Appellate Body Report, EC - Hormones, paras. 214-215. See also: Appellate
} 
With respect to the first element, not all situations may be regarded as "different" ones in the context of Article 5.5. According to the Appellate Body, in order to examine the "arbitrariness" of distinctions in the levels of SPS protection, the different situations must also be "comparable". ${ }^{1360}$ The situations may be considered comparable if they sufficiently present some common element or elements. For example, this may be situations involving the same substances or the same adverse health effects, the same deceases or similar potential economic and biological consequences. ${ }^{1361}$ If, on the contrary, "the situations proposed to be examined are totally different from one another, they would not be rationally comparable and the differences in levels of protection cannot be examined for arbitrariness". ${ }^{1362}$

Furthermore, in Australia - Salmon, the Panel held that the chosen appropriate levels of SPS protection for the purposes of Article 5.5, even if not provided by a WTO Member, could be reflected in the SPS measures applied. The distinctions in the levels of protection could thus also be discerned from the differences in the SPS measures. ${ }^{1363}$

According to the second element of the test, under Article 5.5, the levels of SPS protection must show arbitrary or unjustifiable differences. In order to determine whether this element is fulfilled panels and the Appellate Body consider whether there is a reasonable and convincing explanation for the differences in the levels of SPS protection, i.e. whether these differences might be reasonably justified. ${ }^{1364}$ In particular, the examination shall include a consideration of whether the distinctions in the established

Body Report, Australia - Salmon, para. 140; Panel Report, US - Poultry (China), para. 7.221.

1360 See: Appellate Body Report, EC - Hormones, para. 217. See also: Panel Report, Australia-Apples, paras. 7.938-7.939.

1361 See: Panel Report, EC - Hormones (US), para. 8.176; Panel Report, EC - Hormones (Canada), para. 8.179; Appellate Body Report, EC - Hormones, paras. 216 - 217; Appellate Body Report, Australia - Salmon, para. 146; Panel Report, AustraliaApples, para. 7.944; Panel Report, US - Poultry (China), paras. 7.227 - 7.228.

1362 Appellate Body Report, EC - Hormones, para. 217. See also: Panel Report, US Poultry (China), para. 7.226.

1363 This finding by the Panel was not appealed. See: Panel Report, Australia-Salmon, para. 8.129; Appellate Body Report, Australia - Salmon, para. 153, footnote 106. However, it must be noted that in the same case, and in the context of Article 5.6, the Appellate Body concluded that the a chosen level of SPS protection could be deduced from an applied SPS measure only if a WTO Member using the measure does not express the chosen level of protection, or does this too vaguely. See: Appellate Body Report, Australia - Salmon, paras. 200 - 207; see also the relevant part of the discussion with respect to Article 5.6 of the SPS Agreement in Section 5.3.4.2.2 of the present Chapter.

1364 See: Panel Report, Australia - Salmon, para. 8.133 as upheld in Appellate Body Report, Australia-Salmon, para. 158. See also: Panel Report, US - Poultry (China), para. 7.262. 
levels of SPS protection are related and commensurate to the differences in the levels of risks. For example, in Australia-Salmon, the Panel and the Appellate Body examined the notable differences in Australia's levels of SPS protection for ocean-caught Pacific salmon and for herring used for bait or ornamental finfish. The differences were found to be arbitrary and unjustifiable because these types of fish presented similar risks. ${ }^{1365}$

In EC - Hormones, the Appellate Body considered the differences in the levels of protection established by the EU for hormones on growth promotion on the one hand, and for hormones naturally accruing in food products or hormones used for therapeutic and zootechnical purposes on the other. The Appellate Body emphasised the "fundamental distinction between added hormones (natural or synthetic) and naturally-occurring hormones in meat and other foods". ${ }^{1366}$ According to the Appellate Body, the impossibility of imposing meaningful governmental requirements regarding naturally-occurring hormones "reduces the comparison itself to an absurdity" ${ }^{1367}$ Concerning the therapeutic and zootechnical hormones, the Appellate Body took into account the significant differences in the burden of controlling the risks as compared to situations regarding growth hormones. ${ }^{1368}$ The Appellate Body thus disagreed with the Panel that the distinctions in the levels of SPS protection in these situations were arbitrary or unjustifiable. ${ }^{1369}$

Finally, the arbitrary or unjustifiable character of differences in the level of SPS protection alone is not sufficient for constituting a violation of Article 5.5 of the SPS Agreement. According to the third element of the test under Article 5.5, the arbitrary or unjustifiable differences must result in discrimination or disguised restrictions on international trade. Whether the discrimination or disguised restrictions are in place may be determined only on a case-by-case basis depending on particular circumstances. In order to help with this determination, three "warning signals" were identified in WTO case law. According to the Appellate Body, these "warning signals" shall be regarded together with the other relevant factors of a case and may not be solely regarded as conclusive evidence of discrimination or disguised restrictions. ${ }^{1370}$ These "warning signals" are:

1365 See: Panel Report, Australia - Salmon, paras. 8.134-8.141; Appellate Body

Report, Australia-Salmon, paras. 154-158.

1366 Appellate Body Report, EC - Hormones, para. 221.

1367 Appellate Body Report, EC - Hormones, para. 221.

1368 Appellate Body Report, EC - Hormones, paras. 223 - 224.

1369 Appellate Body Report, EC - Hormones, paras. 221 - 225

1370 See: Appellate Body Report, EC - Hormones, para. 240. See also: Panel Report, US - Poultry (China), para. 7.282. 
- the arbitrary or unjustifiable character of the differences in levels of protection (as required by the second element of the test under Article 5.5);

- the rather substantial difference in established levels of SPS protection; and

- inconsistency of an SPS measure with Articles 2.2 and

5.1 of the SPS Agreement, i.e. the absence of scientific justification and appropriate risk assessment. ${ }^{1371}$

With respect the last "warning signal" the Appellate Body clearly explained in Australia - Salmon:

We note that a finding that an SPS measure is not based on an assessment of the risks to human, animal or plant life or health - either because there was no risk assessment at all or because there is an insufficient risk assessment - is a strong indication that this measure is not really concerned with the protection of human, animal or plant life or health but is instead a traderestrictive measure taken in the guise of an SPS measure, i.e., a "disguised restriction on international trade". ${ }^{1372}$

The second sentence of Article 5.5 provides that WTO Members shall cooperate in the SPS Committee in order to develop guidelines to assist with the practical implementation of the Article's provisions. In July 2000, the SPS Committee adopted such Guidelines after series of consultations. ${ }^{1373}$ The Guidelines are mainly based on the developed case law and provide a number of practical directions with respect to the implementation of Article 5.5, including instructions on the indication of chosen levels of SPS protection by WTO Members, the review of these levels, and the use of the three "warning signals". The Guidelines, however, are not mandatory and "do not provide any legal interpretation or modification to the [SPS] Agreement itself". ${ }^{1374}$

Arguably, the discussed disciplines of the SPS Agreement, with respect to the choice of appropriate level of SPS protection, are hardly suitable for the regulation of private-sector standards, particularly those adopted and applied without meaningful governmental support or incentives. First of all, since such private-sector standards are voluntary and are applied by various private entities, it is appropriate to speak about the levels of protection established by the private entities, and not by WTO Members. Second, due

1371 See: Panel Report, Australia - Salmon, paras. 8.149-8.151 as upheld in the Appellate Body Report, Australia - Salmon, paras. 161 - 166; Panel Report, US Poultry (China), para. 7.277. The first two "warning signals" were also referred to in Appellate Body Report, EC - Hormones, paras. 215, 240.

1372 Appellate Body Report, Australia-Salmon, para. 166.

1373 See: Guidelines to Further the Practical Implementation of Article 5.5, WTO, SPS Committee, G/SPS/15, Geneva, 18 July 2000.

1374 Ibid., p. 1. 
to the huge diversity of private-sector standards, the differences in levels of protection promulgated by these standards may frequently be rather substantial and, arguably, also rather arbitrary. The motivation behind these differences is usually not related to the extent of risks involved or to the difficulties of SPS control, but might rather be linked to the issues of brand reputation, profit gains, the creation of niche markets, etc. In this regard, private standard-setting organizations could hardly be expected to predominantly pursue the goals related to the interests of the general public. It is thus hardly possible to hold WTO Members responsible for the differences in the appropriate levels of protection established in private-sector standards, unless the Members are meaningfully involved in the adoption and application of the standards.

\subsection{Choice of an SPS Measure}

The first rule on the choice of an SPS measure to be applied in order to achieve the appropriate level of protection is specified in Article 5.3. This rule is applicable only with respect to risks to animal or plant (not human) life or health, and it enumerates the relevant economic factors which WTO Members must take into account in decision-making processes on the applicable SPS measure. ${ }^{1375}$

The second and indeed the more important rule on the choice of an SPS measure is prescribed in Article 5.6, which reads:

Without prejudice to paragraph 2 of Article 3, when establishing or maintaining sanitary or phytosanitary measures to achieve the appropriate level of sanitary or phytosanitary protection, Members shall ensure that such measures are not more traderestrictive than required to achieve their appropriate level of sanitary or phytosanitary protection, taking into account technical and economic feasibility.

The meaning of this rule is clarified in a footnote to Article 5.6:

For purposes of paragraph 6 of Article 5, a measure is not more trade-restrictive than required unless there is another measure, reasonably available taking into account technical and economic feasibility, that achieves the appropriate level of sanitary or phytosanitary protection and is significantly less restrictive to trade.

1375 As has been discussed, according to Article 5.3 these economic factors (i.e. potential damage, costs of control or eradication, cost-effectiveness of alternative approaches) must be also taken into account in assessing the risk to animal or plant life or health; see Section 5.3.4.1.1 of the present Chapter. 
The provisions of the footnote refer to certain elements of the necessity test. Indeed, as has been pointed out before, the norms of Article 5.6 represent the more specific reflection of the general necessity requirements under Article 2.2 of the SPS Agreement. ${ }^{1376}$ And, according to WTO case law, a violation of Article 5.6 will automatically entail a violation of necessity provisions of Article 2.2, but not necessarily vice versa. ${ }^{1377}$ Moreover, in Australia - Apples, the Appellate Body noted that Article 5.6 presents a separate and independent obligation, i.e. as is the case with analysis under Article 5.1 of the SPS Agreement, "Article 5.6 analysis must stand on its own feet". ${ }^{1378}$

Based on the wording of the footnote to Article 5.6, the three-pronged test was developed in WTO case law in order to establish a violation of Article 5.6. The three elements of this test require that, for violation of Article 5.6, there must be an alternative SPS measure which:

- is reasonably available taking into account technical and economic feasibility;

- achieves the Member's appropriate level of SPS protection; and

- is significantly less restrictive to trade than the SPS measure contested. ${ }^{1379}$

These three elements are cumulative, i.e. all of them must be fulfilled in order to establish inconsistency with Article 5.6. ${ }^{1380}$

The first element, alternative SPS measures which are reasonably available, includes the consideration of all factors of the case including alternative measures used by other WTO Members in similar circumstances. ${ }^{1381}$ Of course only the alternatives which are "reasonably" available to a Member, taking into account technical and economic factors, may be considered. As has been suggested by the Panel in Japan - Apples (Article 21.5 - US), these factors must be assessed in "real world" conditions, including the risks of

1376 See Section 5.3.2.1 of the present Chapter.

1377 See: Panel Report, Australia - Apples, paras. 7.1404, 7.1409 - 7.1410; the issue was not appealed by was collaterally upheld in Appellate Body Report, AustraliaApples, para. 340. See also: Appellate Body Report, Australia-Salmon, para. 213.

1378 Appellate Body Report, Australia-Apples, para. 354.

1379 See: Panel Report, Australia - Salmon, para. 8.167 as upheld in Appellate Body Report, Australia - Salmon, para. 194. See also: Appellate Body Report, JapanAgricultural Products II, para. 95; Appellate Body Report, Australia- Apples, paras. 337, 360; Panel Report, US - Poultry (China), para. 7.331.

1380 See: Panel Report, Australia - Salmon, para. 8.167 as upheld in Appellate Body Report, Australia - Salmon, para. 194. See also: Appellate Body Report, JapanAgricultural Products II, para. 95; Appellate Body Report, Australia-Apples, para. 337; Panel Report, US - Poultry (China), para. 7.332.

1381 See: Panel Report, Australia - Salmon, para. 8.171 as upheld in Appellate Body Report, Australia-Salmon, para. 195. See also: Panel Report, Australia-Salmon (Article 21.5-Canada), paras. 7.146-7.148. 
incorrect enforcement. ${ }^{1382}$ For example, in Australia - Salmon, the Panel refused to consider two alternatives suggested by the complainant (the removal of all quarantine restrictions or an import prohibition for all salmon products) as not reasonably available and practically feasible. However, the Panel did examine four other more realistic alternatives specified in Australia's risk assessment. ${ }^{1383}$

In order to establish the second element of the test under Article 5.6, it is necessary to identify the appropriate level of SPS protection adopted by a WTO Member, and to determine that an alternative SPS measure is able to achieve this level of protection or an even higher level. ${ }^{1384}$ From this perspective, it is the task of a complainant to make a prima facie case that an alternative measure meets the appropriate level of protection established by a respondent. In doing this, a complainant may rely on the existing risk assessment or other scientific and factual data as a source of evidence. ${ }^{1385}$

In Australia - Salmon, the Appellate Body emphasized that the determination of the appropriate level of protection is a prerogative of a WTO Member and not of WTO panels or the Appellate Body. It therefore rejected the Panel's reasoning identifying the appropriate level of SPS protection based on a review of the SPS measure and not on the explanations consistently provided by Australia. ${ }^{1386}$ The Appellate Body further clarified that the appropriate level of SPS protection established by a WTO Member, and the SPS measure, must be clearly distinguished, as " $[\mathrm{t}]$ he first is an objective, the second is an instrument chosen to attain or implement that objective". ${ }^{1387}$ Thus, "the determination by a Member of the "appropriate level of protection' logically precedes the establishment or decision on maintenance of an 'SPS measure'." 1388

The Appellate Body recognized that the SPS Agreement does not explicitly prescribe the obligation of WTO Members to determine and explain their appropriate level of SPS protection. However, according to the Appellate Body this obligation is implied in several provisions of the SPS

1382 See: Panel Report, Japan - Apples (Article 21.5 - US), para. 8.171. See also: Panel Report, Australia-Apples, para. 7.1257.

1383 See: Panel Report, Australia - Salmon, para. 8.171 as upheld in Appellate Body Report, Australia-Salmon, para. 195.

1384 See: Appellate Body Report, Australia - Salmon, para. 208; Appellate Body Report, Australia-Apples, para. 344.

1385 See: Appellate Body Report, Australia - Salmon, paras. 209 - 213; Appellate Body Report, Australia-Apples, paras. 364-366.

1386 See: Appellate Body Report, Australia-Salmon, paras. 199, 204. See also the discussion in the context of Article 5.5, particularly, footnote 299 in Section 5.3.4.2.1 of the present Chapter.

1387 Appellate Body Report, Australia - Salmon, para. 200.

1388 Appellate Body Report, Australia - Salmon, para. 201. See also: Appellate Body Report, Australia - Apples, para. 342. 
Agreement: Articles 4.1, 5.4 and 5.6, paragraph 3 of Annex B. ${ }^{1389}$ The failure of a WTO Member to comply with this implicit obligation to determine its appropriate level of SPS protection with sufficient clarity shall thus not exonerate the Member from its responsibilities under the SPS Agreement. The Appellate Body concluded that, in situations where a Member fails to determine its chosen level of SPS protection, or does so with insufficient clarity, the appropriate level of protection may be deduced from the applied SPS measure. In particular, it explained:
...we believe that in cases where a Member does not determine its appropriate level of protection, or does so with insufficient precision, the appropriate level of protection may be established by panels on the basis of the level of protection reflected in the SPS measure actually applied. Otherwise, a Member's failure to comply with the implicit obligation to determine its appropriate level of protection - with sufficient precision - would allow it to escape from its obligations under this Agreement and, in particular, its obligations under Articles 5.5 and 5.6. ${ }^{1390}$

The third element of the test under Article 5.6, that an alternative SPS measure must be significantly less trade-restrictive than the contested one, deals with the comparison of trade effects of the SPS measures. From WTO case law it seems that the third element of Article 5.6 is found to be fulfilled if the market access would be substantially improved in case of the application of an alternative SPS measure. ${ }^{1391}$ For example, a measure which, under specific conditions, allows the importation of a product, was recognized by the Panel in Australia - Salmon to be significantly less trade-restrictive than the one which prohibits the importation of the same product. ${ }^{1392}$

The discussed disciplines on the choice of an SPS measure may hardly have much relevance with respect to the issue of the regulation of "purely" private-sector standards developed, adopted and applied without meaningful governmental involvement or incentives. In fact, Article 5.6 deals with the choice of an SPS measure by a WTO Member in order to meet selected appropriate levels of SPS protection. It thus seems highly unlikely that Article 5.6 could be applied to a private-sector standard, unless it is demonstrated that the standard is an SPS measure enforced with a contribution of a WTO Member in order to achieve its chosen level of SPS protection,

\footnotetext{
1389 See: Appellate Body Report, Australia - Salmon, paras. 205 - 206.

1390 Appellate Body Report, Australia-Salmon, para. 207. See also: Appellate Body Report, Australia-Apples, para. 343.

1391 See: Panel Report, Australia - Salmon, para. 8.182; Panel Report, Australia - Salmon (Article 21.5 - Canada), paras. 7.150 - 7.152; Panel Report, Japan Agricultural Products II, paras. 8.79, 8.95 - 8.97; Panel Report, Australia-Apples, paras. 7.1262 - 7.1265.

1392 See: Panel Report, Australia-Salmon, para. 8.182.
} 
i.e. the Member provides a meaningful amount of governmental support or incentives for the implementation of the standard in a market.

\subsubsection{Provisional SPS Measures and the Role of the Precautionary Principle}

As has been discussed before, the SPS Agreement contains important and rather strict scientific disciplines for the development, adoption and application of SPS measures by WTO Members. The Agreement generally requires that all SPS measures be based on sufficient scientific evidence. However, contemporary science is not "almighty"; and there may be situations where there is not sufficient reliable scientific evidence on a very complex or novel issue. Meanwhile, the responsible governments have to act in order to prevent the occurrence of unknown or insufficiently studied risks and avoid possible harm to important public interests. Governments thus may, and sometimes even must, act with precaution until more scientific research is undertaken and more reliable scientific evidence become available. It is common to say that, in such cases, the governments should use the "precautionary approach" or act in accordance with the "precautionary principle". ${ }^{1393}$

Initially, the precautionary principle arose, and has been traditionally applied, in the area of environmental protection, including such spheres as the mitigation of the global warming process, and the protection of endangered species and biodiversity. But still there are significant differences in the views of various countries and legal scholars concerning the concrete content of this principle and its place in international law; ${ }^{1394}$ and this is even more so in the sphere of SPS protection. However, as has been explained, due to the reason that science cannot as yet explain everything in all situations, it is self-evident that the precautionary approach must have a

1393 For more information on the concept of precaution see, for example: Lukasz Gruszczynski, Regulating Health and Environmental Risks under WTO Law. A Critical Analysis of the SPS Agreement, Oxford University Press, Oxford, 2010, pp. 158 - 165; Tracey Epps, International Trade and Health Protection. A Critical Assessment of the WTO's SPS Agreement, Edward Elgar, Cheltenham, UK, 2008, pp. $169-173$.

1394 See: Lukasz Gruszczynski, Regulating Health and Environmental Risks under WTO Law. A Critical Analysis of the SPS Agreement, Oxford University Press, Oxford, 2010, pp. 158 - 166. See also: Tracey Epps, International Trade and Health Protection. A Critical Assessment of the WTO's SPS Agreement, Edward Elgar, Cheltenham, UK, 2008, pp. 169 - 175; Alberto Alemanno, Trade in Food: Regulatory and Judicial Approaches in the EC and the WTO, Cameron May, London, 2007, pp. 396 - 398, 416 - 417; I. Cheyne, "Risk and Precaution in World Trade Organization Law", Journal of World Trade, 40(5), 2006; D. Collins, "Health Protection at the World Trade Organization: The J-Value as a Universal Standard for Reasonableness of Regulatory Precautions", Journal of World Trade, 43(5), 2009. 
secure place in the determination and management of SPS risks, i.e. in SPS regulation. The main question in this respect is: under which circumstances and to what extent may the precautionary approach be utilized by WTO Members according to the SPS Agreement?

\subsection{Precautionary Approach and Article 5.7 of the SPS Agreement}

The precautionary approach is reflected in Article 5.7 of the SPS Agreement. This Article, under appropriate conditions, allows WTO Members to adopt provisional precautionary measures, and reads:

In cases where relevant scientific evidence is insufficient, a Member may provisionally adopt sanitary or phytosanitary measures on the basis of available pertinent information, including that from the relevant international organizations as well as from sanitary or phytosanitary measures applied by other Members. In such circumstances, Members shall seek to obtain the additional information necessary for a more objective assessment of risk and review the sanitary or phytosanitary measure accordingly within a reasonable period of time.

The text of Article 5.7 does not directly refer to the precautionary principle or approach. It is thus not clear from the reading of the Article what role, if any, the precautionary principle plays in the SPS Agreement, and whether the relevance of this principle for the Agreement is exhausted by the text of Article 5.7. In EC - Hormones, the EU tried to justify its measures by referring to the precautionary principle and arguing that the principle represents the rule of general or customary international law, or at least a general principle of international law applicable to the interpretation of the norms of the SPS Agreement. The Appellate Body, in response, noted that there is a lot of uncertainty with respect to the status of the precautionary principle in international law:

The status of the precautionary principle in international law continues to be the subject of debate among academics, law practitioners, regulators and judges. The precautionary principle is regarded by some as having crystallized into a general principle of customary international environmental law. Whether it has been widely accepted by Members as a principle of general or customary international law appears less than clear. We consider, however, that it is unnecessary, and probably imprudent, for the Appellate Body in this appeal to take a position on this important, but abstract, question. We note that the Panel itself did not make any definitive finding with regard to the status of the precautionary principle in international law and that the 
precautionary principle, at least outside the field of international environmental law, still awaits authoritative formulation. ${ }^{1395}$

The Appellate Body further pointed out that the precautionary principle is indeed not expressly written into the SPS Agreement to justify the measures which are otherwise inconsistent with its provisions. At the same time, the Appellate Body agreed with the EU that Article 5.7 does not exhaust the relevance of the precautionary principle for the SPS Agreement. According to the Appellate Body, this principle is also reflected in the preamble and Article 3.3 of the SPS Agreement, authorizing WTO Members to choose their own level of protection, which may even be higher than the one provided in international standards, guidelines and recommendations. ${ }^{1396}$ It is, however, not really clear how, in the view of the Appellate Body, Article 3.3 may also reflect the precautionary principle. Under Article 3.3, WTO Members may choose to opt for a level of protection higher than the one reflected in international standards only if the measure is consistent with all the other provisions of the SPS Agreement, including the obligations of risk assessment under Article 5.1. Yet precautionary measures are meant to be adopted in those situations where the performance of the full-fledged risk assessment within the meaning of Article 5.1 is not possible due to the lack of available scientific evidence.

With respect to the relevance of the precautionary principle for the reading of Article 5.7, the Appellate Body explained:

[...] a panel charged with determining, for instance, whether "sufficient scientific evidence" exists to warrant the maintenance by a Member of a particular SPS measure may, of course, and should, bear in mind that responsible, representative governments commonly act from perspectives of prudence and precaution where risks of irreversible, e.g. life-terminating, damage to human health are concerned. Lastly, however, the precautionary principle does not, by itself, and without a clear textual directive to that effect, relieve a panel from the duty of applying the normal (i.e. customary international law) principles of treaty interpretation in reading the provisions of the SPS Agreement. ${ }^{1397}$

Thus, according to the Appellate Body, the precautionary principle has a rather limited role in the SPS Agreement and may not, by itself, absolve WTO Members from their obligations under the Agreement. ${ }^{1398}$

\footnotetext{
1395 Appellate Body Report, EC - Hormones, para. 123.

1396 See: Appellate Body Report, EC - Hormones, para. 124.

1397 Appellate Body Report, EC - Hormones, para. 124.

1398 See also on this issue: Joanne Scott, The WTO Agreement on Sanitary and Phytosanitary Measures. A Commentary, Oxford University Press, Oxford, 2007,
} 
The same approach has been followed by the Panel in EC - Approval and Marketing of Biotech Products. Regarding the argument of the EU that the precautionary principle by the time of the dispute became a fully fledged principle of international law, the Panel responded:

It appears to us from the Parties' arguments and other available materials that the legal debate over whether the precautionary principle constitutes a recognized principle of general or customary international law is still ongoing. Notably, there has, to date, been no authoritative decision by an international court or tribunal which recognizes the precautionary principle as a principle of general or customary international law. It is correct that provisions explicitly or implicitly applying the precautionary principle have been incorporated into numerous international conventions and declarations, although, for the most part, they are environmental conventions and declarations. Also, the principle has been referred to and applied by States at the domestic level, again mostly in domestic environmental law. On the other hand, there remain questions regarding the precise definition and content of the precautionary principle.

[...] Since the legal status of the precautionary principle remains unsettled, like the Appellate Body before us, we consider that prudence suggests that we not attempt to resolve this complex issue, particularly if it is not necessary to do so. ${ }^{1399}$

\subsection{Relationship of Article 5.7 With Other Relevant Provisions of the SPS Agreement}

The relationship of Article 5.7 with a few other important provisions of the SPS Agreement, particularly those imposing scientific disciplines on SPS measures, deserves some attention. As has been discussed before, Article 2.2 of the SPS Agreement (the obligation to use scientific principles and sufficient scientific evidence in the adoption and application of SPS measures) specifically refers to Article 5.7. The adoption of provisional measures under Article 5.7, as has been explained, constitutes an exemption from the scope of application of Article 2.2. ${ }^{1400}$ Since Article 2.2 represents a general rule with respect to the obligation to base SPS measures on scientific risk

pp. 127 - 128; Lukasz Gruszczynski, Regulating Health and Environmental Risks under WTO Law. A Critical Analysis of the SPS Agreement, Oxford University Press, Oxford, 2010, pp. 167 - 168; Denise Prévost, Peter Van den Bossche, "The Agreement on the Application of Sanitary and Phytosanitary Meaures", at: Patrick F.J. Macrory, The World Trade Organization: Legal, Economic and Political Analysis, 1 Springer [etc.], New York, 2005, pp. $297-300$.

1399 Panel Report, EC - Approval and Marketing of Biotech Products, paras. 7.88 - 7.89.

1400 See Section 5.3.2.2 of the present Chapter. 
assessment under Article 5.1, the relationship between Articles 5.1 and 5.7 also deserves attention.

This relationship has been examined by the Panel in EC - Approval and Marketing of Biotech Products. In this case, the Panel considered whether the provisions of Article 5.7 represent a justification for violations of Article 5.1, or if these provisions form an autonomous right of WTO Members. In doing so, the Panel applied the test developed by the Appellate Body in EC - Tariff Preferences: one provision may be characterized as an autonomous and qualified right in relation to another provision "where one provision permits, in certain circumstances, behaviour that would otherwise be inconsistent with an obligation in another provision, [where] one of the two provisions refers to the other provision, [and] where one of the provisions suggests that the obligation is not applicable to the said measure". ${ }^{1401}$

Considering the elements of this test, the Panel pointed out that Article 5.7 referred to situations "where relevant scientific evidence is insufficient" to allow for proper risk assessment within the meaning of Article 5.1 and Annex A(4) of the SPS Agreement. Furthermore, according to the Panel, WTO Members are obliged by the second sentence of Article 5.7 to seek "additional information" enabling them to perform "more objective" risk assessment, i.e. the risk assessment prescribed in Article 5.1 and Annex A(4) of the SPS Agreement. ${ }^{1402}$ The Panel also noted that, although neither Article 5.1 nor 5.7 contains explicit cross-references to each other, the language of Article 5.7 (as demonstrated above) implicitly refers to Article 5.1. ${ }^{1403}$ Accordingly, the Panel concluded that Article 5.7 indeed permits the behaviour, which would be otherwise inconsistent with Article 5.1, and Article 5.1 is thus not applicable to the situations covered by Article 5.7. In particular, the Panel explained:

As mentioned by us before, the Appellate Body opined that “'relevant scientific evidence' will be 'insufficient' within the meaning of Article 5.7 if the body of available scientific evidence does not allow, in quantitative or qualitative terms, the performance of an adequate assessment of risks as required under Article 5.1 and as defined in Annex A to the SPS Agreement". Accordingly, if the right conferred by the first sentence of Article 5.7 only arises in cases where the scientific evidence is insufficient for an adequate risk assessment as defined in Annex A(4), and if, as the Appellate Body suggests, Article 5.1 requires such a risk assessment, then the logical conclusion

1401 Panel Report, EC - Approval and Marketing of Biotech Products, para. 7.2985. See also: Appellate Body Report, EC - Tariff Preferences, para. 88.

1402 See: Panel Report, EC - Approval and Marketing of Biotech Products, paras. 7.2986 - 7.2993. See also: Appellate Body Report, Japan-Apples, para. 179.

1403 See: Panel Report, EC - Approval and Marketing of Biotech Products, para. 7.2994. 
to be drawn is that the obligation in Article 5.1 to base SPS measures on a risk assessment was not intended to be applicable to measures falling within the scope of Article 5.7. Indeed, "[i] $\mathrm{n}$ cases where relevant scientific evidence is insufficient", it is impossible, under the Appellate Body's interpretation of that phrase, for Members to meet the obligation to base their SPS measures on a risk assessment as defined in Annex A(4). We find it unreasonable to assume that Members would accept, even in principle, an obligation with which they cannot comply. In our view, the phrase "[i]n cases where relevant scientific evidence is insufficient" should, therefore, be taken to suggest that the obligation in Article 5.1 is not applicable to measures falling within the scope of Article 5.7. ${ }^{1404}$

Thus, the provisions of Article 5.7 represent an autonomous right of WTO Members and not a justification for the violation of other relevant articles of the SPS Agreement. Accordingly, if a WTO Member invokes Article 5.7 as a legal basis for its SPS measure in a WTO dispute, it is the task of a complainant to make a prima facie case that provisions of Article 5.7 are inapplicable to the situation at hand. ${ }^{1405}$ Only then the disciplines of Article 5.1 and 2.2 may be applicable to the matter at hand.

\subsection{Test Under Article 5.7}

As has been determined by the Panel and upheld by the Appellate Body in Japan-Agricultural Products II, Article 5.7 contains four cumulative criteria for its application. According to the first sentence of Article 5.7, an SPS measure must:

- be imposed in respect of a situation where "relevant scientific evidence is insufficient"; and

- be adopted "on the basis of available pertinent information".

According to the second sentence of Article 5.7, a WTO Member which adopted an SPS measure must:

- seek to obtain the additional information necessary

for a more objective risk assessment; and

- review the measure accordingly within a reasonable period of time. ${ }^{1406}$

1404 Panel Report, EC - Approval and Marketing of Biotech Products, para. 7.2995; the Panels refer to Appellate Body Report, Japan - Apples, para. 179.

1405 See: Panel Report, EC - Approval and Marketing of Biotech Products, paras. 7.3000 -7.3002 .

1406 See: Panel Report, Japan-Agricultural Products II, para. 8.54; Appellate Body Report, Japan - Agricultural Products II, para. 89. See also: Panel Report, JapanApples, para. 8.213; Appellate Body Report, Japan - Apples, para. 176. 
The first criterion of Article 5.7 has been addressed by the Panel in Japan - Apples. The Panel indicated that the existence of the situation where "relevant scientific evidence is insufficient" may not be merely presumed when an SPS measure is maintained without sufficient scientific evidence in violation of Article 2.2 of the SPS Agreement. ${ }^{1407}$ According to the Panel:

In the course of our analysis under Article 2.2 we have come across an important amount of relevant evidence, including scientific studies and reports on the risk of transmission of fire blight through apples. This information was submitted not only by the parties but also by the experts consulted by the Panel. The fact that this information may not all support Japan's opinion is in our view not pertinent in the context of this first requirement of Article 5.7. It is indisputable that a large amount of relevant scientific evidence is available. ${ }^{1408}$

The Panel thus clarified that Article 5.7 may be invoked only in situations "where little, or no, reliable evidence was available on the subject matter at issue". ${ }^{1409}$ This was clearly not the case in the situation at hand because "not only a large quantity but a high quality of scientific evidence has been produced over the years that describes the risk of transmission of fire blight through apple fruit as negligible"..$^{1410}$

On appeal, Japan challenged these findings of the Panel because, in its view, they did not take into account possible situations of "unresolved uncertainty", i.e. the "uncertainty that the scientific evidence is not able to resolve, despite accumulated scientific evidence". ${ }^{1411}$ Japan argued that the Panel only considered the so-called situation of "new uncertainty", which arises when a new, insufficiently studied risk, is identified. ${ }^{1412}$ The Appellate Body disagreed with Japan and upheld the Panel's findings. The Appellate Body observed that the statement of the Panel about the invocation of Article 5.7 in the situations with "little, or no, reliable evidence" refers namely to reliable evidence. Thus, "Article 5.7 would be applicable [also] to a situation where a lot of scientific research has been carried out on a particular issue without yielding reliable evidence". ${ }^{1413}$ The Appellate Body also generally pointed out that " $[\mathrm{t}]$ he application of Article 5.7 is trig-

\footnotetext{
1407 See: Panel Report, Japan-Apples, para. 8.215.

1408 Panel Report, Japan-Apples, para. 8.216.

1409 Panel Report, Japan-Apples, para. 8.219.

1410 Panel Report, Japan - Apples, para. 8.219. The Panel also emphasized in the same paragraph: "The current 'situation', where scientific studies as well as practical experience have accumulated for the past 200 years, is clearly not the type of situation Article 5.7 was intended to address".

1411 Appellate Body Report, Japan - Apples, para. 183.

1412 Appellate Body Report, Japan - Apples, para. 183.

1413 Appellate Body Report, Japan - Apples, para. 185.
} 
gered not by the existence of scientific uncertainty, but rather by the insufficiency of scientific evidence". ${ }^{1414}$

In addition, the Appellate Body explained the meaning of the situation "where relevant scientific evidence is insufficient" in the context of Article 5.1 as follows:

[...] "relevant scientific evidence" will be "insufficient" within the meaning of Article 5.7 if the body of available scientific evidence does not allow, in quantitative or qualitative terms, the performance of an adequate assessment of risks as required under Article 5.1 and as defined in Annex A to the SPS Agreement. ${ }^{1415}$

The findings of the Panel and the Appellate Body in Japan - Apples are indeed decisive for the interpretation of Article 5.7. They demonstrate that Article 5.7 may not be invoked in the situations of the mere existence of some scientific uncertainty. ${ }^{1416}$ Article 5.7 deals with the situations where relevant and reliable scientific evidence is insufficient for the performance of proper risk assessment. This may be the case in situations where the existence of new insufficiently studied risks has been discovered, or where the accumulated evidence (even if quite considerable) is inconclusive or unreliable. Thus, if a sufficient amount of reliable scientific evidence is available, Article 5.7 may not be used to justify an exemption from the strict scientific disciplines of the SPS Agreement.

The meaning of the first criterion under Article 5.7 has been further examined by the Panel in EC - Approval and Marketing of Biotech Products. The EU argued that, since safeguard measures imposed by some of its Members have a provisional character, these measures must by definition be covered by the rules of Article 5.7 and not by Article 5.1. ${ }^{1417}$ The Panel disagreed and pointed out that Article 5.7 is triggered not by a provisional character of a measure, but by the insufficiency of relevant and reliable scientific evidence. As has been explained by the Panel:

The first sentence follows a classic "if - then" logic: if a certain condition is met (in casu, insufficiency of relevant scientific evidence), a particular right is conferred (in casu, the right provisionally to adopt an SPS measure based on available pertinent information). Thus, it is clear that Article 5.7 is

1414 Appellate Body Report, Japan - Apples, para. 184.

1415 Appellate Body Report, Japan - Apples, para. 179. See also the discussion on the relationship between Articles 5.1 and 5.7 above.

1416 In fact, a lot of issues in science and their application to real life may not be decided with $100 \%$ certainty. Thus, in many scientific issues it is more appropriate to speak about probabilities.

1417 See: Panel Report, EC - Approval and Marketing of Biotech Products, paras. 7.2930 -7.2933 . 
applicable whenever the relevant condition is met, that is to say, in every case where relevant scientific evidence is insufficient. The provisional adoption of an SPS measure is not a condition for the applicability of Article 5.7. Rather, the provisional adoption of an SPS measure is permitted by the first sentence of Article 5.7. ${ }^{1418}$

The Panel further found that, in the case at hand, there was a sufficient amount of relevant and reliable evidence in order to perform the proper risk assessment under Article 5.1 and that Article 5.7 was thus not applicable. ${ }^{1419}$ Hence, Article 5.7 only allows for the adoption of provisional measures in quite narrowly defined situations when the relevant scientific evidence is insufficient. ${ }^{1420}$ It does not generally authorize the adoption of all kinds of provisional measures.

The second criterion of Article 5.7, that a provisional SPS measure must be adopted "on the basis of available pertinent information", has not as yet been thoroughly interpreted by the WTO dispute settlement process. In fact, in all the existing case laws where Article 5.7 has been invoked, panels found that the first criterion of this Article had not been in place; as a result, they exercised judicial economy over the second criterion. ${ }^{1421}$ However, in EC - Approval and Marketing of Biotech Products, the Panel collaterally examined the meaning of the second requirement while discussing the nature of the relationship of Articles 5.1 and 5.7. ${ }^{1422}$ The Panel noted the reference in the second sentence of Article 5.7 to "more objective risk assessment" and further explained:

We understand the phrase "a more objective assessment of risk", taken as a whole, to refer to a risk assessment which satisfies the definition provided in Annex A(4) - or at least which is closer

1418 Panel Report, EC - Approval and Marketing of Biotech Products, para. 7.2939.

1419 For example, see the findings with respect to the Austria's safeguard measure: Panel Report, EC - Approval and Marketing of Biotech Products, paras. 7.3260 -7.3262 .

1420 The Panel further concluded that, under the first requirement of Article 5.7, the "relevant evidence" must be "insufficient" on the date of adoption of the measure, and not on the date of the review by the Panel, otherwise the third and the forth requirements of Article 5.7 to obtain additional information and to review the measure would be redundant. See: Panel Report, EC - Approval and Marketing of Biotech Products, paras. 7.2953 - 7.2954.

1421 See: Panel Report, Japan - Agricultural Products II, para. 8.59; Panel Report, Japan - Apples, para. 8.222; Panel Report, EC - Approval and Marketing of Biotech Products, paras. 7.3261, 7.3301, 7.3315, 7.3328, 7.3342, 7.3357, 7.3370.

1422 The Panel interpreted the second requirement when applying the test set out in EC-Tariff Preferences to examine whether Article 5.7 permits something, which is prohibited by Article 5.1. See: Panel Report, EC - Approval and Marketing of Biotech Products, paras. 7.2986 - 7.2993; see also the discussion on relationship between Articles 5.1 and 5.7 above. 
to satisfying the definition in Annex A(4) than consideration of "available pertinent information". ${ }^{1423}$

The Panel also pointed out:

The element "more objective" suggests that SPS measures provisionally adopted pursuant to the first sentence of Article 5.7 must also be based on a risk assessment, namely, a risk assessment which takes into account available pertinent information. ${ }^{1424}$

The text of Article 5.7 thus still prescribes the performance of a certain kind of risk assessment based on the "available pertinent information". However, according to the Panel, the risk assessment under Article 5.7 "would necessarily be different in nature from the kind of risk assessment envisaged in Annex A(4)", i.e. it "would not need to meet the definition of a risk assessment contained in Annex A(4)". ${ }^{1425}$ The Panel further reasoned that Article 5.7 may be invoked only when relevant scientific evidence is insufficient for the appropriate risk assessment under Article 5.1 and Annex A(4), and therefore risk assessment under Article 5.7 "by definition could not meet the standard set out in Annex A(4)". ${ }^{1426}$

The third criterion of Article 5.7, that WTO Members must "seek to obtain the additional information necessary for a more objective risk assessment", has been clarified by the Panel and the Appellate Body in Japan - Agricultural Products II. The Appellate Body made the following conclusions in this respect:

Neither Article 5.7 nor any other provision of the SPS Agreement sets out explicit prerequisites regarding the additional information to be collected or a specific collection procedure. Furthermore, Article 5.7 does not specify what actual results must be achieved; the obligation is to "seek to obtain" additional information. However, Article 5.7 states that the additional information is to be sought in order to allow the Member to conduct "a more objective assessment of risk". Therefore, the information sought must be germane to conducting such a risk assessment, i.e., the evaluation of the likelihood of entry, establishment or spread of, in casu, a pest, according to the SPS measures which might be applied. ${ }^{1427}$

The Appellate Body thus approved the findings of the Panel that Japan failed to comply with the third criterion of Article 5.7. This was because

\footnotetext{
1423 Panel Report, EC - Approval and Marketing of Biotech Products, para. 7.2988.

1424 Panel Report, EC - Approval and Marketing of Biotech Products, para. 7.2992.

1425 Panel Report, EC - Approval and Marketing of Biotech Products, para. 7.2992.

1426 Panel Report, EC - Approval and Marketing of Biotech Products, para. 7.2992.

1427 Appellate Body Report, Japan - Agricultural Products II, para. 92.
} 
the information sought and obtained by Japan did not examine the appropriateness of the SPS measure and other core issues, and was thus not the one provided in Article 5.7. ${ }^{428}$ Hence, not all information may qualify as "additional information" within the meaning of Article 5.7; such information must be pertinent and necessary for the performance of more objective risk assessment.

The third criterion of Article 5.7 was further clarified by the Panel in EC-Approval and Marketing of Biotech Products, which generally observed:

Thus, if a Member may provisionally adopt an SPS measure on the basis of available pertinent information in situations where the scientific evidence is insufficient for an adequate risk assessment, as required by Article 5.1 and as defined in Annex A(4), it makes sense to require, as the second sentence of Article 5.7 does, that that Member seek to obtain 'the additional information necessary' for such a risk assessment. Once a Member has obtained the additional information necessary for a risk assessment which meets the definition of Annex A(4), it will be in a position to comply with its obligation in Article 5.1 to base its SPS measure on a risk assessment which satisfies the definition of Annex A(4). ${ }^{1429}$

The fourth criterion of Article 5.7, regarding the reviewing of measures within a reasonable period of time, is a reflection of the provisional and temporary character of such a measure under the SPS Agreement. ${ }^{1430}$ However, since the situation of insufficiency of scientific evidence may persist for considerable periods of time, Article 5.7 does not provide specific time frames for when the provisional measure shall be reviewed and refers only to a "reasonable period of time". The Appellate Body, in Japan - Agricultural Products II, explained the process of determination of such a "reasonable period of time" in each particular case as follows:

In our view, what constitutes a "reasonable period of time" has to be established on a case-by-case basis and depends on the specific circumstances of each case, including the difficulty of obtaining the additional information necessary for the review and the characteristics of the provisional SPS measure. ${ }^{1431}$

The Appellate Body further agreed with the Panel that in the circumstances of the case at hand "collecting the necessary additional information would

1428 See: Appellate Body Report, Japan - Agricultural Products II, para. 92; Panel Report, Japan - Agricultural Products II, para. 8.56.

1429 Panel Report, EC - Approval and Marketing of Biotech Products, para. 7.2990.

1430 See: Peter Van den Bossche, Werner Zdouc, The Law and Policy of the World Trade Organization. Text, Cases and Materials, 3d Edition, CUP, 2013, p. 931.

1431 Appellate Body Report, Japan - Agricultural Products II, para. 93. 
be relatively easy" and upheld the Panel's finding that Japan did not comply with the requirement of Article 5.7 to review the measure within a reasonable period of time. ${ }^{1432}$

A length of time which constitutes a "reasonable period of time" shall thus be determined on a case-by-case basis, and primarily depends on the state of scientific knowledge in a particular area and the availability of relevant scientific evidence. In principle, WTO Members are allowed to keep the provisional measure in force until it becomes possible to collect the necessary additional scientific information; and Article 5.7 indeed provides for a certain flexibility in this respect. However, as can be observed from Japan - Agricultural Products II, this flexibility has its limits.

It is very unlikely that Article 5.7 of the SPS Agreement and the precautionary principle, in general, could play a meaningful role in the process of regulation of private-sector standards, which do not receive substantial governmental support or incentives. First of all, even with respect to clearly governmental SPS measures Article 5.7 has never been successfully invoked yet in order to exempt the SPS measures from the scientific disciplines of Articles 2.2, 5.1 and 5.2 of the SPS Agreement. Obviously, for private-sector standards it would be not less (if not more) difficult to meet the strict test under Article 5.7. Second, the first sentence of Article 5.7 clearly reads: "a Member may provisionally adopt" SPS measures. Thus, it seems that for invocation of Article 5.7, adoption and application of a private-sector standard has to receive such substantial governmental support or incentives, that it could be regarded as a provisional SPS measure of a WTO Member.

\subsubsection{Other Relevant Disciplines of the SPS Agreement}

In addition to a number of important disciplines discussed in the previous sections of the present Chapter, the SPS Agreement also contains a number of other rules which deserve some attention. These are rules on:

- equivalence and adaptation to regional conditions;

- control, inspection and approval procedures;

- transparency and notification; and

- provisions with respect to developing countries.

The following sections will briefly discuss these rules and their possible relevance for the regulation of private-sector standards.

1432 See: Appellate Body Report, Japan - Agricultural Products II, para. 93; Panel Report, Japan - Agricultural Products II, paras. 8.57-8.58. 


\subsubsection{Equivalence and Adaptation to Regional Conditions}

As has been explained in the present Chapter, the task of harmonization of SPS measures with international standards is set out in Article 3 of the SPS Agreement as the goal for the future. ${ }^{1433}$ Moreover, in many situations such harmonization would not really be feasible due to the differences in the geographical and climatic conditions between WTO Members, and also due to the differences in their technical and scientific capacities. At the same time, the resulting discrepancies between SPS measures in such situations may substantially hinder international trade. Thus, in order to reduce the detrimental effects of these discrepancies on international trade, the SPS Agreement contains rules on the equivalence and adaptation of SPS measures to regional conditions. ${ }^{1434}$

\subsection{Equivalence}

According to Article 4.1 of the SPS Agreement, an importing WTO Member is obliged to accept the SPS measures of the exporting Member as equivalent to their own measures, even if the measures are different. This must be the case as far as the exporting Member "objectively demonstrates" to the importing Member that its measure achieves the level of SPS protection established by the importing Member. For this purpose, the exporting WTO Member shall, upon request, grant reasonable access to the importing Member to conduct appropriate procedures, such as inspections, and the testing of goods and production facilities. ${ }^{1435}$ In addition, according to Article 4.2, WTO Members must, upon request, commit themselves to consultations aiming to conclude bilateral or multilateral agreements on the mutual recognition of equivalence of their SPS measures.

The provisions on the recognition of equivalence in Article 4.1 are formulated as a legally binding obligation. However, the condition that an exporting Member needs to demonstrate to an importing Member that its SPS measure is able to achieve the level of protection established by this Member leaves a lot of discretion to the latter. As a result, the recognition of equivalence, especially between developed and developing countries, has not become a widespread practice thus far. In order to improve the implementation of Article 4 and operationalize its provisions, the SPS

1433 See Section 5.3.3 of the present Chapter. See also: Appellate Body Report, EC Hormones, para. 165.

${ }^{1434}$ For further information see, for example: Rüdiger Wolfrum, Peter-Tobias Stoll, Anja Seibert-Fohr, WTO: Technical Barriers and SPS Measures, Nijhoff, Leiden, 2007, pp. 429 - 431; Denise Prévost, Balancing Trade and Health in the SPS Agreement: The Development Dimension, Wolf Legal Publishers, Nijmegen, 2009, pp. $750-753$.

1435 See the text of Article 4.1 of the SPS Agreement. 
Committee engaged in discussions on equivalence and, in October 2001, adopted the Decision on the Implementation of Article 4 (the Equivalence Decision), which was then twice reviewed in 2004. ${ }^{1436}$

The Equivalence Decision contains non-binding guidelines for WTO Members submitting and considering requests on the recognition of equivalence of SPS measures, e.g. procedures for submission and consideration of such requests, and the information to be provided in the request. In general, the Equivalence Decision only obliges WTO Members to consider requests for the recognition of equivalence, but not to grant such recognition. The introduction of the obligation to recognize the equivalence would, perhaps, not be politically and practically acceptable for many WTO Members.

Moreover, the Equivalence Decision recommended to the SPS Committee to revise its notification procedures in order to incorporate the notification of agreements between WTO Members on the recognition of equivalence. The procedures, and the form for such notifications, were adopted in 2002, but have hardly been used thus far. ${ }^{1437}$ Article 4 could thus hardly be viewed as containing the full-fledged legal obligation to recognize the equivalence of SPS measures. The Equivalence Decision, together with other relevant results of the work of the SPS Committee, could thus be said to be aimed at encouraging such recognition.

\subsection{Adaptation to Regional Conditions}

The territories of many WTO Members may comprise various regions with different geographical, climatic and environmental conditions, and a different spread of pests and microorganisms. Taking the local and regional conditions of exporting WTO Members into account, importing Members may significantly decrease the effects of their SPS measures on international trade. Thus, although traditionally SPS measures are applied to the products from entire territories of exporting WTO Members, the importing Members are required by the SPS Agreement to have a differentiated

1436 See: Decision on the Implementation of Article 4 of the Agreement on the Application of Sanitary and Phytosanitary Measures, WTO, SPS Committee, G/ SPS/19, Geneva, 26 October 2001. See also: Decision on the Implementation of Article 4 of the Agreement on the Application of Sanitary and Phytosanitary Measures, WTO, SPS Committee, G/SPS/19/Rev.1, Geneva, 2 April 2004; Decision on the Implementation of Article 4 of the Agreement on the Application of Sanitary and Phytosanitary Measures, WTO, SPS Committee, G/SPS/19/Rev.2, Geneva, 23 July 2004.

1437 See: Notification of Determination of the Recognition of Equivalence of Sanitary or Phytosanitary Measures. Decision by the Committee WTO, SPS Committee, G/ SPS/7/Rev.2/Add.1, Geneva, 25 July 2002. These notification procedures have been used only twice so far: once by Panama (Notification G/SPS/N/EQV/PAN/1 dated 09/08/2007) and once by Dominican Republic (Notification G/SPS/N/EQV/ DOM/1 dated 19/06/2008). 
approach to the products from various exporting Members and from the various regions of these Members. The failure to do so may result in unfair requirements and excessive restrictions on international trade. ${ }^{1438}$

In this regard, Article 6.1 of the SPS Agreement prescribes that importing WTO Members have to ensure that their SPS measures are adapted to the SPS conditions of the regions of origin as well as the destination of the products, whether this is "all of a country, part of a country, or all or parts of several countries". ${ }^{1439}$ According to Article 6.1, in assessing the SPS characteristics of particular regions, WTO Members must consider the level of prevalence of specific pests or diseases in these regions, eradication and control programs in place, guidelines and criteria developed by the relevant international organizations, as well as other relevant factors. Article 6.2 of the SPS Agreement further requires that, in particular, WTO Members recognize "the concepts of pest- or disease-free areas and areas of law of low pest or disease prevalence". ${ }^{1440}$ The existence of such areas is to be determined on the basis of a number of factors, including geography and ecosystems, epidemiological surveillance and the effectiveness of SPS controls. In order to obtain the recognition, an exporting WTO Member shall objectively demonstrate to an importing Member that an area is pest- or disease-free (or with low pest or disease prevalence) and will likely remain as such. This may be done through the provision of appropriate evidence and, upon request, through granting "reasonable access" to the importing WTO Member for testing, inspections, and other relevant procedures. ${ }^{1441}$

It is worth noting that, according to the language of Articles 6.2 and 6.3, WTO Members are not obliged to recognize the appropriate areas in particular situations, but shall recognize the "concepts" of such areas. The decision regarding the recognition shall be taken by an importing Member if the exporting Member "objectively demonstrates" the SPS status of an area. This wording allows for a lot of flexibility and discretion to importing WTO Members, rendering the practical implementation of Article 6 rather difficult. The clarification and operationalization of the rules of Article 6 have, for years, been the subject of complex consultations in the SPS Committee. Finally, after more than six years of preparatory work and discussions, ${ }^{1442}$ the SPS Committee adopted the Regionalization Decision

1438 For further information see, for example: Rüdiger Wolfrum, Peter-Tobias Stoll, Anja Seibert-Fohr, WTO: Technical Barriers and SPS Measures, Nijhoff, Leiden, 2007, pp. 469 - 470; Denise Prévost, Balancing Trade and Health in the SPS Agreement: The Development Dimension, Wolf Legal Publishers, Nijmegen, 2009, pp. $769-770$.

1439 Article 6.1 of the SPS Agreement.

1440 Article 6.2 of the SPS Agreement.

1441 See: Article 6.3 of the SPS Agreement.

1442 See: Denise Prévost, Balancing Trade and Health in the SPS Agreement: The 
in 2008, providing non-binding guidelines for the practical implementation of Article $6 .{ }^{1443}$ This non-binding Decision is aimed at improving transparency, the exchange of information, predictability, credibility and confidence between the Members engaged in the recognition process. However, some Members also expressed their concerns about the weakness of the compromise struck in the provisions of the Decision. ${ }^{1444}$

In fact, the recognition of equivalence and the adaptation to regional conditions may also take place in the "world" of private-sector standards. This is usually performed through the "benchmarking" of different standards against each other, a flexible approach to the formulation of standards' conditions, and to the performance of conformity assessment and certification. ${ }^{1445}$ However, it is doubtful that the discussed provisions of the SPS Agreement contain meaningful obligations with respect to privatesector standards, at least those which do not receive a meaningful amount of governmental support or incentives. First of all, the provisions of both Articles 4 and 6 of the SPS Agreement clearly refer to the obligations of WTO Members with respect to their SPS measures. Second, these provisions are formulated in such a way that they allow a lot of flexibility and discretion to WTO Members. As a result, the practical implementation of these provisions has been problematic, even with regard to governmental SPS regulations.

\subsubsection{Control, Inspection and Approval Procedures}

In order to apply and enforce their SPS requirements, WTO Members use control, inspection and approval procedures. These procedures are sometimes quite complex, expensive and time consuming and may thus potentially create significant barriers to international trade. In order to minimize the negative effects of the administration of the control, inspection and approval procedures by WTO Members, Article 8 of the SPS Agreement requires Members to observe the provisions of Annex C of the Agreement, as well as to ensure the consistency of such procedures with other relevant

Development Dimension, Wolf Legal Publishers, Nijmegen, 2009, p. 779.

1443 See: Guidelines to Further the Practical Implementation of Article 6 of the Agreement on the Application of Sanitary and Phytosanitary Measures, WTO, SPS Committee, G/SPS/48, Geneva, 16 May 2008.

1444 See: Denise Prévost, Balancing Trade and Health in the SPS Agreement: The Development Dimension, Wolf Legal Publishers, Nijmegen, 2009, pp. 778 - 779.

1445 The process of "benchmarking", however, "does not necessarily imply equivalence in the sense of the SPS Agreement", since the benchmarking "compares the processes that are used, not the end result"; see: Gretchen H. Stanton, "Food Safety-Related Private Standards: The WTO Perspective”, at: Axel Marx, Miet Maertens, Johan Swinnen, Jan Wouters, Private Standards and Global Governance. Economic, Legal and Political Perspectives, Edward Elgar, Cheltenham, UK, 2012, p. 241. 
provisions of the SPS Agreement. Annex C of the SPS Agreement contains a complex of rules aimed at facilitating the expediency, reasonableness and transparency of the administration of the control, inspection and approval procedures. $^{1446}$

As a brief introduction to the meaning of these rules for WTO Members, it is appropriate to make a few general comments about the nature of the control, inspection and approval procedures under the SPS Agreement. As has been explained in the beginning of the present Chapter, the SPS Agreement is applicable to (and only to) SPS measures. ${ }^{1447}$ Thus, from the context of the SPS Agreement (including the provisions of Article 8 and Annex C), it would seem that the control, inspection and approval procedures shall also be regarded as SPS measures within the meaning of the SPS Agreement, perhaps as particular types of SPS measures. ${ }^{1448}$ According to this approach, Annex C provides additional and more specific rules for these particular types of SPS measures.

However, the Panel in EC - Approval and Marketing of Biotech Products decided to follow another, perhaps rather questionable, approach. As has been explained in Section 5.1.1.1.2 of the present Chapter, the Panel found that the EU de facto moratorium on the approval of biotech products, as well as their product specific measures, are not "requirements" or "procedures" within the meaning of the definition of SPS measures in Annex A of the SPS Agreement. According to the Panel, they were rather an "application" of the procedures. The Panel thus, rather questionably, found that the de facto moratorium and the product specific measures did not qualify as SPS measures under the SPS Agreement as they failed to meet the "nature" criterion which, in the view of the Panel, was set out in the definition of Annex A. ${ }^{1449}$ At the same time, the Panel examined the de facto moratorium

1446 For further information about control, inspection and approval procedures under the SPS Agreement see, for example: Rüdiger Wolfrum, Peter-Tobias Stoll, Anja Seibert-Fohr, WTO: Technical Barriers and SPS Measures, Nijhoff, Leiden, 2007, pp. 489 - 490; Joanne Scott, The WTO Agreement on Sanitary and Phytosanitary Measures. A Commentary, Oxford University Press, Oxford, 2007, pp.218 - 220; Denise Prévost, Peter Van den Bossche, "The Agreement on the Application of Sanitary and Phytosanitary Meaures”, at: Patrick F.J. Macrory, The World Trade Organization: Legal, Economic and Political Analysis, 1 Springer [etc.], New York, 2005 , pp. $340-342$.

1447 I.e. the measures of WTO Members, which qualify as the SPS measures under Article 1 and the definition in Annex A of the SPS Agreement; see Section 5.1.1.1 of the present Chapter.

1448 As has been discussed in Section 5.1.1.1.2 of the present Chapter, the definition of an SPS measure in Annex A(1) of the SPS Agreement explicitly refers to "procedures".

1449 See: Panel Report, EC - Approval and Marketing of Biotech Products, paras. 7.1338 - 7.1378. For further discussion see also Section 5.1.1.1.2 of the present Chapter. 
and the product specific measures against the requirements of Article 8 and of Annex C of the SPS Agreement.

From the Panel's reasoning it follows that Article 8 and Annex C are not applicable to SPS measures per se (or at least not only to the SPS measures within the meaning of the SPS Agreement). In the Panel's view, Article 8 and Annex C regulate another concept, namely the "application" of control, inspection and approval procedures. ${ }^{1450}$ As has been pointed out above, this conclusion seems rather questionable taking into account the structure and the context of the SPS Agreement.

According to Annex C, WTO Members must ensure that their control, inspection and approval procedures (which may include, "inter alia, procedures for sampling, testing and certification"): ${ }^{1451}$

- are administered and completed without undue delay, and without unnecessary and unreasonable requirements or discrimination, ${ }^{1452}$

- are appropriately published and communicated to interested parties; ${ }^{1453}$

- guarantee a proper and non-discriminatory level of confidentiality with respect to the information about imported products; ${ }^{1454}$

- are only subject to fees which are equitable, non-discriminatory and commensurate to the actual costs of the services rendered; ${ }^{1455}$ and

- could be complained about in accordance with the established procedures. ${ }^{1456}$

In EC - Approval and Marketing of Biotech Products, the Panel thoroughly examined the requirements of paragraph (a) of Annex C(1), which reads as follows:

Members shall ensure, with respect to any procedure to check and ensure the fulfilment of sanitary or phytosanitary measures, that:

(a) such procedures are undertaken and completed without undue delay and in no less favourable manner for imported products than for like domestic products;

The Panel confirmed that the EU approval procedures for biotech products were the procedures "to check and ensure the fulfilment" of SPS measures within the meaning of Annex C(1) which, according to paragraph (a) of

1450 See: Panel Report, EC - Approval and Marketing of Biotech Products, paras. 7.1379 $-7.1383$.

1451 See: Footnote 7 in Annex C of the SPS Agreement.

1452 Paras. (a), (c), (e), (h) of Annex C(1) of the SPS Agreement.

1453 Para. (b) of Annex C(1) of the SPS Agreement.

1454 Para. (d) of Annex C(1) of the SPS Agreement.

1455 Paras. (f), (g) of Annex C(1) of the SPS Agreement.

1456 Para. (i) of Annex C(1) of the SPS Agreement. 
Annex C(1), must be "undertaken and completed without undue delay". In the view of the Panel, the first part of Annex C(1)(a) is essentially "a good faith obligation requiring Members to proceed with their approval procedures as promptly as possible, taking account of the need to check and ensure the fulfilment of their relevant SPS requirements". ${ }^{1457}$ Of course, WTO Members are allowed to allot a certain amount of time to the verification and approval procedures, but this time must be reasonable and necessary for the completion of the procedures, taking into account all the relevant circumstances. In other words, Annex C(1)(a) does not generally prohibit delays in the administration and completion of the approval procedures; it only prohibits delays which are really unnecessary and reasonably unjustified. ${ }^{1458}$ Therefore, the determination about whether "undue delay" has occurred "must be made on a case-by-case basis, taking account of relevant facts and circumstances". ${ }^{1459}$ After having examined the circumstances of the case, the Panel found that the EU's de facto moratorium on the approval of biotech products and the product specific measures violated the requirement of paragraph (a) of Annex C(1) to administer approval procedures "without undue delay" and therefore also Article 8 of the SPS Agreement which mandates compliance with Annex C. ${ }^{1460}$

Argentina, one of the complainants in EC - Approval and Marketing of Biotech Products, also argued that the EU violated the second part of paragraph (a) of Annex C(1) by operating approval procedures in a "less favourable manner for imported products than for like domestic products". ${ }^{1461}$ The Panel explained that this provision of Annex $\mathrm{C}$ requires the determination of two issues: whether the approval procedures are administered in a "less favourable manner" with respect to a foreign product, and whether this foreign product is "like" a domestic product which is treated more favourably. The Panel also pointed out that, in the process of determining the meaning of this obligation, it is useful to consider the jurisprudence under Article III:4 of the GATT 1994. The Panel finally noted that Argentina did not provide sufficient evidence to prove that the approval procedures treated their goods in a less favourable manner due to the origin of these goods and thus rejected Argentina's claim. ${ }^{1462}$

\footnotetext{
1457 Panel Report, EC - Approval and Marketing of Biotech Products, para. 7.1498.

1458 See: Panel Report, EC - Approval and Marketing of Biotech Products, paras. 7.1497 -7.1499 .

1459 Panel Report, EC - Approval and Marketing of Biotech Products, para. 7.1497.

1460 Panel Report, EC - Approval and Marketing of Biotech Products, paras. 8.34(a), 8.38(a).

1461 See: Panel Report, EC - Approval and Marketing of Biotech Products, paras. 7.2394 -7.2395 .

1462 See: Panel Report, EC - Approval and Marketing of Biotech Products, paras. 7.2400 $-7.2412$
} 
The Panel, in EC - Approval and Marketing of Biotech Products, also clarified the meaning of paragraph (b) of Annex C(1). According to the Panel, it contains "five separated, but related, obligations to be observed by members in the operation of approval procedures": ${ }^{1463}$

(i) publication or communication to applicants of the processing period of each procedure;

(ii) examination of the completeness and accuracy of documentation and the communication of possible deficiencies to the applicants;

(iii) transmission of the results of the procedure;

(iv) processing of applications which have deficiencies; and

(v) provision of information about the stage of a procedure and the provision of an explanation of any delay. ${ }^{1464}$

However, the Panel again found that the claims of violation of paragraph (b) were not substantiated by sufficient evidence and therefore rejected the claims. ${ }^{1465}$

In general, the Panel's interpretation of the provisions of Annex C seems to be well founded. However, the context of this interpretation raises some doubts. In particular, the prohibition of undue delays in the administration of control, inspection and approval procedures under paragraph (a) of Annex C seems to be meant for situations of "undue" delays, i.e. delays which are not due to general and deliberate governmental policy. Arguably, it is not well suited for the situations of clear and intentional decisions to ban the importation of products through the suspension of approval procedures (even if these decisions are temporary, unofficial or unwritten), e.g. in a situation of a de facto moratorium as in the case considered by the Panel. It seems that other substantive norms of the SPS Agreement (particularly, risk assessment under Article 5.1) should, in such situations, be applied first.

Finally, it is worth noting the last paragraph of Annex C(1) of the SPS Agreement, which contains rather interesting provisions concerning the application of premarketing approval systems. The paragraph reads as follows:

Where an importing Member operates a system for the approval of the use of food additives or for the establishment of tolerances for contaminants in food, beverages or feedstuffs which prohibits or restricts access to its domestic markets for products based on

1463 Panel Report, EC - Approval and Marketing of Biotech Products, para. 7.1574.

1464 Panel Report, EC - Approval and Marketing of Biotech Products, para. 7.1574.

1465 See: Panel Report, EC - Approval and Marketing of Biotech Products, paras. 7.1582 $-7.1602 ; 7.2435-7.2472$. 
the absence of an approval, the importing Member shall consider the use of a relevant international standard as the basis for access until a final determination is made.

The text of this provision of Annex C seems to allow, although implicitly, for the application of so-called premarketing approval systems by WTO Members in the SPS sphere, and aims at encouraging the use of international standards in the process of such approval. Indeed, on the one hand, control inspection and approval procedures are usually used to verify product compliance with SPS requirements, and the products are not allowed to enter a market pending such verification and approval procedures. In this sense, the operation of premarketing approval systems is normal practice among countries.

On the other hand, the premarketing approval systems may also sometimes be applied with precautionary purposes without the proper risk assessment required by the provisions of Article 5.1 of the SPS Agreement, i.e. the risk assessment obligation. ${ }^{1466}$ Under such "precautionary" approval systems, products are presumed to be unsafe and are thus automatically prohibited without prior risk assessment, unless an official marketing authorization has been granted. In such systems, it is the burden of an importer to prove that imported products are safe for use or consumption. As has been discussed in Section 5.3.4.3 of the present Chapter, Article 5.7 of the SPS Agreement, albeit under strict conditions, provides for the exemption from obligations of risk assessment in situations "where relevant scientific evidence is insufficient".

Thus, the important question is whether the premarketing approval systems used for precautionary purposes are authorized only within the narrow limits of the Article 5.7 exemption, or whether they are generally allowed as the reference to them in the last paragraph of Annex C(1) suggests. The SPS Agreement is rather ambiguous in this respect. ${ }^{1467}$ The le-

1466 For example, Denise Prévost distinguishes between two types of situations with respect to the use of such precautionary premarketing approval systems and the performance of risk assessment: 1 . a temporary ban on products while the risk assessment process is under way which, in principle, may still take a significant amount of time; and 2. a permanent ban of (usually undesired) products by a WTO Member without taking the effort to conduct the proper risk assessment. See: Denise Prévost, Balancing Trade and Health in the SPS Agreement: The Development Dimension, Wolf Legal Publishers, Nijmegen, 2009, pp. 826 - 827

${ }^{1467}$ In the words of the former WTO Director-General Mike Moor, such a situation could be referred to as a "constructive ambiguity" in formulating the controversial treaty provisions by negotiators, in order to enable consensus building among the negotiators; see: Mike Moor, A World Without Walls - Freedom, Development, Free Trade and Global Governance, CUP, Cambridge, 2003, p. 111. See also: Denise Prévost, Balancing Trade and Health in the SPS Agreement: The Development Dimension, Wolf Legal Publishers, Nijmegen, 2009, p. 829. 
gality of the application of premarketing approval systems for precautionary purposes in the SPS sphere by WTO Members remains a controversial issue. The issue has not as yet been examined in WTO dispute settlement practice, although WTO Members have had a number of opportunities to put this issue before a WTO Panel. ${ }^{1468}$ Such opportunities were, however, avoided. The reality is that premarketing approval systems with precautionary purposes are quite commonly used today by various WTO Members in various areas; or at least many Members would like to keep such options open for themselves in future. ${ }^{1469}$ This has perhaps prevented the Members from opening this "Pandora box" and challenging the legality of such a regulatory approach before the WTO dispute settlement system. It remains to be seen what the implications of the provisions of Articles 5.1 and 5.7, and Annex C, of the SPS Agreement will be in this respect. ${ }^{1470}$ In any case, if the relevant claim is brought to the WTO dispute settlement process, a panel and / or Appellate Body will probably try to avoid sweeping conclusions on the issue and limit their determination only to that is strictly necessary for resolving the dispute.

In principle, it is possible to draw a parallel between the control, inspection and approval procedures under the rules of Annex C of the SPS Agreement and the certification and verification procedures for privatesector standards. On the one hand, it is unlikely that the provisions of Annex C could be applied to the procedures of private-sector standards if there is no meaningful governmental support or incentives involved in the performance of such procedures. Thus, again, the issue of responsibility of WTO Members for private certification and verification procedures would depend on the existence and the level of governmental involvement or incentives provided for such procedures. On the other hand, if a WTO Member does have meaningful and sufficient involvement or provides governmental incentives with respect to certification or verification procedures of a private-sector standard, it would be reasonable to expect that such a Member ensure expediency, reasonableness and transparency of these procedures.

1468 For example, as has been explained in Section 5.1.1.1.2, in EC - Approval and Marketing of Biotech Products the complainants chose not to challenge the EU premarketing approval system for GMOs. See also: Panel Report, EC - Approval and Marketing of Biotech Products, paras. 7.1353, 7.1693.

1469 The application of premarketing approval systems is particularly common among developed WTO Members; for particular examples, see: Denise Prévost, Balancing Trade and Health in the SPS Agreement: The Development Dimension, Wolf Legal Publishers, Nijmegen, 2009, pp. 826 - 827.

1470 For example, Denise Prévost argues that the application of premarketing approval systems with precautionary purposes must still be subject to the requirements of risk assessment under Article 5.1 and shall be within the boundaries of the Article 5.7 exemption; see: Ibid. , p. 829. 
And in such situations, the requirements of Article 8 and Annex $\mathrm{C}$ of the SPS Agreement would, arguably, be appropriate and relevant.

\subsubsection{Transparency and Notification}

It is undoubtedly important that the information about SPS measures be adopted and enforced by WTO Members, as well as that the information about changes in these measures be accessible to exporters / importers of goods and to other WTO Members. Indeed, a lack of transparency in the processes of development, adoption and functioning of SPS measures may potentially present significant obstacles to international trade. In this regard, Article 7 of the SPS Agreement requires WTO Members to notify other Members of changes in their SPS measures, and to provide information about such measures according to the provisions of Annex B of the SPS Agreement.

Annex B contains three groups of provisions:

- requirements concerning the publication of SPS regulations; ${ }^{1471}$

- requirements with respect to the establishment of enquiry points; ${ }^{1472}$ and

- requirements concerning notification procedures. ${ }^{1473}$

According to the first group of requirements, WTO Members are obliged to publish their adopted "SPS regulations" promptly and "in such a manner as to enable interested Members to become acquainted with them". Footnote 5 in paragraph 1 of Annex B further clarifies that the term "SPS regulation" means an SPS measure "such as laws, decrees or ordinances which are applicable generally”. WTO Members are also required to allow for reasonable intervals of time between the publication of an SPS regulation and its entry into force in order to allow foreign producers (and particularly those from developing countries) to adapt their products and production methods.

In Japan - Agricultural Products II, Japan (the respondent) appealed the findings of the Panel that the Japanese varietal testing requirements were not properly published in violation of paragraph 1 of Annex B and thus also of Article 7 of the SPS Agreement. According to Japan, its varietal testing rules were set out in the document called "Experimental Guide", which was not a legally enforceable instrument and therefore did not fall within the scope of application of the publication requirement of paragraph 1 of Annex B. ${ }^{1474}$ The Appellate Body disagreed with the arguments of Japan

\footnotetext{
1471 See: Annex B of the SPS Agreement, paras. 1, 2.

1472 See: Annex B of the SPS Agreement, paras. 3, 4.

1473 See: Annex B of the SPS Agreement, paras. 5 - 10.

1474 Appellate Body Report, Japan-Agricultural Products II, para. 104. See also:
} 
and upheld the ruling of the Panel. ${ }^{1475}$ In particular, the Appellate Body explained:

We consider that the list of instruments contained in the footnote to paragraph 1 of Annex B is, as is indicated by the words "such as", not exhaustive in nature. The scope of application of the publication requirement is not limited to "laws, decrees or ordinances", but also includes, in our opinion, other instruments which are applicable generally and are similar in character to the instruments explicitly referred to in the illustrative list of the footnote to paragraph 1 of Annex B. ${ }^{1476}$

The Appellate Body also noted that "[t]he object and purpose of paragraph 1 of Annex B is "to enable interested Members to become acquainted with" the sanitary and phytosanitary regulations adopted or maintained by other Members and thus to enhance transparency regarding these measures". According to the Appellate Body, "the scope of application of the publication requirement of paragraph 1 of Annex B should be interpreted in the light of the object and purpose of this provision". ${ }^{1477}$

The second group of provisions of Annex B obliges each WTO Member to create at least one inquiry point to answer "all reasonable questions from interested Members as well as for the provision of relevant documents" regarding the SPS regime of a Member. ${ }^{1478}$ In particular, this includes the provision of information and answering queries concerning SPS regulations (proposed or adopted on the territory of a Member), control and inspection procedures, risk assessment procedures and factors taken into account therein, membership and participation in international and regional SPS systems, and relevant bilateral or multilateral agreements and other arrangements. If copies of the relevant documents are requested, they must be provided "at the same price (if any), apart from the costs of delivery", as to national producers. ${ }^{1479}$

Finally, under the third group of requirements, WTO Members must fulfil appropriate notification procedures in case the content of their SPS regulations "is not substantially the same as the content of an international standard, guideline or recommendation”, or if such a standard, guideline and recommendation does not exist. ${ }^{1480}$ According to paragraph 5 of Annex

\footnotetext{
1475 See: Appellate Body Report, Japan - Agricultural Products II, paras. 107 - 108; Panel Report, Japan-Agricultural Products II, paras. 8.114-8.116. For more information see also Section 5.1.1.1.2 of the present Chapter.

1476 Appellate Body Report, Japan-Agricultural Products II, para. 105.

1477 Appellate Body Report, Japan - Agricultural Products II, para. 106.

1478 Annex B of the SPS Agreement, para. 3.

1479 Annex B of the SPS Agreement, para. 4.

1480 Annex B of the SPS Agreement, para. 5.
} 
$\mathrm{B}$, the notification procedures must be fulfilled if the SPS regulation (or changes thereof) might have significant effects on trade with other WTO Members. In particular, WTO Members shall:

- publish a notice about the preparation of an SPS regulation at an early stage and allow a reasonable time for comments from other Members, and discuss these comments, taking into account the results of the discussions;

- notify other WTO Members through the WTO Secretariat about SPS regulations to be adopted with specifications of their essential details and at an early stage in order to allow for comments; and

- provide to other WTO Members, upon their request, copies of the proposed regulations indicating their most relevant parts.

All these procedures must be done by a WTO Member in the process of preparation of a draft SPS regulation. According to Paragraph 6 of Annex $\mathrm{B}$, only in cases of "urgent problems of health protection" may a Member omit these steps on the stage of preparation of an SPS regulation. However, in these circumstances a Member is still obliged to undertake the same actions after the enactment of an SPS regulation.

Some of these provisions of Annex B have been interpreted by the Panel in Japan - Apples. The US argued that Japan breached the provisions of paragraphs 5 and 7 of Annex B by failing to notifying certain changes in its fire blight measures. The Panel noted that the changes in the SPS regulation under paragraph 5 of Annex B must not be merely technical, but shall "potentially have a significant effect on trade of other Members"; and "[i]n this regard, it would be relevant to consider whether the change has resulted in any increase in production, packaging and sales costs, such as more onerous treatment requirements or more time-consuming administrative formalities." ${ }^{1481}$ The Panel further concluded that the US did not demonstrate that the amendments in the Japanese SPS regulations resulted in any substantial change affecting international trade. ${ }^{1482}$

Finally, as already has been noted in Section 5.3.1 of the present Chapter, Article 5.8 of the SPS Agreement contains another important obligation with respect to the transparency of SPS measures. According to this provision, WTO Members are obliged, if requested, ${ }^{1483}$ to provide explanations about their SPS measures if the measures are "not based" on the relevant international standards, guidelines or recommendations, or if such international documents do not exist. ${ }^{1484}$

1481 Panel Report, Japan - Apples, para. 8.314.

1482 See: Panel Report, Japan - Apples, paras. 8.319-8.327.

1483 Other WTO Members have the right to request this information if, in their view, an SPS measure "is constraining or has the potential to constrain" their exports; see: Article 5.8 of the SPS Agreement.

1484 This provision has been interpreted by the Appellate Body in: Appellate Body 
In order to assist WTO Members to comply with their transparency obligations under Article 7 and Annex B of the SPS Agreement the WTO SPS Committee adopted the recommended procedures for implementation of these obligations, which were subsequently revised, last time in $2008 .{ }^{1485}$ The recommended procedures provide quite detailed recommendations with respect to the timing, form and content of the notifications, identification of notifying national authorities and enquiry points, publication procedures, etc. As of 15 September 2014, Members had submitted 11 612 regular notifications, 1589 emergency notifications, and 4084 addenda and corrigenda to regular and emergency notifications to the WTO Secretariat. ${ }^{1486}$ Considering such a big number of notifications and other SPS documentation circulated within the WTO, the Secretariat introduced the online database - the SPS Information Management System - which is aimed to assist WTO Members with managing this information flow. ${ }^{1487}$ However, the concerns about the lack of transparency with respect to the SPS measures of different WTO Members are still quite common subject for discussions within the SPS Committee. ${ }^{1488}$

The content of the rules of Article 7 and Annex B of the SPS Agreement may indicate that these provisions are meant for SPS measures and procedures which are adopted or substantially supported by governmental authorities. Indeed, it would be hardly possible to require WTO Members to publish, to notify and to provide information through enquiry points on the documents, which are not part of their governmental or municipal regulatory policies. ${ }^{1489}$ It is in fact doubtful that the treaty negotiators could have intended to put such onerous burden on the shoulders of WTO Members.

Report, EC - Hormones, paras. 99 - 105; see also for more information Section 5.3.1 of the present Chapter.

1485 See: Recommended Procedures for Implementing the Transparency Obligations of the SPS Agreement (Article 7), WTO, SPS Committee, G/SPS/7/Rev.2, G/SPS/7/ Rev.3, Geneva, 2 April 2002, 20 June 2008.

1486 See: Overview Regarding the Level of Implementation of the Transparency Provisions of the SPS Agreement. Note by the Secretariat, WTO, SPS Committee, G/SPS/GEN/804/Rev.7, Geneva, 6 October 2014, para. 3.3.

1487 The database may be found at: http://spsims.wto.org (last visited January 15, 2015). The SPS documents may be also found through the WTO search engine at the "Documents online" page: http://docsonline.wto.org/?language=1 (last visited January 15, 2015).

1488 This may be seen, for example, from the number of specific trade concern raised in the SPS Committee until 2013 concerning the lack of transparency and notification of the SPS measures; see: Specific Trade Concerns. Note by Secretariat, WTO, SPS Committee, G/SPS/GEN/204/Rev.14, Geneva, 4 March 2014 pp. $8-26$.

1489 Although, of course, WTO Members may always publish, notify and provide information on such non-governmental documents voluntarily. 


\subsubsection{Provisions With Respect to Developing Countries}

It is a matter of fact that the obligations of the SPS Agreement are applicable to both developed and developing WTO Members. However, the developing countries, and especially the least-developed ones, often have significant problems with the development and maintenance of their SPS regimes, or with meeting the SPS requirements of other WTO Members. This may be the case due to the deficit of expertise and / or resources in the SPS sphere. The SPS Agreement recognizes the special needs and problems of developing countries and contains separate provisions aimed at assisting developing countries to cope with the burden of the obligations under the Agreement. The rules of the SPS Agreement with respect to developing countries include provisions for:

- technical assistance to developing WTO Members; and

- special and differential treatment for developing WTO Members.

The issue of technical assistance to developing countries is dealt with in Article 9 of the SPS Agreement. According to Article 9.1, WTO Members undertake to facilitate the provision of technical assistance to each other, and especially to developing country Members. Such technical assistance may be provided, "inter alia, in the areas of processing technologies, research and infrastructure, including in the establishment of national regulatory bodies, and may take the form of advice, credits, donations and grants, including for the purpose of seeking technical expertise, training and equipment..." ${ }^{1490}$ Article 9.2 further provides for situations where substantial investment is required from a developing country Member in order to meet the SPS requirements of another importing WTO Member. In such a situation, the importing Member "shall consider providing such technical assistance as will permit the developing country Member to maintain and expand its market access opportunities for the product involved". ${ }^{1491}$ In principle, the rules on technical assistance may be helpful for developing countries, and especially for the least-developed ones. However, the provisions of Article 9 are clearly formulated as "best efforts" or "good will" recommendations, which are very difficult to enforce, if possible at all. ${ }^{1492}$

Article 10 of the SPS Agreement deals with the issue of the SDT of developing and least-developed WTO Member countries. According to Article 10.1, WTO Members must take into account the special needs of

1490 Article 9.1 of the SPS Agreement.

1491 Article 9.2 of the SPS Agreement.

1492 See: Joanne Scott, The WTO Agreement on Sanitary and Phytosanitary Measures. A Commentary, Oxford University Press, Oxford, 2007, pp. 296 - 297; Denise Prévost, Balancing Trade and Health in the SPS Agreement: The Development Dimension, Wolf Legal Publishers, Nijmegen, 2009, pp. 985 - 987. 
developing country Members, and particularly the needs of the least-developed ones, in the preparation and application of their SPS measures.

Thus far in WTO dispute settlement, this provision has been interpreted only once, before the Panel in EC - Approval and Marketing of Biotech Products. Argentina argued that the EU, in the adoption and application of their general de facto moratorium, as well as in their entire legislation on the marketing approval of biotech products, did not take into account the special needs of Argentina as developing country. Argentina emphasized its interest in the access of its agricultural goods to the European market, and further claimed that Article 10.1, being mandatory in nature, requires "positive action" for more favourable treatment of goods from developing country Members, not merely the consideration of developing countries' interests. ${ }^{1493}$

The Panel disagreed with Argentina. It concluded that Article 10.1 only requires WTO Members to "take into account" the special needs of developing country Members, and not to grant them more favourable treatment in all circumstances. ${ }^{1494}$ In the Panel's view, this is an obligation of conduct, and not one of result. ${ }^{1495}$ Moreover, according to the Panel, the mere absence of the reference in the EU legislation to the interests of developing countries does not prove that the EU has not considered these interests. As was explained by the Panel, it is conceivable that the EU did in fact consider the needs of the developing countries, and of Argentina in particular, "but ultimately determined that applications concerning products of export interest to Argentina warranted no special and differential treatment". ${ }^{1496}$ The Panel thus finally concluded that Argentina failed to prove the violation of Article 10.1. ${ }^{1497}$

Article 10.2 further provides that WTO Members should allow longer time-frames for compliance with their SPS measures for products from developing country Members where the level of their SPS protection allows for doing so. The use of the world "should" indicates the hortatory nature of this provision. Furthermore, according to Article 10.3, the SPS Committee

1493 See: Panel Report, EC - Approval and Marketing of Biotech Products, paras. 7.1607 $-7.1611$

1494 As has been explained in Sections 5.1.1.1.2 above, earlier in this case the Panel found that the EU de facto moratorium does not constitute an SPS measure under the SPS Agreement. The Panel therefore decided to consider the Argentina claims under Article 10.1 with respect to the entire EU legislation on marketing approval of biotech products, provisionally assuming that this legislation could constitute an SPS measure. See: Panel Report, EC - Approval and Marketing of Biotech Products, paras. 7.1611-7.1614, 7.1618.

1495 See: Panel Report, EC - Approval and Marketing of Biotech Products, paras. 7.1620

1496 Panel Report, EC - Approval and Marketing of Biotech Products, para. 7.1621

1497 For the full reasoning of the Panel, see: Panel Report, EC - Approval and Marketing of Biotech Products, paras. 7.1619- 7.1626. 
is authorized to grant "specific, time-limited exceptions in whole or in part from the obligations" of the SPS Agreement upon request of a developing country Member, taking into account the financial, trade and development needs of this country. ${ }^{1498}$ Finally, as provided in Article 10.4, WTO Members are invited to "encourage and facilitate the active participation of developing country Members in the relevant international organizations" which develop international standards and recommendations.

Considering the nature of the SDT provisions in the SPS Agreement, it is not really clear which advantages they grant to developing country Members in practice. Taking into account the complaints of developing countries in this respect, the Doha Ministerial Declaration provides for the process of review of the SDT provisions in WTO agreements, including those in the SPS Agreement, in order to make them more precise, effective and operational. ${ }^{1499}$ This was further reaffirmed by the Report of the General Council on proposals for the SDT which urged for the expeditious completion of the work on the SDT. ${ }^{1500}$ Thus far, the SPS Committee has managed to adopt only a number of reports reflecting the discussion on the SDT between the Members within the Committee ${ }^{1501}$ and the decision to enhance the transparency of the SDT which was further reviewed in 2009. ${ }^{1502}$ Such lack of substantial progress in the work on the operationalization of SDT seems to be due to the absence of consensus among WTO Members, as many Members are reluctant to adopt meaningful amendments to Article 10 because they fear that it would undermine the subtle balance of rights and obligations prescribed by the SPS Agreement. ${ }^{1503}$

1498 To date, no such specific and time-limited exceptions have been requested by and granted to a developing country Member.

1499 See: Ministerial Declaration, Ministerial Conference. Fourth Session, WT/MIN(01)/ DEC/1, Doha, 20 November 2001, para. 44.

1500 See: Doha Work Programme. Decision Adopted by the General Council on 1 August 2004, WTO, WT/L/579, 2 August 2004, p.2.

1501 See, for example: Report on Proposals for Special and Differential Treatment. Adopted by the Committee on 30 June 2005, WTO, SPS Committee, G/SPS/35, Geneva, 7 July 2005; Special and Differential Treatment. Report by the Chairman to the General Council, WTO, SPS Committee, G/SPS/46, Geneva, 29 October 2007.

1502 See: Procedure to Enhance Transparency of Special and Differential Treatment in Favour of Developing Country Members. Decision by the Committee, WTO, SPS Committee, G/SPS/33, G/SPS/33/Rev.1, Geneva, 2 November 2004, 18 December 2009.

1503 For example, during the discussions in the SPS Committee, Egypt proposed to change the understanding of Article 10.1 from an obligation of conduct to obligation of result. At the same time, Egypt clarified that the formal amendment of the SPS Agreement was not its primary intention and that the authoritative interpretation by decision of the General Council would be sufficient. However, the proposal did not find sufficient support among WTO Members. See: Special and Differential Treatment. Report by the Chairman to the General Council, WTO, 
The provisions of the SPS Agreement on technical assistance and SDT are quite difficult to implement, even with respect to traditional governmental SPS measures, as many of these provisions have a hortatory character and are therefore not really enforceable. As a result, it seems rather unlikely that these provisions could prescribe something meaningful with regard to private-sector standards.

\subsection{Summary and Conclusions}

The SPS Agreement undoubtedly plays an important role in disciplining the specific types of technical barriers to trade - SPS measures, i.e. measures aimed at the protection of human, animal or plant life and health from foodborne risks or from risks related to the spread of pests and diseases. In this respect, as has been discussed, the SPS Agreement contains a number of rather strict and specific obligations prescribed for WTO Members.

As has been discussed in Section 5.1.1.1 of the present Chapter, the SPS Agreement is applicable to a specific kind of measure, namely SPS measures, which are the measures aimed at fulfilling a number of specific objectives, i.e. the protection of human, animal or plant life and health from specific risks, as well as the prevention or limitation of other relevant damage. On the one hand, and with respect to the regulation of private-sector standards, this means that all non-SPS-related private-sector standards (or their parts) are not covered by the scope of application of the SPS Agreement. On the other hand, considering the reference to "other damage" in the definition of an SPS measure in Annex A(1)(d), as well as the approach adopted by the Panel in EC - Approval and Marketing of Biotech Products, the definition of an SPS measure in the SPS Agreement may, in principle, be open to broad interpretation. However, as has been argued in Section 5.1.1.1.1 excessively broad interpretations of objectives of an SPS measure under the SPS Agreement (particularly, of the objectives provided in Annex A(1)(d)), may result in blurring the distinction between the measures addressed by the SPS Agreement and by the TBT Agreement.

Similarly to the GATT 1994 and the TBT Agreement, the SPS Agreement does not contain its own rules on the attribution of private acts to WTO Members. ${ }^{1504}$ Thus, the customary international law rules on the attribution of private acts to governments may be relevant in the context of the SPS Agreement as well. In this respect, and according to the approach taken by panels in a number of disputes under the GATT, there are no "bright-line rules" excluding the responsibility of WTO Members for the

SPS Committee, G/SPS/46, Geneva, 29 October 2007, paras. 3 - 6.

1504 See Section 5.1.3 of the present Chapter. 
conduct of private entities. For such conduct to be attributable to a WTO Member under the SPS Agreement in general, this conduct shall be subject to sufficient governmental involvement or incentives. ${ }^{1505}$ Accordingly, as in the case of the GATT 1994 and the TBT Agreement as discussed in Chapters III and IV, for a private-sector standard to be recognized as an SPS measure attributable to a WTO Member under the SPS Agreement, the Member shall provide sufficient governmental support or incentives for the adoption and application of such a standard (this is, of course, if all the criteria of the definition of an SPS measure prescribed in Annex A(1) are met).

The fact that the SPS Agreement is applicable to SPS measures attributable to WTO Members is also reflected in the wording of many important disciplines of the SPS Agreement, as was discussed in Section 5.3. In this respect, Article 2.1, for example, refers to the right of WTO Members to take SPS measures; and Articles 2.3, 3.1, 5.1, 6.1, 7 refer to the SPS measures of WTO Members ("their" SPS measures). However, considering the possibility of application of the SPS Agreement to private conduct (and, in particular, to such private conduct as the adoption and application of privatesector standards), the important question is whether the SPS Agreement may only be applicable to those SPS measures that are attributable to WTO Members.

It is hardly possible to provide a straightforward answer to this question. In fact, the answer also depends on the understanding of the notion of "attribution" in the context of WTO agreements in general, and the SPS Agreement in particular. As has been argued in Section 3.4 of Chapter III, the high standards for the attribution of private conduct to States as established by the ICJ and the ICTY, in the context of State responsibility for genocide and individual criminal responsibility for the gravest international crimes, are not necessarily appropriate in the WTO context, including the SPS Agreement.

In any case, it is worth noting that the definition of an SPS measure in Annex A(1) of the SPS Agreement does not provide for the requirement that an SPS measure should be attributable to a WTO Member. At the same time, however, as discussed in Section 5.1.1.1.3, while the TBT Agreement explicitly addresses voluntary measures (standards), the definition of an SPS measure in the SPS Agreement, by referring to "relevant

1505 The "sufficiency" of governmental involvement or incentives shall be determined on a case-by-case basis. See: Panel Report, Japan - Film, para. 10.56, see also paras $10.54-10.55$. The GATT cases which the Panel referred to are Japan-SemiConductors and EEC - Dessert Apples; see: GATT Panel Report, Japan - SemiConductors, para. 102; GATT Panel Report, EEC - Dessert Apples, p. 126. For more information on these cases and the attribution of private behaviour to WTO Members under the GATT 1994, see Section 3.2.2.1.1 of Chapter III. 
laws, decrees, regulation, requirements and procedures", arguably denotes those measures that are not fully voluntary, either in law or in practice due to certain meaningful governmental involvement and incentives. This approach at least seems to be adopted in the rather limited case-law on this issue under the SPS Agreement. ${ }^{1506}$ On the one hand, it is argued in the present Chapter that an SPS measure under the SPS Agreement may be also developed, adopted and applied by non-governmental entities with a meaningful level of governmental involvement or incentives, although this does not necessarily imply or require the attribution of the measure to a WTO Member. On the other hand, however, it appears to be unlikely that fully voluntary private measures, such as "purely" private-sector standards which do not receive any meaningful governmental involvement or incentives, may be regarded as SPS measures under the SPS Agreement.

As is highlighted in Section 5.2, Article 13 of the SPS Agreement contains positive and negative obligations for WTO Members with respect to the relevant conduct of non-governmental entities and regional bodies. The positive obligations include the obligation of WTO Members to take available "reasonable" measures in order to ensure compliance of such entities and bodies with the rules of the SPS Agreement. The negative obligations prohibit WTO Members to encourage non-governmental entities to act in violation of the SPS Agreement, as well as to rely on their services if they are inconsistent with the disciplines of the SPS Agreement.

In light of the understanding of the definition of an SPS measure discussed above, and in line with the approach to the interpretation of the relevant provisions of the TBT Agreement proposed in Chapter IV, ${ }^{1507}$ it seems justified to view the obligation to take available "reasonable" measures with respect to the conduct of non-governmental entities and regional bodies under Article 13 of the SPS Agreement as an obligation of conduct. According to this approach, WTO Members have an obligation of conduct, i.e. the obligation to take available "reasonable" measures with respect to behaviour of such entities and bodies depending on the level of governmental involvement or incentives provided for this behaviour. Thus, according to this approach, an SPS measure under the SPS Agreement should not necessarily be attributable to a WTO Member and could also be developed, adopted and applied by a non-governmental entity with certain meaningful governmental involvement or incentives.

1506 See: Panel Report, Japan - Agricultural Products II, para. 8.111. See also: Appellate Body Report, Japan - Agricultural Products II, paras. 105 - 108; Panel Report, Australia-Apples, paras. 7.157 - 7.163; Appellate Body Report, Australia-Apples, paras. $170-184$.

1507 See Sections 4.2.1.4 and 4.4 of Chapter IV. 
Compliance of WTO Members with this positive obligation provided in Article 13 of the SPS Agreement would therefore depend on the amount of governmental involvement or incentives provided for the conduct of a non-governmental entity, as well as on the level of development and technical capacity of the Member. In this regard, the more governmental involvement or incentives are provided by a Member for such conduct, the more "reasonable" measures shall be available to the Member for disciplining this conduct. If the governmental involvement or incentives provided by a WTO Member for private conduct becomes substantial enough, the obligation of conduct to take available "reasonable" measures may be regarded as something very close, if not identical, to an obligation of result. In practice, this would virtually mean the attribution of private conduct to the Member which is then obliged to ensure compliance of the conduct with the disciplines of the SPS Agreement.

However, the proposed approach also means that if a WTO Member does not provide any meaningful support or incentives for the private conduct (e.g. the adoption and application of a private-sector standard), the Member is not obliged to take any "reasonable" measures in this respect. Indeed, as has been argued in Sections 5.1.3 and 5.2.1 above, the options available to WTO Members for disciplining the private entrepreneurial behaviour on a free market are quite limited. Although governments have certain instruments enabling them to regulate and limit the freedom of private behaviour, which include the rules on market competition and consumer protection, WTO Member may hardly be obliged to have and use such instruments according to the rules of the SPS Agreement. Therefore, it seems to be fair to say that if a WTO Member does not provide any meaningful governmental support or incentives for the private conduct, there no "reasonable" measures available to the Member within the meaning of Article 13 of the SPS Agreement to discipline this conduct.

It is also worth noting that, according to the proposed approach, for a WTO Member to be responsible under the SPS Agreement, the incentives provided for the private conduct (e.g. the adoption and application of a private-sector standard) must be governmental and meaningful. In this regard, free market forces and business practices providing certain incentives for the application of a private-sector standard by market actors would, on their own, be insufficient. This is perhaps also true in cases where there is only minor influence exercised by governments in respect of private entities which is clearly insufficient to provide meaningful incentives for private actors to make certain business decisions in practice. For example, the unconditional financing of a private standard-setting organization by a government without any meaningful governmental incentives for the application and enforcement of its standards would be insufficient for a WTO Member to be held responsible for these standards. 
Regarding the reasonable measures which might be available to WTO Members for disciplining private-sector standards, Section 5.3 of the present Chapter discusses the main substantive obligations of WTO Members according to the SPS Agreement. This discussion reveals that the SPS Agreement contains many onerous and specific requirements with respect to SPS measures, for example obligations of science-based risk assessment, risk management, harmonization, transparency and notification. After considering the nature and content of these important obligations, the conclusions that were made with respect to many of them, are that they are mainly meant to regulate governmental measures, or at least the measures that have a certain nexus with a government. Indeed, many of the onerous obligations of the SPS Agreement could hardly be fulfilled with respect to free private conduct (e.g. the adoption and application of private-sector standards) that is not subject to any meaningful governmental involvement or incentives.

As has been discussed in Section 5.2.3 of the present Chapter, the SPS Committee became the place for active discussions in the WTO on the role of the SPS-related private-sector standards in international trade. These discussions, among other issues, revolved around the interpretation of the provisions of Article 13 of the SPS Agreement concerning the obligations of WTO Members with respect to non-governmental entities and the role of these provisions in the regulation of private-sector standards. However, the progress which has been achieved thus far in the Committee concerning the possible actions to be taken with regard to private-sector standards is very limited. This indicates that consensus-building among WTO Members on this complex and sensitive issue is a very difficult and challenging process.

In summary, it is doubtful that the SPS Agreement may be applicable to private-sector standards adopted and applied without meaningful governmental involvement and incentives. However, it would be incorrect to surmise that the SPS Agreement does not play any role in the regulation of private-sector standards. In fact, it does, and a rather important one. In cases where a WTO Member provides meaningful incentives or support for the adoption and application of an SPS-related private-sector standard, it is reasonable to expect the Member not only to "reap the benefits" of such a measure, but also to bear the "burdens" of compliance with the relevant obligations of the SPS Agreement. Admitting otherwise would allow WTO Members to avoid complying with their obligations under the SPS Agreement by hiding behind a "private veil" of non-governmental SPS measures. The provisions of Article 13 of the SPS Agreement are, arguably, specifically meant to prevent and prohibit such circumventive behaviour of WTO Members, while at the same time allowing for certain flexibility in the disciplining of conduct of non-governmental entities. 


\section{CHAPTER VI \\ CONCLUSIONS}

Private-sector standards, as has been discussed in Chapters I and II of days. ${ }^{1508}$ Indeed, the number of the standards developed and applied within the private sector is substantial and is still proliferating. Compliance with some of these standards on certain markets has become a de facto condition for gaining real market access. That is why the issue of disciplining private behaviour with respect to the development, adoption and application of private-sector standards is widely debated today in various fora, including international intergovernmental organizations, NGOs and the scientific community. The WTO, as the major international organization dealing with issues of international trade in goods on a multilateral level, as well as the WTO rules concerning technical barriers to international trade, are often at issue in this regard. Thus, as has been explained in Section 1.2 of Chapter I, the main research question of this study addresses the applicability and implications of the WTO legal rules for the development, adoption and application of private-sector standards in international trade in goods.

It is a matter of fact that the norms of WTO law are generally aimed at disciplining the behaviour of WTO Members, i.e. States, SCTs and the EU, by providing what Members shall or shall not do in regulating their trade relations with other Members. However, previous chapters of the present study demonstrated that, under certain circumstances, i.e. where there is appropriate governmental involvement or incentives, private conduct may be attributed to WTO Members. In such situations, if the private conduct breaches the provisions of a relevant WTO agreement, WTO Members may be held responsible for the breaches as if the actions were committed by their bodies. Moreover, as has been discussed in two preceding chapters, both the TBT Agreement and the SPS Agreement require WTO Members to take available "reasonable" measures with respect to certain non-governmental bodies or entities in order to ensure their compliance with the provisions of these Agreements. The scope of such available "reasonable" measures to be taken by the Members is not very clear, however, and should perhaps be identified on a case-by-case basis. However, apart from the discussion about whether and to what extent these obligations of

1508 Some parts of the following discussion in this Chapter are based on: Arkady Kudryavtsev, "Private Standardization and International Trade in Goods: Any WTO Law Implications for Domestic Regulation?”, the research paper presented at the SIEL Third Biennial Conference, Singapore 2012, available at the SSRN website: http://papers.ssrn.com/sol3/papers.cfm?abstract_id=2082022 (last visited February 7, 2015). 
the TBT Agreement and the SPS Agreement apply to the standard-setting activities of private standardizing organizations, it is worth considering which reasonable measures, if any, are actually available to WTO Members to discipline such activities in their domestic legal orders.

Clearly, in the majority of developed and developing countries with free market economies, governments are confined to rather narrow sets of options with regard to influencing private entrepreneurial behaviour. These options are usually limited to the protection of important societal objectives, e.g. public health and morals, consumer rights, market competition, etc. Indeed, the very concept of a free market economy is based on the freedom of entrepreneurship and undertaking, where everything which is not directly prohibited by law shall be allowed. Such free commercial behaviour may in fact include the development and application of private-sector standards responding to consumer demands related to the safety or quality of products, and the social or environmental impact of production processes, such as GLOBALG.A.P. or the MSC labelling standards. Such behaviour is, of course, really "free" unless the business behaviour is affected by meaningful governmental involvement or incentives. Indeed, as has been observed by Denise Prévost with regard to the SPS-related private-sector standards:

In a free market economy, the level of government intervention in normal competitive behaviour of economic actors is limited to what is necessary to pursue public policy objectives such as consumer protection and prevention of anticompetitive practices. It is doubtful whether preventing food companies from responding to consumer demands for a higher level of food safety falls within these limits. ${ }^{1509}$

In fact, governments usually have in their hands such instruments as competition law rules for protecting market competition from cartel agreements, concerted practices and abuses of dominant positions. They also usually have at their disposal consumer protection laws to ensure that products are safe for consumers and that consumers are correctly and properly informed about product qualities and characteristics by producers or sellers, which is often done through instructions and labelling. The laws on the protection of market competition and consumer rights may, to certain extent, be helpful in disciplining private-sector standards. This is particularly the case in so-called "severe" situations; for example, if the application of a standard results in serious limitations of market competition or a product labelling standard straightforwardly misinforms consumers.

1509 Denise Prévost, Balancing Trade and Health in the SPS Agreement: The Development Dimension, Wolf Legal Publishers, Nijmegen, 2009, p. 547. 
However, the remedies provided by competition and consumer protection laws with respect to private-sector standards are, arguably, quite limited and are also often not really useful. In fact, such "severe" cases related to the violation of market competition or the abuse of consumer rights are quite rare, as the success of a private-sector standard depends on its popularity among market players. The popularity of a standard, in turn, depends on the quality of a standard and on the reputation of a standard-setting entity. Both these factors may suffer significantly from a scandal related to competition or consumer rights abuses. Moreover, the large majority of developed countries, and many developing countries, have rather advanced laws and enforcement systems devoted to protection of market competition and consumer rights in place. However, this does not resolve the problems related to the trade-restrictive effects of private-sector standards which are mostly invoked namely with regard to developed countries' markets.

Moreover, arguably, WTO Members, at least currently, are not really obliged by the rules of WTO law to have and use the legislation on competition and consumer protection in order to remedy the possible problems related to private technical barriers to trade, including the problems arising from the adoption and application of private-sector standards. In this regard, it is interesting to compare the legal frameworks of the WTO and the EU. The Treaty on Functioning of the EU contains clear rules on the protection of competition and authorizes the EU to legislate in the sphere of consumer protection. WTO law, as has been noted in Section 2.3.4.2 of Chapter II, does not, on the contrary, currently contain rules directly devoted to the protection of competition; and the negotiations concerning the interaction between trade and competition policy in the multilateral framework of the WTO have not brought any meaningful results thus far. ${ }^{1510}$

It is also unlikely that the WTO dispute settlement system will be able and willing to bring competition rules to the WTO legal system through a

1510 It is worth noting in this regard that Article 2.1 of the WTO TRIPS Agreement obliges WTO Members to comply with certain provisions of the Paris Convention for the Protection of Industrial Property 1967. These provisions of the Paris Convention include Articles 10bis and 10ter requiring the countries to ensure "effective protection against unfair competition" and provide effective remedies in their domestic legal systems in this regard. However, these obligations in the area of market competition are prescribed in the context of the protection of IP rights. The present study focuses on private-sector standards as technical barriers to international trade. The complex issues of the relationship between standards, IP rights and competition deserve a separate and comprehensive consideration in a separate study. The scope of the present study does not allow for a detailed analysis of these issues. For more information and a brief discussion on the issue of relationship between standardization, IP rights and competition, see Section 2.3.4.2 of Chapter II. 
"back door" by interpreting certain existing provisions of WTO law. As has been correctly noted by Jan Bohanes and Iain Sandford:

Competition law is a highly sophisticated area of economic law, and it seems highly unlikely that a WTO panel would seek to develop standards in the absence of an express authorization to do so. ${ }^{1511}$

However, the discussion above certainly does not mean that WTO Members under WTO law have no obligations at all to discipline private trade-restrictive behaviour in any circumstances. As has been noted above, WTO Members may be and shall be held responsible for the private conduct in so-called "severe" situations, e.g. in case of flagrant and systematic criminal acts or administrative misconduct, such as the disruption of transportation of imported goods, the destruction of such goods, and the violations of IP rights which systematically go unnoticed or unpunished by a government.

A good example of a situation similar to the one described above and related to the activities of private actors resulting in the responsibility of a State, is the circumstances of the renowned Spanish Strawberries case, ${ }^{1512}$ considered in the EU (then the EC) by the European Court of Justice (ECJ). In this case, France was found to be in violation of Article 28 of the EC Treaty (prohibition of quantitative restrictions on imports and measures having equivalent effect), ${ }^{1513}$ because for a period of several years it systematically failed to prevent, prosecute and punish numerous actions of French farmers which were accompanied by attacks on trucks and the destruction of agricultural products from Spain. The French famers associations also threatened supermarkets selling agricultural products from other EU Member States and even sometimes destroyed the products when they were displayed. The ECJ found that France's persistent inaction and the apparent non-enforcement of its criminal and administrative laws against the farmers amounted to a measure having equivalent effect to a restriction on imports. Moreover, according to the ECJ, France failed to comply with its obligations under Article 5 of the EC Treaty to "take all appropriate measures, whether general or particular, to ensure fulfilment of the obligations" under the EC Treaty and to "facilitate the achievement of the Community's tasks" - so-called "loyalty clause". ${ }^{1514}$

As has been argued in Section 3.1.1.2 of Chapter III, it is unlikely that the relevant provisions of the GATT 1994 impose meaningful "due

1511 Jan Bohanes, Iain Sandford, “The (Untapped) Potential of WTO Rules to Discipline Private Trade-Restrictive Conduct”, Inaugural Conference, Society of International Economic Law, 56/08, Geneva, July, 15-17, 2008, para. 173.

1512 See: C-265/95, Commission v. France, ECJ, (1997) ECR I-6959.

1513 Now Article 34 of the Treaty on the Functioning of the EU.

1514 This provision is currently provided in Article 4 of the Treaty on EU. 
diligence" obligations with respect to a wide range of private actions on WTO Members. Indeed, it seems that the key provisions of the GATT 1994, such as MFN, national treatment, and the prohibition of quantitative restrictions, have different and perhaps less far-reaching wording in comparison with the relevant provisions of EU law. The TBT Agreement and the SPS Agreement, as has been discussed in Chapters IV and V, provide for the "due diligence" obligations of WTO Members to take available "reasonable" measures with respect to certain behaviours of non-governmental bodies or entities. However, as has been argued in both chapters, the scope of these "due diligence" obligations will, to a large extent, depend on the level of governmental involvement or incentives provided for the activities of non-governmental bodies or entities in each particular case. If, however, the appropriate private conduct does not receive any governmental support or incentives, the "due diligence" obligations under the TBT Agreement and the SPS Agreement will not be applicable.

In this respect, considering the circumstances of the Spanish Strawberries case, the rules of WTO law, in contrast with EU law, do not refer to "measures having equivalent effect" to quantitative restrictions and also do not contain a "loyalty clause". Moreover, WTO panels and the Appellate Body, in comparison with the ECJ, tend to be more conservative and do not favour the adoption of "creative" interpretations of legal provisions, as the level of economic and political integration between Member States of the EU and Members of the WTO is very different.

In principle, however, it seems that situations similar to those in the Spanish Strawberries case could amount to a violation of WTO law. First, such situations might be viewed as an unwritten decision by a WTO Member to exercise the selective enforcement of criminal or administrative laws resulting in a de facto discrimination of foreign products and thus violating national treatment obligation under Article III:4 of the GATT 1994. However, it is worth noting that, according to the existing WTO dispute settlement practice, the level of the burden of proof to establish the existence of an unwritten norm is usually quite high. Indeed, as has been stated by the Appellate Body, "a panel must not lightly assume the existence of a "rule or norm" constituting a measure of general and prospective application, especially when it is not expressed in the form of a written document". ${ }^{1515}$ Second, such situations might be captured by the requirements of Article X:3 of the GATT 1994 with regard to the "uniform, impartial and reasonable" administration by WTO Members of their laws, regulations and decisions. Finally, the systematic failure of a WTO Member to stop and punish certain severe criminal acts or administrative misconduct could be also viewed as providing governmental support or incentives

1515 See: Appellate Body Report, US - Zeroing (EC), para. 196. 
for such acts or misconduct. Thus, WTO Members may be found responsible for the failure to fulfil their "due diligence" obligations to take available "reasonable" measures with respect to this private conduct in accordance with the relevant provisions of the TBT Agreement and the SPS Agreement (of course, only if the private conduct qualifies as one of the measures covered by those Agreements).

At the same time, the facts of the Spanish Strawberries case were very serious; they concerned the systematic failure to enforce essential norms of criminal and administrative law. It is unlikely that a comparable situation will arise with respect to private-sector standards. Some private-sector standards and their requirements may, for instance, serve as the instruments of public boycotts of products, such as unsustainably produced timber or chocolate with child labour involved in its production. These standards may also serve as the instruments for informing corporations or consumers about important characteristics of products or production methods in order to enable them to make justified choices. In principle, the application of private-sector standards under certain circumstances may distort market competition or misinform consumers if they contain unjustified requirements or are applied unfairly. However, it is up to WTO Members to decide whether they want to establish developed systems of consumer protection and competition legislation, and whether they shall enforce this legislation effectively. Indeed, it is highly unlikely that the Members be obliged to do so under the existing WTO rules, as no appropriate minimal requirement has been accepted in the WTO thus far in these spheres.

Thus, it seems justified to argue that WTO law, at least nowadays, does not contain sound legally mandatory mechanisms to regulate private standard-setting which takes place without meaningful governmental involvement or incentives. In some of the relevant literature, it has been even argued that, at least in WTO law, such mechanisms would not only be unnecessary, but also undesirable. For example, Steven Bernstein and Erin Hannah argue against the intervention of the WTO into standard-setting by "non-state market driven governance systems" and in favour of creating a free "transnational regulatory space" (in other words, a policy space) for private voluntary regulation aimed at the protection of social values in international trade. ${ }^{1516}$ In view of the arguments discussed above, it seems

1516 See: Steven Bernstein, Erin Hannah, "Non-State Global Standard Setting and the WTO: Legitimacy and the Need for Regulatory Space”, Journal of International Economic Law, 11(3), 2008, pp. 604-605. See also: K.. W. Abbott and D. Snidal, "Strengthening International Regulation Through Transnational New Governance”, Vanderbilt Journal of Transnational Law, 42, 2009; A. Burkeen, "Private Ordering and Institutional Choice: Defining the Role of Multinational Corporations in Promoting Global Labor Standards", Washington University Global Studies Law Review, 6, 2007. 
that such a regulatory policy space already exists both in international and national legal regimes.

However, governments may still be encouraged on a voluntary basis to use certain soft law tools and mechanisms to improve the transparency, reasonableness and relevance of private standard-setting which is not subject to meaningful governmental involvement or incentives. This may include the promotion of voluntary codes of good practices for the development and application of private-sector standards, and encouraging the harmonization and benchmarking of recommendations of the standards. Compliance with such good practices in standardization may generate positive publicity for private standard-setting entities; and their straightforward disregard could lead to "shaming" and losses in reputation of the entities.

Indeed, in the "world" of private-sector standards, the reputation of a standard-setting entity means a lot for the popularity of a standard within a business sector. That is why nowadays private standard-setting organizations in order to promote their reputation sometimes themselves create associations which endorse good practices in standardization. A good example is the ISEAL Alliance - "the global association for social and environmental standards", which develops codes of good practices with regard to standard-setting procedures, compliance verification and standards' impact assessment for its members, which are the "leading private standard developing organizations", such as the FLO, the MSC, the FSC and others. ${ }^{1517}$ The existence of this private initiative seems to indicate that the formulation and promotion of good practices in the field of private standard-setting receives a positive response from business and society. There is thus arguably also room for governmental action in this respect, both in terms of encouraging such private initiatives, as well as in terms of promoting own governmental initiatives related to the good practices of private standard-setting entities.

As has been discussed in Chapter II of the present study, the "world" of private-sector standards is very complex and diverse. These standards may be developed, adopted, applied and enforced by various private organizations on national, regional and international levels. Private standards may also have different objectives and targeted clients. There is thus no clear cut border between private-sector standards and public standards or regulations, as there is no clear cut border between private and public types of

1517 See: http://www.isealalliance.org/content/about-us (last visited January 15, 2015). See also: Jan Wouters, Axel Marx, Nicolas Hachez, "Private Standards, Global Governance and International Trade: The Case of Global Food Safety Governance”, at: Axel Marx, Miet Maertens, Johan Swinnen, Jan Wouters, Private Standards and Global Governance. Economic, Legal and Political Perspectives, Edward Elgar, Cheltenham, UK, 2012, pp. 280 - 281, 283. 
regulation. Indeed, private and public types of regulation do not exist separately and there is a certain "grey area" in between these two regulatory approaches.

Hence, the distinction between private-sector standards and public standards or regulations shall not be formally based only on the type of adopting or enforcing entities, i.e. their governmental or non-governmental nature. This distinction instead mainly depends on the level of governmental involvement or incentives exercised during the development, adoption and application of a measure. Such an approach indeed seems to be in line with the customary rules of international law on the attribution of acts to States, which are restated in the ILC Articles on State Responsibility. Moreover, it is also reflected in the relevant WTO dispute settlement jurisprudence (which is, however, rather limited) where panels and the Appellate Body seem to require evidence for a sufficient level of governmental involvement in or incentives for private actions in order to hold WTO Members responsible for those actions. Thus, the differentiation between private and public standards shall be made on a case-by-case basis.

As has been mentioned, certain WTO rules, particularly those of the TBT Agreement and the SPS Agreement, impose on WTO Members the obligations to take available "reasonable" measures with respect to the relevant actions of non-governmental bodies or entities. However, it is not clear whether and under what conditions these obligations may be applicable to the private standard-setting activities undertaken without meaningful governmental involvement or incentives. There is no consensus between WTO Members with regard to the interpretation of these provisions. However, even those who argue in favour of the coverage of such private standardizing activities by these provisions, do not clearly explain which "reasonable" measures WTO Members would be obliged to take in their domestic legal orders in order to comply. Moreover, as has been explained in two preceding chapters, the references to certain terms in the definitions of the relevant measures in the TBT Agreement and the SPS Agreement ${ }^{1518}$ may suggest that there must be a certain meaningful level of governmental involvement or incentives for a measure in order to make the Agreements applicable to it. Such an interpretation would indeed be in line with the approach adopted under the GATT 1994.

The present study thus suggests that the "due diligence" obligations of WTO Members provided in the TBT Agreement and the SPS Agreement requiring that the Members take available "reasonable" measures with respect to the relevant conduct of non-governmental entities or bodies, have

1518 The term "recognized body" in the definition of a standard in Annex 1 of the TBT Agreement; the terms "relevant laws, decrees, regulations, requirements" in the definition of an SPS measure in Annex A of the SPS Agreement. 
important implications for the regulation of private-sector standards whose adoption and application receives meaningful governmental support or incentives. It is argued that these "due diligence" obligations shall be viewed as obligations of conduct which, on the one hand, are aimed at precluding WTO Members from "hiding behind the veil" of non-governmental measures and, on the other hand, provide the necessary flexibility for dealing with the complex issue of Members' responsibility for private conduct. ${ }^{1519}$ In this regard, the determination about which "reasonable" measures are available to a WTO Member in order to discipline private standard-setting activities may be made only on a case-by-case basis depending on all the relevant circumstances. These relevant circumstances include: 1 . the characteristics of the private activities at issue and, in particular, the level of governmental involvement or incentives for those activities; and 2. the regulatory environment of a WTO Member, including its level of development and technical capacity.

Considering the first type of the relevant circumstances noted above, it seems reasonable to argue that the more governmental involvement or incentives are provided for the adoption and application of a private-sector standard, the more "reasonable" measures shall be available to a WTO Member in order to discipline the adoption and application of the standard. Considering the second type of relevant circumstance, it is indeed fair to say that what may reasonably be expected from a developed country, may not always be expected from a developing, and especially, a least-developed one. In the case of really substantial governmental involvement or incentives provided by a WTO Member, the obligation of conduct to adopt available "reasonable" measures is virtually equal to the obligation of result to ensure the compliance with the disciplines of the TBT Agreement and the SPS Agreement. The private measure could then be attributed directly to the Member which would be fully responsible for it.

In this respect, it is also worth noting that the approach to the interpretation of the "due diligence" obligations of WTO Members to take available "reasonable" measures proposed in the present study, implies only meaningful governmental involvement or incentives provided for private conduct, and does not necessarily require attribution of the conduct to a Member. In other words, the meaningful governmental involvement or incentives might not be enough for the attribution of the conduct to a Member, but might be enough for triggering the obligation of taking available "reasonable" measures under the TBT Agreement and the SPS Agreement. In the WTO

1519 Indeed, as has been argued in Section 5.2.1 of Chapter V with respect to the relevant provisions of Article 13 of the SPS Agreement, these obligations play an important role by providing more options with regard to the responsibility of WTO Members for non-governmental conduct in addition to the two "straightforward" options, i.e. either full responsibility, or no responsibility at all. 
dispute settlement practice, establishing the existence of governmental involvement or incentives for a private measure will, to large extent, be an issue of burden of proof. This burden belongs entirely to a complainant and might not be easy to meet if the governmental involvement or incentives are informal or hidden.

It would thus generally be incorrect to say that the existing norms of WTO law do not apply to private-sector standards at all. Arguably, WTO law does apply to a private-sector standard if its development, adoption and application receives meaningful governmental support or incentives. Concluding otherwise would allow WTO Members to avoid responsibility by hiding behind a "private veil". WTO Members should therefore be cautious in providing governmental support or incentives for private standard-setting activities, as otherwise they might appear to be responsible for those activities. And, if a WTO Member does provide such governmental support or incentives, this shall be at its own risk as the Member would have to ensure that the relevant private-sector standards are in compliance with the appropriate rules of WTO law. However, the private-sector standards which do not receive meaningful governmental support or incentives will, in all likelihood, not be covered by the existing norms of WTO law. Indeed, it seems hardly realistic to require WTO Members to monitor and control all private standard-setting entities operating in their territories. Imposing such onerous requirements on the Members would, arguably, disturb the subtle balance of their rights and obligations established under WTO agreements.

In any case, as has been argued above, it seems that domestic regulatory tools available to governments in their domestic legal orders for disciplining "purely" private standard-setting activities performed without meaningful governmental involvement or incentives are indeed quite limited. Although these tools may include the norms of competition law, consumer protection law and administrative law, they are most likely only helpful in situations of severe and flagrant abuses in private standard-setting and practices of application of private-sector standards. Such situations are, however, not really common.

Thus, it seems that the main tools available to governments with respect to regulation of "purely" private-sector standards, are soft law mechanisms, such as creating and promoting voluntary codes of good practice for private standard-setting, facilitating transparency through the exchange of information and establishing enquiry points, and technical assistance for foreign producers. On the one hand, such mechanisms are quite flexible and diverse, and allow a wide range of actions by governments. On the other hand, however, the effectiveness of these mechanisms may be often at issue. 
Based on the discussion of the main disciplines of the three WTO agreements above, it appears that many of these disciplines, including those of the Code of Good Practice in Annex 3 of the TBT Agreement, are primarily targeted at dealing with public measures adopted and applied by WTO Members. It would seem therefore that the WTO currently is not well equipped to deal with the challenges posed by the proliferation of privatesector standards. It is in fact disputable whether the regulation of "purely" private-sector standards developed, adopted and applied without meaningful governmental involvement or incentives in principle falls within the mandate of the WTO which was originally created to address measures taken by its Members. It is also quite obvious, however, that the regulatory realities have seriously changed since the time of inception of the WTO, i.e. governments no longer hold the regulatory monopoly; and the process of privatization of market governance is progressing because the application of private regulatory norms, such as private-sector standards, is becoming more and more common. ${ }^{1520}$ It seems therefore that the WTO will have to evolve and make certain adjustments to its regulatory framework in order to be able to deal with such new realities.

Thus, in order to promote the harmonization of domestic soft law tools and improve their effectiveness, further development of the WTO rules with regard to private-sector standards appears to be desirable. Considering the objectives and diversity of private-sector standards, these new WTO rules should be specific but flexible. In this respect, the adoption of a voluntary WTO code of good practices specifically devoted to private standard-setting would, arguably, be a good and perhaps a realistic step. However, the WTO is a Member-driven organization and for this step to thus be a realistic one, WTO Members will have to recognize the challenges presented by the proliferation of private-sector standards to the WTO legal system and agree to grant the appropriate mandate to the WTO in this regard. Such a voluntary code of good practices could include recommendations on transparency and publication, recognition of equivalence, technical assistance and the exchange of information. In contrast to the rules in the GATT 1994, the TBT Agreement and the SPS Agreement, the recommendations in the code would be specifically adapted to the realities of the private standard-setting "world".

In any event, more research is clearly necessary in order to understand the various aspects of the effects of private-sector standards on international trade and the options available to address the challenges that these standards create, including the options for their regulation by both domestic legal regimes and WTO law. This indeed applies not only to

1520 See: Harm Schepel, The Constitution of Private Governance: Product Standards in the Regulation of Integrating Markets, Oxford [etc.] : Hart, 2005, pp. 11 - 12. 
private-sector standards in the area of trade in goods, but also to the standards in the areas of trade in services, governmental procurement, as well as to the important issue of the interplay between the standards and the rules on IP rights and competition. In fact, for instance, such greatly important field of private standard-setting as trade in services largely remains intact currently by legal researchers. And in this regard, the knowledge obtained about private-sector standards in the area of trade in goods may serve as a solid basis for further research in this and other important areas of private standard-setting. 


\section{SUMMARY}

Drivate-sector standards are playing an increasingly important role in international trade. These standards are widely adopted and applied within national and international markets by a large variety of players, including supermarket chains, transnational corporations, and manufacturers of goods. In fact, private-sector standards may be used throughout entire industry sectors under the administration of industry associations or NGOs at national or international levels. In recent years, there has been a significant proliferation of private-sector standards, and the provision of services with respect to certification under such standards has grown into a significant and lucrative business. This is especially true in developed countries and is attributable to globalization, new types of health threats, environmental degradation and global warming which, in turn, has led to ongoing and increasing concerns among consumers about product safety and quality, sustainability, the environmental and social impact of products, and production processes. The requirements of governmental regulations and standards are, in this respect, frequently regarded as insufficient by consumers, corporations and NGOs. These considerations commonly drive private actors to develop, adopt and apply their own, often more stringent or detailed, guidelines, requirements or recommendations, i.e., standards.

The process of proliferation and wide scale use of private-sector standards in the markets of goods generates certain challenges for interested stakeholders. Being adopted and applied by non-governmental entities, private-sector standards are voluntary de jure; i.e. their application is not legally mandatory. However, due to the immense purchasing power of large retail chains and multinational corporations which frequently apply such standards, compliance with these standards may become mandatory de facto for suppliers in order to gain real market access. In this respect, private-sector standards may, arguably, create both positive effects and pose challenges for international trade and development.

On the one hand, private-sector standards, if properly complied with, may potentially guarantee long-term market access for certified products, appropriate price premiums for producers, enhanced product safety and quality, and the dissemination of modern, efficient and environmentally friendly technologies. Private-sector standards may also contribute to the differentiation of products and the creation of niche-markets which could be favourable for small-scale and developing country producers. However, on the other hand, it seems that this potential of private-sector standards often fails to materialize for many small-scale, medium-sized and developing country producers. Indeed, such standards may present unnecessary, unjustified or inappropriate requirements for local methods of production and, as a result, lead to discriminatory or excessively trade-restrictive 
effects. Moreover, the costs of compliance with and certification under private-sector standards may be too expensive for small-scale, medium-sized and developing country producers, especially while there is no guarantee of the fair distribution of a price premium for compliance with a standard along a supply chain. In addition, the diversity of private-sector standards per se, as well as their lack of harmonization, pose a serious problem because producers have to comply with multiple and varying private requirements.

The WTO is the main international organization that deals with issues of international trade in goods on a multilateral level. The rules of the WTO establish an important international legal framework for the application of technical barriers to trade in goods by WTO Members, such as regulations and standards. In this regard, the relevant provisions of WTO agreements, such as the GATT 1994, the TBT Agreement, and the SPS Agreement, are often at issue with respect to the topic of the regulation of private-sector standards in order to minimize their negative effects on international trade.

It seems that the wide scale application of private-sector standards presents serious challenges for the WTO system. If compliance with the requirements of private-sector standards becomes a predominant factor for real access to the markets of WTO Members, while the WTO is not able to address it, this may potentially render the WTO regulatory system for technical barriers to trade practically irrelevant. Moreover, if WTO Members are allowed to encourage and provide meaningful incentives for the development, adoption and application of the private-sector standards which are inconsistent with the relevant WTO rules, these rules could be circumvented by the Members through such regulatory policies. Private-sector standards thus arguably pose the risk of "blurring" the existing WTO legal framework for technical barriers to trade in goods. This, in turn, might affect the credibility of the WTO system, especially in the eyes of developing countries which expected to gain real benefits regarding market access for their goods from the WTO rules at the time these rules were negotiated.

Since the WTO is an international intergovernmental organization, the rules of this organization per se create rights and obligations only for its Members, and not for private parties. Accordingly, it is quite clear that, at least nowadays, the rules of WTO law on technical barriers to trade in goods may not apply directly to private standard-setting organizations. However, the private conduct under appropriate conditions may, in principle, be attributed to WTO Members. Moreover, the rules of WTO law, whether explicitly or implicitly, might oblige WTO Members to adopt certain measures in order to discipline private trade-restrictive behaviour, including the development, adoption and application of private-sector standards. The WTO rules might also directly prohibit the Members to perform certain actions with respect to such private behaviours, for example, to 
support or encourage the development and application of certain privatesector standards.

Thus, in order to gain insight into the implications of the WTO rules for the regulation of private-sector standards and private standard-setting activities in international trade in goods, the present study first discusses the "world" of private-sector standards and the reasons for the proliferation of these standards, and thereafter examines the appropriate provisions of the relevant WTO agreements.

\section{The "world" of private-sector standards}

The "world" of private-sector standards is very complex and diverse and, as a result, it is difficult to describe the concept of private-sector standards with precision. Generally, referring to the definitions of a standard in the ISO/IEC Guide 2 and Annex 1 of the WTO TBT Agreement, a privatesector standard may be defined as a document adopted by a private entity, such as an industry association, an NGO, or a business corporation. This document prescribes characteristics of products or PPMs for common and repeated use. By definition, it is not legally mandatory for compliance by market players as it is adopted and applied by private entities.

However, just because a standard is adopted by an NGO, does not necessarily mean that it is a private-sector standard and not a public one. An NGO may, in principle, be authorised by a government to perform elements of public authority by developing and adopting standards and, as such, the standards adopted by such an entity would then be public standards. Accordingly, private-sector standards are developed and adopted by NGOs which act within the private sector without exercising elements of governmental authority. In this respect, the differentiation between private-sector standards and public ones may appear to be quite complex task in certain situations and should thus be done only on a case-by-case basis in the context of the overall regulatory environment of a country.

Although private-sector standards, as well as standards in general, are not legally mandatory for compliance, they may, in principle, become mandatory de facto for suppliers who wish to gain or maintain market access. This may be the case if a standard is applied by big corporations, a group of corporations, or even entire industries which, to a large extent, control a market. Moreover, a de jure voluntary private-sector standard may gain a de facto mandatory character if its application is encouraged through significant support or incentives provided by a government. In fact, such governmental support or incentives may even transform a private-sector standard into a de facto mandatory regulation. Thus, the distinction between voluntary and mandatory measures is not always clear cut and may depend on the circumstances of each particular case, taken in the context of a national 
regulatory environment. Concluding otherwise could indeed allow States to "camouflage" their mandatory measures as voluntary ones based on their formal appearance.

Due to their voluntary character, private-sector standards, as well as standards in general, have several operational stages which are not the same as the operational stages of mandatory measures. First, a private-sector standard is developed and adopted by a private standard-setting entity; it is then applied by business corporations to their own business activities (i.e. internally applied standards), or to their suppliers who have to implement the standard (i.e. externally applied standards). The conformity assessment and enforcement of private-sector standards are performed by business corporations purchasing a product or, most commonly these days, by independent private organizations - accredited certifiers (i.e. third-party verification or certification).

The typology of private-sector standards offered in this study is based on multiple criteria relevant for the present study, although it is not exhaustive. One of the most important criteria of the typology in the context of the present study is the level of governmental involvement or incentives for the development, adoption and application of private-sector standards. According to this criterion, private-sector standards may be classified into so called "purely" private-sector standards which do not receive any governmental support or incentives for any of their operational stages, and into private-sector standards which do receive some such support or incentives. However, if a private-sector standard receives a considerable or significant amount of governmental support or incentives for some of its operational stages, this may well transform it into a pubic standard or even a mandatory regulation. Accordingly, there is no clear cut border between private-sector standards and public standards or regulations, as there is no clear cut border nowadays between private and public types of regulation.

Private-sector standards may address various objectives which, in principle, may be classified into technical, societal and commercial ones. For example, technical objectives may relate to the establishment of common terminology, the interoperability of products, or the application of knowhow and production technologies. Societal objectives may include the safety and quality of products, or the protection of the environment and human rights. Commercial objectives may deal with the differentiation of products and the protection of brand reputation. The information about compliance with private-sector standards may target different clients; this may be business corporations (B2B standards) only; mainly consumers who, as a rule, are targeted through the labelling on a product (B2C standards); or both. Private-sector standards may address product characteristics, PPMs, marking, labelling or the packaging of products. In this respect, one of the distinctive features of private-sector standards is that most of them contain 
requirements regarding PPMs, including npr-PPMs; i.e. PPMs which do not affect the physical characteristics of a final product. Arguably, this potentially makes them more trade-restrictive in the eyes of producers who have to adjust their production methods to the requirements of different private-sector standards.

There may be different approaches to meeting the challenges posed by private-sector standards, which includes improving the transparency of standard-setting processes, providing technical assistance to interested smallholders, and imposing rules with respect to the content of the standards. The regulation of the development, adoption and application of private-sector standards may, in principle, be exercised by private standard-setting organizations themselves (individually or collectively), or by governments. In this regard, as has been explained above, the rules of WTO law, and particularly those provided in the GATT 1994, the TBT Agreement, and the SPS Agreement, impose important obligations on governments of WTO Members to discipline measures that create technical barriers to trade in goods.

\section{Private-sector standards and the GATT 1994}

The GATT 1994 establishes the general legal framework for the measures of WTO Members that affect international trade, including technical barriers to international trade in goods. In this respect, the relevant requirements of the GATT 1994 include: the MFN treatment obligation (Article I); the national treatment obligation (Article III); the prohibition of quantitative restrictions for import or export (Article XI); transparency, uniformity, impartiality and reasonableness in the administration of trade laws, regulations and decisions (Article X). The possibility of the so-called "non-violation complaints" of WTO Members under Article XIII:1(b) may, arguably, also be relevant. Article XX provides for the justification of trade restrictions imposed to protect public health, morals, exhaustible natural resources, etc. According to the chapeau of Article XX, such trade restrictions may not constitute arbitrary or unjustifiable discrimination, or disguised restrictions on international trade.

There is a rather extensive dispute settlement case law for the interpretation and application of many of these provisions, and a lot of relevant information in this respect may be found in dispute settlement reports of panels or the Appellate Body, as well as in WTO law text books. However, in the context of the present study, the most relevant question to be answered is whether and to what extent these disciplines of the GATT 1994 may be applicable to the development, adoption and application of private-sector standards. In fact, because the development, adoption and application of private-sector standards is a form of private conduct, the question stated 
above is indeed part of a more general issue, namely whether, and under what conditions, the GATT 1994 is applicable to private conduct.

Generally, the provisions of the GATT 1994 apply to measures which are employed by WTO Members. Thus, WTO Members are fully responsible under WTO agreements for their own governmental measures which may underpin private behaviour. Indeed, governmental measures may seriously affect the competitive opportunities on a market and force (or provide meaningful incentives for) private actors to act in certain ways. Such governmental measures per se may well constitute violations of the appropriate provisions of the GATT 1994.

However, the question remains whether, under certain conditions, private conduct may be directly attributable to a WTO Member, i.e. regarded as the conduct of a Member per se. The GATT 1994 does not generally clarify which measures are to be regarded as those of the Members. In other words, the GATT 1994 does not contain its own general norms on the attribution of acts to WTO Members. Since, as has been rightly noted by the Appellate Body, the GATT rules are "not to be read in clinical isolation from public international law", the general customary international law rules on the attribution of acts to States seem to be relevant in this respect. These customary international law rules are reflected in the many provisions of the ILC Articles on State Responsibility.

According to the ILC Articles, States are responsible for the measures adopted or enforced by their organs and persons or entities exercising elements of governmental authority. Furthermore, acts or omissions may be attributable to a State in cases where the measure is adopted by other persons and entities acting under the direction or control of a State, or if a State acknowledged and adopted this measure as its own. However, international courts and tribunals, such as the ICJ and the ICTY, established rather high standards of control to be exercised by a State over private actors for the attribution of their conduct to it; i.e. "effective" and "overall" control tests.

In principle, it seems that the approach taken to the attribution of private actions to WTO Members in the WTO dispute settlement practice under the GATT 1994 and some other WTO agreements, is in line with the general rules of customary international law on the attribution of acts to States. Similarly to the ILC Articles, GATT or WTO panels and the Appellate Body required the existence of an appropriate and sufficient nexus between the government of a WTO Member and a private conduct for attribution of the latter to the former. In fact, in several cases considered under the GATT 1994, panels ruled that there are no "bright line rules" allowing automatic exclusion of the acts of private parties from the scope of application of the GATT 1994. And thus private conduct may be attributed to WTO Members if there is sufficient governmental involvement in or incentives for the conduct, which shall be evaluated on a case-by-case 
basis. Similarly, under the more specific provisions of Article XVII: 1 of the GATT 1994 devoted to the issue of responsibility of WTO Members for the conduct of their STEs, such STEs are meant to enjoy the "exclusive or special rights or privileges, including statutory or constitutional powers" granted to them by Member governments.

It seems, however, that the high standards of control (i.e. "effective" and "overall" control) required by the ICJ and the ICTY in the context of State responsibility for genocide and individual criminal responsibility for the gravest international crimes, are inappropriate for the WTO which mainly deals with issues pertaining to international trade and commerce. In fact, it seems that the "control test" could be more relaxed in the WTO context. At the same time, most likely, WTO panels and the Appellate Body will not easily assume the responsibility of WTO Members for the conduct of private actors without convincing evidence of a sufficient nexus between a private action and a Member.

Thus, considering this approach to the attribution of private conduct to WTO Members under the GATT 1994, it seems that the relevant provisions of the GATT 1994 may be applicable to private-sector standards only if there is a sufficient nexus between the standard and the government of a WTO Member. In particular, this could be the case due to sufficient governmental involvement in or incentives for the development, adoption and application of a private-sector standard. Establishing the existence of such sufficient governmental involvement or incentives before a WTO panel and the Appellate Body, will be the decisive step to be fulfilled by a complainant. However, it seems justified to conclude that the GATT 1994 may not be applicable to "purely" private-sector standards which are developed, adopted and applied without any meaningful governmental involvement or incentives.

\section{Private-sector standards and the TBT Agreement}

The TBT Agreement is applicable to certain types of technical barriers to trade, such as technical regulations, standards, and conformity assessment procedures (i.e. procedures aimed at verifying compliance with the requirements of technical regulations and standards). A technical regulation is defined in Annex 1 to the TBT Agreement as a mandatory measure specified in a document laying down product characteristics and / or PPMs, and which may also include terminology, packaging, marking or labelling requirements. A standard is defined in similar terms, but only as a voluntary measure prescribed in a document and approved by a recognized body for common and repeated use.

Technical regulations and standards may be adopted, and conformity assessment procedures performed, by different types of bodies, including 
central or local governmental and non-governmental bodies. A non-governmental body is defined rather broadly in Annex 1 of the TBT Agreement as a body "other than a central government body or a local government body". Moreover, a standard, according to its definition in Annex 1, shall be approved by a "recognized body". However, it is not further explained what constitutes such "recognition" and by whom a body must be "recognized"; e.g. by governmental agencies, markets or society, etc. The unique feature of the TBT Agreement is thus that it is applicable to voluntary measures which may be developed and adopted by non-governmental "recognized" bodies.

The TBT Agreement clearly recognizes that WTO Members have the inherent right to protect their important societal objectives. This inherent right of Members, however, is subject to rather strict requirements. In this regard, the Agreement contains a number of important obligations for WTO Members. The articles of the Agreement per se prescribe the disciplines with respect to technical regulations and conformity assessment procedures. The disciplines with respect to standards are provided for in Annex 3 of the TBT Agreement, the Code of Good Practice for the Preparation, Adoption and Application of Standards. The relevant disciplines of the TBT Agreement include the MFN and national treatment obligations, the prohibition of creating unnecessary obstacles to trade, harmonization with relevant international standards, the avoidance of duplications in standard-setting work, equivalence and mutual recognition (which is prescribed only for technical regulations and conformity assessment procedures), transparency and notification, and technical assistance.

Generally, regarding the issue of disciplining private standard-setting activities, it appears that, based on the approach to the attribution of private conduct to WTO Members adopted under the GATT 1994 and certain other WTO agreements, the TBT Agreement may apply to private-sector standards if their development, adoption and application are subject to substantial governmental involvement or incentives. A private-sector standard may then be attributable to a WTO Member. However, the TBT Agreement also contains a number of special obligations with respect to certain types of bodies, including non-governmental bodies. WTO Members are obliged to take available "reasonable" measures in order to ensure that non-governmental bodies developing and adopting technical regulations and standards comply with the requirements of the Agreement. WTO Members are also required to refrain from requiring or encouraging these bodies to behave inconsistently with rules of the TBT Agreement.

It seems justified to argue that the obligation to take available "reasonable" measures is aimed at allowing a certain amount of flexibility to WTO Members with respect to their non-governmental bodies or entities, depending on the level of a Member's development and the technical 
feasibility. In this context, these provisions may be interpreted as an obligation of conduct and not as an obligation of result. However, it is also reasonable to argue that the Members shall be obliged to take measures only with respect to those non-governmental entities or bodies which they "recognize" as standardizing bodies and thus meaningfully support or encourage in their standard-setting activities or in the application of their standards in a market. This is, of course, assuming that the term "recognized body" in the definition of a standard in Annex 1 of the TBT Agreement implies the necessary recognition by a government, and not by a market or a society alone.

Under the proposed approach, the amount of reasonable measures available to a WTO Member for disciplining private-sector standards depends mainly on two factors: 1. the level of Member's development and the technical feasibility; and 2. the amount of governmental involvement or incentives provided for the development, adoption and application of a private-sector standard. In this respect, the private-sector standards adopted without any governmental involvement or incentives do not require any available reasonable measures to be taken by WTO Members according to the TBT Agreement. An increase in governmental involvement or incentives for the development, adoption and application of a measure results in an increased level of obligation of a WTO Member for disciplining such a measure. In this regard, the more governmental involvement or incentives are provided in support of the activities of an entity, the more reasonable measures shall be available to a WTO Member to discipline such activities.

Mandatory technical regulations present the highest level of governmental incentives. Therefore, with respect to the technical regulations adopted by central governmental authorities, WTO Members have the obligation of result to ensure that the requirements of the TBT Agreement are complied with. For technical regulations adopted by local governmental and non-governmental bodies receiving high levels of governmental support or incentives, obligations of the WTO Members are very close to those of result, but may still be regarded as obligations of conduct.

The proposed approach seems to suggest a relatively restrictive interpretation of the terms "technical regulation", "standard", and "non-governmental body" in the TBT Agreement, preventing them from capturing "purely" private-sector standards which are developed, adopted and applied without any meaningful governmental involvement or incentives. It indeed seems unfair and unrealistic to oblige WTO Members to ensure that all non-governmental standard-setting entities on their territory, including those which they did not support and might not even be unaware of, comply with the strict disciplines of the TBT Agreement. 


\section{Private-sector standards and the SPS Agreement}

The SPS Agreement is applicable to a specific kind of measure, namely SPS measures, which are the measures aimed at fulfilling a number of specific objectives, i.e. the protection of human, animal or plant life and health from specific risks, as well as the prevention or limitation of other relevant damage. On the one hand, with respect to the regulation of private-sector standards, this means that all non-SPS-related private-sector standards (or their parts) are not covered by the scope of application of the SPS Agreement. On the other hand, considering the reference to "other damage" in the definition of an SPS measure in Annex A(1)(d), as well as the approach adopted by the Panel in EC - Approval and Marketing of Biotech Products in this respect, the definition of an SPS measure in the SPS Agreement may, in principle, be open to a rather broad interpretation.

Similarly to the GATT 1994 and the TBT Agreement, the SPS Agreement does not contain its own rules on the attribution of a conduct to WTO Members. Thus, the customary international law rules on the attribution of acts to governments may be relevant in the context of the SPS Agreement as well. Accordingly, as in the case of the GATT 1994 and the TBT Agreement, for a private-sector standard to be recognized as an SPS measure attributable to a WTO Member under the SPS Agreement, the Member shall provide sufficient governmental support or incentives for the adoption and application of such a standard (this is, of course, if all the criteria of the definition of an SPS measure prescribed in Annex A(1) are met).

Indeed, the fact that the SPS Agreement is applicable to SPS measures attributable to WTO Members is also reflected in the wording of many important disciplines of the SPS Agreement. In this respect, for example, Article 2.1 refers to the right of WTO Members to take SPS measures; and Articles 2.3, 3.1, 5.1, 6.1, 7 refer to the SPS measures of WTO Members ("their" SPS measures). However, considering the possibilities of application of the SPS Agreement to a private conduct (and, in particular, to private conduct such as the adoption and application of private-sector standards), the important question is whether the SPS Agreement is only applicable to SPS measures attributable to WTO Members.

It is hardly possible to give a straightforward answer to this question. In fact, the answer will also depend on the understanding of the notion of "attribution" in the context of WTO agreements in general, and the SPS Agreement, in particular. In any case, it is worth noting that the definition of an SPS measure in Annex A(1) of the SPS Agreement in fact does not provide for the requirement that an SPS measure be attributable to a WTO Member. At the same time, while the TBT Agreement explicitly addresses voluntary measures (standards), the definition of an SPS measure in the 
SPS Agreement arguably, by referring to "relevant laws, decrees, regulation, requirements and procedures", denotes the measures, which are not fully voluntary either in law or in practice due to certain meaningful governmental involvement and incentives. At least this seems to be the approach adopted in the rather limited case-law on this issue under the SPS Agreement.

Accordingly, this study argues that an SPS measure under the SPS Agreement may, on the one hand, be developed, adopted and applied by non-governmental entities with certain meaningful level of governmental involvement or incentives but which nonetheless do not necessarily imply or require the attribution of the measure to a WTO Member. On the other hand, however, it appears unlikely that fully voluntary private measures, such as "purely" private-sector standards, which do not receive any meaningful governmental involvement or incentives, may be regarded as SPS measures under the SPS Agreement.

As in case with the appropriate provisions of the TBT Agreement, Article 13 of the SPS Agreement contains the positive and negative obligations of WTO Members with respect to the relevant conduct of non-governmental entities and regional bodies. The positive obligations include the obligation of WTO Members to take available "reasonable" measures in order to ensure compliance of such entities and bodies with rules of the SPS Agreement. The negative obligations prohibit WTO Members to encourage non-governmental entities to act in violation of the SPS Agreement, as well as to rely on their services, if they are inconsistent with the disciplines of the SPS Agreement. In light of the understanding of the definition of an SPS measure as discussed above, and in line with the proposed interpretation of the relevant provisions of the TBT Agreement, it seems justified to view the obligation to take available "reasonable" measures, with respect to the conduct of non-governmental entities and regional bodies under Article 13 of the SPS Agreement, as an obligation of conduct. According to this approach, WTO Members have an obligation of conduct; i.e. the obligation to take available "reasonable" measures with respect to the behaviour of such entities and bodies depending on the level of governmental involvement or incentives provided for this behaviour.

The compliance of WTO Members with the positive obligation provided in Article 13 of the SPS Agreement would therefore depend on the amount of governmental involvement or incentives provided for the conduct of a non-governmental entity, as well as on the level of development and technical capacity of the Member. In this regard, the more governmental involvement or incentives are provided by a Member for such a conduct, the more "reasonable" measures shall be available to the Member for disciplining this conduct. If the governmental involvement or incentives provided by a WTO Member for a private conduct becomes substantial 
enough, the obligation of conduct to take available "reasonable" measures may be regarded as something very close, if not identical, to the obligation of result. In practice this would mean the attribution of a private conduct to a Member which is then obliged to ensure the compliance of the conduct with the disciplines of the SPS Agreement. The proposed approach thus also means that if a WTO Member does not provide any meaningful support or incentives for a private conduct (e.g. the adoption and application of a private-sector standard), the Member is not obliged to take any "reasonable" measures in this respect.

The discussion of the main substantive obligations of WTO Members according to the SPS Agreement reveals that the Agreement contains many onerous and specific requirements with respect to SPS measures, for instance, obligations of science based risk assessment, risk management, harmonization, transparency and notification. After considering the nature and the content of these important obligations, it was concluded that many of them are mainly meant for the regulation of governmental measures, or at least for the measures that have a certain nexus with a government. Indeed, many of the onerous obligations of the SPS Agreement can hardly be fulfilled with respect to a free private conduct (e.g. the adoption and application of private-sector standards), which is not subject to any meaningful governmental involvement or incentives.

\section{Conclusions}

It is a matter of fact that the norms of WTO law are generally aimed at disciplining the behaviour of WTO Members, i.e. States, SCTs and the EU, by providing rules about what Members shall or shall not do in regulating their trade relations with other Members. However, the present study has demonstrated that under certain circumstances, i.e. where there is sufficient governmental involvement or incentives, private conduct may be attributed to WTO Members. In such situations, if the private conduct breaches the provisions of a relevant WTO agreement, WTO Members may be held responsible for the breaches as if the actions were committed by their bodies.

Moreover, as has been discussed, both the TBT Agreement and the SPS Agreement require WTO Members to take available "reasonable" measures with respect to certain non-governmental bodies or entities in order to ensure their compliance with the provisions of these Agreements. The present study suggests that these "due diligence" obligations of WTO Members have important implications for the regulation of private-sector standards whose adoption and application receives meaningful governmental support or incentives. It is argued that these obligations shall be viewed as obligations of conduct which, on the one hand, are aimed at precluding WTO Members from "hiding behind the veil" of a non-governmental 
measure and, on the other hand, at providing the necessary flexibility for dealing with the complex issues of Member responsibility for a private conduct. In this regard, the determination about which "reasonable" measures are available to a WTO Member in order to discipline private standardsetting activities may be made only on a case-by-case basis depending on all the relevant circumstances. These relevant circumstances include: 1 . the characteristics of the private activities at issue and, in particular, the level of governmental involvement or incentives for those activities; and 2. the regulatory environment of a WTO Member, including its level of development and technical capacity.

It could thus be said that WTO law, arguably, applies to those privatesector standards whose development, adoption and application receives meaningful governmental support or incentives. Concluding otherwise would allow WTO Members to avoid their responsibility by hiding behind a "private veil". WTO Members should therefore be cautious in providing governmental support or incentives for private standard-setting activities as they might appear to be responsible for those activities. If a WTO Member does provide such governmental support or incentives, this shall be at its own risk, since the Member would have to ensure that the relevant privatesector standards are in compliance with the appropriate rules of WTO law. However, those private-sector standards which do not receive meaningful governmental support or incentives will, most probably, not be covered by the existing norms of WTO law. Indeed, it hardly seems realistic to require WTO Members to monitor and control all private standard-setting entities operating in their territories. Imposing such onerous requirements on the Members could, arguably, disturb the subtle balance of their rights and obligations established under WTO agreements.

In any case, it seems that the domestic regulatory tools available to governments in their domestic legal orders for disciplining "purely" private standard-setting activities performed without meaningful governmental involvement or incentives are quite limited. Indeed, in the majority of developed and developing countries with free market economies, governments are confined to rather narrow sets of options with regard to their influence on private entrepreneurial behaviour. These options are usually limited to the protection of important societal objectives, e.g. public health and morals, consumer rights, market competition, etc. The tools which governments may use in this respect thus include the norms of competition law, consumer protection law and administrative law. These tools, however, are only helpful, if at all, in situations of severe and flagrant abuses in private standard-setting and practices of the application of private-sector standards. Such situations are, arguably, not really common as the success of a private-sector standard depends on its popularity among market players; the popularity, in turn, depends on the quality of a standard and on the 
reputation of a standard-setting entity. Both of these factors may suffer significantly from a scandal related to competition or consumer rights abuses.

In fact, a large majority of developed countries, as well as many developing countries, have rather advanced laws and enforcement systems devoted to the protection of market competition and consumer rights in place. Nonetheless, this does not resolve problems related to the trade-restrictive effects of private-sector standards which are mostly invoked with regard to developed country markets. In addition, WTO Members, at least currently, are hardly obliged by the rules of WTO law to have and use the legislation on competition and consumer protection in order to remedy the possible problems related to the private technical barriers to trade, including the problems arising from the adoption and application of private-sector standards. It is quite unlikely that the WTO dispute settlement system will be able and willing to bring competition rules into the WTO legal system through a "back door" by interpreting certain existing provisions of WTO law.

Thus, it seems that the main tools available nowadays to governments, with respect to regulation of "purely" private-sector standards, are soft law mechanisms such as creating and promoting voluntary codes of good practice for private standard-setting, facilitating transparency through the exchange of information and establishing enquiry points, and technical assistance for foreign producers. Such mechanisms, on the one hand, are flexible, diverse and allow a wide range of actions by governments. On the other hand, however, the effectiveness of these mechanisms is often at issue.

Based on the discussion of the main disciplines of the three relevant WTO agreements, the present study argues that many of these disciplines are primarily designed for dealing with public measures adopted and applied by WTO Members. It would therefore seem that the WTO is not currently well equipped to address the challenges posed by the proliferation of private-sector standards. On the one hand, it is disputable whether the regulation of "purely" private-sector standards developed, adopted and applied without meaningful governmental involvement or incentives falls, in principle, within the mandate of the WTO which was originally created to address measures taken by its Members. On the other hand, however, it is also quite obvious that the regulatory realities have undergone serious changes since the inception of the WTO. In particular, governments no longer hold the regulatory monopoly, and the process of privatization of market governance is progressing because the application of private regulatory norms, such as private-sector standards, is becoming more and more common. The WTO will thus have to evolve and make certain adjustments to its regulatory framework in future in order to be able to deal with such new realities. 
Therefore, to promote the harmonization of domestic soft law tools and improve their effectiveness, the further development of the WTO rules with regard to private-sector standards appears to be desirable. Considering the objectives and the diversity of private-sector standards, these new WTO rules should be specific but flexible. In this respect, the adoption of a voluntary WTO code of good practices specially devoted to private standardsetting would, arguably, be a positive and realistic step. However, the WTO is a Member-driven organization and this step, as such, is a realistic one only if WTO Members recognize the challenges presented by the proliferation of private-sector standards to the WTO legal system and agree to grant the appropriate mandate to the WTO in this regard. Such a voluntary code of good practices could include recommendations on transparency and publication, the recognition of equivalence, technical assistance, and the exchange of information. In contrast to the rules in the GATT 1994, the TBT, and the SPS Agreements, the recommendations in the code would be specifically adapted to the realities of the private standard-setting "world".

In any event, more research is clearly necessary in order to understand the various aspects of the effects of private-sector standards on international trade and the options of addressing the challenges that these standards create, including the options for their regulation by both domestic legal regimes and WTO law. 


\section{APPENDix I}

Proposed Working Definition of SPS-Related Private Standards. Noted by the Secretariat, WTO, SPS Committee, G/SPS/W/265/Rev.2, Geneva, 28 September 2012

\section{ADDITIONAL ELEMENTS TO CONSIDER}

6. SPS-related private standards include technical requirements, guidelines and recommendations.

7. To assess whether an SPS-related private standard may affect international trade, the Member concerned should consider relevant available information such as: the value or other importance of imports to the importing and/or exporting Members concerned, whether from other Members individually or collectively; the potential development of such imports; and difficulties for producers in other Members, particularly in developing country Members, to comply with the proposed SPSrelated private standard. The concept of a significant effect on trade of other Members should include both import-enhancing and importreducing effects on the trade of other Members, as long as such effects are significant.

8. SPS-related private standards can be developed by [private] [non-governmental] entities themselves, or may be derived from existing private, official or international standards, and are applied for [private] [nongovernmental] entities' commercial objectives as part of a private, commercial and contractual relationship. SPS-related private standards are not developed, endorsed or promulgated by the Codex Alimentarius Commission (Codex), the International Plant Protection Convention (IPPC) and the World Organization for Animal Health (OIE).

9. Official SPS measures implemented by a Member (including SPS measures implemented by governments other than the national government, or by non-governmental entities on behalf of a Member) are not SPS-related private standards.

10. [Where an SPS-related private standard becomes an official SPS measure, it is no longer considered to be an SPS-related private standard.] 


\section{A PPEndix 2}

Report of the Co-Stewards of the Private Standards E-Working Group on Action 1 (G/SPS/55). Submission by the Co-Stewards of the E-Working Group, SPS Committee, G/SPS/W/276, Geneva, 18 March 2014

The rationale for the elements of this working definition includes the following:

a. a set of requirements: There was general agreement among the e-WG to include the concepts of "written" requirements, and that it could be a requirement or a set of requirements. Some Members also considered "for common and repeated use" should be incorporated in the working definition, while others noted concern about possible redundancy or lack of clarity with this term. Taking into consideration the definition of a "standard" contained in Annex 1 of the WTO Agreement on Technical Barriers to Trade, the co-stewards recommend the language: " $a$ written requirement or a set of written requirements for common and repeated use".

b. of a non-governmental entity: This was probably the element of the definition where there was the most diverse views expressed. An alternative proposal was made that the requirement "... is not applied under the exercise of governmental authority". However, the co-stewards make the following points in support of inclusion of the term "non-governmental entity":

i. the term is generic, not specific to the SPS Agreement; and the ownership approach (by using "of") can help avoid the confusion of "private standards" with "official standards";

ii. "non-governmental entity" is the term used in the SPS Committee's Decision G/SPS/55; and

iii. A working definition does not entail any legal interpretation as to whether or not private standards are covered by the terms of the SPS Agreement.

c. which are related to food safety, animal or plant life or health: There was a suggestion to replace "related to" with "for the purposes of" however the co-stewards consider this could easily be confused with the role of the ISSBs. Furthermore, "for the purposes of" means that the standard is imposed primarily in order to achieve that particular objective and some Members question whether the primary objective of a private standard is genuinely food safety. It was hence suggested to go with "related to" which is a broader term to reflect the fact that 


\section{Appendices}

the standard has some link to food safety, but this is not necessarily its primary objective.

d. Footnote: in general the e-WG was in agreement or could be flexible with the use of a footnote. An accompanying explanatory document was also proposed by one member of the e-WG. The co-stewards noted the comments by the WTO Legal Affairs Division with regard to the legal implications of the China/New Zealand joint proposal and its accompanying footnote $(\mathrm{G} / \mathrm{SPS} / \mathrm{W} / 272)$, and would like to propose a revised optional footnote for consideration by the Committee:

"This working definition or any part of it shall be without prejudice to the rights and obligations of Members under the WTO Agreement on the Application of Sanitary and Phytosanitary Measures or the views of Members on the scope of this Agreement." 


\section{A PPENDIX 3}

Existing Definitions of Private Standards in Other International Organizations. Note by the Secretariat. Revision, SPS Committee, G/SPS/GEN/1334/Rev.1, Geneva, 5 August 2014

\section{EXISTING DEFINITIONS OF A PRIVATE STANDARD IN OTHER INTERNATIONAL ORGANIZATIONS}

2.1. The table below presents a compilation of the existing definitions of a "private standard" as used in other international organizations.

\begin{tabular}{|c|c|c|}
\hline Organization & $\begin{array}{l}\text { Existing Definition of } \\
\text { a Private Standard }\end{array}$ & Source/Reference \\
\hline $\begin{array}{l}\text { FAO/WHO } \\
\text { Codex } \\
\text { Alimentarius } \\
\text { Commission }\end{array}$ & $\begin{array}{l}\text { Private standards are } \\
\text { standards that are designed } \\
\text { and owned by non- } \\
\text { governmental entities. }\end{array}$ & $\begin{array}{l}\text { "Consideration of the Impact } \\
\text { of Private Standards" } \\
\text { (citing Liu, P: "Private } \\
\text { standards in international } \\
\text { trade: issues, opportunities } \\
\text { and long-term prospects". } \\
\text { FAO expert meeting, } \\
\text { Feeding the World by } \\
\text { 2050, Rome 2009, p.2) } \\
\text { CX/CAC 10/33/13 } \\
\text { Joint FAO/WHO Food } \\
\text { Standards Programme. } \\
\text { Codex Alimentarius } \\
\text { Commission, 33rd } \\
\text { Session, 5-9 July 2010 } \\
\text { ftp://ftp.fao.org/codex/ } \\
\text { Meetings/CAC/cac33/ } \\
\text { cac33_13e.pdf }\end{array}$ \\
\hline $\begin{array}{l}\text { International } \\
\text { Trade Centre }\end{array}$ & $\begin{array}{l}\text { Private standards are } \\
\text { understood as norms } \\
\text { developed by private entities } \\
\text { such as companies, non- } \\
\text { governmental organizations } \\
\text { or multi-stakeholder } \\
\text { coalitions. These standards } \\
\text { may vary in scope, ownership } \\
\text { and objectives. Objectives } \\
\text { range from environmental } \\
\text { conservation, ensuring } \\
\text { food safety or protection }\end{array}$ & $\begin{array}{l}\text { "When do Private Standards } \\
\text { Work?” Geneva: ITC, } 2012 . \\
\text { ix, } 52 \text { pages (Literature } \\
\text { Review Series on the Impacts } \\
\text { of Private Standards; Part IV) } \\
\text { Doc. No. MAR-12-227.E, p.2 } \\
\text { When do Private Standards } \\
\text { Work: http://www.intracen. } \\
\text { org/When-do-Private- } \\
\text { Standards-Work/ }\end{array}$ \\
\hline
\end{tabular}




\begin{tabular}{|c|c|c|}
\hline Organization & $\begin{array}{l}\text { Existing Definition of } \\
\text { a Private Standard }\end{array}$ & Source/Reference \\
\hline & $\begin{array}{l}\text { of social and human rights to } \\
\text { promoting good agricultural } \\
\text { and manufacturing practices. } \\
\text { Private standards can be } \\
\text { numerical standards defining } \\
\text { required characteristics of } \\
\text { products such as contaminant } \\
\text { limits or maximum } \\
\text { residue limits, or process } \\
\text { standards prescribing } \\
\text { the production processes } \\
\text { (including performance } \\
\text { objectives) or pertaining to } \\
\text { management systems and } \\
\text { documentation requirements. }\end{array}$ & \\
\hline OECD & $\begin{array}{l}\text { The efficacy of exchange } \\
\text { is enhanced by two main } \\
\text { functions of a standard - as } \\
\text { a guarantee of a minimum } \\
\text { quality and by defining } \\
\text { the characteristics or } \\
\text { specifications of the product } \\
\text { or its production process } \\
\text { and associated criteria of } \\
\text { performance. Standards } \\
\text { reflect the needs of the } \\
\text { groups that express them } \\
\text { and as long as groups differ, } \\
\text { their optimal standards will } \\
\text { reflect these differences. } \\
\text { Draft OECD definition of } \\
\text { private standards from } \\
\text { a forthcoming report on } \\
\text { synergies between private } \\
\text { standards and public } \\
\text { regulations (as referred } \\
\text { to by Canada at the July } \\
2014 \text { informal meeting on } \\
\text { private standards). }{ }^{1521}\end{array}$ & $\begin{array}{l}\text { "Interaction of Public and } \\
\text { Private Standards in the Food } \\
\text { Chain", Smith, G. (2009), } \\
\text { OECD Food, Agriculture } \\
\text { and Fisheries Papers, No. 15, } \\
\text { OECD Publishing, p.11. } \\
\text { http://dx.doi.org/10.1787/ } \\
221282527214\end{array}$ \\
\hline
\end{tabular}

1521 The document entitled "Synergies between Private Standards and Public Regulations" is only available on "OLIS" with an embargo, and therefore not for public or official use yet. Declassification and publication of the final document is likely to occur only at the end of November. 


\begin{tabular}{|c|c|c|}
\hline Organization & $\begin{array}{l}\text { Existing Definition of } \\
\text { a Private Standard }\end{array}$ & Source/Reference \\
\hline OIE & $\begin{array}{l}\text { Private standards can be } \\
\text { defined as "commercial } \\
\text { requirements developed, } \\
\text { owned and implemented by } \\
\text { non-governmental entities, } \\
\text { with which suppliers must } \\
\text { comply to have access to } \\
\text { specific markets for animals } \\
\text { and animal products. } \\
\text { They sometimes include } \\
\text { sanitary safety and animal } \\
\text { welfare issues."1522 }\end{array}$ & $\begin{array}{l}\text { Report of OIE ad hoc } \\
\text { Group on Private } \\
\text { Standards and International } \\
\text { Trade in Animals and } \\
\text { Animal Products, 4-5 } \\
\text { June 2009, p. } 1007 . \\
\text { http://www.oie.int/fileadmin/ } \\
\text { Home/eng/Internationa_- } \\
\text { Standard_Setting/docs/ } \\
\text { pdf/A_TAHSC_Sept_2009_ } \\
\text { Part_B_b_.pdf }\end{array}$ \\
\hline UNCTAD & $\begin{array}{l}\text { Sustainability claims } \\
\text { by design are private } \\
\text { standards. They are } \\
\text { designed and implemented } \\
\text { by organizations outside the } \\
\text { public sector and promoted } \\
\text { for use by producers and } \\
\text { retailers as a service. In } \\
\text { the case of agriculture, } \\
\text { this document, referred to } \\
\text { as a standard, will define } \\
\text { which pest products are } \\
\text { allowed or prohibited, soil } \\
\text { preparation mechanisms that } \\
\text { are allowed, and handling } \\
\text { practices of all farm inputs. }\end{array}$ & $\begin{array}{l}\text { Environmental Sustainability } \\
\text { Claims: a Summary of } \\
\text { Issues for ACP Countries } \\
\text { http://www.unctad.info/ } \\
\text { en/Sustainability-Claims- } \\
\text { Portal/Discussion-Forum/ } \\
\text { Environmental/ }\end{array}$ \\
\hline World Bank & $\begin{array}{l}\text { Private standards are } \\
\text { standards that are set } \\
\text { (created) by commercial } \\
\text { or non-commercial private } \\
\text { entities, including firms, } \\
\text { industry organisations, } \\
\text { nongovernmental } \\
\text { organisations, etc. } \\
\text { Private standards may serve } \\
\text { as catalysts, further reducing } \\
\text { the transaction costs in long- } \\
\text { distance trade, providing }\end{array}$ & $\begin{array}{l}\text { http://web.worldbank.org/ } \\
\text { WBSITE/EXTERNAL/ } \\
\text { TOPICS/TRADE/0,,con } \\
\text { tentMDK:20629901 me } \\
\text { nuPK:222955 pagePK:1 } \\
\text { 48956 piPK:216618 the } \\
\text { SitePK:239071,00.html }\end{array}$ \\
\hline
\end{tabular}

1522 Official working definition of private standards used by OIE as described in the Terms of Reference and ad hoc Group meeting report.

${ }^{1523}$ This definition previously available on the World Bank website now appears to have been replaced with definition included above. 


\begin{tabular}{|l|l|l|}
\hline Organization & $\begin{array}{c}\text { Existing Definition of } \\
\text { a Private Standard }\end{array}$ & Source/Reference \\
\hline $\begin{array}{l}\text { both a stimulus and guide } \\
\text { for investments in firm and } \\
\text { supply chain modernization, } \\
\text { and providing increased } \\
\text { incentives for the adoption } \\
\text { of better and safety farming } \\
\text { and manufacturing practices. }\end{array}$ & \\
\hline
\end{tabular}

\section{EXISTING DEFINITIONS OF A PRIVATE STANDARD OR OF A STANDARD FROM ADDITIONAL SOURCES}

3.1. The table below presents an additional compilation of existing definitions of a "private standard" or of a "standard" from other pertinent sources.

\begin{tabular}{|c|c|c|}
\hline Organization & $\begin{array}{l}\text { Existing Definition of } \\
\text { a Private Standard }\end{array}$ & Source/Reference \\
\hline $\begin{array}{l}\text { TBT } \\
\text { Agreement }\end{array}$ & $\begin{array}{l}\text { Standard - Document ap- } \\
\text { proved by a recognized body, } \\
\text { that provides, for common } \\
\text { and repeated use, rules, } \\
\text { guidelines or characteristics } \\
\text { for products or related pro- } \\
\text { cesses and production meth- } \\
\text { ods, with which compliance } \\
\text { is not mandatory. It may also } \\
\text { include or deal exclusively } \\
\text { with terminology, symbols, } \\
\text { packaging, marking or label- } \\
\text { ling requirements as they } \\
\text { apply to a product, process } \\
\text { or production method. }\end{array}$ & $\begin{array}{l}\text { TBT Agreement, Annex } \\
\text { 1, paragraph } 2 \\
\text { http://www.wto.org/eng- } \\
\text { lish/docs_e/legal_e/17- } \\
\text { tbt_e.htm\#annexI }\end{array}$ \\
\hline ISO & $\begin{array}{l}\text { A standard is a document } \\
\text { that provides requirements, } \\
\text { specifications, guidelines or } \\
\text { characteristics that can be } \\
\text { used consistently to ensure } \\
\text { that materials, products, } \\
\text { processes and services are } \\
\text { fit for their purpose. } \\
\text { A standard is a document, } \\
\text { established by consensus and }\end{array}$ & $\begin{array}{l}\text { http://www.iso.org/iso/ } \\
\text { home/standards.htm } \\
\text { "ISO/TMB policy and } \\
\text { principles statement global } \\
\text { relevance of ISO technical } \\
\text { work and publications" } \\
\text { ISO, 2004, p.1 } \\
\text { http://www.iso.org/iso/ } \\
\text { global_relevance.pdf }\end{array}$ \\
\hline
\end{tabular}




\begin{tabular}{|c|c|c|}
\hline Organization & $\begin{array}{l}\text { Existing Definition of } \\
\text { a Private Standard }\end{array}$ & Source/Reference \\
\hline & $\begin{array}{l}\text { approved by a recognized } \\
\text { body that provides, for } \\
\text { common and repeated } \\
\text { use, rules, guidelines or } \\
\text { characteristics for activities } \\
\text { or their results, aimed at } \\
\text { the achievement of the } \\
\text { optimum degree of order } \\
\text { in a given context. }\end{array}$ & \\
\hline UNIDO & $\begin{array}{l}\text { Industry/private/buyer } \\
\text { standards can be broken } \\
\text { down into three categories: } \\
\text { 1. Consortia standards } \\
\text { - which are often } \\
\text { developed by a sector- } \\
\text { specific consortium } \\
\text { (i.e. GlobalGAP); } \\
\text { 2. Civil society standards } \\
\text { - established as an } \\
\text { initiative by an non-profit } \\
\text { organization usually as a } \\
\text { response to concerns over } \\
\text { social and environmental } \\
\text { conditions (e.g. Forest } \\
\text { Stewardship Council); and } \\
\text { 3. Company-specific } \\
\text { standards - which are } \\
\text { developed internally and } \\
\text { apply to the whole supply } \\
\text { chain of a company } \\
\text { (i.e. codes of conduct). }\end{array}$ & $\begin{array}{l}\text { http://www.unido.org/ } \\
\text { en/what-we-do/trade/ } \\
\text { quality-and-compliance- } \\
\text { infrastructure/standards- } \\
\text { and-conformity/ } \\
\text { private-standards.html }\end{array}$ \\
\hline
\end{tabular}




\section{Appendix 4}

Report of the Co-Stewards of the Private Standards E-Working Group to the March 2015 Meeting of the SPS Committee on Action 1 (G) SPS/55). Submission by the Co-Stewards of the E-Working Group, SPS Committee, G/SPS/W/283, Geneva, 17 March 2015

\section{E-WG VIEWS AND CONSIDERATION OF THE DRAFT WORKING DEFINITION}

\section{Textual issues remaining}

8. There has been general agreement on the co-Stewards' proposed text for a working definition with the exception of the European Union and the United States, who remain concerned with the use of the terms "non-governmental entity" and "requirement" in the working definition. (Note that Argentina supports the proposal by China and New Zealand in document G/SPS/W/272 as discussed below).

9. The European Union suggested:

- replacing "non-governmental entity" with "private body"; and

- deleting the term "requirement".

10. However, for a number of e-WG members (such as Argentina, Belize, Brazil and China) it is very important to maintain in the definition the terms "requirement" and "non-governmental entity". Some e-WG members (such as Australia and Japan) indicated flexibility and could accept either the co-Stewards' proposal or the EU proposal.

11. Canada has been able to agree to the inclusion of the terms "requirements" and "non-government entities" due to the presence of other disciplines within the definition. If those other disciplines are removed or changed, the use of these terms may once again become problematic from Canada's perspective.

12. The co-Stewards recall that the mandate of the Committee to develop a working definition of SPS-related private standards originates from Action 1 of the Committee Decision on "Actions regarding SPS-related Private Standards" (G/SPS/55), where the terms "requirements" and "non-governmental entities" are used. Besides, the co-Stewards believe that the two terms are generic, and not 
specific to the SPS Agreement. Therefore, the co-Stewards consider it necessary and appropriate to maintain the two terms in the working definition.

13. In addition to its concern with the terms "requirement" and "nongovernmental entity", the United States also noted that it considered the term "related to" to be ambiguous.

14. The co-Stewards note that the term being defined is "SPS-related private standard", and hence would consider this an appropriate term.

15. Argentina would like to discuss the term "written" as it considers this restricts the scope of the definition by excluding certain requirements resulting from customary practice.

\section{Disclaimer placement}

16. A number of e-WG members submitted comments on which option they preferred. The majority of respondents preferred the option to include the disclaimer wording in the text of the Decision (as opposed to a footnote), and most also indicated flexibility on this point.

\section{Wording of the disclaimer}

17. The European Union suggested amending the wording of the disclaimer as follows:

"This working definition is without prejudice to the rights and obligations of Members provided for in the WTO Agreement on the Application of Sanitary and Phytosanitary Measures, including, but not limited to, the question of the scope of that Agreement."

Instead of:

"This working definition is without prejudice to the rights and obligations of Members, or the views of Members on the scope of the WTO Agreement on the Application of Sanitary and Phytosanitary Measures."

(The main area of difference between the two has been underlined by the co-Stewards). 
18. The United States supported this change but said it still did not sufficiently address its concerns as it did not think it was sufficient with respect to the issue of scope.

\section{Consideration of other definitions (by OIE and Codex)}

19. Argentina noted that the OIE and Codex definitions of private standards listed in document G/SPS/GEN/1334 and Rev.1 were agreed and official. Argentina particularly highlighted the terms "non-governmental entities" and "requirements" used in those definitions. Argentina considered that the current proposal did not take sufficient notice of definitions developed by the OIE and Codex. Argentina recalled that the OIE definition was developed by an ad-hoc group on "Private Standards and International Trade on Animals and Animal Products". Argentina considered the version that was most consistent with those definitions was the one submitted in document G/SPS/W/272 by China and New Zealand prior to the establishment of the e-WG. Argentina therefore supported that definition (with the amendment that a private standard could also consist of one requirement).

20. The co-Stewards take note of the existing definitions of private standards in the OIE, Codex and other international organisations contained in document G/SPS/GEN/1334 and Rev.1. The co-Stewards consider that the latest text proposed in document G/ SPS/W/281 builds on the previous work in the SPS Committee, the latest comments of e-WG members and the relevant elements of other existing definitions. 


\section{Valorization AdDendum}

\section{Private-Sector Standards as Technical Barriers in International Trade in Goods: In Search of WTO Disciplines}

Arkady Kudryavtsev

\section{Social and economic relevance}

Private-sector standards are playing an increasingly important role in international trade in goods currently and are widely applied within national and international markets by a large variety of players, including supermarket chains, transnational corporations and manufacturers of goods. Because they are developed, adopted and applied by non-governmental entities, private-sector standards are voluntary de jure, i.e. their application is not legally mandatory. However, due to the immense purchasing power of big retail chains and multinational corporations which frequently apply such standards, compliance with these standards may become mandatory de facto for suppliers in order to gain real market access.

Private-sector standards may in fact be used through entire industry sectors under the administration of industry associations or NGOs on national or international level. This is especially true for "developed world" markets where consumer demands, intense market competition and the regulatory environment encourage private actors to develop, adopt and apply their own requirements, guidelines and recommendations for products or production methods. These requirements, guidelines and recommendations presented by private-sector standards are, as a rule, more stringent or detailed than the regulations or standards adopted and applied by public authorities. This is, of course, in cases where such public regulations or standards exist at all in the relevant regulatory area.

The process of proliferation and wide use of private-sector standards in the markets of goods undoubtedly presents a number of challenges for the relevant stakeholders, such as farmers, producers, product suppliers, traders, and retailers. This is especially the case if the stakeholders are small or medium sized enterprises, as the resources available to them in order to participate in the development of private-sector standards, as well as to implement their stringent and detailed requirements, are quite limited. The smallholders may also find it more difficult to secure their interests and to ensure the fair distribution of a price premium along a supply chain for compliance with private-sector standards. It is thus not surprising that the role of private-sector standards and their effects on international trade are highly topical issues for discussions today in various fora, including the WTO, the OECD, the UNCTAD, the FAO and the World Bank. 
The WTO is the major international organization dealing with issues of international trade in goods on a multilateral level. But the proliferation and wide application of private-sector standards presents a number of serious challenges for the WTO system. Indeed, if compliance with the requirements of private-sector standards becomes a predominant factor for real access to the goods markets of WTO Members but the WTO is not able to address this factor, this may potentially render the WTO regulatory system for technical barriers to trade practically irrelevant. Moreover, if WTO Members are allowed to encourage and provide meaningful incentives for the development, adoption and application of private-sector standards that are inconsistent with the relevant WTO rules, these rules of WTO law could then be circumvented by the Members through such regulatory practices. In other words, private-sector standards may pose the risk of "blurring" the existing WTO legal framework for technical barriers to trade in goods.

This, in turn, might seriously affect the credibility of the WTO system, especially in the eyes of developing countries, which expected to gain real benefits from the WTO rules at the time they were negotiated with respect to market access for their goods.

The social and economic relevance of the results of the present study is thus established due to the challenges posed by private-sector standards for international trade in goods and for the WTO legal system. The relevance of the results is also ascertained due to the importance and the complexity of the real-life issues arising with respect to private-sector standards, as described above. Many of the stakeholders in international trade in goods, including business corporations, industry associations, standard-setting NGOs, relevant international intergovernmental organizations, WTO Members and their national standardizing bodies are, undoubtedly, interested in having a clear understanding of the "rules of the game" with respect to private-sector standards operating in markets. The results of the present study thus contribute to the clarification and the better understanding of the rules applicable to private-sector standards on the multilateral level according to the relevant provisions of WTO law. This study also offers a number of proposals for further development of the WTO regulatory system in this area.

\section{Target groups}

The research results of the present study should be of interest to various actors operating in the areas of policy making, trade regulation, and standardsetting, as well as sales, marketing and the consumption of goods. In particular, these are: WTO Members, their national standardizing bodies and other relevant regulatory bodies, relevant international intergovernmental organizations, international and regional standard-setting organizations, 
standard-setting NGOs and industry associations, business corporations and even ordinary consumers.

WTO Members may be interested in the research results in order to gain a clearer understanding of their existing rights and obligations with respect to the development, adoption and application of private-sector standards according to the rules of WTO law. This particularly concerns the national standardizing bodies of WTO Members, as well as their other public bodies involved in the regulation of trade in goods. Indeed, as is argued in the conclusions of this study, WTO Members should be cautious in providing governmental support or incentives for the development, adoption and application of private-sector standards, as they might appear to be responsible for those standards and would have to ensure that they are in compliance with the appropriate rules of WTO law.

Moreover, this study concludes that the further development of the WTO rules with regard to private-sector standards, such as the adoption of a voluntary WTO code of good practices specially devoted to private standard-setting, appears to be desirable. The WTO, however, is a Memberdriven organization and the development of WTO law in this regard would thus only be possible if there is a consensus among the Members regarding the challenges posed by the proliferation of private-sector standards to the WTO legal system and the need for further development of WTO law in this area.

The results of this study should be also of interest to a number of international intergovernmental organizations, such as the WTO, the OECD, the UNCTAD, the FAO and the World Bank. Indeed, these organizations are the important policy makers in the field of regulation of international trade and development and, as has been noted above, they became popular fora for the discussions about the role of private-sector standards and their effects on international trade. The research results therefore might be taken into account in reports and papers prepared by these organizations, as well as in the work of their appropriate bodies. Particularly, the recommendations and proposals concerning the interpretation of the existing relevant norms of WTO law and the further development of WTO law in the area offered by this study, may be considered by the appropriate bodies of the WTO, such as the Council for Trade in Goods, the TBT Committee, the SPS Committee, and the Committee on Trade and Environment. This study might also be interesting and useful for the officials of the WTO Secretariat dealing with trade negotiations, the administration of the relevant WTO agreements and the WTO dispute settlement system; and namely for the officers of the Legal Affairs Division, the Rules Division, the Agriculture and Commodities Division, the Trade and Environment Division, the Appellate Body Secretariat, and perhaps, even for the "judges" of the WTO, i.e. the Appellate Body Members and panellists. 
Furthermore, the research results may be of interest to international intergovernmental and regional standard-setting organizations, such as the Codex Alimentarius Commission, the ISO, the CEN, the CENELEC, and the ETSI. And, of course, this study has direct relevance for those private entities which develop and adopt private-sector standards, namely national, regional or international standard-setting NGOs and industry associations (e.g. GLOBALG.A.P., FLO, MSC, and FSC), and business corporations (e.g. Tesco, Marks \& Spencer, Carrefour). Even if a business corporation does not develop its own private-sector standards, it may frequently be the case that it applies a private-sector standard to its suppliers, or has to implement the requirements of a private-sector standard as a supplier of a product due to buyer demands. Thus, business corporations producing, processing, purchasing, marketing and selling various types of goods might also find the results of this study interesting and useful. Moreover, certain parts of the study may even be of interest to ordinary consumers who encounter private product labelling schemes in supermarkets and shops on a daily basis.

Finally, the results of the present research should be useful and interesting for academic researchers, legal practitioners, policy experts and policy makers who are active in the field of international trade, international economic law, standardization, private regulation, and corporate social responsibility.

\section{Activities and products}

This study will result in a published book. It will, as a result, be publicly available for consultation at libraries and for purchase by academic researchers, legal practitioners, policy experts, policy makers, governmental officials, international civil servants, and other stakeholders or persons interested in the challenges posed by the proliferation of private-sector standards and their legal regulation. As has been mentioned already, this study presents a number of recommendations and proposals concerning the understanding of the "world" of private-sector standards, the interpretation of the existing relevant norms of WTO law, and ideas for possible further development of WTO law in the area of private standard-setting. The author thus hopes that at least some of these recommendations and proposals will influence the policies pursued by WTO Members and their relevant authorities or standardizing bodies, as well as by the WTO and other relevant international intergovernmental organizations. The author also anticipates that his recommendations and proposals will be considered and taken into account in the decision-making processes of standard-setting NGOs, industry associations, and business corporations. 
As concluded at the end of the study, more research is necessary to understand various aspects of the effects of private-sector standards on international trade, as well as the options available for addressing the challenges that these standards create, including options for their regulation by both domestic legal regimes and WTO law. And, of course, I am planning to be actively involved into the ongoing discussion and research on this fascinating topic.

\section{Innovation}

Although there exists a number of reports, research papers and publications on private-sector standards, their effects on trade in goods, and the implications of WTO law for their regulation, a comprehensive monographic legal research on the regulation of private-sector standards by the norms of the WTO has not been undertaken to date. The present study thus contributes to the existing body of literature and research on this important topic. In fact, this study, through its analysis of the work on private-sector standards undertaken by various organizations and authors from various perspectives, together with an examination of the relevant rules of WTO law, helps to clarify the overall "picture" of the existing international regulatory framework in this area.

Moreover, the study contributes to exploring the possible ways of interpretation and further development of the WTO rules in order to address the challenges presented by the proliferation and widespread use of private-sector standards. In this respect, as has been noted, this study presents a number of innovative recommendations and proposals.

\section{Planning and implementation}

The author hopes that the results of this study will be taken into account in the ongoing discussions on private-sector standards taking place in the SPS Committee, the TBT Committee, the Committee on Trade and Environment, and other relevant bodies of the WTO. The research results might also be considered by the panellists, Appellate Body Members, and WTO Secretariat officers dealing with the settlement of disputes between WTO Members. This in fact would be particularly useful if and when a dispute related to the use of a private-sector standard is brought to the WTO dispute settlement system by a WTO Member.

The author also expects that the research results will be taken into account in upcoming reports and papers on private-sector standards prepared and issued by the OECD, the UNCTAD, the FAO, the World Bank and other relevant international intergovernmental organizations. The research results may also be considered and applied in the work of international and 
regional intergovernmental standardizing organizations; national, regional or international standard-setting NGOs and industry associations; and business corporations which develop, adopt, apply or implement privatesector standards.

The author will endeavour to promote the results of this study among academics and practitioners, as well as to participate actively in the ongoing discussions on legal and economic issues related to private-sector standards. This will be done through further publications on the topic, participation in scientific conferences, roundtables and other meetings organized by universities, international organizations, scientific societies, NGOs and other organizations active in the field. 


\section{Table of Cases}

\section{GATT Panel Reports}

\author{
Belgium-Family Allowances \\ Canada-FIRA \\ Canada-Gold Coins \\ (unadopted) \\ Canada-Herring \\ and Salmon
}

Canada-Provincial

Liquor Boards (EEC)

Canada-Provincial

Liquor Boards (US)

EEC - Animal Feed Proteins

EEC - Imports of Beef
GATT Panel Report, Belgian

Family Allowances, G/32, adopted

7 November 1952, BISD 1S, p. 59

GATT Panel Report, CanadaAdministration of the Foreign Investment Review Act, L/5504, adopted 7 February 1984, BISD 30S, p. 140

GATT Panel Report, Canada-Measures Affecting the Sale of Gold Coins, L/5863, 17 September 1985, unadopted

GATT Panel Report, Canada-Measures Affecting Exports of Unprocessed Herring and Salmon, L/6268, adopted 22 March 1988, BISD 35S, p. 98

GATT Panel Report, Canada-Import, Distribution and Sale of Alcoholic

Drinks by Canadian Provincial Marketing Agencies, L/6304, adopted 22 March 1988, BISD 35S, p. 37

GATT Panel Report, CanadaImport, Distribution and Sale of Certain Alcoholic Drinks by Provincial Marketing Agencies, DS17/R, adopted 18 February 1992, BISD 39S, p. 27

GATT Panel Report, EEC - Measures on Animal Feed Proteins, L/4599, adopted 14 March 1978, BISD 25S, p. 49

GATT Panel Report, European Economic Community - Imports of Beeffrom Canada, L/5099, adopted 10 March 1981, BISD 28S, p. 92 
EEC-Minimum
Export Prices

EEC-Oilseeds I

EEC - Parts and Components

EEC-Dessert Apples

Italy-Agricultural

Machinery

Japan-Agricultural

Products I

Japan-Alcoholic Beverages I

Japan-Semi-Conductors
GATT Panel Report, EEC - Programme of Minimum Import Prices, Licences and Surety Deposits for Certain Processed Fruits and Vegetables, L/4687, adopted 18 October 1978, BISD 25S, p. 68

GATT Panel Report, European Economic Community - Payments and Subsidies Paid to Processors and Producers of Oilseeds and Related Animal-Feed Proteins, L/6627, adopted 25 January 1990, BISD 37S, p. 86

GATT Panel Report, European Economic Community - Regulation on Imports of Parts and Components, L/6657, adopted 16 May 1990, BISD 37S, p. 132

GATT Panel Report, European Economic Community - Restrictions on Imports of Dessert ApplesComplaint by Chile, L/6491, adopted 22 June 1989, BISD 36S, p. 93

GATT Panel Report, Italian Discrimination Against Imported Agricultural Machinery, L/833, adopted 23 October 1958, BISD 7S, p. 60

GATT Panel Report, JapanRestrictions on Imports of Certain Agricultural Products, L/6253, adopted 2 March 1988, BISD 35S, p. 163

GATT Panel Report, Japan - Customs Duties, Taxes and Labelling Practices on Imported Wines and Alcoholic Beverages, L/6216, adopted 10 November 1987, BISD 34S, p. 83

GATT Panel Report, Japan - Trade in Semi-Conductors, L/6309, adopted 4 May 1988, BISD 35S, p. 116 
Spain-Unroasted Coffee

Thailand-Cigarettes

US - Malt Beverages

US - Tuna

(Mexico, unadopted)

US - Tuna (EEC, unadopted)

US - Section 337 Tariff Act

US - Taxes on Automobiles (unadopted)

US - Canadian Tuna
GATT Panel Report, Spain - Tariff

Treatment of Unroasted Coffee, L/5135, adopted 11 June 1981, BISD 28S, p. 102

GATT Panel Report, Thailand Restrictions on Importation of and Internal Taxes on Cigarettes, DS10/R, adopted 7 November 1990, BISD 37S, p. 200

GATT Panel Report, United States - Measures Affecting Alcoholic and Malt Beverages, DS23/R, adopted 19 June 1992, BISD 39S, p. 206

GATT Panel Report, United States - Restrictions on Imports of Tuna, DS21/R, 3 September 1991, unadopted, BISD 39S, p. 155

GATT Panel Report, United States - Restrictions on Imports of Tuna, DS29/R, 16 June 1994, unadopted

GATT Panel Report, United States Section 337 of the Tariff Act of 1930, L/6439, adopted 7 November 1989, BISD 36S, p. 345

GATT Panel Report, United States - Taxes on Automobiles, DS31/R, 11 October 1994, unadopted

GATT Panel Report, United StatesProhibition of Imports of Tuna and Tuna Products from Canada, L/5198, adopted 22 February 1982, BISD 29S, p. 91 


\section{WTO Panel Reports}

Argentina-Hides

and Leather

Argentina-Import Measures

Australia-Apples

Australia-Salmon

Australia-Salmon

(Article 21.5-Canada)

Brazil-Retreated Tyres
Panel Report, Argentina-Measures

Affecting the Export of Bovine Hides and Import of Finished Leather, WT/

DS155/R and Corr.1, adopted 16

February 2001, DSR 2001:V, p. 1779

Panel Reports, Argentina-Measures

Affecting the Importation of Goods,

WT/DS438/R/WT/DS444/R /

WT/DS445/R, adopted 26 January

2015, as modified by Appellate Body

Reports WT/DS438/AB/R/WT/

DS444/AB/R/WT/DS445/AB/R

Panel Report, Australia-Measures

Affecting the Importation of Apples from

New Zealand, WT/DS367/R, adopted

17 December 2010, as modified by

Appellate Body Report WT/DS367/

AB/R, DSR 2010:VI, p. 2371

Panel Report, Australia-Measures

Affecting Importation of Salmon, WT/DS18/R and Corr.1, adopted 6 November 1998, as modified by Appellate Body Report WT/DS18/ AB/R, DSR 1998:VIII, p. 3407

Panel Report, Australia-Measures

Affecting Importation of SalmonRecourse to Article 21.5 of the DSU by Canada, WT/DS18/RW, adopted 20 March 2000, DSR 2000:IV, p. 2031

Panel Report, Brazil-Measures Affecting Imports of Retreaded Tyres, WT/ DS332/R, adopted 17 December 2007, as modified by Appellate Body Report WT/DS332/AB/R, DSR 2007:V, p. 1649 
Canada-Autos

Canada-Continued

Suspension

Canada-Dairy

Canada-Periodicals

Canada-Wheat Exports and Grain Imports

China-Publications and Audiovisual Products
Panel Report, Canada-Certain Measures Affecting the Automotive Industry, WT/ DS139/R, WT/DS142/R, adopted 19 June 2000, as modified by Appellate Body Report WT/DS139/AB/R, WT/ DS142/AB/R, DSR 2000:VII, p. 3043

Panel Report, Canada-Continued Suspension of Obligations in the ECHormones Dispute, WT/DS321/R, adopted 14 November 2008, as modified by Appellate Body Report WT/DS321/ AB/R, DSR 2008:XV, p. 5757

Panel Report, Canada-Measures Affecting the Importation of Milk and the Exportation of Dairy Products, WT/DS103/R, WT/DS113/R, adopted 27 October 1999, as modified by Appellate Body Report WT/DS103/AB/R, WT/DS113/ AB/R, DSR 1999:VI, p. 2097

Panel Report, Canada-Certain Measures Concerning Periodicals, WT/DS31/R and Corr.1, adopted 30 July 1997, as modified by Appellate Body Report WT/DS31/AB/R, DSR 1997:I, p. 481

Panel Report, Canada-Measures Relating to Exports of Wheat and Treatment of Imported Grain, WT/ DS276/R, adopted 27 September 2004, upheld by Appellate Body Report WT/ DS276/AB/R, DSR 2004:VI, p. 2817

Panel Report, China-Measures Affecting Trading Rights and Distribution Services for Certain Publications and Audiovisual Entertainment Products, WT/DS363/R and Corr.1, adopted 19 January 2010, as modified by Appellate Body Report WT/DS363/AB/R, DSR 2010:II, p. 261 
China-Rare Earths

China-Raw Materials

Colombia-Ports of Entry

Dominican RepublicImport and Sale of Cigarettes

EC-Approval and

Marketing of Biotech Products

EC-Asbestos
Panel Reports, China-Measures Related to the Exportation of Rare Earths, Tungsten and Molybdenum, WT/DS431/R/WT/ DS432/R/WT/DS433/R, adopted 29 August 2014, as modified by Appellate Body Reports WT/DS431/AB/R/WT/ DS432/AB/R/WT/DS433/AB/R

Panel Reports, China-Measures Related to the Exportation of Various Raw Materials, WT/DS394/R/WT/DS395/R / WT/DS398/R / and Corr.1, adopted 22 February 2012, as modified by Appellate Body Reports WT/DS394/AB/R/WT/ DS395/AB/R/WT/DS398/AB/R

Panel Report, Colombia - Indicative Prices and Restrictions on Ports of Entry, WT/DS366/R and Corr.1, adopted 20 May 2009, DSR 2009:VI, p. 2535

Panel Report, Dominican Republic - Measures Affecting the Importation and Internal Sale of Cigarettes, WT/ DS302/R, adopted 19 May 2005, as modified by Appellate Body Report WT/ DS302/AB/R, DSR 2005:XV, p. 7425

Panel Reports, European Communities - Measures Affecting the Approval and Marketing of Biotech Products, WT/DS291/R/WT/DS292/R / WT/DS293/R, Add.1 to Add.9, and Corr.1, adopted 21 November 2006, DSR 2006:III, p. 847

Panel Report, European Communities

- Measures Affecting Asbestos and AsbestosContaining Products, WT/ DS135/R and Add.1, adopted 5 April 2001, as modified by Appellate Body Report WT/DS135/ AB/R, DSR 2001:VIII, p. 3305 


\begin{tabular}{|c|c|}
\hline EC - Bananas III (Ecuador) & $\begin{array}{l}\text { Panel Report, European Communities } \\
\text { - Regime for the Importation, Sale and } \\
\text { Distribution of Bananas, Complaint by } \\
\text { Ecuador, WT/DS27/R/ECU, adopted } \\
25 \text { September 1997, as modified by } \\
\text { Appellate Body Report WT/DS27/ } \\
\text { AB/R, DSR 1997:III, p. } 1085\end{array}$ \\
\hline $\begin{array}{l}\text { EC - Bananas III } \\
\text { (Guatemala and Honduras) }\end{array}$ & $\begin{array}{l}\text { Panel Report, European Communities } \\
\text { - Regime for the Importation, Sale and } \\
\text { Distribution of Bananas, Complaint by } \\
\text { Guatemala and Honduras, WT/DS27/R/ } \\
\text { GTM, WT/DS27/R/HND, adopted } \\
25 \text { September 1997, as modified by } \\
\text { Appellate Body Report WT/DS27/ } \\
\text { AB/R, DSR 1997:II, p. } 695\end{array}$ \\
\hline EC - Bananas III (Mexico) & $\begin{array}{l}\text { Panel Report, European Communities } \\
\text { - Regime for the Importation, Sale and } \\
\text { Distribution of Bananas, Complaint by } \\
\text { Mexico, WT/DS27/R/MEX, adopted } \\
25 \text { September 1997, as modified by } \\
\text { Appellate Body Report WT/DS27/ } \\
\text { AB/R, DSR 1997:II, p. } 803\end{array}$ \\
\hline EC - Bananas III (US) & $\begin{array}{l}\text { Panel Report, European Communities } \\
\text { - Regime for the Importation, Sale and } \\
\text { Distribution of Bananas, Complaint } \\
\text { by the United States, WT/DS27/R/ } \\
\text { USA, adopted } 25 \text { September 1997, as } \\
\text { modified by Appellate Body Report WT/ } \\
\text { DS27/AB/R, DSR 1997:II, p. } 943\end{array}$ \\
\hline EC-Hormones (Canada) & $\begin{array}{l}\text { Panel Report, European Communities } \\
\text { - Measures Concerning Meat and Meat } \\
\text { Products (Hormones), Complaint by } \\
\text { Canada, WT/DS48/R/CAN, adopted } \\
13 \text { February 1998, as modified by } \\
\text { Appellate Body Report WT/DS26/AB/R, } \\
\text { WT/DS48/AB/R, DSR 1998:II, p. } 235\end{array}$ \\
\hline
\end{tabular}


EC-Hormones (US)

EC - IT Products

EC-Poultry

EC-Sardines

EC-Seal Products

EC-Selected

Custom Matters
Panel Report, European Communities - Measures Concerning Meat and Meat Products (Hormones), Complaint by the United States, WT/DS26/R/ USA, adopted 13 February 1998, as modified by Appellate Body Report WT/DS26/AB/R, WT/DS48/ AB/R, DSR 1998:III, p. 699

Panel Reports, European Communities and its member States - Tariff Treatment of Certain Information Technology Products, WT/DS375/R/WT/ DS376/R/WT/DS377/R, adopted 21 September 2010, DSR 2010:III, p. 933

Panel Report, European Communities - Measures Affecting the Importation of Certain Poultry Products, WT/DS69/R, adopted 23 July 1998, as modified by Appellate Body Report WT/DS69/ AB/R, DSR 1998:V, p. 2089

Panel Report, European Communities

- Trade Description of Sardines, WT/

DS231/R and Corr.1, adopted 23 October 2002, as modified by Appellate Body Report WT/DS231/ $\mathrm{AB} / \mathrm{R}$, DSR 2002:VIII, p. 3451

Panel Reports, European Communities Measures Prohibiting the Importation and Marketing of Seal Products, WT/DS400/R / WT/DS401/R, adopted 18 June 2014 as modified by Appellate Body Reports WT/DS400/AB/R/WT/DS401/AB/R

Panel Report, European Communities Selected Customs Matters, WT/DS315/R, adopted 11 December 2006, as modified by Appellate Body Report WT/DS315/ AB/R, DSR 2006:IX, p. 3915 
EC-Tariff Preferences

EC-Trademarks
and Geographical
Indications (Australia)

EC-Trademarks and Geographical Indications (US)

India-Autos

India-Quantitative Restrictions

Indonesia-Autos
Panel Report, European Communities - Conditions for the Granting of Tariff Preferences to Developing Countries, WT/ DS246/R, adopted 20 April 2004, as modified by Appellate Body Report WT/ DS246/AB/R, DSR 2004:III, p. 1009

Panel Report, European Communities - Protection of Trademarks and Geographical Indications for Agricultural Products and Foodstuffs, Complaint by Australia, WT/DS290/R, adopted 20 April 2005, DSR 2005:X, p. 4603

Panel Report, European Communities - Protection of Trademarks and Geographical Indications for Agricultural Products and Foodstuffs, Complaint by the United States, WT/DS174/R, adopted 20 April 2005, DSR 2005:VIII, p. 3499

Panel Report, India - Measures Affecting the Automotive Sector, WT/DS146/R, WT/DS175/R and Corr.1, adopted 5 April 2002, DSR 2002:V, p. 1827

Panel Report, India - Quantitative Restrictions on Imports of Agricultural, Textile and Industrial Products, WT/ DS90/R, adopted 22 September 1999, upheld by Appellate Body Report WT/ DS90/AB/R, DSR 1999:V, p. 1799

Panel Report, Indonesia-Certain Measures Affecting the Automobile Industry, WT/DS54/R, WT/DS55/R, WT/DS59/R, WT/DS64/R and Corr.1 and 2, adopted 23 July 1998, and Corr. 3 and 4, DSR 1998:VI, p. 2201 
Japan-Agricultural

Products II

Japan-Alcoholic Beverages II

Japan-Apples

Japan-Apples

(Article 21.5-US)

Japan-Film

Korea-Alcoholic Beverages

Korea-Commercial Vessels
Panel Report, Japan - Measures Affecting Agricultural Products, WT/DS76/R, adopted 19 March 1999, as modified by Appellate Body Report WT/ DS76/AB/R, DSR 1999:I, p. 315

Panel Report, Japan - Taxes on Alcoholic Beverages, WT/DS8/R, WT/DS10/R, WT/DS11/R, adopted 1 November 1996, as modified by Appellate Body Report WT/DS8/ AB/R, WT/DS10/AB/R, WT/ DS11/AB/R, DSR 1996:I, p. 125

Panel Report, Japan-Measures Affecting the Importation of Apples, WT/DS245/R, adopted 10 December 2003, upheld by Appellate Body Report WT/DS245/ AB/R, DSR 2003:IX, p. 4481

Panel Report, Japan - Measures Affecting the Importation of Apples - Recourse to Article 21.5 of the DSU by the United States, WT/DS245/RW, adopted 20 July 2005, DSR 2005:XVI, p. 7911

Panel Report, Japan-Measures Affecting Consumer Photographic Film and Paper, WT/DS44/R, adopted 22 April 1998, DSR 1998:IV, p. 1179

Panel Report, Korea-Taxes on Alcoholic Beverages, WT/DS75/R, WT/DS84/R, adopted 17 February 1999, as modified by Appellate Body Report WT/DS75/AB/R, WT/ DS84/AB/R, DSR 1999:I, p. 44

Panel Report, Korea-Measures Affecting Trade in Commercial Vessels, WT/DS273/R, adopted 11 April 2005, DSR 2005:VII, p. 2749 
Korea-Various

Measures on Beef

Mexico-Taxes on Soft Drinks

Thailand-Cigarettes (Philippines)

Turkey-Textiles

US - Clove Cigarettes

US - Continued Suspension
Panel Report, Korea-Measures Affecting Imports of Fresh, Chilled and Frozen Beef, WT/DS161/R, WT/DS169/R, adopted 10 January 2001, as modified by Appellate Body Report WT/DS161/AB/R, WT/ DS169/AB/R, DSR 2001:I, p. 59

Panel Report, Mexico - Tax Measures on Soft Drinks and Other Beverages, WT/ DS308/R, adopted 24 March 2006, as modified by Appellate Body Report WT/DS308/AB/R, DSR 2006:I, p. 43

Panel Report, Thailand-Customs and Fiscal Measures on Cigarettes from the Philippines, WT/DS371/R, adopted 15 July 2011, as modified by Appellate Body Report WT/DS371/ AB/R, DSR 2011:IV, p. 2299

Panel Report, Turkey-Restrictions on Imports of Textile and Clothing Products, WT/DS34/R, adopted 19 November 1999, as modified by Appellate Body Report WT/DS34/ AB/R, DSR 1999:VI, p. 2363

Panel Report, United States - Measures Affecting the Production and Sale of Clove Cigarettes, WT/DS406/R, adopted 24 April 2012, as modified by Appellate Body Report WT/DS406/AB/R

Panel Report, United States - Continued Suspension of Obligations in the EC Hormones Dispute, WT/DS320/R, adopted 14 November 2008, as modified by Appellate Body Report WT/DS320/ AB/R, DSR 2008:XI, p. 3891 


\begin{tabular}{|c|c|}
\hline$U S-C O O L$ & $\begin{array}{l}\text { Panel Reports, United States - Certain } \\
\text { Country of Origin Labelling (COOL) } \\
\text { Requirements, WT/DS384/R/WT/ } \\
\text { DS386/R, adopted } 23 \text { July 2012, as } \\
\text { modified by Appellate Body Reports } \\
\text { WT/DS384/AB/R/WT/DS386/AB/R }\end{array}$ \\
\hline US - Export Restraints & $\begin{array}{l}\text { Panel Report, United States - Measures } \\
\text { Treating Exports Restraints as Subsidies, } \\
\text { WT/DS194/R and Corr.2, adopted } 23 \\
\text { August 2001, DSR 2001:XI, p. } 5767\end{array}$ \\
\hline US - Gambling & $\begin{array}{l}\text { Panel Report, United States - Measures } \\
\text { Affecting the CrossBorder Supply of } \\
\text { Gambling and Betting Services, WT/ } \\
\text { DS285/R, adopted } 20 \text { April 2005, as } \\
\text { modified by Appellate Body Report WT/ } \\
\text { DS285/AB/R, DSR 2005:XII, p. } 5797\end{array}$ \\
\hline US - Gasoline & $\begin{array}{l}\text { Panel Report, United States - } \\
\text { Standards for Reformulated and } \\
\text { Conventional Gasoline, WT/DS2/R, } \\
\text { adopted } 20 \text { May 1996, as modified } \\
\text { by Appellate Body Report WT/ } \\
\text { DS2/AB/R, DSR 1996:I, p. } 29\end{array}$ \\
\hline US - Poultry (China) & $\begin{array}{l}\text { Panel Report, United States - Certain } \\
\text { Measures Affecting Imports of Poultry } \\
\text { from China, WT/DS392/R, adopted } 25 \\
\text { October 2010, DSR 2010:V, p. } 1909\end{array}$ \\
\hline US - Shrimp & $\begin{array}{l}\text { Panel Report, United States - Import } \\
\text { Prohibition of Certain Shrimp and } \\
\text { Shrimp Products, WT/DS58/R and } \\
\text { Corr.1, adopted } 6 \text { November 1998, as } \\
\text { modified by Appellate Body Report WT/ } \\
\text { DS58/AB/R, DSR 1998:VII, p. } 2821\end{array}$ \\
\hline US - Tuna II (Mexico) & $\begin{array}{l}\text { Panel Report, United States - Measures } \\
\text { Concerning the Importation, Marketing } \\
\text { and Sale of Tuna and Tuna Products, } \\
\text { WT/DS381/R, adopted } 13 \text { June } \\
\text { 2012, as modified by Appellate } \\
\text { Body Report WT/DS381/AB/R }\end{array}$ \\
\hline
\end{tabular}




\section{Appellate Body Reports}

Argentina-Import

Measures

Australia-Apples

Australia-Salmon

Brazil-Retreated Tyres

Canada-Autos

Canada-Continued

Suspension

Canada-Dairy
Appellate Body Reports, Argentina-

Measures Affecting the Importation of Goods, WT/DS438/AB/R/WT/DS444/AB/R/WT/ DS445/AB/R, adopted 26 January 2015

Appellate Body Report, Australia-Measures Affecting the Importation of Apples from New Zealand, WT/DS367/AB/R, adopted 17 December 2010, DSR 2010:V, p. 2175

Appellate Body Report, AustraliaMeasures Affecting Importation of Salmon, WT/DS18/AB/R, adopted 6 November 1998, DSR 1998:VIII, p. 3327

Appellate Body Report, Brazil-Measures Affecting Imports of Retreaded Tyres, WT/ DS332/AB/R, adopted 17 December 2007, DSR 2007:IV, p. 1527

Appellate Body Report, Canada-Certain Measures Affecting the Automotive Industry, WT/DS139/AB/R, WT/DS142/AB/R, adopted 19 June 2000, DSR 2000:VI, p. 2985

Appellate Body Report, CanadaContinued Suspension of Obligations in the EC-Hormones Dispute, WT/ DS321/AB/R, adopted 14 November 2008, DSR 2008:XIV, p. 5373

Appellate Body Report, CanadaMeasures Affecting the Importation of Milk and the Exportation of Dairy Products, WT/DS103/AB/R, WT/ DS113/AB/R and Corr.1, adopted 27 October 1999, DSR 1999:V, p. 2057 
Canada-Dairy

(Article 21.5-New

Zealand and US)

Canada-Dairy

(Article 21.5 - New

Zealand and US II)

Canada-Periodicals

Canada-Wheat Exports and Grain Imports

Chile-Alcoholic

Beverages

China-Auto Parts

China-Publications and Audiovisual Products
Appellate Body Report, Canada-Measures Affecting the Importation of Milk and the Exportation of Dairy Products - Recourse to Article 21.5 of the DSU by New Zealand and the United States, WT/DS103/AB/RW, WT/ DS113/AB/RW, adopted 18 December 2001, DSR 2001:XIII, p. 6829

Appellate Body Report, Canada-Measures Affecting the Importation of Milk and the Exportation of Dairy Products - Second Recourse to Article 21.5 of the DSU by New Zealand and the United States, WT/DS103/ AB/RW2, WT/DS113/AB/RW2, adopted 17 January 2003, DSR 2003:I, p. 213

Appellate Body Report, Canada

- Certain Measures Concerning Periodicals, WT/DS31/AB/R, adopted 30 July 1997, DSR 1997:I, p. 449

Appellate Body Report, Canada-Measures Relating to Exports of Wheat and Treatment of Imported Grain, WT/DS276/AB/R, adopted 27 September 2004, DSR 2004:VI, p. 2739

Appellate Body Report, Chile-Taxes on Alcoholic Beverages, WT/DS87/ AB/R, WT/DS110/AB/R, adopted 12 January 2000, DSR 2000:I, p. 281

Appellate Body Reports, China-Measures Affecting Imports of Automobile Parts, WT/DS339/AB/R/WT/DS340/ $\mathrm{AB} / \mathrm{R} / \mathrm{WT} / \mathrm{DS} 342 / \mathrm{AB} / \mathrm{R}$, adopted 12 January 2009, DSR 2009:I, p. 3

Appellate Body Report, China-Measures Affecting Trading Rights and Distribution Services for Certain Publications and Audiovisual Entertainment Products, WT/DS363/AB/R, adopted 19 January 2010, DSR 2010:I, p. 3 


\begin{tabular}{|c|c|}
\hline China-Rare Earths & $\begin{array}{l}\text { Appellate Body Reports, China-Measures } \\
\text { Related to the Exportation of Rare Earths, } \\
\text { Tungsten and Molybdenum, WT/DS431/ } \\
\text { AB/R/ WT/DS432/AB/R/WT/DS433/ } \\
\text { AB/R, adopted } 29 \text { August } 2014\end{array}$ \\
\hline China-Raw Materials & $\begin{array}{l}\text { Appellate Body Reports, China- } \\
\text { Measures Related to the Exportation of } \\
\text { Various Raw Materials, WT/DS394/ } \\
\text { AB/R/WT/DS395/AB/R/WT/DS398/ } \\
\text { AB/R, adopted } 22 \text { February } 2012\end{array}$ \\
\hline $\begin{array}{l}\text { Dominican Republic } \\
\text { - Import and Sale } \\
\text { of Cigarettes }\end{array}$ & $\begin{array}{l}\text { Appellate Body Report, Dominican } \\
\text { Republic-Measures Affecting the } \\
\text { Importation and Internal Sale of Cigarettes, } \\
\text { WT/DS302/AB/R, adopted } 19 \text { May } \\
\text { 2005, DSR 2005:XV, p. } 7367\end{array}$ \\
\hline EC-Asbestos & $\begin{array}{l}\text { Appellate Body Report, European } \\
\text { Communities - Measures Affecting } \\
\text { Asbestos and AsbestosContaining Products, } \\
\text { WT/DS135/AB/R, adopted } 5 \text { April } \\
\text { 2001, DSR 2001:VII, p. } 3243\end{array}$ \\
\hline EC - Bananas III & $\begin{array}{l}\text { Appellate Body Report, European } \\
\text { Communities - Regime for the Importation, } \\
\text { Sale and Distribution of Bananas, WT/ } \\
\text { DS27/AB/R, adopted } 25 \text { September } \\
\text { 1997, DSR 1997:II, p. } 591\end{array}$ \\
\hline $\begin{array}{l}\text { EC-Export } \\
\text { Subsidies on Sugar }\end{array}$ & $\begin{array}{l}\text { Appellate Body Report, European } \\
\text { Communities - Export Subsidies on } \\
\text { Sugar, WT/DS265/AB/R, WT/DS266/ } \\
\text { AB/R, WT/DS283/AB/R, adopted } 19 \\
\text { May 2005, DSR 2005:XIII, p. } 6365\end{array}$ \\
\hline EC-Hormones & $\begin{array}{l}\text { Appellate Body Reports, European } \\
\text { Communities - Measures Concerning Meat } \\
\text { and Meat Products (Hormones), WT/ } \\
\text { DS26/AB/R, WT/DS48/AB/R, adopted } \\
13 \text { February 1998, DSR 1998:I, p. } 135\end{array}$ \\
\hline
\end{tabular}


EC-Poultry

EC-Sardines

EC - Seal Products

EC-Selected

Custom Matters

EC-Tariff Preferences

Guatemala-Cement I

Japan-Agricultural

Products II

Japan-Alcoholic

Beverages II
Appellate Body Report, European

Communities - Measures Affecting the Importation of Certain Poultry Products, WT/DS69/AB/R, adopted 23 July 1998, DSR 1998:V, p. 2031

Appellate Body Report, European Communities - Trade Description of

Sardines, WT/DS231/AB/R, adopted 23 October 2002, DSR 2002:VIII, p. 3359

Appellate Body Reports, European Communities - Measures Prohibiting the Importation and Marketing of Seal Products, WT/DS400/AB/R/WT/ DS401/AB/R, adopted 18 June 2014

Appellate Body Report, European Communities - Selected Customs Matters, WT/DS315/AB/R, adopted 11 December 2006, DSR 2006:IX, p. 3791

Appellate Body Report, European Communities - Conditions for the Granting of Tariff Preferences to Developing Countries, WT/DS246/AB/R, adopted 20 April 2004, DSR 2004:III, p. 925

Appellate Body Report, GuatemalaAntiDumping Investigation Regarding Portland Cement from Mexico, WT/ DS60/AB/R, adopted 25 November 1998, DSR 1998:IX, p. 3767

Appellate Body Report, Japan-Measures Affecting Agricultural Products, WT/ DS76/AB/R, adopted 19 March 1999, DSR 1999:I, p. 277

Appellate Body Report, Japan - Taxes on Alcoholic Beverages, WT/DS8/AB/R, WT/ DS10/AB/R, WT/DS11/AB/R, adopted 1 November 1996, DSR 1996:I, p. 97 
Japan-Apples

Korea-Various

Measures on Beef

Mexico-Taxes

on Soft Drinks

Thailand-Cigarettes

(Philippines)

US - Anti-Dumping

and Countervailing

Duties (China)

US - Carbon Steel

US - Clove Cigarettes

US - Continued

Suspension
Appellate Body Report, Japan - Measures

Affecting the Importation of Apples, WT/ DS245/AB/R, adopted 10 December 2003, DSR 2003:IX, p. 4391

Appellate Body Report, Korea-Measures

Affecting Imports of Fresh, Chilled and Frozen Beef, WT/DS161/AB/R, WT/DS169/AB/R, adopted 10 January 2001, DSR 2001:I, p. 5

Appellate Body Report, Mexico - Tax

Measures on Soft Drinks and Other Beverages, WT/DS308/AB/R, adopted 24 March 2006, DSR 2006:I, p. 3

Appellate Body Report, Thailand-Customs and Fiscal Measures on Cigarettes from the Philippines, WT/DS371/AB/R, adopted 15 July 2011, DSR 2011:IV, p. 2203

Appellate Body Report, United StatesDefinitive Anti-Dumping and Countervailing Duties on Certain Products from China, WT/DS379/AB/R, adopted 25 March 2011, DSR 2011:V, p. 2869

Appellate Body Report, United States

- Countervailing Duties on Certain CorrosionResistant Carbon Steel Flat Products from Germany, WT/DS213/ $\mathrm{AB} / \mathrm{R}$ and Corr.1, adopted 19 December 2002, DSR 2002:IX, p. 3779

Appellate Body Report, United States - Measures Affecting the Production and Sale of Clove Cigarettes, WT/DS406/ AB/R, adopted 24 April 2012

Appellate Body Report, United States - Continued Suspension of Obligations in the EC-Hormones Dispute, WT/ DS320/AB/R, adopted 14 November 2008, DSR 2008:X, p. 3507 


\begin{tabular}{|c|c|}
\hline$U S-C O O L$ & $\begin{array}{l}\text { Appellate Body Reports, United States- } \\
\text { Certain Country of Origin Labelling (COOL) } \\
\text { Requirements, WT/DS384/AB/R / WT/ } \\
\text { DS386/AB/R, adopted } 23 \text { July } 2012\end{array}$ \\
\hline $\begin{array}{l}\text { US - Corrosion- } \\
\text { Resistant Steel } \\
\text { Sunset Review }\end{array}$ & $\begin{array}{l}\text { Appellate Body Report, United States } \\
\text { - Sunset Review of AntiDumping Duties } \\
\text { on CorrosionResistant Carbon Steel Flat } \\
\text { Products from Japan, WT/DS244/AB/R, } \\
\text { adopted } 9 \text { January 2004, DSR 2004:I, p. } 3\end{array}$ \\
\hline US - Cotton Yarn & $\begin{array}{l}\text { Appellate Body Report, United States } \\
\text { - Transitional Safeguard Measure on } \\
\text { Combed Cotton Yarn from Pakistan, WT/ } \\
\text { DS192/AB/R, adopted } 5 \text { November } \\
\text { 2001, DSR 2001:XII, p. } 6027\end{array}$ \\
\hline $\begin{array}{l}\text { US - Countervailing } \\
\text { and Anti-Dumping } \\
\text { Measures (China) }\end{array}$ & $\begin{array}{l}\text { Appellate Body Report, United States- } \\
\text { Countervailing and Anti-dumping Measures } \\
\text { on Certain Products from China, WT/ } \\
\text { DS449/AB/R, adopted } 22 \text { July } 2014\end{array}$ \\
\hline $\begin{array}{l}\text { US - Countervailing } \\
\text { Duty Investigation } \\
\text { on DRAMS }\end{array}$ & $\begin{array}{l}\text { Appellate Body Report, United States } \\
\text { - Countervailing Duty Investigation } \\
\text { on Dynamic Random Access Memory } \\
\text { Semiconductors (DRAMS) from Korea, } \\
\text { WT/DS296/AB/R, adopted } 20 \text { July } \\
\text { 2005, DSR 2005:XVI, p. } 8131\end{array}$ \\
\hline$U S-F S C$ & $\begin{array}{l}\text { Appellate Body Report, United States - Tax } \\
\text { Treatment for "Foreign Sales Corporations", } \\
\text { WT/DS108/AB/R, adopted } 20 \text { March } \\
\text { 2000, DSR 2000:III, p. } 1619\end{array}$ \\
\hline $\begin{array}{l}\text { US - FSC } \\
\text { (Article } 21.5-E C)\end{array}$ & $\begin{array}{l}\text { Appellate Body Report, United States - Tax } \\
\text { Treatment for "Foreign Sales Corporations" } \\
\text { - Recourse to Article } 21.5 \text { of the DSU by the } \\
\text { European Communities, WT/DS108/AB/RW, } \\
\text { adopted } 29 \text { January 2002, DSR 2002:I, p. } 55\end{array}$ \\
\hline
\end{tabular}




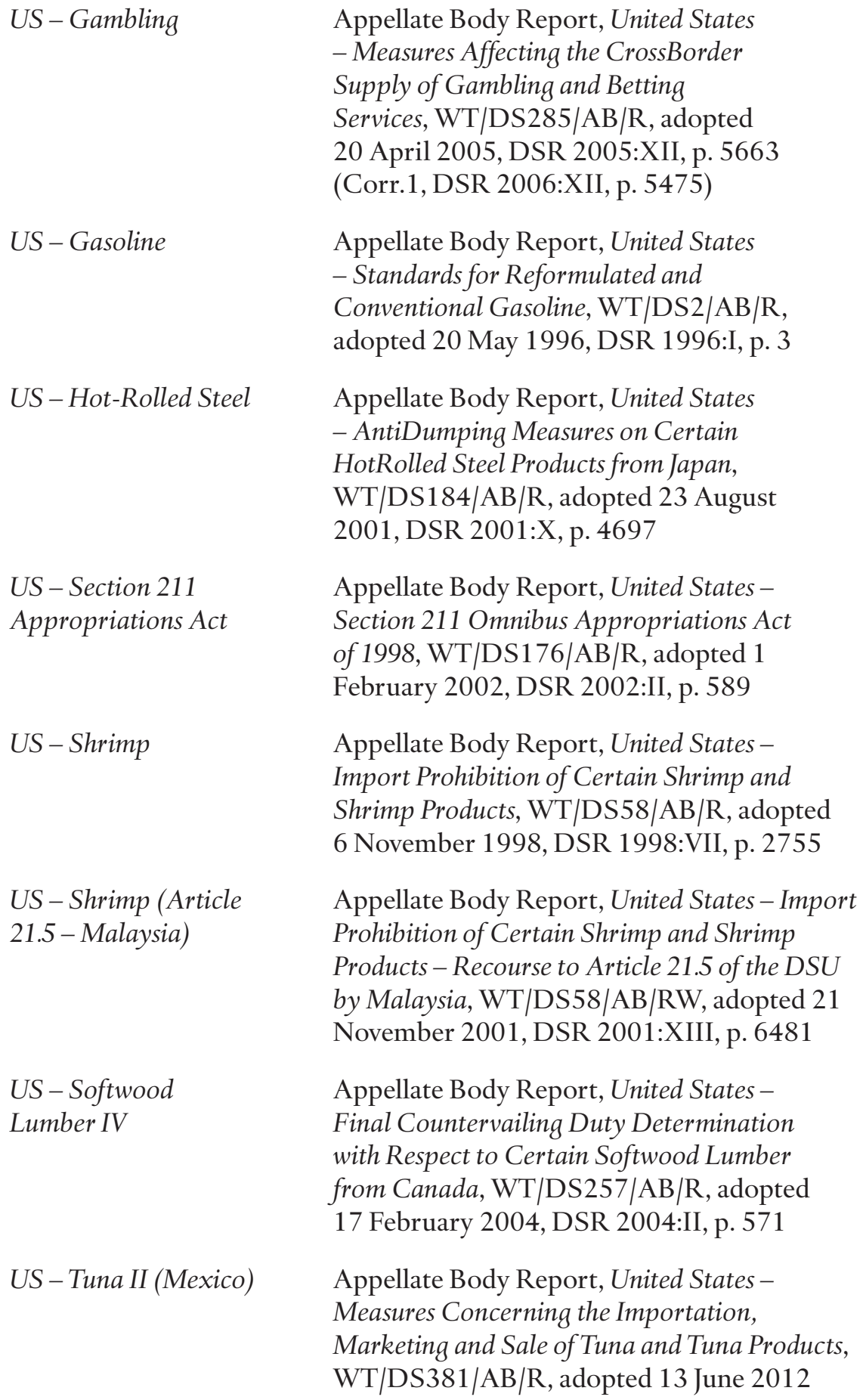

Appellate Body Report, United States - Measures Affecting the CrossBorder Supply of Gambling and Betting Services, WT/DS285/AB/R, adopted 20 April 2005, DSR 2005:XII, p. 5663 (Corr.1, DSR 2006:XII, p. 5475)

Appellate Body Report, United States - Standards for Reformulated and Conventional Gasoline, WT/DS2/AB/R, adopted 20 May 1996, DSR 1996:I, p. 3

Appellate Body Report, United States - AntiDumping Measures on Certain HotRolled Steel Products from Japan, WT/DS184/AB/R, adopted 23 August 2001, DSR 2001:X, p. 4697

Appellate Body Report, United StatesSection 211 Omnibus Appropriations Act of 1998, WT/DS176/AB/R, adopted 1 February 2002, DSR 2002:II, p. 589

Appellate Body Report, United StatesImport Prohibition of Certain Shrimp and Shrimp Products, WT/DS58/AB/R, adopted 6 November 1998, DSR 1998:VII, p. 2755

Appellate Body Report, United States - Import Prohibition of Certain Shrimp and Shrimp Products-Recourse to Article 21.5 of the DSU by Malaysia, WT/DS58/AB/RW, adopted 21 November 2001, DSR 2001:XIII, p. 6481

Appellate Body Report, United StatesFinal Countervailing Duty Determination with Respect to Certain Softwood Lumber from Canada, WT/DS257/AB/R, adopted 17 February 2004, DSR 2004:II, p. 571

Appellate Body Report, United StatesMeasures Concerning the Importation, Marketing and Sale of Tuna and Tuna Products, WT/DS381/AB/R, adopted 13 June 2012 


\begin{tabular}{|c|c|}
\hline US - Underwear & $\begin{array}{l}\text { Appellate Body Report, United States } \\
\text { - Restrictions on Imports of Cotton and } \\
\text { Manmade Fibre Underwear, WT/DS24/AB/R, } \\
\text { adopted } 25 \text { February 1997, DSR 1997:I, p. } 11\end{array}$ \\
\hline $\begin{array}{l}\text { US - Wool Shirts } \\
\text { and Blouses }\end{array}$ & $\begin{array}{l}\text { Appellate Body Report, United States } \\
\text { - Measure Affecting Imports of Woven } \\
\text { Wool Shirts and Blouses from India, WT/ } \\
\text { DS33/AB/R, adopted 23 May 1997, } \\
\text { and Corr.1, DSR 1997:I, p. } 323\end{array}$ \\
\hline US - Zeroing (EC) & $\begin{array}{l}\text { Appellate Body Report, United States- } \\
\text { Laws, Regulations and Methodology for } \\
\text { Calculating Dumping Margins ("Zeroing”), } \\
\text { WT/DS294/AB/R, adopted } 9 \text { May 2006, } \\
\text { and Corr.1, DSR 2006:II, p. } 417\end{array}$ \\
\hline
\end{tabular}




\section{Award / Decisions of Other Courts and Tribunals}

Bosnian Genocide case

Democratic Republic of the Congo v. Uganda

eBay Inc.v.

MercExchange

Nicaragua case

Rambus, Inc. v.

Infineon Tech. AG

Spanish Strawberries case

Tadić case

Tehran Hostages case

United Brands case
Case Concerning the Application of the Convention on the Prevention and Punishment of the Crime of Genocide (Bosnia and Herzegovina v. Serbia and Montenegro), Merits, ICJ Reports 2007

Case Concerning Armed Activities on the Territory of the Congo (Democratic Republic of the Congo v. Uganda), Merits, ICJ Reports 2005

eBay Inc. v. MercExchange, L.L.C., 547 U.S. 388 (2006)

Military and Paramilitary Activities in and against Nicaragua (Nicaragua v. United States of America), Merits, ICJ Reports 1986

Rambus, Inc. v. Infineon Tech. AG, 304 F. Supp. 2d 812 (E. D. Va. 2004)

C-265/95, Commission v. France, ECJ, (1997) ECR I-6959.

Case IT-94-1-A, Prosecutor v. Tadić, ICTY, Appeals Chamber, 15 July 1999

United States Diplomatic and Consular Staff in Tehran, Merits, ICJ Reports 1980

United Brands Co. and United Brands Continental BV vs. EC Commission, Judgment of the ECJ, 14 February 1978 


\section{Bibliography}

\section{Articles, Books and Reports}

Abbott, K. W. and D. Snidal, "Strengthening International Regulation Through Transnational New Governance", Vanderbilt Journal of Transnational Law, 42, 2009

Ahold's Corporate Responsibility Report 2009, available at: http://www. annualreport2009.ahold.com/documents/reports/Ahold_CR_2009.pdf (last visited November 20, 2014)

Akyoo, A. and E. Lazaro, "The Spice Industry in Tanzania: General Profile, Supply Chain Structure, and Food Standards Compliance Issues”, DIIS Working Paper no 2007/8, Danish Institute for International Studies, Copenhagen, 2007

Alemanno, A., Trade in Food: Regulatory and Judicial Approaches in the EC and the WTO, Cameron May, London, 2007

Allshouse, J., J. C. Buzby, et al., "International Trade and Seafood Safety", at: J. C. Buzby, International Trade and Food Safety: Economic Theory and Case Studies, 828 United States Department of Agriculture, Economics Research Service, Washington D.C., 2003

Alvarez-Jimenez, A., "International State Responsibility for Acts of Non-State Actors: The Recent Standards Set by the International Court of Justice in Genocide and why the WTO Appellate Body Should not Embrace them", Syracuse Journal of International Law and Commerce, 35, 2007

Appleton, A. E., “Conformity Assessment Procedures”, at: T. Epps, M. J. Trebilcock, Research Handbook on the WTO and Technical Barriers to Trade, Edward Elgar, Cheltenham, UK, 2013

Appleton, A. E., "Supermarket Labels and the TBT Agreement: "Mind the Gap”“, Business Law Brief, 4, Fall 2007

Appleton, A. E., "The Agreement on Technical Barriers to Trade", at: P. F. J. Macrory, The World Trade Organization: Legal, Economic and Political Analysis, 1 Springer [etc.], New York, 2005 
Aragrande, M., A. Segré, et al., "Food Supply Chains Dynamics and Quality Certification”, Final Report, EU DG Joint Research Centre, Brussels, 31 May 2005

Arcuri, A., "The TBT Agreement and Private Standards”, at: T. Epps, M. J. Trebilcock, Research Handbook on the WTO and Technical Barriers to Trade, Edward Elgar, Cheltenham, UK, 2013

Asfaw, S., D. Mithöfer, et al., "What Impact Are EU Supermarket Standards Having on Developing Countries Export of High-Value Horticultural Products? Evidence from Kenya”, Paper for the 105th EAAE Seminar 'International Marketing and International Trade of Quality Food Products', Bologna, Italy University of Hanover, Hanover, Germany, March 8-10, 2007

Bartels, L., "Article XX of GATT and the Problem of Extraterritorial Jurisdiction. The Case of Trade Measures for the Protection of Human Rights “, Journal of World Trade, 36(2), 2002

Bartenhagen, E. P., "The Intersection of trade and the Environment: An Examination of the Impact of the TBT Agreement on Eco-labeling Programs”, Virginia Environmental Law Journal, 17, 1997

Berdegué, J. A., F. Balsevich, et al., “Central America Supermarkets’ Private Standards of Quality and Safety in Procurement of Fresh Fruits and Vegetables", Food Policy, 30, 2005

Bernstein, S. and E. Hannah, "Non-State Global Standard Setting and the WTO: Legitimacy and the Need for Regulatory Space”, Journal of International Economic Law, 11(3), 2008

Bismuth, R., "Financial Sector Regulation and Financial Services Liberalization at the Crossroads: The Relevance of International Financial Standards in WTO Law”, Journal of World Trade, 44(2), 2010

Bohanes, J. and I. Sandford, "The (Untapped) Potential of WTO Rules to Discipline Private Trade-Restrictive Conduct”, Inaugural Conference, Society of International Economic Law, 56/08, Geneva, July, 15-17, 2008

Bonsi, R., A. L. Hammett, et al., "Eco-Labels and International Trade: Problems and Situations”, Journal of World Trade, 42(3), 2008

Bossche, P. V. d. and W. Zdouc, The Law and Policy of the World Trade Organization. Text, Cases and Materials, 3d Edition, CUP, 2013

Bossche, P. V. d., "Looking for Proportionality in WTO Law”, Legal Issues of Economic Integration, 35(3), 2008 
Bossche, P. V. d., "NGO Involvement in the WTO: A Comparative Perspective”, Journal of International Economic Law, 11(4), 2008

Bossche, P. V. d., D. Prévost, et al., "WTO Rules on Technical Barriers to Trade”, Maastricht, 2005-6

Bratton, W. W., "Private Standards, Public Governance: A New Look at the Financial Accounting Standards Board”, Boston College Law Review, 48, January, 2007

Burkeen, A., "Private Ordering and Institutional Choice: Defining the Role of Multinational Corporations in Promoting Global Labor Standards”, Washington University Global Studies Law Review, 6, 2007

Busch, L., D. Thiagarajan, et al., "The Relationship of Third-Party Certification (TPC) to Sanitary/Phytosanitary (SPS) Measures and the International Agri-Food Trade: Final Report”, RAISE SPS Global Analytical Report, 9, USAID, Washington, December 2005

Buzby, J. C., P. D. Frenzen, et al., "Product Liability and Microbial Foodborne Illness”, Agricultural Economic Report, 799, United States Department of Agriculture, Economics Research Service, Washington D.C., 2001

Byers, A., D. Giovannucci, et al., "Value-adding standards in the North American food market. Trade opportunities in certified products for developing countries”, FAO Commodities and Trade Technical Paper, 11, FAO, Rome, 2008

Cafaggi, F., "New Foundations of Transnational Private Regulation”, Journal of Law and Society, 38(1), 2011

Cafaggi, F., “Transnational Governance by Contract: Private Regulation abd Contractual Networks in Food Safety”, at: A. Marx, M. Maertens, J. Swinnen, J. Wouters, Private Standards and Global Governance. Economic, Legal and Political Perspectives, Edward Elgar, Cheltenham, UK, 2012

Canivet, N., “Food Safety Certification”, FAO, 2006

Cary, G. S., M. W. Nelson, et al., "The Case for Antitrust Law to Police the Patent Holdup Problem in Standard Setting”, Antitrust Law Journal,(3), 2011

Casella, A., "Product Standards and International Trade - Harmonization Through Private Collations?”, 54 (2/3), Kyklos, 2001 
Cerber, D. J., "Competition Law and the WTO: Rethinking the Relationship”, Journal of International Economic Law, 10(3), 2007

Challenges and Opportunities Arising from Private Standards on Food Safety and Environment for Exporters of Fresh Fruit and Vegetables in Asia: Experiences of Malaysia, Thailand and Viet Nam, UNCTAD, UNCTAD/DITC/TED/2007/6, New York, Geneva, 2007

Chazournes, L. B. d. and M. M. Mbengue, "GMOs and Trade: Issues at Stake in the EC Biotech Dispute", Review of European Community and International Environmental Law, 13(3), 2004

Cheyne, I., "Risk and Precaution in World Trade Organization Law", Journal of World Trade, 40(5), 2006

Clapp, S., "Private Sector Standards Seen Harming Developing Countries”, Food Chemical News, 49(33), 2007

Codecision. May 1999 to December 2006. Some Statistical Data, available at: http://ec.europa.eu/codecision/institutional/analysis/ codecision_stat_en.pdf(last visited November 20, 2014)

Collins, D., "Health Protection at the World Trade Organization: The J-Value as a Universal Standard for Reasonableness of Regulatory Precautions”, Journal of World Trade, 43(5), 2009

Conrad, C. R., "PPMs, the EC-Biotech Dispute and Applicability of the SPS Agreement: Are the Panel's Findings Built on Shaky Ground?”, Research Paper No. 8-06, Hebrew University, Jerusalem, August 2006

Conrad, C. R., Process and Production Methods (PPMs) in WTO Law. Interfacing Trade and Social Goals, CUP, 2011

Cooper, T., "Picture This: Promoting Sustainable Fisheries through EcoLabeling and Product Certification”, Ocean and Coastal Law Journal, 10, 2004 / 2005

Cottier, T. and P. C. Mavroidis, Regulatory Barrier and the Principle of Non-Discrimination in World Trade Law, The University of Michigan Press, 2000

Cottier, T., The Challenge of WTO Law: Collected Essays, Cameron May, London, 2007

Course on Dispute Settlement. World Trade Organization. 3.10.

Technical Barriers to Trade, UNCTAD, New York and Geneva, 2003 
Cuffaro, N. and P. Liu, “Technical regulations and standards for food exports: trust and the credence goods problem”, Commodity Market Review, FAO, Rome, 2008

Cunningham, L. A., "Private Standards in Public Law: Copyright, Lawmaking and the Case of Accounting”, Michigan Law Review, 104, November, 2005

Cuyvers, L. and T. D. Meyer, "Market-Driven Promotion of International Labour Standards in Southeast Asia: the Corporatization of Social Justice”, at: A. Marx, M. Maertens, J. Swinnen, J. Wouters, Private Standards and Global Governance. Economic, Legal and Political Perspectives, Edward Elgar, Cheltenham, UK, 2012

Dankers, C. and P. Liu, "Environmental and Social Standards, Certification and Labelling for Cash Crops”, FAO, Rome, 2003

Dankers, C. and P. Liu, "Private Standards in the United States and European Union Markets for Fruit and Vegetables - Implications for developing countries”, FAO Commodity Studies, 3, FAO, 2007

Dolan, C. and J. Humphrey, "Governance and Trade in Fresh Vegetables: The Impact of UK Supermarkets on the African Horticulture Industry”, Journal of Development Studies, 37(2), 2000

Du, M. M., "Reducing Product Standards Heterogeneity Through International Standards in the WTO: How Far Across the River?", Journal of World Trade, 44(2), 2010

Dutch HACCP - GFSI Case Study, available at: http://www.myciesnet. com/gfsijoomla/gfsifiles/GFSI_Case_Study_Dutch_HACCP.pdf (last visited November 20, 2014)

Eco-Labeling Standards, Green Procurement and the WTO: Significance for World Bank Borrowers, Center for International Environmental Law, Washington, DC, Geneva, Switzerland, March, 2005

Ehring, L., “De Facto Discrimination in World Trade Law. National and Most-Favoured-Nation Treatment - or Equal Treatment?”, Journal of World Trade, 36(5), 2002

Epps, T., International Trade and Health Protection. A Critical Assessment of the WTO's SPS Agreement, Edward Elgar, Cheltenham, UK, 2008

EU Import Conditions for Seafood and Other Fishery Products, European Commission, Directorate-General for Health \& Consumers, 
available at: http://ec.europa.eu/food/international/trade/im_cond_fish_ en.pdf (last visited November 20, 2014)

Ewers, J., "Dueling Risk Assessments: Why the WTO and CODEX Threaten U.S. Food Standards”, Environmental Law, 30, 2000

Finn, M., “Case Comment: When the Chips Are Down”, European Intellectual Property Review, 24(5), 2002

Food Safety and Agricultural Health Standards: Challenges and Opportunities for Developing Country Exports, Report No. 31207, World Bank, Poverty Reduction \& Economic Management Trade Unit and Agriculture and Rural Development Department, Washington D.C., January 10, 2005

Food Safety and Environmental Requirements in Export Markets Friend or Foe for Producers of Fruit and Vegetables in Asian Developing Countries?, UNCTAD, UNCTAD/DITC/TED/2006/8, New York and Geneva, 2007

Food Safety Body Agrees to E-Working Group "Time Out” on Definition of Private Standards, March 26 - 27, 2015, WTO News Items 2015, available at: https://www.wto.org/english/news_e/news15_e/ sps_26mar15_e.htm (last visited April 1, 2015)

Fulponi, L., "Final Report on Private Standards and the Shaping of the Agro-Food System”, AGR/CA/APM(2006)9/FINAL, OECD, Working Party on Agricultural Policies and Markets, July 2006

Fulponi, L., "Private Standard Schemes And Developing Country Access To Global Value Chains: Challenges And Opportunities Emerging From Four Case Studies”, AGR/CA/APM(2006)20/FINAL, OECD, August 2007

Fulponi, L., "Private Voluntary Standards in the Food System: the Perspective of Major Food Retailers in OECD Countries”, Food Policy, 31(1), 2006

Fulponi, L., "The Globalization of Private Standards and the Agri-food System", at: J. F. M. Swinnen, Global Supply Chains, Standards and the Poor. How the Globalization of Food Systems and Standards Affects Rural Development and Poverty, Cromwell Press, Trowbridge, 2007

Gandhi, S. R., "Disciplining Voluntary Environmental Standards at the WTO: An Indian Legal Viewpoint”, Working Paper No.181, Indian Council for Research on International Economic Relations, 2006 
Gandhi, S. R., "Regulating the Use of Voluntary Environmental Standards Within the World Trade Organization Legal Regime: Making a Case for Developing Countries”, Journal of World Trade, 39(5), 2005

Gandhi, S. R., "Voluntary Environmental Standards: The Interplay Between Private Initiatives, Trade Rules and the Global Decision-Making Process", 3rd Global Administrative Law Seminar, Viterbo, June 15-16, 2007

Graffham, A., E. Karehu, et al., "Impact of EurepGAP on Small-Scale Vegetable Growers in Kenya”, Fresh Insights 6, September 2007

Greaker, M., "Eco-labels, Trade and Protectionism”, Environmental \& Resourse Economics, 33, 2006

Green, A., "Climate Change, Regulatory Policy and the WTO. How Constraining are Trade Rules", Journal of International Economic Law, 8(1), 2005

Greve, G. C. F., "Analysis on Balance: Standardisation and Patents. Comments on the "IPR in ICT Standardisation Workshop" “, Free Software Foundation Europe, December 2, 2008

Gruère, G. P. and D. Sengupta, "Biosafety and Perceived Commercial Risks. The Role of GM-Free Private Standards”, Brief Number 15, International Food Policy Research Institute, 2009

Gruszczynski, L., Regulating Health and Environmental Risks under WTO Law. A Critical Analysis of the SPS Agreement, Oxford University Press, Oxford, 2010

Haufler, V., "Private Sector and International Standards-Setting: The Challenge for Business and Government", Discussion Paper 3, Study Group on the Role of the Private Sector, Carnegie, 2008

Hayes, E. T., "Changing Notions of Sovereignty and Federalism in the International Economic System: A Reassessment of WTO Regulation of Federal States and the Regional and Local Governments Within Their Territories", Northwestern Journal of International Law and Business, 25(1), 2004

Heiskanen, V., "The Regulatory Philosophy of International Trade Law", Journal of World Trade, 38(1), 2004

Henson, S. and J. Humphrey, "Private Standards in Global AgriFood Chains", at: A. Marx, M. Maertens, J. Swinnen, J. Wouters, 
Private Standards and Global Governance. Economic, Legal and Political Perspectives, Edward Elgar, Cheltenham, UK, 2012

Henson, S. and J. Humphrey, "The Impacts of Private Food Safety Standards on the Food Chain and on Public Standard-Setting Processes”, Codex thirty-second Session, FAO, WHO, Codex Alimentarius Commission, Rome, May 2009

Henson, S. and J. S. Wilson (eds.), The WTO and Technical Barriers to Trade, Edward Elgar, 2005

Henson, S. and S. Jaffee, "A Strategic Perspective on the Impact of Food Safety Standards on Developing Countries”, Paper for the International Association of Agricultural Economists Conference, Gold Coast, Australia, August 12-18, 2006

Henson, S. and S. Jaffee, "Understanding Developing Country Strategic Responses to the Enhancement of Food Safety Standards", World Economy, 31(4), 2008

Henson, S., "The Role of Public and Private Standards in Regulating International Food Markets”, Food Regulation and Trade: Institutional Framework, Concepts of Analysis and Empirical Evidence, IATRC, Bonn, Germany, May 28-30, 2006

Henson, S., O. Masakure, et al., "Do Fresh Produce Exporters in SubSaharan Africa Benefit from GlobalGAP Certification?”, InFERG Working Paper No. 2 FT, University of Guelph, Guelph, Ontario, Canada, July 2009

Hock, T., "The Role of Eco-Labels in International Trade: Can Timber Certification Be Implemented as a Means to Slowing Deforestation?”, Colorado Journal of International Environmental Law and Policy, 12, 2001

Howse, R. and E. Turk, "The WTO Impact on Internal Regulations. A Case Study of the Canada - EC Asbestos Dispute”, at: G. Bermann, P. Mavroidis (eds.), Trade and Human Health and Safety, CUP, 2006

Humphrey, J., "Private Standards in Kenyan Horticulture: Did the Donors Respond Effectively to the Challenge?", Paper for Conference 'Towards Priority Actions for Market Development for African Farmers', International Livestock Research Institute, Nairobi, April 2009

Humphrey, J., "Private Standards, Small Farmers and Donor Policy: EUREPGAP in Kenya”, IDS WORKING PAPER 308, Institute of Development Studies, University of Sussex, Brighton, UK, July 2008 
lizuka, M. and Y. Borbon-Galvez, "Compliance With the Private Standards and Capacity Building of National Institutions Under Globalization: New Agendas for Developing Countries?”, Working papers Series \#2009-025, UNU-Merit, Maastricht, 2009

International Standards and "Private Standards", ISO, Geneva, February 2010

Jaffee, S. and S. Henson, "Standards and Agro-Food Exports from Developing Countries: Rebalancing the Debate", Policy Research Working Paper 3348, World Bank, June 2004

Johnson, J. L., "Public-Private-Public Convergence: How the Private Actor Can Shape Public International Labor Standards", Brooklyn Journal of International Law, 24, 1998

Joshi, M., "Are Eco-labels Consistent with World Trade Organization Agreements?”, Journal of World Trade, 38(1), 2004

Josling, T. E., D. Roberts, et al., "Food Regulation and Trade: Toward a Safe and Open Global Food System”, Institute for International Economics, Washington DC, 2004

Kamperman Sanders, A., "Standards Setting in the ICT Industry? IP or Competition Law? A Comparative Perspective”, Paper prepared for the 5th Annual Conference of the EPIP Association, Maastricht, 2010

Karmakar, S., "Private Standards on SPS and TBT: Non-Tariff Barriers or Regulatory”, WTO News \& Views, 3(1), 2007

Kennedy, K., “GATT 1994”, at: P. F. J. Macrory, The World Trade Organization: Legal, Economic and Political Analysis, 1 Springer [etc.], New York, 2005

Kleih, U., F. Ssango, et al., "Impact of EurepGAP on Small-Scale Fruit and Vegetable Growers in Uganda”, Fresh Insights, 10, November 2007

Kudryavtsev, A., "Private Standardization and International Trade in Goods: Any WTO Law Implications for Domestic Regulation?”, the research paper presented at the SIEL Third Biennial Conference, Singapore 2012, available at the SSRN website: http://papers.ssrn.com/ sol3/papers.cfm?abstract_id=2082022 (last visited February 7, 2015)

Kudryavtsev, A., "The TBT Agreement in Context”, at: T. Epps, M. J. Trebilcock, Research Handbook on the WTO and Technical Barriers to Trade, Edward Elgar, Cheltenham, UK, 2013 
Lee, G. C.-H., "Private Food Standards and Their Impacts on Developing Countries”, European Commission DG Trade Unit G2, Brussels, 2006

Lewis, S., "Private Retail Standards Seen Threatening Codex Standards”, Food Chemical News, 50(21), 2008

Lind, S. N., "Eco-Labels and International Trade Law: Avoiding Trade Violations while Regulating the Environment”, International Legal Perspectives, 8, 1996

Liu, P., "Certification in the Value Chain for Fresh Fruits. The example of banana industry”, FAO Commodity Studies, 4, FAO, Rome, 2009

Liu, P., "Private Standards in International Trade: Issues and Opportunities", Workshop on Environment-Related Private Standards, Certification and Labelling Requirements Geneva, Switzerland, July 9, 2009

Maertens, M. and J. Swinnen, "Private Standards, Global Food Supply Chains and the Implications for Developing Countries", at: A. Marx, M. Maertens, J. Swinnen, J. Wouters, Private Standards and Global Governance. Economic, Legal and Political Perspectives, Edward Elgar, Cheltenham, UK, 2012

Mansoor, F., "Laughter and Tears of Developing Countries: The WTO and the Protection of International Labor Standards", International Trade Law Journal, 14, 2005

Marceau, G. and J. P. Trachtman, "The Technical Barrier to Trade Agreement, the Sanitary and Phytosanitary Measures Agreement, and the General Agreement on Tariffs and Trade: A Map of the World Trade Organization Law of Domestic Regulation of Goods”, Journal of World Trade, 36(5), 2002

Marceau, G. and J. P. Trachtman, "A Map of the World Trade Organization Law of Domestic Regulation of Goods: The Technical Barriers to Trade Agreement, the Sanitary and Phytosanitary Measures Agreement, and the General Agreement on Tariffs and Trade", Journal of World Trade, 48(2), 2014.

Marx, A., E. Becault, et al., "Private Standards in Forestry: Assessing the Legitimacy and Effectiveness of the Forest Stewardship Council”, at: A. Marx, M. Maertens, J. Swinnen, J. Wouters, Private Standards and Global Governance. Economic, Legal and Political Perspectives, Edward Elgar, Cheltenham, UK, 2012

Marx, A., M. Maertens, et al., "Introduction: Private Standards and Global Governance”, at: A. Marx, M. Maertens, J. Swinnen, J. Wouters, 
Private Standards and Global Governance. Economic, Legal and Political Perspectives, Edward Elgar, Cheltenham, UK, 2012

Masson-Matthee, M. D., The Codex Alimentarius Commission and Its Standards, T.M.C. Asser Press, 2007

Mathis, J. H., "WTO Core Principles and Prohibition: Obligations Related to Private Practices, National Competition Laws and Implications for a Competition Policy Framework”, UNCTAD, New York and Geneva, 2003

Mathis, J. H., "WTO Panel Report, European Communities - Trade Description of Sardines, WT/DS231/R, 29 May 2002”, Legal Issues of Economic Integration, 29(3), 2002

Mathis, J. H., “The WTO Agreement on Technical Barriers to Trade”, Consumer Policy Review, 16(1), 2006

Matsushita, M., T. J. Schoenbaum, et al., The World Trade Organization. Law, Practice, and Policy, Oxford University Press, Oxford, 2003

Mauscha, K., D. Mithöferb, et al., "Impact of EurepGAP Standard in Kenya: Comparing Smallholders to Large-Scale Vegetable Producers”, Conference on International Agricultural Research for Development, University of Bonn, October 11-13, 2006

Mavroidis, P. C., Trade in Goods. The GATT and the Other WTO Agreements Regulating Trade in Goods, OUP, Oxford, 2012

Mbengue, M. M., "Private Standards and WTO Law”, Bridges Trade BioRes Trade \& Environment Review, 5(1), Spring 2011

McCluskey, J. J., "Public and Private Food Quality Standards: Recent Trends and Strategic Incentives”, at: J. F. M. Swinnen, Global Supply Chains, Standards and the Poor. How the Globalization of Food Systems and Standards Affects Rural Development and Poverty, CABI, Trowbridge, 2007

McDonald, J., “Domestic Regulation, Harmonization, and Technical Barriers to Trade”, World Trade Review, 4(2), 2005

Members Take First Steps on Private Standards in Food Safety, Animal Plant Health, March 30 - 31, 2011, WTO News Items 2011, available at: http://www.wto.org/english/news_e/news11_e/sps_30mar11_e.htm (last visited November 20, 2014)

Middleton, R. W., “The GATT Standards Code”, Journal of World Trade Law, 14, 1980 
Moor, M., A World Without Walls - Freedom, Development, Free Trade and Global Governance, CUP, Cambridge, 2003

Moorman, Y., "Integration of ILO Core Rights Labor Standards into the WTO”, Columbia Journal of Transnational Law, 39, 2001

Motaal, D. A., "The "Multilateral Scientific Consensus" and the World Trade Organization”, Journal of World Trade, 38(5), 2004

Naiki, Y., "Accountability and Legitimacy in Global Health and Safety Governance: The World Trade organization, the SPS Committee, and International Standard-Setting Organizations”, Journal of World Trade, 43(6), 2009

Neumann, J. and E. Turk, "Necessity Revisited: Proportionality in World Trade Organization Law After Korea - Beef, EC - Asbestos and EC Sardines”, Journal of World Trade, 37(1), 2003

Pauwelyn, J., "Non-Traditional Patterns of Global Regulation: Is the WTO 'Missing the Boat'?”, Conference on Legal Patterns of Transnational Social Regulations and Trade, European University Institute, Florence, 2004

Pauwelyn, J., "Cross-Agreement Complaints before the Appellate Body: A Case Study of the EC-Asbestos Dispute”, World Trade Review, 1, 2002

Pauwelyn, J., "Is It International Law or Not, and Does It Even Matter?”, at: J. Pauwelyn, R. A. Wessel, J. Wouters, Informal International Lawmaking, OUP, Oxford, 2012

Pauwelyn, J., "The Role of Public International Law in the WTO: How Far Can We Go?”, American Journal of International Law, 95, 2001

Peel, J., “A GMO by Any Other Name ... Might Be an SPS Risk!: Implications of Expanding the Scope of the WTO Sanitary and Phytosanitary Measures Agreement”, European Journal of International Law, 17(5), 2007

Phillips, B., T. Ward, et al., Eco-Labelling in Fisheries. What Is It All about?, Blackwell Science, 2003

Plunkett, D. and C. S. DeWaal, "Who Is Responsible for the Safety of Food in a Global Market? Government Certification v. Importer Accountability as Models for Assuring the Safety of Internationally Traded Foods”, Food and Drug Law Journal, 63(3), 2008

Porter M. E., and M. R. Kramer, "Strategy \& Society: The Link between Competitive Advantage and Corporate Social Responsibility”, Harvard 
Business Review, December 2006, p. 4, available at: http://custom.hbsp. harvard.edu/custom_pdfs/FSGIMR0612D2006122113.pdf (last visited November 20, 2014)

Prévost, D. and P. V. d. Bossche, "The Agreement on the Application of Sanitary and Phytosanitary Meaures", at: P. F. J. Macrory, The World Trade Organization: Legal, Economic and Political Analysis, 1 Springer [etc.], New York, 2005

Prévost, D., "Opening Pandora's Box: The Panel's Findings in the ECBiotech Products Dispute”, Legal Issues of Economic Integration, 34(1), 2007

Prévost, D., "Transparency Obligations under the TBT Agreement", at: T. Epps, M. J. Trebilcock, Research Handbook on the WTO and Technical Barriers to Trade, Edward Elgar, Cheltenham, UK, 2013

Prévost, D., Balancing Trade and Health in the SPS Agreement: The Development Dimension, Wolf Legal Publishers, Nijmegen, 2009

Private Standards Are a Mixed Blessing, Committee Hears, WTO News Items, March 2007, available at: https://www.wto.org/english/news_e/ news07_e/sps_28feb_1march07_e.htm (last visited January 15, 2015)

Private-sector-set Standards and Developing Counties' Exports of Fresh Fruit and Vegetables: Synthesis of Country-case Studies in Africa (Ghana, Kenya, Uganda), Asia (Malaysia, Thailand, Vietnam), and Latin America (Argentina, Brazil, Costa Rica), Background Note by the UNCTAD secretariat for the FAO-UNCTAD Regional Workshop on Good Agricultural Practices in Eastern and Southern Africa: Practices and Policies, UNCTAD, Nairobi, Kenya, 6-9 March 2007

Processes and Production Methods (PPMs): Conceptual Framework and Considerations on Use of PPM-Based Trade Measures, OECD, OCDE/ GD(97)137, Paris, 1997

Reardon, T., P. Timmer, et al., "The Rapid Rise of Supermarkets in Developing Countries: Induced Organizational, Institutional, and Technological Change in Agrifood Systems", Journal of Agricultural and Development Economics, 1(2), 2004

Referencing International Standards in Government Procurement. International Standards and Technical Barriers to Trade. Legal Opinion Summaries, ISEAL Alliance, CIEL, Switzerland, United Kingdom, July, 2006 
Roberts, D., "Preliminary Assessment of the Effects of the WTO Agreement on Sanitary and Phytosanitary Trade Regulations", Journal of International Economic Law, 1(2), 1998

Rollo, J. and L. A. Winter, "Developing Countries and the Next Round of WTO Negotiations - Subsidiarity and Governance Challenges for the WTO: Environmental and Labour Standards”, The World Economy, 23(4), 2000

Schefer, K., Social Regulation in the WTO. Trade Policy and International Legal Development, Edward Elgar, Cheltenham, UK, 2010

Schepel, H., The Constitution of Private Governance: Product Standards in the Regulation of Integrating Markets, Oxford [etc.] : Hart, 2005

Scott, J., The WTO Agreement on Sanitary and Phytosanitary Measures. A Commentary, Oxford University Press, Oxford, 2007

Smyth, S., P. W. B. Phillips, et al., "Global Governance Quandaries Regarding Transformative Technologies for Bioproducts, Crops, and Foods”, Journal of World Trade, 43(6), 2009

Stanton, G. H., "Food Safety-Related Private Standards: The WTO Perspective”, at: A. Marx, M. Maertens, J. Swinnen, J. Wouters, Private Standards and Global Governance. Economic, Legal and Political Perspectives, Edward Elgar, Cheltenham, UK, 2012

Stewart, T. P., The GATT Uruguay Round. A Negotiating History (19861992), Vol. 1, Kluwer Law and Taxation Publishers, Denver. Boston, 1993

Subedi, S. P., "Balancing International Trade with Environmental Protection: International Legal Aspects of Eco-labels”, Brooklyn Journal of International Law, 25, 1999

Sustainability Standards in International Trade: Hurdles or Opportunities? Round Table Regional Programme for Europe and Newly Independent States, T. S. General Conference, UNIDO, Vienna, 9 December 2009

The Implications of Private-Sector Standards for Good Agricultural Practices Exploring Options to Facilitate Market Access for DevelopingCountry Exporters of Fruit and Vegetables: Experiences of Argentina, Brazil and Costa Rica, UNCTAD, UNCTAD/DITC/TED/2007/2, New York, Geneva, 2007 
The Right Track, NEN Brochure, 2002, available at: http://www2.nen. $\mathrm{nl} / \mathrm{cmsprod} /$ groups/public/documents/bestand/185033.pdf (last visited November 20, 2014)

The World Trade Organization in Brief, WTO, Geneva, 2009, available at: http://www.wto.org/english/res_e/doload_e/inbr_e.pdf (last visited November 20, 2014)

Understanding the Codex Alimentarius, $\mathrm{WHO} / \mathrm{FAO}$, third edition, Rome, 2006, available at: ftp://ftp.fao.org/codex/Publications/understanding/ Understanding_EN.pdf (last visited November 20, 2014)

Using and Referencing ISO and IEC Standards for Technical Regulations, ISO / IEC, Geneva, September 2007

Villalpando, S., "Attribution of Conduct to the State: How Rules of State Responsibility May Be Applied Within the WTO Dispute Settlement System”, Journal of International Economic Law, 5(2), 2002

Vitalis, V., "Private Voluntary Eco-Labels: Trade Distorting,

Discriminatory and Environmentally Disappointing”, OECD, Paris, 2002

Voon, T., A. Mitchell, et al., "Consumer Information, Consumer Preferences and Product Labels under the TBT Agreement", at: T. Epps, M. J. Trebilcock, Research Handbook on the WTO and Technical Barriers to Trade, Edward Elgar, Cheltenham, UK, 2013

Waarden, F. v., "Governing Global Commons: The Public-Private Protection of Fish and Forests", at: A. Marx, M. Maertens, J. Swinnen, J. Wouters, Private Standards and Global Governance. Economic, Legal and Political Perspectives, Edward Elgar, Cheltenham, UK, 2012

Wagner, M., "International Standards", at: T. Epps, M. J. Trebilcock, Research Handbook on the WTO and Technical Barriers to Trade, Edward Elgar, Cheltenham, UK, 2013

Ward, H., "Trade and Environment Issues in Voluntary Eco-Labelling and Life Cycle Analysis”, RECIEL, 6(2), 1997

Washington, S. and L. Ababouch, "Private Standards and Certification in Fisheries and Aquaculture. Current Practice and Emerging Issues”, FAO, Rome, 2011

Webb, M., "Survey of Fresh Fruit and Vegetable Exporters in Sub-Saharan Africa. Changing Buyer Requirements and Their Impact on Supply Chains", PIP - Survey, COLEACP PIP, Brussels, Belgium, May 2009 
Webb, R. M., “There Is a Better Way: It's Time to Overhaul the Model for Participation in Private Standard-Setting”, Journal of Intellectual Property Law,(12), Fall, 2004

Weymann, V., “GLOBALGAP Aquaculture Standard. Towards More Species Coverage”, News. Good Agricultural Practice, October 2008

Wilson, N. L. W., "Clarifying the Alphabet Soup of the TBT and the SPS in the WTO”, Drake Journal of Agricultural Law, 8, 2003

Wirth, D. A., “The International Organization for Standardization: Private Voluntary Standards as Swords and Shields”, Boston College Environmental Affairs Law Review, 36, 2009

Wit, S. d., "The Case eBay Inc. v. MercExchange LLC, Its Impact on NPE's and Patent Enforcement”, at: C. Heath, A. Kamperman Sanders, Landmark Intellectual Property Cases and Their Legacy, Kluwer Law International, The Netherlands, 2010

Wlostowski, T., "Selected Observations on Regulation of Private Standards by the WTO”, Polish Yearbook of International Law, XXX, 2010

Wolfrum, R., "State Responsibility for Private Actors: An Old Problem of Renewed Relevance”, at: M. Ragazzi, International Responsibility Today: Essays in Memory of Oscar Schachter, Martinus Nijhoff Publisher, Leiden, 2005

Wolfrum, R., P.-T. Stoll, et al., WTO: Technical Barriers and SPS Measures, Nijhoff, Leiden, 2007

Wolfrum, R., P.-T. Stoll, et al., WTO - World Economic Order, World Trade Law, Nijhoff, Leiden, 2006

World Trade Report 2005: Exploring the links between Trade Standards and the WTO, WTO, 2005

World Trade Report. Exploring the Links Between Trade, Standards and the WTO, WTO, 2005

Wouters, J., "Private Law, Global Governance and the European Union”, KUL, Leuven, March 2012

Wouters, J., A. Marx, et al., "In Search of a Balanced Relationship: Public and Private Food Safety Standards and International Law”, Working Paper No. 29, KUL, Leuven, June 2009

Wouters, J., A. Marx, et al., "Private Standards, Global Governance and International Trade: The Case of Global Food Safety Governance”, at: A. 
Marx, M. Maertens, J. Swinnen, J. Wouters, Private Standards and Global Governance. Economic, Legal and Political Perspectives, Edward Elgar, Cheltenham, UK, 2012

WTO Agreements and Public Health.A Joint Study by the WHO and the WTO Secretariat, WTO / WHO, 2002

Zaheer, D. A., "Breaking the Deadlock: Why and How Developing Countries Should Accept Labor Standards in the WTO”, Stanford Journal of Law, Business \& Finance, 9, 2003

Zedalis, R. J., "When Do the Activities of Private Parties Trigger WTO Rules?”, Journal of International Economic Law, 10(2), 2007

Zleptnig, S., Non-Economic Objectives in WTO Law. Justification Provisions of GATT, GATS, SPS and TBT Agreements, Vol. 1, Martinus Nijhoff Publishers, Leiden - Boston, 2010

\section{Official Documents of the WTO}

Actions Regarding SPS-Related Private Standards. Communication from China, WTO, SPS Committee, G/SPS/GEN/1261, Geneva, 8 July 2013

Actions Regarding SPS-Related Private Standards. Decision of the Committee, WTO, SPS Committee, G/SPS/55, Geneva, 6 April 2011

Concerns with Private and Commercial Standards. Communication from Belize, WTO, SPS Committee, G/SPS/GEN/1240, Geneva, 27 March 2013

Decision on the Implementation of Article 4 of the Agreement on the Application of Sanitary and Phytosanitary Measures, WTO, SPS Committee, G/SPS/19, Geneva, 26 October 2001

Decision on the Implementation of Article 4 of the Agreement on the Application of Sanitary and Phytosanitary Measures, WTO, SPS Committee, G/SPS/19/Rev.1, Geneva, 2 April 2004

Decision on the Implementation of Article 4 of the Agreement on the Application of Sanitary and Phytosanitary Measures, WTO, SPS Committee, G/SPS/19/Rev.2, Geneva, 23 July 2004

Decisions and Recommendations Adopted by the Committee since 1 January 1995. Note by the Secretariat, TBT Committee, G/TBT/1/Rev.8, Geneva, 23 May 2002 
Documents and other Information on Private Standards. Note By Secretariat, WTO, Committee on Sanitary and Phytosanitary Measures, G/ SPS/GEN/865, Geneva, 11 July 2008

Doha Work Programme. Decision Adopted by the General Council on 1 August 2004, WTO, WT/L/579, 2 August 2004

Effects of SPS-Related Private Standards - Compilation of Replies. Note by the Secretariat, WTO, SPS Committee, G/SPS/GEN/932/Rev.1, Geneva, 10 December 2009

Environmental Requirements and Market Access. Recent Work in OECD and UNCTAD. Note by the Secretariat, WTO, Committee on Trade and Environment, WT/CTE/W/244, 8 December 2006

Executive Summary of a Study on Agri-Food Safety and SPS Compliance in Guinea Conakry, Mozambique and Tanzania. Communication from UNCTAD, WTO, SPS Committee, G/SPS/GEN/567, Geneva, circulated on 17 June 2005

Existing Definitions of Private Standards in Other International Organizations. Note by the Secretariat. Revision, WTO, SPS Committee, G/SPS/GEN/1334/Rev.1, Geneva, 5 August 2014

First Triennial Review of the Operation and Implementation of the Agreement on Technical Barriers to Trade, TBT Committee, G/TBT/5, Geneva, November 1997

Good Practices in SPS-Related Technical Assistance. An Overview and Synthesis of the Findings of STDF/OECD Research. Note by the Secretariat, WTO, SPS Committee, G/SPS/GEN/875, 24 September 2008

Guidelines to Further the Practical Implementation of Article 5.5, WTO, SPS Committee, G/SPS/15, Geneva, 18 July 2000

Guidelines to Further the Practical Implementation of Article 6 of the Agreement on the Application of Sanitary and Phytosanitary Measures, WTO, SPS Committee, G/SPS/48, Geneva, 16 May 2008

Impact of Private Food Standards in the Southern Cone: Financial Costs and Legal Implications. Communication from the Inter-American Institute for Cooperation on Agriculture (IICA), WTO, SPS Committee, G/SPS/GEN/1100, Geneva, 27 June 2011

Labelling for Environmental Purposes. Submission by the European Communities under Paragraph 32(iii), WTO, Committee on Trade and Environment, WT/CTE/W/225, 6 March 2003 
Labelling. Submission by the European Communities, WTO, TBT Committee, Committee on Trade and Environment, G/TBT/W/175, WT/ CTE/W/212, 12 June 2002

Legal Framework for Private Standards in the WTO. Communication from MERCOSUR (Argentina, Brazil, Paraguay and Uruguay), WTO, SPS Committee, G/SPS/W/246, Geneva, 30 September 2009

Marking and Labelling Requirements. Submission from Switzerland, WTO, Committee on Trade and Environment, TBT Committee, WT/ CTE/W/192, G/TBT/W/162, Geneva, 19 June 2001

Ministerial Declaration, Ministerial Conference. Fourth Session, WT/ MIN(01)/DEC/1, Doha, 20 November 2001

Minutes of the Meeting Held on 30 March 2001, TBT Committee, G/ TBT/M/23, Geneva, 8 May 2001

Negotiating History of the Coverage of the Agreement on Technical Barriers to Trade with Regard to Labelling Requirements, Voluntary Standards and Production Methods Unrelated to Product Characteristics. Note by Secretariat, TBT Committee, CTE, WT/CTE/W/10, G/ TBT/W/11, Geneva, 29 August 1995

Notification of Determination of the Recognition of Equivalence of Sanitary or Phytosanitary Measures. Decision by the Committee WTO, SPS Committee, G/SPS/7/Rev.2/Add.1, Geneva, 25 July 2002

Overview Regarding the Level of Implementation of the Transparency Provisions of the SPS Agreement. Note by the Secretariat, WTO, SPS Committee, G/SPS/GEN/804/Rev.4, Geneva, 13 October 2011

Possible Actions for the SPS Committee Regarding Private SPS Standards. Note by the Secretariat, WTO, SPS Committee, G/SPS/W/247, Geneva, 20 October 2009

Possible Actions for the SPS Committee Regarding SPS-Related Private Standards. Note by the Secretariat, WTO, SPS Committee, G/SPS/W/247/ Rev.3, Geneva, 11 October 2010

Private and Commercial Standards. Statement by Ecuador at the Meeting of 27 - 28 June 2007, WTO, SPS Committee, G/SPS/GEN/792, Geneva, circulated on 5 July 2007

Private Industry Standards. Communication from Saint Vincent and the Grenadines, WTO, SPS Committee, G/SPS/GEN/766, 28 February 2007 
Private Sector Standards and Developing Country Exports of Fresh Fruit and Vegetables. Communication from the United Nations Conference on Trade and Development (UNCTAD), WTO, SPS Committee, G/SPS/ GEN/761, 26 February 2007

Private Sector Standards and Developing Country Exports of Fresh Fruit and Vegetables. Communication from the United Nations Conference on Trade and Development (UNCTAD). Corrigendum, WTO, SPS Committee, G/SPS/GEN761/Corr.1, Geneva, 9 March 2007

Private Standards - Identifying Practical Actions for the SPS Committee - Summary of Responses. Note by the Secretariat, WTO, SPS Committee, G/SPS/W/230, 25 September 2008

Private Standards and the SPS Agreement. Note by the Secretariat, WTO, SPS Committee, G/SPS/GEN/746, Geneva, 24 January 2007

Private Standards. Statement by MERCOSUR (Argentina, Brazil, Paraguay and Uruguay), WTO, SPS Committee, G/SPS/W/249, Geneva, 23 December 2009

Private Voluntary Standards and Developing Country Market Access: Preliminary Results. Communication from OECD, Fulponi, L., WTO, SPS Committee, G/SPS/GEN/763, Geneva, 27 February 2007

Private Voluntary Standards within the WTO Multilateral Framework: Submission by the United Kingdom. A report prepared by Digby Gascoine and O'Connor and Company, WTO, SPS Committee, G/SPS/ GEN/802, Geneva, 9 October 2007

Procedure to Enhance Transparency of Special and Differential Treatment in Favour of Developing Country Members. Decision by the Committee, WTO, SPS Committee, G/SPS/33, G/SPS/33/Rev.1, Geneva, 2 November 2004, 18 December 2009

Proposed Revisions to Action Six of the Report of the Ad Hoc Working Group on SPS-Related Private Standards (G/SPS/W/256), WTO, SPS Committee, G/SPS/W/261, Geneva, 20 June 2011

Proposed Working Definition of an SPS-Related Private Standard. Submission by China and New Zealand, WTO, SPS Committee, G/ SPS/W/272, Geneva, 8 October 2013

Proposed Working Definition of SPS-Related Private Standards. Noted by the Secretariat, WTO, SPS Committee, G/SPS/W/265/Rev.2, Geneva, 28 September 2012 
Questionnaire on SPS-Related Private Standards. Note by the Secretariat, WTO, SPS Committee, G/SPS/W/232, Geneva, 8 December 2008

Recommended Procedures for Implementing the Transparency Obligations of the SPS Agreement (Article 7), WTO, SPS Committee, G/ SPS/7/Rev.2, G/SPS/7/Rev.3, Geneva, 2 April 2002, 20 June 2008

Relevant Work of the International Standards Organization (ISO). Statement by the representative of ISO at the meeting of 29-30 June 2005, WTO, SPS Committee, G/SPS/GEN/589, Geneva, 11 July 2005

Report by the Commonwealth of the Bahamas to the WTO-SPS Committee on Private Standards and the SPS Agreement: The Bahamas Experience. Communication from the Bahamas, WTO, SPS Committee, G/ SPS/GEN/764, Geneva, 28 February 2007

Report of the Ad Hoc Working Group on SPS-Related Private Standards to the SPS Committee, WTO, SPS Committee, G/SPS/W/256, Geneva, 3 March 2011

Report of the Co-Stewards of the Private Standards E-Working Group on Action 1 (G/SPS/55). Submission by the Co-Stewards of the E-Working Group, WTO, SPS Committee, G/SPS/W/276, Geneva, 18 March 2014

Report of the Co-Stewards of the Private Standards E-Working Group to the March 2015 Meeting of the SPS Committee on Action 1 (G/SPS/55). Submission by the Co-Stewards of the E-Working Group, WTO, SPS Committee, G/SPS/W/283, Geneva, 17 March 2015

Report on Proposals for Special and Differential Treatment. Adopted by the Committee on 30 June 2005, WTO, SPS Committee, G/SPS/35, Geneva, 7 July 2005

Second Report of the Co-Stewards of the Private Standards E-Working Group on Action 1 (G/SPS/55). Submission by the Co-Stewards of the E-Working Group, WTO, SPS Committee, G/SPS/W/281, Geneva, 30 September 2014

Special and Differential Treatment. Report by the Chairman to the General Council, WTO, SPS Committee, G/SPS/46, Geneva, 29 October 2007

SPS/STDF/OECD Workshop on Good Practices in SPS-Related Technical Cooperation, WTO, SPS Committee, G/SPS/GEN/874, 26 September 2008 
Submission by the International Organization for Standardization (ISO) to the SPS Committee Meeting - 28 February and 1 March 2007, WTO, SPS Committee, G/SPS/GEN/750, Geneva, 16 February 2007

Submission by the ISO to the meeting of the TBT Committee, WTO, TBT Committee, G/TBT/GEN/38, Geneva, 28 July 2006

Summary of the Meeting Held on 29-30 June 2005. Note by the Secretariat. Revision, WTO, SPS Committee, G/SPS/R/37, Geneva, 11 August 2005

Summary of the Meeting Held on 29-30 June 2005. Note by the Secretariat. Revision, WTO, SPS Committee, G/SPS/R/37/Rev.1, Geneva, 18 August 2005

Summary of the Meeting of 8-9 October 2008. Note by the Secretaria, WTO, SPS Committee, G/SPS/R/53, Geneva, 22 December 2008

Summary Report of the Information Session on Product Carbon Footprint and Labelling Schemes. Note by the Secretariat", WTO, Committee on Trade and Environment, WT/CTE/M/49/Add.1, 17 February 2010

Summary Report of the Information Session on Product Carbon Footprint and Labelling Schemes 17 february 2010. Note by the Secretariat, WTO, Committee on Trade and Environment, WT/CTE/M/49/ Add.1, 28 May 2010

The Results of the Uruguay Round of Multilatreral Trade Negotiations. The Legal Texts., WTO, 1995

Tokyo Round Agreement on Technical Barriers to Trade, BISD 26th Supp, 1980,8

Typology of Global Standards. Communication from the United Nations Conference on Trade and Development (UNCTAD), WTO, SPS Committee, G/SPS/GEN/760, Geneva, 26 February 2007

Update on the Operation of the Standards and Trade Development Facility. Note by the Secretariat, WTO, SPS Committee, G/SPS/GEN/877, 26 September 2008

Voluntary Standards. Submission by Switzerland, WTO, SPS Committee, G/SPS/GEN/967, Geneva, 20 October 2009 


\section{Official Documents of Other International Organizations}

Articles on Responsibility of States for Internationally Wrongful Acts, ILC, UN Doc. A/56/10, 2001

Commentaries on the Articles on Responsibility of States for Internationally Wrongful Acts, International Law Commission, UN Doc. $1 / 56 / 10,2001$

Communication from the Commission concerning Corporate Social Responsibility: A Business Contribution to Sustainable Development, Brussels, 2 July 2002, $\operatorname{COM(2002),~} 347$ final, p. 3, available at: http:// trade.ec.europa.eu/doclib/docs/2006/february/tradoc_127374.pdf (last visited November 20, 2014)

Guidance Document on the Implementation of Procedures Based on the HACCP Principles, and on the Facilitation of the Implementation of the HACCP Principles in Certain Food Businesses, European Commission, Brussels, November 16, 2005, available at: http://ec.europa.eu/food/food/ biosafety/hygienelegislation/guidance_doc_haccp_en.pdf (last visited November 20, 2014)

Guide to the implementation of directives based on the New Approach and the Global Approach, European Commission, Luxembourg, 2000

Healthcare Terminology: Principles for International Standard Development Organizations, TC215 Working Group 3, ISO/TC 215 WG3 N238, 29 March 2006

ISO/IEC 17000: 2004, Conformity Assessment - Vocabulary and General Principles

ISO/IEC Guide 2: 1991, General Terms and Their Definitions Concerning Standardization and Related Activities

ISO/IEC Guide 2: 2004, Standardization and Related Activities - General Vocabulary

Regulation (EC) No 178/2002 Laying Down the General Principles and Requirements of Food Law, Establishing the European Food Safety Authority and Laying Down Procedures in Matters of Food Safety, Official Journal of the European Communities, 1 February 2002, available at: http://eur-lex.europa.eu/LexUriServ/LexUriServ.do?uri=OJ:L:2002:03 1:0001:0024:EN:PDF (last visited November 20, 2014) 
Regulation (EC) No 852/2004 on the hygiene of foodstuffs, Official Journal of the European Communities, 30 April 2004, available at: http:// eur-lex.europa.eu/LexUriServ/LexUriServ.do?uri=OJ:L:2004:139:0001:0 054:EN:PDF (last visited November 20, 2014)

Regulation (EC) No 852/2004 on the Hygiene of Foodstuffs, Official Journal of the European Communities, 30 April 2004, available at: http:// eur-lex.europa.eu/LexUriServ/LexUriServ.do?uri=OJ:L:2004:139:0001:0 054:EN:PDF (last visited November 20, 2014)

Standards and Patents, Standing Committee on the Law of Patents, Thirteenth Session, SCP/13/2, D. p. b. t. Secretariat, WIPO, Geneva, February 18, 2009

Statute of the International Law Commission, UN General Assembly, 1947, as amended in 1950, 1955, 1981 


\section{Curriculum Vitae}

Arkady Kudryavtsev was born on 20 February 1982 in Kurgan, Russia (the USSR at that time). He was a student at the Ural State Law Academy in Yekaterinburg, Russia, from 1999 and graduated cum laude in 2004 with a degree in law and English - Russian legal interpretation. From 2006 to 2007, thanks to the MTEC scholarship provided by the government of the Netherlands, he completed the Master's program at the School of Law at the University of Amsterdam, obtaining his LL.M Degree in International and European Law with specialization in Public International Law. During his studies at the University of Amsterdam, Arkady successfully participated in the Philip C. Jessup Moot Court Competition and completed a research project for the Ministry of Foreign Affairs of the Netherlands within the framework of the International Law Clinic of the University of Amsterdam.

From September 2008 to April 2013, Arkady was a PhD candidate (promovendus) in International Economic Law at the Faculty of Law and the Institute for Globalization and International Regulation of the Maastricht University conducting research towards his $\mathrm{PhD}$ and teaching wide range of subjects, including courses in Public International Law, International Trade Law, EU Law and Policy. From April 2013 to October 2014, Arkady worked as a dispute settlement lawyer at the Legal Affairs Division of the Secretariat of the WTO in Geneva, where he dealt with the resolution of international trade disputes between WTO Members and other issues of international trade and WTO law. Before starting his $\mathrm{PhD}$ research project at the Maastricht University, Arkady practiced law in Yekaterinburg and Moscow, Russia, for several years, advising in the areas of mergers and acquisitions, international investments, corporate law and cargo air transportation. 